

\section{Cornell University Library}

The original of this book is in the Cornell University Library.

There are no known copyright restrictions in the United States on the use of the text. 


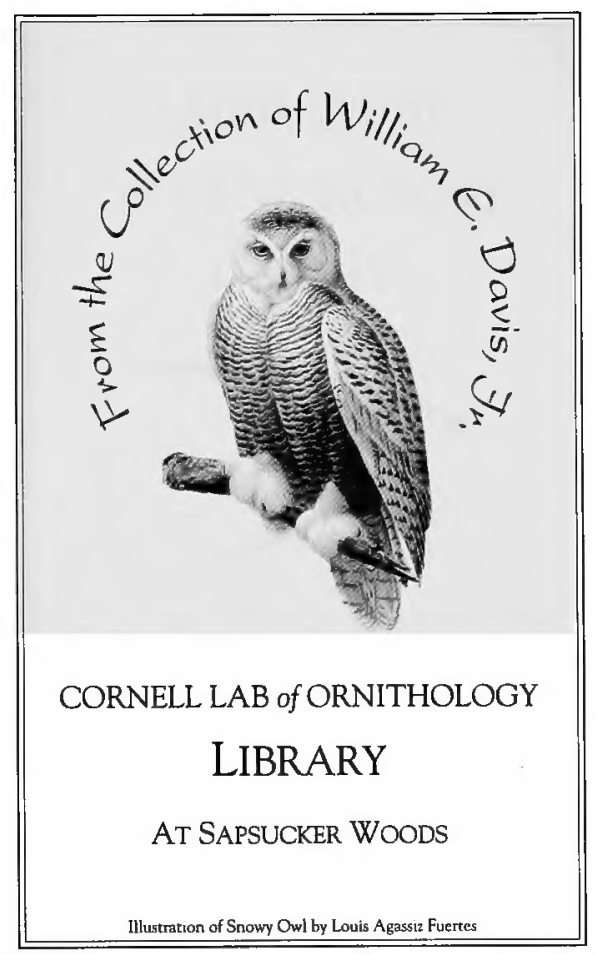


Camplimentio o) Obubutst. Reliy.

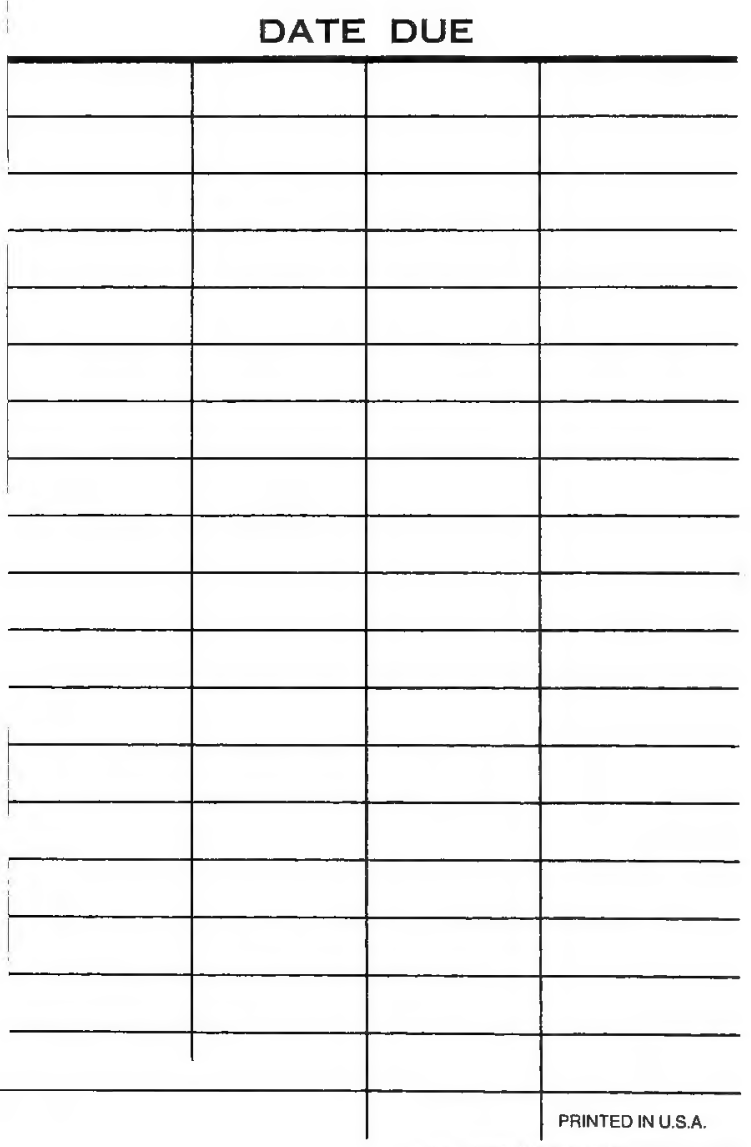






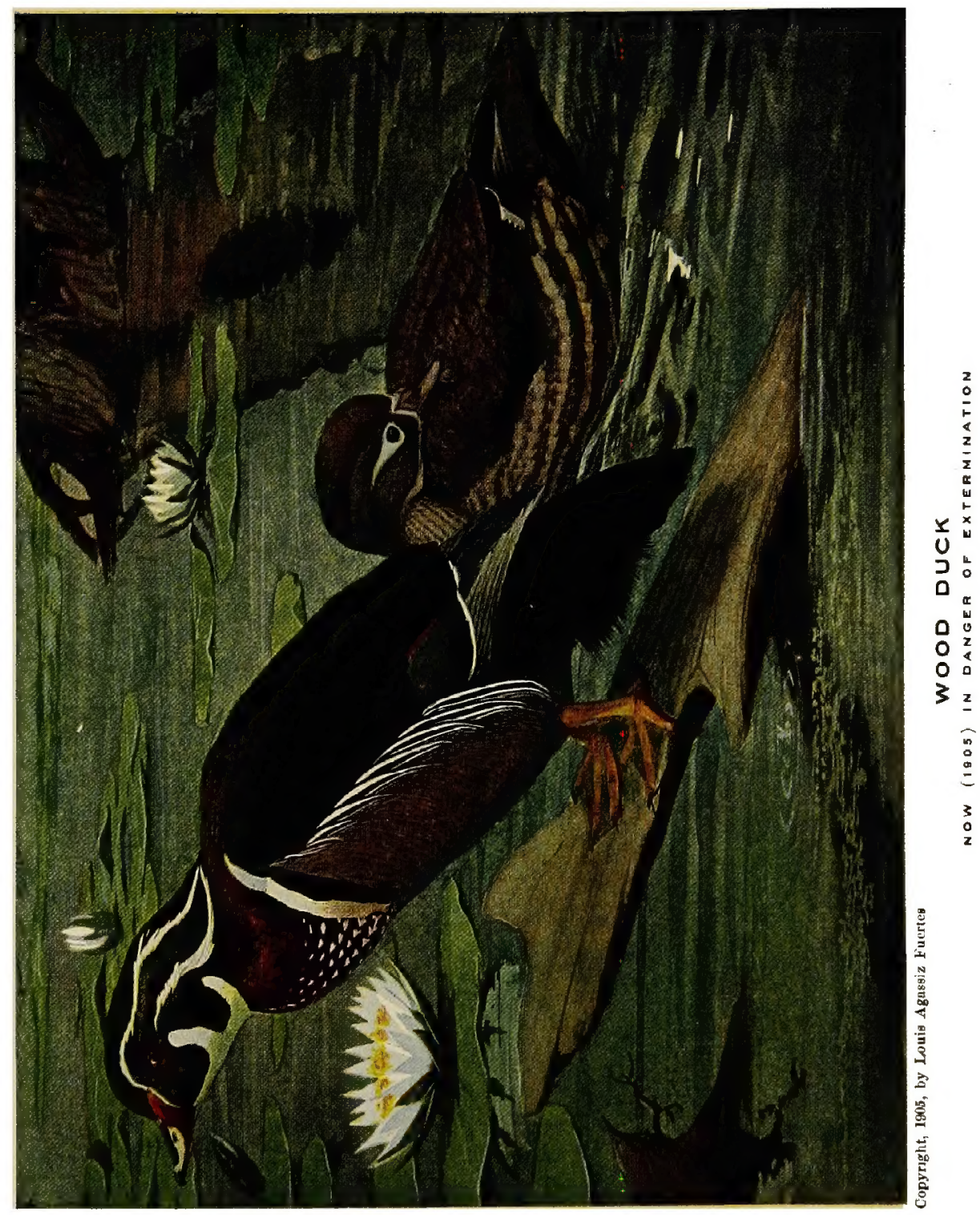






\title{
USEFUL BIRDS
}

AND THEIR PROTECTION.

CONTAINING

BRIEF DESCRIPTIONS OF THE MORE COMMON AND USEFUL SPECIES OF MASSACHUSETTS, WITH ACCOUNTS OF THEIR FOOD HABITS, AND A CHAPTER ON THE MEANS OF ATTRACTING AND PROTECTING BIRDS.

\author{
BY \\ EDWARD HOWE FORBUSH, \\ Ornithologist to the MassachusetTs State Board of \\ AGRICULTURE. \\ ILLUSTRATED BY THE AUTHOR, \\ C. ALLAN LYFORD, CHESTER A. REED, AND OTHERS.
}

\section{Sirnni Edttiun.}

Published Under DiRection of

The Massachusetts State Board of Agriculture, By Authority OF the Legislature.

1907. 


\section{ORNITH $S B$ 995 F 7 1907}

APPROVED BY

THE STATE BOARD OF PUBLICATION. Boston, Massachusetts. 


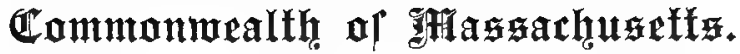

\author{
Resolves of rgo5, Chapter 51 .
}

A Resolve to provide For plieptring and printing a special REPORT ON THE HIRDS OF TIE COMMIONWEAL'TH.

Resolved, That there be allowed and paid out of the treasury of the Commonwealth a sum not exceeding three thousand clollars for preparing and printing, under the direction of the state board of agrieulture, in an edition of fire thousand copies, a special report on the birds of the Commonwealth, economically considered, to inclucle the facts relating to the usefulness of birds and the necessity for their protection already ascertained by the ornithologist of the state board of agriculture, to be distributed as follows: - Two copies to each free public library in the Commonwealth; two copies to each high school, and two copies to such schools in towns which have no high school as the school comnittee may designate; one copy to the lilirary of congress, and one copy to each state or territorial library in the United States; twenty-five copies to the state library; five copies to the governor; two copies to the lieutenant governor and each member of the council; two copies to the secretary of the Commonwealth; two copies to the treasurer and receiver general; two copies to the auditor of accounts; two copies to the attorney-general, and one copy to each member of the present general court applying for the same; the remainder to be distributed under the direction of the state board of agriculture. [Approved April 17, 1905. 


$$
\begin{aligned}
& \text { ORNITH } \\
& \text { SB } \\
& 995 \\
& F 7 \\
& 1907
\end{aligned}
$$

APPROVED BY

THE STATE BOARD OF PUBLICATION. 


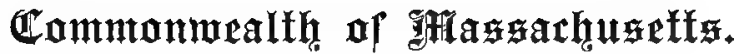

\section{Resolves of 1905 , Chapter $5 \mathrm{I}$.}

\author{
A Resolye to PROVIDE FOR PIEPARING AND PRINTING a SPECIAL \\ REPORT ON THE BIRDS OF THE COMMUNWEALTI.
}

Resolved, Thit there be allowed and paid ont of the treasury of the Commonwealth a sum not exceeding three thousand dollars for preparing and printing, under the direction of the state board of agriculture, in an edition of five thousand copies, a special report on the birds of the Commonwealth, economically considered, to include the facts relating to the usefulness of birds and the necessity for their protection aIready ascertained by the ornithologist of the state board of agriculture, to be distributed as follows: - Two copies to each free public library in the Commonwealth; two copies to each high school, and two copies to such schools in towns which have no high school as the school committee may designate; one copy to the library of congress, and one copy to each state or territorial library in the United States; twenty-five copies to the state library; five copies to the governor; two copies to the lientenant governor and each member of the council; two copies to the secretary of the Commonwealth; two copies to the treasurer and receiver general; two copies to the auditor of accounts; two copies to the attorney-general, and one copy to each member of the present general court applying. for the same; the remainder to be distributed under the direction of the state board of agriculture. [Approved April 14, 1905. 
to Mr. Bailey's untimely death and Mr. Mosher's occupation in a new field, it was deemed best to publish some of the field notes of these observers with little editing, in order to avoid any possible distortion of their evidence.

In presenting in Chapter I. some of the evidence, given by the earlier writers, regarding the utility of birds as protectors of crops and trees, it has been necessary to use such material as was obtainable. No carefully guarded experiments or observations in this direction were made until the latter part of the nineteenth century, and it is only recently that scientific investigators have been employed in this little-known field. It is not an alluring task for the scientist, in which his work brings him neither material reward, credit, nor honor.

That portion of the final chapter which treats of the means of attracting birds is drawn mainly from six years' experience at the author's home at Wareham, Mass. The first three chapters were mainly written there. Most authors quoted or cited in these chapters are given full credit.

The remaining chapters, which are largely based on the author's own investigations and observations, were written and the proof was read while he was away from home, in the woods, or travelling from place to place, often at a distance from any ornithological library. Under such circumstances it was impossible to quote verbatim, but in most cases authors are named when facts have been gathered from their writings.

The averages of the components of the food of each species are taken mainly from the publications of the Bureau of Biological Survey of the United States Department of Agriculture, except where credit is otherwise given.

Thanks are due to Dr. L. O. Howard, who has read critically that part of the introduction devoted to insects, and the author is greatly indebted to him for information; also, more than be can tell, to Mr. William Brewster for counsel and suggestions; and especially to Mr. J. A. Farley, who read a large part of the manuscript.

The limited time at the author's disposal has prevented such painstaking revision and abridgment of the manuscript 
as would be required to attain the highest literary excellence; but both manuscript and proof were critically read by Mrs. A. Drew, whose work has added much to the appearance of the volume, and whose suggestions have been very valuable.

Mr. F. H. Fowler has placed the author under great obligations by doing a large amount of clerical work, and giving much assistance in his official position as first clerk and librarian of the State Board of Agriculture.

The scientific ornithological nomenclature is that of the American Ornithologists Union. The grouping of birds according to their habitats (as birds of woodland, etc.) is based more on their food habits than on their choice of nesting sites. This classification is of necessity arbitrary, and not always consistent, for it is sometimes influenced by other considerations, such as are evident in the inclusion of the Whip-poor-will among birds of the air.

The nomenclature of plants is mainly that used by Britton and Brown in their Flora of the Northern United States, Canada, and the British Possessions, except in some cases where Dr. Judd or other authors are quoted. That of insects has been derived from various sources at different times, and for this reason some of the scientific names are not the latest.

In the original plan of the report no descriptions of species were included; but the suggestion was made by Mr. J. A. Farley that it would be useless to descant to a man on the usefulness of the Chickadee if he did not know the bird. The brief, untechnical descriptions of bird, nest, eggs, and bird notes, and the illustrations of the species, are all in: tended as helps to identification. The descriptions of birds are calculated merely to call attention to the principal colors and marks that serve to identify birds afield. Brief descriptions of haunts, habits, and manners are also given, as guides to identity.

A species that is found throughout the year within the limits of the State is denominated a resident. No attempts have been made to give fixed dates of arrival and departure, for these vary somewhat in different parts of the State, as 
well as in different seasons; but the months in which each species is most commonly seen are given. For example, the season for the Tree Swallow is given as April to September; but no mention is made of the fact that it sometimes appears in small numbers in March; neither is it stated that this bird has been seen in flocks in southeastern Massachusetts in late October and even in November, for such occurrences are unusual. It may be taken for granted that most of the insect-eating birds that arrive in March or April come in the latter part of those months, while most of those that depart for the south in September or October leave in the earlier weeks of their respective months.

Our attempts to represent the songs of birds in printed syllables are not often of much assistance to the beginner, for they lack the variation, quality, and expression of bird songs, and birds do not sing in syllables. Also, the imagination of the writer often greatly affects these syllabic renditions, as may be seen by comparing the various sentences attributed by different people to the White-throated Sparrow. Nevertheless, some such imitations of bird songs which are now accepted and are quite generally considered helpful are given in this report; in other cases the author's own interpretations of well-marked bird notes are given.

The line cuts of birds, nesting boxes, appliances, etc., are mainly reproductions of the author's pen and ink sketches and drawings. The attitudes have been caught by sketching the living birds afield; but as most of the drawings were necessarily made in winter, the measurements and the details of markings were taken mainly from bird skins. While this method does not give so good results as does the use of the dead bird, it obviates the necessity of killing birds for the purpose. The sketches for Figs. 19, 22, 23, and 25 were suggested by half-tone plates in American Ornithology. Figs. $1,27,53,71,73,79,109,113-117,142$, and 143 were made from pen drawings by Lewis E. Forbush. The wood-cuts of insects were taken chiefly from Harris's Insects Injurious to Vegetation, Flint's Manual of Agriculture, and various papers published by Dr. A. S. Packard while serving as entomologist to the Massachusetts State Board of Agriculture. 
Mr. C. Allan Lyford has given valuable assistance in taking photographs illustrating bird feeding, nesting boxes, etc. The author is also greatly indebted to Messrs. C. A. and C. K. Reed for the use of half-tone plates from American Ornithology; to Mr. Frank M. Chapman, the Massachusetts Comnission on Fisheries and Game, Mr. A. C. Dike, and others, to whom credit is given in the text or captions, for the use of photographs, half-tone plates, or cuts; and to Messis. William Brewster and Ralph Holman for the use of bird skins. Plates VI. and VII. are from E. A. Samuels.

The credit for the publication of this volume rightly belongs to the State Board of Agriculture, which, through its secretary, introduced and advocated the resolve providing for preparing and printing; to the Massachusetts Audubon Society, which supported the resolve before the Legislature; to the various associations, officials, and friends who upheld the resolve; and to those members of the House and Senate who were instrumental in securing the appropriation which made possible the production of the report. For its many shortcomings the author alone is responsible. 



\section{CONTENTS.}

\begin{tabular}{|c|c|c|c|c|}
\hline \multirow{2}{*}{\multicolumn{2}{|c|}{ INTRodUctory. - The UTILITy OF BIRDs in NATURE, }} & \multicolumn{3}{|r|}{ PAGE } \\
\hline & & - & • & \\
\hline Chapter I. - The Value of Birds to Man, . & - & - & . & \\
\hline Primitive Man's Relations to Nature, & - & - & - & \\
\hline Changed Relations produced by Agriculture, . & . & - & • & \\
\hline Man at War with Nature in the New World, . & . & . & & \\
\hline rease of Insect Pests, . & - & - & - & 27 \\
\hline amber of Insects, & - & - & - & 28 \\
\hline The Reproductive Capacity of Insects, . & - & , & - & 28 \\
\hline The Voracity of Insects, . . . . & - & $\cdot$ & - & 30 \\
\hline The Great Loss to American Agriculture by Ix & Insect $R$ & vages, . & . & \\
\hline by Insect Ravages in Massachusetts, & - & - & - & \\
\hline The Capacity of Birds for destroying Pests, & - & . & . & 40 \\
\hline The Digestion of Birds, . & - & • & - & 40 \\
\hline The Growth of Young Birds, . & $\bullet$ & $\cdot$ & - & \\
\hline The Amount of Food required by Young I & Birds, & • & . & \\
\hline The Time required for Assimilation of Fo & ood, . & • & - & \\
\hline The Number of Insects eaten by Young B & Birds in & $1 \mathbf{N}$ & . & \\
\hline The Amount of Food eaten by Adult Bird & ds, & - & - & - $\mathbf{5 7}$ \\
\hline Birds save Trees and Crops from Destruction, & , & - & - & 63 \\
\hline The Increase of Injurious Insects following th & e & & rds & 72 \\
\hline The Destruction of Injurious Mammals by Bir & irds, & $\cdot$ & - & . 76 \\
\hline The Value of Water-birds and Shore Birds, & . & - & . & \\
\hline The Commercial Value of Birds, . & • & . & - & 81 \\
\hline The Asthetic, Sentimental, and Educational & Value & $\mathbf{B i}$ & - & \\
\hline Y OF BIRDs IN Woo & ODLAN & $\cdot$ & - & \\
\hline The Relations of the & . & · & - & \\
\hline The Forest Planters, & . & • & . & \\
\hline
\end{tabular}

The Influence exerted by Birds and Squirrels on the Succession of

Forest Trees, . . . . . . . . . . . 96

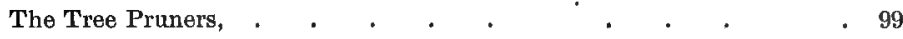

The Guardians of the Trees, . . . . . . . . . . 100

Chapter III. - Birds as Destroyers of Hairy Caterpillars and

Plant Lice, . . . . . . . . . . . . . 111

Chapter IV. - The Economic Service of Birds in the Orchard, - 149

Chapter $\nabla$. - Song Birds of Orchard and Woodland, . . 155

Woodland Thrushes, . . . . . . . . . 155

Kinglets, . . . . . . . . . . . . . 160

Nuthatches and Tits, . $\quad . \quad$. $\quad . \quad$. . . . 163 
Chapter V. - Song Birds of Orchard and Woodland-Con. page

Creepers, . . . . . . . . . . . . 177

Thrashers and Mockingbirds, . . . . . . . . . 178

Warblers, . . . . . . . . . . . . . 185

Vireos, . . . . . . . . . . . . 203

Waxwings, . . . . . . . . . . . . 209

Tanagers, . . . . . . . . . . . . . . . 211

Finches, Grosbeaks, and Towhees, . . . . . . . . . . 215

Blackbirds, Grackles, Orioles, etc., . . . . • . • . . . 224

Chapter VI. - Songless Birds of Orchard and Woodland, . . 229

Flycatchers, . . . . . . . . • • * . 229

Hummingbirds, . . . . . . . . . . . 240

Woodpeckers, . . . . . . . . . . . . 245

Cuckoos, Kingfishers, etc., . . . . . . . . . . . . 262

Grouse, Partridges, etc., . '. . . . . . . . . . 266

Chapter VII.-The Utility of Birds in Field and Garden, . : $275^{\circ}$

Chapter Vili. - Brrds of Field and Garden, . • . . . 282

Thrushes and their Allies, . . . . . . . . . 282

Wrens, . . . . . . . . . . . . . 292

Sparrows, . . . . . . . . . . . . . . 294

Blackbirds, Grackles, etc., . . . . . . . . . . 312

Pigeons and Doves, . . . . . . . . . . . . . 323

Grouse, Partridges, etc., . . . . . . . . . . . 325

Pheasants, . . . . . . . . . . . . 332

Snipe, Sandpipers, Woodcock, etc., . . . . . . . . 334

Chapter IX. - Birds of The Air, . . . . . . . . . . 339

Swifts, . . . . . . . . . . . . . 340

Nighthawks, Whip-poor-wills, etc,, . . . . . . . . 341

Swallows, . . . . . . . . . . . . . 343

Chapter X. - Birds of Marsh and Watersme, . . . . . 349

Perching Birds, . . . . . . . . . . . 349

Rails, . . . . . . . . . . . . . 350

Herons, . . . . . . . . . . . . . 351

Water-fowl, . . . . . . . . . . . . 353

Chapter XI. - Checks upon the Increase of Useful Birds, . . 354

The Destruction of Birds by Man, . . . . . . . . . . . 356

The Natural Enemies of Birds, . . . . . . . . . 361

Introduced Four-footed Enemies, . . . . . . . . . . 362

Cats, . . . . . . . . . . . . . 362

Native Four-footed Enemies, . . . . . . . . . . . 364

Squirrels, . . . . . . . . . . . . 364

Rats and Mice, . . . . . . . . . . . . 366

Feathered Enemies, . . . . . . . . . . . 366

Hawks, , . : . . . . . . . . . 366

Owls, . . . . . . . . . . . . . . 367

Crows and Jays, . . . . . . . . . . 368 
Chapter XI, - Checks upon the Increase of Useful Birds - Con. phae Feathered Enemies - Con.

The House Sparrow, . . . . . . . . . . 370

Shrikes, . . . . . . . . . . . . 370

Other Bird Enemies,. . . . . . . . . . . . . . 371

Reptilian Enemies, . . . . . . . . . . . 371

Fish, . . . . . . . . . . . . . . 371

Chapter XiI. - The Protection on Birds, . . . . . . 372

Methods of attracting Birds, . . . . . . . . . 373

Feeding and Assembling the Winter Birds, . . . . . 377

Attracting the Summer Birds, . . . . . . . . 384

Providing Nesting Places about Buildings, . . . . . . 386

Bird Houses and Nesting Boxes, . . . . . . . 388

Furnishing Nesting Material, . . . . . . . . 398

Feeding the Summer Birds, . . . . . . . . . 399

Attracting Water-fowl, . . . . . . . . . 402

The Protection of Birds against their Natural Enemies, . . . . 403

The Protection of Farm Products from Birds, . . . . . . 410

To protect Grain from Crows and Other Birds, . . . . . 411

To protect Small Fruits, . . . . . . . . . . 412

To protect Chickens from Hawks and Crows, . . . . . 412

General Protective Measures, . . . . . . . . . 413

Game Protection, . . . . . . . . . . 414

Measures and Legislation necessary for the Protection of Game and Birds, . . . . . . . . . . . . 415

Artificial Propagation of Game Birds, . . . . . . 417

The Movement for Bird Protection, . . . . . . . 418

Papers on Ormithology, published by the Massachusetts State Board of

Agriculture, . . . . . . . . . . . 421

INDEX, . . . . . . . . . . . . . . . . 493 



\section{LIST OF ILLUSTRATIONS.}

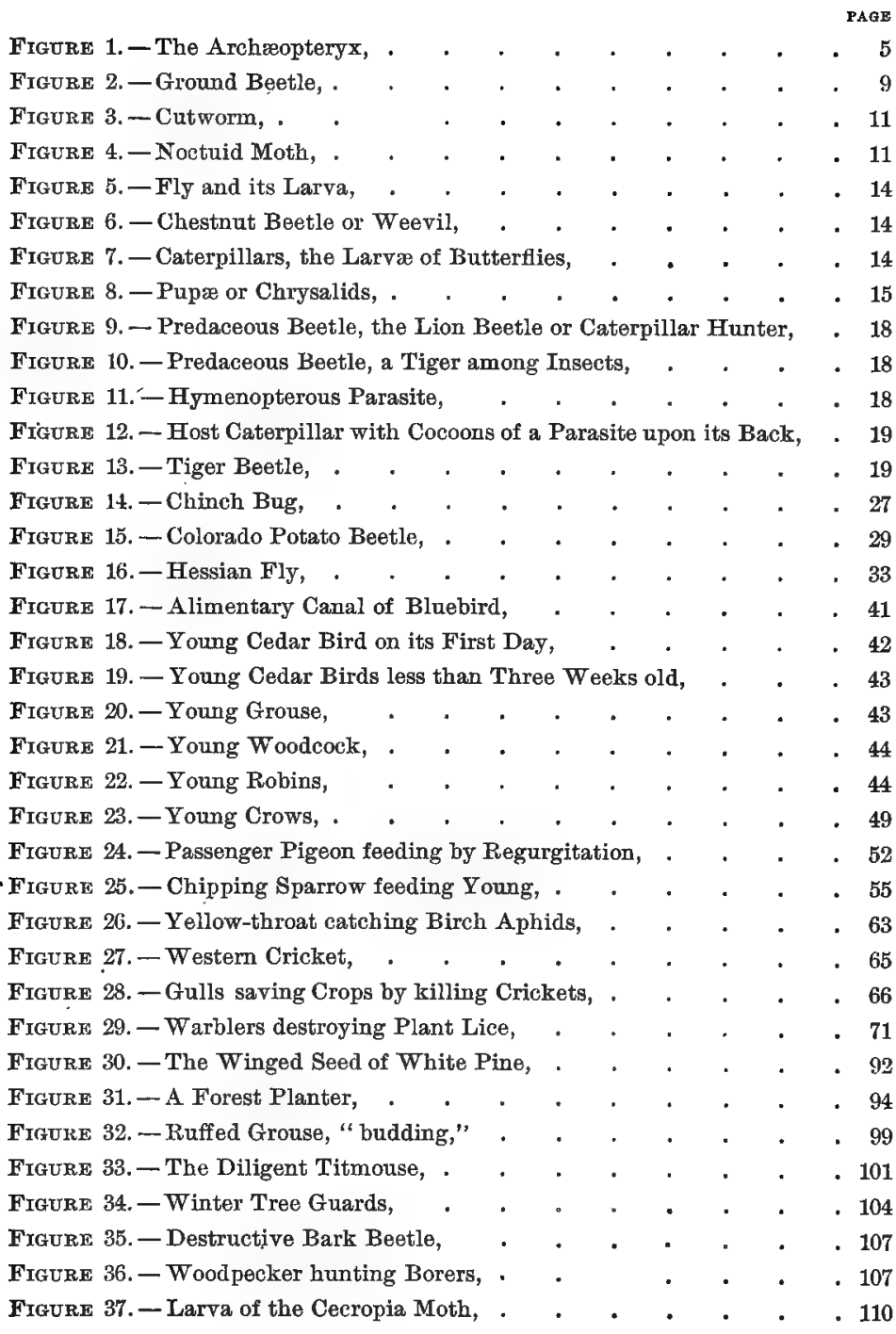


Frgure 38. - Woolly Bear Caterpillar, . . . . . . . 120

Figure 39. - Yellow Bear Catcrpillar, . . . • . . . . . 120

Figure 40.-Caterpillar of the White-marked Tussock Moth, . . . 121

Figure 41. - Web of the Brown-tail Moth Caterpillar, . . . . 130

Figure 42. - Nashville Warbler, . . . . . . . . . . 133

Frgure 43. - Caterpillar of the Brown-tail Moth, . . . . . 133

Figure 44. - Warblers feeding on Young Caterpillars of the Gipsy Moth, . 135

Frgure 45. - Egg Cluster of the Gipsy Moth, . . . . . . 148

Figure 46. - Wilson's Thrush, . . . . . . . . . . 157

Figure 47. - Wood Thrush, . . . . . . . . . 158

Figure 48. - Golden-crowned Kinglet, . . . . . . . . . 161

Figure 49. - Chickadee, . . . . . . . . . . . . 164

Figure 50. - Eggs of the Tent Caterpillar Moth, _ . . . . 167

Figure 51. - Codling Moth, Parent of the Apple Worm, . . . 168

Figure 52. - Fall Cankerworm Moth, . . . . . . . . . . 169

Figure 53. - Apple Twig with Eggs of the Cankerworm Moth, . . . 169

Figure 54. - White-breasted Nuthatch, . . . . . . . . 172

Frgure 55. - Nuthatches, . . . . . . . . . . . 173

Figure 56. - Wood-boring Beetle, . . . . . . . . . 175

Figure 57. - Red-breasted Nuthatch, . • . . . . . . . . 176

FIGURe 58. - Brown Creeper, . . . . . . . . . . . . . 177

Frgure 59. - Brown Thrasher, . . . . . . . . . . . 180

Figure 60.- Catbird, . . . . . . . . . . . 182

Figure 61. - Northern Yellow-throat, . . . . . . . . . 187

Figure 62. - Ovén-bird and Nest, . . . . . . . . . . 189

Figure 63.-Black and White Warbler, . . . . . . . . . 191

Figure 64.-Chestnut-sided Warbler, . . . . . . . . . 193

Figure 65. - Yellow Warbler, . . . . . . . . . . . 195

FiGURE 66. - American Redstart, . . . . . . . . 197

Figure 67. - Black-throated Green Warbler, . . . . . . . 199

Figure 68. - Pine Warbler, . . . . . . . . . . . 201

Figure 69. - Myrtle Warbler, . . . . . . . . . . 202

Figure 70. - Woolly Apple Tree Aphis, . : . . . . . . 202

Figure 71. - Red-eyed Vireo, . . . . . . . . . . 204

Figure 72.- Warbling Vireo, . . . . . . . . . 206

Figure 73. - Yellow-throated Vireo, . . . . . . . . . . 208

Figure 74. - Cedar Bird, . . . . . . . . . . . 209

Figure 75.-Passing the Cherry, . . . . . . . . . 210

Figure 76. - Good Work in the Orchard, . . . . . . . . 211

FIgURE 77. - Scarlet Tanagers and Gipsy Moth Caterpillars, . . . 212

FIGURE 78, - Rose-breasted Grosbeak, Male, . . . . . . . 216

Figure 79. - Rose-breasted Grosbeak, Female, . . . . . . . 217

Figure 80.-Towhee, . . . . . . . . . . . . . 219

Figure 81. - Purple Finch, . . . . . . . . . . . . 221

Figure 82.-American Goldfinch, . • . • . . . . 222 


\begin{tabular}{|c|c|c|c|c|c|c|c|c|c|}
\hline URE 83. - Baltimore Oriole, & & & - & - & ' & - & - & - & . 22 \\
\hline aE 84. - Pea Weevil, . & - & $\cdot$ & & - & 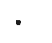 & $\cdot$ & . & . & $\cdot 22$ \\
\hline IGURE $85 .-$ Tent Caterpillars, $\mathrm{F}$ & Eggs, & , and & Coco & & . & 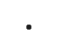 & . & 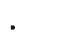 & 00 \\
\hline IGURE 86. - Click Beetle, . & & $\cdot$ & & - & - & 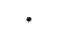 & $\cdot$ & $\cdot$ & \\
\hline GURE 87. - Cucumber Beetle an & nd $\mathrm{Cr}$ & ureuli & lios, & . & - & - & . & - & \\
\hline IGURE 88. - Gipsy Moth, Male, & - & - & . & . & - & - & . & - & \\
\hline 2E $89 .-\mathrm{C}$ & . & - & 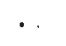 & - & - & 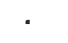 & - & 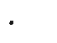 & \\
\hline $\mathrm{E} 90 .-\mathrm{Y}$ & . & . & - & - & - & . & - & . & 23 \\
\hline IGURE $91 .-\mathbf{T c}$ & 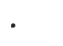 & - & . & . & . & - & . & . & \\
\hline 2E $92 .-\mathrm{T}$ & . & 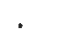 & - & - & - & 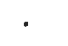 & . & . & \\
\hline RE 93. $-\mathrm{Pl}$ & . & - & - & . & . & 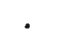 & . & - & 23 \\
\hline FIGURE $94 .-$ Moth of Spring Can & akerw & Worm, & . & $\cdot$ & . & - & - & 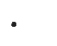 & 23 \\
\hline IGURE 95. - Wood-boring Click & Beet & tle, & - & · & . & - & - & - & . \\
\hline E $96 .-\mathrm{Br}$ & . & - & . & . & - & 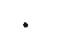 & - & - & 234 \\
\hline E $97 .-\mathbf{K i}$ & 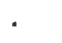 & - & - & 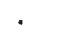 & - & 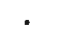 & • & 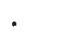 & 23 \\
\hline E $98 .-\mathrm{Cet}$ & & - & . & . & . & - & . & . & \\
\hline RE 99. - May & & . & 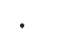 & & - & 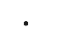 & . & . & 28 \\
\hline IGURE 100. — Hummingbirds abo & out $\mathbf{T}$ & Two $\mathrm{Y}$ & Weeks & s old, & . & 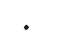 & & . & $24:$ \\
\hline IGURE 101. - Hummingbird feed & ding & Youn & & 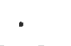 & . & . & . & - & \\
\hline IGURE 102. - Young Hummingbi & iro & ne & y fled & lged, & . & - & & . & 244 \\
\hline IGURE 103. - Skull and Tongue c & of $\mathrm{W}$ & Toodpe & pecker & & & ${ }^{\circ}$ & . & 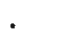 & 240 \\
\hline IGURE 104. - Spearlike Tongue-t & tip of & f Dow & wny h & Woodp & & & & - & \\
\hline afe $105 .-\mathrm{Pi}$ & . & . & - & $\cdot$ & - & . & & - & 247 \\
\hline E 106. - Pale & . & & . & 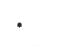 & & - & . & . & 248 \\
\hline rGURE 107. - Cocoon of Codling I & Moth & $\mathrm{h}$ pier & rced b & by Wo & ood & eck & & . & \\
\hline GURE 108. - App & & & 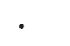 & & 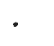 & . & & . & 251 \\
\hline GURE 109. - Sec & Tree s & saved & d by $D$ & Dor & & oodp & ecker, . & . & 258 \\
\hline IGURE 110. - Downy Woodpecke & er anc & d his & Worl & & $\cdot$ & - & . & - & \\
\hline IGURE 111. - Bark pierced by Do & ow & Woc & odpec & oker, & $\cdot$ & . & & - & 254 \\
\hline IGURE 112.-The Same, showing & g the & Char & mnels & made & & Bark & & les, & 254 \\
\hline Figure 113. - Pine Top killed by & Pine & e We & evil, & & & , & - & - & 25 \\
\hline IGURE 114. - Tree ruined for Tin & mber & by $P$ & Pine $\mathrm{K}$ & We & & : & & - & .255 \\
\hline 115. - Sec & pl & apr & $d$ for $s$ & $s$ & & - & & 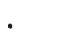 & . $25 t$ \\
\hline GURE $116 .-A$ & & . & - & - & • & . & & $\cdot$ & 257 \\
\hline GURE $117 .-\mathrm{Hz}$ & & . & . & . & . & • & . & - & 258 \\
\hline E $118,-F$ & & & - & 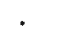 & . & . & . & . & . 261 \\
\hline $\mathrm{RE} 119 .-\mathrm{B}$ ] & & $\cdot$ & & . & • & . & & & 264 \\
\hline Gure 120. - Catert & & & & . & . & . & . & 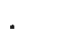 & 264 \\
\hline E $121 .-S p$ & & & - & . & & - & - & $\cdot$ & 264 \\
\hline E $122 .-\mathrm{Fa}$ & & . & . & e & $\cdot$ & - & • & & 26 \\
\hline E 123. - Red-hu & & & & . & . & . & . & 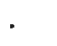 & . 272 \\
\hline -Tree & & - & & 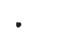 & . & - & . & & 273 \\
\hline Robin, & & & - & 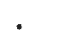 & . & 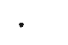 & 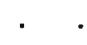 & & 28 \\
\hline$-W$ & & . & 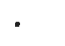 & . & . & . & . & & \\
\hline - Bluebird, & & & & & - & 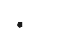 & 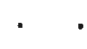 & - & 29 \\
\hline
\end{tabular}




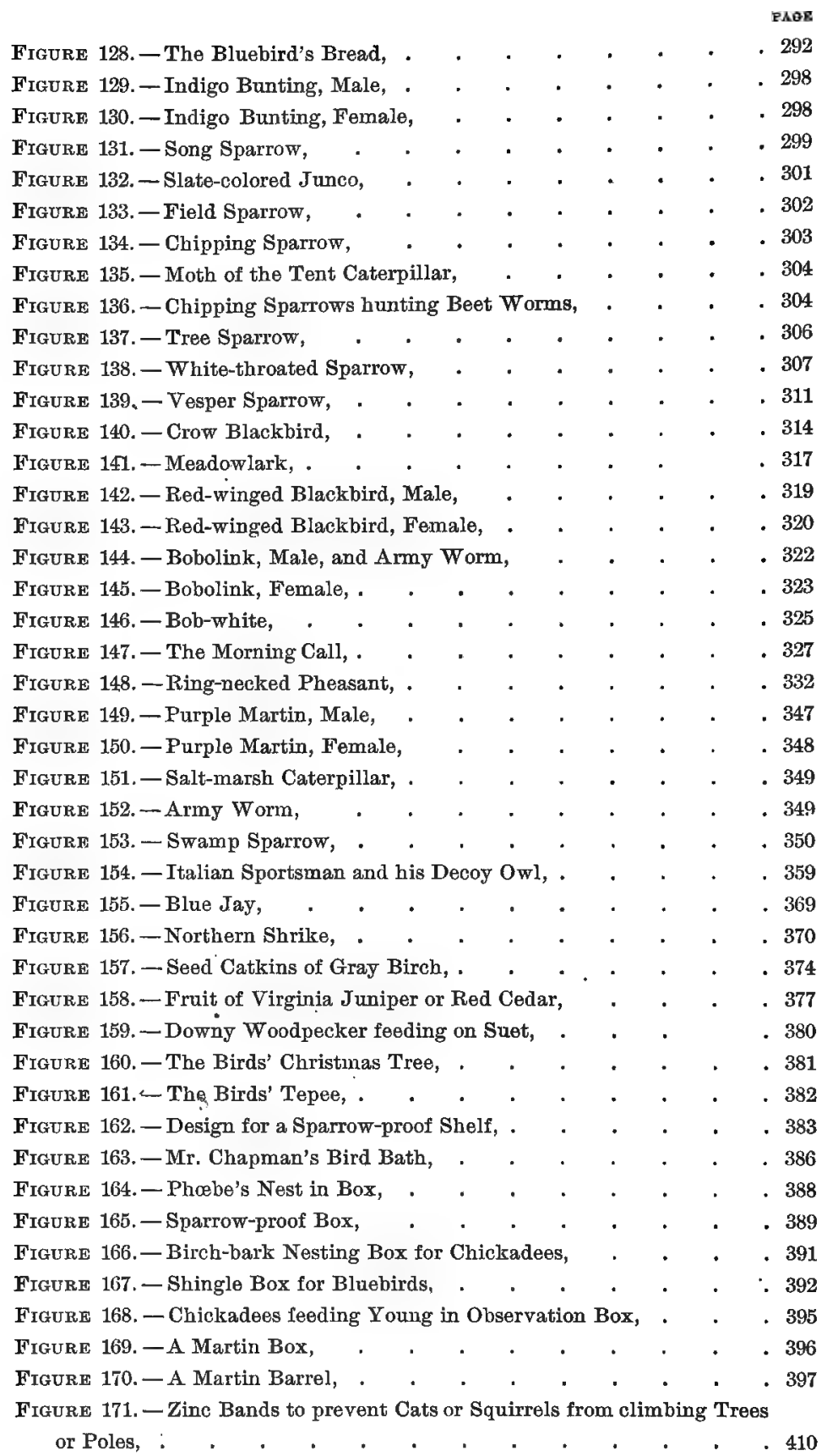


Wood Duck (Colored Plate), . . . . . . . Frontispiece Plate I. - The American Silkworm Moth, . . . . . faces page 31 Plate II. - The Destructiveness of the Gipsy Moth, between pages 38 and 39 Plate III. - Expensive Work of destroying the Eggs of the

Gipsy Moth in Woodland Parks, . . . . between pages 38 and 39 Plate IV. - Red-ejed Vireo feeding Young, . . . . faces page 51 Plate V. - Chickadee, with Insects in its Beak, . . . faces page 54 Plate VI. - Field or Meadow Mouse, . . . . . faces page 76 Plate VII. - White-footed or Deer Mouse, . . . . faces page 76 Plate VIII. - A Useful Mouse-eating Owl, . . . . . faces page 78 Plate IX. - Regurgitated Owl Pellets, . . . . . faces page 80 Plate X. - The Same Pellets, dissected, . . . . . faces page 80 Plate XI. - Albatrosses on Laysan Island, H. I., . . . faces page 82 Plate XII. - The Cecropia Moth, . . . . . . faces page 109 Plate XIII. - Web of Tent Caterpillar, which had been

attacked by Birds, . . . . . . . . . faces page 118

Plate XIV. - Various Stages of the Brown-tail Moth, . . faces page 137

Plate XV. - Various Stages of the Gipsy Moth, . . . faces page 142

Plate XVI. - General View of Georgetown Woodland, . . faces page 144

Plate XVII. - Pines, Oaks, and Other Trees, stripped by the

Omnivorous Caterpillars of the Gipsy Moth, . . . faces page 144

Plate XVIII. - Luna Moth, . . . . . . . faces page 214

Plate XIX. - Least Flycatcher on Nest, . . . . . faces page 229

Plate XX. - Downy Woodpecker at Nest Hole, . . . faces page 249

Plate XXI. - Ruffed Grouse on Nest, . . . . . faces page 267

Plate XXII. - Ruffed Grouse, One Day old, . . . . faces page 268

Plate XXIIr. - Ruffed Grouse, Four Months old, . . . faces page 268

Plate XXIV.-Ruffed Grouse, strutting, . . . . faces page 270

Plate XXV. - Robin's Nest in Hollow Tree, . . . . faces page 283

Plate XXVI. - Robin on Nest, . . . . . . . . faces page 289

Prate XXVII. - Wren at Nest Hole, . . . . . f faces page 293

Plate XXVIII. - Chipping Sparrows feeding their Young, . faces page 304

Plate XXIX. - American Woodcock, . . . . . faces page 336

Plate XXX. - Nighthawk, . . . . . . . faces page 341

Plate XXXI. - Whip-poor-will, . . . . . . faces page 341

Plate XXXII. - A Swallow Roost, . . . . . . faces page 343

Plate XXXII. - Nest Robbers, . . . . . . faces page 359

Plate XXXIV.-Work which drives out the Birds, . . faces page 360

Plate XXXV. - Cat with Young Robin, . . . . . faces page 362

Plate XXXVI. - Barred Owl, . . . . . . . faces page 367

Plate XXXVII. - Blue Jay's Nest in Author's Grove, - . faces page 369

Plate XXXVIII. - Fruits that are valuable as Bird Food, . faces page 375

Plate XXXIX. - A Bountiful Repast, . . . . . faces page 378

Plate XL. - A Scratching Shed, . . . . . . faces page 378

Plate XLI. - Chickadee seen through Window, at Author's

Home, . . . . . . . . . . . faces page 380 
Plate XLII. - Chickadees on Pork Rind, . . . . faces page 380 PLATE XLIII. - Ernest Harold Baynes taming a Chickadee, . faces page 381 Plate XLIV. - Chickadee feeding from the Hand, . . . faces page 381 Plate XLV. - Chickadees seen on a Frosty Morning, through

Author's Window, . . . . . . . . faces page 382

Plate XLVI. - A Red-breasted Nuthatch at the Window, . 'faces page 382

Plate XLVII. - Bird Houses and Nesting Boxes, . . . faces page 391

Plate XLVIII. - Inexpensive Nesting Boxes, . . . . . faces page 392

Plate XLIX. - Chickadee about to enter its Nest, in an old

Varnish Can, . . . . . . . . . . faces page 392

Plate L. - Owl Box, at Author's Home, . . between pages 394 and 395

Plate LI. - Owl on Nest, . . . . . between pages 394 and 395

Plate LII. - Chickadeo's Nest, made of Çotton, in Box on

Author's Window, . . . . . between pages 400 and 401

Plate LIII. - Chickadee on Nest, . . . between pages 400 and 401

Plate LIV. - Mother Chickadee bringing Food to Young,

between pages 400 and 401

Plate LV. - Mother Chickadee cleaning Nest, between pages 400 and 401

Plater LVI. - Domesticated Canada Goose on Nest, . . faces page 417 


\section{USEFUL BIRDS AND THEIR PROTECTION.}

\section{INTRODUCTORY.}

\section{THE UTILITY OF BIRDS IN NATURE.}

There is no sulject in the field of natural science that is of greater interest than the important position that the living bird occupies in the great plan of organic nature.

The food relations of birds are so complicated and have such a far-reaching effect upon other forms of life that the mind of man may never be able fully to trace and grasp them. The migrations of birds are so vast and widespread that the movements of many species are still mole or less shrouded in mystery. We do not yet know, for instance, just where certain common birds pass some of the winter months. Some species sweep in their annual flights from Arctic America to the plains of Patagonia, coursing the entire length of the habitable portion of a hemisphere. Many of the birds that summer in northern or temperate America winter in or near the tropics. Some species remain in the colder or temperate regions only long enough to mate, nest, and rear their young, and then start on their long journey toward the equator.

The annual earth-wide sweep of the tide of bird life from zone to zone renders the study of the relations of birds to other living forms throughout their range a task of the utmost magnitude. This vast migration at once suggests the question, Of what use in nature is this host of winged creatures that with the changing seasons sweeps over land and sea?

Our first concern in answering this question is to determine what particular office or function in the economy of nature birds alone are fitted to perform. The relations 
they may bear to the unnatural and semi-artificial conditions produced by the agriculturist may then be better understood. The position occupied by birds among the forces of nature is unique in one respect at least; their structure fits them to perform the office of a swiftly moving force of police, large bodies of which can be assembled at once to correct disturbances caused by abnormal outbreaks of plant or animal life. This function is well performed. A swarm of locusts appears, and birds of many species congregate to feed upon locusts. An irruption of field mice, lemmings, or gophers occurs, and birds of prey gather to the feast from far and near.

This habit of birds is also serviceable in clearing the earth of decaying materials, which otherwise might pollute both air and water. A great slaughter of animals takes place, and Eagles, Vultures, Crows, and other scavengers hasten to tear the flesh from the carcasses. A dead sea monster is cast upon the shore, and sea birds promptly assemble to devour its wasting tissues. The gathering of birds to feed is commonly observed in the flocking of Crows in meadows where grasshoppers or grubs abound, the assembling of Crows and Blackbirds in cornfields, and in the massing of shore birds on flats or marshes where the receding tide exposes their food.

A study of the structure and habits of birds shows how well fitted they are to check excessive multiplication of injurious creatures or to remove offensive material. Birds are distinguished from all other animals by their complex, feathered wings, - the organs of perfect flight.

The tremendous muscular power exhibited by birds is only such as might be expected in creatures provided with such perfect respiratory, circulatory, and assimilative organs. The strength of birds as compared with that of man is enormously out of proportion to their size; but it is largely concentrated in the muscles that move the wings, for it is by flight that the bird is enabled to live. No other animals have such sustained power of flight or such perfect command over themselves while in the air. Even the bat, which is a most skillful flyer, being remarkably quick in aerial evolutions, 
cannot at its best equal the bird. I once saw a bat make seven attempts to catch a moth fluttering along the still surface of a moonlit river. A Swallow could have seized it at once with no perceptible effort. No creature can equal the soaring of the Eagle or Vulture, or that of the Man-o'-War Bird as it sails on high above the storm; while the speed that the Hummingbird attains is such that the eye can scarcely follow its most rapid flight.

Birds are provided with wings to enable them (1) to procure food, (2) to escape their enemies, (3) to migrate.

All birds have wings, though a few, like the Apteryx, have them only in a rudimentary form. Others, like the Penguin and the Ostrich, have small wings, but cannot raise themselves in the air.

All birds that cannot fly, however, are reminders of a past age, and are not fitted to live on the same earth with man. Such birds are either already extinct or in a fair way to become so, either at the hands of man or at the teeth or claws of the dogs, cats, or other animals that man introduces. Flight alone might save the few that remain. The Great Auk, using its wings only in pursuing its prey under water, disappeared before the onslaught of the white man; while the Loon, flying both under water and above it, still survives.

Birds are pursued by many enemies. Water-fowl fly to the water and dive to escape the Hawk or Eagle, and fly to the land to escape the shark, alligator, or pike. Sparrows fly to the thicket to elude the Hawk, and to the trees to avoid the cat. Evidently this great power of flight was given to birds to enable them not only to concentrate their forces rapidly at a given point, but also to pursue other flying creatures. Birds can pursue bats, flying squirrels, flying fish, and insects through the air. Bats and insects are their only competitors in flight. Comparatively few insects can escape birds by flight, and this they do mainly by quick dodging and turning. The speed at which birds can fly on occasion has seldom been accurately measured. The maximum flight velocity of certain wild-fowl is said to be ninety miles an hour. Passenger Pigeons killed in the neighbor- 
hood of New York have had in their crops rice probably taken from the fields of the Carolinas or Georgia, which indicates that within six hours they had flown the three or four hundred miles intervening, at about the rate of a mile a minute. ${ }^{1}$

The rate of flight of a species must be sufficiently rapid to enable it to exist, and so perform its part in the economy of nature.

Birds find distant food by the senses of sight and hearing mainly. The sense of smell is not highly developed, but the other perceptive powers are remarkable. The perfection of sight in birds is almost incomprehensible to those who have not studied the organs of vision. The keen eye of the Hawk has become proverbial. The bird's eye is much larger in proportion to the size of its owner than are the eyes of other vertebrates. It is provided with an organ called the pecten, by which, so naturalists believe, the focus can be changed in an instant, so that the bird becomes nearsighted or farsighted at need. Such provision for changing the focus of the eye is indispensable to certain birds in their quick rush upon their prey. Thus the Osprey or Fish Hawk, flying over an arm of the sea, marks its quarry down in the dark water. As the bird plunges swiftly through the air its eye is kept constantly focussed upon the fish, and when within striking distance it can still see clearly its panic-stricken prey. Were a man to descend so suddenly from such a height he would lose sight of the fish before he reached the water. The Flycatcher, sitting erect upon its perch, watching passing insects that are often invisible to the human eye, in like manner utilizes the pecten in the pereeption, pursuit, and capture of its prey. Most of the smaller birds will see a Hawk in the sky before it becomes visible to the human eye. The Vulture, floating on wide wings in upper air, discerns his chosen food in the valley far below, and as he descends toward it he is seen by others wheeling in the distant sky. As they turn to follow him they also are seen by others soaring at greater distances, who, following, are pur-

\footnotetext{
1 American Ornithology, Wilson and Bonaparte, Vol. IV, pp. 319, 320. Evidently a quotation from Audubon's Ornithological Biography.
} 
sued from afar by others still, until a feathered host concenters from the sky upon the carrion feast.

Birds are lower in the organic scale than the class of mammals which includes man, the four-footed animals, and even the seal and the whale. Birds are closely allied in structure to reptiles. The earliest bird known, the Archropteryx, had teeth, two fingers on each wing, and a long reptilian tail adorned with feathers. Still, notwithstanding the comparatively $10 \mathrm{w}$ place which is given by the systematists to birds, their physical organization excels in some respects that of all otheranimals. They surpass all other vertebrate animals in breathing power or lung capacity, as well as in muscular strength and activ-

ity. The tempera- Fig. 1. - The Archæopteryx, a bird with teeth. Reture of the blood is stored from the Jurassic epoch. A bout one-fifth natural higher in birds than

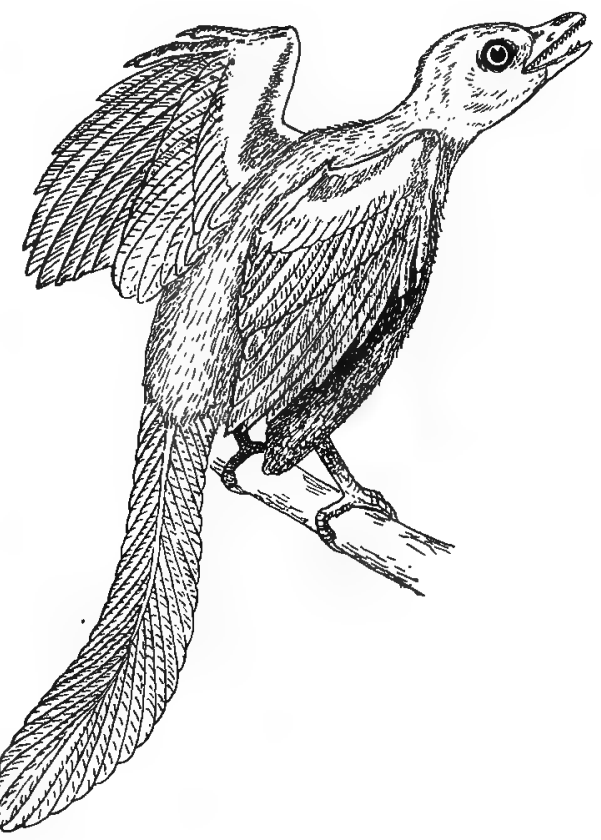

in other animals, and the circulation is more rapid. To maintain this high temperature, rapid circulation, and great activity, a large amount of food is absolutely necessary. Food is the fuel without which the brightly burning fires of life must grow dim and die away. Birds are, therefore, fitted for their function of aerial police not only by their powers of flight and perception, but also by their enormous capacity for assimilating food. When food is plentiful, birds gorge themselves, accumulating fat in quantities. Shore birds frequently become so fat during the fall migra- 
tions that, when shot, their distended skins burst open when their bodies strike the ground. This accumulation of fatty tissue may aid to tide the birds over a season of scarcity, but the moment they need food they must seek it far and wide, if need be, as they cannot live long without it. Birds are not always the ethereal, care-free creatures of the poet's dream. In time of plenty, the joys of flight, of sunshine, of singing, of riding swinging boughs, or tossing to and fro on flashing waves, are theirs to the full; but in times of scarcity, or when rearing their helpless young, their daily lives are often one continued strenuous hunt for food. Food, therefore, is the mainspring of the bird's existence. Love and fear alone are at times stronger than the food craving. The amount of food that birds are capable of consuming renders them doubly useful in case of an emergency.

The utility of birds in suppressing outbreaks of other animals by massing at threatened points is of no greater value in the plan of nature than is the perennial regulative influence exerted by them individually everywhere as a check on the undue increase of other forms of life.

He who studies living birds, other animals, or plants, and the relations which these living organisms bear to one another, will soon learn that the main effort of each plant or animal is to preserve its own life and produce seed or young, and so multiply its kind. He will see, also, that the similar efforts of other organisms by which it is surrounded tend to hold its increase in check.

The oak produces many hundreds of acorns; and were each acorn to develop into a tree, the earth eventually would be full of oaks, for all other trees would be crowded out. But many animals feed on the acorns or the young seedlings; other trees crowd out the young oaks; caterpillars feed on the foliage; other insects feed on the wood and bark, destroying many trees; so, on the average, each oak barely succeeds in producing another to occupy its place.

Certain moths deposit hundreds of eggs in a season; and were each egg to hatch and each insect to come to maturity and go on producing young at the same rate, the entire earth 
in a few years would be carpeted with crawling caterpillars, and the moths in flight would cover the earth like a blanket of fog. But under natural conditions the caterpillars that hatch from the eggs of the moth are destroyed by birds, mammals, insects, or other animals, by disease or the action of the elements, so that in the end only one pair of moths succeeds another. If every Robin should produce five young each year, and each Robin should live fifteen years, in time every square foot of land on this continent would be packed with Robins; but the surplus Robins are killed and eaten by various other birds or by mammals, each striving to maintain itself; so that, eventually, the number of Robins remains about the same.

Thus we see that, while birds, insects, other animals, and plants are constantly striving to increase their numbers, the creatures that feed upon them operate continually to check this undue multiplication. The Hawk preys upon the smaller birds and mammals. The smaller birds and mammals feed on insects, grass, seeds, leaves, and other animal and vegetable food, each virtually endeavoring to gain strength and increase the numbers of its race at the expense of other living organisms.

There is a competition among various dissimilar organisms, also, in seeking certain .kinds of food. Grazing mammals, such as cattle, sheep, and deer, eat grass. Grass is eaten also by birds, mice, and insects. If any one lind of these creatures should be left without check, and become too numerous, it might consume the food supply of all.

In the great struggle for existence, each perpetuating form of life that we call a species is really an expansive force, that can be restrained and kept in its proper place only by the similar expanșive forces (other species) by which it is surrounded. It is as if the whole field of animal and vegetable life consisted of a series of springs, each exerting a pressure in all directions, and each held in place only by the similar expansion of the springs surrounding it. This action and reaction of natural forces constitute what is known as the balance of nature. Any serious disturbance of this balance is always fraught with serious consequences. 
All animals and plants are sustained and nourished by air, water, and food. Food supplies the material for growth and development. Its abundance increases the energy and fertility of a species, - its ability to produce young abundantly. The study of the food and food habits of birds and other animals is of the utmost importance, for by this study alone we are enabled to trace their life relations to each other, to plants, and to man. Some progress has already been made in this study. We know in a general way the character of the food of some of the common birds of the United States; but we know so little as yet of the food of the smaller mammals, the reptiles, batrachians, many insects and other lower animals, that it is impossible to tell what may be the ultimate effect of the destruction of any one of these animals by birds.

On the other hand, no one can tell what grave and farreaching results might follow the extermination of a single species of bird; for it is probable that the food preferences of each species are so distinctive that no other could fill its place.

Birds are guided by their natural tastes in selecting their food, unless driven by necessity. Of the food which suits their tastes, that which is most easily taken is usually first selected. In the main, species" of similar structure and habits often choose similar food, but each species usually differs from its allies in the selection of some certain favorite insects. Were a species exterminated, however, its place might be taken eventually by the combined action of many species, for nature always operates to restore her disturbed balances.

The complexity of the food relations existing between birds and other organisms may be indicated hypothetically by a brief illustration. The Eagles, larger IJawks, and Owls feed to some extent on Crows, and probably the nocturnal, tree-climbing, nest-haunting raccoon also robs them of eggs and young; otherwise, they seem to have very few natural enemies to check their increase. Crows feed on so many different forms of animal and vegetable life that they are nearly always able to find suitable food; therefore they are common and widely distributed. 
The genelal fitness of the Crow is admitted by all. Undoubtedly it has a useful work to perform in the world; but a careful study of its food habits shows so many apparently harmful traits that it may well leave the investigator in some doubt as to the Crow's value in the general plan. Crows rob the nests of Robins, eating very many eggs and young birds; they therefore constitute a serious check on the increase of this species. Robins feed largely on common black beetles, called ground beetles (Carabidx), which run about on the ground, hiding under stones and other rubbish. As these beetles are not quick to fly by day, and are easily caught, they form a considerable part of the food of many groundfrequenting birds. But ground beetles feed, to a greater or less extent, on other insects. The question then arises, Is not the Robin doing harm in killing ground beetles, and does it not merit the destruction of its eggs and young by the Crow? If the Robin's habit of eating these beetles

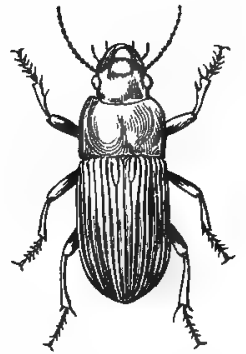

Fig. 2. - Ground beetle. is harmful, is not the Crow rendering a service by destroying a bird so apparently destructive as the Robin? Perhaps, if there were too many Robins, they might eat too many ground beetles, and thus become the indirect cause of the destruction of much vegetation, by saving the lives of the caterpillars and other harmful insects that the ground beetles, had they been left to themselves, might have destroyed. ${ }^{1}$

Many ground beetles that are eaten by the Robin feed much on vegetable matter. ${ }^{2}$ This makes these beetles doubly useful in one respect, for they can maintain their numbers

- These questions can be answered only by one having a thorough knowledge of the food of our ground beetles, - a knowledge which no living man yet possesses; but enough has been learned to throw some light on their food habits. Insects that feed promiscuously on other insects are generally classed as beneficial in so far as they take insect food, even though they may destroy some so-called useful insects; for, as the so-called injurious insects far outnumber the useful ones, it is censidered safe to regard the habit of feeding on insects a beneficial one.

2 The ground beetles of the genus Calosoma and those of some closely allied genera are believed to feed entirely on animal food, as their structure fits them for that alone. They feed ravenously upon both beneficial and injurious insects, and when too numerous they devour one another. These are not the beetles that are generally eaten by the Robin, however, but rather by the Crow. 
when insect food is not plentiful, and so be ready to check any increase of insects which may occur. On the other hand, if they become too numerous, they may create serious disturbances by destroying grass, grain, or fruit. I have witnessed attacks made by certain of these beetles on grain and strawberries; and were they not held in check by birds, it is probable that they would soon become serious pests. Their destruction by Robins and other birds tends to keep these beetles within those normal bounds where they will do most good and least harm; while the check kept by the Crow on the increase of the Robin may prevent the latter from destroying too many ground beetles. If certain low-feeding caterpillars became so numerous as to be injurious, ground beetles and Robins would feed largely on them. The caterpillars would then largely take the place of the beetles in the Robin's food. The beetles, therefore, would increase in numbers, and the force of both bird and beetle would be exerted to reduce the caterpillars to their normal limit. This accomplished, the Robin would again attack the ground beetles, and thus tend to reduce them to normal numbers.

Let us now go back to the beginning of our chain of destruction. The Eagles, Hawks, Owls; and raccoons may indirectly allow an increase in the number of Robins by preventing too great an increase of the Crow. But Hawks and Owls also prey on the Robin, and, by dividing their attention between Robin and Crow, assist in keeping both birds to their normal numbers. Whenever Crows became rare, Robins as a consequence would become very numerous, were it not that the Hawks also eat Robins. (Hawks and Owls eat also some species of insects that are eaten by both Robin and Crow.)

There are compensations in the apparently destructive career of the Crow. An omnivorous bird, it seems inclined to turn its attention to any food which is plentiful and readily obtained. It is a great feeder on May beetles (miscalled "June bugs"), the larvæ of which, known as white grubs, burrowing in the ground, sometimes devastate grass lands and also injure the roots of many plants, including trees. 
The Crow is also a destroyer of cutworms. These are the young or larve of such noctuid moths or "millers" as are commonly seen fluttering from the grass by any one who disturbs them by walking in the fields. Robins also feed largely on cutworms, as well as on the white

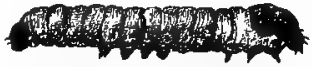

Fig. 3. - Cutworm. grub of the May beetle. When these insects are fow in number, a part of the usual food supply of both Robin and Crow is cut off. This being the case, the hungry

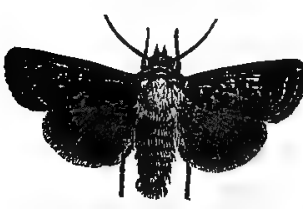

Fig. 4. - Noctuid moth. Crows are likely to destroy more young Robins and other young birds than usual, in order to make up the supply of animal food for themselves and their ravenous nestlings. In a few years this would decrease perceptibly the number of Robins and other small birds, and would be likely in turn to allow an increase of May beetles and cutworms. As these insects became more plentiful, the Crows would naturally turn again to them, paying less attention to the young of Robins and other birds for the time, and allowing them to increase once more, until their multiplication put a check on the insects, when the Crows would of necessity again raid the Robins.

The Blue Jay may be taken as another instance of this means of preserving the balance of nature. Hawks and Owls kill Blue Jays, Crows destroy their eggs and young; thus the Jays are kept in check. Jays are omnivorous feeders. They eat the eggs and young of other birds, particularly those of Warblers, Titmice, and Vireos, - - birds which are active caterpillar hunters. But Jays are also extremely efficient caterpillar hunters. Thus the Jays compensate in some measure for their destruction of caterpillar-eating birds, by themselves destroying the caterpillars which they unconsciously have allowed to increase in numbers by destroying these birds. Like the Crow, they virtually kill the young of the smaller birds, and eat them, that they (the Jays) may eventually have more insect food for their own young. When this object bas been attained, the Jays may again, perhaps, allow an increase of 
the smaller birds, the survivors of which they have unwittingly furnished with more insect food, thus making conditions favorable for the increase of the smaller birds. These oscillations or alternate expansions and contractions in the numbers of birds or insects are usually so slight as to escape common observation. It is only in those cases where they are carried to extremes that they result disastrously. Under nature the checks on the increase of birds are essential, else they would increase in numbers until their food supply had become exhausted, when they would starve, and other consequences even more grave and much more complex would then follow.

While these examples of the way in which the balance of nature is preserved may be regarded as somewhat hypothetical, they probably approximate what actually takes place, although the feeding habits of birds undoubtedly produce far more complicated results than are here outlined.

It is a law of nature that the destroyer is also the protector. Birds of prey save the species on which they prey from overproduction and consequent starvation. They also serve such species in at least two other ways: (1) the more powerful bird enemies of a certain bird usually prey upon some of its weaker enemies; (2) these powerful birds also check the propagation of weakness, disease, or unfitness, by killing off the weaker or most unfit individuals among the species on which they prey, for these are most easily captured and killed.

We have seen already that Jays, which are enemies of the smaller birds, are preyed upon by the more powerful Crows, Hawks, and Owls. These latter also destroy skunks, weasels, squirrels, mice, and snakes, all of which are also enemies of the smaller birds. No doubt these animals would be much more injurious to the smaller birds were they without these wholesome feathered checks on their increase.

In a state of nature, albino birds or those that are rendered conspicuous to their enemies by any unusual mark or color are soon captured by some bird of prey, and seldom live to perpetuate their unfitness. 
An experience with domestic Pigeons, related to me by Mr. William Brewster, will serve as proof of this statement. He had kept a flock of twenty-five or thirty Pigeons in confinement at Cambridge for many years. Under such protective domestication the individuals of the flock had assumed a variety of shades and colors. There were blue Doves, white Doves, and many pied individuals varying between the two extremes. He removed the flock to his farm in Concord, where they were at liberty to roam at will during the day. Here they were attacked by Hawks, and in five years' time the white and pied birds were practically all weeded out, and the flock consisted of blue rock Doves alone.

The preservation of birds by the weeding out of sickly or wounded individuals did not escape the notice of Prof. Spencer F. Baird, who wrote :-

It has now been conclusively shown, I think, that Hawks perform an important function in maintaining in good condition the stock of game birds, by capturing the weak and sickly, and thus preventing reproduction from unhealthy parents. One of the most plausible hypotheses explanatory of the occasional outbreaks of disease amongst the grouse of Scotland has been the extermination of these correctives, the disease being most virulent where the game keepers were most active in destroying what they considered vermin. ${ }^{1}$

It appears, then, that under natural conditions the birds of prey destroy merely. the unfit and surplus individuals of the species on which they prey, and do not, on the whole, reduce their numbers below what the land will support:

The relations of birds to insects merit the most profound thought and study. No one can study intelligently the effect produced by birds upon insect life unless he first acquires some knowledge of the habits and transformations of insects, and is able to distinguish the so-called injurious and beneficial groups. A brief explanation here of the transformations of insects will better enable the reader to understand the terms used later in describing them as food for birds.

\footnotetext{
1 Letter from Prof. Spencer F. Baird to Mr. J. W. Shorton, published in the Journal of the Cincinnati Society of Natural History, 1882, Vol. V, pp. 69, 70.
} 
Most insects emerge from eggs, which ordinarily are deposited and fixed by the female parent in positions where

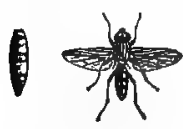

Fig. 5. - Fly and its larva. the young will find suitable food in readiness for them when the eggs hatch. Some insects bring forth their young alive, but this is an exception to the general rule. The young insect that emerges from the egg is called the larva (plural, larvæ). Some larvæ are provided with short legs or feet, others have none that can be seen; but all are without wings, and move about mainly by crawling. Their principal occupation is to feed. Some species, such as the
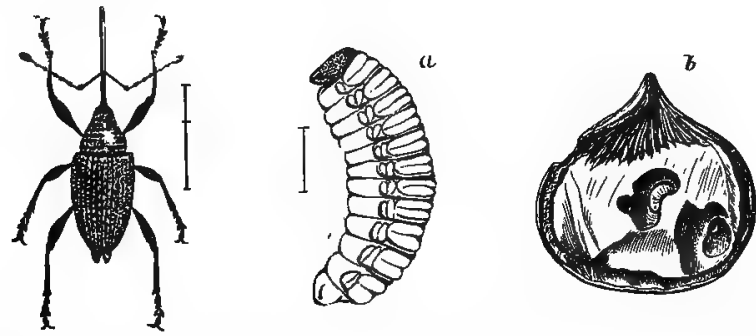

Fig. 6.-Chestnut beetle or weevil, enlarged. $a$, larva or grub, enlarged; $b$, young larva in chestnut, natural size.

leaf-eating caterpillars, rest during certain parts of the day; others, like the larvæ of flesh-feeding flies, apparently feed constantly. As all eat enormously and grow rapidly, they are capable, when in great numbers, of doing much harm or good, as the case may be. The larvæ of flies are commonly called maggots or slugs, those of beetles are called grubs, and those of butterflies and moths are called caterpillars. Much of the injury done by insect pests is attributable to the larvæ; a l t h o u g h

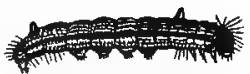

Fig. 7.-Caterpillars, the larvæ of butterfies. some, like certain leaf-eating beetles, are injurious in the perfect form. During the rapid growth of a larva the skin is shed several times, until full size is reached, when the next transformation is effected, and the larva becomes a pupa or chrysalis. Among the butterflies and moths (Lepidoptera) the insect often spins from within itself a thread, which it weaves into a case or cocoon which encloses it while in the 
pupal form. This stage it passes without food and while fixed to some object. The pupe or nymphs of some other insects, however, move about freely, as is the case with locusts, grasshoppers, and like insects (Orthoptera). ${ }^{1}$

The pupa finally throws off its outer shell, and emerges a fully developed or perfect insect or imago with wings; although some insects which, like some birds, have lost the use of their wings, never fly. ${ }^{2}$ After the union of the sexes the female insect eventually deposits the eggs for the
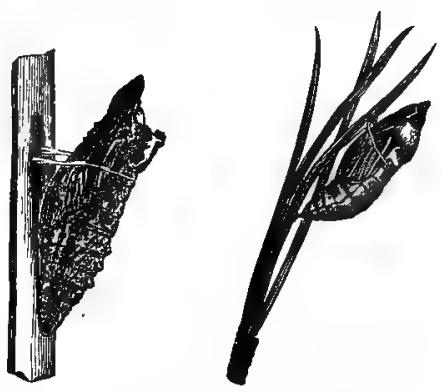

Fig. 8. - Pupæ or chrysalids. next generation. Thus we have four forms which insects assume : (1) the egg, (2) the larva, (3) the pupa or nymph, (4) the imago or perfect winged insect.

Practically all living animals of appreciable size, as well as most plants that are visible to the unaided eye, furnish food for certain insects. Other insects feed on dead animals, dead trees, or other decaying animal or vegetable matter. A certain larva has been known even to tunnel into marble. Those insects which feed on live vegetation or living animals are capable of doing great harm if they increase unduly; while those that feed only on dead animals or dead and decaying vegetation can do only good in nature, although they may be injurious to man by destroying hides, furs, preserved meats, or clothing.

It is difficult to perceive the usefulness of those so-called injurious species which feed on the different parts of plants; still, the larvæ that eat the buds, the caterpillars that feed

\footnotetext{
1 In the Orthoptera the transformations are imperfect; the larvæ of grasshoppers, for example, are provided with well-developed legs, and much resemble tho imago or perfect insect, but are without wings. In this stage they are usually called nymphs. As they approach maturity they enter what is virtually an imperfect pupal stage, but retain their shape, limbs, and activity. They now show rudimentary wings, but it is only at maturity that they are capable of flight.

2 The Thysanura, or lowest order of insects, including " bristle tails," "spring tails," "fish moths," and the like, never become winged or develop any trace of wings.
} 
on the leaves, the borers that attack the twigs, and the insects that destroy the blossom or the fruit, all probably, when in normal numbers, exert a useful influence by a healthful and necessary pruning, which at least does no injury to the tree. It is only when these insects increase abnormally in numbers that they seriously injure or destroy many vigorous plants and trees. During such outbreaks birds often come to the rescue of the trees. Birds feed very largely on such insects, and by keeping down their excessive multiplication perform a great service in the economy of nature.

Here the keen senses and remarkable flight powers possessed by birds aid them in concentrating their forces immediately when and where they are most needed. The rule will bear repetition here that, other things being equal, birds will take such suitable food as is most plentiful and most easily obtained. This is especially true of the feeding of birds on insects, although there are some insects that are so protected by prickly spines or acrid secretions that few birds will eat them. Such are the caterpillars of the mourningcloak butterfly (Euvanessa antiopa) and the imagoes of the Colorado potato beetle (Doryphora decemlineata).

Birds are quick to assemble wherever in the woods the disappearing foliage denotes the presence of great numbers of destructive caterpillars, or where patches of dead and dying grasses indicate that grubs are destroying the grass roots on meadow or prairie. Birds flock to such places to feed on the easily procured insects, and so take a prominent part in repressing such insect outbreaks. This is so well known as to be worthy of only passing mention here, were it not to inquire whether the birds that assemble in such localities do not neglect their normal and special work of holding in check certain species elsewhere. If the Robin, for example, which feeds normally on such ground-frequenting insects as white grubs, cutworms, grasshoppers, March flies, and ground beetles, goes to the woods to feed on caterpillars, as is sometimes the case, does it neglect to devour any one of the insects on which it usually feeds, and so give this insect a chance to increase? If so, it would be merely suppressing one outbreak and permitting another. But birds 
do not neglect any one element of their ordinary food in such cases. They neglect them all, both animal and vegetal, for the time being, and turn to the now abundant insect food that is more readily accessible. This I have observed in studying outbreaks of cankerworms, and Professor Forbes records a similar experience with birds feeding on cankerworms. ${ }^{1}$

This apparently agrees with the experience of the forest authorities in Bavaria during the great and destructive outbreak of the nun moth (Liparis monacha) which occurred there from 1889 to 1891 . The flight of Starlings collected in one locality alone was credibly estimated at ten thousand, all busily feeding on the caterpillars, pupæ, and moths. Enormous flights of Titmice and Finches were similarly engaged. The attraction of Starlings to such centers became so great that market gardeners at a distance felt their absence seriously. ${ }^{2}$

Evidently in such cases the birds, changing their usual fare entirely for the time being, remove their restraining influence from both useful and injurious insects, leaving one to exert its full force as a check on the other, until the urgent business of the serious outbreak of grasshoppers, caterpillars, or some other pest has been attended to; then the birds return to their usual haunts and food, and exert the same repressive influence as before.

Although the insects which are potentially injurious are greatly in the majority, there are many species which per- form a very apparent useful function in nature. Such are the bees and some of their allies of the order Hymenoptera, - insects which travel from flower to flower in search of sweets, and, becoming loaded with pollen, fertilize the blossoms, rendering the trees fruitful. Other insects seem especially adapted to hold the potentially injurious species in check. Some which are called predaceous insects attack other insects and devour them, as do the ground beetles

\footnotetext{
1 The Regulative Action of Birds upon Insect Oscillations, by S. A. Forbes. Bulletin No. 6, Illinois State Laboratory of Natural History, 1883, p. 21.

2 Protection of Woodlands, by Herman Fürst. English edition, translated by John Nisbet, 1893, p. 126.
} 
(Carabidæ) already mentioned, the tiger beetles (Cicindelidæ), the ladybirds (Coccinellidæ), and many of the true bugs. Such insects are often miscalled parasites, but they do not merit this misnomer.

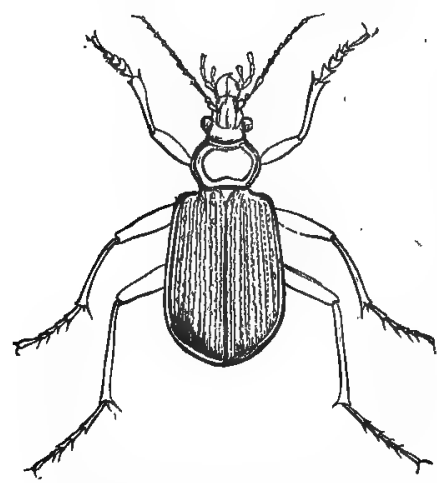

Fig. 9.- Predaceous beetle; the lion veetle or caterpillar hunter.

The predaceous beetles are the wolves, lions, and tigers of the insect world. They hunt down their prey, pouncing upon it and killing it when found. Often these insects are so ravenous that they content themselves with drawing the life blood and other juices from their quarry, leaving the rest to be devoured by ants or other scavengers. While the larger predaceous beetles attack many of the larger insects, smaller species, such as ladybirds, assail other minute insects, such as the aphids or plant lice.

The bugs are the vampires of the insect world. Armed with a strong proboscis, the bug pursues its prey, pierces it and sucks its juices, leaving it drained and lifeless; but the so-called parasitic insects feed in a manner entirely different.

Certain families of the Hymenoptera and Diptera contain parasitic genera and species. These insects range in size from that of a large wasp down to that of a small midge. Most of them have the habit of depositing their eggs on, or in, the bodies of other living insects.

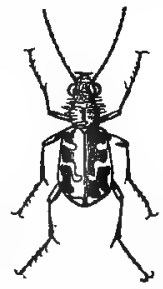

Fig. 10. - Predaceous beetle; a tiger among insects.

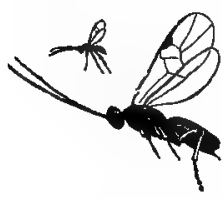

Fig. 11. - Hymenopterous parasite. Imago, natural size and enlarged.

Each ichneumon fly is armed with a long ovipositor, which operates somewhat like a hollow sting, by means of which it is enabled to pierce the skin of the larvæ of other insects and pass its eggs through the puncture, depositing them in the body tissues beneath the skin. These eggs soon hatch, and the young larræ, emerging from 
them, feed first upon the fatty portions of the caterpillar in which they find themselves. The caterpillar thu's unwillingly becomes their host, furnishing them with food and lodging from and within its own substance. When they have made their growth, and it is nearly time for them to pupate, they attack the vitals of their host, killing it, and then pupating either within or upon its body. Soon they emerge as perfect flies, the females again seeking other caterpillars as hosts for their progeny. Often these parasites do not kill their host until it has sought some place of safety and pupated. Every cat-

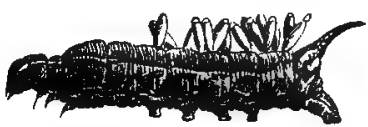

Fig. 12. - Host caterpillar, with cocoons of the parasite upon its back.

erpillar or pupa thus destroyed nourishes one or many of these parasites, to emerge and attack surviving caterpillars. The parasites themselves, however, are often attacked in the same manner by a secondary parasite, which destroys them precisely as they destroyed the caterpillar. The larger primary parasites may deposit a single egg or only a few in each caterpillar, while the smaller ones may deposit the entire brood in the body of a single caterpillar.

Birds eat both predaceous and parasitic insects. We have seen that they eat ground beetles, many of which are provided with acrid secretions that are supposed to render them

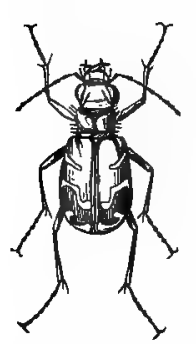

Fig. 13.-Tiger beetle; a useful form, eaten by very few birds. disagreeable and offensive to the taste, and so give them a certain immunity from their enemies. Evidently, however, it takes a very strong flavor to take the edge off a bird's appetite, for birds eat bugs; and any child who has ever eaten berries from the bushes, and inadvertently put one of the berry-eating bugs in his mouth, knows how disgusting their flavor is. There are some useful insects that are seldom eaten by birds. The very smallest are beneath the notice of most birds. The tiger beetles and some of the useful flies are so quick that birds find it difficult to catch them. Wasps and bees, though eaten by some birds, can protect themselves very well with their stings. Probably, however, 
birds eat a great many caterpillars containing parasites, though birds will reject any caterpillars that show signs of weakness or disease. The question then arises, Is the bird doing harm by eating caterpillars or other larvæ containing parasites? The bird certainly ends the destructive career of the larva at once. The parasites would have ended it eventually; but had it been left to them, it might lave gone on for some time in its destructive career, doing as much injury as if not parasitized; the parasite merely destroys it in time to prevent it from propagating its kind. So far the evidence is in favor of the bird. The question remains, however, whether the bird and its young would eventually destroy more caterpillars than would the progeny of the parasites had they not been eaten by the bird. This question evidently is unanswerable. Birds act as the primary check on the increase of destructive insects; parasitic insects are the secondary check provided by nature to operate in conjunction with the birds, or to supplement the regulative action of birds where the number of birds is insufficient to check the increase of insects.

Birds sometimes kill many of the imagoes of parasitic insects in flight, where such insects are numerous. At first sight, this would seem to condemn the birds; on further study, it seems probable that this is often a harmless habit. Where parasitic insects are found in great numbers, it is probable that the birds destroy mainly the surplus flies, which otherwise, failing to find hosts for their young, would merely live out their time and die without issue were they not killed by the birds. Such harm as birds do in killing primary parasites may be offset by the killing of secondary parasites by birds, for this acts as a protection to the primary parasites.

Certain predaceous bugs feed not only on insects but also on vegetable food. They also attack other predaceous or useful insects. Birds, by preventing their undue increase, may prevent excessive injury to both useful plants and insects.

All reasoning from known premises leads to one conclusion 
regarding the utility of birds in nature. It may be stated confidently, as a general rule (not without exceptions, however), that, in the natural order of things, the species that is kept within normal numbers without great fluctuations, whether beast, bird, reptile, batrachian, or insect, will serve a useful purpose; while the species that increases unduly will devour too much animal or vegetable food, and, by disturbing the balance of nature, become a pest. It is the abnormal increase of the gipsy and brown-tail moths and the "English" Sparrow in this Commonwealth that has been responsible for the injury they have done. If birds do well their part in holding in check native insects, small mammals, reptiles, batrachians, and other forms of life on which they feed, they have fulfilled their mission, even if in doing this they destroy some individuals of some species that are classed as useful.

This, then, is the chief mission of the birds in organic nature : to fill their peculiar place in preserving the balance of nature's forces, - a place that cannot be filled by any other class of animals.

In much of the foregoing it appears that the birds are engaged in checking the increase of insects and other animals, exerting that check constantly when and where it is most needed. The vegetable food of birds is perhaps of less importance, but here also they exercise a restraining influence by destroying seed as well as in other ways. They also exert a beneficial influence by planting seed.

Birds also play a great part in the distribution of plants, the upbuilding and fertilizing of barren islands, and a minor part in the distribution of insects. Wild-fowl and Herons may sometimes carry small seeds for many miles embedded in particles of mud which adhere to their feet. Where this mud drops from their feet, the seeds may sprout and grow. The fruit-eating birds are among the most valuable of tree planters, distributing the seeds far and wide. Certain insects which eling to the feet or feathers of birds are sometimes distributed in this way. The part taken by birds in forest planting and fertilizing barren lands will be taken up far- 
ther on, in connection with their relations to forestry and agriculture.

Taken all in all, the relations of birds to the natural world are beneficent. Evidently birds are an essential part of nature's great plan. This being the case, they must be serviceable to man also, for man, the animal, is a mere inte-. gral part of nature. 


\section{CHAPTER I.}

\section{THE VALUE OF BIRDS TO MAN.}

Birds are classed as useful or injurious only as they affect man or his property. In an uninhabited country birds cannot be ranked as beneficial or harmful, good or bad, for there is no agriculture. There the earth, untroubled by man, brings forth vegetation, and animals after their kind. Nature's laws, working in harmony, need none of man's assistance. The condition of the earth before man appeared is typified in the Biblical account of the garden of Eden.

\section{PRIMITIVE MAN'S RELATIONS TO NATURE.}

We have seen that under such natural conditions all birds are essential to the general welfare, each filling well its appointed place. But trouble and discord come to Eden. Man appears, and becomes the dominant power on the earth. He sets up artificial standards of his own, and bids nature conform to them. He is constantly at war with nature. He classes wild creatures as injurious, provided they either injure his person, or cause him loss by destroying or harming any of his property or any of the wild animals or plants which he regards as useful. He considers all wild creatures beneficial that contribute directly or indirectly to his own welfare, or to the increase in value of his property.

$\mathrm{He}$ is often in error, even from his own standpoint, in thus classifying animals, owing to an insufficient knowledge of their food habits ; but the principle holds good, and standards change with the acquisition of knowledge.

Man in a savage state lived, like other animals, in harmony with nature. At first he practised no agriculture and domesticated no animals. He made war mainly upon his fellows and the larger beasts of prey, killing them in self-defence or for food. (It seems probable that primitive man was a cannibal.) Otherwise, he fed altogether upon the wild 
products of forest, meadow, sea, lake, or river. The only creatures that he then could regard as injurious were those that attacked his own person or the persons of his family.

Any irruption of animals, such as vast herds of deer, bison, or antelopes, hordes of monkeys or rats, flights of birds or locusts, outbreaks of caterpillars or other creatures, was about as likely to benefit as to injure hin. For instance, when locusts became so numerous as to destroy a part or all of his vegetable food, he followed the example of other creatures, and, by feeding for the time on the superabundant locusts, exerted an influence toward restoring the balance of nature. (There are still savage tribes in various parts of the earth that eat monkeys, rats, locusts, grubs, or caterpillars.)

In times of plenty primitive man feasted, as did other animals; and in times of want, like them, he starved. But usually he was indifferent to any ordinary injury done to the animal or vegetable life around him, as he owned no property, and could readily move his camp from a region of want to one of plenty.

\section{CHANGED RELATIONS PRODUCED BY AGRICULTURE.}

With the beginning of agricultural practice, however, all this was changed. When man began to domesticate animals, he faced immediately a host of enemies. Wild animals and birds attacked his cattle, horses, sheep, goats, and hogs, or devoured their young. Tormenting insects stampeded his herds, or carried disease and death among them. His poultry were decimated by scores of rapacious animals. When he began to plant seed and raise grain, both his growing and his garnered crops were attacked by a host of enemies; for now he had begun to disturb nature's balance, and nature asserted herself in the effort to resume her interrupted sway. This was the beginning of a war with nature which will never cease so long as man inhabits the earth; for the agriculturist does not work altogether with nature, but largely against her. Most of the animal and vegetable forms that he produces are at variance with those produced by nature, and must be continually fostered and protected 
if they are to maintain their artificial characters and excellences. Left to themselves, the various breeds of domesticated Pigeons would all disappear, merging into the original Dove from whence they sprang. All artificial varieties of animals, plants, and fruits would, under nature, become, in time, like the wild stock from which they originated. Hence man must wage war continually against organic nature, in order to maintain his artificial standards against her inexorable laws.

The beginning of agriculture was the first step toward civilization as well, for the necessity of remaining near his crops to guard them from their enemies compelled the primitive farmer to erect a permanent habitation. This took his attention from war and the chase, for much of his time was now occupied in tilling the soil and caring for his crops and animals.

The slow growth of primitive agriculture in the older civilized countries gave time for a gradual adjustment of the forces of nature to the new conditions established and maintained by man. The gradual or partial clearing away of the forests occupied centuries. The planting of crops merely kept pace with the natural increase of population, while the destruction of wild animals and their replacement with domesticated species were similarly gradual and progressive. So, although in the older countries agriculture suffered much from the pests to which its operations must always give rise, it remained for the peopling of newer lands to develop the greatest difficulties in the path of the farmer.

Agriculture produces an increased food supply. The population increases correspondingly, and the overflow seeks new fields. In these new lands, of which America is the most prominent example, the conditions of civilization and agriculture have replaced with marked rapidity those of savagery and primeval nature.

\section{MAN AT WAR WITH NATURE IN THE NEW WORLD.}

All the greater changes that were effected gradually by man in Europe, where, in the course of centuries, civilization was slowly evolved from savagery, - all these stupen- 
dous changes, - were wrought here in a few years by the tide of immigration from the eastern world.

In many communities only a score of years elapsed between the subjugation of the unbroken wilderness and the building of a farming town or growing city. In Massachusetts the settlers cut down the forest; killed off most of the larger mammals and birds ; imported and bred horses, cattle, and poultry; cleared and planted much of the arable land; introduced many new plants ; and rapidly changed the appearance of the country from that of a wilderness to that of an agricultural colony. Thirty years after the landing of the Pilgrim Fathers at Plymouth, eastern Massachusetts was well colonized; with several growing seaport towns; with prosperous farms, fertile fields and green pastures; with flocks and herds grazing on many a hill, where the wild Indian and the red deer formerly roamed.

All these changes, taking place so rapidly, produced great disturbances in the economy of nature. As the wolf, lyux, puma, and bear were killed or driven away, the smaller animals on which they had formerly preyed increased in numbers and attacked the crops. Crows, Blackbirds, and many insects, finding in the grain crops new sources of food supply, swarmed upon them and multiplied exceedingly. Birds and insects attacked the cultivated fruit. Thousands of acres of cleared meadow land were producing crops of grass. Given this increased food supply, locusts and other grass-eating insects increased in numbers. The settlers, meantime, were destroying the Heath Hen, Quail, Plover, Blackbirds, Hawks, and Crows, the natural enemies of the locusts. As time went on, many new plants were introduced from Europe, and in some cases insect pests unwittingly were brought with them. The two succeeding centuries brought about a tremendous immigration from Europe. As settlement extended into the western States, great fields of wheat and other grains were established, covering the plains in some instances as far as the cye could see. Hundreds of thousands of acres were planted to orchards and vineyards; great areas near the cities were devoted to garden vegetables; north and south, corn, wheat, and cotton clothed the land. 
THE INCREASE OF INSECT PESTS.

Insects introduced from foreign lands found here a paradise, in which to multiply, in the great areas planted year after year to the same crops. Having escaped their native enemies, they had come to an abundance of food in a land where many of the insect-eating birds and other insectivorous animals had been much reduced in number by the unwise policy of the settlers. Hence the rate of increase of imported insect pests in America has far exceeded that of the same insects in their native lands.

Certain native American insects, finding their food plants destroyed by the cutting down of the forests or the breaking up of the prairie, turned their attention to the crops of the farmer, and became important pests. Such are the cutworms (Noctuidæ); their name is legion. Others, having been reached in their desert or mountain homes by the advance of civilization, left their natural food for the more succulent plants raised by man, and so spread over the country from farm to farm. Such are the chinch bug and the Colorado potato beetle, which, as civilization

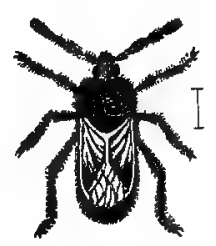

Fig. 14.-Chinch bug, much enlarged. advanced westward, met it and spread toward the east.

The enormous losses which have occurred in the United States from the destruction of growing crops by insects must seem incredible to those who do not realize how vast are the numbers of insects, how stupendous their power of multiplication, how insatiable their voracity.

When we fully appreciate the consuming powers of insects, they assume an economic importance greater than can be accorded to the ravening beast of prey. Let us consider briefly, then, the potency for evil that lies hidden in the tiny but innumerable eggs of injurious insects, which require only the warmth of the summer sun to release from confinement their destructive energies. 


\section{THE NUMBER OF INSECTS.}

The number of insect species is greater by far than that of the species of all other living creatures combined. More than three hundred thousand have been described. There are many thousands of undescribed species in museums. Dr. Lintner, the late distinguished State entomologist of New York, considered it not improbable that there were a million species of insects. The number of individual insects is beyond human comprehension or computation.

Dr. Lintner says that he saw at a glance, in a small extent of roadway near Albany, more individuals of a single species of snow flea, as computed by him, than there are human beings on the entire face of the earth. A small cherry tree ten feet in height was found by Dr. Fitch to be infested with an aphid or plant louse. He estimated (first counting the number of these insects on a leaf, the number of leaves on a branch and the number of branches on the tree) that there were.twelve million plant lice on the tree; and this was only one tree of a row similarly infested. To give the reader an approximate idea of the number of insects on the tree, it was stated that, were a man to count them singly and as rapidly as he could speak, it would require eleven months' labor at ten hours a day to complete the enumeration. ${ }^{1}$

In the days of their abundance the Rocky Mountain locusts in flight filled the air and hid the sun. From the high peaks of the Sierra Nevada they were seen filling the valleys below and the air above as far as a powerful field glass could bring the insects within focus. The chinch bug in countless millions infests the grain fields over towns, counties, and States. The army worm moves at times in solid masses, destroying the crops in its path.

\section{THE REPRODUCTIVE CAPACITY OF INSECTS.}

Insects are enormously productive, and, were the progeny of one pair allowed to reproduce without check, they would cover, in time, the entire habitable earth.

${ }^{1}$ Our Insect Enemies, by J. A. Lintner. Sixteenth Annual Report, New Jersey State Board of Agriculture, 1888-89, pp. 293, 294. 
The rapidity of propagation shown by some insects is perhaps without a parallel in the animal world.

In order to give some idea of the powers of multiplication of the Colorado potato beetle, the Canadian Entomologist states that all its transformations are effected in fifty days; so that the result of a single pair, if allowed to increase without molestation, would in one season amount to over sixty millions. ${ }^{1}$

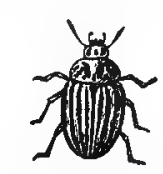

Fig. 15. - Col. orado potato beetle.

Speaking of the great power of multiplication shown by plant lice or aphids, Dr. Lintner says that Professor Riley, in his studies of the hop vine aphis (Phorodon humuli), has observed thirteen generations of the species in the year. Now, if we assume the average number of young produced by each female to be one hundred, and that every individual attains maturity and produces its full complement of young (which, however, never occurs in nature), the number of the twelfth brood alone (not counting those of all of the preceding broods of the same year) would be $10,000,000,000,000,000,000,000$ (ten sextillions) of individuals. Where, as in this instance, figures fail to convey any adequate conception of numbers, let us take space and the velocity of light as measures. Were this brood marshalled in line with ten individuals to a linear inch touching one another, the procession would extend to the sun (a space which light traverses in eight minutes), and beyond it to the nearest fixed star (traversed by light only in six years), and still onward in space beyond the most distant star that the strongest telescope may bring to our view, — to a point so inconceivably remote that light could only reach us from it in twenty-five hundred years.

The remotest approach to such unchecked multiplication on the part of this insect might paralyze the hop-growing industry in one season. While the aphids may represent the extreme of fecundity, there are thousands of insect species the unchecked increase of any one of which would soon overrun a continent. Mr. A. H. Kirkland has com-

\footnotetext{
1 Report of Townend Glover, entomologist, in Annual Report of the United States Commissioner of Agriculture, 1871, p. 74.
} 
puted that the unrestricted increase of the gipsy moth would be so great that the progeny of one pair would be numerous enough in eight years to devour all the foliage in the United States.

\section{THE VORACITY OF INSECTS.}

Many insects are remarkably destructive because of the enormous amount of food which they must consume to grow rapidly to maturity. Many caterpillars daily eat twice their weight of leaves; which is as if an ox were to devour, every twenty-four hours, three-quarters of a ton of grass. ${ }^{1}$

This voracity and rapid growth may be shown by the statement of a ferv facts. A certain flesh-feeding larva will consume in twenty-four hours two hundred times its original weight; a parallel to which, in the human race, would be an infant consuming; in the first day of its existence, fifteen hundred pounds of food. There are vegetable feeders, caterpillars, which during their progress to maturity, within thirty days, increase in size ten thousand times. To equal this remarkable growth, a man at his maturity would have to weigh forty tons. In view of such statements, need we wonder that the insect world is so destructive and so potent a power for harm ? ${ }^{2}$

Mr. Leopold Trouvelot, who introduced the gipsy moth into this country, was occupied for some time in raising silkworms in Medford, Mass. He made a special study of the American silkworm (Telea polyphemus). Regarding its food and growth he says:-

It is astonishing how rapidly the larva grows, and one who has had no experience in the matter could hardly believe what an amount of food is devoured by these little creatures. One experiment which I made can give some idea of it. When the young worm hatches out, it

\footnotetext{
1 A probable cause for this voracity in the case of herbivorous larvæ is that the stomachs do not have the power of dissolving the vegetable matter received into them, but merely of extracting from it a juice. This is proved both by their excrement, which consists of coiled-up and hardened particles of leaf, which, when put into water, expand like tea, and by the great proportion which the excrement bears to the quantity of food consumed (Kirby and Spence's Entomology, p. 259).

${ }^{2}$ Our Insect Enemies, by J. A. Lintner. Sixteenth Annual Report, New Jersey State Board of Agriculture, 1888-89, p. 295.
} 



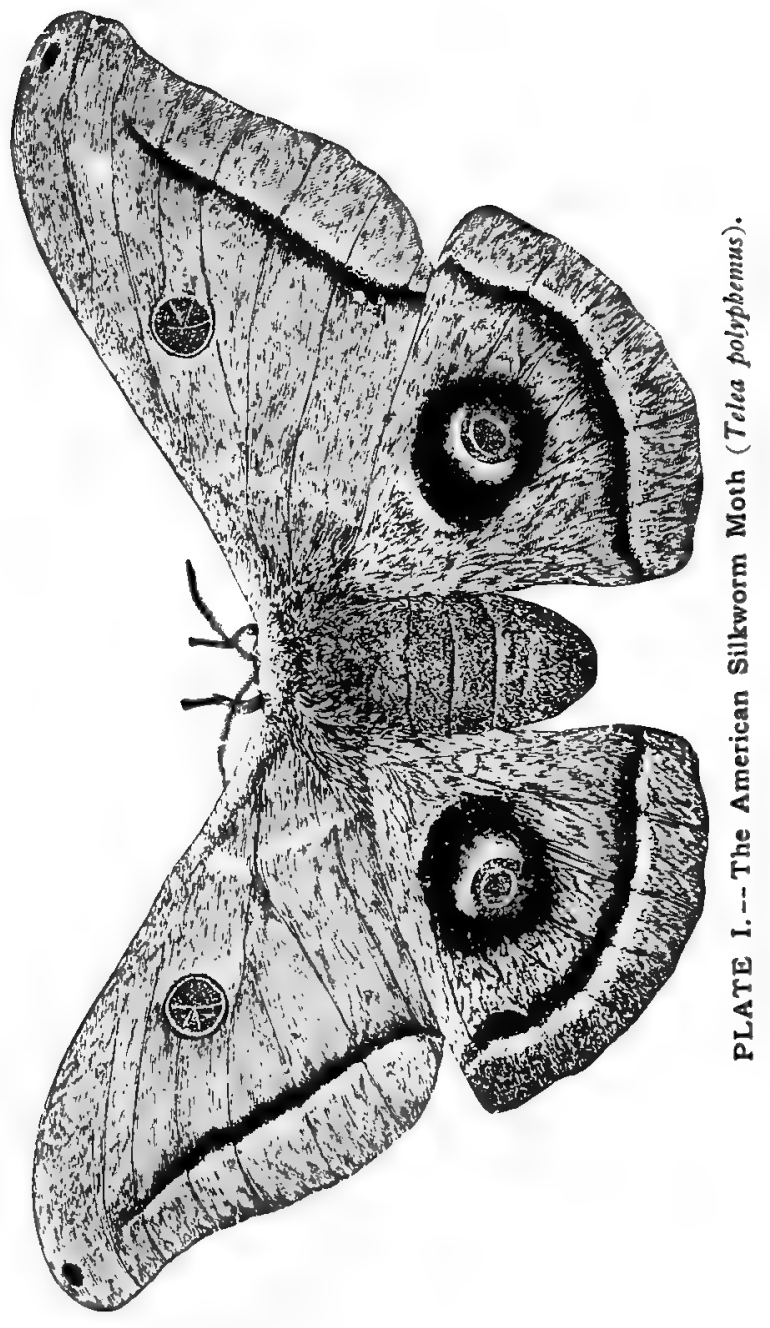


weighs one-twentieth of a grain; when ten days old, it weighs one-half a grain, or ten times the original weight; when twenty days old, it weighs three grains, or sixty times the original weight; when thirty days old, it weighs thirty-one grains, or six hundred and twenty times the original weight; when forty days old, it weighs ninety grains, or eighteen hundred times the original weight; and when fifty-six days old, it weighs two hundred and seven grains, or forty-one hundred and forty times the original weight.

When a worm is thirty days old, it will have consumed about ninety grains of food; but when fifty-six days old it is fully grown, and has consumed not less than one hundred and twenty oak leaves, weighing three-fourths of a pound; besides this, it has drunk not less than onehalf an ounce of water. So the food taken by a single silkworm in fifty-six days equals in weight eighty-six thousand times the primitive weight of the worm. Of this, about one-fourth of a pound becomes excrementitious matter, two hundred and seven grains are assimilated, and over five ounces have evaporated. What a destruction of leaves this single species of insect could make, if only a one-hundredth part of the eggs laid came to maturity! A few years would be sufficient for the propagation of a number large enough to devour all the leaves of our forests. ${ }^{1}$

When we consider the dangers arising from the immense numbers, fecundity and voracity of insects, the fact that insects new to cultivated crops are continually appearing becomes a source of grave apprehension.

\section{THE GREAT LOSS TO AMERICAN AGRICULTURE BY INSECT RAVAGES.}

Economic entomologists, who are constantly increasing our knowledge regarding insect pests, discover every year new species attacking important crops or trees. Dr. Lintner made a list of the insects injuring apple trees in the United States, which was published in the appendix to his first report as entomologist of New York State. It contained one hundred and seventy-six species, while large though lesser numbers have been found on the plum, pear, peach, and cherry.

The study of the insect enemies of the forest trees of the United States has not yet progressed far enough to deter-

* The American Silkworm, by L. Trouvelot. American Naturalist, Vol. I, p. 85 . 
mine with approximate accuracy the numbers of insects that infest our forest trees. The forest insects of some sections of Europe have been studied longer, and the numbers of insects found injuring the principal trees are surprising. Kaltenbach enumerates five hundred and thirty-seven species of insects, from central Europe, injurious to the oak; to the elm he ascribes one hundred and seven. The poplars feed two hundred and sixty-four species; the willows harbor three hundred and ninety-six ; the birches, two hundred and seventy; the alder, one hundred and nineteen; the beech, one hundred and fifty-four; the hazel, ninety-seven; and the hornbeam, eighty-eight. Among the coniferous trees, the pines, larch, spruce, and fir, collectively, are attacked by two hundred and ninety-nine species of insects. ${ }^{1}$

Dr. Packard enumerated over four hundred species which prey upon our oaks, and believed it not improbable that ultimately the number of species found on the oaks of the United States would be from six hundred to eight hundred or even one thousand. ${ }^{2}$

The list of insects which feed on grasses, cereals, field and garden crops is very large and constantly growing, for it is continually receiving accessions from both native and foreign sources. The destructiveness of some of these insects is so enormous and widespread that the financial loss resulting therefrom amounts to a heavy annual tax on the people of the United States. Hence since the first settlement of the country the amount of this annual tax has been increasing.

In 1854 the loss in New York State alone from the ravages of the insignificant wheat midge (Diplosis tritici), as estimated by the secretary of the New York State Agricultural Society, was fifteen million dollars. Whole fields of wheat were left ungarnered. So destructive was this insect in the following years as to stop the raising of white wheat, and reduce the value of all wheat lands forty per cent. ${ }^{8}$

\footnotetext{
- Die Pflanzenfeinde aus der Klasse der Insekten.

2 Insects Injurious to Forest and Shade Trees, by A. S. Packard. Fifth Report of the United States Entomological Commission, 1886-90, p. 48.

${ }^{s}$ Report on the Rocky Mountain Locust, by A. S. Packard. Ninth Annual Report of the United States Geological and Geographical Survey of the Territories, 1875, p. 709.
} 
In 1856, in Livingston County, New York, two thousand acres on flats which would have yielded thirty bushels of wheat per acre were not harvested because of the destructive work of this insect. ${ }^{1}$

Dr. C. L. Marlatt, of the Bureau of Entomology of the United States Department of Agriculture, who has made careful calculations of the loss still occasioned by the Hessian fly (Cecidomyia destructor) in the wheat-growing States, says that in comparatively few years does it cause a loss of less than ten per cent. of the crop. On the valuation of the crop of 1904 this would amount to over fifty million dollars. Dr. Marlatt states that in the year 1900 the loss in the wheat-growing States from this tiny midge undoubtedly approached one hundred million dollars. ${ }^{2}$

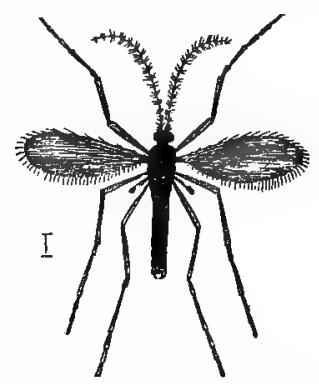

Fig. 16. -IIessian fly. Alsout twelve times natural aize.

The chinch bug (Blissus leucopterus) attacks many staple crops, and has been a seriously destructive pest in the Mississippi valley States for many years, where it injures chiefly wheat and corn. Dr. Shimer in his notes on this insect estimates the loss caused by it in the Mississippi valley in 1864 at one hundred million dollars, ${ }^{3}$ while Dr. Riley gives the loss in that year as seventy-three million dollars in Illinois alone. ${ }^{4}$ These are only a few of the extreme losses. Year after year the injuries from the depredations of this bug have amounted to many millions of dollars.

The cotton worm (Alabama argillacea) has been known as a serious pest to the cotton crop for more than a century. The average loss in the cotton States from this caterpillar

1 First Annual Report on the Injurious and Other Insects of the State of New York, by J. A. Lintner, 1882, p. 6.

2 The Annual Loss occasioned by Destructive Insects in the United States, by C. L. Marlatt. Yearbook, United States Department of Agriculture, 1904, p. 467.

s Report on the Rocky Mountain Locust, by A. S. Packard. Ninth Annual Report of the United States Geological and Geographical Survey of the Territories, 1875, p. 697 .

${ }^{4}$ First Annual Report on the Injurious and Other Insects of the State of New York, by J. A. Lintner, 1882, p. 7. 
for fourteen years following the civil war was estimated at fifteen million dollars per year. ${ }^{1}$

In 1873 the injury to the cotton crop reached twenty-five million dollars, and later averaged from twenty-five million to fifty million dollars annually. ${ }^{2}$ Now a new enemy, the Mexican cotton boll weevil (Anthonomus grandis), threatens equal destruction.

The Rocky Mountain locust (Melanoplus spretus) began to destroy crops as soon as the country it inhabits was settled, and is still injurious. From time to time its enormous flights have traversed a great part of the Mississippi valley. It reached a maximum of destructiveness from 1874 to 1877 , when the total loss from its ravages in Kansas, Nebraska, Iowa, Missouri, and neighboring States, including injury by depression of business and general ruin, was estimated at two hundred million dollars. ${ }^{3}$

In those years this devastating insect swept over the Mississippi valley. Wherever its vast flights alighted or its young developed, they destroyed nearly all vegetation, ruining great numbers of farmers, causing a famine in the land, and driving many people to emigration. This was an extreme calamity, such as is not likely to occur again.

A still larger but more widely distributed loss from insect pests, however, is still borne annually by the American people. Dr. Lintner states his belief that the annual and periodical injury caused by cutworms in the United States is greater than that caused by the Rocky Mountain locust.

In September, 1868," Prof. D. B. Walsh, editor of the American Entomologist, estimated that the country then suffered to the amount of three hundred million dollars annually from the depredations of noxious insects. By the census of 18.75 the agricultural products of this country were valued at two billion, five hundred million dollars. Of this

\footnotetext{
- Fourth Report of the United States Entomological Commission, by C. V. Riley, 1885, p. 3.

${ }^{2}$ Report on the Rocky Mountain Locust, by A. S. Packard. Ninth Annual Report of the United States Geological and Geographical Survey of the Territories, 1875 , p. 591.

${ }^{3}$ Report on the Rocky Mountain Locust, by Riley, Packard, and Thomas. First Report of the United States Entomological Commission, 1877, pp. 115-122.
} 
amount, Dr. Packard says that in all probability we annually lose over two hundred million dollars from the attacks of injurious insects. In the report of the Department of Agriculture for 1884 (p. 324) the.losses occasioned by insects injurious to agriculture in the United States, it is said, are variously estimated at from three hundred million to four hundred million dollars annually.

Prof. C. V. Riley, in response to a letter of inquiry, in 1890 , stated that no very recent estimate of the injury done by insects had been made; but that he had estimated, some time previously, that the injury done to crops in the United States by insects exceeded three hundred million. dollars annually.

Dr. James Fletcher, in his annual address as president of the Society of Economic Entomologists, in Washington, in 1891, stated that the agricultural products of the United. States were then estimated at about three billion, eight hundred million dollars. It was believed that a sum equal to about one-tenth of this amount, or three hundred and eighty million dollars, was lost annually through the ravages of injurious insects.

It is evident that, in spite of the improved methods of fighting insects, the aggregate loss from this source increases in proportion as the land under cultivation increases.

The most recent estimate of the loss occasioned by insect injury in the United States which has come to my notice is that of Dr. C. L. Marlatt, who by careful estimates approximates the percentage of loss to cereal products, hay, cotton, tobacco, truck crops, sugars, fruits, forests, miscellaneous crops, animal products, and products in storage.

Dr. Marlatt attributes an annual loss of eighty million dollars to the corn crop alone, and approximates the loss to the wheat crop at one hundred million dollars each year. The injury to the hay crop is estimated at five hundred and thirty thousand dollars, while the codling moth alone is believed to injure fruit crops to the amount of twenty million dollars annually.

This statement, based on the value of farm products as given in the reports of the Bureau of Statistics of the United 
States Department of Agriculture for 1904, gives the loss from insect depredations for that year as seven hundred and ninety-five million, one hundred thousand dollars; and this is believed to be a conservative estimate of the tax now imposed by injurious insects on the people of the United States, without reckoning the millions of dollars that are expended annually in labor and insecticides in the fight against insects. ${ }^{1}$

\section{LOSSES BY INSECT RAVAGES IN MASSACHUSETTS.}

The proportion of this loss that Massachusetts is called upon to bear has not received the attention that it deserves. Some figures, however, may be given. In 1861 the army worm (probably Heliophila unipuncta) swept eastern Massachusetts. The damage done to crops, according to Dr. Packard, exceeded five hundred thousand dollars. ${ }^{2}$ We have no estimates of the loss occasioned by more recent invasions of this insect. Prof. C. H. Fernald ${ }^{3}$ estimates that an amount of cranberries equal to one-third the possible crop of the Cape Cod region is annually destroyed by insects. Thus a sum not less than five hundred thousand dollars is yearly lost to the people of that region.

In 1890 Dr. Henry H. Goodell, president of the Massachusetts Agricultural College, stated that it was costing the farmers of the United States two million dollars, and the farmers of Massachusetts eighty thousand dollars, each year, to hold the Colorado potato beetle in check by the use of Paris green. ${ }^{4}$

In 1901 Hon. J. W. Stockwell, then secretary of the Massachusetts State Board of Agriculture, asked me to estimate the annual loss to the Commonwealth through the ravages of insect pests. My estimate, which seemed to me at

1 The Annual Loss occasioned by Destructive Insects in the United States, by C. L. Marlatt. Yearbook, United States Department of Agriculture, 1904, p. 464 .

${ }^{2}$ First Report on Injurious and Beneficial Insects of Massachusetts, by A. S. Packard. Anmual Report of the Massachusetts State Board of Agriculture, 1870, Part I, p. 353.

s In Bulletin No. 19 of the Fatch Experiment Station of the Massachusetts Agricultural College, Professor Fernald gives statistics of the cranberry crop, and evidence from which his estimate is made.

1 Agricultural Education, by H. H. Goodell. Sixth Annual Report of the Rhode Island State Board of Agriculture, 1891, p. 186. 
the time a most safe and conservative one, was three million, one hundred thousand dollars. Mr. Stockwell also asked Dr. H. T. Fernald and Mr. A. H. Kirkland, both expert economic entomologists, to make, independently, a similar estimate. Their replies follow, showing how they made up their figures. These gentlemen had every facility for obtaining knowledge of insect injury in the Commonwealth. It will be seen that their approximations considerably exceeded my own. Dr. H. T. Fernald says $:^{1}-$

Years ago a number of experts, figuring independently, came to the conclusion that for farm, market-garden and orchard crops the loss by the attacks of insects in an average year would represent one-tenth of the value of the crop, or about two million, six hundred thousand dollars for Massachusetts. Recently, however, prominent entomologists have expressed the opinion that this per cent. is too low. Three factors have caused this change: first, the concentration of crops of the same kind into large contiguons acreage; second, the introduction of over one hundred pests from foreign countries, which have been here long enongh to make their presence seriously felt; and third, the great reduction in the number of insectivorous birds.

I believe it will be entirely safe to take fifteen per cent. of the crop valuation of Massachusetts, and that you will be sufficiently conservatire in using that amount as representing part of the damage. I have never seen a cherry tree killed by plant lice, yet I have often seen lice so abundant on cherry trees as to much reduce the crop, which is true of a large proportion of our crops; and it is loss of this kind which is covered by the fifteen per cent. estimate, . . . but how are we to place a money value on the defoliation of an elm tree unless it be repeated year after year until the tree dies? I would be inclined to add, to the fifteen per cent. estimate already given, two hundred and fifty thousand dollars for labor, apparatus, poison, etc., used in the fight against insects, and another two hundred and fifty thousand dollars to cover damage actually done, but which cannot be reduced to figures, making a total jearly damage of four million, four hundred thousand dollars for Massachusetts.

Mr. Kirkland says : ${ }^{1}-$

The best figures available for estimating the loss caused by pests in this State are those of the 1895 census. From the report of this census I have taken figures giving the value of certain crops notably attacked

\footnotetext{
${ }^{1}$ Report of Secretary J. W. Stockwell, Annual Report of the Massachusetts state Board of Agriculture, 1901, pp, xiii, xiv.
} 
by insects, and have estimated in each case the probable average yearly rednction in value caused by these pests. The data used are given below. I have tried to make a conservative estimate in the case of each product, since, to have any value, such an estimate should fall below rather than abore the actual amount. Even then the figures afford material for serious reflection on the part of agriculturists.

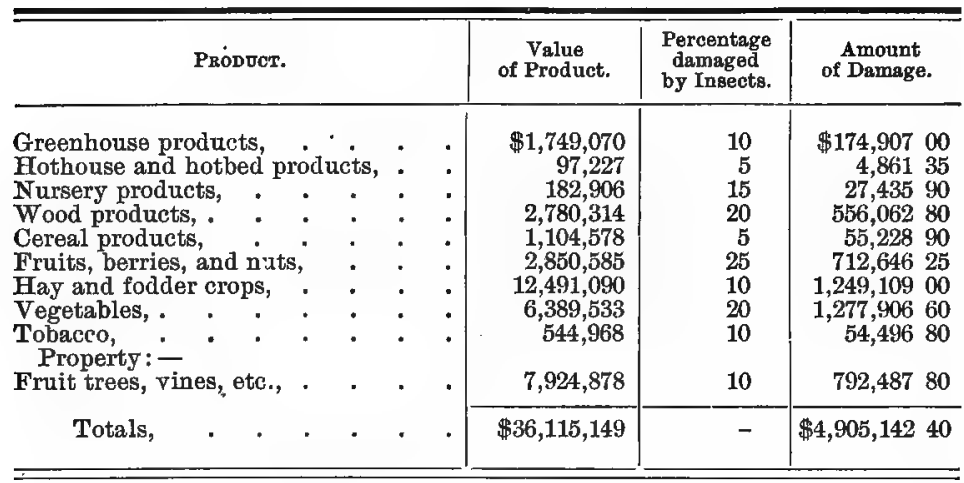

Assuming the accuracy of these data, and exclusive of the damage wrought by insects to our woodlands, street trees, parks, etc., we have in round figures five million dollars as the average annual damage from insects to agricultural products and property in this Commonwealth.

While the cost of insect injury is enormous, the expense of fighting injurious insects in the attempt to protect crops and trees from their ravages is proportionately great. In recent years Massachusetts has had, and is still having, a costly experience in attempting to control or suppress an imported insect.

The gipsy moth (Porthetria dispar), a well-known pest of European countries, was introduced into Medford, Mass., by Mr. Leopold Trouvelot, in 1868 or 1869 . Twenty years later the moths had increased in numbers to such an extent that they were destroying the trees and shrubbery in that section of Medford where they were first liberated.

They swarmed over the houses of the inhabitants, invaded their gardens, and became such a public nuisance that in 1890 the Legislature appropriated fifty. thousand dollars for their extermination. It was learned within the next two years that the moths had spread over thirty towns. The State 



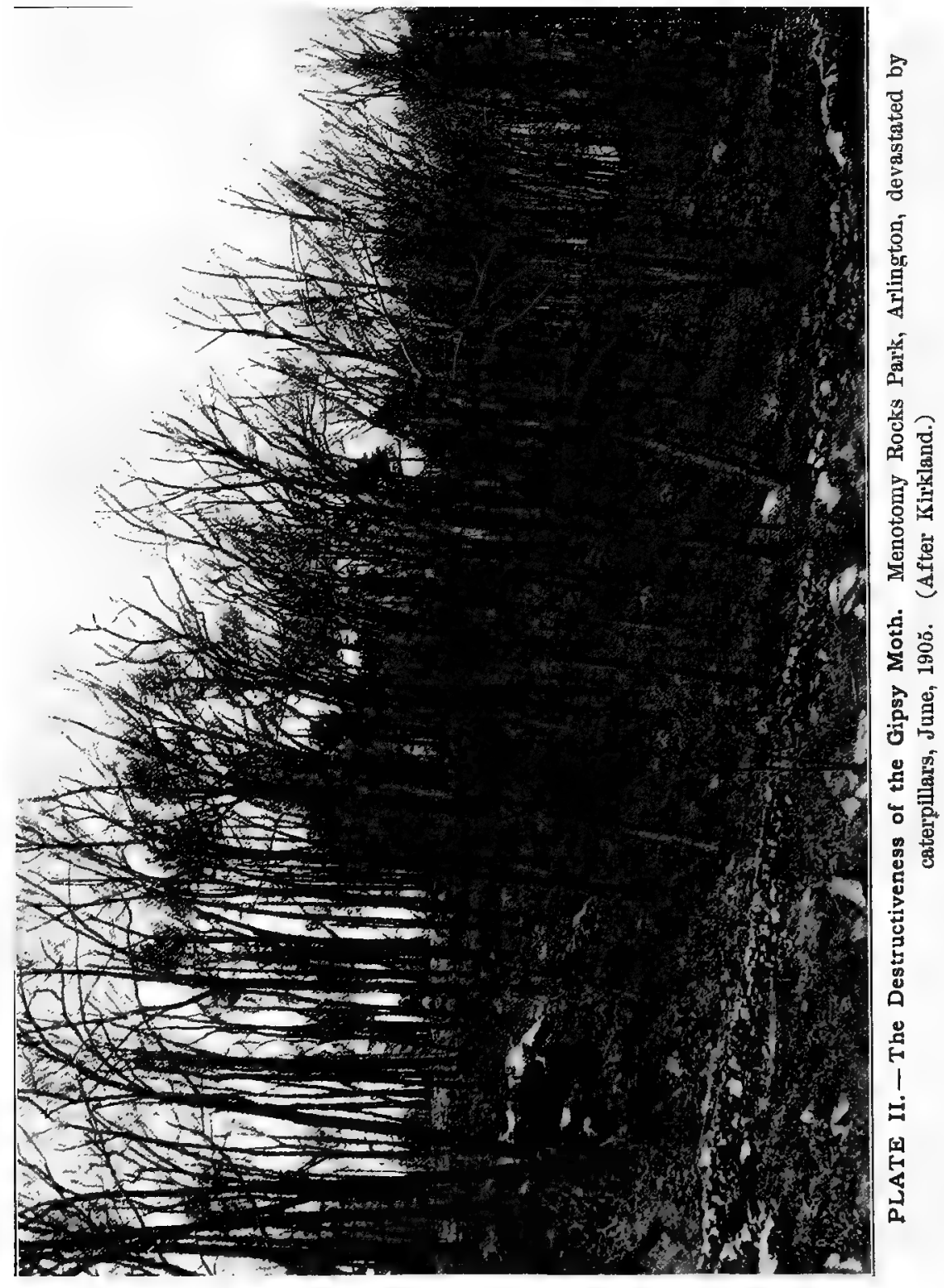



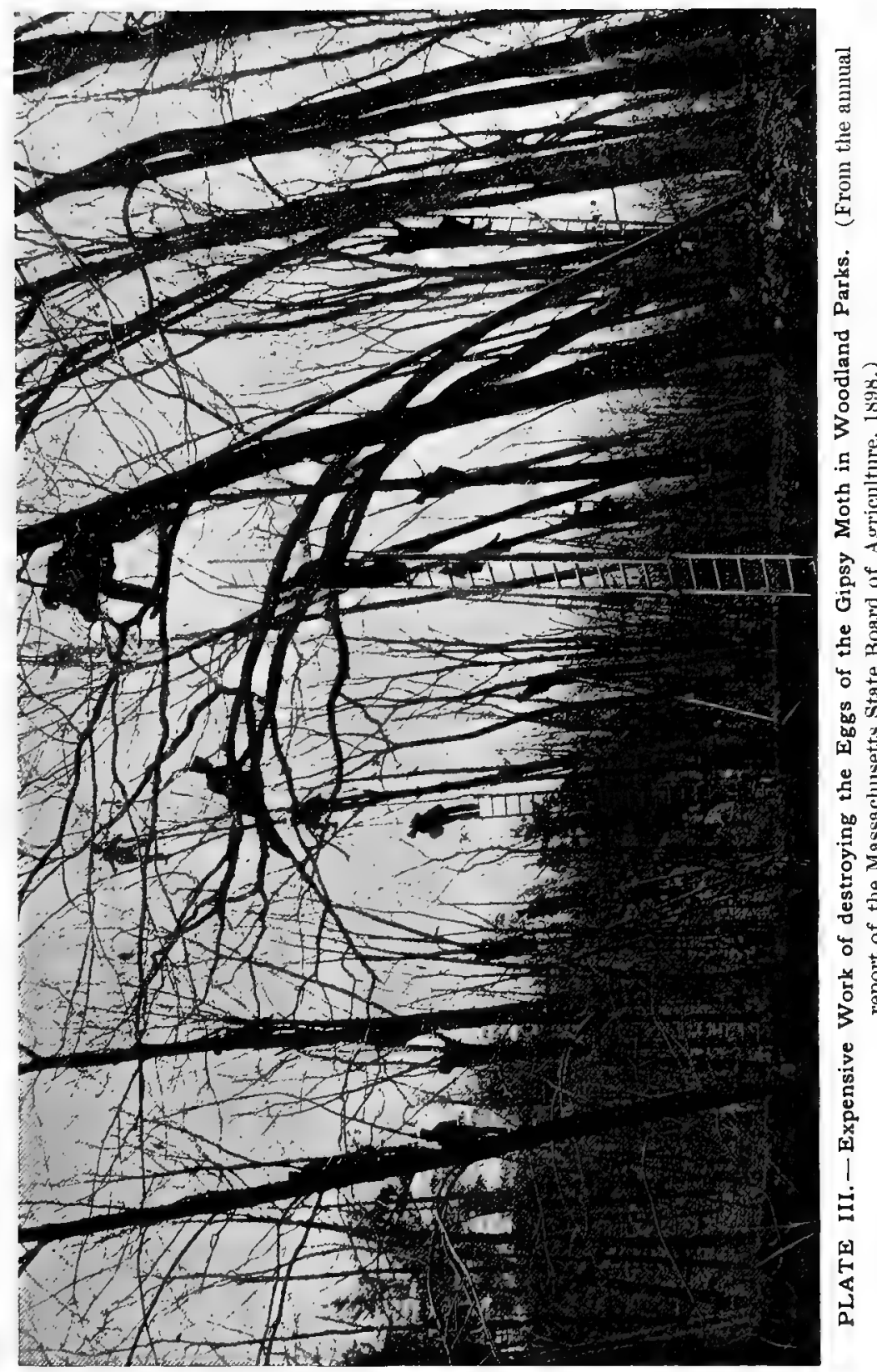

Board of Agriculture was given charge of the work in 1891, and over one million dollars were expended within the next ten years in the attempt to exterminate the insect. As at the expiration of that time all the larger moth colonies had been destroyed, the Legislature, deeming further expenditure unwise, gave up the work, despite the protest of the Board of Agriculture, and its prediction that a speedy rise of the moth would follow the cessation of concerted effort against it. This prediction has been abundantly fulfilled, and the policy of the Board has been fully justified.

Dr. Marlatt, who in 1904 visited the region infested by the moth, reported to the Bureau of Entomology at Washington that the people of the infested district were then fighting the insect at a greater annual cost than that formerly assumed by the State. Since the State gave up the work, a single citizen, Gen. Samuel C. Lawrence of Medford, has expended over seventy-five thousand dollars to protect the trees and plants on his estate.

Finally, in 1905 the Legislature was obliged to renew the fight, and appropriate the sum of three hundred thousand dollars for work against both this insect and another imported pest, - the brown-tail moth (Euproctis chrysorrhea), which had been introduced into Somerville some time in the latter part of the nineteenth century.

The State has also been obliged to call on municipalities and individuals to assist in the work of suppressing these moths, at an annual expense to those concerned which exceeds all previous yearly expenditures for this purpose.

These insects have gained a much larger territory than ever before, and thousands of acres of woodland have been attacked by them during the present year (1905), and many pine and other trees have been killed.

The gipsy moth has been found in Rhode Island, Connecticut, and New Hampshire, and the brown-tail moth is also spreading into other States.

The prospect now seems to be that our protective expenses against these two insects, as well as the injury done by them, will increase constantly; and that other States also will be put to similar expense, with no prospect of permanent relief 
save by such checks as may come, in time, through natural causes.

In view of the dangers threatened by insect increase and voracity, how fortunate it is for the human race that so many counter-checks are provided against the multiplication of these destructive creatures. If we could increase by so much as one per cent. the efficiency of the natural enemies of insects, a large proportion of the loss occasioned by insect injury might be saved. Hence the importance of the study of these natural enemies, among which birds hold a high place.

\section{THE CAPACITY OF BIRDS FOR DESTROYING PESTS.}

When wo realize the losses that insects are capable of inflicting, we see at once that birds, in their capacity of insect destroyers, continually operate to prevent the destruction of some of our most important industries. If birds are present in sufficient numbers, they will prevent the excessive increase of any kind of a pest which they will eat.

The number of birds required to accomplish this bighly desirable end need not be very large in comparison with the number of insects; for each bird can devour an incredible number of insects, and the young birds in the nests require more of this food, in proportion to their size, than do their parents.

\section{The Digestion of Birds.}

The digestive organs of birds are so constructed and equipped that they can both contain and dispose of a very large quantity of food. The stomachs of many species quickly separate the indigestible portions of the food from the digestible parts, and the former are thrown out of the mouth, thus relieving the stomach of much worthless material, and enabling the bird immediately to consume more food. The alimentary canal (including the crop, gullet or cesophagus, the first division of the stomach or proventriculus, the gizzard, gigerium or second division of the stomach, the intestine and the cloaca) consists of a tube reaching from mouth to anus, conveying the food. The nutritious qualities of the food are drawn off by the lacteals as it passes; the 
refuse is voided. This is digestion. The food is often manipulated, crushed, or divided by the beak. It then receives saliva from the mouth, and passes through the pharynx into either the gullet (a muscular and membranous tube) or crop (a pouch), as the case may be, organs capable of great distention, and connecting with the first division of the stomach. Here, then, is the first receptacle of the food. Birds of prey, Herons and some other large birds sometimes fill the gullet to the very mouth, while awaiting the digestion of the food in a stomach already full. The Pelicans have also another great receptacle or pouch, external and beneath the beak, where a store of food can be carried. Many of the smaller birds also are able, after filling the stomach, to stow away a still larger supply of food in the gullet. The stomach is large, and usually capable, by distention, of containing a considerable quantity of food. The food passes from the gullet or the crop to the proventriculus or glandular portion of the stomach. This is where the process of digestion begins. Mixed with salivary, ingluvial, and proventricular secretions, the food next passes to the gizzard or muscular

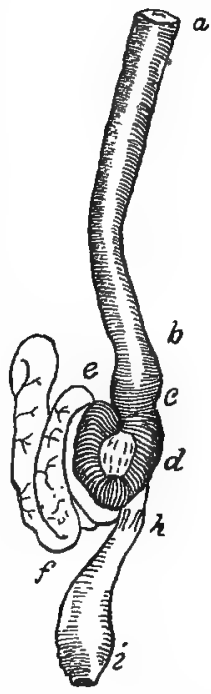

Fig. 17. - Alimentary canal of Bluebird, reduced; after Audubon. $a, b, g u l$ let or csophagus; $c$, proventriculus; $d$, gizzard; $e, f, h$, intestine; $i$, cloaca. division of the stomach, where the food grist is ground fine. Among seed-eating birds the heavy, powerful muscles of this portion of the stomach are, with the rough, calloused stomach lining, assisted in their work by sand and gravel which are swallowed. This mineral matter takes the place of teeth in grinding the food.

In vegetable-feeding birds the intestine is very long and much coiled, while the digestive tract is generally shorter and simpler in the flesh-eating and fish-eating species. All the processes of digestion are remarkably rapid. The salivary glands, the liver and the pancreas all quickly pour their copious secretions into the alimentary canal; the food is chylified after impregnation with the biliary and pancreatic 
fluids; the chyle is drawn off by the lacteals, and the residue is excreted. The vigor, perfection, and rapidity of these processes in insect-eating birds are such as might be expected among animals of such high temperature, perfect respiration, and rapid circulation.

The various dilations of the digestive tract serve well their purpose of enabling the bird to consume the large amount of food necessary for its maintenance. Digestion is particularly rapid in the growing young of most birds, for they require not only food sufficient to sustain life, but an extra supply as well to enable them to increase daily in size, and to grow, in a fer days, those wonderful appendages that we call feathers.

The Growth of Young Birds.

The growth of many birds from the egg to the hour of fight requires less time than is needed by some insects to reach the flight stage. It is most significant that young birds

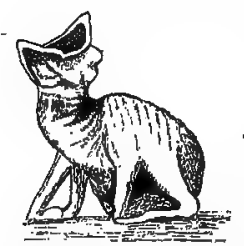

Fig. 18.-Young Cedar Bird on its first day, naked, blind, and helpless, with mouth open for food. Reduced; after Herrick. can develop as rapidly as can many insects on which they feed, for it shows how readily, under favorable conditions, the increase of birds might keep proportionate pace with that of insects. Weed and Dearborn, in their interesting manual, entitled "Birds in their Relations to Man," state that they watched four young Song Sparrows that were out of the nest on the eighth day. Mr. Owen records another instance where a brood of young Song Sparrows were fledged and left the nest within the same period. ${ }^{1}$ Probably this is exceptional ; but many of the smaller birds rear their young from the egg to the first flight within two or three weeks. Mr. Owen found that on one particular day this family of five young Song Sparrows increased in average weight forty-eight per cent., while the smallest bird gained fifty-five per cent. in a single day.

The young of perching birds (Insessores) come into the world tiny creatures, either naked or covered with down,

${ }^{2}$ A Family of Nestlings, by D. E. Owen. The Auk, Vol. XVI, No. 3, July, 1899, pp. 221-225. 
blind, and helpless; yet in a few days, or at most a few weeks, they have grown to nearly the size of their parents, and produced a perfect suit of feathers, including the strong quills of wings and tail. In a few weeks more they are able to begin a journey of hundreds or thousands of miles over land and sea, in their first migration.

The young of præcocial birds, such as Grouse, Snipe and Plover, are able to run about soon after they are hatched. Young Grouse learn to fly Fig. 18. - Young Cedar Birds, less than three when quite small, but they

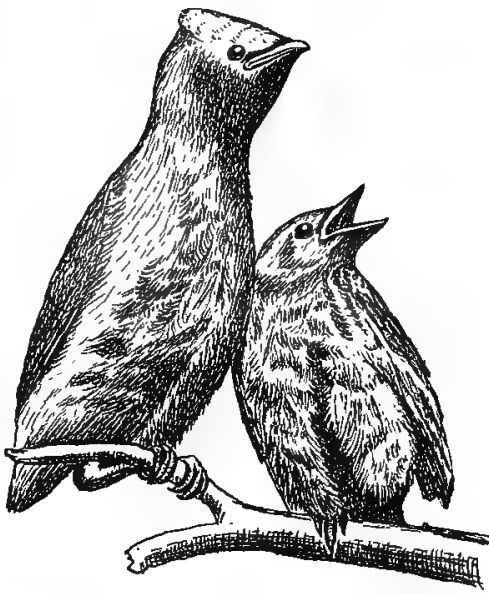
develop more slowly than do the young of the smaller altricial birds. It is difficult, therefore, to determine the

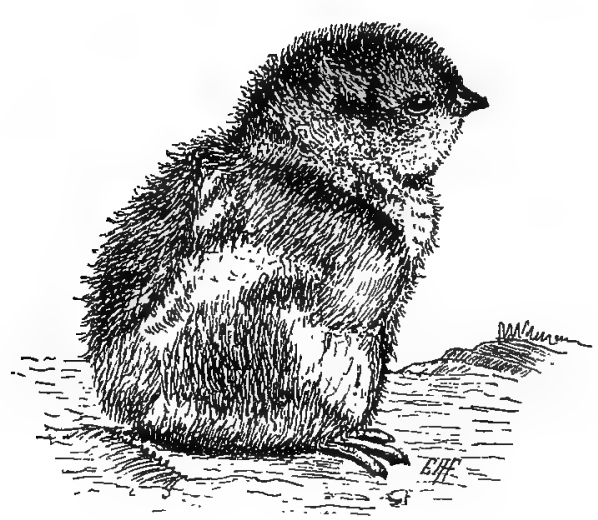

Fig. 20. - Young Grouse, just from the egg, but able to walk. amount of food they require, as they leave the nest at once and wander from place to place, picking up their own food.

The young of the altricial perching birds, however, remain quite helpless in the nest until nearly fledged, affording an excellentopportunity. for the investigator

to determine the amount and character of their food, and to watch the progress of their development. We can learn how much food such young birds require by feeding them in confinement. 
The Amount of Food required by Young Birds.

It seems necessary to the health and comfort of the nestling bird that its stomach be filled with food during most of the day. Nearly half a century ago Prof. D. Treadwell

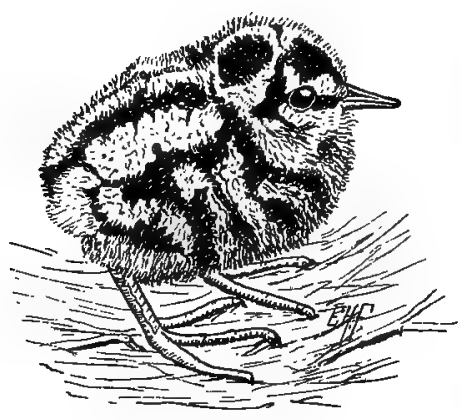

Fig. 21. - A young Woodcock, ready to leave the nest.

called attention to the great food requirements of the young Robin. Two young birds from the nest were selected for his experiment. One soon died of starvation, as the supply of food given then at first was much too small. The food of the remaining bird was gradually increased from day to day, until on the seventh day it was given thirty-one angleworms; but there was no increase in its weight until, on the fourteenth day, it received sixtyeight worms, weighing, all told, thirty-four pennyweights. ${ }^{1}$

Later the same bird ate nearly one-half its own weight of beef in a day. A young man eating at this rate would consume about seventy pounds of beefsteak daily. The Robin even when full grown required one-third of its weight of beef daily.

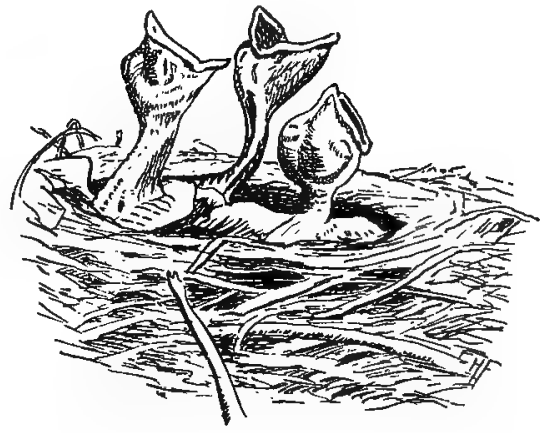

Fig. 22. - Young Robins, in the nest.

Mr. Charles W. Nash fed a young Robin from fifty to seventy cutworms and earthworms a day for fifteen days. While experimenting to see how many cutworms the bird would eat in a day, he fed it five and one-half ounces of this food, or one hundred and sixty-five cutworms. As the Robin weighed but three ounces in the morning, it must

${ }^{2}$ The Food of Young Robins, by D. Treadwell. Proceedings of the Boston Society of Natural History, Vol. VI, pp, 396-399. 
have eaten, during the day, a quantity one and five-sixths times its own weight. ${ }^{1}$

Three young Robins, about ten days old, fed by their parents, were watched by $\mathrm{W}$ eed and Dearborn. By an ingenious method of weighing and calculating, the observers arrived at the conclusion that apparently there was eaten a daily amount equal to more than half the birds' own weight. ${ }^{2}$

Mr. Daniel E. Owen kept a young Hermit Thrush, which ate regularly half its weight of raw steak daily, and would, he says, probably have eaten as much more had it been fed oftener. $^{3}$

In 1895 two young Crows were kept and fed by Messrs. A. H. Kirkland and H. A. Ballou, then my assistants, from August 7 to September 2, when one bird was killed by accident. The survivor was kept until September 14, when it was killed to determine some points regarding digestion. These birds were confined in a large cage or enclosure in an insectary, and were also allowed access during the day to an enclosed yard,' which they reached through the window. This gave them considerable exercise.

A careful record was kept of most of their food. Nevertheless, they occasionally picked up some sprouted grain in the yard, and probably a few insects that could not be recorded or weighed. For this reason the quantity of the daily food supply recorded is probably, on the average, too low, or, in other words, on the safe side. Some of the smaller animals fed to the birds (toads, frogs, and salamanders) were not always weighed, but they were measured and could be compared with others of known weight, so that the weight was approximated closely.

The birds were well grown when they were first received; but the amount of food at first given them probably was not sufficient for their needs, as their weight did not increase, although they were fed a variety of both vegetal and animal

\footnotetext{
1 Birds of Ontario in their Relation to Agriculture, by Charles W. Nash. Toronto, Department of Agriculture, 1898, p. 22.

${ }^{2}$ Birds in their Relations to Man, by Clarence M. Weed and Ned Dearborn, 1903, p. 65 .

${ }^{s}$ Notes on a Captive Hermit Thrush, by Daniel E. Owen. The Auk, Vol. XIV, No. 1, January, 1897, pp. 1-8.
} 
food. They were designated by number. On August 20 No. 1 weighed seventeen ounces and No. 2 fourteen ounces. That day the two birds had two ounces of tomato, five ounces of sweet corn, fifty grasshoppers (about three-fourths of an ounce), - in all, nearly eight ounces, - and they also had free access to some grain in the yard. As their weight remained the same, they were fed the next day one-half ounce of tomato, one ounce of corn, one ounce of muskmelon, five ounces of meat, one ounce of beets, and fifty grasshoppers, - in all, fully nine ounces. An apple also was eaten to some extent, and there was still some grain in the yard. Nevertheless, each bird lost about an ounce in weight that day.

They were fed at about the same rate the following day, and, as they were losing weight, they were given on the $23 \mathrm{~d}$ two ounces of melon, all the grasshoppers that could be collected near their place of confinement, four frogs, a salamander, two ounces of tomato, and five ounces of corn. On this diet the Crows regained some of the weight they had lost, weighing the next morning sixteen and one-half and thirteen and one-half ounces respectively. On the 24th they were fed more than twelve ounces, and the larger bird lost half an ounce and the smaller gained about the same weight. On the 25th they received over seventeen ounces of food, the smaller bird gaining another half ounce and the larger bird remaining the same. No. 1 now weighed sixteen ounces and No. 2 fourteen and one-half ounces. The next day, with twelve ounces of food, the smaller bird lost one-half ounce and the larger bird made no gain. Evidently where any gain was made by one bird on this amount of food the bird either got more than its share, or found some food in the yard.

On August 28 nearly twenty-seven ounces of food were given. This was all vegetal matter except thirty grasshoppers (one-third of an ounce). It was all eaten, and apparently all needed, for neither bird increased in weight, No. 1 losing half an ounce. It seemed evident throughout the experiment that the birds required much animal food, and when vegetal food alone was given, a larger amount 
than usual was needed. The next day about twenty ounces of food, containing a large proportion of animal matter, were given; and on August 30 the larger bird had again regained its weight of seventeen ounces, while the other held its own. So far the experiment seemed to show that when they were fed from twenty to twenty-five ounces of a ration containing both animal and vegetable food the birds held their own or gained slightly; but if fed less than twenty ounces of this ration, one or both of the birds fell off in weight.

After the death of one bird the other and all its food were weighed daily. All opportunity to secure scattered grain or other food than that weighed was denied. The greatest weight reached by this bird was eighteen and one-half ounces on September 13, on which date it was fed as much corn, cucumber, and tomato as it cared to eat, also a frog, two toads, twenty-seven grasshoppers, thirty-one borers, eight beetles, and eighteen crickets. The record of the twelve days during which this bird was alone seems to show that less than eight ounces of food daily was hardly sufficient for its needs, as on a less amount it tended to lose in weight, while when the amount was increased to ten ounces or more the tendency toward a daily gain in weight was marked.

When the quantity of food given these birds was largely reduced in any one day, there was a corresponding reduction in their weight. On September 13 the larger Crow was given only two ounces of tomato, fifty-six grasshoppers, twelve crickets, and a little grain, - in all, not much over three gunces of food. The next morning it had lost one and one-half ounces in veight. The fact that a bird, while in confinement and without a great amount of exercise, could lose nearly ten per cent. of its weight in a single day, even when fed a quantity of food equal to about one-sixth its weight, shows how dependent birds are upon their supply of food.

If this single experiment can be regarded as conclusive, we may assume that young Crows, when fledged, absolutely require a daily amount of food equal to about one-half their own weight; and it is evident that they will consume much more than this to their own advantage if they can get it. It 
seems quite probable- that a young bird at liberty, depending largely on its own exertions to procure food, and thus exercising more than in confinement, would require still more food to repair the consequent extra waste of the tissues.

Others have made similar experiments with Crows in confinement. Samuels says that he has kept specimens in captivity, and has proved by observation that at least eight ounces of such food as frogs, fish, etc., are eaten daily by our common Crow. He says that a Crow can live on a very limited allowance, but believes eight ounces to be a reasonable amount. He leaves us to infer that he is speaking of adult Crows, which undoubtedly require less food than their growing young. ${ }^{1}$

Weed and Dearborn kept a wounded adult Crow in a small box, twelve by thirteen by twenty inches. In these cramped quarters, where the bird could hardly streteh its wings, it ate fish for three days in succession at the rate of four and eighty-three hundredths ounces per day, - more than a quarter of its own weight, or about half what our young Crows ordinarily required. ${ }^{2}$

Probably the amount of food eaten by this captive bears about the same proportion to the quantity eaten by a vigorous Crow at liberty that the food taken by a prisoner in solitary confinement, or that consumed by a sedentary clerk, bears to the amount required by a strong man at hard labor, or by a prize-fighter in training.

The amount of food taken by young birds could not be disposed of by such limited powers of digestion as are given to other animals. What a wonderful contrast is presented between the quantity of food required by the hot-blooded, quick-pulsing, active bird, and that needed by the coldblooded vertebrates. Many reptiles can live for months without food. Even some of the mammals do not eat at all during their hibernation.

\footnotetext{
1 Birds of New England, by Edward A. Samuels, 1870, p. 359.

2 Birds.in their Relations to Man, by Clarence M. Weed and Ned Dearborn, 1908 , p. 61 .
} 
The Time required for Assimilation of Food.

If we assume that the stomach and cosophagus of a young Crow can contain but an ounce of food, then the bird would be required to digest from eight to twelve meals a day, according to its appetite and opportunity. The question at once arises, How can any digestive system complete such a task? Experiments were made with our young Crows to determine the time required for digestion. The birds were kept without food until the stomach and intestines were empty. They were then fed insects' eggs, in the belief that some parts of the shells would escape the grinding processes of the stomach and be voided in the excreta. Subsequent occurrences justified this belief. Ten experiments of this kind were made with the two birds.

From the time when the birds

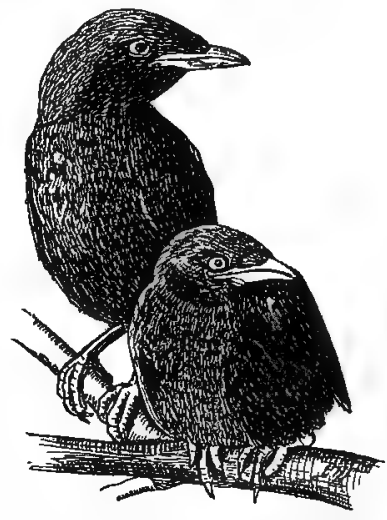

Fig. 23. - Young Crows, well fledged.

began to feed until the time when the first eggshells were dropped in the excreta there elapsed, on the average, one hour, twenty-nine minutes and forty-five seconds. The shortest time was forty-eight minutes, and the longest one hour and fifty-four minutes. This, it should be noted, was not merely the time that the food remained in the stomach, but the fill interval occupied in digesting and assimilating it, for within this period at least a part of the food had passed the entire digestive tract.

In most cases all evidence of the food used in the experiment had disappeared from the excreta in from two to two and one-half hours. If we contrast this with the slower digestion of man, we shall see how birds readily dispose of more meals each day than a man is capable of digesting. To learn how long food remains in a Crow's stomach, it would be necessary to kill a large number of Crows, each being killed at a longer or shorter interval after it had filled its empty 
stomach. I am not aware that this has ever been done, but have no doubt that the majority of the farmers of Massachusetts would not object to the destruction of a considerable number of young Crows for this purpose, or any other.

The Crow which was accidentally killed had fed freely upon grasshoppers for twenty minutes, and died ten minutes after the close of the feeding period. An examination of the alimentary canal showed the stomach to be quite full, but less than fifty per cent. of its contents, consisting mainly of the hard parts of wings, thoraces, and lege, was in a condition to be recognized. The strongly chitinized pronota and hind femora of the grasshoppers offered the most resistance to the digestive processes. The other fifty per cent. of the stomach contents had been so finely divided, in the very brief time that it had been in that receptacle, that one would hardly have cared to express a positive opinion as to its identity. This condition of stomach contents is not unusual. In examining the contents of birds' stomachs we often find more than fifty per cent. of the food so finely comminuted and mixed as to be practically unrecognizable. The presence of insects in a bird's stomach is sometimes made known by a mere mandible or some other recognizable portion, which has resisted for a time the grinding of this remarkable digestive organ. It is significant, however, that, in the thirty minutes intervening between the beginning of a feeding period and death, the stomach had thoroughly pulverized half the food eaten.

This experiment was carried further with the second Crow. On September 14 the only food materials given the bird were six crickets and eleven grasshoppers. These it ate within four minutes, and thirty minutes later it was killed.

Only about twenty-five per cent. of the stomach contents was recognizable, but this is not all. The alimentary canal was thirty-six inches in length, and in the intestine at a distance of from twelve to fifteen inches from the stomach, and again at twenty-five to twenty-eight inches from that organ, were found a few small pieces of the fore wings of the grasshoppers. As the bird had not been fed since 4 o'clock in the afternoon of the previous day, these remains probably 



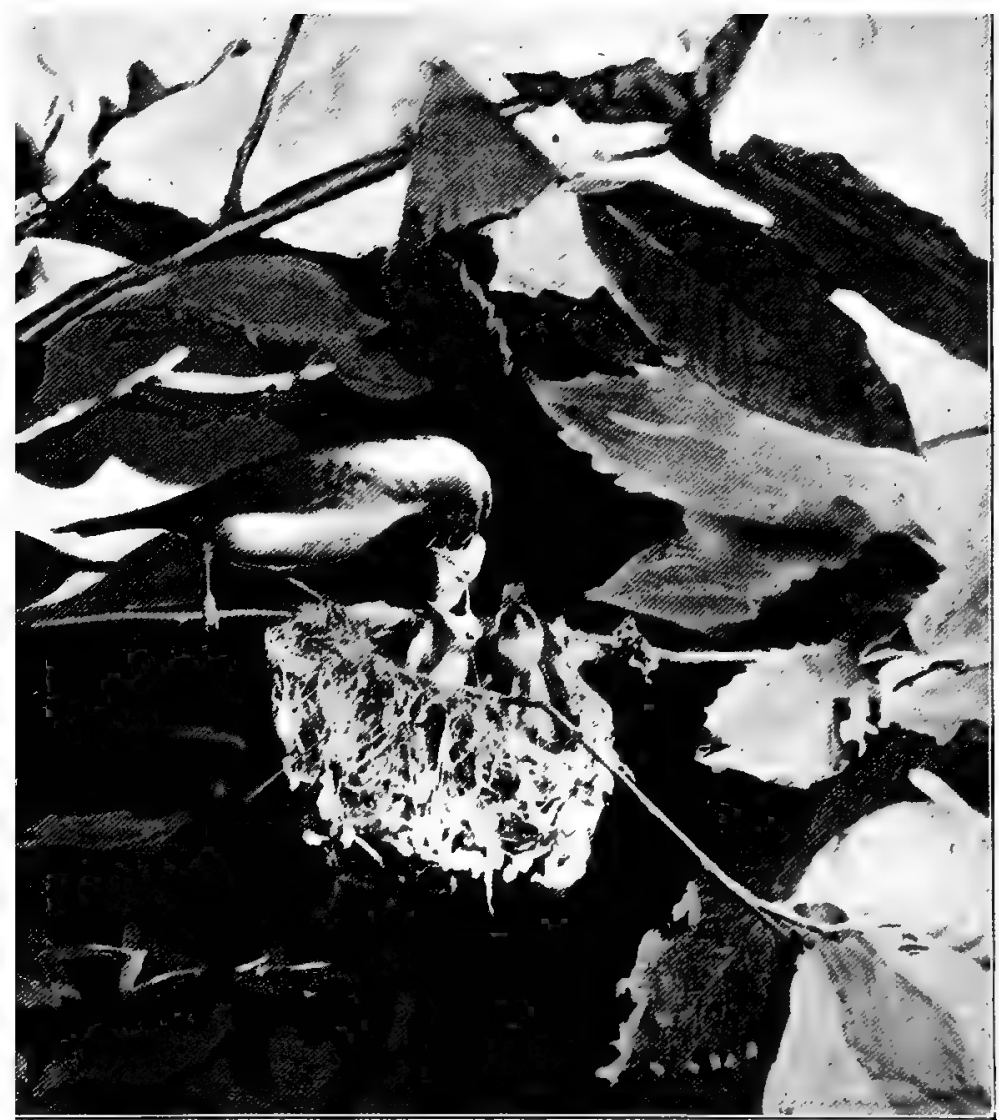

PLATE IV. - Red-eyed Vireo feeding Young. (Photograph by C. A. Reed.) 
came from the insects fed to it not more than thirty-three minutes before it was killed.

In summing up the results, Mr. Kirkland says: "I think, from what we have seen, that we might expect to find the gizzard empty in from one to one and one-half hours."

Such an experiment should be carried further, but enough was learned to show that the stomach of a young Crow probably can be filled with food and emptied of the digested material from eight to twelve times a day during the long days of midsummer, when their appetites are at their best.

Digestion in some of the smaller birds is doubtless even more rapid, for they are enabled to dispose of a still larger amount of food in proportion to their size. Mr. Owen informs us that the time required for a blueberry to traverse the digestive tract of his Hernit Thrush was practically an hour and a half. Mr. C. J. Maynard once told me that in a similar experiment a Cedar Bird passed the residue of food within thirty minutes after the food was taken. Weed and Dearborn found that a blackberry was digested by a young Cedar Bird in half an hour.

The Number of Insects eaten by Young Birds in the Nest.

The remarkable appetites of young birds keep their devoted parents very busy supplying food most of the time from morning till night. The mother bird spends practically all her time either in searching for food, brooding, protecting, and feeding the young, or cleaning the nest (for all the smaller birds that nest openly are obliged to dispose of the excreta of their young, that it may neither befoul the nest nor betray its location to their enemies). Most of the visits made by the old birds to the nest during the day are for the dual purpose of feeding the young and keeping the nest clean. Records kept of the number of these visits show the industry of the parent birds and the food capacity of the young.

My assistant, Mr. F. H. Mosher, watched a pair of Redeyed Vireos feeding their young on June 13, 1899. There were three nestlings, about one day old. At this early age the young of most small birds are fed mainly by regur- 
gitation. The parent birds swallow the food, and probably soften or partly digest it, ejecting it afterwards through their own mouths into the open mouths of the young. No attempt was made, therefore, in this case, to determine the character or amount of the food, for fear of disturbing the parents and interrupting the regularity of the feeding. The birds were

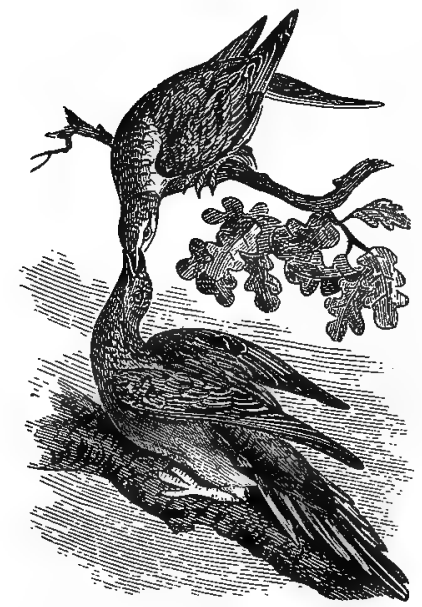

Fig. 24. - Passenger Pigeon feeding by regurgitation. From Samuels. fed between 7 and 8 A.r. fourteen times; between 8 and 9 , nine times; between 9 and 10 , twelve times; between 10 and 11 , seven times; between 11 and 12, sixteen times; between 12 and 1 , nine times; between 1 and 2, twelve times; between 2 and 3 , fifteen times; between 3 and 4 , thirteen times; and between 4 and 5 , eighteen times.

It will be seen that one or the other parent came to the nest with food one hundred and twenty-five times in ten hours, even when the observer was watching near by; but this leaves four hours unaccounted for, to fill out the long June day, from dawn to evening. The feeding periods averaged less than six minutes apart during the time the birds were watched; so it seems probable that, had the entire record for the day been kept, at least one hundred and fifty visits to the young would have been recorded. Young birds are fed oftenest at morning and evening, or during the hours when these Vireos were not watched.

Mr. Mosher watched a pair of Rose-breasted Grosbeaks feeding their young on June 12, 1899. The young were nearly ready to leave the nest, as one of them stood on a branch near its edge. The nest was situated about fifteen feet from the ground, in the top of a slender white birch in the woods. The ground was well covered with hazel bushes about three and one-half feet high, which nearly concealed the observer. During the first half hour he made no record, as the birds were alarmed by his presence. As they com- 
menced bringing food regularly, he began the record at 6 A.M. Between 6 and 7 they came to the nest fifty-two times; between 7 and 8 , forty-seven times; between 8 and 9 , fortythree times; between 9 and 10 , thirty times; between 10 and 11, thirty-six times; between 11 and 12, twenty-seven times; between 12 and 1, thirty-two times; between 1 and 2 , thirty-eight times; between 2 and 3 , forty-one times; between 3 and 4, twenty-two times; between 4 and 5, fiftyeight times. The majority of the larvæ seemed to be leaf rollers from the oak trees. The female came on the average about three times to each two visits of the male; he was occupied much of the time in keeping other birds away from the vicinity of the nest.

When the young of most insect-eating birds are well grown, the parents feed them whole insects just as they are picked up. With a glass, therefore, the insects brought by these Grosbeaks could be seen in the birds' beaks. Their lusty youngsters were fed almost entirely on insect larvæ or caterpillars taken from the forest trees. On only four visits did either parent bird bring less than two larvæ each. In eleven hours, then, they made four hundred and twenty-six trips, and must have fed their nestlings at least eight hundred and forty-eight larvæ or caterpillars, and possibly more, as a bird has been observed to carry as many as eleven small caterpillars on one visit to its young.

In comparing the records of the two nests as given above, it is noticeable that the Grosbeaks fed the young much oftener than did the Vireos. This difference is due mainly to the fact that about the time the young birds are ready to fly, as were these Grosbeaks, they require much more food than when first hatched, as was the ease with the Vireos. This, of course, is mainly owing to their increased size. The difference in the number, age, and size of the young probably accounts largely for the great variation in the number of visits made to them by the parent birds, as recorded by different observers.

I have published some notes on the feeding of young Chickadees by the parent birds. Six visits were made to these young within thirteen minutes. In each case the bills 
of the parent birds were filled with a mass of small insects, mainly ants and plant lice, to which were added a few spiders. These young were also fully fledged. ${ }^{1}$

The number of young in the nests of the smaller perching birds is usually from three to five. In the case of the Chickadees mentioned above there were seven, and in another case that I have recently observed there were nine. Chickadees and Wrens, because of their insectivorous habits and the large broods they rear, probably reach the maximum in the number of insects brought to their young.

Dr. Judd gives an account of the feeding of some young House Wrens by the mother bird alone. These young Wrens were about three-fourths grown, and were visited one hundred and ten times in four hours and thirty-seven minutes. They were fed, during this time, one hundred and eleven insects and spiders. Among these were identified one white grub, one soldier bug, three millers (Noctuida), nine spiders, nine grasshoppers, fifteen May flies, and thirty-four caterpillars. On the following day, in three hours and five minutes, the young were fed sixty-seven times. ${ }^{2}$

Professor Aughey states that during a locust year in Nebraska he saw a pair of Long-billed Marsh Wrens take thirty-one small locusts to their nest in an hour. It is interesting to note that a pair of Rock Wrens that he watched took just thirty-two locusts to their nest in another hour. ${ }^{3}$

Another observer is reported by Dr. Barton to have seen a pair of Wrens coming from their box and returning with insects from forty to sixty times an hour. In an exceptional hour they carried food seventy-one times. $\mathrm{He}$ estimates that at that time they took from the garden six hundred insects per day. 4

Few people, unfortunately, who are qualified for the task,

1 Two Years with the Birds on a Farm. Annual report of the Massachusetts State Board of Agriculture, 1902, p. 129.

2 The Birds of a Maryland Farm, by Sylvester D. Judd. Bulletin No. 17, United States Department of Agriculture, Division of Biological Survey, pp. 45,46 .

3 Notes on the Nature of the Food of Nebraska Birds, by S. A. Aughey. First Report of the United States Entomological Commission, 1877, Appendix, p. 18.

4 Fragments of the Natural History of Pennsylvania, by Dr. B. S. Barton, Part I, 1799, p. 22. 


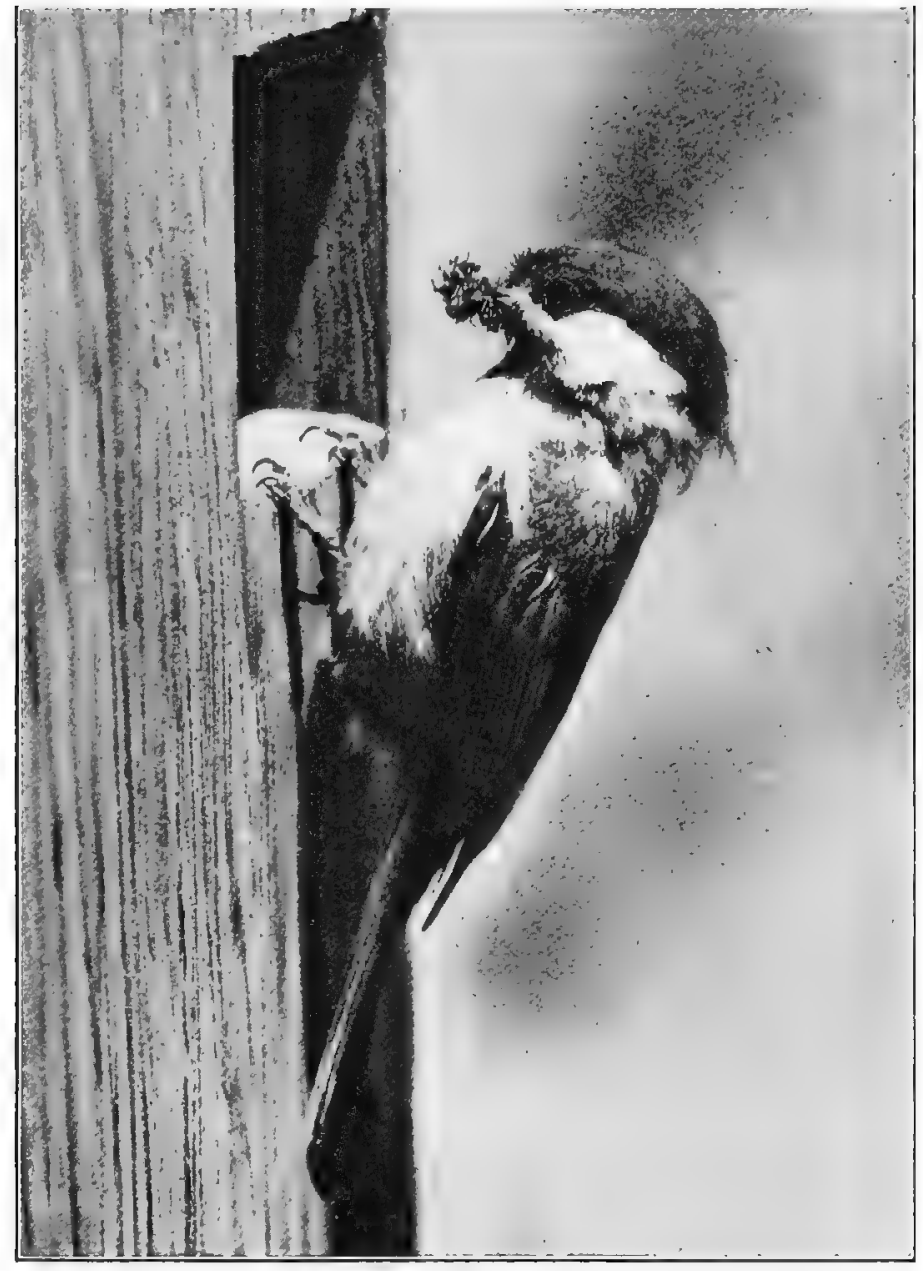

PLATE V. - Chickadee. Female. with mass of insects in lier heak, entering nesting box at author's window. (From tmericau Oruithology.) 

have both the time and patience to watch the feeding of young birds for an entire day. Dr. C. M. Weed and Mr. W. F. Fiske, however, have accomplished this feat. They watched the nest of a Chipping Sparrow from 3.40 A.r. to 7.49 P.M. on June 22, 1898. The valuable record of these observations

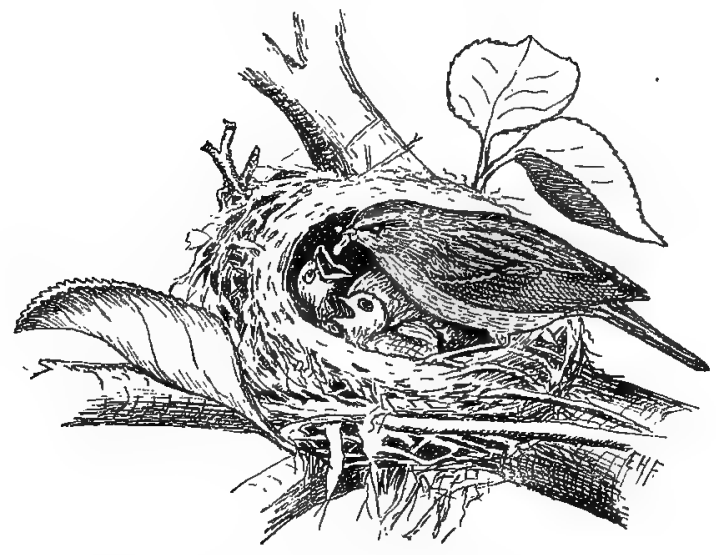

Fig. 25. - Chipping Sparrow feeding young.

shows that these two birds, having only three young in the nest, visited it at least one hundred and eighty-two times during that day; and Dr. Weed says that they made almost two hundred trips, although some of the trips evidently were made to furnish grit for grinding the food. The birds were busy from daylight to dark, with no long intermission. The food, so far as identified, consisted largely of caterpillars. Crickets and crane flies were seen, and it was believed that a great variety of insect food was brought. ${ }^{1}$

A committee on useful birds, selected from the Pennsylvania State Board of Agriculture, reported that an observer had watched the nest of a pair of Martins for sixteen hours, from 4 A.x. until 8 P.M., to see how many visits the parent birds made to the young. One hundred and nineteen visits were made by the male and one hundred and ninety-three by the female. ${ }^{2}$

\footnotetext{
1 The Feeding Habits of the Chipping Sparrow, by C. M. Weed. Bulletin No. 55, New Hampshire College Agricultural Experiment Station, 1898.

2 C. C. Musselman, in Agriculture of Pennsylvania, 1887, p. 105.
} 
The number of insects consumed daily by young birds in their nests is difficult of estimation, because of the variation in size among insects and the great difference in size between the mature insect and the newly hatched larva. Five hundred of the young larvæ of a moth might occupy less space in the stomach of a bird than would the moth itself; while a thousand aphids might take no more room than a full-grown caterpillar.. Nevertheless, many estimates have been made, based on known data, as to the number of insects fed to young birds.

The introduced House Sparrow (Passer domesticus), commonly called the English Sparrow, undoubtedly eats fewer insects, here, in proportion to the rest of its food than any of our smaller native birds. The young are fed very largely on grain and other non-insectivorous food. Still, a Sparrow's nest in the city of Paris is said to have contained seven hundred pairs of chafer wing-cases. ${ }^{1}$

Mons. P. Pélicot gives a table of the estimates, made by several foreign authors, of the numbers of insects eaten by Sparrows in a given time. These approximations vary from that of Blatin, who estimates that two Sparrows will destroy twelve hundred chafers in twelve days, to that of Tschudi, who believes that a single Sparrow will destroy fifteen hundred larvæ within twenty-four hours. ${ }^{2}$

Bradley mentions watching a bird's nest and discovering that five hundred caterpillars were consumed in one day. ${ }^{3}$ He says (according to Samuels) that a pair of Sparrows will destroy thirty-three hundred and sixty caterpillars for a week's family supplies. A single pair of Sparrows is reported to have carried to the nest five hundred insects in an hour.

These statements may be exaggerated, but if they approximate the facts, what immense numbers of insects must be

\footnotetext{
1 Notes on Recent Progress of Agricultural Science, by David A. Wells. Report (on Agriculture) of the United States Commissioner of Patents, 1861, p. 323.

${ }^{2}$ A Favorable View of the English Sparrow, a Review of "Un Passereau a Protéger," Insect Life, Riley and Howard, Vol. XV', 1891, p. 153, published by the United States Department of Agriculture.

${ }^{8}$ Birds and Bird Laws, by J. R. Dodge. Annual Report of the United States Commissioner of Agriculture, 1864, pp. 436, 437.
} 
consumed by the young of native Massachusetts birds that are fed almost entirely upon insect food.

Weed and Dearborn watched three young Cedar Birds in the nest for the fifteen days they remained there, and found that they each devoured not less than ten ounces of food in that time, or more than ten times their weight on the day they left the 'nest.

The Amount of Food eaten by Adult Birds.

There is no way of determining how much food is required daily by the adult bird, except it be kept in confinement; in that case, the food taken can be weighed or measured. This has been done. Dr. Stanley mentions sixteen Canaries which ate one hundred grains of food per day, or an amount equal to about one-sixth of their weight, which is probably much less than wild birds of the same species would eat. ${ }^{1}$ Seedeating birds, like the Canary, however, require less food than the insectivorous species, as their food is more concentrated. Mr. Robert Ridgway, the distinguished ornithologist of the Smithsonian Institution, makes the statement in the American Naturalist for August, 1869, that a Western Kingbird (Tyrannus verticalis), which be kept in a cage, devoured one hundred and twenty locusts in a single day.

Compared with the wild bird, the specimen that is caged or confined is a poor, weak thing at best, short of breath, low in vitality, and lacking the vigorous assimilative powers of the free bird. Keepers of cage birds, who know well the capacity of their pets, find it difficult to believe that wild birds can possibly consume the amount of food that actually has been found in their stomachs by economic ornithologists.

When the reader is told that thirty grasshoppers were found in the stomach of a single Catbird, he conjures up a mental photograph of the full-grown grasshopper (the imago) that he sees in the field in late summer, and fails to remember, perhaps, that grasshoppers come from eggs, and in their growth to maturity may be found of all sizes, between that of the newly hatched insect and the full-winged hopper.

1 History of Birds, p. 225. 
While the Catbird's stomach might not be large enough to contain thirty full-grown locusts, it would easily contain more than thirty small ones. The statement that thirty grasshoppers were found in the Catbird's stomach might also need modification in another way. The least fragment of an insect found in a bird's stomach is usually considered good proof that the bird has eaten that insect. There might be found in the stomach of a bird a mass of unrecognizable material, from which the expert would be able to sort out and recognize enough of the harder parts of different grasshoppers to prove that thirty of these insects, of considerable size, had been eaten within a certain time, even though a greater part of those first swallowed had already disappeared from the stomach.

Prof. F. E. L. Beal writes me as follows regarding the methods used at the United States Department of Agriculture in counting the insects found in the stomachs of birds : -

In the case of grasshoppers and caterpillars it is the jaws (mandibles) that are counted. Birds when not sleeping appear to eat all the time when not occupied in other duties, such as nest-making or feeding their young. The process of digestion is continuous. The more easily digested parts pass out of the stomach very quickly, but the hard parts remain somewhat longer. In this way when a bird is feeding upon grasshoppers the jaws of those first eaten remain after the rest of the body has passed on. When the stomach is opened the jaws are counted, and for every two we estimate at least one grasshopper killed. In cases where only a few insects were involved I have taken the pains to pair the jaws, and in this way have often found that the number that had been eaten was more than half the number of jaws. In this work each head that appears to be whole is carefully examined, to see that it has not lost one or more of its jaws; were it not for this precaution, the insect might be counted twice. Caterpillars, like grasshoppers, are ensily broken up, and so the heads are counted when whole; otherwise the jaws are counted.

The variation in size of different species of insects should also be considered. While the caterpillars of some species of moths reach three or four inches in length, others never grow to be half an inch long.

These and other similar considerations, well known to 
the economic ornithologist, lead him to accept as facts the extreme statements made by competent investigators.

It will be seen from the foregoing explanations that, while a large number of injurious insects found in a bird's stomach may indicate its usefulness, it may not always mean that it has eaten ar great bulk or quantity of such food.

The question which most interests the farmer, however, is, not so much what birds require to sustain life, as how much they will eat if they can get their fill. If in times of plenty birds will eat more than they really need, then they become more useful or injurious, as the case may be, than they would be if they ate only enough to live. The amount of food that has been found in birds' gizzards indicates that they will eat until surfeited.

Professor Beal, who has examined the contents of over twenty thousand stomachs, says, regarding this habit:-

The majority of people have no idea of how nuch these insects can be compressed in the stomach of a bird. It is often the case that when a stomach has been opened, and the contents placed in a pile, the heap is two or three times as large as the original stomach with the food all in it. Moreover, in the cases where remarkable numbers of insects have been found, the crops or gullets usually have been full, as well as the stomach itself. It is a fact, perhaps not generally known, that with birds that have no special enlargement of the gullet in the nature of a crop, the whole gullet is used for the purpose; and when favorite food is abundant, the bird will fill itself to the throat. I hare seen a Snowbird so full of seeds that they were plainly in sight when the beak was opened, and from the bill to the stomach was a solid mass of seed. The stomachs of birds are often packed so hard and tight with food that it is a wonder how the process of digestion can go on; but it does, nevertheless.

In giving the maximum amounts of food found in birds' stomachs, I shall be obliged to refer to the publications of the Bureau of Biological Survey of the United States Department of Agriculture; and it is but just to say here that the world owes much to Dr. Merriam, chief of the Bureau, for his indefatigable labors in behalf of science and agriculture.

In connection with the work of the survey, the conntents of more than thirty-five thousand bird stomachs have been 
examined, and much has been done in observing the feeding habits of birds in the field. The work in economic ornithology performed by Merriam, Fisher, Barrows, Beal, and Judd is of great value. Its results rank above those of all other similar investigations, and must be considered as authoritative.

Professor Beal found in the stomach of a Yellow-billed Cuckoo two hundred and seventeen fall webworms, and in another two hundred and fifty American tent caterpillars. Two Flickers were found to have eaten respectively three thousand and five thousand ants. Sixty grasshoppers were found in the stomach of a Nighthawk.

Professor Harvey found five hundred mosquitoes in a Nighthawk's stomach. In this case the insects must have been fully grown, as the larvæ of the mosquito are found mainly in water, and the Nighthawk takes its food on the wing. The stomach of this useful bird is much larger in proportion to its size than that of most other birds; but seventy-five hundred seeds of the yellow wood sorrel had been eaten by a Mourning Dove, sixty-four hundred by another, and ninety-two hundred seeds, chiefly of weeds, were found in another. Here we have twenty-three thousand one hundred seeds, mostly those of weeds, eaten at a meal by three birds. Probably where these large numbers are given, the result is approximate, and is arrived at by counting a part of the contents for a measure, and from this estimating the rest in bulk.

Dr. Judd says that the stomachs of four Bank Swallows contained, all together, just two hundred ants, and that a Nighthawk has been known to eat one thousand at a single meal. He speaks of seventeen hundred seeds of weeds having been taken at one feeding by a Bob-white; three thousand leguminous seeds were found in the stomach of another, and no less than five thousand seeds of pigeon grass were taken from a third. Dr. Warren has taken twenty-eight cutworms from the stomach of a Red-winged Blackbird. Stomachs of Snowflakes have each contained from five hundred to fifteen hundred seeds of amaranth. Professor Forbes found in the stomachs of seven Cedar Birds a number 
of cankerworms varying from seventy to one hundred and one each, the number found in most cases averaging nearly one hundred for each bird.

A Ruffed Grouse, killed in winter, had in its crop twelve leaves of sheep laurel and four hundred and thirty-five buds and bits of branches, all taken for its morning meal. The crop of another contained over five hundred buds and twigs. As these birds eat such food both at morning and at night, it would seem that they must require daily, for these two meals alone, between eight hundred and one thousand buds and twigs. ${ }^{1}$

The following notes, received from Professor Beal since the above was written, are of great interest : -

From the stomach of a Franklin's Gull (Larus franklinii) there were taken seventy entire grasshoppers and the jaws of fifty-six more; from another, ninety grasshoppers and one hundred and two additional jaws; from another, forty-eight grasshoppers and seventy more jaws ; and still another contained sixty-seven grasshoppers. Another stomach of this species contained sixty-eight crickets. These grasshoppers and crickets were each more than one inch in length. We examined the stomach of a Franklin's Gull which contained three hundred and twenty-seren entire nymphs of dragon flies, each three-fourths of an inch in length. In the stomach of a Cliff Swallow were found one hundred entire beetles (Aphodius inquinatus), with remains of others. These insects are a little more than three-eighths of an inch in length. We are now examining birds" stomachs from Texas, and from the stomach of a Yellow-billed Cuckoo were taken the remains of eighty-two caterpillars that originally were from one to one and a half inches in length. From another stomach were taken eighty-six, and from forty to sixty from several others.

All evidence acquired by observation as to the amount of food eaten by wild birds at liberty must perforce be fragmentary, for such observation is necessarily limited to brief periods. The difficulties attending such work make its results somewhat uncertain and unsatisfactory; nevertheless, some information as to the quantity of food eaten by wild birds may be obtained in this way. Vultures are said to so gorge themselves that they are unable to fly. I have known

${ }^{2}$ Birds in their Relation to Man, by Clarence M. Weed and Ned Dearborn, 1903, p. 62 . 
a Goshawk in winter to kill a domestic Cock of more than its own weight, and devour the greater part at two meals. I have learned, by following certain Warblers and Titmice through the woods, that their search for and consumption of insects are almost continuous during most of the forenoon. As the noon hour approaches they become less active, and on warm days devote some time to resting and bathing. In the afternoon their activity increases, until toward night their quest for food is almost as strenuous as in the early morning. They are, therefore, actually engaged for the larger part of the day in capturing and eating insects. In feeding wild birds in winter I have noticed that Chickadees come to the food supplied for them about three times an hour all day long, and that in the intervals they are mainly occupied in finding their natural food. On May 28, 1898, Mr. Mosher watched a pair of Northern Yellow-throats eating plant lice from the birches in the Middlesex Fells Reservation, where these insects swarmed. He was equipped with a good glass, and concealed close to the spot where the birds were feeding, and so was able to count in turn the number of times each bird picked up an insect. One of these Warblers apparently swallowed eighty-nine of these tiny insects in one minute. The pair continued eating at this rate for forty minutes. Mr. Mosher states that they must have eaten considerably over seven thousand plant lice in that time. It would seem impossible for the birds to crowd that number of insects into their stomachs; but we must remember that the insects were infinitesimal in size, soft-bodied, easily compressed in the stomach, and quickly digested, so that by the time a part were eaten those first taken would be well disposed of, leaving room for more. Mr. Mosher is a very careful, painstaking, and trustwortby observer ; undoubtedly his statement is accurate; but, to eliminate any possibility of error, we will assume for purposes of calculation that they ate only thirty-five hundred in an hour.

A pair of Yellow-throats (presumably the same) were seen to come daily and many times each day to the birch trees which were infested with these aphids. Probably they spent at least three hours each day feeding on these insects. If 
the two birds ate only thirty-five hundred an hour for three hours a day, they would consume ten thousand five hundred aphids each day, or seventy-three thousand five hundred in a week. It requires no draft on the imagination to see how such appetites may become useful to the farmer if they are satiated on his insect enemies.

Two Scarlet Tanagers were seen eating very small caterpillars of the

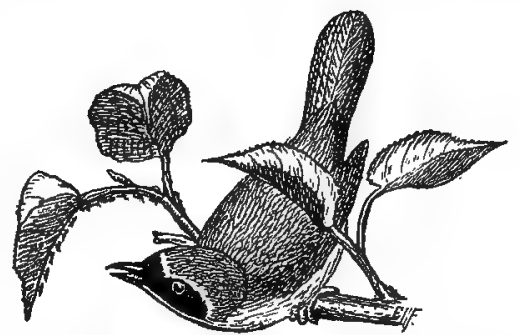

Fig, 26. - Yellow-throat catching birch aphids. gipsy moth for eighteen minutes, at the rate of thirty-five a minute. These birds spent much time in that way. If we assume that they ate caterpillars at this rate for only an hour each day, they must have consumed daily twenty-one hundred caterpillars, or fourteen thousand seven hundred in a week. Such a number of caterpillars would be suffcient to defoliate two average apple trees, and so prevent fruitage. The removal of these caterpillars might enable the trees to bear a full crop. It is easily possible, therefore, for a single pair of these birds in a week's time to save the fruit of two average apple trees, - a crop worth from two to five dollars or more, according to the productiveness of the trees and the price paid for apples.

\section{BIRDS SAVE TREES AND CROPS FROM DESTRUCTION.}

Since birds evidently operate to check insect outbreaks, it follows that in their capacity of insect destroyers they must in many instances have saved trees and crops from destruction by insect pests. If, however, we turn to the literature of agriculture, entomology, and ornithology, we shall not find it replete with such instances. Still, there are enough on record to show that conspicuous services of birds have been noted occasionally; and I am convinced by my own experience that such checks to insect increase occur commonly, but escape both observation and record.

Some brief but striking accounts of this class of occur- 
rences may be gleaned from European records. Samuels writes that in Pomerania in 1847 an immense forest that was in danger of being utterly ruined by caterpillars was very unexpectedly saved by Cuckoos, which, though on the point of migrating, established themselves there for some weeks, and so thoroughly cleared the trees that the next year" "neither depredators nor depredations were to be seen." $1 \mathrm{He}$ also speaks of a European outbreak of the gipsy moth (Bombyx dispar) in 1848, saying that the hand of man was powerless to work off the infliction, but that on the approach of winter Titmice and Wrens paid daily visits to the infested trees, and before spring had arrived the eggs of dispar were entirely destroyed. This account agrees with the following translation from Altum :-

In the year 1848 endless numbers of the larvæ of Bombyx dispar had eaten every leaf from the trees of Count Wodzicki, so that they were porfectly bare. In the fall all the branches and limbs were covered with the egg clusters. After he had recognized the impracticability of it, he gave up all endeavor to remove them by hand, and prepared to see his beautiful trees die. Towards winter numerous flocks of Titmice and Wrens came daily to the trees. The egg clusters disappeared. In the spring twenty pairs of Titmice nested in the garden, and the larra plague was noticeably reduced. In the year 1850 the small feathered garden police had cleaned his trees, so that he saw them during the entire summer in their most beautiful verdure. ${ }^{2}$

According to Reaumur, these larvæ were so extremely numerous on the limes of the Alle verte at Brussels in $\mathbf{1 8 2 6}$ that many of the great trees of that noble avenue were nearly defoliated. The moths swarmed like bees in the summer. They were also very numerous in the park, and if one-half the eggs had hatched in the following spring, probably scarce a leaf would have remained in these favorite places of public resort. Two months later, however, he could scarcely discover a single egg cluster. This happy result was attributed to the Titmice and Creepers, which were seen busily running up and down the tree trunks. ${ }^{3}$

\footnotetext{
1 Agricultural Value of Birds, by E. A. Samuels. Annual Report of the Massachusetts State Board of Agriculture, 1865-66, pp. 116, 117.

2. Translated from Forstzoologie, II, 1880, p. 324.

${ }^{\circledR}$ Reau. 1387 . Cited by Kirby and Spence in their Introduction to Entomology, 1857, pp. 117, 118.
} 
The value of birds has already been recognized at the antipodes. Australian farmers have suffered greatly from inroads of locusts upon their crops and pastures.

The Australian correspondence of the Mark Lane Express of March 7, 1892, had a paragraph relating to the value of the Ibis to farmers during the locust incursions of that year and the year previous. In the Glen Thompson district several large flocks, one said to number fully five hundred birds, were seen eating the young locusts in a wholesale manner. Other insectivorous birds were flourishing upon the same diet. Near Ballarat, Victoria, a swarm of locusts was noted in a paddock; and just as it was feared that all the sheep would have to be sold for want of grass, flocks of Starlings, Spoonbills, and Cranes made their appearance, and in a few days made so complete a destruction of the locusts that only about forty acres of grass were lost. ${ }^{1}$

American farmers have had many similar experiences. When the Mormons first settled in Utah their crops were almost utterly destroyed by myriads of crickets that came

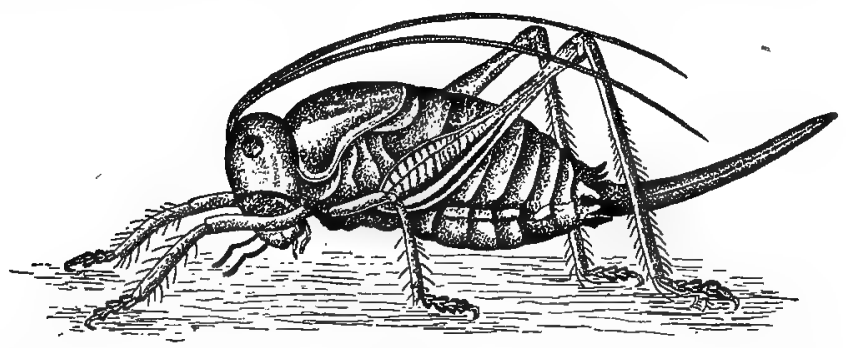

Fig. 27. - The western cricket that destroyed the settlers' crops at Salt Lake. Natural size; after Glover.

down from the mountains. Hon. Geo. Q. Cannon, as temporary chairman of the third irrigation congress, told how it happened. The first year's crop having been destroyed, the Mormons had sowed seed the second year. The crop promised well, but when again the crickets appeared, the people were in danger of starvation. In describing the conditions in $1848 \mathrm{Mr}$. Cannon says:- 
Black crickets came down by millions and destroyed our grain crops; promising fields of wheat in the morning were by evening as smooth as a man's hand,- - devoured by the crickets. . . At this juncture sea Gulls came by hundreds and thousands, and before the crops were entirely destroyed these Gulls clevoured the insects, so that our fields were entirely freed from them. . . The settlers at Salt Lake regarded the advent of the birds as a heaven-sent miracle. . . . I have been along the ditches in the morning and have seen lumps of these crickets vomited up by the Gulls, so that they could again begin killing.

These "lumps of crickets" were probably pellets composed of indigestible portions of the insects, regurgitated by the birds. These crickets (Anabrus purpurascens) trav-

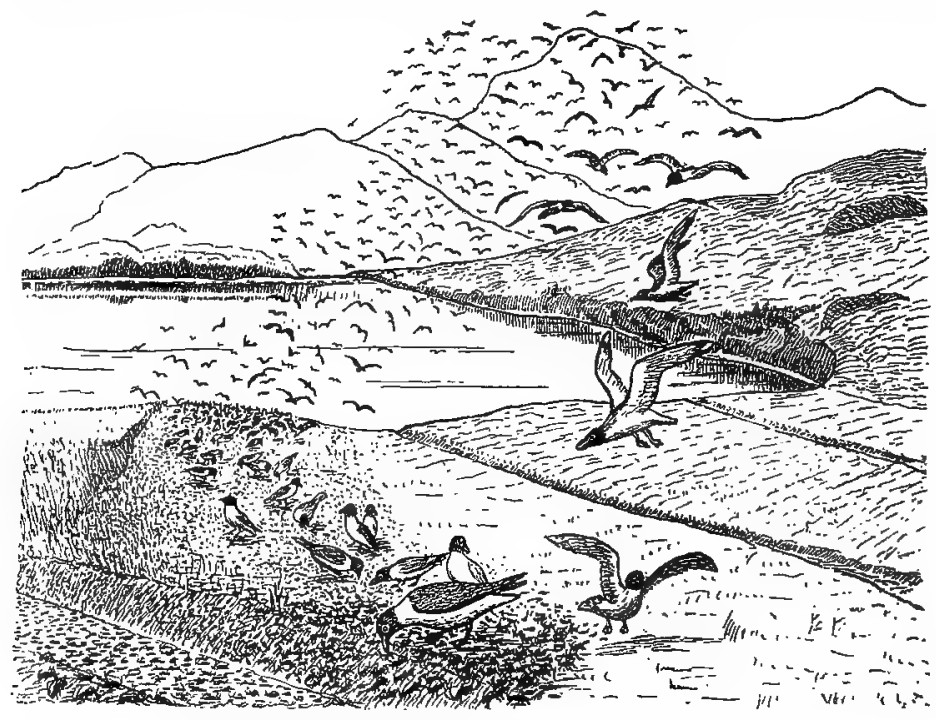

Fig. 28. - Gulls saving crops by killing crickets.

elled in enormous hordes, stopping at no obstacle, even crossing rivers. Several times afterward the crops of the Mormons were attacked by them, and were saved by the Gulls. ${ }^{1}$ Dr. A. K. Fisher is authority for the statement

1 This account of the deliverance of the Mormons by the Gulls is rouched for by many witnesses. See Irrigation Age, 1894, p. 188 ; also, Insect Life, Vol. VII, p. 275; Annual Report of the Massachusetts State Board of Agriculture, 1871, p. 76; Annual Report of the United States Commissioner of Agriculture, 1871, p. 79; and Second Annual Report of the United States Entomological Commission, 1875-79, p. 166. 
that the bird referred to is undoubtedly Franklin's Gull (Larus franklinii), which occurs in enormous flocks about the small fresh-water lakes of the northwest, and feeds in great companies on Orthoptera of all sorts. The Gulls were practically canonized by the grateful Mormons, and protected by both law and public sentiment, as a recognition of their worth.

Similar services were performed by birds during the great locust ravages which followed the settlement of the Mississippi valley. When large swarms of locusts appeared, nearly all birds, from the tiny Kinglet to the great Whooping Crane, fed on them. Fish-eating birds, like the Great Blue Heron, flesh-eating birds, like the Hawks and Owls, shore birds, Ducks, Geese, Gulls, - all joined with the smaller land birds in the general feast. Prof. Samuel Aughey learned this by dissecting birds and observing their feeding habits in Nebraska. In a paper published by him in 1877 , but not often quoted, he gives some of the practical results of the work done by birds in protecting crops from the mighty swarms of locusts which were devastating most of that region. He says :-

In the spring of 1865 the locusts hatched out in countless numbers in northeastern Nebraska. Very few fields of corn and the cereal grains escaped some damage. Some fields were entirely destroyed, while others were hurt to the amount of from ten to seventy-five per cent. One field of corn northwest of Dakota City was almost literally covered with locusts, and there the indications were that not a stalk would escape. After, and about the time the corn was up, the Yellow-headed Blackbirds in large numbers made this field their feeding ground. Visiting the field frequently, I could see a gradual diminution of the number of the locusts. Other birds, especially the Plovers, helped the Yellow-heads; and, although some of the corn had to be replanted once, yet it was the birds that made the crop that was raised possible at all. During the same season I visited Pigeon Creek valley, in this county, and I found among the eaten-up wheat fields one where the damage done was not over five per cent. 'The Irishman who pointed it out to me ascribed it to the work of the birds, chief among which were the Blackbird and Plover, with a few Quail and Prairie Chickens.

Professor Aughey speaks of a locality where, on several old fields, locusts hatched to the number of about three hun- 
dred to the square foot. Birds soon found them, and the ground was frequented by Blackbirds, Plover, Curlews, Prairie Chickens and small land birds. Long before the middle of June most of the locusts had disappeared. In 1886 locusts, he says, invaded Cedar and Dixon counties in swarms that darkened the sun. Nevertheless, at one point under observation the great number of birds that attacked these insects very materially lessened their numbers. In 1869 more than ninety per cent. of the locusts in one neighborhood were destroyed, apparently by birds, in one week. Other experiences are given, and several interesting letters from farmers are published, one of which follows :-

Dear SIR:- In answer to your question about the birds and the locusts, I must say this : every farmer that shoots birds must be a fool. I had wheat this Iast spring on new breaking. The grasshoppers came out apparently as thick as the wheat itself, and indeed much thicker. I gave up that field for lost. Just then great numbers of Plover came, and flocks of Blackbirds and some Quail, and commenced feeding on this field. They cleaned out the locusts so well that I had at least three-fourths of a crop, and I know that without the birds I would not have had any. I know other farmers whose wheat was saved in the same way.

S. E. Goodmore.

Fremont, Neb.

Another farmer wrote that the locusts hatched in immense numbers in his corn fields, but flocks of Blackbirds came and destroyed the insects, so that he raised a good crop. In another case, related by State Senator Crawford, a wheat field was swept clean by the locusts when the wheat was about two inches high; but flocks of Blackbirds came and devoured the locusts, and the wheat sprang up again and made a good crop. The menbers of the United States Entomological Commission were much impressed with the value of birds as locust destroyers. They said that the ocular demonstration of the usefulness of birds as insect destroyers was "so full and complete that it was impossible to entertain any doubt on this point." In one instance a farmer took one of the members of the commission out into the field, to show him how numerously the young locusts were hatching. 
When they arrived, the insects had disappeared from the place where they had been so abundant in the morning. The statement by the family that a flock of Blackbirds had been there during the farmer's absence solved the mystery. In another instance a garden was attacked by an innumerable host of little locusts. The owner battled bravely. with them for awhile, but at last, giving up in despair, sat down to watch the destruction of his vegetables and flowers, when suddenly a flock of Blackbirds alighted on the young cottonwoods he had planted in his yard. Having chirped a song, as if to cheer him, they flew into the garden; when they left, an hour or so later, the dreaded "hoppers" were gone, and his garden was saved. ${ }^{1}$

A severe outbreak of the forest tent caterpillar (Malacosoma disstria) occurred in New York and some of the New England States in 1897-98. Thousands of acres of woodland were devastated, great damage was done to the sugarmaple orchards of New York and Vermont, and the injury extended into Massachusetts. Birds and other natural enemies attacked the caterpillars vigorously in many localities, and by the year 1900 the plague had been reduced so that the injury was no longer seen. Miss Mary B. Sherman of Ogdensburg, N. Y., wrote on May 18 of that year that the town was then full of birds which were feeding on the caterpillars. There had been numerous Warblers in the maples, and the Orioles, Sparrows, Robins, Cedar Birds, several species of Warblers, and probably the House Wren, were killing caterpillars. Birds were reported in large numbers in the county. On May 26 she wrote again, stating that there were practically no caterpillars left, cold weather having killed many, and the birds apparently having destroyed the remainder. ${ }^{2}$

The good accomplished by birds in quelling great insect invasions should be patent to all, but very few people realize what the birds are doing. Many Nebraskans failed to notice

\footnotetext{
1 First Report of the United States Entomological Commission. Riley, Packard, and Thomas. 1877 , pp. 335, 336, 338-344.

${ }^{2}$ Report on the Injurious and Other Insects of the State of New York, by E. P. Felt, 1900, p. 1019.
} 
that birds were feeding on the locusts until Professor Aughey called their attention to this fact by articles published in the press.

Birds are doing the same kind of work in Massachusetts to-day, in repressing smaller outbreaks of common insects. Had we more observing people to record such services, their amount and variety probably would astound as. Professor Beal saw a family of Rose-breasted Grosbeaks clear the potato beetles from a potato patch of about one-fourth of an acre. Mr. E. W. Wood of West Newton, a well-known horticulturist, informed me that during one season, when the spring cankerworms ( Paleacrita vernata) became quite numerous in his orchard, a pair of Baltimore Orioles appeared, built a nest near by, and fed daily upon the cankerworms. This they continued to do assiduously; by the time the young birds were hatched, the numbers of the worms were considerably reduced. The birds then redoubled their diligence, carrying ten or eleven worms to the nest at once. Soon the cankerworms had disappeared, and there has been no trouble from them for many years.

Instances were recorded during the first State campaign against the gipsy moth, from 1890 to 1895 , where small isolated moth colonies appeared to have been suppressed and even annihilated by birds. A serious outbreak was discovered in Georgetown, Mass., in 1899. It had been in existence for a long time, but its spread had evidently been limited by the great number of birds that were feeding there on all forms of the moth. Several months later the State abandoned the work against the moth, and little hope was entertained that anything more than a severe check had been given the insect in Georgetown. Nevertheless, in the six years that have since elapsed comparatively few moths have been found in that locality. The most feasible explanation of this seems to be that up to 1906 the birds have kept the numbers of the moths below the point where they can do appreciable injury.

I have had several opportunities, within the last fifteen years, to watch the checking of insect uprisings by birds. One morning in the fall of 1904 I noticed in some poplar 
trees near the shore of the Musketaquid a small flock of Myrtle and Black-poll Warblers, busily feeding on a swarm of plant lice. There were not more than fifteen birds. The insects were mainly imagoes, and some of them were flying. The birds were pursuing these through the air, but were also seeking those that remained on the trunks and branches. I watched these birds for some time, noted their activity, and then passed on, but returned and observed their movements quite. closely at intervals all day. Toward night some of the insects had scattered to neighboring trees, and a few of the birds were pursuing them there; but most of the latter remained at or about the place where the aphis

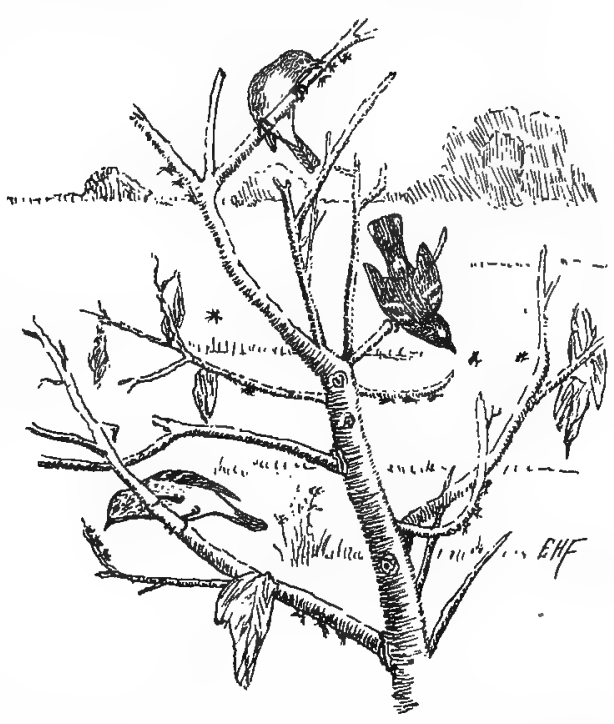

Fig. 29. - Warblers destroying a swarm of plant lice. swarm was first seen, and they were still there at sundown. The swarm decreased rapidly all day, until just before sunset it was difficult to find even a few specimens of the insect. The birds remained until it was nearly dark, for they were still finding a few insects on the higher branches. The plant lice I had secured for identification were destroyed or liberated during the night, probably by a deer mouse which frequented the camp; so the next morning at sunrise I went to the trees to look for more specimens. The birds, however, were there before me, and I was unable to find a single aphis on the trees. The last bird to linger was more successful than I, for it was still finding a few; but it soon gave up the effort, and left for more fruitful fields. Probably a few insects escaped by flight; but in examining the locality in $1905 \mathrm{I}$ could not find one. The apparently complete 
destruetion of these insects may have been due in part to the hard winter that ensued, but the effect produced by the birds was most obvious.

Such instances of the quelling of insect outbreaks by birds are noticeable, but the regulative influence steadily and perennially exerted by them, which tends to keep hundreds of species of injurious insects below the point where their injury to trees and plants would become apparent, is very. seldom appreciated.

\section{THE INCREASE OF INJURIOUS INSECTS FOLLOWING THE DESTRUCTION OF BIRDS.}

Many cases have been noted where the destruction of birds has been followed by an immediate increase in the numbers of injurious insects. Frederick the Great, king of Prussia, being particularly fond of cherries, was annoyed to see that the Sparrows were destroying his favorite fruit. An edict was issued ordering Sparrow extermination. All the resources of the fowler were brought to bear, and the campaign was so successful that not only were the Sparrows destroyed, but many other birds were either killed or driven away by the extraordinary measures taken against the Sparrows. Within two years cherries and most other fruits were wanting. The trees were defoliated by caterpillars and other insects, and the great Frederick, seeing his error, imported Sparrows at considerable expense to take the place of the birds that had been killed.1

In the year 1798 the forests in Saxony and Brandenburg were attacked by a general mortality. The greater part of the trees, especially the firs and pines, died as if struck at the roots by some secret malady. The foliage was not devoured by caterpillars; the trees perished without showing any signs of external disease. This calamity became so general that the regency of Saxony sent naturalists and skillful foresters to find out the cause. They soon found it in the multiplication of one of the lepidopterous insects, which in its larval state fed within the tree upon the wood. When-

\footnotetext{
1 Agricultural Value of Birds, by E. A. Samuels. Annual Report of the Massachusetts State Board of Agriculture, 1865-66, pp. 116, 117.
} 
ever any bough of the fir or the pine was broken this insect was found within it, and had often hollowed it out even to the bark. The naturalists reported that apparently the extraordinary increase of the insect was owing to the entire disappearance of several species of Woodpecker and Titmouse, which had not been seen in the forest for some years. ${ }^{1}$

In 1858 Kearly wrote to the Entomologists' Intelligencer that a friend who had been spending a short time in Belgium informed him that in the previous year Sparrows and other birds had appeared in the park at Brussels in unusual numbers. These birds probably were attracted by an unusual supply of insect food; but complaint was made of the Sparrows as a nuisance, and their destruction was ordered. "But," says Kearly, "it now turns out that in exterminating the birds the park goers have got rid of one evil only to entail upon themselves a greater. Throughout the past summer the place has swarmed with insect pests." He says also that the larva of the gipsy moth stripped nearly all of the trees of their foliage, and was one of the chief offenders. He adds that, had the authorities known what Kirby and Spence say on this subject (regarding the destruction of this insect by birds in Brussels in 1826), they would have remained guiltless of killing their feathered protectors.

During the year 1861 the harvests of France gave an unusually poor return, and a commission to investigate the cause of the deficiency was appointed at the instance of the Minister of Agriculture. ${ }^{2}$ The commission took counsel of experienced naturalists, St. Hilaire, Prevost, and others. By this commission the deficiency was attributed in a great degree to the ravages of insects which it is the function of certain birds to check.

It seems that the French people had been killing and eating not merely the game birds, but the smaller birds as well. Insect-eating birds had been shot, snared, and trapped throughout the country. Fruit-eating and graineating species especially had been persecuted. Birds' eggs

\footnotetext{
- Utility of Birds, by Wilson Flagg. Annual Report of the Massachusetts State Board of Agriculture, 1861, pp. 66, 67.

2 Notes on the Progress of Agricultural Science, by David A. Wells. Report of the United States Commissioner of Patents, 1861, pp. 322, 323.
} 
had been taken in immense numbers. A single child had been known to come in at night with a hundred eggs, and the number of birds' eggs destroyed in the country each year was estimated at eighty to one hundred millions. Before such persecution the birds were actually dying out. Some species had already disappeared, and others were rapidly diminishing. As an apparent result of the destruction of birds, the vines, the fruit trees, the forest trees, and the grain in the fields, had suffered much from the attacks of destructive insects, that had increased as a result of the disturbance of nature's balance caused by the decrease of birds. In one department of the east of France the value of the wheat destroyed by insects in a single season was estimated at five million francs. It was concluded that by no agency save that of little birds could the ravages of insects be kept down. The commission called for prompt and energetic remedies, and suggested that the teachers and clergy should endeavor to put the matter in its proper light before the people.

In 1895 I received a letter from Mons. J. O. Clercy, secretary of the Society of Natural Sciences, Ekaterinburg, Russian Siberia, in which he stated that the ravages of two species of cutworms and some ten species of locusts had contributed (together with the want of rain) to produce a famine in that region. One of the evident causes which permitted such a numerous propagation of insect pests was, he said, the almost complete destruction of birds, most of which had been killed and sent abroad by wagonloads for ladies' hats. A law for the protection of birds was then enacted, and, said M. Clercy, "The poor little creatures are doing their best to reoccupy their old places in the woods and gardens." The reoccupation, however, did not go on as rapidly as did the destruction. ${ }^{1}$

Mr. R. E. Turner, in an important paper upon insects, read before an agricultural conference at Mackay, Quecnsland, stated that he considered that the decrease of insectivorous birds, owing to their indiscriminate shooting by the Kanakas on the plantations, had a great deal to do with the

1 The Gipsy Moth, by E. H. Forbush and C. H. Fernald, p. 206. Published by the Massachusetts State Board of Agriculture, 1896. 
increase of the sugar-cane insects, particularly white grubs, which were then so abundant. ${ }^{1} \quad$ A similar effect was observed by the early settlers of America to follow the shooting of the birds which attacked their crops. Kalm states, in his Travels in America, that in 1749, after a great destruction among the Crows and Blackbirds for a legal reward of three pence per dozen, the northern States experienced a complete loss of their grass and grain crops. The colonists were obliged to import hay from England to feed their cattle. The greatest losses from the ravages of the Rocky Mountain locust were coincident with, or followed soon after, the destruction by the people of countless thousands of Blackbirds, Prairie Chickens, Quail, Upland Plover, Curlew, and other birds. This coincidence seems significant, at least.

Professor Aughey tells how this slaughter was accomplished: He says that the Blackbirds and many other birds decreased greatly in Nebraska in the twelve years previous to 1877. He first went to the State in 1864. He never saw the Blackbirds so abundant as they were during 1865 over eastern Nebraska. Vast numbers of them were poisoned around the corn fields in spring and fall during the twelve years, so that often they were gathered and thrown into piles. This was done in the belief that the Blackbirds were damaging the crops, especially the corn. Great numbers of birds of other species were destroyed at the same time. A single grain of corn soaked with strychnine would suffice to kill a bird. In one autumn, in Dakota County alone, not less than thirty thousand birds must have been destroyed in this way. Regarding this slaughter he wrote :-

Supposing that each of these birds averaged eating one hundred and fifty insects each day, we then have the enormous number of onc hundred and thirty-five million insects saved in this one county in one month that ought to have been destroyed through the influence of birds. When we refiect, further, that many of these birds were migratory, and that they helped to keep down the increase of insects in distant regions, the harm that their destruction did is beyond calculation. The killing of such birds is no local loss; it is a national, a continental loss. ${ }^{2}$

\footnotetext{
I Insect Life, by Riley and Howard. 1894, Vol. VI, No. 4, p. 333.

${ }^{2}$ First Report of the United States Entomological Commission. Riley, Packard, and Thomas. 1877, pp. 343, 344 .
} 
Professor Aughey gathered statistics regarding the killing of Quail and Prairie Chickens for the market during this period, and concluded that in thirty counties the average yearly slaughter of these birds must have been at least five thousand Quail and ten thousand Prairie Chickens for each county, or four hundred and fifty thousand birds in all. We can only conjecture as to how great was the destruction of other game birds.

The poisoning of birds in the west permitted an increase of many other insects besides the locusts. A farmer from Wisconsin informed me that, the Blackbirds in his vicinity having been killed off, the white grubs increased in number and destroyed the grass roots, so that he lost four hundred dollars in one year from this cause.

THE DESTRUCTION OF INJURIOUS MAMMALS BY BIRDS.

The injury to trees and crops by insects is not the only evil that has followed the destruction of birds and other animals by man. Rapacious birds hold a chief place among the forces which are appointed to hold in check the gnawing mammals or rodents, which breed rapidly, and, unless kept within bounds, are very destructive to grass fields, crops, and trees. The great swarms of lemmings which have appeared from time to time upon the Scandinavian peninsula are historical. Their migrations, during which they destroy the grass or grain in their path, until finally they reach the sea and perish in a vain attentpt to cross it, have been recorded often. A similar increase of rodents may take place anywhere whenever their natural enemies are unduly reduced in numbers. Such cases are on record in England and Scotland. In Stowe's Chronicle, in 1581, it is stated :-

About Hallontide last past (1580) in the marshes of Danessey Hundred, in a place called South Minster, in the county of Essex, there sodainlie appeared an infinite number of mice, which overwhelming the whole earth in the said marshes, did sheare and gnaw the grass by the rootes, spoyling and tainting the same with their venimous teeth in such sort, that the cattell which grazed thereon were smitten with a murraine and died thereof; which vermine by policie of man could not be destroyed, till at the last it came to pass that there flocked together such 


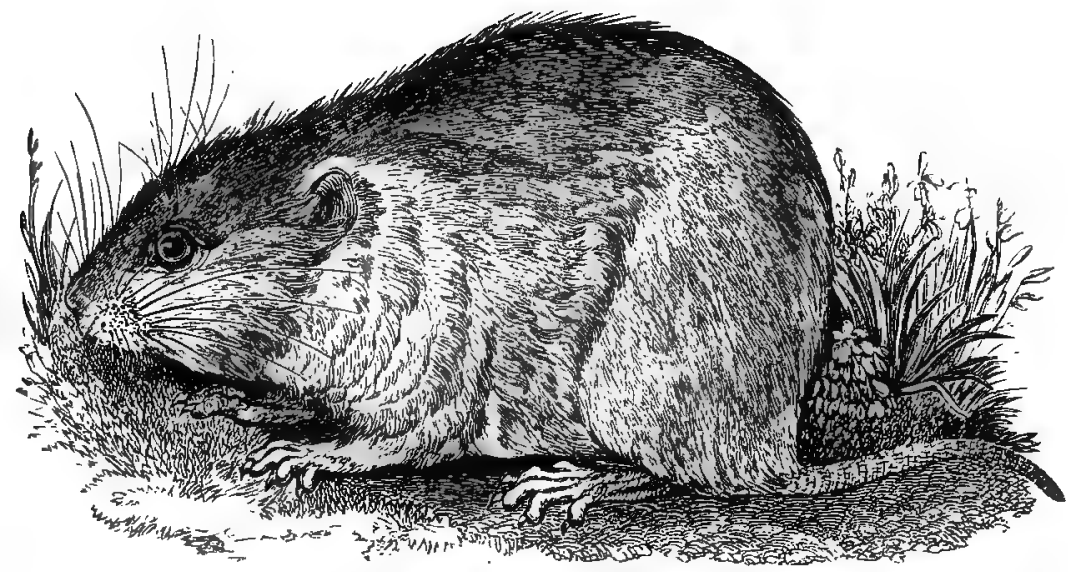

PLATE VI. - Field or Meadow Mouse. A proliflc and destructive species, held in cleck by Hawks and Owls.

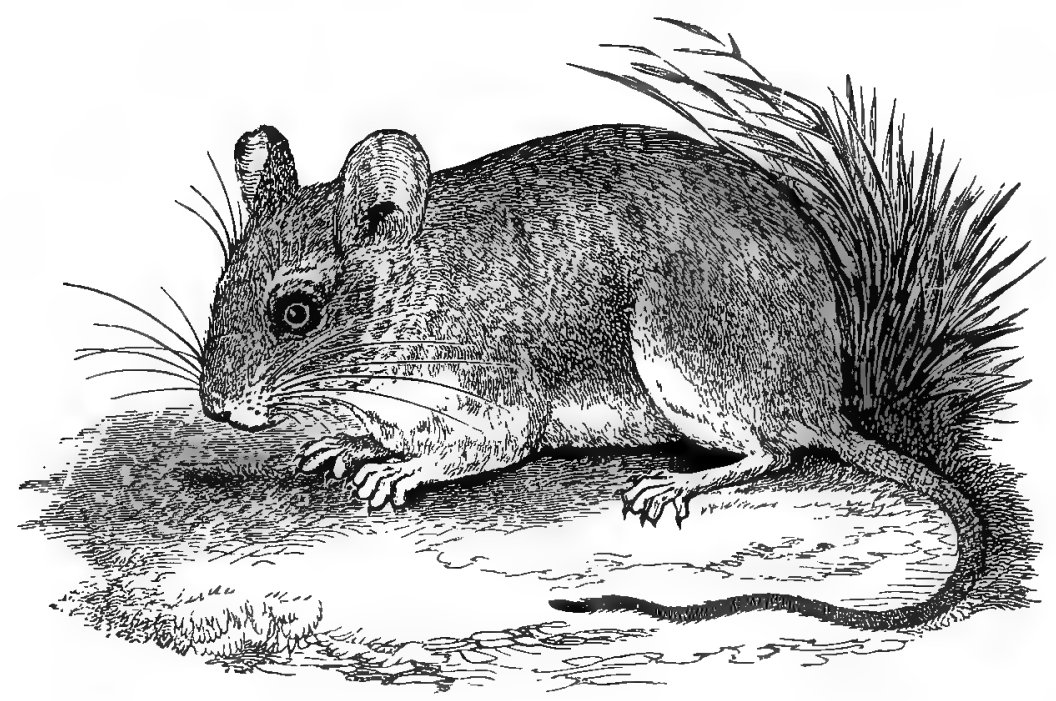

PLATE VII. - White-footed or Deer Mouse. A destructive wood mouse, the increase of which is controlled by Hawks and Uwls. 

a number of Owles, as all the shire was able to yield, whereby the marsh-holders were shortly delivered from the vexation of the said mice. The like of this was also in Kent.

This reads a little like a fable or legend, and we must be permitted to doubt the statement as to the cause of the "murraine;" but the accuracy of the story, in the main, is corroborated by the records of later occurrences of a similar nature in the same region. Childrey also records this occurrence in his Britannia Baconica, 1660, p. 14.

Similar "sore plagues of strange mice" were experienced in Essex again in 1648, near Downham Market, Norfolk, in 1745, and again in Gloucestershire and Hampshire in 181314.1 With regard to Norfolk, the following extract is of interest : -

Once in about six or seven years, Hilgay, about one thousand acres, is infested with an incredible number of field mice, which, like locusts, would derour the corn of every kind. Invariably there follows a prodigious flight of Norway Owls, and they tarry until the mice are entirely destroyed by them. ${ }^{2}$

Notwithstanding that both the cause and remedy of these frequent outbreaks of field mice were apparent, the destruction of their natural enemies by man still goes on. In 1875-76 a noted outbreak of mice occurred in the borders of Roxburghshire, Selkirkshire, and Dumfriesshire, also in parts of Yorkshire. The abundance of the mice attracted Hawks, Owls, and foxes in unusual numbers. In 1892 an alarming increase of these field mice again occurred in the south of Scotland. In Roxburgh and Dumfries alone the plague was estimated to have extended over an area of eighty thousand to ninety thousand acres. ${ }^{3} \quad$ A preponderance of opinion among farmers was reported, tracing the cause of this outbreak to the scarcity of Owls, Hawks, weasels, and other so-called vermin. All these animals, and Crows also, are to be ranged among the natural enemies of mice. The state-

\footnotetext{
1 See Journal of the Royal Agricultural Society, 1892, p. 223, and papers there cited.

${ }^{2}$ Gentleman's Magazine, 1754, Vol. 24, p. 215.

${ }^{8}$ Report to the Board of Agriculture on the Plague of Field Mice or Voles in the South of Scotiand, 1892.
} 
ment made by Childrey as to the assemblage of Owls when the field mice swarmed in Essex in 1580 received confirmation during 1892. Local observers reported that, after the great increase of voles was noticed, the Short-eared Owl (Otus brachyotus) became much more numerous on the bill farms, and that many pairs, contrary to precedent, remained to breed.

Dr. W. B. Wall expresses the opinion, from his experience with the pests, that their chief enemies are the Owl and the Kestrel (a Hawk), which do more to reduce their ranks than all the traps of the farmers and the "microbes of the scientists" combined. Both farmers and game keepers in England and Scotland are inclined to regard these birds as vermin, to be shot at sight.

In some parts of the United States the destruction of the natural enemies of rodents by man has been so complete that these animals have greatly increased in numbers. Prairie hares, or Jack rabbits, as they are called, became so numerous in some States at times that they could not be kept in check by ordinary hunting, and the people of whole townships congregated to drive them into great pens, where thousands were killed with clubs. Gophers or spermophiles have so increased in numbers that they have become pests. Farmers have been obliged to resort to extraordinary measures to destroy them. In Montana such large sums were paid out in six months of 1887 in bounties for the destruction of ground squirrels or gophers and prairie dogs, that a special session of the Legislature was called to repeal the law, lest it should bankrupt the State.

In New England our common hares (miscalled rabbits) are kept in check in thickly settled regions by hunters; but the field mice, which are not subject to this check, have increased so rapidly in many localities that during the hard winters of 1903-04 and 1904-05 thousands of young fruit trees in the New England States were attacked by them and ruined. These mice have become so numerous that in some places young trees cannot be grown unless protected from them. They also destroy a great quantity of grass and grain, some small fruit, and vegetables. Unfortunately, the food habits of these little animals have never been fully studied. 


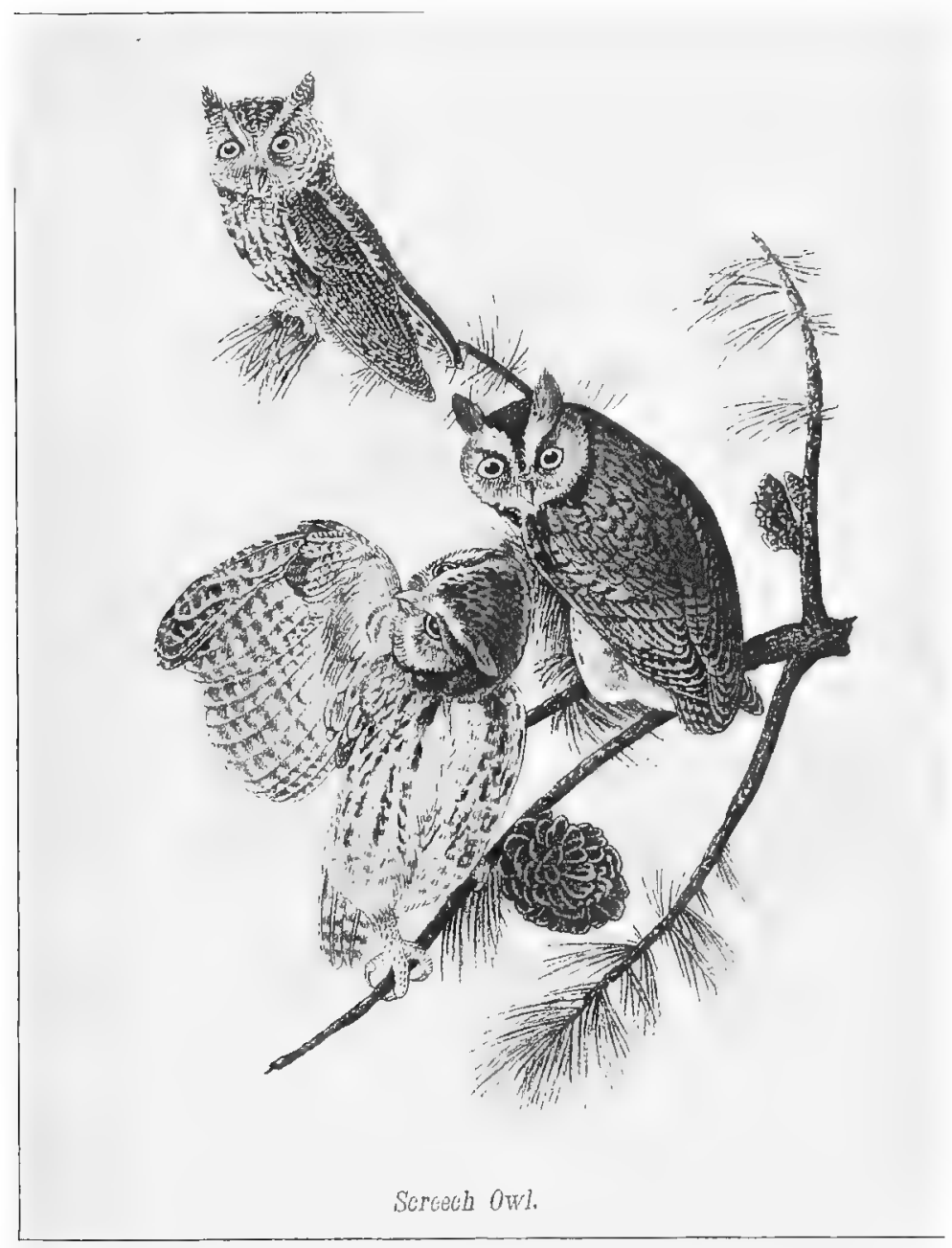

PLATE VIII. - A Useful Mouse-eating Owl. (From Wartell, after Audulon.) 

Enough is known, however, to show that they have some beneficial habits, as well as some injurious ones; but they constitute a very potential force for harm, on account of their great fecundity. I do not know how many young our common species can produce in a year, but two female European field mice kept in captivity gave birth to thirty-six young within five months. The tally was ended by'the escape of one of the pair, else there probably would have been recorded a still larger number. The interval between the birth of one litter of young and that of the next was only from twenty-four to twenty-nine days. This shows the danger that might easily arise from the unchecked increase of a creature which, feeding upon both crops and trees, is capable of unmeasured devastation. It also shows the folly of extirpating those Hawks and Owls which are known to feed largely on field mice, for they constitute the only natural force, that can quickly assemble at a threatened point, for the reduction of these pests.

The number of small rodents eaten by the rapacious birds is almost as remarkable in proportion to their size as is the number of insects taken by smaller birds. Lord Lilford says that he has seen a pair of Barn Owls bring food to their young no less than seventeen times within half an hour, and that he has fed nine mice in succession to a young Barn Owl two-thirds grown. ${ }^{1}$ During the summer of 1890 a pair of Barn Owls occupied a tower of the Smithsonian building at Washington. It is the habit of Owls to regurgitate the indigestible portions of their food. Dr. A. K. Fisher found the floor strewn with pellets of bones and fur which these birds and their young had thrown up. An examination of two hundred of the pellets gave a total of four hundred and fifty-four skulls : two hundred and twenty-five of these were meadow mice; two, pine mice; one hundred and seventynine, house mice ; twenty, rats ; six, jumping mice ; twenty, shrews; one, a star-nosed mole; and one, a Vesper Sparrow. ${ }^{2}$ In my examinations of the stomachs and pellets of

1 An article on the Barn Owl, by W. B. Tegetmeier. Field, Vol. LXXV, No. 1956, June 21, 1890, p. 906.

${ }^{2}$ The Hawks and Owls of the United States, by Dr. A. K. Fisher. United States Department of Agriculture, 1893. 
small Owls I have almost invariably found that the food consisted very largely of field mice and wood mice, with a few shrews, and rarely a bird or two. Several species of Hawks seem to feed almost entirely on field mice; small reptiles, batrachians, and insects.

The young of Hawks and Owls remain a long time in the nest, and require a great quantity of food. They probably tax the resources of the parent birds excessively in the effort to find enough food for them; hence some species are forced to commit depredations on the poultry yard, while a few kill birds and poultry from choice. But most of these birds are, on the whole, useful to the farmer. Dr. Fisher, having examined the contents of two thousand six hundred and ninety stomachs of Hawks and Owls from various parts of the United States, and collected the evidence of many observers, concludes that Owls are among the most beneficial of all birds; and that Hawks, with possibly one or two exceptions, are in some degree beneficial to the farmer.

\section{THE VALUE OF WATER-BIRDS AND SHORE BIRDS.}

Many shore birds are to some extent insectivorous. Many Gulls and Terns might be reckoned among the friends of the farmer, were they fully protected by law and public sentiment, as they now are in some countries and in some western localities in our own country. But here they have been so persecuted that they usually keep well away from the vicinity of field and farm. Even as it is, however, they render some service to man. Certain water-birds are useful to navigators, fishermen, and pilots. In thick summer weather the appearance of Terns or Gulls in numbers, or the sound of their clamorous voices, gives warning to the mariner that he is nearing the rocks on which they breed. Shore fishermen enshrouded in fog can tell the direction of the islands on which the birds live by watching their undeviating flight homeward with food for their young. The keen senses of sea birds enable them to head direct for their nests, even in dense mist. Fishermen often discover schools of fish by watching the sea birds, that, like the larger fish, pursue the small fry. 


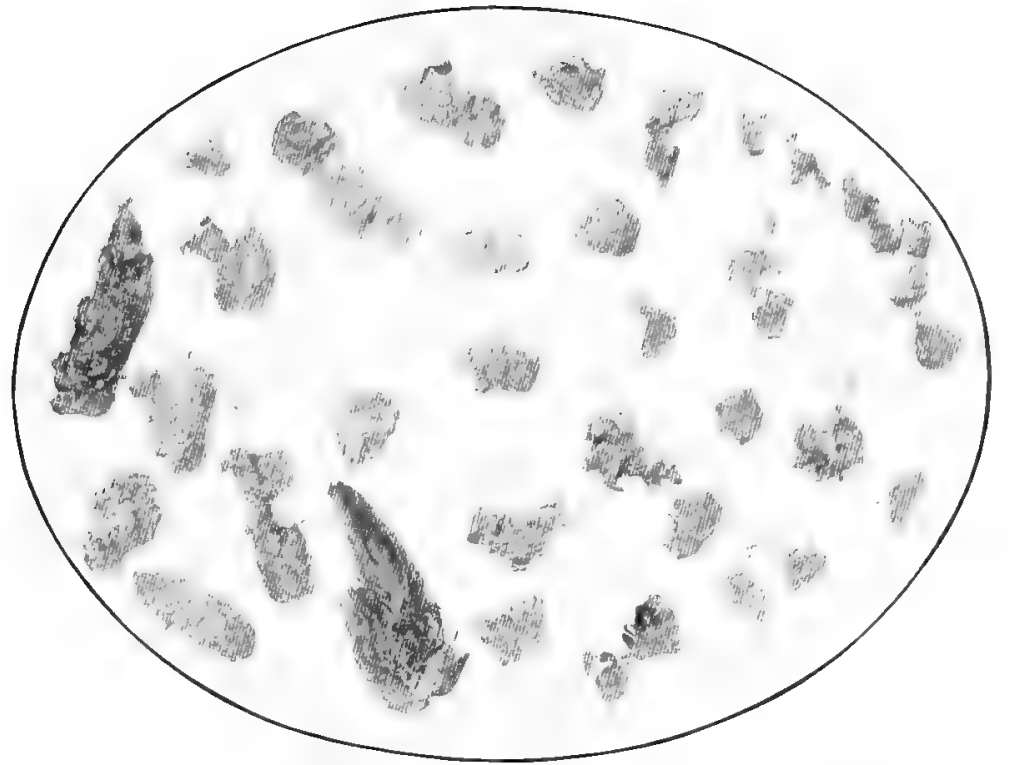

PLATE [X. - Regurgitated Ow] Pellets. These pellets, composid of bone-and fur. alos featlers of a kohin, were left near anthor"s homse by sicreech Uwls.

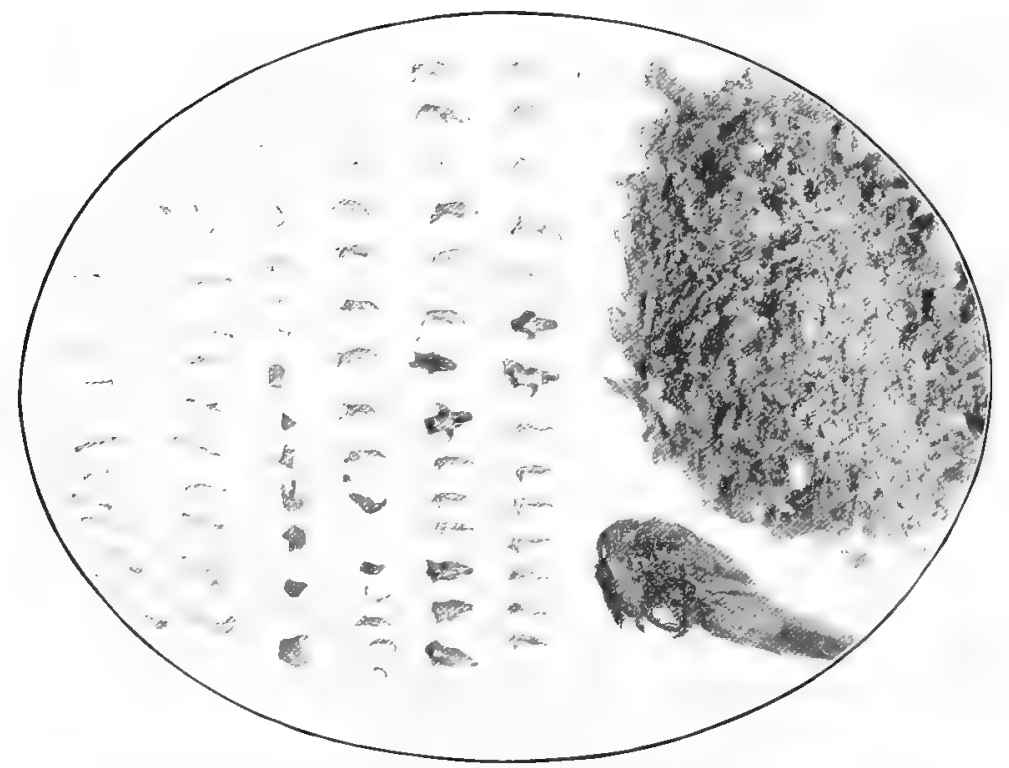

PLATE X. - The Same Pellets, dissected. The fur is shown in a pile on the right, and, on the left, portions of sikulh and other bones of mice, slirews, and moles, waten by the owh. 

Navigators approaching their home port during seasons of bird migration welcome the appearance of faniliar land birds which are seen while land is still far out of sight. Mr. Frank M. Chapman has shown, in an interesting paper on the ornithology of the first voyage of Columbus, that we possibly owe the discovery of America by Columbus to the fact that he happened to approach the land at the right time and place to cross the line of the fall flight of land birds that were going from the Bermudas to the Bahamas and Antilles. The discouraged seamen were on the verge of mutiny, and might have compelled Columbus to return to Spain, had not small land birds come aboard unwearied and singing. The course of the vessel was changed to correspond with the direction of their flight, and the voyage was thus shortened two hundred miles and pursued to its end. ${ }^{1}$

The well-known services of Vultures, which destroy garbage and carrion in the tropics, have no real counterpart in the north. Crows are of some use, but Gulls and other water-birds are most valuable to man in this respect, in that they devour the garbage and refuse that are cast into harbors and arms of the sea, thus undoubtedly preventing the pollution of many bays and beaches by floating filth and refuse from great cities.

Sea birds must be reckoned among the chief agencies which have rendered many rocky or sandy islands fit for human habitation. The service performed by birds in fertilizing, soil-building, and seed-sowing on many barren islands has entitled our feathered friends to the gratitude of many a shipwrecked sailor, who must else have perished miserably on barren, storm-beaten shores.

\section{THE COMMERCIAL VALUE OF BIRDS.}

In all the foregoing we have considered mainly "the good offices that birds voluntarily take upon themselves in our service." We have yet to take into account the tax which we impose upon them for our own revenue of profit or pleasure, - a tax which we collect unsparingly, and with the strong hand of force.

\footnotetext{
2 Papers presented at the World's Congress on Ornithology, 1896, pp. 181-185.
} 
This tribute of flesh, blood, and feather is levied largely upon those orders of birds which in domestication become poultry, and in the wild state are known as game birds ; but many small land birds have become victims of man's greed, and the sea birds have been forced to contribute to his food supply.

The eggs of certain Gulls, Terns, Herons, Murres, and Ducks that breed in large colonies find a ready sale in the market, or furnish a part of the food supply of the people who live near these breeding places. Wholesale egging was carried on along the coast of Massachusetts and other New England States, until the Gulls and Terns were in most cases driven away from their breeding places. The inhabitants along the shores of the southern States, as well as those on the Pacific coast, gathered the eggs of the sea birds by boatloads for many years. For nearly fifty years Murres' eggs were collected on the Farallone Islands and shipped to the San Francisco market. It is said that in 1854 more than five hundred thousand eggs were sold there in less than two months. This must have been an important item in the food supply of the young and growing eity. Mr. H. W. Elliot mentions that on the occasion of his first visit to Walrus Island in the Behring Sea six men loaded a badarrah, carrying four tons, to the water's edge with Murres' eggs. On Laysan, one of the Hawaiian Islands, there is a great breeding place of an Albatross (Diomedea immutabilis). Such immense quantities of their eggs have been gathered that cars have been loaded with them. ${ }^{1}$ All this egg collecting, however, should be stopped, for it tends to exterminate the birds, and all the eggs needed for human consumption can be produced by poultry.

Sea birds which breed on isolated islands or barren shores feed mainly on animal food, which they get from the sea. Guano consists of the excreta and ejecta of sea birds, mixed with the remains of birds, fish, and other animals. It is found on the gathering places of these birds. In the rainless lati-

1 A Review of Economic Ornithology in the United States, by Dr. T. S. Palmer. Yearbook, United States Department of Agriculture, 1899, pp. 271, 272. See this paper also for an account of the guano trade. 


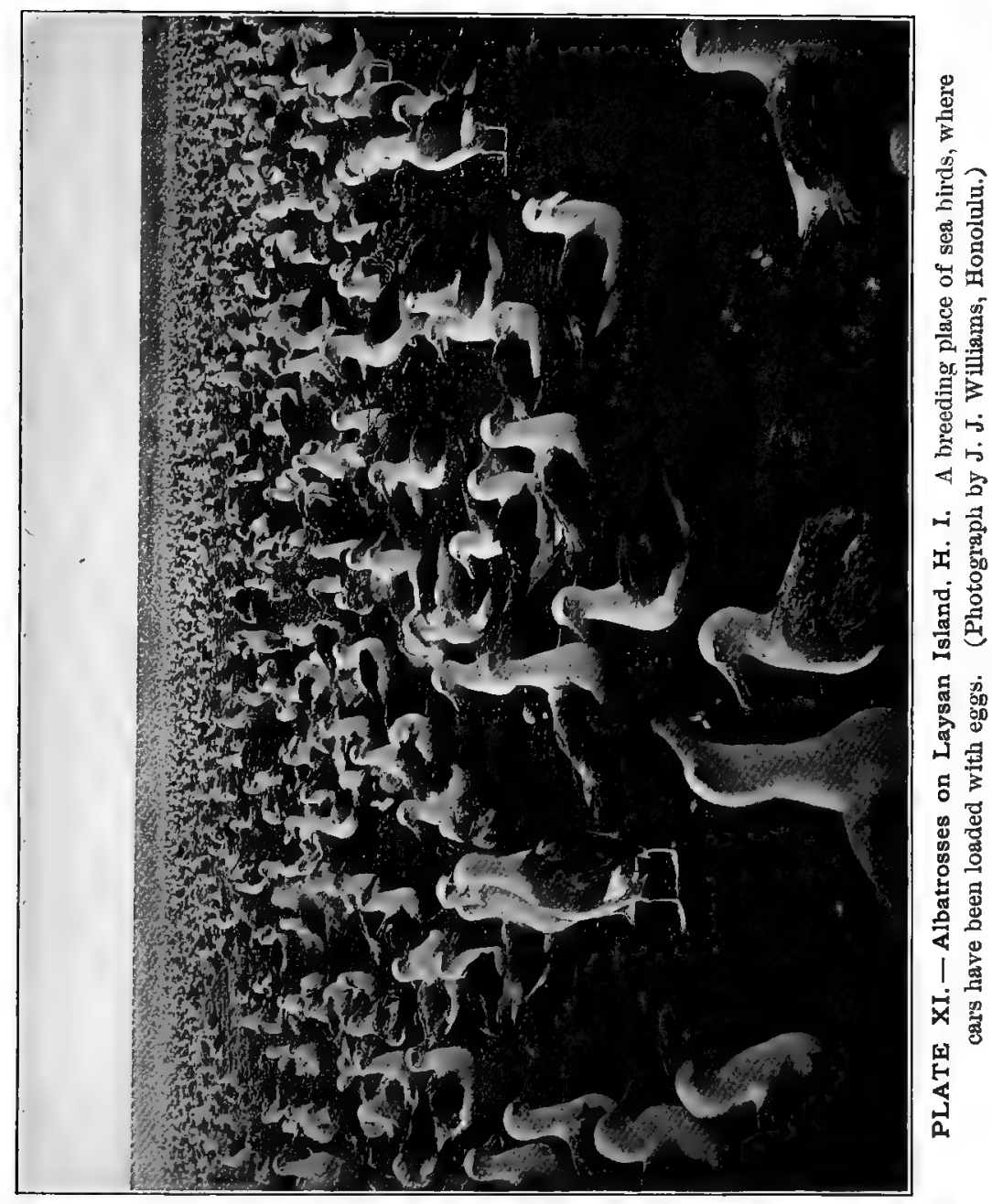



tudes of the Pacific, near the equator, guano once accumulated in tremendous deposits. It dried quickly, and where there were no rains to wash it away it was preserved with most of itsfertilizing constituents intact. The guano found on islands outside the dry latitudes is of less value, as its nitrogen is quickly washed out or dissipated. The importance of guano. as a fertilizer was recognized in Peru by the Indians more than three centuries ago. Under the Incas the birds on the Chincha Islands were carefully protected, and the deposits of guano jealously guarded. It is said that the penalty of death was inflicted on any one who killed birds near these rocks in the breeding season.

Humboldt, returning from his travels in tropical America in 1804, carried some samples of guano to Europe, and first called attention to the value of the deposits of this substance on the Chincha Islands; but it was nearly forty years later that guano became a stimulus to intensive agriculture, and furnished a source of revenue to civilized nations. The vast deposits on these three islands covered the rocks in some places to a depth of ninety or one hundred feet. The amount still undisturbed in 1853 was estimated by the official surveyors of the Peruvian government as twelve million, three hundred and seventy-six thousand, one hundred tons. Its use was first attempted in England in 1840 ; at that time the beds seemed inexhaustible. The guano trade soon became so important as to be a source of diplomatic correspondence between nations. It is said to have brought Peru and Chile to the verge of war. By 1850 the price of Peruvian guano had advanced in the United States to fifty dollars a ton, and American enterprise began to seek guano elsewhere.

- Americans have since filed with the government claims to about seventy-five guano islands in the South Pacific or in the Caribbean Sea. The vast deposits on the Chinchas are nearly exhausted, and fertilizers are now manufactured to supply the demand. Undoubtedly, however, the discovery and use of guano marked the beginning of the present enormous trade in commercial fertilizers. The manurial value of the phosphoric acid and nitrogen contained in fish has now become quite generally recognized, and fleets of small 
vessels are employed in seining menhaden and other fish for use in the manufacture of fertilizers.

Notwithstanding the value of birds to man as destroyers of insects and vermin, they are killed and utilized by him in various ways.

The destruction of game birds has been so great in Massachusetts, and the demand so much in excess of the supply, that birds are now imported from other States and from other countries. It is becoming a serious question, with those most interested, how we shall so regulate the shooting of game birds that the supply may be kept up. The game birds of America have a great intrinsic value as game. The flesh of many is cousidered to rank high among delicacies. The pursuit of these birds has formed a large part of the occupation of many members of the rural population during the shooting seasons, and a vast business has grown out of the traffic in birds' flesh. An enormous game business has been carried on by provision dealers in this country, and the demand for game is continually increasing. Few accurate statistics of the amount of game sold are obtainable; but Mr. D. G. Elliot, writing in 1864, states that one dealer in New York was known to receive twenty tons of Prairie Chickens in one consignment, and that some of the larger poultry dealers were estimated to have sold from one hundred and fifty thousand to two hundred thousand game birds in the course of six months. ${ }^{1}$

The killing of birds for sport has a certain economic affinity with market hunting, in that it supports a large trade in guns, ammunition, boats, dogs, and all the tools, appliances, and impedimenta of the sportsman. It furnishes employment to guides, dog breakers, and boatmen, and helps support many country hosteliries and seaside hotels. The manufacture of firearms and ammunition for sportsmen has become a great industry. Altogether, many thousands of men are dependent for a part of their livelihood on the killing of game for sport or food, while a still larger army finds its chief outdoor recreation in the pursuit of game birds. The

- Report of the United States Conmissioner of Agriculture, 1864, pp. 383, 384. 
value of game birds to the farmer, epicure, marketman, and sportsman should insure them the most stringent protection. Nevertheless, some of the migratory species, through lack of effectual protection, have already been so reduced in numbers that they are no longer of any commercial importance.

The domestication of birds probably was coincident with that of animals, and grew from the desire of the primitive agriculturist to have always at hand a fresh supply of delicate and nutritious animal food. No other animals can ever be so adapted to the environments of civilization as to furnish us with a similarly valuable supply of both meat and eggs.

The poultry business of this country has grown to such importance that the total value of the annual poultry product has reached nearly three hundred million dollars. Massachusetts imported probably about eighteen million dollars' worth of poultry products in 1903 . When we consider that in all the centuries the work of domestication has included but a few species, it is evident that the possibilities in this direction have not been exhausted.

Within the last half-century fashion has been responsible for the killing of millions of birds for the millinery trade. This trade is now limited by laws making it illegal to kill or use most native birds, except game birds, for this purpose. Instances of the destruction of birds for millinery purposes will be.given in another chapter. The American demand for feathers for ornamental uses is now largely met by articles manufactured from the feathers of domestic fowls and game birds. The demand for Ostrich plumes has resulted in the establishment of a new industry in America, the raising of Ostriches.

There has been a growing demand for American song birds for cage purposes; but this traffic is now prohibited by law.

\section{THE ÆSTHETIC, SENTIMENTAL, AND EDUCATIONAL VALUE OF BIRDS.}

Thus far I have written solely from the standpoint of "enlightened selfishness," entertaining no consideration of the rsthetic, humane, sentimental, or educational. I have 
attempted to look at birds solely from the utilitarian point of view, and to demonstrate the fact that their contributions to man's welfare have at least a material value. Now let us turn for a moment from the contemplation of such utility of birds as money can measure to "some of the higher and nobler uses which birds subserve to man." In so doing we step at once from the beaten path of economic ornithology into a boundless realm, sacred to art, letters, sentiment, and poetry on the one hand, while on the other lie the fair fields in which we may take up, if we will, the fascinating study of birds, which may end merely in delightful experiences, or lead to the class room, the museum, the laboratory, or the closet of the systematist. Wherever it may lead us, this phase of our subject is of the highest importance, and demands the most serious consideration. Although presented last, its benefactions should perhaps come first among the items which go to make up the sum of our indebtedness to birds.

The beauty of birds, the music of their songs, the weird wildness of their calls, the majesty of their scaring flight, the mystery of their migrations, have ever been subjects of absorbing interest to poets, artists, and nature lovers everywhere. Prominent among the undying memories of men are mental pictures of the birds of childhood, their coming in the spring, their nesting, and their chosen haunts. Many an exiled emigrant longs in vain to hear again the outpouring melody of the Skylark, as it soars above the fields of England. Many a New England boy, shut in by western mountains, yearns for the bubbling, joyous song of the Bobolink in the June meadows. The characters and traits of birds, their loves and battles, their skill in home building, their devotion to their young, their habits and ways, - all are of human interest. Birds have become symbolic of certain human characteristics; and so the common species have come to be so interwoven with our art and literature that their names are household words. What biblical scholar is not familiar with the birds of the Bible? Shakespeare makes over six hundred references to birds or bird life. Much of the best literature would lose half its charm were it shorn of poetic allusions to birds. 
Birds often have inspired the poets. Bryant's lines "To a Water-fowl," and Shelley's "Skylark," each exhibit a phase of such inspiration. These are but instances of the stimulating power exerted on the mind of man by the bird and its associations. Some of the grandest poems ever written have been dependent on their authors' observation of birds for some touch of nature which has helped to render them immortal. Thus Gray, in his famed "Elegy written in a Country Churchyard":-

\footnotetext{
The breezy call of incense-breathing mom, The Swallow twittering from the straw-built shed, The Cock's shrill clarion, or the echoing horn, No more shall rouse them from their low ly bed.
}

Who, reared in a country home, can fail, as he reads these lines, to recall the twittering of the Swallows under the spreading rafters in the cool of early morning? The mental contemplation of that peaceful pastoral scene, the train of tender recollections of the time of youth and innocence, all tending toward better impulses and higher aspirations, are largely due to the mention of the familiar bird in its association with the home of childhood. Is not literature the richer for the following lines of Longfellow in his "Birds of Passage"?

\author{
A bove, in the light \\ of the star-lit night, \\ Swift birds of passage wing their flight \\ Through the dewy atmosphere. \\ I hear the beat \\ Of their pinions fleet, \\ As from the land of snow and sleet \\ They seek a southern lea.
}

How much of life and color the presence of birds adds to the landscape! The artist appreciates this. What marine view is complete without its Gulls in flight? How much a flock of wild-fowl adds to a lake or river scene !

Birds are a special boon to child life, and a never-ending source of entertainment to many children who live upon isolated farms, where the observation of birds' habits adds greatly to the rational enjoyment of existence.

It is not a far cry from the poet to the philosopher, and 
he also sees a value in birds for the opportunity they afford for the culture of the intellect. Every page of the book of nature is educational. But, as Dr. Coues says, there is no fairer or more fascinating page than that devoted to the life history of a bird. The systematic study of birds develops both the observational faculties and the analytical qualities of the mind. The study of the living bird afield is rejuvenating to both mind and body. The outdoor use of eye, ear, and limb, necessitated by field work, tends to fit both the body and mind of the student for the practical work of life, for it develops both members and faculties. It brings one into contact with nature, - out into the sunlight, where balmy airs stir the whispering pines, or fresh breezes ripple the blue water. There is no purer joy in life than that which may come to all who, rising in the dusk of early morning, welcome the approach of day with all its bird voices. The nature lover who listens to the song of the Wood Thrush at dawn - an anthem of calm, serene, spiritual joy, sounding through the dim woods - hears it with feelings akin to those of the devotee whose being is thrilled by the grand and sacred music of the sanctuary. And he who, in the still forest at evening, harkens to the exquisite notes of the Hermit, - that voice of nature, expressing in sweet cadences her pathos and her ineffable mystery, - experiences amid the falling shades of night emotions which must humble, chasten, and purify even the most upright and virtuous of men.

The uplifting influence that birds may thus exert upon the lives of men constitutes to many their greatest value and charm. A growing appreciation of the esthetic and the educational value of birds has sent many cultured folk to the woods, fields, and shores. People are turning toward nature study, and the observation of birds in the field is one of the most popular manifestations of an increased and abiding interest in nature. To the utilitarian this movement has an economic aspect. Students who have become familiar with the common birds of their own vicinity long for new fields and new birds. Let a well-known writer describe in print any locality in Massachusetts where rare or interesting birds are to be found, and soon some of his readers will be upon the 
ground. This travelling about of those in search of birds bids fair eventually to assume considerable proportions, and cannot fail to be of some pecuniary importance to transportation companies, as well as to those who minister to the wants of man and beast. Many people prefer to spend their vacations in localities where both the larger and smaller birds are plentiful. Thus the resthetic value of the soaring Hawk or the wading Heron becomes of practical importance to the farmer and hotel keeper who are looking for summer boarders. People of means are fully sensible of the many advantages of life in the country, and are making homes for themselves on our farms. But a merchant prince who established such a home found his enjoyment of the place greatly abridged by the scarcity of birds. With the growing interest in birds, towns or localities where birds are plentiful will have an added value as places of residence.

Possibly, however, the greatest boon that the study of birds can confer upon man is seen in the power of the bird lover to keep his spirit young. One who in his early years is attracted to the study of birds will find that with them he always renews his youth. Each spring the awakening year encompasses him with a flood of joyous bird life. Old friends are they who greet him, and they come as in the days of childhood, bringing tidings of good cheer. Thus it is ever. Years roll on, youth passes, the homes and woods of our childhood disappear, the head becomes bowed with sorrow and frosted by the snows of time, the strong hand trembles, the friends of youth pass away; but with each returning spring the old familiar bird songs of our childhood come back to us, still unchanged by the passing years. The birds turn back, for us, the flight of time. Their songs are voices from our vanished youth. Let us, then, teach our children to love and protect the birds, that these familiar friends of their childhood may remain to cheer them with song and beauty, when, toward the sunset of life, the shadows will grow long upon the pathway. 


\section{CHAPTER II. \\ THE UTILITY OF BIRDS IN WOODLANDS.}

Massachusetts contains very little land that can be dignified by the name of forest. She has practically no forests such as are cared for by European States, nor has she any extensive primeval wilderness of trees such as still exist on some western mountain ranges; nevertheless, a large area of the State is forested with coppice 'growth or seedling trees, which are usually allowed to grow from thirty to fifty years, and are then cut for either firewood or lumber.

While this large area of woodland produces comparatively little valuable timber, its aggregate value, as estimated in the census of 1895 , is twenty-three million, nine hundred and thirty-six thousand, three hundred and sixty-two dollars. It is no exaggeration to say that for the preservation of this great woodland estate from the ravages of insects we are largely indebted to birds. The service that birds perform in protecting woodland trees is more nearly indispensable to man than any other benefit they confer on him ; for the money value of forest trees, while large in the aggregate, is not ordinarily great enough to pay the owners to protect them against their many enemies, even if this were possible. The little things of life are the most difficult for man to control. The wild animals and venomous serpents of the woods he may exterminate; but insects, which are even more dangerous to human life or property, will still possess the land. Were the natural enemies of forest insects annihilated, every tree in our woods would be threatened with destruction, and man would be powerless to prevent the calamity. He might make shift to save some orchard or shade trees; he might find means to raise some garden crops; but the protection of all the trees in all the woods would be beyond his powers. Yet this herculean task ordinarily is accomplished as a matter of course by birds and 
other insectivorous creatures, without trouble or expense to man, and without appreciable injury to his great woodland interests.

Birds attain their greatest usefuiness in the woods, mainly because the conditions there closely approach the natural, and organic nature has an opportunity to adjust her balances without much human interference. Man may be supreme in the garden, field, or orchard, but in the woods nature reigns. There her laws, unhampered, operate for the good of her children.

\section{THE RELATIONS OF THE BIRD TO THE TREE.}

A mere glance at the economy of the forest shows us a series of interrelations and interdependences existing between the bird and the tree. Mr. Frank M. Chapman thus indicates tersely and clearly the nature of these relations:-

Between bircls and forests there exist what may be termed primeval, economic relations. Certain forest trees have their natural insect foes, to which they furnish food and shelter; and these insects, in turn, have their natural enemies among the birds, to which the trees also give a home. Here, then, we have an undisturbed set of economic relations: (1) the tree; (2) the insect, which lives in the tree, preys upon it, and may assist in the fertilization of its blossoms; (3) the bird, which also finds a home in the tree, and, feeding upon insects, prevents their undue increase. Hence it follows that the existence of each one of these forms of life is dependent upon the existence of the other. Birds are not only essential to the welfare of the tree, but the tree is necessary to the life of the bird. Consequently, there has been estalulished what is termed "a balance of life," wherein there is the most delicate adjustment between the tree, the insect, the bird, and the sum total of the conditions which go to make up their environment. The more trees, the greater the number of insects, and hence an increase not only in food supply for the birds, but an increase in the number of nesting sites. ${ }^{1}$

Nearly all the wood birds are dependent upon trees. Destroy the trees, and some of the insects might find new food in the crops of the farmer, but the birds lose their home

1 The Economic Value of Birds to the State, by Frank M. Chapman. Seventh Annual Report of the Forest, Fish and Game Commission of New Fork State, 1903, p. 6 . 
when the tree falls. Lacking the nesting sites, protection, and shelter once afforded them among the trees, they must find other shelter, or perish. The interests of birds and trees are identical, and each must protect the other for the good of all. Birds are conspicuously useful in distributing the seed, and in planting, pruning, and protecting the trees.

\section{THE FOREST PLANTERS.}

If we take a white pine cone, containing seeds, break it open and examine a seed, we find that it is enveloped in a membrane with a wing-like appendage. Now take the seed and toss it into the air, and it will descend to the ground with

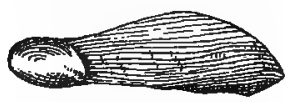

Fig. 30.-The winged seed of the white pine. a rotary motion, like that of a pickerel spoon when drawn through the water. As the seed descends, its wing in rotating forms a spiral plane at an angle with the direction of its descent, serving as a parachute to sustain it in the air. If there is the slightest breeze, the seed floats off upon it and descends diagonally to the ground. The phenomenon is much the same as that observed in falling seeds of the ash and some other deciduous trees. Such seeds are winged, like the pine seed, for distribution. Although they will not float on a gentle breeze, like thistle or dandelion seeds, still, in a strong wind they are carried fifteen or twenty rods, or more. When pine seeds fall to the ground they soon separate from their wings. A heary washing rain or the foot of some animal may bury them with earth mould, or falling leaves may cover them, and the planting is done. Should they fall upon the surface of a lake, the gentle breeze would waft them along over the surface, like a fleet of little boats, to islands or distant shores; should they fall upon a stream, they would float away with the current.

Although the seeds of many forest trees do not grow their own wings, we find them as widely distributed as the seeds of the pine. Notice the distribution of the wild cherry along the roadsides. In spring we see here and there, on bushes or trees, the webs of the tent caterpillar. They are usually found upon the apple and wild cherry; and if, late in May, 
we search woods and fields, along walls and on bushy hillsides, we may be surprised in certain years to find wild cherry trees everywhere. When they are rendered conspicuous by the caterpillar webs they bear, we see how they are scattered through the woods, where birds that fed upon the fruit dropped the stones as they flew. It is a law of nature that the destroyer of the fruit is also the distributer of the seed.

When first I found the nest of the Wood Thrush, some thirty-five years ago, I noticed that after the young had flown, a little heap of cherry stones, polished clean and white, was left in the nest. I did not know at the time how the birds were able to do this. On Oct. 21, 1896, Mr. Thomas Proctor wrote me that he had seen similar collections of cherry stones in the nests of the Wood Thrush, and that by keeping individuals of the species in captivity he had learned that they swallowed cherries whole, taking several in succession and at almost regular intervals; and that, prior to the next feeding, they expelled the polished stones by the mouth. This is a provision of nature for the distribution of the cherry tree. The pits found in the nest were probably left there by the young birds just before leaving the nest; but after the birds have flown it is not probable that many pits are left together in the same place except when the birds are at roost. The cherry stones found by $\mathrm{Mr}$. Proctor in the nest were, he said, probably such as are known to. botanists as "escapes," or varieties which have escaped from cultivation. Much of the planting of such trees is due, no doubt, to birds; but wild cherry pits are oftener planted by their agency. Mr. Proctor wrote that he had kept several hundred birds of different species, and that he had come to the conclusion, from observation of their feeding habits, that other Thrushes and Warblers in general reject the larger indigestible portions of their food in this way.

Mr. Proctor has since then published in The Auk the results of his observations on this subject. The seeds of berries are often expelled or excreted with their vitality unimpaired. Thus birds are instrumental in extending the growth of the woodlands and thickets in which they dwell. 
One day I noticed a young pine growing some ten feet from the ground in the fork of a maple by the roadside. There were no other pines near. What planted it there? This was merely an illustration of the fact that tree seeds are furnished with transportation by the wings or legs of animals that feed upon them.

The Jays alight in the tree top; each Jay breaks off an acorn with his feet, hammers it open with his beak, and eats the kernel on the spot, or carries it off to some hiding place,

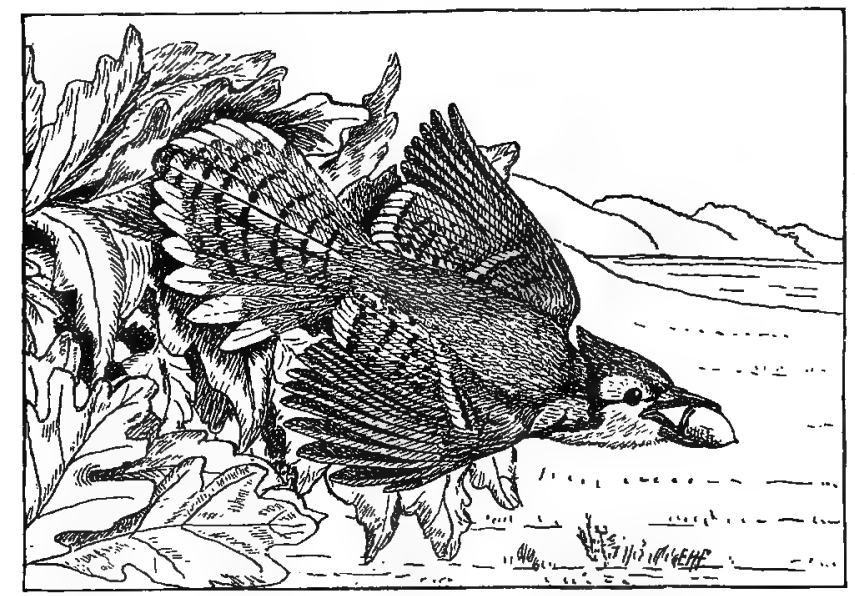

Fig. 31. - A forest planter. The Blue Jay lends wings to the acorn.

sometimes dropping it from the tree or while flying, apparently by accident or for no purpose except perhaps to hear it strike the earth. A sudden fright will cause a bird to drop whatever food it may be carrying. Such acorns are usually left where they happen to fall.

We cannat study the relations of birds to the forest without noting also the important part that squirrels take in tree planting. In the autumn of 1897 the mast crop was light in some sections of eastern Massachusetts, but here and there an oak tree was found which bore a good crop. Such trees were soon discovered by the Jays and squirrels, several of which might be seen gathering the acorns from each tree. The ground squirrels work in pairs, as do the squirrels of 
the Pacific coast, one climbing the tree and throwing the acorns down to the other.

Jays, Crows, and squirrels seem to have a mania for distributing and hiding things. I recall an old shellbark hickory by a farmhouse-door, the crevices of its ragged bark ornamented with walnuts, tucked in here and there all over the trunk. Any one watching the Jays and squirrels in the fall will find them filling crevices with nuts or seeds, dropping nuts, acorns, corn, and other things into cavities and hollows in the trees, or burying them in the leaf mould on the ground.

I once watched a Crow killing a large, brightly colored beetle, probably Calosoma scrutator, which it buried carefully beneath a tuft of grass. Returning a few moments later, the sable bird unearthed the brilliant insect, carried it away and buried it in another place. In a pine wood in Medford, on April 16, 1897, several Crows flew from the ground. Here, under the pines, an interrupted feast was found. Crows, Jays, and squirrels had been digging out stores of acorns which probably had been buried there the previous fall. The interrupted diggers had left six acorns which they had dug from one hole; others were partly unearthed.

It is said that squirrels bite off the germ ends of the acorns before burying them. This habit has never come under my observation. These acorns not only had their germ ends intact, but seven of them had sprouted. One had sent the tap root down four inches into the mould. They had been carefully set with the points downward, as if by a squirrel, and at just the right depth for planting. A man could not have done it better. They were deeply covered with light mould and pine needles. Some of the digging looked like the work of squirrels, but marks on some of the acorns were apparently made by the beak of a bird. A gray squirrel was seen near by. Had its feast been interrupted by the Crows, or had all been at work together? How could the Crow know that the acorns lay buried just there? Did he remember that he planted them? Had he seen the disturbance of the pine needles, caused by the young sprout? Or 
had he watched the squirrel, and descended to rob it of its stores? Who is wise enough to interpret the workings of a Crow's mind? Who can tell how far its perceptive faculties will serve, or mark the boundary between instinct and reason? We may say that some creature had been merely storing up food against a season of want, and that may be true, but it is only half the truth. Many of the seeds which are dropped or hidden by birds and squirrels are never found by them again. There is an immense amount of vitality in these animals, which must be expended in some way. When the red squirrel is not eating, sleeping, providing food for itself, or getting into some abominable mischief, it is usually scolding or chattering in profane squirrel language at some intruder, or busy burying something or digging it up. The squirrel makes its journeys back and forth, burying acorns, pine seeds, chestnuts, beech nuts, and hickory nuts in secret places. One day, however, as it is going its accustomed way up the walnut tree, a Hawk swoops down, and the squirrel is no more. That squirrel has stored up a supply of food which it will never gather. As Thoreau say's, it has planted "a hickory wood for all creation." That Hawk has protected the planted seed.

The part ordinarily taken by birds in forest planting is not so conspicuous as that of the squirrels, but it results in a wider distribution of seed. The birds and squirrels destroy a large part of the seed crop, but the trees produce a great surplus, and the wild creatures plant an abundance of good seed which they leave to germinate. Thus it is that the destroyer of the seed disseminates it, and so perpetuates the tree which furnishes him sustenance.

The Influence exerted by Birds and Squirrels on the Succession of Forest Trees.

When we cut down an oak or chestnut wood that is composed of old and heavy timber, a pine wood is likely to spring up in its place, particularly if there are pines near by ; while if we cut off pines, they are usually succeeded by a wood composed mainly of deciduous trees, mostly hard woods, or the nut-bearing or acorn-bearing kinds. Such a 
succession of trees has long been considered by farmers to be the rule. In other words, in some way there often comes rotation of crops when wood lots are cut off. This is believed by some people to be due to the springing up of seed which has been buried in the ground for many years. When an oak wood springs up where a pine wood has been cut away, there is no doubt that it has sprung from seed in the ground; probably, however, it has not come from seed which has been buried for many years, but from seed sown by birds and squirrels within a few years, and which has been given a new lease of life by the sun's rays let in by the removal of the dense foliage from above. All through the autumn months, when nuts and acorns are plentiful, Jays, Crows, and squirrels are gathering and storing away the seed among the pines, where they resort for shelter.

Thousands of Crows will roost in a pine wood for months during the winter, when the leaves are off the deciduous trees. The pines then offer the best hiding places for all woodland creatures. In some of the large Crow roosts among the pines extensive deposits of various seeds and other material ejected by Crows are found. When a pine wood is surrounded by oak and nut trees, when squirrels and Jays are plentiful, and the trees bear well, quantities of acorns and nuts will be carried into the pine wood by these creatures and buried beneath the dead "needles" or hidden away in crevices. Many of these nuts and acorns are dug up during the winter months, especially by the red squirrel, but many others are never found.

Note an opening in the pines made by cutting away a few trees. Here young oaks spring up, and we find oaks and walnuts in such openings quite as often as we find pines. Examine the ground under the pines in summer, and you may find many little oak, walnut, and maple trees coming up from beneath the pine needles, and you will also find young pines here and there. All these young trees soon die in the dense shade of the larger pines. ${ }^{1}$ But let the pine

\footnotetext{
${ }^{1}$ If the lot is not favorably situated, if the woods are very dense, if birds and squirrels are not plentiful, and, above all, if the crop of mast has been light the year before, there may be no young walnuts and oaks springing up.
} 
wood be cut off, and if the conditions are favorable, the young hard-wood trees spring up and flourish. But why do not pines spring up where pines are cut off? For this there are several reasons: (1) pines do not sprout from the stump; (2) there is not a crop of pine seed each year, therefore, when the pine wood is cut there may be little good seed in the ground; (3) young pines need some shade and protection, and if the larger trees are all cut down, many of the young pines may die when exposed to the sun. Those who, with a knowledge of this fact, plant pines on unshaded ground, usually sow rye or some other cereal with the pines, so that the quick-growing grain may shade the young plants for the first year. The shaded trees grow, and in time furnish shade for others, and so the wood extends.

Now let us see why pines sometimes appear where hard woods have been cut off. This kind of succession is not common. The trees growing on most wood lots are cut for cord wood as soon as they are of sufficient size. Immediately on the opening of the season, sprouts shoot up rapidly from the hard-wood stumps, choking many young pines. Still some will live and flourish, and so there comes a mixed growth of pines and hard-wood trees. This is the character of much of the wooded region near Boston. But if an oak or walnut wood is allowed to grow until the trees are old, and is cut when the roots have lost their vigor, the sprouts, if they come up at all, are not so vigorous, and the young pines have a better opportunity. Where birds and squirrels are numerous, a considerable part of the fruitage of the pine is removed by them, and cones or detached seeds are buried or scattered about, not only among the pincs, but among the hard-wood trees. The winds also scatter pine seed far and wide among deciduous trees; so, if there are pines near hardwood lots, young pines usually sprout among the hard-wood trees. When an old growth of deciduous woods is cut off, these young pines, having had a start in the shade, flourish and afford some shade for still younger seedlings, which quickly germinate from the seed in the ground; thus occasionally the pines succeed the broad-leaved trees. 


\section{THE TREE PRUNERS.}

If the young tree escapes or survives the assaults of its many enemies, and grows vigorously, it is prone to an overproduction of fruit or leaves. Orchardists and some foresters practise pruning, and believe that when it is judiciously done it is good for the tree. Nature has many ways of pruning. Superfluous buds are nipped off by birds and squirrels, or destroyed by insects. When the sun lies warm in February and March on wooded hillsides, the Ruffed Grouse or Partridge may be seen "budding" on the wild apple trees, alders, poplars, and birches. In May the Rose breasted Grosbeak and the Purple Finch attack both buds and blossoms, scattering snowy petals far and wide. We have seen that all trees have numerous insect enemies, which live upon them; but most of these insects, when occurring in normal numbers, are either harmless or beneficial rather $\mathrm{than}$

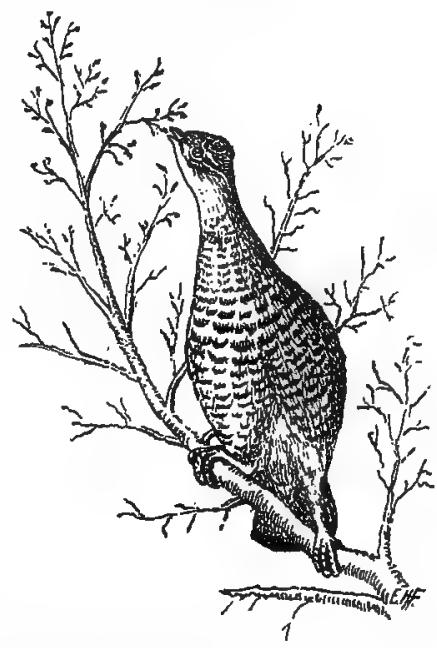

Fig. 32. - Ruffed Grouse, "budding.", injurious. 'Their interests, like those of the birds, are identical with those of the tree which supplies them with sustenance. A few leaf-eating caterpillars may be a benefit to the tree, by removing surplus foliage, and thus checking a too vigorous development, which otherwise might be injurious. Other insects, if not too numerous, may destroy the surplus fruit or seed, and thus direct the energies of the tree toward perfecting larger and better fruit. Certain insects cut off the twigs ; others destroy branches. The numbers of these insects are regulated by birds. In 1896 oak pruners (Elaphidion villosum) were numerous in eastern Massachusetts. They attacked several species of oaks, hickories, and maples. They also assailed the apple trees. Their occurrence in numbers seems to be periodical, and thus the trees 
are subject to a more or less regular periodical pruning. Large quantities of twigs and small branches fell from the oaks and other trees in 1896, and it appeared as if the oak pruners might do considerable injury to these trees; but ljirds and other natural enemies attacked the insects, and the trees were not injured, - very likely in most cases they were even benefited by this removal of the twigs from the upper branches. Jays, Crows, and Hawks break off strong twigs and small branches to use in their nest building. Squirrels gnaw off many twigs while gathering nuts and acorns, or while building their nests. When branches are injured by insects or overshading to such an extent that they die, they are removed later (when weakened by decay) by the action of the wind, or are broken off in winter by ice and snow. Thus the pruning of the trees is effected.

\section{THE GUARDIANS OF THE TREES.}

Birds guard the Trees the Year round. - We know that trees are subject to many injuries by reason of the undue multiplication of animals that feed upon them. The foliage is devoured by insects and other animals; the fruit and seeds by insects, birds, and squirrels; the twigs are killed by borers or girdlers ; the bark is eaten by mice, hares, squirrels, or porcupines; the trunks are attacked by wood borers; the roots have insect enemies; even the very life blood, the sap, is sucked out by aphids. When we consider well the fecundity, voracity, and the consequent great possibilities for mischief possessed by their enemies, we wonder that trees survive at all. Still, trees spring up and grow apace. In a wooded country a few years' neglect of field and pasture suffices to clothe them with a growth of bushes and saplings, and in time a wood lot succeeds the cleared land. That trees are able thus to spring up and grow to maturity without man's care is sufficient evidence that they are protected by their natural friends from the too injurious inroads of their natural enemies. Among these friends birds hold a high place.

It is generally believed that there are few birds in deep woods. Travellers often have remarked the scarcity of birds 
in the forest. It is true that usually there are fewer birds, both in numbers of species and individuals, in most northern forests than in more open or cultivated lands. This is particularly true of coniferous forests, for such woods harbor fewer insects than deciduous forests, and so furnish a more meager food supply for birds. Those birds that live and breed in the deep woods, however, are especially fitted to destroy the trees' enemies.

This care of the trees is kept up throughout the year by the ebb and flow of the tide of bird life. In the chill days of March and early April, when sunshine and shadow fleck the lingering snow, in silent, leafless woods and along swollen streams, the lusty Fox Sparrow searches for seeds and for dormant insects, which only await the warmer sun of April or May to emerge from their hiding places and attack the trees. This Sparrow and its companions, the Tree Sparrow and the. Junco, soon pass on to the north, making way for the White-throats and Thrushes, which continue the good work, to be followed in their turn by other Thrushes and the Towhees. Birds are not plentiful in the woods in early April, but nevertheless diligent Titmice, Woodpeckers, Jays, Nuthatches, and Kinglets are there and at work. In the warm days of May, when nature has awakened from her long winter's sleep; when the little, light-green oak leaves are just opening; when the bright young birch leaves decorate, but do not hide,

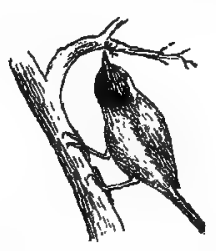

Fig. 33.-The diligent Titmouse. the twigs; when every leaflet vies with the early flowers in beauty, and every branch upholds its grateful offering; when insects which were dormant or sluggish during the earlier days of the year become active, and their swarming offspring appear on bud and leaf, - then the south wind brings the migratory host of birds which winter near the equator. Unnoticed by men, they sweep through the woods, they encompass the trees; flight after flight passes along on its way to the north, all resting daily in the woods and gleaning insects ere they go. No one who has not watched these beautiful birds hour after hour and day after day, and 
who has not listened to their multitudinous notes, as, night after night, they have passed overhead, can realize the numbers that sweep through the woods in the spring and fall migrations. Those who watched the great flights of Warblers during the season of 1905 could but marvel at their vast and changing procession.

One must be in the woods most of the time, during both spring and autumn, to form any adequate conception of these movements; and even then he may be mystified by the sudden changes he will observe. While at Amesbury, Mass., on May 11, 1900, I went out at daybreak with a few friends who were interested in bird study. As we walked through the streets of the village many male Blackburnian Warblers were seen among the street trees. A little later we saw them all about us in the orchards, their brilliant orange breasts flashing in the sunlight. As we approached the woods it was everywhere the same. The night had been very cold, and other insect-eating birds were seeking benumbed insects on or near the ground. There were four bright Redstarts flitting about on the upturned sod of a newly plowed garden. These and other species of Warblers were to be seen in every orchard, wood, and thicket. The Blackburnian Warblers had come in during the night, and were busy hunting for their breakfasts until 7 o'clock, when we went to ours. At 8 o'clock not a single Blackburnian was to be seen. I scoured the country until nearly noon, finding all the other Warblers as at daybreak, but not a Blackburnian could be found. They had done their share in the good work, and had passed on. A later riser would have missed them. Had we not been afield that morning, the flight might have been unrecorded.

In May most of the smaller birds that pass the summer in our northern woods - Thrushes, Warblers, Vireos, Cuckoos, Towhees and their kin - arrive, mate, and build their nests. In June the growing insect hosts increase, and the activities of the parent birds in procuring food for their young are at their height. Each occupied nest is a sepulchre for worms, spiders, and insects; each young bird's mouth is an open door, yawning for their destruction. The parent birds are 
ever hunting, hunting, hunting, to find the wherewithal to stop those insistent, hungry cries; for hunger is not good for young birds, and their cries may betray them to their enemies. This continual search for food for the callow young goes far towards checking the uprising host of insects in June and July, and preventing the absolute destruction of the trees.

When the young birds are out of the nest, their parents lead them to some spot where insects are most plentiful, and there continue to feed them for a time. When the fledgelings are strong and well able to fly about and find their own sustenance, the old birds usually drive them away from the vicinity of the home, and they scatter in search of food, drifting here and there, wherever food is most plentiful, until they find themselves moving southward, with the receding tide of bird life, toward that land where frost and snow are never known.

Some of the Warblers are ready to leave for the south by midsummer. Such of the summer residents as still remain wander through the woods in late summer and early fall, in search of insect outbreaks, wild fruit, and seeds, feeding as they move along. They are now slowly migrating. The chill of autumn evenings accelerates their southward movement, and on clear, still nights their call notes and even their beating wings may be heard as they fly southward.

The birds are now without home attachments, and gather wherever food is most plentiful. Those that have found insects in plenty call to others that are flying by or overhead, bidding them also to the feast. So the tide of bird life sweeps back through the woods of the temperate zone toward the equator. In late October bird songs are heard no more. A few Thrushes, Woodpeckers, Chickadees, Kinglets, Creepers, and Nuthatches flit here and there; Blue Jays mournfully call; a Crow caws now and then; but otherwise the woods seem deserted. Still, at this season of the year and all through the winter and early spring months the few birds that remain are accomplishing the greatest good for the forest; for now the development and increase of all insects are arrested, while their destruction. by birds goes on. In 
winter the smaller wood birds that remain in the north must subsist largely on the hibernating eggs of insects, for many insects pass the colder months in the egg; the bird that eats these eggs can destroy at least a hundred times as many

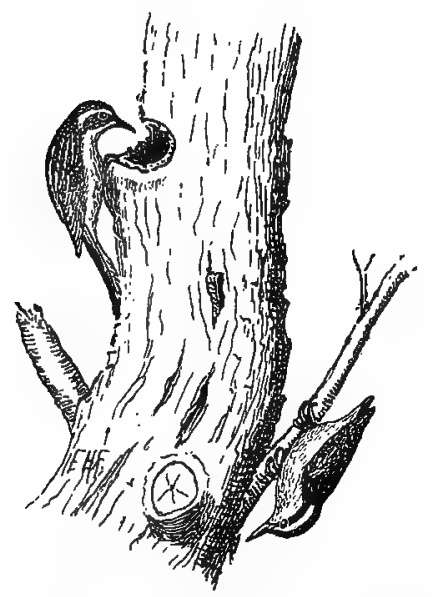

Fig. 34. - Winter tree guards, a Creeper and a Nuthatch. insects in this minute, embryonic form as it could in the summer, after the caterpillars had hatehed and grown toward maturity. The Jays, 'Titmice, Nuthatches, and Woodpeckers, which remain through the winter in the northern woods, give months more of service to our trees than do the majority of birds that come here as summer residents or migrants only. These all-the-year-round birds, with the Creepers and Kinglets, are the most valuable guardians of the wood. Millions upon millions of insects and their eggs are destroyed by them during the long winter months. In this work they are assisted to some extent by certain of the winter Finches and Sparrows.

Birds guard All Parts of the Tree. - Even insects which feed upon the roots are dug out of the ground by birds, or attacked by these feathered enenies whenever they appear above the surface. Sparrows, Thrushes, and Towhees search among the dead leaves for caterpillars which drop from the trees and crawl on the ground, and for those which pupate among the litter of the forest floor. Woodpeckers, tapping the trunks, find and bring forth injurious ants, bark beetles, and wood-boring insects. Creepers, Kinglets, Titmice, and Nuthatches search the bark and cavities of the trunk and limbs for insects' eggs, scale insects, bark lice, borers, bark beetles, and other insects which hide there. Jays, Warblers, Tanagers, Wrens, Titmice, Vireos, Cuckoos, and other treeloving birds pry about among the leaves and branches in search of caterpillars of all sorts. Even the hidden leaf- 
rollers are sought out. The gall insects are dragged from their hiding places by Jays and Grosbeaks. Titmice get the bud worms, and Woodpeckers search out the fruit worms. When the spanworms, disturbed by the movements of the caterpillar-hunting Warblers, Vireos, and Sparrows among leaves and twigs, spin down on their gossamer threads, and so escape one class of enemies, they are marked by Flycatchers sitting on the watch or hovering in the air ready to dart upon them. When the mature insects, gaining wings, attempt to escape by flight, they are snapped up by these same Flycatchers, that sit waiting on the outer limbs of the trees; or, escaping these, they are pursued by Swallows and Swifts in the upper air. Those whose flight is nocturnal must run the gauntlet of the Screech Owl, Nighthawk, and Whip-poor-will. Each family of birds seems exactly fitted for the pursuit and capture of insects that feed on a certain part of the tree, while nearly all species can so adapt themselves, at need, as to feed readily on insects not ordinarily taken by them.

While living in the woods, much of the time alone, for several seasons, I have been greatly impressed by both the vast yearly uprising of insect pests and the strong repressive influence exerted by birds upon their increase. When the buds open in spring, broods of tiny, hungry caterpillars emerge, only to be preyed upon by the constantly increasing flights of birds that peer, swing, flutter, or hop from twig to twig through all the woods. At this time these caterpillars are not at all noticeable, and are very difficult to find; still, the great majority of them are readily found and eaten by birds, and therefore never become apparent to ordinary observation. As summer comes and the caterpillars grow in size, each brood is reduced in number, until, as they approach full size, a band which erstwhile numbered hundreds of little crawlers has shrunk to a score or two, a "baker's dozen," or even less. When the survivors pupate they are still attacked by birds, and the moths or butterflies as they emerge and try their wings are pursued by their swifter feathered enemies.

In studying the increase of the gipsy moth it was found 
that during the first few years after its introduction into a locality its inroads on the foliage were not noticeable; nearly all the insects resulting from each egg cluster fell victims to their natural enemies. This is true to a still greater extent of most of our native insects. As the season advances the few large caterpillars that are left from each brood injure the leaves a little, so that on close inspection in July the foliage appears somewhat ragged and riddled, but at a distance, or to the casual observer, the trees seem in fine foliage.

$\mathrm{He}$ who watches the birds feeding from day to day can only wonder how they can possibly find so many caterpillars; for birds do find them continually, by going over the same ground day after day. When it is difficult for us to see even a single specimen on the leaves, the birds continue to find them until summer wanes and the leaves begin to fall.

The value of the service performed in woodlands by birds that eat caterpillars is far greater than it seems at first sight, for wherever the foliage of a tree is destroyed by insects the fruit of that tree cannot mature, and the tree also suffers a serious check in growth. There is much woodland in Massachusetts that pays very little in excess of the taxes. A leafless tree makes no wood growth; therefore, whenever trees that are grown for wood or lumber are stripped of their leaves by caterpillars, the size of the annual wood ring is so much below the normal that the owner realizes no profit, and may even suffer a loss on his wood lot that year.

But this is the least danger that is threatened by the attacks of caterpillars. Most people know that the tree "breathes through its leaves," and when for a long period these organs are prevented from developing, it must inevitably die. Most coniferous trees, like the pine and hemlock, die when stripped of their foliage for one season; and deciduous or broadleaved trees, such as the oak, ash, and maple, often succumb if deprived of their leaves for a considerable length of time each year for even two or three years in succession. Most trees would soon be killed in this way were it not for the birds, for there is a succession of many species of caterpillars that feed upon the trees all summer, and, were they not held in check by birds, they would destroy the foliage month 
after month. The consequent weakened condition of the trees would invite the bark beetles and other borers which attack such trees, and, multiplying exceedingly, cut channels beneath the bark until all the vital tissues are destroyed. I have seen naany trees defoliated by the gipsy moth that afterward succumbed to the attacks of these insidious borers, which are probably the ultimate cause of the death of many defoliated trees.

The destruction of these larvæ in their retreats under the bark is effected mainly by

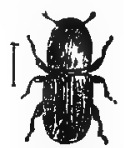

Fig. 35. - Destructive bark beetle, eaten by birds. Enlarged. insect parasites, predaceous insects, the various species of Woodpeckers, and possibly by Titmice. The adult beetles, when they emerge from their retreats in the spring, are also attacked by many birds. The Woodpeckers are most valuable, because they drag from secret hiding places certain

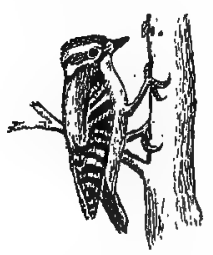

Fig. 36. - Woodpecker hunting borers. boring coleopterous and lepidopterous larvæ that might otherwise destroy the trees. A single borer may be sufficient to kill a young tree, but the Woodpecker takes the pernicious grub from its burrow, and by eating several at a meal may save many trees in the course of a year.

When the European leopard moth appeared in New York and Brooklyn, causing great havoc among the trees in the parks, it was feared that as the insect spread it would become a serious enemy to the trees of the entire country; but I was informed by Dr. John B. Smith, entomologist to the New Jersey Agricultural College Experiment Station, that this moth, while a pest in cities, was doing little damage in the country, where the native birds seemed to keep it in check. At first it looked as if the large larve, because of their habits, would escape the birds. They are borers, beginning life within the small twigs, and when these get too narrow for them they eat their way out and crawl down outside to larger twigs. It is then that they are taken by many native birds, though the "English" Sparrows do not appear to check them. Dr. Smith says that the Woodpeckers eat the female moths, 
and probably drag the young larvæ out of the smaller twigs.

It is extremely difficult and expensive to raise forest trees in regions where there are no arboreal birds. The larvæ of several large nocturnal moths are among the most destructive insects known. Mons. Trouvelot's statement (pp. 30, 31) regarding the quantity of food eaten by the larva of polyphemus illustrates the power for harm that these creatures possess. The larvæ of Platysamia cecropia and Actias luna are so gigantic and their rate of increase is so great that they constitute one of the gravest dangers that constantly menace our woodlands, yet we never hear of any serious injury done by them in Massachusetts. Indeed, such species, although large and conspicuous, are not often seen except by entomologists and collectors of insects, who know their haunts and habits. The main reason for their comparative scarcity is indicated by Trouvelot's experience in rearing the larvæ of Telea potyphemus, the "American silkworm." He had a tract of about five acres enclosed, and covered with netting for the protection of these caterpillars. The vegetation on this land as I saw it years afterward was largely scrub oak and whortleberry or huckleberry bushes. Trouvelot says that when he began rearing silkworms the bushes were of about five years' growth, and it seemed as if there would be very little to do after the place was enclosed and the insects put in ; but he found that most of his time was occupied in defending his treasures against the birds. The smaller of these would push through the meshes or get under the edges, while the larger ones would find some hole by which they could enter. He says that he was obliged to chase them "all the day long," as when he was pursuing them on one side they would fly to the other and quietly feed until he reappeared. ${ }^{1}$ "Birds," he says, "are the greatest foes of silkworms, especially the Thrushes, Catbirds, and Orioles." He believes it probable that in a state of nature ninety-five per cent. of the silkworms become the prey of these feathered insect hunters. ${ }^{2}$

Samuels tells us that Trouvelot was obliged, in self-defence,

$$
{ }^{1} \text { American Naturalist, Vol. 1, p. 14j. } \quad \text { "Ibid, p. } 89 .
$$





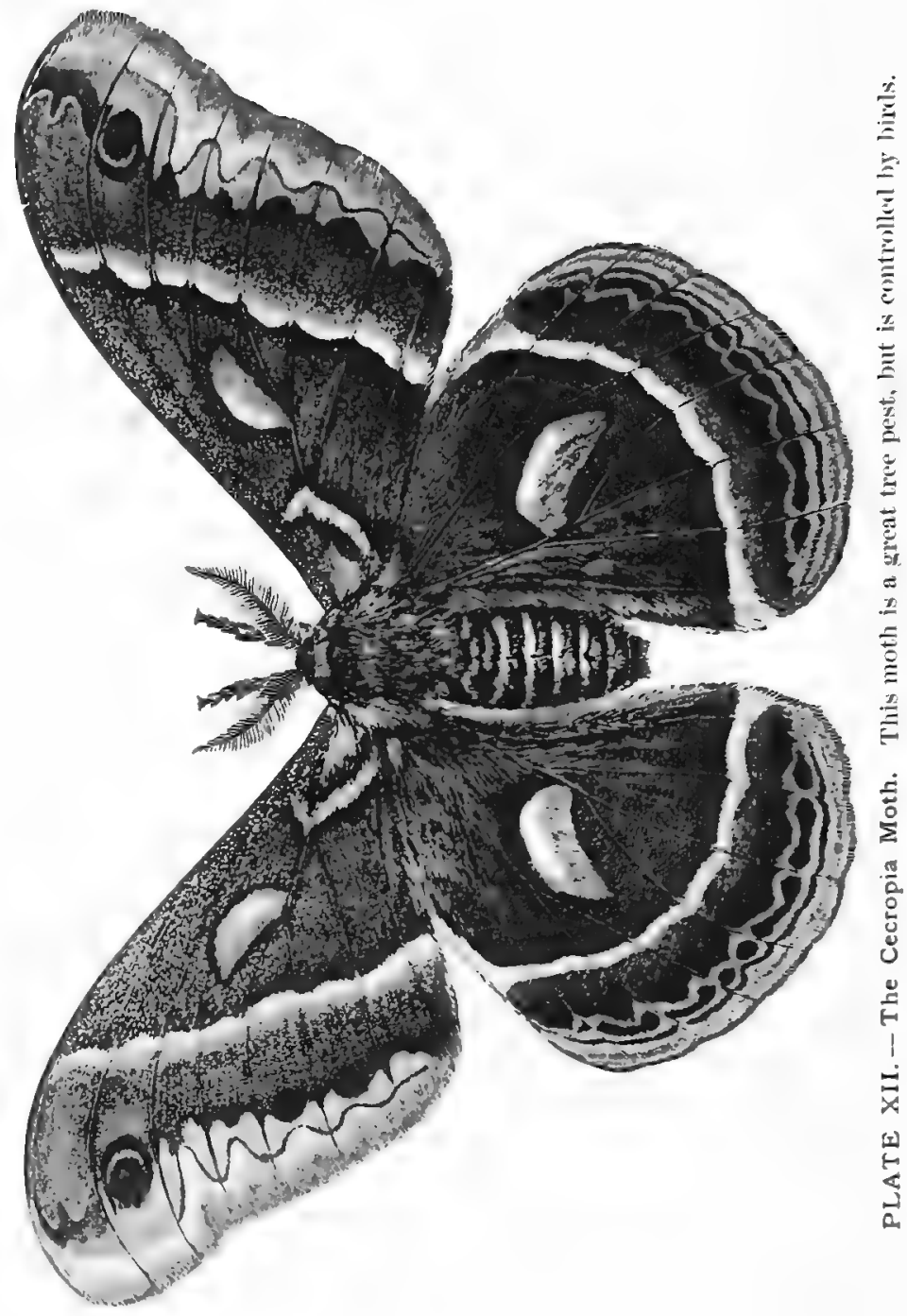


to shoot the birds which thus penetrated into his enclosures for the purpose of eating the worms. Although the land on all sides sustained a good growth of huckleberry bushes, he never found the berries in the stomachs of the birds he killed, but always found insects. He said that birds came from all quarters to destroy his silkworms. To test the destructiveness of the birds, he placed two thousand larvæ of polyphemus on a scrub oak near his door. In a few days the Robins and Catbirds had eaten them all. His experience of several years in rearing the silkworm led him to the belief that, were the birds to be killed off, all vegetation would be destroyed. Such experiences show the difficulty of rearing caterpillars, even under artificial protection, in a land frequented by arboreal birds, and explain the rarity of serious injury by such larvæ in our woods.

The rapidity with which caterpillars propagate where there are no such birds, and their destructiveness under such circumstances, may be shown by the experience of many settlers in their attempts to establish groves on the open prairies. It has been the beneficent policy of our government to grant certain tracts of land (tree claims) to settlers, provided they would plant trees. This was done with the purpose of providing wind-breaks on the prairies, which would eventually furnish the people with a supply of wood and lumber. At first, however, this work met with little success, for there were few tree-loving birds in the prairie country except along the timbered river bottoms. The settlers introduced insect pests on imported trees. The enemies of tree insects being absent, because the country was destitute of well-grown groves and orchards, the insects multiplied and overran the seedling trees; the larger moths, like cecropia and polyphemus, were the worst pests of all, increasing rapidly, eating voraciously, and making it almost impossible to raise trees. Dr. Lawrence Bruner, in a paper on insects injurious to tree claims, states that the absence alone of so great a factor as tree-loving birds in keeping down insect pests and ridding the country of them soon becomes apparent in the great increase and consequent damage done by these pests. He asserts, also, that as an enemy 
to tree culture cecropia has no equal in some portions of the prairie country, and that its large caterpillars often defoliate entire groves. Mr. W. C. Colt, who has had experience in raising trees in Dakota, told me that the caterpillars of this

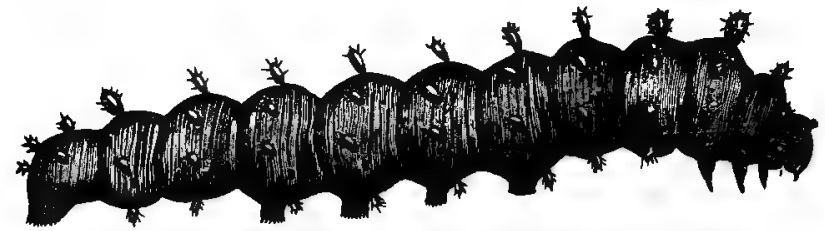

Fig. 37. - The larva of the cecropia moth, a destructive leaf-eating insect, held in check by birds.

and other large species were terribly destructive there. As groves and orchards became established, however, and arboreal birds spread over the country, these caterpillars were reduced to a state of comparative harmlessness. There is good reason, therefore, for the belief that the caterpillars so commonly eaten by practically all arboreal birds would, together with the borers, destroy all the forests were the birds to be banished from their chosen haunts. ${ }^{1}$

1 The latter part of this chapter consists of revised portions of several papers by the author, originally published by the Massachusetts State Board of Agriculture. 


\section{CHAPTER III. \\ BIRDS AS DESTROYERS OF HAIRY CATERPILLARS AND PLANT LICE.}

Certain caterpillars are provided with defences which are supposed to give them immunity from the attacks of birds. It is now believed quite generally, by both ornithologists and entomologists, that such protective devices are effective against nearly all birds. I have learned, however, by both observation and dissection, that in many cases such protection does not protect. American writers seem to have accepted the evidence of Europeans on this subject without having taken the trouble to investigate the matter fully by obscrvation at home. Among the earliest of this European "evidence" now at hand is a paper by a writer in the Annales de l'Institut Horticole de Fromont, Vol. 5, p. 311, published in Paris in 1833. In discussing the opinion promulgated by the Natural History Society of Gorlitz, that the diminution of fruits is on account of the diminution of birds, he places the caterpillar of the gipsy moth at the head of the list of injurious caterpillars, saying that "above all it is very essential that it be destroyed." He says further, that, as these caterpillars are armed with long hairs, the birds guard well against bringing them to their young; and that in twenty years of observation he has nerer seen a bird take one to its young. He also states that these insects when in the chrysalis are not sought by birds.

A more recent source of this widespread belief is indicated by Dr. Packard, who, writing in 1870 , notices some interesting facts brought out by Mr. J. J. Wier of the London Entomological Society, in the following words :-

He finds, by caging up birds whose food is of a mixed character (purely insect-eating birds could not be kept alive in confinement), that all hairy caterpillars were uniformly uneaten. Such caterpillars are the "yellow bears" (Arotia and Spilosoma) and the salt-marsh 
caterpillars (Leucarctia acrcea), the caterpillar of the vaporer moth (Orgyia) and the spiny larvæe of butterflies; with these perhaps may be classed the European currant sawfly. He was disposed to consider the "flavor of all these caterpillars as nauseous, and not that the mechanical troublesomeness of the hairs prevents their being eaten. Larve which spin webs, and are gregarious, are eaten by birds, bnt not with avidity; they appear very much to dislike the web sticking to their beaks, and those completely concealed in the web are left unmolested. When branches covered with the web of Hyponomenta evonymella (a little moth of the Tinea family) were introduced into the aviary, those larvæ only which ventured beyond the protection of the web were eaten." "Smooth-skinned, gaily colored caterpillars (such as the currant Abraxas or spanworm), which never conceal themselves, but, on the contrary, appear to court observation," were not touched by the birds. He states, on the other hand, that "all caterpillars whose habits are nocturnal, and are dull colored, with fleshy bodies and smooth skins, are eaten with the greatest avidity. Every species of green caterpillar is also much relished. All Geometræ, whose larvæ resemble twigs, as they stand out from the plant on their anal prolegs, are invariably eaten." 1

Such statements as these are at least interesting, but they must be classed as negative evidence, and cannot justify the assertions so often made that_birds do not eat hairy caterpillars, when there is convincing, positive evidence that certain species do eat them. This statement that birds do not eat such caterpillars, which has been so long reiterated, parrot-like, by one writer after another, is entirely at variance with my experience, and my opportunities for investigating this subject probably have been better than those of most observers. The great burden of proof is upon those who make the allegation, for it is always hard to prove such sweeping generalizations, and often not at all difficult to disprove them. A naturalist may with propriety say what he has seen a bird do, but he should be cautious in stating what it does not do. The reiterated assertion that hairy caterpillars are immune from the attacks of birds has been modified of late by some writers, and is now oftener given, in effect, that few birds eat them; but this statement needs still further modification. We cannot rely on results secured by

- First Report on Injurious and Beneficial Insects of Massachusetts, by A. S. Packard. Annual Report of the Massachusetts State Board of Agriculture, 1870-71, pp. 358, 359. 
feeding a few European birds in captivity, or upon the mere casual observations of any one, to establish facts.

No one, however, is warranted in attempting to dispute assertions made by eminent naturalists, unless he is prepared to show that his own experience has been extended and varied enough to warrant him in assuming them to be in error. To justify my own position, I shall present here some revised portions of some papers previously published, and some field notes from a few observers, that the reader may judge of the character of the evidence offered to disprove the statement that birds do not eat hairy caterpillars. It will first be necessary, however, to explain how the evidence was secured. For more than thirty years I have observed, from time to time, the feeding of birds upon caterpillars, and during nine years of this time I had an opportunity to compare notes on this subject with many other field workers. During the prosecution of the work against the gipsy moth by the State Board of Agriculture more than a thousand men were employed, among whom were many who knew the more common birds. Some were keen field naturalists. In the early history of the work, when it was seen that birds were feeding on the hairy caterpillars, all those employees who knew birds were requested to watch both birds and insects, and report results. There were eleven such observers on the force at that time. Others joined the force from time to time, until the number of competent persons whose experiences were recorded was increased to thirtyeight. Some of these observers were employed only one season; others were in the employ of the Board for six, seven, or eight years, and made observations during each year. The conditions under which these studies were made were such that most of the birds could be observed within either a few feet or a few yards. Those which could not be so readily approached were watched with the aid of good field glasses or opera glasses, and, where there appeared to - - be doubt, birds were shot, and the contents of their stomachs were carefully examined. Much that was learned by experience in the earlier studies was turned to good account in conducting those made later. The value of such observa- 
tions may be questioned by those who rely solely upon the examination of stomach contents to determine the food of birds; but for the purpose for which these investigations are made they are, if skilfully conducted, quite as serviceable as stomach examinations. In fact, one must supplement the other. Were one to follow the birds about through the fields and woods, no doubt some interesting facts might be learned in regard to their food; but it is not in this way that a series of accurate observations can be made. For our purpose, the method pursued was to find an outbreak of hairy caterpillars situated in a locality where many species of birds would be likely to find it. The watcher first made sure as to the kind of insects to be found upon the trees or plants to be watched; he then concealed himself near the insects whose destruction he wished to observe, and watched the birds which came there to feed. When this method is followed methodically by trustworthy, painstaking naturalists, and when results obtained by different observers, working independently, agree in the main, there can be no reasonable doubt as to the value of such observations. When the caterpillars are small, certain marked branches are selected to be watched, or certain nests, webs, or tents are studied at close range. By this method, as well as by stomach examinations, fifty-one species or subspecies of birds were found to be feeding to a greater or less extent upon hairy caterpillars. A list of these is given below. It will be seen that it comprises most of the common summer birds found in Massachusetts woodlands, and some not commonly found there.

Birds observed feeding on Hairy Caterpillars.

Yellow-billed Cuckoo.

Black-billed Cuckoo.

Hairy Woodpecker.

Downy Woodpecker.

Yellow-bellied Sapsucker.

Northern Flicker.

Kingbird.

Crested Flyoatcher.

Phœbe.

Wood Pewee.

Least Flycatcher.
Blne Jay.

Crow.

Red-winged Blackbird.

Baltimore Oriole.

Purple Grackle or Crow Blackbird.

Bronzed Grackle.

White-throated Sparrow.

Chipping Sparrow.

Field Sparrow.

Song Sparrow.

Towhee. 
Birds observed feeding on Hairy Caterpillars - Concluded.

Rose-breasted Grosbeak.

Indigo Bunting.

English Sparrow.

Scarlet Tanager.

Cedar Waxwing.

Red-eyed Vireo.

Yellow-throated Vireo.

Warbling Vireo.

White-eyed Vireo.

Black and White Warbler.

Parula Warbler.

Golden-winged Warbler.

Nashville Warbler.

Yellow Warbler.

Chestnut-sided Warbler.
Northern Yellow-throat.

Black-throated Green Warbler.

Oven-bird.

American Redstart.

Catbird.

Brown Thrasher.

House Wren.

White-breasted Nuthatch.

Red-breasted Nuthatch.

Chickadee.

Wood Thrush.

Wilson's Thrush.

American Robin.

Bluebird.

Birds feeding on the Pupce or Imagoes.

Yellow-billed Cuckoo.

_Black-billed Cuckoo.

Hairy Woodpecker.

Downy Woodpecker.

Yellow-bellied Sapsucker.

Kingbird.

Crested Flycatcher.

Phobe.

Wood Pewee.

Least Flycatcher.

Blue Jay.

Crow.

Baltimore Oriole.

Chipping Sparrow.

Towhee.

Rose-breasted Grosbeak.

Indigo Bunting.

English Sparrow.

Scarlet 'Tanager.

Red-eyed Vireo.

Yellow-throated Vireo.

Black and White Warbler.

Yellow Warbler.

American Redstart.

Catbird.

Brown Thrasher.

Chickadee.

Robin.

Bluebird.

It is interesting to note that certain birds feed on the eggs of some of the parent moths, and that many birds take the moths in flight. Without going further into details here, I shall endeavor later, in connection with the life history of our more common and useful birds, to give some information regarding the kind of hairy caterpillars each species eats, and its comparative usefulness in this respect.

Assuming that our observations have proved that birds eat hairy caterpillars, it may be interesting to inquire why this 
fact has not been previously noticed. It will be seen at once, by one who makes a study of the subject, that the error which has been so long persisted in arises, first, from a lack of careful observation. It is noteworthy that most of the more observing writers give the Cuckoo as an exception to their established (?) rule that birds do not eat hairy caterpillars. It is not strange that the Cuckoos should have been known for years to feed on such caterpillars. The Cuckoos are sizable birds; they are not very shy, and, as they feed on the larger caterpillars when those insects are full-grown, and as both Cuckoos and caterpillars are common in the vicinity of dwellings, their habits in this respect could not escape the most casual observer. But it is much more difficult to observe the habits of shy birds, such as the Crows and Jays, which feed on the larger caterpillars; and to learn the feeding habits of the smaller birds, which feed mainly on the minute larvæ soon after these have hatched from the egg, requires the most painstaking care. Most of the caterpillars that are eaten by the smaller birds are taken when the larvæ are so small and have done so little injury that they have not become apparent to common observation. Thus they are destroyed before most people even suspect their presence; while, per contra, those which escape the smaller birds and grow to a large size are seldom eaten in this stage except by a few species of the larger birds, which, like the Cuckoo, Catbird, Jay, and Crow, bolt them whole. Thus another source of the prevalent opinion is explained. A few smaller birds, such as the Titmice, Vireos, and Orioles, tear caterpillars open, and thus avoid swallowing the head, skin, and hair. Sometimes, when the adult birds put such caterpillars down the throats of their well-grown young, the little birds will reject them. A young Oriole put its foot upon the protruding end of a larva, and pulled the wriggling creature back to daylight. There is no doubt that when these caterpillars grow large many small birds experience the same difficulty in eating them whole that we should encounter were we attempting to swallow the bones of a fish. So, when larvæ have grown large, and are çovered with stiff spines or hairs, only the larger birds or the most 
intelligent, industrious, and persevering of the smaller birds will attack and devour them. When caterpillars are enclosed in webs they are not quite so much exposed to the attacks of birds as when they are feeding upon the foliage ; for many birds lack either the intelligence, industry, or perseverance exhibited by those that tear open the webs and hale forth the inmates. Caterpillars get comparatively little protection, however, by retreating into their webs, unless they feed at night and remain clustered in the web during the entire day. Even then they must run the gauntlet of some of the almost crepuscular Thrushes and Flycatchers, the Owls and Whippoor-wills. Those who tell us glibly that tent caterpillars are never attacked by birds forget that these larvæ are out feeding upon the leaves during most of the day, where they are just as much exposed to the attacks of birds as is any other insect. It is true that at early morning and early evening, a time when most birds are actively feeding, these caterpillars are hidden away in their tents. Undoubtedly this habit came through natural selection. Those that had acquired the habit were more likely to escape the birds at morning and evening than those that were out upon the leaves at those times, and so, through generations, the habit has become fixed. These caterpillars also may have some immunity from birds by remaining in their tents during some of the colder weather of early. spring; nevertheless, the tents are not an infallible protection. Many species of birds besides the Cuckoo tear open caterpillars" "nests." Some do this merely to get at the larvæ, others mainly to procure web with which to bind together the other materials of which their own nests are composed. This caterpillar web is much used by birds for this purpose. Tent caterpillars really have very little protection from birds where the conditions are as they should be.

For five years the birds have been mainly depended upon to clear these larvæ from the trees about my home, and we have not in any year removed more than one or two tents from the trees. In the spring of 1905 there were two which appeared to have escaped the attacks of birds, and one day, as we were about leaving home for the summer, I exam- 
ined these tents, and concluded to remove them. At that moment we were called to dinner, and left the trees for half an hour; when we returned, the largest tent had been torn open, and several dead caterpillars were scattered about that had been dealt with in the manner characteristic of the Oriole or the Chickadee. Several large holes in the web showed how they had been extracted. Being obliged to leave at once, I was unable to watch the tree, to see what bird was doing the good work; but Mr. C. Allan Lyford, who was with me, remained and photographed the caterpillars' nest. The accompanying illustration made from his photograph shows plainly an opening made by the birds, as well as several of the dead caterpillars lying upon the limb or hanging from it. We did not take off the tents, but left them and their occupants to the tender mercies of the birds; and our confidence in their protective service was fully justified by the results observed later.

But, it may be asked, wliry have not those who have dissected the stomachs of the birds discovered that they were eating hairy caterpillars? To this it may be answered that up to the present time most of the knowledge that has been gained in regard to the destruction of hairy caterpillars by birds has come from stomach examinations, and it is mainly by stomach examinations that light has been thrown on this question. Yet he who examines the stomachs of small birds labors under many difficulties in determining the specific character and quantity of this kind of food. Minute caterpillars are speedily reduced to a pulpy mass in the bird's stomach. While the field observer may readily identify the small tent caterpillars, for instance, on which the birds are feeding, and even count the number eaten, it might be impossible for the man in the laboratory, working without exact knowledge of the conditions under which the bird was shot, to do either. Most of the larger caterpillars eaten by some of the smaller birds are not swallowed whole, but picked to pieces; therefore the portion of the caterpillar swallowed would be entirely unrecognizable when found in the bird's stomach. Other caterpillars are dissected, as it were, by the bird, and only the internal parts chosen as food; these can- 


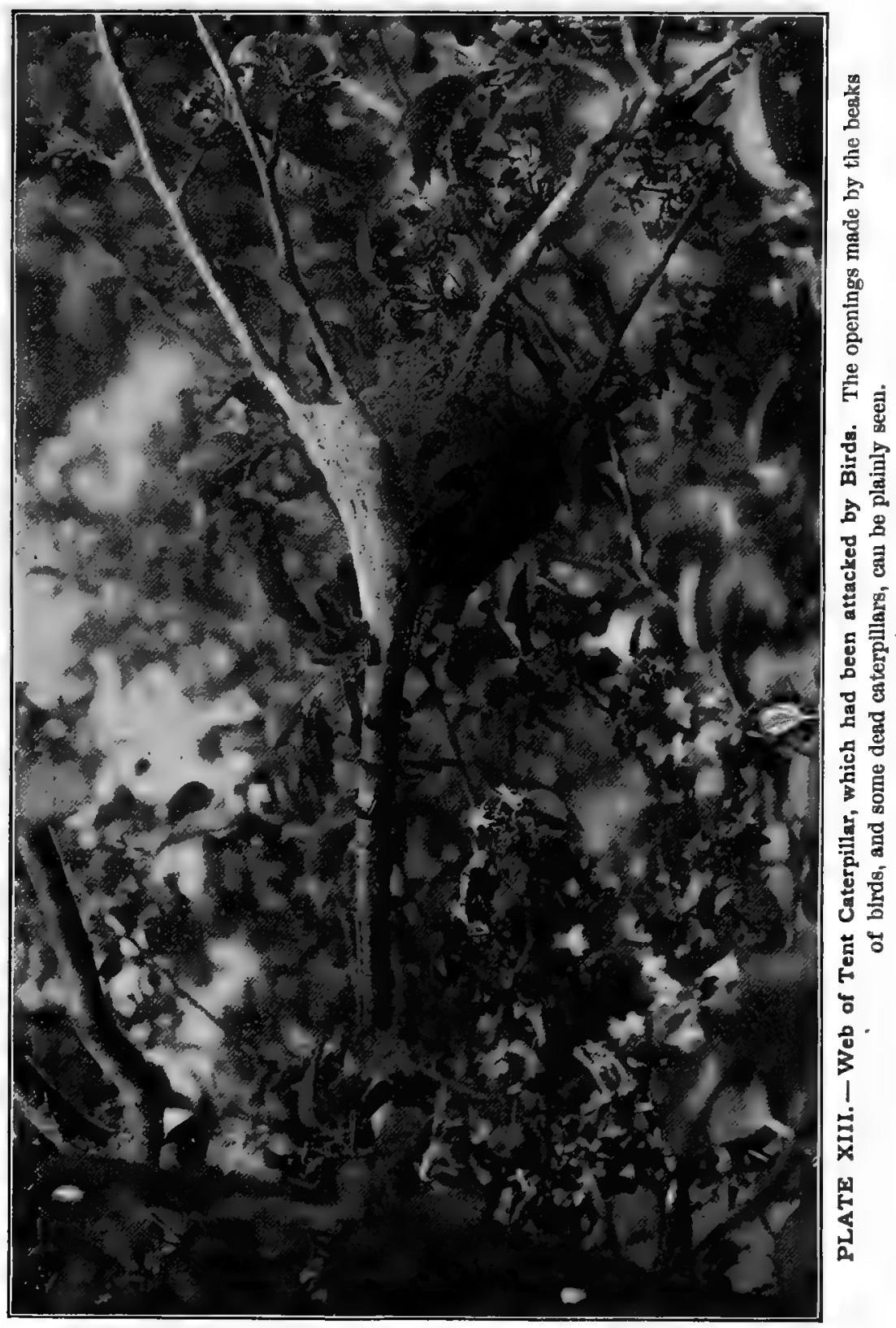



not be identified in the stomach of a bird. Orioles, Vireos, and Titmice are among the birds that commonly dissect caterpillars in this way. This is not a rare or exceptional habit, nor is it difficult to observe. It seems to be a device adopted by certain of the smaller birds mainly when feeding on caterpillars too large to be swallowed whole without causing some inconvenience; therefore, they choose the parts which can be digested readily, and reject the others.

There are two facts which have gone far to justify the conclusions of those who believe that birds do not eat hairy caterpillars; they are: (1) most birds appear to prefer hairless caterpillars with which to feed their young; (2) when small hairless caterpillars are abundant, most birds seem to prefer them to large hairy caterpillars. The first statement may be accepted as a rule; nevertheless, fifteen species of birds were seen by my assistants in the act of carrying away hairy larva apparently to feed their young, and some of these were actually scen to put large hairy caterpillars down the throats of the young birds. These fifteen species are: the Robin, Wood Thrush, Catbird, Chickadee, Chestnut-sided Warbler, Yellow Warbler, Black and White Warbler, Yellowthroated Vireo, Red-eyed Vireo, Scarlet Tanager, Crow, Blue Jay, Baltimore Oriole, Black-billed Cuckoo, and Ycllow-billed Cuckoo. Statement No. 2 is proved by records made by several observers, in years when cankerworms were abundant. They found that when birds had for some time been feeding on the hairy caterpillars of the gipsy moth they neglected these larvæ, for a time, at least, to feed on the young cankerworms. While the above observations show that the hairy caterpillars are not so eagerly sought after by most birds as are many hairless kinds, and that the hairy species enjoy seasons of partial immunity from the attacks of birds, they form no adequate excuse for the sweeping, erroneous generalizations regarding this subject that have been given a wide circulation.

If we turn to the literature of economic entomology, we shall find many records which are corroborative of my statēments. The occurrence of the great flight of Starlings and other birds that flocked to feed on the caterpillars of the nun 
moth (as cited on p. 17), may be-mentioned here in refutation of the assertions of European writers to the effect that hairy caterpillars are not eaten by birds. The fact that birds have been seen to feed more commonly on such caterpillars in Massachusetts than elsewhere suggests the probability that this habit of feeding is local and exceptional. But records of the destruction of the forest tent caterpillar by birds in New York and New England, as given by Miss Soule, Dr. Felt, and others, show that the species that attack hairy larvæ in Massachusetts are useful in this respect elsewhere. There are many other records in the literature of American economic entomology and ornithology which might be offered to corroborate the specific instances hereinafter given. This habit of birds has been observed more in Massachusetts than elsewhere merely because the conditions here have been exceptional, and the birds have been carefully watched.

It seems quite probable, from my experience, that those extremely hairy and destructive caterpillars, the Arctians,

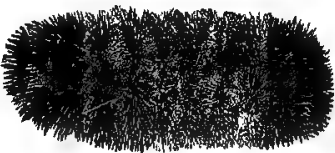

Fig. 38. - The woolly bear caterpillar. commonly represented by the yellow bear (Diacrisia virginica) and the woolly bear (Isia isabella), are not chosen as food by many birds. Still, I have never known either of these species to be very abundant, and think it not improbable that their comparative scarcity may be largely due to their being eaten when very small by birds. The earlier Thrushes take some of these larvæ that winter upon the ground. Should these caterpillars ever become very abundant at any

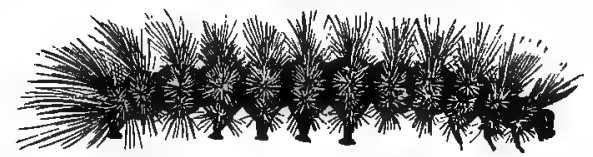

Fig. 39. - The yellow bear caterpillar. This und the woolly bear are destructive hairy species, such as are eaten by Thrushes, Robins, and Bluebirds. time, it seems probable that other birds would attack them. The tussock moth caterpillars (Hemerocampa leucostigma) and others, which Dr. Packard instances as probably immune from the attacks of birds, are eaten by a goodly number; and I have no doubt that the exemption of our trees in the 
country from injury by these insects is largely due to the good work of native birds, while the greater destructiveness of this insect in our cities is no doubt in consequence of the scarcity of such birds there.

Regarding the immunity of brightly colored caterpillars from destruction by birds, my evidence is mainly of a negative character, and thcrefore of little value. I have never known birds to eat certain of the most gaudily colored caterpillars, while others are commonly eaten by them. It would seem that such larvæ

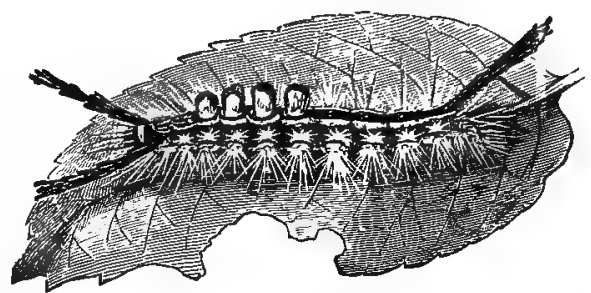

Fig. 40.-Caterpillar of the white-murked tussock moth, a destructive shade-tree pest, eaten by many birds.

as are made conspicuous by their coloring must have some means of protection against their enemies. In some instances these bright colors may serve to warn birds that the creature displaying them is distasteful or unfit for food. Usually, however, such caterpillars are not numerous, and must, therefore, be preyed upon by natural enemies.

In that most admirable local economic study of bird life by Dr. Judd, "The Birds of a Maryland Farm," we find the following statements: "The pea plant louse is a new species, unfamiliar to birds, which, however, seldom eat plant lice" (p. 28); "The fact that plant lice are not selected by birds has been mentioned in the notes on the pea plant louse" (p. 29). I cannot understand how Dr. Judd could have been led into making such erroneous statements, for the facts are that, while some species of plant lice appear to be ignored by birds, other species often form for them a staple food supply. For example, I have never seen any bird eat the melon plant louse, but several species eat the cabbage plant louse, and the birch aphis is a favorite food for birds. It is also a well-known and undisputed fact that some birds subsist largely during the winter on the eggs of plant lice. Before Dr. Judd's paper was given to the public, several investigators had published the fact that certain birds eat cer- 
tain plant lice; and two years previously I had published a list of thirty-four species which feed upon plant lice. It is a widely known fact in Massachusetts that practically all of the resident and migrant Warblers eat the birch plant louse. It is only necessary for one to find a locality where these insects are numerous if he wishes to make sure of finding in their seasons about all the Warblers that breed in that region or migrate through it, and also many other birds not ordinarily found among the birches. Trees are seldom killed by plant lice; but they are often seriously weakened, their fruitage lessened, and their growth greatly retarded by the attacks of these prolific creatures. Undoubtedly the plant lice of the birch would greatly reduce the annual crop of birch wood and lumber were it not for the manner in which their increase is checked by birds. A list of thirty-eight species of birds that have been found, either by myself or my assistants, feeding on birch plant lice, is appended :-

Downy Woodpecker.

Northern Flicker.

Chimney Swift.

Ruby-throated Hummingbird.

Wood Pewee.

Least Flycatcher.

Purple Finch.

Rusty Blackbird.

Red-winged Blackbird.

Baltimore Oriole. .

American Goldfinch.

Slate-colored Junco.

Chipping Sparrow.

White-throated Sparrow.

Field Sparrow.

Bobolink.

Towhee.

Rose-breasted Grosbeak.

Indigo Bunting.
Chickadee.

Scarlet Tanager.

Red-ered Vireo.

Yellow-throated Vireo.

Black and White Warbler.

Myrtle Warbler.

Parula Warbler.

Yellow Warbler.

Black-throated Blue Warbler.

Magnolia Warbler.

Chestnut-sided Warbler.

Northern Yellow-throat.

Black-throated Green Warbler.

Black-poll Warbler.

Oven-bird.

American Redstart.

Catbi:

White-breasted Nuthatch.

American Robin.

Some of the evidence from which my conclusions were drawn regarding the economic relations existing between birds on the one hand and plant lice and hairy caterpillars on the other, is here presented, that the reader may have an 
opportunity to judge for himself as to the value of these birds. If this volume does no more than to correct the prevalent erroneous impression regarding the relations between birds and hairy caterpillars, and call attention to the necessity of protecting the birds that eat such larvæ, it will have accomplished something worth while. The question whether or not birds will eat the caterpillars of Bombycid moths is of vast inportance to the Commonwealth, the adjoining States, and the nation; for, unless we can get help from the natural enemies of the gipsy moth and the brown-tail moth, the fight against these insects is likely to cost the State many millions of dollars in the end, while other States that surely will be invaded must suffer also. If it can be shown that birds are capable of doing effective work against these insects, it ought not to be difficult to create such a public sentiment in favor of bird protection as will result in a considerable increase in the numbers of the useful species which obtain a part of their sustenance from this abundant food supply.

In May, 1898, injurious insects were unusually prominent in the Middlesex Fells. The birches swarmed with aphids; cankerworms appeared on the apple and elm trees; the growing webs of tent caterpillars were seen on most of the wild apple and wild cherry trees; forest caterpillars were gathering on oaks and maples; sawflies, mosquitoes, ants, leaf-rollers, and many other injurious species were abundant. The brown-tail moth was just getting a good foothold in the woods, while the ever-present gipsy moth larvæ were beginning to swarm up the trees from the furry egg clusters hidden among the loose stones and seamed ledges of the rocky hills. As usual at such times, birds were present in large numbers. Warblers were flitting among the birch trees, regaling themselves on countless thousands of plant lice, plucking young tent caterpillars from the opening buds of wild apple trees or from the fast-forming webs. They alighted on the tree trunks and climbed around them, as they eagerly sought tiny hairy larvæ of the gipsy moth, or fluttered in the sunlight as they chased winged gnats in air.

It seemed that there could be no better opportunity to ob- 
serve the usefulness of birds as destroyers of plant lice and hairy caterpillars, and we determined to have both insects and birds watched at intervals through the spring and summer, that others might learn much that a lack of time rendered it impossible for us to determine by personal observation. It was evident that certain birds were living very largely at this time on plant lice and three or four species of hairy caterpillars, and we wished to learn whether they and others would follow up this practice through the spring, and also whether they were learning to eat the larvæ of the brown-tail moth. These larvæ are provided not only with long hairs but with a coating of short, loosely attached hairs on the posterior part of the body, which are easily detached, barbed like the quills of a porcupine, and so tenacious that they will work quickly into the human skin and cause a violent irritation and an itching eruption, which lasts for sereral days. It was to be expected that these, more than any other hairy caterpillar, would prove distasteful to birds, but the result of the investigation that followed showed that birds were learning how to manage them. Messrs. Charles E. Bailey and F. H. Mosher, both woodsmen and thoroughly competent observers, well acquainted with both birds and insects, were instructed to make frequent visits to places where the conditions were such that they could readily observe the feeding of birds on hairy caterpillars and plant lice. They were asked to take notes and report the results each day. In order to give the reader a clear idea as to the character of the evidence thus secured; some of their field notes are transcribed below. The following notes are from Mr. Mosher's reports :-

MAy 26, 1898. - I went to the park near Hemlock Pool, Stoneham. An Oven-bird stayed near me twenty minutes; took eight gipsy moth larvæ, several larræ that I could not determine, and many plant lice; then hopped to the ground and walked away, searching in the leaves. Three Chickadees came to the trees, and two of them took a gipsy larva each. They were picking plant lice and scales from the bark, and were picking off the loose bark, but I could not see what they got from beneath it. Two Black and White Warblers flitted from tree to tree. picking something from the bark and leaves, and were particularly busy 
with the small twigs of the oaks. On looking at them after the birds were gone I found small scales on the twigs. The birds also took plant lice from the under sides of the birch leaves, four larva that looked like cankerworms, and three gipsy larvæ. A Red-eyed Vireo came four different times, taking each time respectively seven, three, twelve, and fifteen gipsy larve. Besides these, he took plant lice and other insects from the leaves and bark. Yellow-throated Vireos were coming and going constantly, and I could not distinguish between them. They were eating plant lice and insects from the bark and leaves. I saw them eat thirty-two gipsy larvæ. I heard a commotion among the Robins that have a nest a short distance away. On going to the spot, I found a Crow in the act of carrying away one of the young birds. Probably he came later and took the remainder of the young, for the nest was empty when I returned. I changed my position to the edge of the woods. A pair of Bobolinks that are living in the ficlds near by came to the birches and picked plant lice for over half an hour, then a movement on my part frightened them away. The Orioles were busy taking the plant lice, and several times the male went to the tent caterpillars' nest and ate them. I saw them eat over forty of the gipsy caterpillars, that I was sure of, in the hour they were in sight. There were Chewinks, Least Flycatchers, Redstarts, Scarlet 'Tanagers, Brown Thrushes, Wood Thrushes, and one Red-winged Blackbird that were feeding, but I could not see plainly what they were feeding on.

MAY 28, 1898. - A Black-billed Cuckoo went to an oak tree and ate thirty-six forest tent caterpillars inside of five minutes. Its nest was near by, with two eggs, and both birds were carrying the withering blossoms of the oak and poplar to line it. The Black and White Warblers were eating forest tent caterpillars, cankerworms, and other larvæ, besides plant lice. I could not see them for more than a moment at a time, but when seen they were continually eating. They were also picking insects from the crevices of the bark. The Rose-breasted Grosbeaks were eating plant lice and the gall insects from the galls on the oak leaves. The Red-eyed Vireos were eating plant lice, forest tent caterpillars, cankerworms, and other larvæ that I could not determine. From one oak tree the Red-eyed Vireos took ninety-two forest tent caterpillars in an hour. The Purple Finches were eating plant lice in the tops of the birches, but were so wild that their habits could not be observed. . . . A Red-winged Blackbird perched for a moment in the birches, and ate the plant lice while there. A pair of Catbirds have a nest near the grove, and they would both perch in the branches and pick the plant lice for an hour at a time. The Tanagers confined themselves almost wholly to the oaks, taking larva from the leaves. One took seven forest tent caterpillars from a mass on a branch. The Redstarts were equally as industrious as the Yellow-throats, ${ }^{1}$ but they did not con-

- See Mr. Mosher's report regarding these Yellow-throats, on p. 62. 
fine themselves to any one tree, and would dart about in such a manner, taking insects on the wing, flies, moths, winged plant lice, etc., that one could not keep count of what they ate. A male Chewink came to a tent caterpillars' nest that was on a wild cherry, and he was eating the caterpillars. When I made a movement to enable me to see more plainly, he flew away.

MaX 31, 1898. - I went to Rural Avenue, Medford. During the first hour the birds were very plentiful, but by 9 A.M. there were but few there. There was a family of Crows in the place all the time, but they were in the tops of the pine trees, therefore I could not see what they were feeding their young, but could hear their feeding cries very frequently. A Blue Jay was carrying food to her young. I got near enough to see her take two gipsy larvæ and carry them away. A Wood Thrash was singing in the bushes near the water. I got near enough to see him picking jarvæ from the leaves. He took five gipsy larva alter I came in sight; the cracking of a twig caused him to fly away. The Catbird was present, as usual, first eating larvæ (both gipsy and other species), then perching on the top of the highest bush and singing with all its might, now and then throwing in a fairly good imitation of the "caw" of the Crow. A new bird now made his appearance. He was of a bluish color, and was seen picking plant lice before I was certain of his identity. He then took a short flight to the oak sprouts, revealing his yellow back. This Parula Warbler ate three small gipsy caterpillars and four or five green larvæ, and then flew out of sight. A Rose-breasted Grosbeak ate plant lice, gipsy larvæ, gall insects, and took some kermes from a branch, cracking them with his bill and dropping the shells to the ground. A Yellow-billed Cuckoo came, and ate forty-one gipsy larvæ in about fifteen minutes; she then flew away. On my way out of the woods I stopped at the edge of the open to observe what birds were feeding on plant lice on the birch trees. Some Indigo Birds were busy eating them, and while I was looking I saw a Robin alight in the birches and pick up plant lice.

JuNe 1, 1898. - I went to the park near the Malden-Stoneham line, and took up my position in a grove of small white birches and some wild cherry trees with tent caterpillar nests on them. A Brown 'Thrush came to the cherry trees and took five tent caterpillars from the outside of the nest, and ate them. Several Chestnut-sided Warblers came to the birches and were picking plant lice all the time they were there, also larvæ of different kinds. They were coming and going all the time I was in the place. A Chipping Sparrow remained in the birches for sixteen minutes, and ate plant. lice and green larvæ during that time. A Flicker alighted on an oak tree and took two forest tent caterpillars from the trunk. He also took insects from the crevices of the bark. A Wood Pewee alighted on a dead branch, and took moths, flies, and plant lice on the wing. An Oriole came four times, and each time took a tent caterpillar from the nest to his young. An Indigo Bird came 
twice and ate plant lice and some small larva. Three Red-eyed Vireos came to the oak trees and ate the larvic from the leaves and the plant lice from the birch leaves.

June 3, 1898. - I went to the park near the boulevard. Saw an Oriole take four forest tent caterpillars, one at a time, and carry them away to its young. A Yellow Warbler was eating plant lice for fifteen minutes, although it rained quite hard. A pair of Oven-birds were feeding on plant lice for a long time. Several Chestnut-sided Warblers came to the birch trees and ate plant lice, then went to the oaks and poplars and took larve of different kinds and ate them. A Catbird was picking larvæ from the under sides of the leaves; most of them were green larvæ. Two Chewinks (Towhees) were scratching in the leaves, but I could not see what they got from the ground. They took some forest tent caterpillars from the trunks of the oaks. A Maryland Yellow-throat came out of the thick brush and ate plant lice for about ten minutes. A Rose-breasted Grosbeak was busy in the oak trees. He came to the birches for a moment and ate plant lice. A Red-eyed Vireo ate two forest tent caterpillars, taking them from the under side of a limb. The Indigo Bird could not be easily observed; he was evidently eating plant lice. The Brown Thrush could not be seen distinctly; he was searching in the fallen leaves. A Black-billed Cuckoo had a nest near, and carried forest tent caterpillars to its mate.

June 6, 1898. - The Red-eyed Vireos seem to be feeding on more gipsy larvæ than the other birds that come near enough to be observed. They will take a larva from the under side of a leaf or a crevice in the bark, and, putting one foot on the larva, will proceed to pull it to pieces, eating the softer parts and dropping the hairy parts. An Orenbird came to the colony and ate four of the small larva, picking them from the under sides of the leaves. I saw a Black and White Warbler carrying cankerworms to its young; it would take two and sometimes three at a time. A Baltimore Oriole was taking tent caterpillars to its young, taking those that were on the outside of the nest. A male Bobolink came to the birch trees and remained about twenty minutes, picking plant lice. The Field Sparrows and Indigo Birds were also busy feeding on plant lice. A Wood Thrush took the cankerworms away to its young. A Chewink took two tent caterpillars from a bush and ate them. A Scarlet Tanager flew from the oaks into the apple tree and ate cankerworms. The Chestnut-sided Warblers were the most plentiful of any of the birds, and were eating plant lice almost constantly.

June 8, 1898. - I went to the park, Stoneham, near Spot Pond, to observe the feeding habits of birds. A pair of Brown Thrushes were feeding their young; they averaged going to the nest one every five minutes, and carried several larvæ each time. A Kingbird caught a Buprestid beetle and ate it. I had made an attempt at catching it when it was on the trunk of the apple tree; it flew, and was snapped up by the Kingbird. This orchard is infested with cankerworms. It is situ- 
ated near the woods, in fact, there are woods on both sides, and no houses near. The following birds were seen in the orchard during the forenoon: Crow, Blue Jay, Red-winged Blackbird, Yellow Warbler, Chestnut-sided Warbler, Black and White Warbler, Maryland Yellowthroat, Bobolink, Indigo Bird, Rose-breasted Grosbeak, Goldfinch, Chipping Sparrow, Song Sparrow, Kingbird, Brown 'Thrush, Catbird, Robin, Baltimore Oriole, Scarlet Tanager, and Black-billed Cuckoo. A Black-billed Cuckoo came to the orchard and ate twenty-seven cankerworms in two minutes; he remained over half an hour, and part of the time was eating much faster than when I counted. A Grosbeak came and ate both cankerworms and birch aphids. A pair of Song Sparrows were carrying cankerworms to their young. A male Oriole came a long distance to the orchard, for when he had got some cankerworms in his bill he would start across the woods in a straight line, flying out of sight ; lie would come back in about half an hour. The Red-winged Blackbirds came to the orchard from a swamp nearly half a mile away, and ate the cankerworms and carried them to their young. A Catbird came occasionally and ate cankerworms, then would go and perch in the alders beneath which his mate was sitting on her eggs, and sing with all his might. I saw a Chimney Swift taking plant lice on the wing.

On July 9, 1898, Mr. Bailey made some interesting early morning notes on birds feeding on the gipsy moth. These are quoted below:-

I left Malden for Medford at 3.30 A.M., and went to Forest Street, Medford. I arrived there at 4 A.M., and there were some birds in the place then. The first bird that I saw eating the gipsy caterpillars was the Red-winged Blackbird. The Blackbirds came in almost at the same time that I arrived, and they stayed until 6 o'clock, then left and did not come back. I could not tell how many caterpillars were eaten by these birds, but they took them very often, both the large and the small ones. I saw them take no pupæ. All the caterpillars were taken from the tops of the trees. I did not see the birds come near the ground. There were seven Baltimore Orioles, and they were eating caterpillars all the time from 4.30 until 8 ; then they stopped eating, but did not go outside the woods. As nearly as I could judge, the Orioles did not pick out small caterpillars, but took as large ones as there were. I did not see them take any pupæ. The Black-billed and Yellow-billed Cuckoos were there all the time that I was. They did not take the caterpillars as often as did the other birds. 'Those that they did take were picked from the trunk of the tree or from the ground; they went very little to the tops of the trees. Pupre were eaten by these birds. I could get within ten feet of them very often. The Blackbirds and Orioles ate more caterpillars than the other birds. There was one Catbird in the woods; it 
came about the same time as the Blackbirds, but I saw it for only a short time; it took caterpillars and pupæ. There were four Red-eyed Vireos, but I saw them take only one caterpillar, and they were in the place all the time that I was. There were also six Downy Woodpeckers, but I did not see them take any caterpillars or pupæ. A brood of Chickadees was there all the time, and they took caterpillars and pupæ of the gipsy moth and some kind of a green caterpillar. They took all their food from near the ground, and would pick the pupæ and caterpillars open before eating them. There was a nest of the American Redstart, and the tree had been stripped of leaves by the caterpillars. There were four young birds in the nest. I saw the old birds take but one very small gipsy moth caterpillar to the young, but they would pick the large ones off the nest and drop them to the ground very often." There were no pupæ near the nest that I could see. Two Robins came to the colony very often to get food for their young. I could not tell how many they took with them each time, but should judge from the cluster of caterpillars in the bill that there were as many as six. The Robins took all the caterpillars from near the ground or from the ground. I did not look for the Robins' nest, but could see the birds go one hundred and twenty-five yards to a large maple tree, and I think the nest was in this tree. One Blue Jay came, but stayed only a very short time. It took two caterpillars, but, as they were in the tops of trees, I was not sure that they were gipsy caterpillars. A brood of Crows (four young and two old birds) came, and stayed till I moved, and then left and did not come back. They came at 8 o'clock and stayed until almost 9 . They were all in the trees directly over me for a long time; at times they were within ten feet of me. They would go to a cluster of pupæ and caterpillars and eat some, but drop more than they ate. I think they took more pupæ than caterpillars, but took a large number of caterpillars. The young birds took many more than the old ones. The old birds left the place for a short time, but came back. I think the six Crows took two hundred pupæ while in sight. Some of the time they took them as fast as a hen would pick up corn.

After this time most of the smaller birds neglected the hairy caterpillars to attack the cankerworms, which were then becoming very prominent. When the cankerworms had disappeared the larger species continued to feed on the gipsy moth so long as it could be obtained.

These observations were begun rather late in the season, and the records kept by the observers were not very full, on account of the pressure of other duties, which also limited

\footnotetext{
1 Redstarts are among the most useful birds that eat the smaller caterpillars, but at this season the larva were nearly all too large for the bird to manage.
} 
the time that could be spared for this kind of work. In 1899, however, Mr. Mosher was detailed for this work early in the season, and instructed to spend such time daily as was necessary to observe the feeding of birds on these insects. He was requested also to make full notes each day. As many of these field notes as the available space will permit are given below. Many of the observations were made in the morning, but not during the earlier morning hours, when birds feed most actively. The weather being mild, on the 24th of April a few brown-tail moth larvæ that had wintered on the trees began to crawl out.

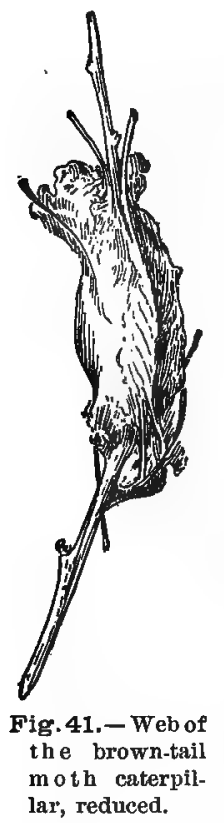

APRIL 24. - In Cambridge, near Fresh Pond, I saw a large flock of Red-winged Blackbirds foraging on a newly plowed field, and from a large pile of dressing they were taking flies. From a pear tree near by three of them took brown-tail moth larvæ from the opening buds. They were in the tree seventeen minutes, and were eating all the time.

APRIL 26. - In Revere, near the Malden line, I found a pear tree with a brown-tail moth web on it. A pair of Crow Blackbirds came, and remained about forty-five minutes in that tree and the one adjoining. They plumed their feathers for a while, then began looking over the tree for food. They alighted several times on the branch that was most infested, and picked the larvæ from the buds and from the crevices of the bark.

A little later the tent caterpillars began hatching, under the influence of the warm spring sun, and the birds could find a few of them.

APrIL 27. - In Stoneham, off Forest Street, I observed the birds feeding on tent caterpillars. A Black and White Warbler came three different times, and took the small caterpillars from the buds. The Chickadees visited the bush, and took a few caterpillars. None seemed to take them from the web. The May flies were unusually plentiful, and the Least Flycatchers were feeding on them.

April 28. - On Mr. Dutton's estate, Malden, I saw Black and White Warblers feeding freely on tent caterpillars, and also Chickadees 
feeding on them. A pair of Robins were building near by. When the female was arranging the materials of the nest the male was searching for food. When she started for another load he would fly after her. He flew to a small wild cherry tree and picked a few of the young tent larvæ from the branch just above the web.

MaY 1. - Near the Fells, Malden. The White-throated Sparrows were quite plentiful all day. I observed one come from the thick brush along the edge of the swamp, and forage along in the lower trees. It went to a tent caterpillars' web, and ate at least eight of them. Most of these Sparrows were foraging in the low bushes and on the ground.

MaY 2. - A Field Sparrow took a number of tent caterpillars from a branch. The Field Sparrows were very plentiful, but I could not often get near enough to see what they were eating. A Chewink took some of the tent caterpillars from the branch that I had placed in the thicket to see if they would eat them.

MaY 3. - In Malden. I saw a Robin go to a tree with many browntail larvæ on it, and eat several of them. The day was very cold, and the larvæ were clustered together on the branches. The bird picked into the mass five times, and must have taken several each time.

MAY 4.- In Stoneham. Six Cedar Waxwings came to an apple tree on which was a tent caterpillars' web, and two of them picked the larva from the branches just above the web. Most of the time they were picking the small cankerworms. A Brown Thrush came to the wild eherry trees, and, after singing for a short time, ate a great many tent caterpillars, then flew to the thick bushes and began searching in the dead leaves.

MaY 5.- An Oriole came to the small wild cherry tree and ate several tent caterpillars from the outside of the web, then tore it open and ate out nearly all that were in it. This was a large web when I first saw it; now there are but few of the caterpillars left, - the birds and bugs have nearly cleaned them out. A Redstart came to another small tree and took out three of the tent caterpillars from the twigs.

MaY 6.- A Rose-breasted Grosbeak went to an apple tree with a tent caterpillars' web on it, and took at least two of the larvæ and probably took away more.

MAY 9. - I observed a number of Golden-winged Warblers working near the cherry trees. Finally one went to the larger one, and after working in it for a time went to the branch that had the web on it and ate fourteen of the tent caterpillars. A male Nashville Warbler came to the tree and took a few of the tent caterpillars, but he was so shy I could not make out distinctly how many he ate.

MAY 10. - I located a male Red-winged Blackbird and two females that were building in a small swamp hole. They were feeding, every time I went past, in a small place where there were no bushes. There 
were small tufts of grass growing out of the water. I took a branch from an apple tree, put twenty-four tent caterpillars on it, and stuck it up in the mud on their feeding grounds. I went away and was gone twenty-five minutes, and when I came back the male was looking the branch over. On examining the branch, $\mathbf{I}$ found but two caterpillars left, They had crawled to the under side of the branch, and were well concealed by leaves. At the apple tree with the brown-tail larvæ there were three species of birds seen to feed: Oriole, Robin, and Black and White Warbler. The Oriole came three times during the afternoon, and took fourteen the first time in six minutes, twenty-seven the second time in eight minutes, and ten the last time in three minutes. The Robin came but once, and took over thirty and stayed but little over four minutes. The Black and White Warbler took twelve while in sight, but was on the opposite side of the trunk and branches at least half the time, and stayed nine minutes. The first took most of his from the leaves, the second from the upper sides of the horizontal branches, and the last from the bark crevices of the upright trunk.

MAY 11. - A pair of Blue Jays came to the apple tree and took forty-seven of the brown-tail larvæ. They were in the tree eighteen minutes. A Robin came and picked off four brown-tail larvæ and ate then, then flew away. A Black and White Warbler ate fifteen browntail larvæ; stayed about ten minutes. A pair of Chestnut-sided Warblers came to the apple trees and ate cankerworms for about twenty minutes. They must hare eaten a great many, as they were pecking all the time, but were behind the leaves a part of the time, so I could not see the number. A Parula Warbler also came to the tree and ate the cankerworms, then went to the wild cherry tree and ate five tent caterpillars. I counted seven Yellow Warblers at one time in two apple trees, and they were all eating cankerworms. One of them went to the cherry tree and ate three tent caterpillars that were on the outside of the web. Several Golden-winged Warblers came to the orchard and ate cankerworms, but they were very shy. A Nashville Warbler ate eight of the tent caterpillars, and stajed only three minutes. The Yellow-throats were in the apple trees nearly all the forenoon, and were busy most of the time eating the small cankerworms. I did not see them trouble the tent caterpillars.

Cankerworms and gipsy moth caterpillars were now hatching in some numbers, and the birds could take their choice.

May 12. - There was a large flight of Warblers this morning. On first arriving at the orchard I found the trees literally alive with them. There were Golden-winged, Yellow, Chestnut-sided, Parula, Black and White, Nashville, Yellow-throated, and others that I was not sure of. They would stop but a moment in any one place, but were chasing each other from tree to tree, and were all singing in chorus. I saw all of 
the above-mentioned eating cankerworms, but could not keep any one individual in sight more than a few seconds at a time. By 7.45 most of them had left the orchard. I saw a Least Flycatcher alight on a branch of an apple tree near me, and when it saw a cankerworm more, it would fly and snap it up from the leaf. I saw it take nine in this way before it flew away. In the swamp a Yellow Warbler came to the willows, and, after foraging in the top for a time, alighted on one of the shoots that was infested with the gipsy moth, took fifteen of the larvæ in less than five minutes, then flew out of sight. A Nashville Warbler also came and remained among the willows for about half an hour, and took forty-two gipsy moth larræ while in sight, but must have taken away many more, for he was not in sight all the time. A Rosebreasted Grosbeak came to the apple tree and ate

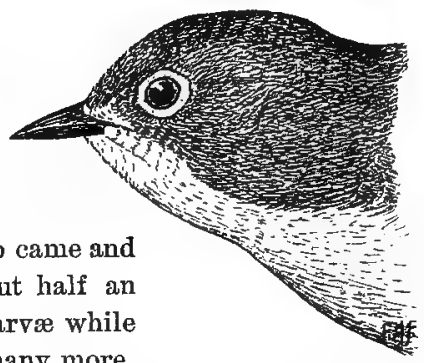

Fig. 42. - Nashville Warbler, natural size. fifty-seven brown-tail larræ. He was in the tree about twenty minutes, and was singing and eating all the time. He probably ate more than I was sure of.

MaY 15. - An Oriole ate fifteen of the tent caterpillars from the web at one sitting, and nine in about twenty minutes after. 'The Robin was still hanging around the brown-tail moth tree, but I did not see her eat any. A Chestnut-sided Warbler came and stayed about twelve minutes, and I counted twenty-eight brown-tails that he ate.

MAY 16. - I found that one large tent that was full of caterpillars a week ago contained only three to-day, and a large part of the web had been carried away by the birds for nesting material. Just after I had

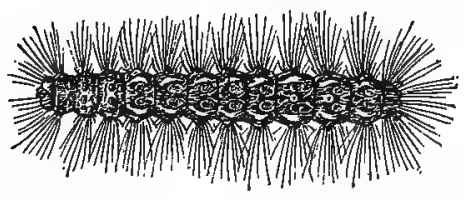

Fig. 43. - Caterpillar of the brown-tail moth. opened the web an Oriole flew to it and took one of the remaining caterpillars. The Orioles are eating immense numbers of cankerworms. The row of apple trees nearest the woods now show but little signs of the presence of cankerworms. A pair of Scarlet Tanagers came to the brown-tail moth tree. The male stayed seventeen minutes and the female ten minutes. The male ate at least fortyfour larve, and probably many more. They took only those that were on the leaves, and they examined all leaves that were curled up, and took from them all the larvæ they contained. A Wood Thrush came to the tree just at night, and perched and sang for nearly half an hour. Occasionally he would move along the branch and pick a brown-tail larva or two. The Black and White Warblers came again, stopped a moment, taking two and three each, then flew away. 
MaY 17. - A male Yellow Warbler came to the brown-tail moth tree and began eating the larvæ. He had eaten four when a floek of English Sparrows flew into the tree and drove him out, one of them chasing him across the boulevard. The remaining five Sparrows pecked a few times at the larve, then they flew to the street below. A Song Sparrow came to the tree in the early morning.and perched a while and sang, then he went to the ground and foraged for about twenty minutes, searching in the grass, then among the leaves. I saw him take two small green grasshoppers. He then went to the tree and picked five brown-tail larvæ from the branch, then flew away. A pair of Wood Thrushes came to the orchard and stayed thirteen minutes. 'They were chasing each other through the trees most of the time, but $\mathrm{I}$ saw one of them take several cankerworms from the leaves. Finally they were chased out by a Kingbird that is nesting near by. A Yellow-throated Vireo came to one of the apple trees that has a tent caterpillars' web on it, took two of the caterpillars, and, after hammering them well on the branch, swallowed them whole. He then went to another tree and began eating cankerworms.

The number of gipsy moth caterpillars increased from this time on, as the eggs hidden away in cool and shady places hatched out; the number of birds seen feeding on them also increased.

M AY $_{\text {A }}$ 18. - Malden. In the deer park, just back of Mr. Dutton's, I found the gipsy moth larvæ quite plentiful. A Black and White Warbler came to the infested trees and hopped along on the trunk of a tree near me, picking at the bark, and finally hopped to one of the branches with larvæ on the leaves, took eight gipsy larvæ in a very short time, then flew over the ledge out of sight. A pair of Golden-winged Warblers were busy for a long time in the thick bushes. They came to the small infested trees and picked the larvæ from the leaves. Saw them take twelve gipsy larvæ, and they must have taken more. Yellow Warblers were constantly passing through the trees. They would alight for a moment and pick three or four gipsy larræ, then fly on. I should think there were as many as twenty-five that passed through. A single Chestnut-sided Warbler came to the trees and stayed fourteen minutes, and took twenty-two of the gipsy larvæ that I saw, and many besides, I presume. He also took some kind of green larre from the leaves. He would pick a few, and then sing. A pair of Oven-birds were apparently building near. They were chasing each other through the trees every few minutes, and would alight on the low bushes and pick the larve from the leaves. They would stay but a moment at a time. A Brown Thrasher, after scratching in the leaves in the bushes out of sight for a while, came out into the opening, hopped along under the small cherry 
trees, and took two of the tent caterpillars from a low branch. She would hammer them on the ground for quite a time, then swallow them whole. When she had swallowed the second one she saw me, and flew away.

MAX 19. - A pair of Redstarts were in the orchard most of the forenoon, and were apparently eating cankerworms most of the time. 'They would take those that were spinning down by threads. In the afternoon I saw one come to the apple tree and remain for about five minutes, and take eleven brown-tail larvæ. A pair of Tanagers came to the apple tree and remained four minutes, and one took nine and the other sixteen brown-tail larvæ. A Black and White Warbler came to the apple tree and remained about ten minutes, and took twenty-eight brown-tail larvie, that I saw, from the leaves and trunks. He probably took many more. A pair of Yellow

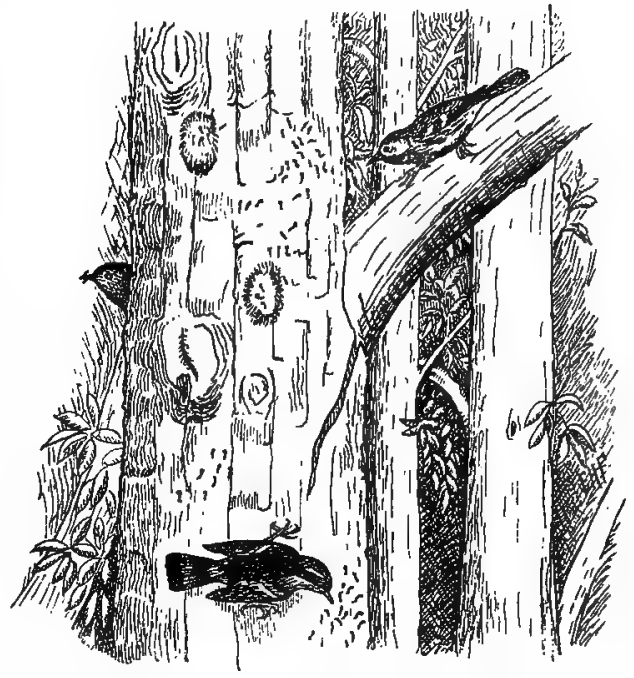

Fig. 44. - Warblers feeding on young caterpillars of the gipsy moth.

Warblers came to the tree, and each took a few, but they were so active $I$ could keep them in sight but a moment at a time.

MaY 20. - In the swamp off Broadway, Everett, the Warblerș were very plentiful in the morning, and were present in quite large numbers until about 10 o'clock. Most of them were in the tops of the trees, and it was a difficult thing to see what they were eating. The Yellow Warblers, Yellow-throats, and Redstarts were feeding on the trunks of the trees. There are very few limbs on the trees for a distance of fifteen or twenty feet from the ground. The Warblers would cling to the bark and pick the gipsy moth larve from the crevices of the bark. Their habits were different from those of a Creeper. Instead of clinging to the bark with the body lengthwise of the trunk, and supported by the tail, their bodies were crosswise of the trunk, and they depended wholly on their feet to hold and balance them. They were hopping round and round the trunks so that it was impossible to count the number of larve eaten by any one Warbler, or to keep him in sight any length of time, on account of his swift movements. There were a great many Crow Blackbirds that were nesting in the erergreens in Woodlawn Cem- 
etery. They were also eating the gipsy larve. There was only one that I conld get near enough to see what and how many he was eating. $\mathrm{He}$, in a little over three minutes, ate forty larvæe that I was sure of. 'Two pairs of Wilson's Thrushes were near me nearly all the forenoon. They did not stay in the trees much of the time. I saw one alight on a small sprout on a willow and eat five gipsy moth larve, then fly to the ground. They were feeding almost wholly on the hummocks among the bushes and grass.

MaY 22. - A pair of Chickadees came to the apple tree and stayed seven minutes. One ate fifteen and the other twenty-one brown-tail larve. They must have eaten more than twice that number, for they were not so we could see them nearly all of the time, but we could see that they were busy. Mr. Kirkland observed one, and I the other. A Yellow-throated Vireo came to the tree and ate three brown-tail larvæ as he passed through:

MaY 23. - A Robin was in the apple tree when I got there, but flew away. Soon she came back and foraged on the ground for a while, then went to the apple tree and to a fork near the top where the browntail larvæ were congregated in great numbers, picked into the mass and swallowed them. I saw her take eight mouthfuls. The next bird to come was a Red-eyed Vireo. He confined himself to the branches where the larvæ were comparatively scarce, and went about picking them from the leaves. I saw him take forty-three brown-tails in ten minutes. He stayed longer than that, but changed to the opposite side of the tree, so I could not see him. He was finally driven out by an English Sparrow. A Yellow Warbler passed through the tree and stopped for a moment. I saw him take six brown-tail larvæ. The next visitor was a Blue Jay. He came in a very noisy manner, and perched on one of the upper branches.. He looked suspiciously at me for a few seconds, then went to feeding on the larva. He hopped from one branch to another, and took them from the forks where they were clustered. I could not count how many he ate, but there were at least thirty brown-tails. A female Chestnut-sided Warbler came into the tree and ate eleven brown-tails, when she was followed by the male. He would eat one or two, then chase his mate through the apple tree and the adjoining trees. They were in and out of the tree, back and forth, for nearly twenty minutes. A Chipping Sparrow came to one of the upper branches and took a larva, fiew to the ledge near me, hammered it, and ate it, swallowing it whole. She then flew back, took another, flew to a lower branch with it, and ate it in the same way. Then she flew away.

MAY 24. - A Black-billed Cuckoo came to the apple tree that has a tent caterpillars' nest in it, pulled open the web and took two caterpillars from it, when he was seen by a lingbird and chased out. The Kingbird went to the nest and pulled ont a mouthful of web and took it away to its nest. A male Oriole came soon afterward, and took three 



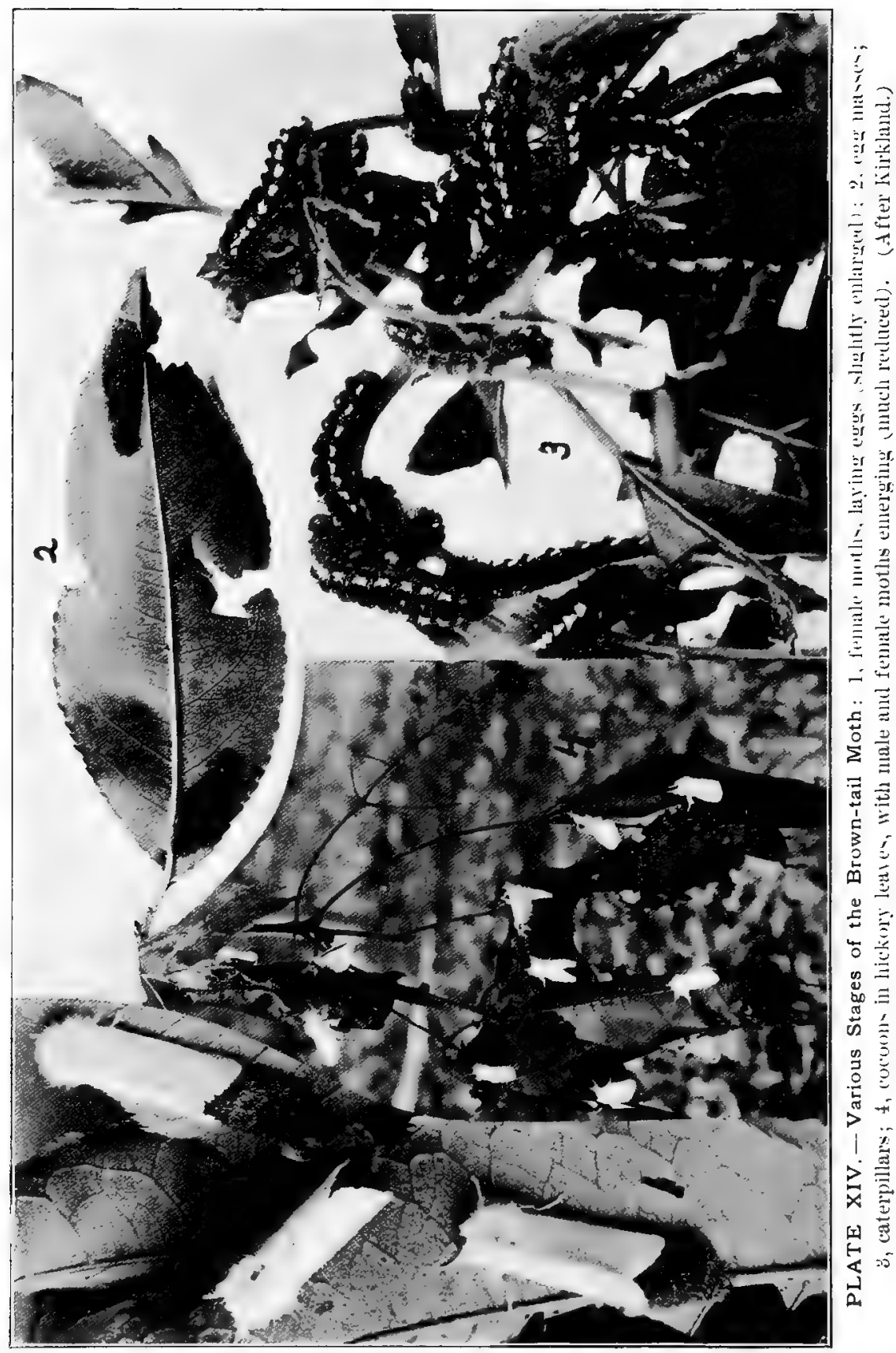


caterpillars from the web and ate them. There were two Crows in the brown-tail moth tree when I came in sight of it. I saw one of them peck twice at the branch, and swallow something. In attempting to get nearer to them I made a noise, and frightened them away. Could find nothing on the branch they were on except brown-tail moths, which they were eating. The next visitor was an Oriole, who came to the tree and ate thirty-four larve in six minutes, then flew away. He hammered each larva once or twice before swallowing it. 'The next visitor was a Wilson's Thrush. He first perched on a small oak on the top of the ledge, then hopped to the dry leaves, and seemed to be searching among them for fool for about five minutes. Then he flew to the tree and took a larva while in sight and swallowed it. He probably took more while in the tree. He was in the tree four minutes. He then flew down and began searching in the grass. A Red-eyed Vireo perched in the oaks and searched for about nine minutes. I saw him take over fifty larvæ of various kinds from the leaves, some of which were leaf-rollers. I could see him picking insects from the under sides of the leaves. 'To accomplish this he would grasp the petiole with his feet, and hang, back down, and pick the larvæ off. IIe then went to the apple tree and took twenty-nine larvæ (brown-tail) before flying across the boulevard. He was in the apple tree about six minutes. He beat nearly every one on the branch before eating it.

From this and later experiences it seems that many birds have learned to eat the larvæ of the brown-tail moth even when the caterpillars reach an age when the detachable hairs are dangerous. Probably by shaking off these hairs the birds render the larve eatable, and even fit to feed to their young.

MAY 25. - A Golden-winged Warbler came to the oak trees next the boulevard, and sang for nearly five minutes in a low, wiry voice. He then began searching for food. Frequently I would see him take some small green larra from the leaves, but could not tell what kind it was. He then flew to the apple tree and picked eleven brown-tail larvæ from the leaves and swallowed them, after lammering them on the limbs. He probably took more while feeding in the tree, about eight minutes. Ile then flew over the ledge. A pair of Orioles were back and forth over the ledge, and would occasionally stop and eat the brown-tail larvæ for a moment or two, but did not make a long stay while I was there. They had probably got their fill earlier in the day. An Indigo Bird lit in the top of one of the oak trees for a moment, then flew to the apple tree and ate six of the brown-tail larvæ, and was then chased out by the English Sparrows. 'Three of the Sparrows perched in the tree and picked off two or three brown-tail larvæ apiece, then flew to the boulevard. A pair of Scarlet Tanagers perched for about 
twelve minutes in the apple tree, and were busy all the time eating brown-tail larvæ. I could see but one distinctly, and he ate forty-three brown-tails that I saw, and probably a few more, but not many.

MaY 26. - I watched a Maryland Yellow-throat on the low willow sprouts, and saw him pick off fifty-two gipsy moth larvæ before fiying away. I saw Warblers flying in and out among the trees, taking one here and another there all the time I was there, but could not watch any one individual for any length of time. The Yellow Warblers were taking them from the trunks as well as the sprouts, and also in the tops of the tall trees. A pair came to a bunch of sprouts near me, and I counted thirty-five gipsy larvæ that they took in the two minutes they were there. A pair of English Sparrows have a nest in a hollow tree in the grove, and they are almost continually chasing the Warblers and other birds that come near them; but I did not see them feed any in the grove, - they go out to the streets and dooryards. The Redstarts were also eating large numbers of the larvæ. One that I got near enough to observe ate thirty-one gipsy larvæ before he left the clump of willows. At the brown-tail moth tree a Black-billed Cuckoo came, and, going to a branch where the larva were very numerous, began eating them greedily. He had taken four mouthfuls when a Robin, that has a nest in a pine tree near, chased him out. A Yellow-throated Vireo came to the tree and ate fourteen brown-tails in less than five minutes. He probably ate many more, as he could not be distinctly seen nearly all of the time. A Red-eyed Vireo came to the opposite side of the tree and ate several larva, but his doings could not be clearly seen. A male Indigo Bird perched on the topmost branch of the apple tree and sang for several minutes, then hopped down a branch or two and picked the larvæ from the branch. I saw him eat sixteen of them (brown-tails) after he had hammered them on the branch.

MAY 27. - A Yellow-billed Cuckoo came to a willow tree near me and ate forty-seven forest tent caterpillars in six minutes, then flew to a small maple tree and sat on a branch for nearly ten minutes and plumed his feathers, then returned to the willow and ate sixteen more, and flew away. He would take the caterpillar and hammer it once or twice, then swallow it. A Blue Jay came, and took two of the forest tent caterpillars and flew away with them. A male Redstart ate three forest tent caterpillars. He would take one, fly to a neighboring branch, hammer it well, swallow it, then go back for another. A male Oriole came to the tree three times during the forenoon, and fecl on the forest tent caterpillars. The first time he came he stayed four minutes, and took eighteen caterpillars; the second time he stayed seven minutes, and took twenty-six larvæ; and the last time he stayed about ten minutes, and ate fourteen larvs. At the brown-tail moth tree there were quite a number of bircls feeding in the surrounding trees, but not nearly all the species visited the apple tree. A Red-eyed Vireo came to the tree and would take the brown-tail moth larvæ and hammer them a 
few minutes, then pull the larger ones to pieces, and swallow them; the smaller ones she would swallow whole. I saw her eat fifteen in the eight minutes she was in the tree. A Catbird came to the tree, picked four brown-tail larve from the branch, and ate them, and would probably have eaten more, but a Robin chased her out of the grove toward the boulevard. She would give the larvæ a knock or two, then swallow them.

MAY 29. - A pair of Blue Jays were very busy carrying food to their young. They came twenty-four times to a willow tree, with forest tent caterpillars on it, during the three hours I was there, and took at least two or three larva each time. Once they went to some hazel bushes near by, where a Chestnut-sided Warbler was sitting, and would probably have taken the eggs, if I had not interfered. A White-breasted Nuthatch came to a willow and climbed around the trunk for a time, when she found two forest tent caterpillars. She ate one after hammering it for a moment, but passed over the other. I saw her pass over two others in the same way, apparently preferring to pick the smaller insects from the bark. These were so small that I could not see what they were. A Wood Thrush took two of the forest tent caterpillars and ate them, and later in the day I saw a Wood Thrush go to the apple tree and eat five of the brown-tail larvæ, and then fly away. I saw a Flicker alight on an ant hill and make a hole in the hill with her bill, and pick up the ants. She was busy in this way for nearly fifteen minutes, and must have eaten large numbers of them. I found in the thick woods a few oak trees that were badly infested with forest tent caterpillars, and there were quite a number of them on the low bushes on the ground. A Chewink came to the brush, scratched in the leaves and pulled out large grubs, but $I$ could not make sure what they were. She then hopped about and took six of the forest tent caterpillars, beat them on the ground, and ate them. An unwise move on my part frightened her away. A Black-billed Cuckoo came and gorged himself. He ate twenty-nine forest tent caterpillars at first, then rested between ten and fifteen minutes, then ate fourteen more. He would shake and hammer one on the branch, then swallow it, and pick up another. A Nashville Warbler came to the apple tree, picked a brown-tail larva from the leaves, beat and shook it for about thirty seconds, and swallowed it; then took another, hammered it in the same way, and swallowed it. He then flew to the low shrubs. A Robiu was passing to and fro, but I did not see her eat any of the brown-tails; she seemed to eat nothing but what she took from the ground. The angleworms were plentiful that day, and she had no appetite for anything else.

MaY 31. - An Indigo Bird came to the brown-tail moth tree, took a brown-tail larva from the leaves, and flew to a low branch, shook and hammered the larva, and ate it. He then went back, took another, and Hew with it to a neighboring oak, ate the larva, and flew away. A Warbling Vireo sung and fed in the oak trees for nearly thirty minutes. 
He then went to the apple tree and took a brown-tail moth larva, picked it to pieces, and swallowed it. He then took another, and was proceeding in the same way, when he was driven out by the English Sparrow, and flew up over the ledge out of sight. A pair of Red-eyed Vireos were in the oaks near the apple tree for a long time, foraging. They would hold on to the petiole of the leaf, hang with their heads down, and take insects from the under sides of the leaves. One of them went to the apple tree, took a brown-tail larva from the leaves, beat it on the branch, and swallowed it. His mate then flew across the street, and he followed. A Yellow-throated Vireo went to a small oak tree and took three gipsy moth larvæ that were resting on a burlap band. She scarcely stopped to shake them at all, but swallowed them at once. A pair of Chestnutsided Warblers were busy, taking cankerworms to their young. They averaged one each, every three minutes for nearly thirty minutes. In the mean time they themselves ate quite a number. The young could not have been more than a day old. A Yellow Warbler came to an oak tree on the edge of the orchard and took two forest tent caterpillars, then flew to the thick apple trees and fed on cankerworms. Four Waxwings visited the orchard for a few minutes and ate a few cankerworms, but they seemed to be picking into the blossoms of the young fruit more than anything else: A Redstart took a forest tent caterpillar from a branch, hammered it, and ate it. He then flew out and caught a small moth, then flew into the thick woods. A female Black and White Warbler took a forest tent caterpillar from the trunk of an oak, flew with it to the ground, hammered it until she broke it in pieces, and then swallowed the pieces.

JUNE 1. - An English Sparrow caime to the apple tree, took a browntail moth larva, and, after hammering it for a moment, flew away with it to her young. A Field Sparrow came to the open space around the apple tree, foraged among the bushes for a few moments, then perched in a small oak and sang. He then flew to the apple tree, took a brown-tail larva, flew to the ground with it, and ate it. He then flew to the open fields across Highland Avenue. A pair of Orioles came to the tree, and the male ate sixteen and the female twenty-five brown-tails. They were in the tree seven minutes. A Yellow-billed Cuckoo came to the tree and stayed about eighteen minutes, including a rest he took. He ate thirty-four brown-tails, then rested seven minutes, and ate twelve more. He would give them a couple of shakes, and swallow them. 'The Robin coming in spied him, and chased him out. A Rose-breasted Grosbeak visited a tree for a moment and took at least five brown-tail larvæ.

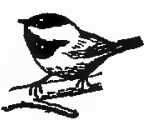
He probably took more, as he was not in sight all the time. A pair of Chickadees also visited the tree; they stayed about five minutes. One ate nineteen brown-tail larvæ, and the other ate eight that I saw; he probably ate many more, as I could not watch him all the time, 
being occupied with the other birl. A Yellow-throated Vireo came through the place, visited the tree for a moment, and took two larvae, then passed on. A nale Golden-winged Warbler ate two forest tent caterpillars, after hammering them a long time until he got them in pieces. A female Black and White Warbler took a forest tent caterpillar from the trunk of a tree near me, flew to the ground and beat it until she got it in pieces, when she took the inside parts and flew away to her young, leaving the other parts on the ground; she did not come back for them. A Red-eyed Vireo took a forest tent caterpillar from a branch and hammered it, then he pulled it to pieces and ate it all. The next one he treated in the same way, except that he ate only the inside, and dropped the skin and head to the ground. A Chestnutsided Warbler came to an oak tree infested with the gipsy larve and took six in a few seconds, then flew to the high trees. An Oven-bird came to the same tree and took eight gipsy larvæ from the leaves, then flew away. A Yellow Warbler ate thirty-three cankerworms in a little over six minutes. A Song Sparrow took two of the gipsy larva and carried them away to her young.

Burlap bands were placed around the trees as a shelter or trap for the gipsy caterpillars. Jays and Orioles soon learned where to find them when hidden there. An interesting note on another bird follows :-

JuLY 5. - I saw a Red-breasted Nuthatch take gipsy larva from under the burlaps and eat them. When first seen, it was on the trunk of a pine tree just below the burlap. The bird examined the burlap all around the tree, then flew to the next and examined it in the same way, and found nothing. On the fourth tree examined it found a small, smooth-skinned larva, just under the burlap, and ate it; then it found a medium-sized gipsy larva, and, beating it a few times on the trunk, swallowed it. It took another on the same tree. On the next tree it took another, and, after beating it more than the first, started to fly away with it, when a Wood Pewee chased it away.

As the season advanced, the caterpillars began pupating, and birds that were not particularly fond of hairy caterpillars pursued the imagoes as they emerged from the pupa.

JuLY 6. - Medford. A company of English Sparrows were picking the brown-tail moths from the elm trees and from fruit trees near the street. Some of these would get away from the Sparrows and fly out into the street, and were snapped up by a Least Flycatcher that was sitting on a dead limb, and also by two Kingbirds that were sitting on the telephone wires. On Highland Avenue, near the Hook farm, I saw a Great-crested Flycatcher take two of the brown-tail moths. 
All the above notes, taken, as they were, in different localities in several different towns, seem to establish the fact that birds are not by any means indifferent to hairy larvæ. Reference may also be made to a summary of the observations of a large number of men, published in 1896, which show the avidity with which certain birds eat the larvæ of the gipsy moth. ${ }^{1}$

Mr. Mosher's notes, quoted above, fail to show the attraction of birds to caterpillar outbreaks, for at that time there were no great irruptions of any such insects in that region. The greatest swarms of gipsy moths and brown-tail moths had been suppressed by the work of the State Board of Agriculture, and neither the American tent caterpillar nor the forest tent caterpillar was in very great numbers. Going back to 1895 , we find $\mathrm{Mr}$. Bailey recording briefly his experience in a visit to a destructive swarm of the gipsy moth. Mr. Henry Shaw and others give similar experiences. Mr. Shaw says :-

June 28, 1895 . - The newly found colony of gipsy moths in Dorchester seems to be a great attraction for birds of all kinds. In the last three days I have seen the Black-billed Cuckoo in great numbers eating larvæ, also the Rose-breasted Grosbeak. I have seen the Catbird, Red-eyed Vireo, and Yellow-throated Vireo feeding on the larvæ of the gipsy moth. The-Red-eyed Vireos seem to be living on them. They take large ones, and swallow them whole. The Purple Grackles are around there apparently after the larvæ.

Mr. Bailey says, regarding the gipsy moth :-

JULY 27, 1895. - I left here at 4.15 A.M., and started for Woburn, to see how many birds there were in the infested woods. I think there were more than I have seen at any one place this summer. The following is a list of species seen: Chickadee, Black and White Creeper, Yellow-throated Vireo, Red-eyed Vireo, Catbird, Crow, Blue Jay, Phœbe, Wood Pewee, Least Flycatcher, Kingbird, Towhee, Chipping Sparrow, Song Sparrow, Scarlet Tanager, Swamp Sparrow, Chestnutsided Warbler, Yellow Warbler, Rose-breasted Grosbeals, Downy Woodpecker, Redstart, Baltimore Oriole, Black-billed Cuckoo, Yellowbilled Cuckoo. Most of the birds left the woods by 11 A.M., or, if they did not, they kept very quiet after that hour. I think some of the birds have come a long way to feed here, for $I$ saw some of them go about

2 The Gipsy Moth, by E. H. Forbush and C. H. Fernald, 1896, pp. 206-243. 


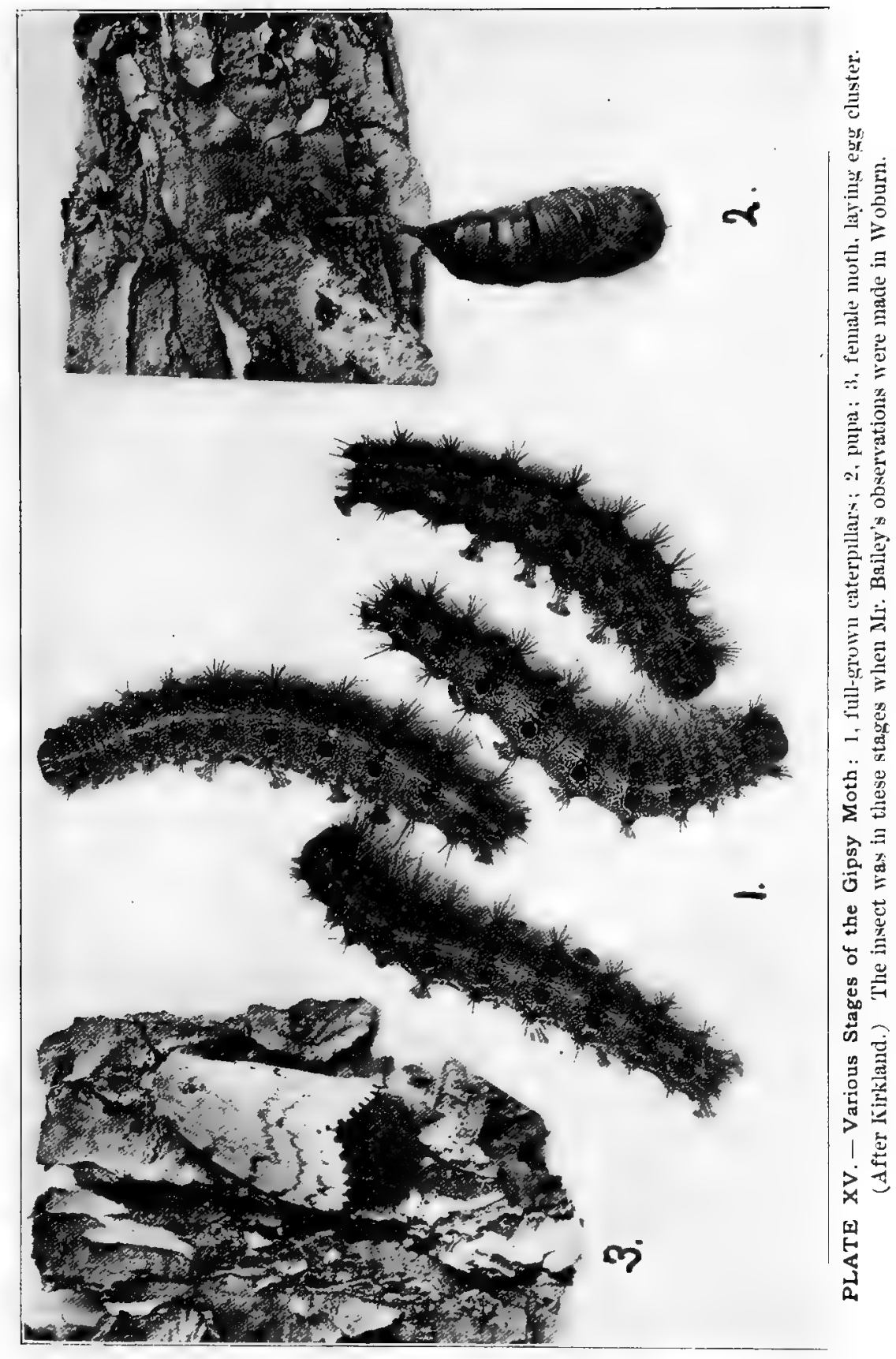



half' $a$ mile. I think the best bird to destroy the moths is the Kingbird. The Kingbirds came into the woods at 6.15 A.M. There were seven of them, and they did nothing but hunt the moth until 9.30. I saw them take seventy-nine males and twenty-four females. They dropped six of the females. They would cut the wings off both males and females with the bill. It is safe to say that the seven Kingbirds from 6.15 A.M. to $9.30 \mathrm{~A} . \mathrm{M}$. killed two hundred and fifty males. I could not keep one bird from the rest, so I took the number each time I saw a bird catch one. I did not see the birds take any males except on the wing, and most of the females were taken from branches of trees near the ground. They almost all stopped feeding at one time, left the woods, and did not come back while I was there. I saw the Chipping Sparrow take five females; three were taken from the ground, two from a tree. They took a number of males on the wing. They would peck both males and females before eating them. There were six Least Flycatchers, and I saw them take thirty-one males and nine females. Two of the female moths were caught by the birds when the moths were falling from the tops of trees; sume other bird might have dropped them. One was taken from the ground and six from the trunks of trees near the ground. They took the wings off, just as the Kingbird did. They took the noths only when they canue near them. The Wood Pewee took twenty-two males and seven females, that I saw. There were three of these birds in the woods. Eight of the male moths were taken off the trunks of trees, and twelve were taken on the wing. The Cuckoos fed very little. I saw them take eight larvæ and three pupx. The larve were pecked several times before they were eaten. I did not see them take any notice of the moths. The Black-billed Cuckoo was hunting for a small larva in the tops of the trees; I could not get one to determine the species, but it was not the gipsy larva. A large number of Chickadees came into the woods at b.30 A.x., and stayed there until I left, but were not feeding all the time. I saw them take several male gipsy moths from the bark of the trees, but did not see them take any on the wing. I saw one bird take a female moth and pick it all up in very small parts. Another bird took

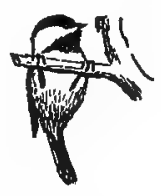
a female, took only the wings off, and ate her. They were hunting for some small insect that is feeding on the new leaves, but I could not tell what it was. I saw eight pupæ taken by the Clickadees, and all of them were pecked open by the bird before any part was eaten. 'The Baltimore Oriole came, found four smail gipsy moth larva, and I am sure took one male moth on the wing. The Redstarts took several male moths on the wing. A Yellow Warbler took a male moth from the trunk of a tree and ate it. A number of Towhees were hunting for the moths, and took the female as readily as the male. I saw them take eighteen in all; then they left the ground where they had been hunting, and went into the tops of the trees, hunting for the moths. 
In September, 1895, a second brood of the gipsy moth hatched in Woburn. The Warblers were then migrating southward, and had stopped there to feed on the young caterpillars. Mr. Mosher refers to this briefly, as follows :-

SEPT. 21, 1895. - I went to the Woburn colony in the forenoon, to observe the young larvæ. I found that many of them were gone, probably having been eaten by birds. Since these warm days the eggs are hatching again. 'The birds were very numerous, especially the Warblers and Vireos, and the Chickadees, Blue Jays, and Hairy Woodpeckers were quite plentiful.

In July, 1899 , a serious outbreak of gipsy moths was discovered in Georgetown at some distance from the region then known to be infested by this insect. On visiting the place I found birds very plentiful there, and most species appeared to be feeding on the gipsy moth in some of its forms. Mr. Mosher was sent there, and spent several days investigating the natural enemies of the moth. Some of the notes taken there by him are given below:-

JulY 11. - A Chickadee came, and ate one larva and one pupa. He held them with his feet, pulled them to pieces, and ate the fragments. I saw an Oven-bird carrying a gipsy moth larva to her young. A young Black-billed Cuckoo came to an oak tree, took a larva from a branch, flew to a lower branch, and began working the larva around in its bill. It continued this for several minutes, when it dropped the larva to the ground, flew and picked it up, and finally swallowed it. A Blue Jay remained in sight about four minutes, and was seen to eat ten pupre and three larvæ. A pair of Rose-breasted Grosbeaks could be seen among the pine trees, feeding steadily when they were in sight. They were in the colony at least two hours. There were seven Blue Jays in the colony at one time, and all were eating both larve and pupx steadily when seen. A pair of Scarlet Tanagers were in the trees for nearly an hour, and were eating. caterpillars pretty steadily while they were in sight, which was about half the time. Several times a Black and White Creeper came, and ate a few pupæeach time. A Downy Woodpecker was heard several times on the edge of the defoliated tract; finally he came into it, and was seen to take a few pupa from the clustered masses, pull them in pieces, and eat them. A pair of Greatcrested Flycatchers were passing to and fro. One of them alighted on a tree near me, and, after hopping about for a little and taking one or two small moths on the wing, it took a pupa from among the pine needles on a small bough, and ate it. There was a family of Black- 


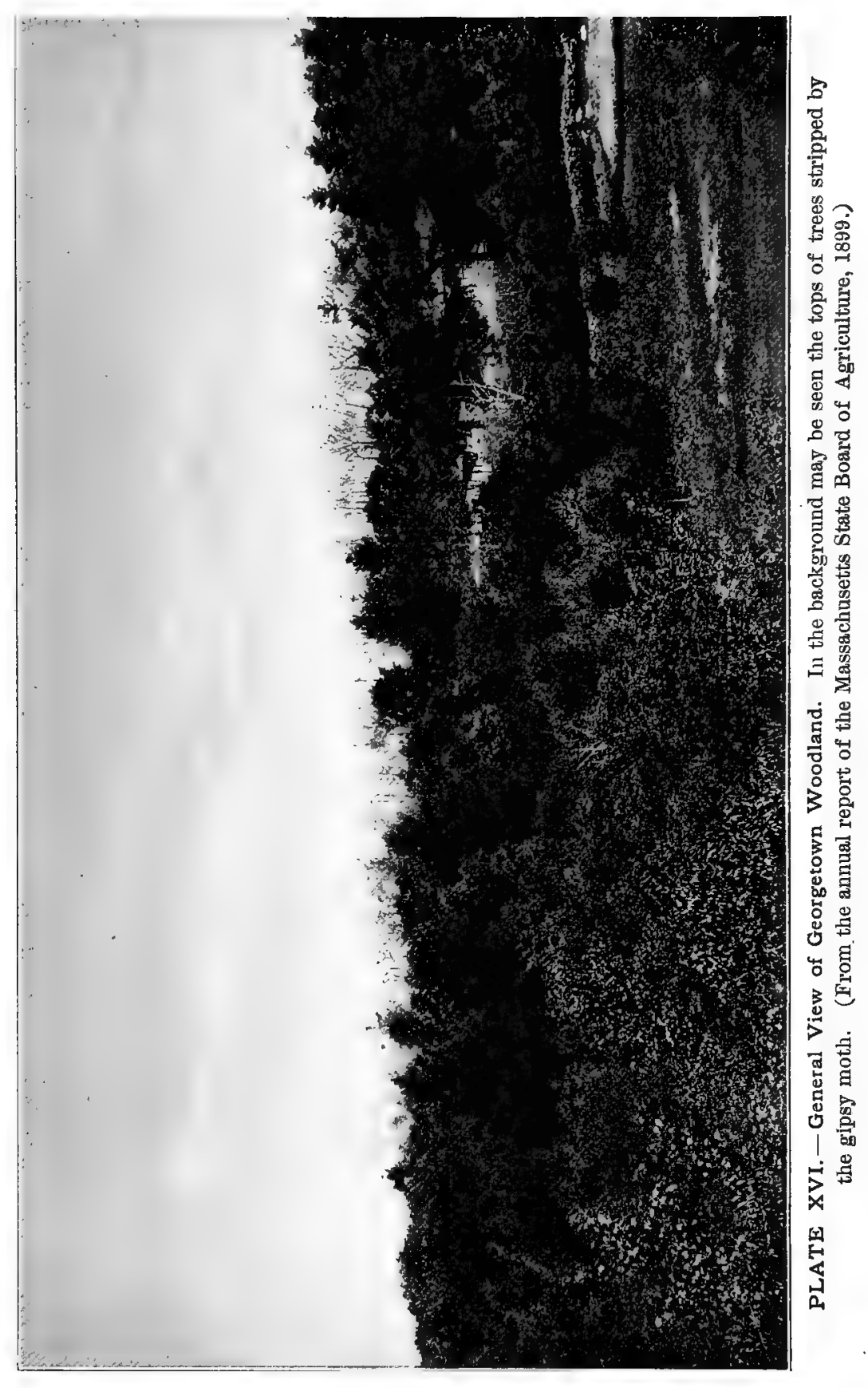





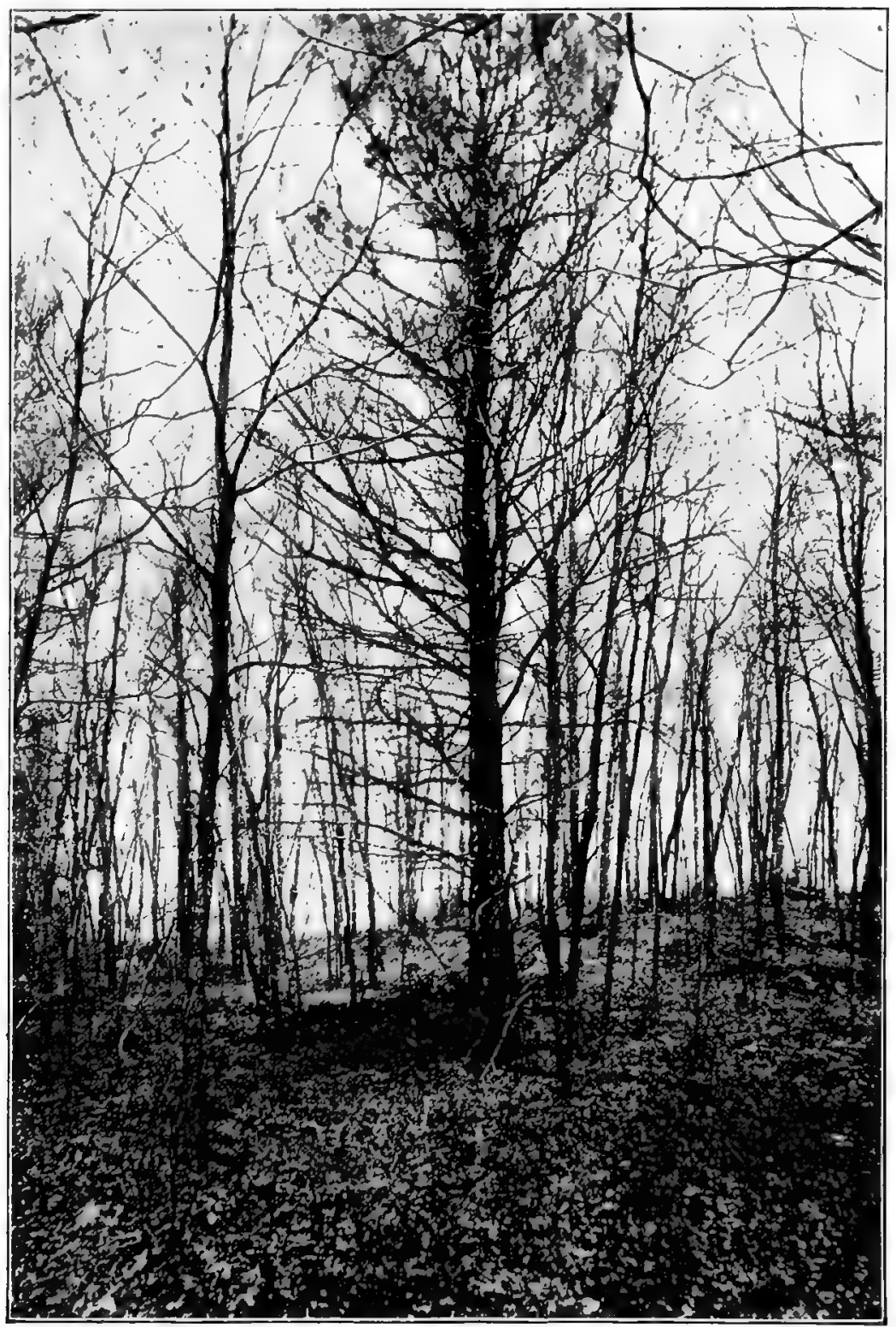

PLATE XVII. - Pines, Oaks, and Other Trees, stripped by the Omnivorous Caterpillars of the Gipsy Moth. Georgetown (where Mr. Mosher's observations were made), July 11, 1899. (From the annual report of the Massachusetts State Board of Agriculture, 1899.) 

billed Cuckoos that were coming and going all the time I was there. and they were eating large quantities of larvæ. 'The young would take a larva and work it over with the bill for a long time, and then swallow it. The old ones would take a larva, beat it on a limb a few times, and swallow it. Most of the birds were gone by 8.30 A.M. 'They were most plentiful between 5.30 and 7 A.M. The Cuckoos and Chickadees were coming and going all day. ${ }^{1}$ When we came in sight of the place after dinner we saw nine Crows fly to the edge of the stripped pateh, and alight in the trees that were partially stripped, but when we tried to get near them, they flew away. When I went into the colony I found there were still two Crows there. I saw one of them eat three pupæ, then they took flight. Several species that were not seen to eat the moth were heard in the woods outside the stripped area. Among the number were the Red-eyed Vireo, Indigo Bird, Wood 'Thrush, Chewink, Maryland Yellow-throat, Black-throated Green Warbler, Chestnut-sided and Yellow Warblers.

JULY 12. - In the morning, when I came in sight of the place, I found the whole flock of Crows there, and could hear them feeding their young very frequently. When I tried to get near enough to see what they were doing, they all flew away. The Grosbeaks were back again to-day. They kept on the farther side of the tract, and were eating both pupæ and larvæ when they could be observed. The Blackbilled Cuckoos were eating great numbers of the larvæ, as was the case yesterday. There were three of them in sight at one time, and they were coming and going all day. The Blue Jays were around the colony all the time, just outside the stripped area, and when seen were eating both pupe and larve. They are so shy that it is very hard to get near them. There were a great many Chickadees flying back and forth through the colony. Each one would stop now and then, take a larva from the trunk, take it to a branch, and with its feet on the larva would pull it to pieces and eat it. A pair of Phœbes came to

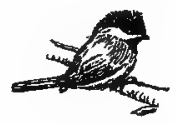
the colony about 8 o'clock and remained nearly two hours, and caught all the male moths that came near them. One of the Great-crested Flycatchers was in and out of the colony at intervals all day, taking food to its young in a hollow apple tree near by. I saw the pair take all forms of the moth to-day, - caterpillar, pupa, and male and female moths. They would hop along on a branch, and at a distance might be taken for Robins. I saw them take five pupx, two larve, and two female moths, besides a great many male moths, and carry them to their young. A Kingbird also came, remained nearly half an hour, and took many male moths.

JULY 13. - The Crows were in the colony when I arrived, and all

- Most birds leave the defoliated woods during the hotter part of the day, retiring to the cool shade, and feeding in the stripped woods mostly at morning and night. 
flew out and went to the meadow land near by, and were searching for grasshoppers most of the day. I could hear them feeding their young there very often. Whenever I left the place for a few minutes to go to the spring they would fly back again. I counted nine Blue Jays in the colony at one time, and they were all busy eating the larva and pupæ. I could see only one distinctly, and he ate five prupæ and two larvæ in two and one-half minutes. A family of Oven-birds were scratching about on the ground among the thick bushes. They were walking about like a flock of chickens, and took the larve that were crawling on the ground or that happened to fall from the leaves. A young Cuckoo was perched in the oak sprouts near me. The old bird brought him larvæ at the rate of one every two minutes for about thirty-six minutes; he then went into the swamp. A Red-eyed Vireo came into the colony and ate steadily for forty minutes. He ate seventy-three larvæ that I saw. He would hold the larvæ with his feet, pull out the inside, eat it, and drop the outside. A Downy Woodpecker came into the colony, ate two pupæ, and then flew away.

JuLY 14. - The Crows are still in the colony, back and forth, when no one is there. They fly out when they see any one. They seem to be eating great numbers of the pupæ. A Yellow-billed Cuckoo came in the early morning and fed forty-eight minutes, and ate eighty-one larvæ. He would beat each one once or twice and swallow it, then rest a short time before taking another. Chickadees are still here in large numbers, and are eating a great many caterpillars, as they

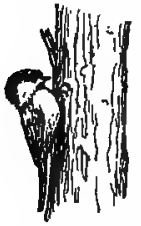
eat only the inside. Blue Jays are still eating large quantities of larvæ and pupæ, but their actions cannot be seen accurately, as they are so shy. Black-billed Cuckoos are here to-day, as before. I saw four at one time, and they were here at intervals all day, and always euting the caterpillars. There were several Tanagers, or the same one several times; each one would eat two or three of the larve each time he was in sight. He seemed to pick out the small ones. He would hammer them well before he swallowed them.

JuLY 15. - When I arrived this morning there were three Flickers in the path where the larvæ were crossing to get green food. These birds were picking the larvæ up as they crossed, and eating them. They would hammer them on the ground. Yesterday there was a Hairy Woodpecker around the colony, but I could not see what he was doing. To-day he came and picked into the mass of pupæ, pulled them in pieces, and ate them. The Downy Woodpecker was also here again to-day. I saw him eat three pupæ. He was around nearly all day. 'The Crows are getting tamer, and came several times during the day, and I saw them take both larvæe and pupæe and feed their young with them. The Chickadees are here in greater numbers than any day before; there were evidently two families of them. All were feeding on the larvæ, in the same manner as mentioned before. A Chewink perched 
in a tree near the edge of the colony, sang for a few minutes, then flew to the sprouts that are infested, then to the ground. He scratched in the leaves, and I saw him take seven pupæ from the leaves, and two larva that were crawling on the ground. There was a pair of Greatcrested Flycatchers coming and going all day. They took a great many male moths, and I saw them take five female moths from the tree trunks. A Robin perched in the tops of the oak trees, picked off fourteen of the pupæ from the branches, and ate them. A Yellow-bellied Sapsucker came, and I saw it eat two pupæ. It remained at least half an hour more, but I could not see what it was doing. A Yellowbilled Cuckoo ate ten larvæ in a few minutes.

Thousands of these insects are undoubtedly eaten by birds, for every one that they are seen to eat; but, it may be asked, if the birds are effective enemies of these introduced gipsy larvæ, why have they not kept down the increase of these insects? To this it must be answered that we have not birds enough, nor are there likely ever to be enough, to do away with these pests entirely, unless birds learn to eat the eggs. Other natural enemies must also help in this work, if we are to see an end of the moth plague; but there is little that we can do to protect the insect enemies, of the moth or to insure their multiplication, while we can protect and feed the birds, and so secure an increase in their numbers. In so far as we are able to take measures that will result in increasing the numbers of certain birds, just so far shall we be able to prevent the increase of destructive insects. As time goes on, it is probable that birds will become more and more efficient as enemies of the gipsy moth and the brown-tail moth, as they learn better how to manage them. It seemed apparent that they had not learned to eat the eggs of the gipsy moth up to 1896 , when my last studies on that subject were made; still, now that ten years have passed, the subject should be investigated again. It is quite possible that by this time some birds may have learned that these eggs are good for food. As the gipsy moth spends more than half the year in the egg, this is its most vulnerable point. If Jays, Creepers, Nuthatches, Woodpeckers, and other birds could learn to eat these eggs, as European birds are said to do, they would then have an increased food supply the year round. Naturally they would increase in numbers, and thus 
an effective natural check to the gipsy moth in America would be established, provided these birds were protected. But the egg clusters of these insects are covered with a fine,

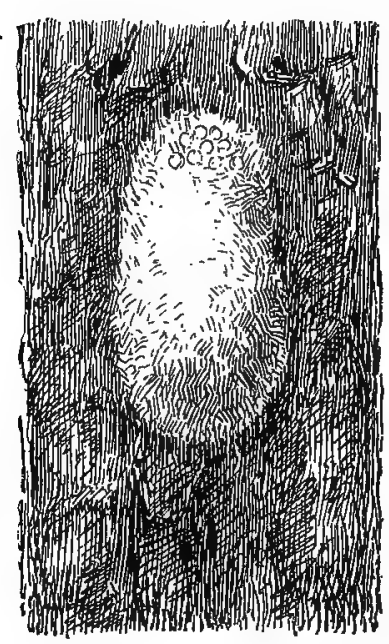

Fig. 45. - Egg cluster of gipsy' moth. yellow hair, which causes them to resemble in appearance a fungous growth which often appears on trees. Apparently the birds failed to recognize anything edible in them, and whenever a bird broke open an egg cluster, the fine hairs sticking to the beak seemed to disgust it.

The brown-tail moth is more exposed to the attacks of birds than is the gipsy moth, since the larvæ hibernate in their nests in curledup leaves that remain on the tree all winter. Already some birds are learning to open these winter nests and to extract the larvæ from them.

If the birds once learn this lesson thoroughly, the power of this pest will be greatly lessened. 


\section{CHAPTER IV.}

\section{THE ECONOMIC SERVICE OF BIRDS IN THE ORCHARD.}

The conditions in the orchard regarding bird life approximate those in the woods. The trees offer some shelter to birds, and also nesting places secure from such of their enemies as cannot climb or fly. The cutting over of wood lots destroys the breeding places of such birds as nest in hollow trees. Apple trees, on the other hand, are allowed to stand for a century or more if they still bear profitable fruit crops. Many orchard trees are much decayed, as a result of neglect or bad pruning, and the dead and hollow trunks furnish homes to such birds as once bred in the decaying trees of the woods. The trees in the orehard also provide an abundance of insect food. They are usually planted in or near fields or gardens, where many species of insects find food and shelter. For these reasons, orchards are much frequented by birds. The service rendered by birds in protecting the orchard is not, however, as effectual for man's purposes as that given by them to the woodland; for birds are the servants of nature, and in planting and cultivating the orchard man sets nature at defiance. His object here is not the mere growing of trees, but rather the production of an improved variety of fruit. Nature's efforts, on the other hand, are put forth mainly to produce such fruit as will make for the production and distribution of good seed that will insure the propagation of the tree. The fruit grown by nature is often considered by man as unfit for food. He wants fruit suited to his tastes. The seed is of little value to him, for he does not often use it, but propagates the tree of his cboice by grafting or budding.

The production of a vastly increased quantity of fruit, of a better quality than the natural product, offers an increased food supply for the creatures that feed upon that fruit. So the planting of large fruit-bearing orchards gives the insects 
which feed upon the fruit, seed, or other parts of the tree an increased opportunity to multiply. Insects unfamiliar to our native birds are introduced. The undergrowth, shrubbery, and vines which shelter many such useful birds are cleared away. This drives these birds away, and so the fight against insects in the orchard is begun with an inadequate number and variety of birds and an unusual abundance of insects.

Even under these adverse conditions, the entire protection of the foliage from insects may be left to birds, provided that the orchard is favorably situated, that the birds are attracted to it in winter, and that those which nest there in summer are protected, encouraged, and furnished with nesting places. This I have demonstrated by a series of experiments, covering a period of about ten years.

The protection of the trees and their foliage by birds insures the maturing of such fruit as the trees will bear; and, as probably two-thirds of the fruit trees in Massachusetts receive little care at the hands of their owners, the people of the Commonwealth are largely indebted to the birds for a great part of their annual fruit crop. Even as it is, insect pests destroy a large part of the apple crop in some seasons, and hardly a hand appears to be raised to stay them. Hence I repeat that such fruit crops as we get are largely due to the protection our trees receive from the birds.

My first attempt at availing myself of the services of the birds in an orchard was made in 1894-95, and the result was given in a bulletin issued by the State Board of Agriculture. The winter birds were attracted to the orchard, and frequented the trees during the entire winter of 1894-95. In the fall, winter, and spring they destroyed many thousands of the imagoes and eggs of the fall and spring cankerworm moths, the eggs of the tent caterpillar, and probably also the pupæ and imagoes of the codling moth, besides scales, tineids, and other enemies of the trees. When spring came, efforts were made to attract the summer birds to the orchard. These attempts met with such signal success that, although most of the eggs and young birds were destroyed by cats, boys, Crows, and other agencies, the remaining injurious insects 
were so completely disposed of by the birds that the trees bore luxuriant foliage during the entire summer, and produced a good crop of fruit. This occurred in a season when both the tent caterpillar and the cankerworm were remarkably prevalent. The only other orchard in the neighborhood that produced any fruit whatever was that of the nearest neighbor. (See p. 169.) This had been partly protected by tarred bands and partly by the birds from my place. Elsewhere in the town most of the apple trees were defoliated, and very few produced any fruit that year. While the result secured in such an exceptional year seemed remarkable, the experience of succeeding years has demonstrated that it was not so. Year after year we have kept the trees free from serious insect injury, without spraying or otherwise protecting the foliage, merely by a little effort and expenditure to attract the birds and furnish them safe homes. While the protection of the tree itself is essential (i.e., its trunk, limbs, twigs, and bark), the protection of its foliage, which shades the fruit and so allows it to mature, is also imperative.

It must be admitted, however, that he who wishes a large crop of the finest fruit must himself prevent the inroads of those insects which attack the fruit directly. There are two insects of this class which the birds have thus far failed to control completely; and, while birds might possibly check such insects under the most favorable circumstances, I believe that ordinarily they cannot be relied upon to do so. The insects referred to are the codling moth (Carpocapsa pomonella) and the apple-fruit maggot or "railroad worm" (Rhagoletis pomonella). These insects are for a greater part of their lives protected from the attacks of birds by being hidden either in ground, rough bark, or fruit. Only a few birds are known to dig out the larvæ of the codling moth from their hiding places; probably fewer still find the railroad worm. Weevils or curculios are eaten by many birds; still, sufficient numbers usually escape to spoil much fruit; and the pernicious introduced San José scale seems to be overlooked thus far by birds.

It cannot be expected of the birds that they will become efficient allies of man in protecting his artificially propagated 
fruit from the attacks of all the too numerous insects that are introduced and fostered by his methods. The bird is designed to assist in carrying on nature's work in maintaining such a balance of her forces as will allow the production of a natural fruitage. Birds merely perform a service in the orchard similar to their natural work in the woodland, by protecting the tree from the enemies which, under normal conditions, attack its different members. In the mean time, birds feed to a greater or less extent on the fruit which they protect. While such service as they may render in direct protection of the fruit should be placed to their credit, they cannot be expected to deviate much from those habits which they have contracted under natural conditions, or to make any special effort to assist man in producing an unnatural surplus of fruit. Birds are not as essential to the orchard of the intelligent, enterprising, modern fruit grower, who sprays his trees and cares for them in every possible way, as they are to those of ordinary mortals. Nevertheless, so long as human nature continues as it is to-day, the birds will always be a great help in the orchards of the poor, or of those who for various reasons have not the spare time or money necessary to enable them to care for their trees in the most approved and scientific way.

A series of poison sprays used for the destruction of the codling moth will destroy most other leaf-eating insects, and so protect both fruit and foliage. 'There is, however, a host of tiny insects that are not affected by any amount of arsenical spraying, - insects so small, indeed, that their presence is seldom noticed until the injury done by them has progressed so far as to destroy the fruit. Such insects are the plant lice and their allies, the bark lice, scales, and all the lilliputian host that unnoticed sucks out the juices of the tree from trunk, limbs, twigs, leaves, or fruit. Warblers, Titmice, Creepers, and Nuthatches are often very efficient helps in holding the increase of such insects in check.

As an instance of the unnoticed beneficial guardianship of the birds over our orchard trees, I will relate a recent experience of my own. The reader has already been told how in the spring of $1905 \mathrm{I}$ left my trees to the tender mer- 
cies of the caterpillars, trusting them to the care and protection of the birds. I visited the place occasionally during the summer, and in the fall saw that measures were taken, as usual, to attract the birds. On November 12 I returned for the winter, and noticed no evidence of insect injury among the fruit trees. A small flock of Myrtle Warblers and some Goldfinches were very busy among the apple trees, and were paying particular attention to the pear trees near the house. I was told that they had been coming there for about two weeks. Realizing at once that they must be engaged upon those leafless trees in the suppression of some insect, I examined the trees casually, but at first was unable to find the object of their quest. One of the birds was watched closely. It was taking something from the lower sides of the twigs and the erevices between them. With a glass it was seen to take some very small insects that were hiding in these situations. Evidently the insects were no longer plentiful, as the birds had to search somewhat to find them, and the only way in which I could find a specimen was by driving a bird away just as it was about to attack the insect, and then examining the twig. Three tiny insects, which appeared like little cicada-shaped flies, were found and secured in this way. Two of these were forwarded to Dr. L. O. Howard, chief of the Bureau of Entomology, at Washington, who identified them as adults or imagoes of the pear tree psylla (Psylla pyri), a pest imported into this country from Europe about 1832. According to Circular No. 7, second series, issued from Dr. Howard's office, an overwhelming invasion of this insect occurred in the year 1894 in one of the largest pear orchards in Maryland; there were similar occurrences in Virginia and New Jersey. This insect has long been known as a pest of the pear tree. It is a true bug, of the order Homoptera, intermediate between the scale insects and the plant lice on the one hand, and the cicadas and larger plant bugs on the other. The Psyllidx are commonly known as the jumping plant lice, on account of their vaulting ability. They are extremely prolific, having several broods each year. In the infested Maryland orchards the leaves and fruit fell, the latter before it was half grown, 
and the trunks of the trees appeared as if smoked. The enormous secretion of honeydew that the hosts of these insects produced from the sap of the trees fell like rain, drenching the horses used in cultivating the orchard, and running down the trunks in such quantities that it extended in a discolored circle from six to eight inches from the base of each tree. This information comes from the above-mentioned circular.

If the birds had been engaged for more than two weeks in clearing these insects from the few pear trees about my home, there must have been a great number of insects on those trees, for the pests are so small that each bird might eat thousands of them in a day. At the time of my return the insects were evidently becoming scarce ; but the birds persevered in their attentions to those trees, until in a few days I could not discover a single specimen of the insect; but even after that they looked the trees over occasionally, and still found a few. By the end of another week, however, they had exhausted the supply, and, although they were seen occasionally in the woods, they seldom visited our trees. Apparently this was an incipient outbreak of a pest, brood after brood of which had probably been attacked by birds during the summer. As autumn came on, and the summer Warblers left on their southern migration, the last brood developed. The latecoming Warblers found them, and eagerly completed the task left unfinished by the summer birds. The pear trees had continued to bear both foliage and fruit as usual, and showed no injury. They will probably receive a similar protection next year.

Dr. Howard intimates in his bulletin that the causes which control the increase and decrease in numbers of this insect are not fully understood. Here is one agency of control that we can understand. It would be interesting to know to what extent this insect is distributed in Massachusetits, and how much the birds are doing to control it. These insects are so tiny as to escape observation, and this episode would have passed unrecorded, like so many others of its kind, had I remained away from home a few days longer. 


\section{CHAPTER V.}

\section{SONG BIRDS OF ORCHARD AND WOODLAND.}

The common birds that live and feed in woodland or orchard are usually of the greatest service there. Those few that nest in orchard or woodland, but seek most of their food elsewhere, while occasionally of much service in protecting the trees, are ordinarily of more value in the field or garden, and will be considered later among the birds of those localities. Those common species that may be found in Massachusetts throughout the year, and therefore are known as residents, are most useful to man; but those that remain here only in summer or winter have considerable economic value. Such familiar birds will be briefly described and also figured in this chapter and those following. Those species that merely pass through the State in migration will receive but brief mention, or none, except such as are known to be conspicuously useful while here. The Shrikes, Hawks, Owls, Crows, and Jays will be treated separately among the enemies of birds.

\section{WOODLAND THRUSHES.}

The Thrush family is considered the highest group among birds, and is ranked accordingly, although the Crows, Jays, and Titmice exhibit in certain ways a higher degree of intelligence.

The Thrushes of the genus Hylocichla are mainly woodland birds; although some members of the family are commonly seen feeding in gardens and fields.

Professor Forbes's studies of the food of the American genera of this family in Illinois (including also the Catbird and Brown Thrasher) show that sixty-one per cent. of their food consists of insects, one per cent. of myriapods (com-

- monly called thousand legs), and thirty-two per cent. of fruit. Thirty parts of the food consist of injurious insects, and only seven of beneficial species. His examinations were 
made on adult birds; and, were the food of the nestlings considered, the percentage of injurious insects eaten would probably be higher. A large proportion of the fruit eaten by these birds in Massachusetts consists of wild berries, particularly such as are unfit for human consumption. The family, therefore, as a whole is eminently, beneficial.

The Robin and Bluebird are not typical woodland birds, although the Robin both breeds and feeds in the woods to a considerable extent. Both birds nest in the orchard, but feed generally in gardens and fields. For this reason they will be considered farther on, among the birds of the field and garden. The Hermit which breeds sparingly in the State and the other Thrushes will be omitted.

Wilson's Thrush. Tawny Thrush. Veery.

Hylocichla fuscescens.

Lerigth. - About seven and one-half inches.

Adult. - Above, tawny brown; no white eye ring ; below, mainly whitish; throat and upper breast washed with buffy or yellowish brown, faintly marked with a few dark spots.

Nest. - Usually on or quite near the ground, containing no mud or leaf mold, and composed of grass, dried leaves, grapevine bark, etc.

Eggs. - Greenish-blue; smaller than those of the Robin and lighter than the Catbird's.

Season. - May to September.

This gentle bird may be recognized by its light tawny upper parts and the faintness of the elongated spots on its light brown-washed breast. It is a summer resident throughout most of Massachusetts, but is generally confined to the vicinity of swampy woods or streams, and is not found ordinarily on the summits of the highest elevations. It runs about much in the manner of the Robin, but rather more listlessly, and often with drooping wings. Alert, but not suspicious, it seems to be aware of its protective coloring, which makes difficult the task of distinguishing it from the leafy ground of its favorite groves. Its flight is rapid, and when much alarmed it vanishes swiftly among the vistas of the woods. Although it often alights on the lower branches of trees, it is seldom seen among tree tops, but keeps habitually near the ground, where it finds most of its food. The song of this Thrush, one of the sweetest sounds of the wood- 
land, is among the earliest notes of the morning, and is often heard during the day and in the dusk of evening. It consists of several ringing phrases or triplets, which its name Veery describes fairly well. It is not so full-toned as the songs of other Thrushes, but has an attenuated sound. Robert Ridgway expresses the quality of the phrases by the syllables "taweel"ah, taweel"ah, tuilah, twil-ah." The last two phrases are lower in tone than the first, and end with a vibrating chord which suggests the vanishing of the note into ethereal space. The melody often has a muffled sound when heard near by, but at a distance it seems to ring out clear. To be fully appreciated, this song. must be heard when one is

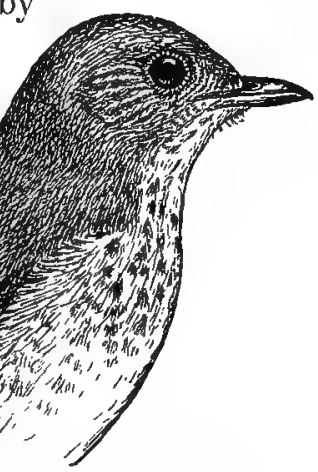

Fig. 46.-Wilson's Thrush, two-thirds natursl size.

alone in the deep woods, among the falling shades of the coming night. It breathes the spirit of the dying day. Sometimes at evening these Thrush songs reply to one another like echoes in the moonlight.

The bird sings soon after its arrival in May, and usually ceases when the molting period begins. It sings little during a long drought, but becomes vocal after a rain. The ordinary note of the Veery is a sort of whee-oo, half chirp, half whistle, which often has a peculiarly liquid sound. It has also a sharp chick, a prolonged, bleating aaah, and other occasional cries.

The Veery feeds very largely on insects. Those which frequent the ground and the lower parts of trees are commonly sought. Ants, ground beetles, curculios, and grasshoppers are favorites. It goes to the fields sometimes at early morning, probably in search of beetles, cutworms, and earthworms. It has been seen, now and then, to eat the hairy caterpillars of the gipsy moth. It feeds considerably in the trees, and so takes many caterpillars; but is not usually seen much in gardens or orchards, except such as are situated near woods. In summer and fall it eats wild fruit, 
but seldom troubles cultivated varieties. Taken all in all, it is a harmless and most useful species.

Wood Thrush. Song Thrush. Wood Robin.

Hylocichla mustelina.

Length. - About eight inches.

Adult. - Above, mostly cinnamon-brown, reddest on head ; eye ring white; below, mainly white, with large, rounded, dark-brown spots on breast and sides.

Nest.-On shrub sapling or low branch, six to ten feet up; much like that of the

Robin, but usually composed of more woodsy material; the mud is often replaced by leaf mold.

Eggs. - Usually four; greenish-blue ; resembling those of the Robin, but smaller. Season. - May to September.

The Wood Thrush is, as its name indicates, primarily a bird of the woods, preferring the tall timber in some shady dell, where pure tloods from the never-failing springs of

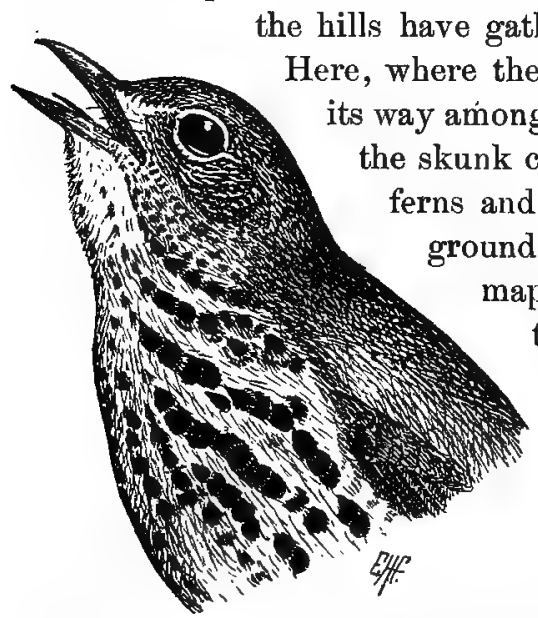

Fig. 47. - Wood Thrush, two-thirds natural size.

mond and where great swamp ples stand cool and tall, the Wood Thrush loves to dwell. Its apparent native modesty and retiring disposition, its love for shade and solitude, seem to be prominent characteristics of this sylvan recluse. Still, of recent years the bird is

often found about the haunts of men, particularly in places where it is protected, and where large and clustering shade trees afford it cool retreats. Its carriage as it hops or runs upon the ground is somewhat like that of a Robin. Rather sedentary in habit, it seems to be confined during the breeding season to a limited area around its home, where its song may be heard more or less at all hours, but mainly during the cooler portions of the day, throughout the summer months. 
The song of the Wood Thrush is one of the finest specimens of bird music that America can produce. Among all the bird songs that I have ever heard, it is second only in quality to that of the Hermit Thrush. It is not projected upon the still air with the effort that characterizes the bold and vigorous lay of the Robin, or the loud and intermittent carol of the Thrasher. Its tones are solemn and serene. They seem to harmonize with the sounds of the forest, the whispering breeze, the purling water, or the falling of rain drops in the summer woods. As with most other birds, there is a great difference in the excellence of individual performers, and, while some males of the species can produce such notes as few birds can rival, this cannot truly be said of all. At evening the bird usually mounts to the higher branches of the taller trees, often upon the edge of the forest, where nothing intervenes to confine or subdue his " heavenly music." There, sitting quite erect, he emits his wonderful notes in the most leisurely fashion, and apparently with little effort. A olee, he sings, and rests; then, unhurried, pours forth a series of intermittent strains which seem to express in music the sentiment of nature; powerful, rich, metallic, with the vanishing vibratory tones of the bell, they seem like a vocal expression of the mystery of the universe, clothed in a melody so pure and ethereal that the soul still bound to its earthly tenement can neither imitate nor describe it. The song rises and falls, swells and dies away, until dark night has fallen. The alarm note of the bird is a sharp pit, pit, several times repeated; this alarum often rises to a long roll. A soft cluck, also repeated, is sometimes heard. A mellow, rather liquid chirp is another common note.

The food of the Wood Thrush consists largely of insects. A considerable portion of fruit is taken in summer and fall. Owing, perhaps, to the usually retiring habits of the bird, cultivated fruit is seldom eaten; but, as wild blackberries, strawberries, cherries, and gooseberries are taken, the cultivated varieties of those fruits probably are eaten to some extent where the birds breed in the vicinity of dwellings. The amount taken, however, is not large in any case. In examining twenty-two specimens of this Thrush, taken from 
April to September, Professor Forbes found that seventy-one per cent. of their food consisted of insects, twenty per cent. of fruit, and a small percentage of mollusks and spiders, together with a large portion of myriapods. Mollusks, particularly clams, mussels, and snails, are eaten by many birds, while the myriapod, or thousand legs, and the ground spiders are eaten by most ground-frequenting species.

The Wood Thrush takes its food from ground, shrubbery, and trees in the woods, and even invades the grass land at times, where it is said, like the Robin, to take earthworms. It eats injurious grasshoppers and crickets, also ground beetles and their larva, click beetles, wireworms, and other Coleoptera, both tree-feeding and ground-feeding species. It gleans cutworms from lawn and field, and is particularly fond of ants. It also does good service in killing some of the most destructive caterpillar pests, not neglecting the hairy species, like the forest tent caterpillar, and the larvæ of the gipsy moth and the brown-tail moth, as well as most of the hairless species, such as both the fall and spring cankerworms, of which it is fond. It also destroys the rose beetle, as Professor Forbes found the stomach of one specimen crammed with them.

This species appears to be quite as valuable as the Robin in its insectivorous habits; and, as it eats far less fruit than the Robin, it must be of great service to man whenever it can be induced to nest about his dwellings. Were cats, birds'-egging boys, and bird-killing Italians suppressed, this bird might become as domestic as the Robin, if not as common. The prospect of the transmutation of the substance of noxious caterpillars, grubs, and beetles into the glorious music of the Song Thrush, should stimulate us to learn how to attract it to our homes and domesticate it there for all time.

\section{KINGLETS.}

These pigmy birds are probably among the most useful species in woodlands. They are extremely small, ranking next in size to Hummingbirds, and therefore feed to a considerable extent on minute forest insects so small as to escape most other birds. They are peculiarly fitted to care for the trees, for they are able not only to creep about the trunks 
and limbs, like the Creepers and Titmice, but they have all the skill of the Warblers in searching the foliage, and they are also such excellent flycatchers that it is difficult for the smallest and swiftest insects to escape them. The Rubycrowned Kinglet is a mere migrant through the State in fall and spring, but the Golden-crowned Kinglet may be found in our woods, orehards, or shade trees not only in fall and in spring but during the winter, and it breeds in northern Worcester County and in Berkshire County.

\section{Golden-crowned Kinglet.}

Regulus satrapa.

Length. - About four inches.

Adult Male. - Abovo, gray and olivengreen mainly, with yellowish-olive showing decicledly on wings and tail; a bright, glossy orange crown spot, edged with yellow, fronted and bordered on the sides by a black streak, which also is bordered by a whitish streak, above the eye; below, dull grayish-white.

Adult Female. - Like male, but lacking the orange center of the crown patch, which is replaced by yellow.

Nest. - A ball of moss, feathers, etc., in an evergreen tree.

Eggs. - Numerous, white, thickly but faintly speckled with buffy spots.

Season. - Resident in some localities, but usually seen between September and April.

The Golden-crowned Kinglet probably does not breed in Massachusetts except where the Canadian flora is found on some of the higher lands of the central and western sections. Its note, as commonly heard, is a weak chirp or a fine tsee, tsee, tsee. Its song I cannot attempt to describe.

Unfortunately, no careful study of its food habits has ever been made, but it is said to be almost entirely insectivorous. It is believed to feed largely on bark beetles, scale insects,

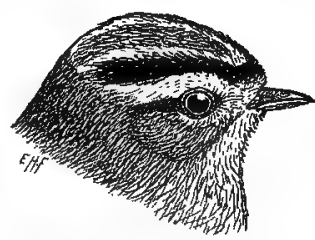

Fig. 48. -Golden-crowned Kinglet, natural size. and the eggs of injurious moths and plant lice.

Kinglets are particularly serviceable in woodlands, especially among the coniferous trees in which they dwell. At Wareham, on Dec. 25, 1905, I watched the Gold-crest hunting its insect food amid the pines. The birds were fluttering about among the trees. Each one would hover for a moment before a tuft of pine "needles," and then either alight upon it and feed, or pass on to another. I examined 
the "needles" after the Kinglets had left them, and could find nothing on them; but when a bird was disturbed before it had finished feeding, the spray from which it had been driven was invariably found to be infested with numerous black specks, the eggs of plant lice. Evidently the birds were cleaning each spray thoroughly, as far as they went.

Since the above was written several of these infested sprays have been sent to Prof. F. E. L. Beal of the Biological Survey, who submitted them to Mr. Pergande of the Bureau of Entomology, who says that they are the eggs of a plant louse of the genus Lachnus, and in all probability Lachnus strobi, the white pine louse. The pines are considerably infested, and several pairs of Kinglets have been seen feeding upon the eggs.

Again since the above was written I have had occasion to observe the work of Kinglets in our home grove of white pine. For the past two years certain plant lice or bark lice that infest these trees have been increasing so rapidly in the grove as to menace the trees; but on Dec. 29, 1905, seven Kinglets were seen feeding there. As it was unusual to see so many there, they were carefully watched. They were not working upon the foliage, as in the case mentioned above, but mainly on the trunks and larger branches. They were very unsuspicious, and it was easy to see that they were feeding upon the eggs of the aphids. Some of these eggs were sent to Dr. L. O. Howard, who gave it as his opinion that they belonged to some species of Lachnus. These eggs were deposited in masses on the bark of the pines from a point near the ground up to a height of thirty-five feet. The trees must have been infested with countless thousands of these eggs, for the band of Kinglets remained there until March 25, almost three months later, apparently feeding most of the time on these eggs. When they had cleared the branches the little birds fluttered about the trunks, hanging poised on busy wing, like Hummingbirds before a flower, meanwhile rapidly pecking the clinging eggs from the bark. In those three months they must have suppressed hosts of little tree pests, for I have never seen birds more industrious and assiduous in their attentions to the trees. One might 
expect such work of Creeper's or of Woodpeckers; but the Kinglets seemed to have departed from their usual habits of gleaning among limbs and foliage, to take the place of the missing Creepers, not one of which was seen in the grove last winter.

\section{NUTHATCHES AND TITS.}

This useful family is well represented here in woodland and orchard by three common species, one Titmouse and two Nuthatches. The Hudsonian 'litmouse is too rare to be of any economic importance. The common Titmouse or Chickadee is a well-known species that visits every village and farm. The Nuthatches may be known by their short tails and their habit of climbing about over the trunks and limbs of trees, somewhat after the manner of Woodpeckers, except that they do not use the tail as a support, as the Woodpeckers and Creepers do, and that they often move about head downwards, or suspend themselves in this manner, which Woodpeckers seldom do. The name Nuthatch probably originated from nuthack or nuthacker. It was first applied to the European species because of its habit of cracking nuts or acorns, presumably for the keruel; but the American species seem to open nuts or acorns mainly for the insects that feed within. In winter, however, these birds will eat the kernels of broken nuts that are often put out for them by humane people. They can scarcely be called song birds, but sometimes the males twitter softly, as if attempting to whisper a song.

\section{Chickadee. Black-capped Titmouse.}

Parus atricapillus.

Length. - About five and one-quarter inches.

Aclult. - Top of head, nape, and throat black; sides of head and neck white; back ashy; breast white; wing feathers and tail feathers margined with whitish; belly and sides washed with ereamy buff.

Nest.-Sometimes built in a natural hollow of some tree in the woods or orchard; often placed in a cavity hollowed out by the birds themselves in a decayed birch or pine stump, and composed of moss, feathers, and other warm materials.

Eggs. - Usually six or seven, but sometimes even ten; white, and finely spotted with reddish-brown or a paler shade.

Season. - Resident.

The Chickadee remains in Massachusetts throughout the year, but is usually morẽ commonly seen in winter than in 
summer. It nests in April or May, and sometimes rears two broods in a season. The ordinary cheery chattering call, from which the bird derives its name, is often varied in the milder weather of winter and toward spring by its so-

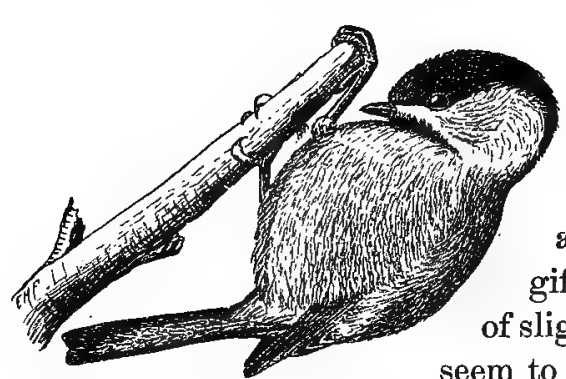
called "phœbe" note, a musical, whistling call, which by the children is sometimes translated "Spring's come." Now and then some peculiarly gifted male essays a jumble seem to be an attempt to express Fig. 49.- Chickadee, one-half natural size. the unconquerable cheerfulness of its nature; but the Chickadee's attempts at song never give very brilliant results. Nevertheless, the little bird is so happy, companionable, and contiding that in New England it is one of the most beloved of the feathered race. While, for a bird, it exhibits remarkable intelligence in many ways, it seems to confide in man to an unusual degree. It is an easy mark for the small boy with his air gun, and numbers of these birds fall victims to their misplaced confidence in human nature.

Chickadees sometimes go to the camps of woodchoppers, in hard winters, and learn to take food from the hand. One day while I was sitting on the ground in the woods a Chickadee alighted on a branch about two feet away and looked up in my face; and they have often hovered within a few inches of my head, as if about to alight there. Occasionally one may be readily taught to feed from the hand. Minot says that they are so merry, genial, and sociable that their company is sought by other birds, such as Creepers, Nuthatches, Kinglets, and Woodpeckers, whose habits are like their own. This has been observed by every ornithologist, but no one seems to have mentioned the fact that many birds other than those given above seek the company of the Chickadee for a different reason. Every fall the Warblers, on their way south, stop for a time in favorable localities, and accompany the small roving bands of Chickadees. At this season 
one has but to follow the note of the Chickadee to find most of the smaller wood birds. Warblers are not plentiful in the woods at any time when there is a scarcity of their insect food; but the industrious, prying, resident Chickadee knows the ground, and where to find food. His cheery notes call the other birds to him. The Chickadees extract caterpillars from webs or from rolled-up leaves; and the Warblers immediately follow and do likewise, though not with the skill of the Chickadee. Now Chickadee finds some caterpillars too large for him to swallow; he catches one, places it on a branch, puts his foot upon it, and soon extracts from it with his beak all that he desires, leaving the remains where they fall. The Warblers, less skillful, come along and exhaust themselves in vain attempts to swallow the large caterpillars whole. They eat what smaller ones they can, however, and leave the rest to the Chickadees and Vireos. I never yet have seen a Chickadee fail to manage any insect that it attacked, although occasionally it drops one into the underbrush. I once saw a Chickadee attempting to hold a monster caterpillar, which proved too strong for it. The great worm writhed out of the confining grasp and fell to the ground, but the little bird followed, canght it, whipped it over a twig, and, swinging underneath, caught each end of the caterpillar with a foot, and so held it fast over the twig by superior weight, and proceeded, while hanging back downward, to dissect its prey. This is one of the most skillful acrobatic feats that a bird can perform, - although I have seen a Chickadee drop over backward from a branch, in pursuit of an insect, catch it, and, turning an almost complete somersault in the air, strike right side up again on the leaning trunk of the

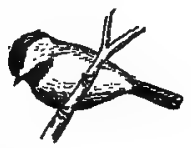
tree. Indeed, the complete somersault is an every-day accomplishment of this gifted little fowl, and it often swings completely round a branch, like a human acrobat taking the "giant swing." Although the Chickadee ordinarily is no flycatcher, it can easily follow and catch in the air any insect that drops from its clutch. This bird stands very close to the first place among the useful birds of orchard and woodland, and therefore its food habits merit an extended notice here. 
Much of the daylight life of the Chickadee is spent in a busy, active pursuit of or search for insects and their eggs. This is particularly the case in winter, when hibernating insects or their eggs must be most diligently sought, for then starvation always threatens. But the Chickadee is one of the few insectivorous birds that is keen-witted enough to find abundant food and safe shelter during the inclement northern winter. Nevertheless, its busy search for food is sometimes interrupted for so long a time during severe storms, when the trees are encased in ice, that it dies from cold and hunger. During a sleet storm Mr. C. E. Bailey saw two Chickadees creep under the loose clapboards of an old building for shelter. Their tails were so weighted down with ice that they could hardly fly, and had he not cared for them they might have perished.

The Chickadee, notwithstanding its hardiness, requires protection from cold winds and storms at night. It finds such shelter either in some hollow tree or in some deserted bird nest. Late one cold and snowy afternoon Mr. Bailey detected a movement in a cavity under an old Crow's nest, and on climbing the tree he found two Chickadees nestling there. They remained there until he had climbed to the nest and put his hand on one, when they flew out, only to return before he had reached the ground. Minot speaks of a Chickadee that slept alone in winter in a Phobe's nest under his veranda. It retires to its refuge rather early at night, and does not come out until the Tree Sparrow, Song Sparrow, and Junco are abroad.

Although the digestive organs of the Chickadee are not those of a typical seed eater, it can digest and assimilate seeds at need, and often lives to a considerable extent on the seeds of the birch. Oats are sometimes eaten in winter, but they are taken from waste grain found along the roads. The fruit of the common sumacs, bayberry, and poison sumac are also eaten ; pieces of lichens and bud scales sometimes form a portion of the stomach contents; but the food of this bird is preferably of an animal nature. In winter 
over half its food consists of insects, and in spring the percentage of insect food often runs up to nearly one hundred.

Among the pests which it eats are the tent caterpillars and their eggs; both species of cankerworm moths, their larvæ, and eggs ; codling moths with their larvæ; the forest tent caterpillar; and the larva, chrysalis, and imago of the gipsy moth and brown-tail moth. The birch, willow, and apple plant lice or their eggs form a large part of

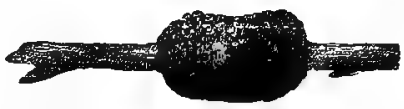

Fig. 50.-Egge of the tent caterpillar moth, eaten by Chickadees. the Chickadee's food at times. The eggs are eaten mainly in autumn and winter, when fixed upon the twigs of trees. Bark beetles, so destructive to many species of fruit, shade, and forest trees, are a favorite food of the Chickadees. Destructive flea beetles also are eaten by them. They frequently may be seen tearing open spiders" "nests," and eating the eggs or young. At first sight this appears to be a harmful habit, as spiders are supposed to be useful; but no doubt much destruction of spiders is needed to keep them within normal bounds. Let any one go out into the fields some foggy summer morning, and note the thousands of "cobwebs" on the grass, and he will see that the fields are "full of spiders." One night in September, 1904, I slept on the ground upon a hill top in the Concord woods. Early in the night it rained a little, and toward morning a river fog rose. At daylight the whole country appeared to be covered with spiders' webs. They hung from the trees, every branch was ornamented with them, each tuft of pine needles had its web, long streamers ran from tree to tree, festoons of spiders' webs hung across the wood roads. The shrubbery, the vines, the grass, all were enshrouded in dew-spangled webs. The work of a million spiders, ordinarily unnoticed, had become visible, as if by magic, in a night. It was plain that the woods as well as the fields were spider-ridden. At other times flights of migrating spiders are wafted on the air by their little balloons or parachutes, rising high and crossing ponds and rivers. Such sights as these suggest what might occur were not spiders held in check by birds. When we consider the vast numbers of spiders and the possibilities 
of their increase, we may be content that Chickadees and other birds eat them.

Dr. Weed, who has studied the winter food of the Chickadee, says that the destruction of the myriad eggs of plant lice, which infest fruit, shade, and forest trees, is probably the most important service which the Chickadee renders during its winter residence. More than four hundred and fifty eggs are sometimes eaten by one bird in a single day. On the supposition that one hundred were eaten daily by each of a flock of ten Chickadees, there would be destroyed one thousand a day, or one hundred thousand during the days of winter, by ten birds only, - a number which he believes to be far below the real condition, could we determine it precisely. Dr. Weed has found in Chickadees' stomachs a carabid beetle, a snout beetle, a leaf hopper, and remains of what appeared to be the oyster-shell bark louse. This prying bird eats many of the most injurious insects that might escape the observation of larger birds. The cocoons of certain microlepidoptera that hibernate on the twigs of fruit trees are eagerly sought by these birds. The little case-bearers are greedily eaten by them.

Thus we see that the Chickadee feeds on borers which live under the bark, on plant lice which suck the sap, on caterpillars which destroy the leaves, and on the codling moth which injures the fruit. It even digs into decaying twigs, and extraets wood borers. It has not the skill of the Woodpecker in going directly to the spot where the borer is located, but it finds the burrow, and pecks and chips away the decayed wood along it until the larva

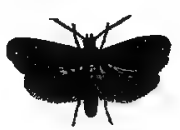

Fig. 51. - Cor. ling moth, parent of theapple worm, eaten by the Chickadee. is reached. Undoubtedly Chickadees kill many of the destructive white pine weevils ( $P$ issodes strobi). While working among pine trees I saw several Chickadees go to infested shoots, peck them, and apparently extract the larvæ. These dying shoots seemed to be the principal attraction which brought them to the pines.

The practical value of the Chickadee to the orchardist may be inferred from the results of the experiment referred to on 
p. 150, in which an attempt was made to foster and protect the birds in an old and neglected orchard, with a view to observing the effect of such a policy upon the trees. The Chickadees were attracted to the orchard in winter, and were seen destroying thousands of eggs of the fall cankerworm moth, and many egg-bearing females as well. A few of the birds

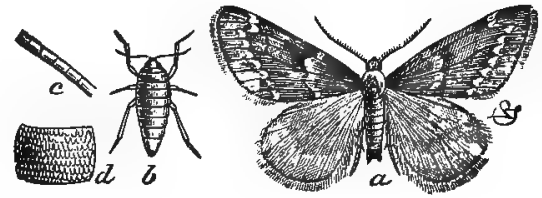

Fig. 52. - Fall cankerworm moth: $u$, male moth; $b$, wingless female moth ; $c, d$, structural details.

were killed, and their stomachs examined for evidence corroborative of our observations. The following notes are taken from the record of the experiment, as published in the annual report of the Massachusetts State Board of Agriculture for 1895 :-

Eggs of the fall cankerworm found in stomachs of Chickadees:-

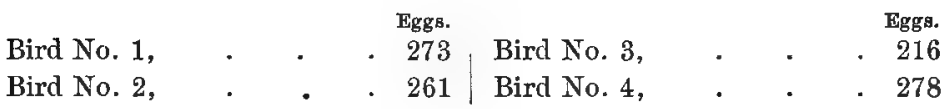

Making in all ten hundred and twenty-eight eggs found in the stomachs of four birds. Four birds killed later in the season had eaten the female imagoes of the spring cankerworm (Paleacrita vernata), as follows: -

Bird No. 1 Moths. Bird No. 2, 41 Bird No. 3, Moths. Bird No. 2,

Making a total of one hundred and five. In Nos. 2, 3, and 4 of the last table there were a large number of eggs also. It is safe to say that there were one hundred and fifty eggs in each stomach, in addition to the female moths eaten.

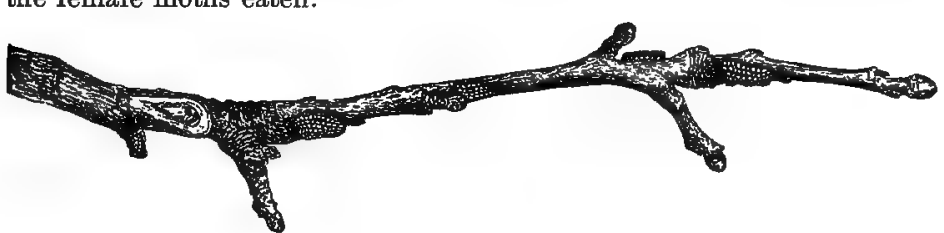

Fig. 53. - Apple twig, with eggs of the cankerworm moth. These eggs are eaten by the Chickadee.

Mr. C. E. Bailey carefully counted the eggs in the ovaries of twenty of these female moths, with the following results :- 


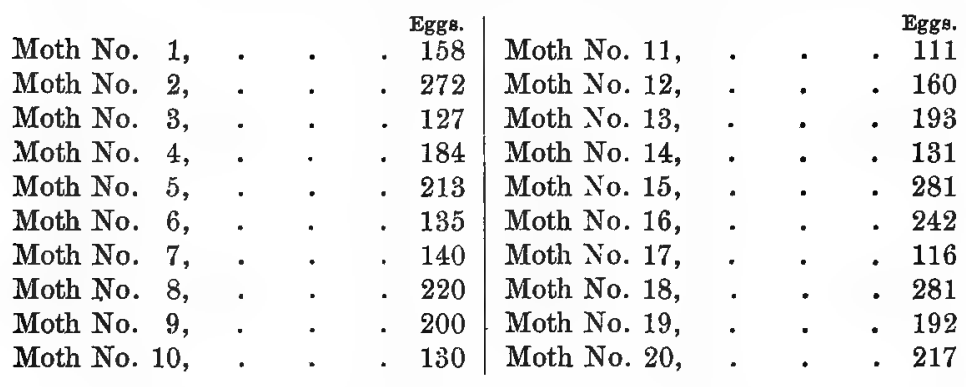

It will be seen from this table that the average number of eggs found in the ovaries of each moth was one hundred and eighty-five. Mr. Bailey was very positive, from his continuous field observations, that each Chickadee would devour on the average thirty female cankerworm moths per day from the 20th of March to the 15th of April, whenever these insects were plentiful. If the average number of eggs laid by each female is one hundred and eighty-five, one Chickadee would thus destroy in one day five thousand, five bundred and fifty eggs; and in the twenty-five days in which the cankerworm moths "run" or crawl up the trees, one hundred and thirty-eight thousand, seven hundred and fifty. It is probable that some of the moths were not captured until they had laid some of their eggs, but the Chickadees found and ate most of these eggs also. When we consider, further, that forty-one of these insects, distended as they were with eggs, were found packed within the stomach of one Chickadee, and that the digestion of the bird is so rapid that its stomach was probably filled many times daily, the estimate made by Mr. Bailey seems a very conservative one. As the frost left the ground on the first warm days of spring the wingless females of the spring cankerworm moth appeared in the orchard and began ascending the trees in great numbers. The Chickadees commenced catching these insects and eating them and their eggs. Mr. Bailey placed twenty-two of the females on one tree, and in a few minutes twenty of them were captured and eaten by Chickadees. As a practical result of the presence of the Chickadee in that orchard during the winter, there were so few eggs of the cankerworm moths left in the spring that, as heretofore 
stated, the summer birds were able to destroy the worms resulting from them.

In early spring Chickadees feed much upon the ground in the woods. At such times $\mathrm{I}$ have seen them opening softened acorns, that have lain all winter beneath the snow, and extracting grubs from them.

The Chickadee is not known to have any harmful habits. Wilson says that it has been known to attack and injure its own kind, but he gives no positive evidence of this, and I can find no record of this habit elsewhere. Their fondness for animal food leads them sometimes to eat the bodies of other birds that have been stuck on thorns by the Butcher Bird, or to feed from the carcass of any fox or other animal left hanging in the woods by trappers. This habit probably accounts for the fact that feathers or hair are sometimes found in their stomachs.

One mild day in the winter of 1903-04 Mr. Mosher saw two Chickadees catching a few bees that had come out of a hive and were becoming benumbed by the cold. This was a particularly hard winter, during which many birds died of starvation and exposure, and the birds were doing no harm, as the bees, once away from the hive, would never have been able to return to its shelter. The Chickadee is not known to injure grain or cultivated fruit. Occasionally it pecks a frozen apple left hanging on the tree in winter, but I can find no record of its having injured fruit at any other time. It would be hard to find a bird more harmless or more useful than this species.

White-breasted Nuthatch.

Silta carolinensis.

Length. - About six inches.

Adult. - Upper parts a rather light bluish-gray ; crown, nape of neck, and upper back black; wings and tail marked somewhat with black and white; lower parts and sides of head mainly white.

Nest. - In an old post or an excaration in a tree trunk, which is sometimes hollowed out by the birds.

Eggs. - Much like those of the Chickadee, but larger.

Season. - Resident.

Most writers regard this common and familiar species as a bird of the forest; but in eastern Massachusetts it has 
become a frequenter of orchard and shade trees, and is commonly seen along village streets in fall, winter, spring, and sometimes even in midsummer, although comparatively few

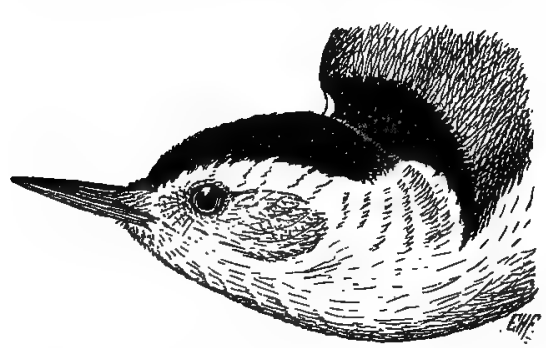

Fig. 54. - White-breasted Nuthatch, two-thirds natural size. breed in the State. In the fall it may be seen here and there in the woods or orchards, often in company with Chickadees and other tree gleaners. In winter this species is almost always engaged during daylight in a diligent search over the trunks and larger limbs of trees, particularly on the rough bark of the larger trunks, where it finds a great part of its insect food. In one instance, where a workman had pared off most of the outer bark from a large oak, two of these Nuthatches were seen busily engaged for two days in searching and delving among the pile of bark chips left on the ground.

This Nuthatch is the particular guardian of the deciduous trees, preferring the oak, chestnut, elm, and other hard-wood trees to the pine. It also frequents old orchards, where the rough bark affords concealment for many injurious insects, and offers a good foothold. It is a cheerful bird, and often manifests much curiosity. It will sometimes come quite near any one who attracts its attention, and, hanging head downward on trunk or limb, utter its nasal quank, quank, - a peculiar, weird sound, somewhat like the quack of a duck, but higher keyed and with less volume, having rather a musical twang.

No other native birds are so often seen upside down as are the Nuthatches. Audubon and Wilson both say that these birds sleep in this position. In winter the White-breast passes the night in some cleft or hollow in a tree trunk. Dr. G. V. Harvey of California says that one evening he saw twenty-nine White-breasted Nuthatches come singly to an old, dead, yellow pine, alight upon a knot, and vanish into a large crack in the trunk. They came at quite regular in- 
tervals, one after another, and evidently used the cavity as a lodging place, for that night at least. ${ }^{1}$

Even the Woodpeckers, supplied as they are with a reversed toe and a stiff, supporting tail, cannot compete with the Nuthatches in descending head first. The Woodpecker when going down the trunk finds itself in the same predicament as the bear, - its climbing tools work only one way. It is dependent on its stiff tail for support, and so must needs hop down backwards. The Creeper is still more hide-bound in its habits, and its motto seems to be "Excelsior." It begins at the foot of its ladder and climbs ever upward. But the climbing ability of the Nuthatch is unlimited. It circles round the branches, or moves up, down, and around the trunks, apparently oblivious to the law of gravitation. Its readiness in descending topsy-turvy is due in part to the fact that, as the quills of its tail are not stiff enough to afford support, it is obliged to depend upon its legs and feet. As it has on each foot three toes in front and only one behind, it reverses the position of one foot in going head downward, throwing it out sidewise and backward, so that the three long claws on the three front toes grip the bark and keep the bird from falling forward.

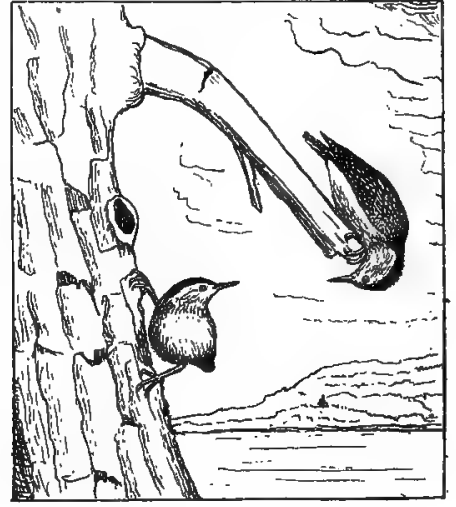

Fig. 55. - Nuthatches.

The other foot is thrown forward, and thus with feet far apart the "little gymnast has a wide base beneath him." In the third volume of Reed's American Ornithology Rev. Leander S. Keyser describes and illustrates this manner of progression. The Nuthatch not only straddles in going down the tree, but spreads its legs widely in going round the trunk, as will be seen by the accompanying cut, sketched from life in 1895. Mr. William Brewster has photographed the Redbreasted Nuthatch in similar positions, but bird artists gen- 
erally seem to have overlooked this habit. The slightly upturned bill of the Nuthatch, and its habit of hanging upside down, give it an advantage when in the act of prying off scales of bark under which many noxious insects are secreted.

The food of this bird consists very largely of insects, although it is capable of subsisting on seeds, for it has a strong muscular gizzard, and consumes much sand or gravel for grinding its food. In winter, when it is difficult to find sufficient insect food, the Nuthatch feeds in part on such seeds as it can pick up. Oats and corn are then eaten wherever they can be found.

Prof. E. Dwight Sanderson, who examined thirty-four stomachs of this species taken in Michigan, found many seeds, among them ragweed and wild sunflowers. The birds had eaten seeds in winter to the amount of sixty-seven and four-tenths per cent. of the stomach contents, while the remainder consisted of gravel and insects ; but in early spring only thirteen and five-tenths per cent. of the food was of a vegetable nature, while seventy-nine and five-tenths per cent. consisted of insects. He found Piesma cineria the most common noxious insect in these stomachs. This insect, as he remarks, "never does any considerable injury." Its frequent presence in the stomach of the Nuthatch may possibly explain why it is not more injurious. Although seven orders of insects were represented in these stomachs, Professor Sanderson regards the birds as neutral, for no first-class pests were recognized, and many beneficial and neutral insects were found; but we have seen that the destruction of parasitic or predaceous insects by birds is not necessarily or always an injurious habit; in Massachusetts several pests are eaten by the Nuthatch, and we have not yet recognized in their stomachs any large proportion of beneficial insects. This suggests the possibility that the conditions in Michigan, when the examinations were made by Professor Sanderson, were unusual. He notes that he was unable to obtain a specimen from any orchard infested with insect pests. ${ }^{1}$

1 The Economic Value of the White-bellied Nuthatch and the Black-capped Chickadee, by E. Dwight Sanderson. The Auk, Vol. XV., 1898, pp. 145-150. 
Profeșsor King in Wisconsin found beetles, including snap beetles and boring beetles, in the stomachs of fourtecn birds of the species. In Massachusetts it feeds largely on beetles, taking many that bore in the bark or wood. It also feeds on the eggs of insects, and on hiluernating larvæ and ants. Scale insects are taken in winter. The oyster-shell bark seale louse (Lepidosaphes ulmi), injurious to the apple, pear, currant, and other useful plants and trees, is eaten greedily. The proportion of insect food increases as spring advances, and the young are fed largely if not entirely on insects. On Nov. 26, 1897, Mr. Kirkland examined the stomach

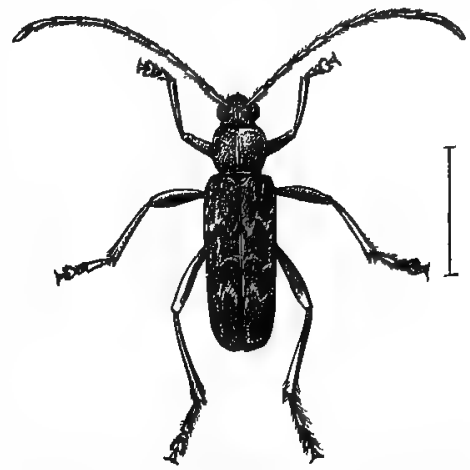

Fig. 56. - Wood-boring beetle, much enlarged. Ninthatches eat such beeties. of one of these birds, which contained one thousand, six hundred and twenty-nine eggs of the fall cankerworm moth. As there were no moth remains, it was evident that the bird had gathered these eggs from the bark.

One day Mr. Bailey watched a pair of these Nuthatches in Brookline. The birds went regularly from tree to tree, searching beneath the burlap bands for gipsy caterpillars, which for several hours they carried continually and fed to their full-fledged young. The young birds also found and killed a few. The preference shown by these particular birds for the hairy gipsy caterpillars at this place seems remarkable, as there were comparatively few of these larvæ to be found there at the time.

This Nuthatch has been seen to eat cankerworms, forest caterpillars, and plant lice, and there is no doubt that ordinarily it is a valuable species while here. 
Red-breasted Nuthatch. Canada Nuthatch.

Sitta canadensis.

Length. - Four and one-half to nearly five inches.

Adult Male. - Above, deep, bright bluish-gray; chin and throat whitish ; other lower parts rusty or deep buff ; tail feathers marked with black and white; a white stripe above the eye, a broad black stripe through the eye, and a black crown.

Adult Female. - Similar, but duller; the eye stripe dusky, and the crown lighter than that of the male.

Nest and E'ggs. - Much like those of the Chickadee.

Season. - Resident, but local in the breeding season.

This dainty little bird is considered rare in Massachusetts in the breeding season. While a few nest in suitable localities, the great majority retire to the northern wilderness

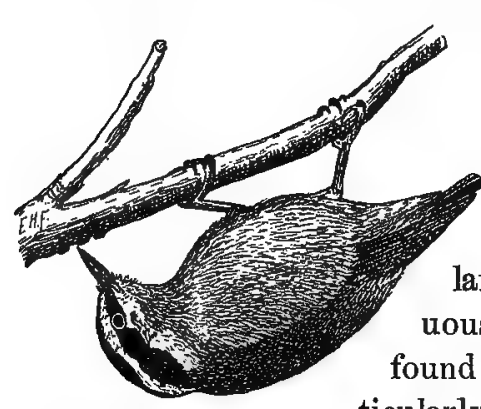

Fig. 5 7.- Red-breasted Nuthatch, one-half natural size. rigida).

in summer. From October to April, however, it is quite common in this State during some seasons. It performs for the pines a similar service to that rendered by its larger relative among the deciduous trees. It is almost constantly ticularly fond of the pitch pine (Pents

The common notes of the bird are not unlike those of the White-breasted Nuthatch, but higher, sharper, and quicker. It has also a musical varied twitter, not mentioned in books, so far as I know, which can be heard but a few feet away.

It runs about much in the manner of the White-breasted Nuthatch, but is perhaps oftener seen beneath a limb. It sometimes feeds nearer the ends of the branches in winter, perhaps because it more commonly extracts the seeds from pine cones. It picks up corn wherever it can be found in winter, and I have watched it hiding the kernels behind scales of bark on the pitch pine, - a habit common to both Nuthatches and Titmice. A large majority of these birds go farther south than Massachusetts in winter, but many remain wherever they can find pine seed, suitable insect food, 
and safe shelter. They are seen more in woods and less about orchards than is the preceding species, and, though probably very useful in the pine woods, they are not of so much value in orchards, unless attracted there by artificial means.

\section{CREEPERS.}

This family of bark-climbing specialists has but one representative in Massachusetts. The Creepers climb upward and fly downward.

\section{American Brown Creeper.}

Certhia familiaris americana.

Length. - About five and one-third inches.

Adult. - Sepia-brown above, varying in intensity, finely marked with whitish; under parts white.

Nest. - Usually built behind some loose flake of bark or in a cleft in a tree trunk.

Eggs. - Grayish-white, nearly oval, and sparingly sprinkled with brown spots, chiefly at larger end.

Season. - Resident, but local in summer.

This is a modest, quiet, and unobtrusive species. Its curved bill and long, rigid tail distinguish it from all other birds. It is quite common in Massachusetts in fall and spring, less so in winter, and rather rare in summer. Most individuals of this species that do not go farther north to breed retire in spring to dark, cool cedar swamps, where they nest.

The usual note of this bird is a thin screep, suggesting that of the Goldencrowned Kinglet, often repeated twice or more. It has also a fine chip, and in summer a sweet, wild, indescribable song. The Creeper is pre-eminently a bird of the forest. Everywhere in great tracts of woods it may be found laboring day after day to surmount one giant trunk after another, only to fly

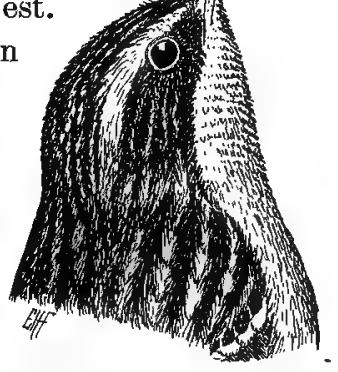

Fig. 58. - Brown Creeper, natural size. down to the foot of still another, that it may climb again. In the tall, dark forests of fir, pine, and cedar on the Pacific slope of the Cascade Mountains the Creeper's chirp is one of the few characteristic bird notes that come down to the . 
wanderer from the dizzy heights of those towering trunks. In the pine woods of New England or Canada the Creeper ever goes its ceaseless rounds. It is a guardian of the tree trunk. It is not very often seen among the branches, although it sometimes feeds on the seed of the pine.

The Creeper feeds very largely on insects, which it finds on the bark or extracts from the cracks and crevices with its long, sharp bill. I have often tried to determine by observation the food of this bird, but can only say that it seems to find boring grubs and the pupæ and eggs of insects. In this quest it examines a large number of trees daily. Mr. Bailey spent an hour watching one of these birds on March 30 , 1899. It inspected forty-three trees, beginning about two feet from the ground, or at just about the height to which the ground-frequenting birds would reach. Thirty-six trees were white oak and seven white pine. It went up each tree about twenty feet, going round and round the trunk, then flew to another. It appeared to prefer the white oak to any other tree, probably because the oaks in that locality were infested with numerous insects. It progressed in this manner about one hundred yards within the hour. At night a Creeper, probably the same bird, was still in the near-by woods. We have little accurate knowledge of the food of this bird. The only precise determination of its food that has come to my notice is recorded by Dr. Judd in Maryland. The stomach contained such beetles as Helops acreus and Bruchus hibisci; also sawflies, ants, spiders, and seeds of scrub pine.

\section{THRASHERS AND MOCKINGBIRDS.}

This group is represented here by the Thrasher and C'atbird. Both are birds of the thicket, and are found habitually in sprout growth or young coppice, and in shrubbery on the borders of woods. They feed largely on or near the ground and in shrubbery, but often make excursions into woods, pastures, fields, or gardens. 
Brown Thrasher. Brown Thrush. Red Mavis. Planting Bird.

Toxostoma rufum.

Length. - Nearly eleven and one-half inches.

Adult. - Reddish-brown above, with white wing bars; below, mainly white; breast, belly, and sides of throat streaked or spotted with blackish.

Nest. - Loosely built of twigs, etc., on the ground or in a brush pile or low bush.

Eggs. - As large as the Robin's; white or greenish, thickly spotted with light reddish-brown.

Season. - April to October.

This bird may be distinguished from the true Thrushes by its large size, long tail, and long, curved beak. It arrives in Massachusetts the latter part of April, and leaves for the south in October. Its rich, bold, and varied song may be heard along the borders of woodland, in coppice growth, or from some tall tree about the farmyard or pasture.

The song was first brought prominently to my attention when as a barefoot boy of ten I was dropping corn in the field at planting time. The Thrasher sat in a tree near the cornfield, its swelling throat pouring forth a flood of music on the warm May wind. Just over the wall in the adjoining field a dusty plowman stopped his team. "There, boy," he said, "that is the Planting Bird. Some folks call it the Red Mavis. Hear him sing, 'Drop it, drop it, drop it; cover it up, cover it up, cover it up ; I'll pull it up, I'll pull it up." " Both words and song made so strong an impression on my youthful mind that they have never been effaced from my memory. Later we found that the Thrasher had kept his promise, and pulled up some of the corn that we had planted.

This is the only really harmful habit of this bird, and this seems to be more local than general; for, while it pulls a little corn on some farms, there is no complaint from it elsewhere. Thoreau reports a similar phrasing of the Thrasher's song, but omits every reference to the bird as a corn puller, giving the last part of the song as "Pull it up." He also mentions the common name Mavis, by which I think the bird is now known only among the older people. This name is probably of European origin, and came down to us from the early settlers; but the bird is still known among farmers in some sections of the State as the Planting Bird or Brown Thrush. 
Its alarm note is a loud smack or chick, very incisive, and frequently followed by a mournful whistle. It also makes a hissing or wheezing sound, which is often heard when it is defending its young.

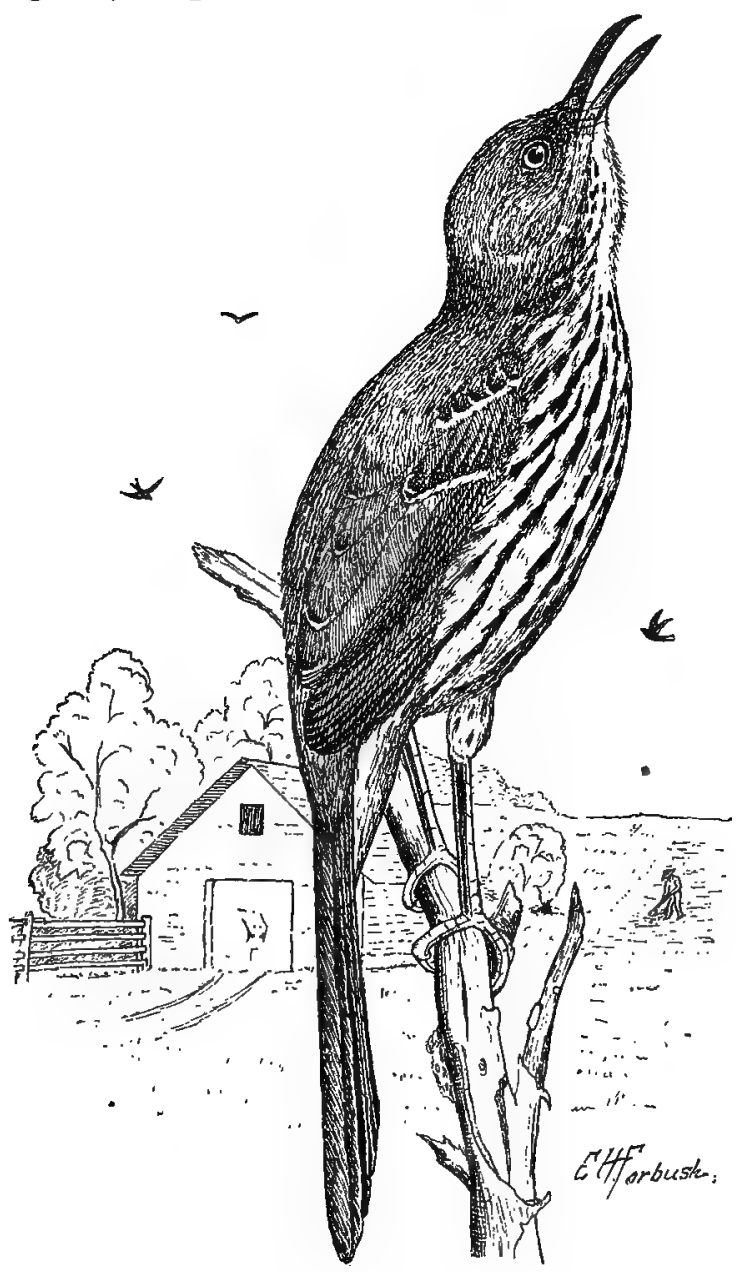

Fig. 59.-Brown Thrasher, one-half natural size.

The Brown Thrasher feeds largely on insects. As it usually retires during the breeding season to scrubby lands or sprout growth near woodland, it takes very little cultivated fruit, and the small amount of corn it consumes is usually more than made up for by the white grubs taken from 
woodland, cornfield, and garden. Dr. Judd gives a summary of the results of an examination of the stomachs of one hundred and twenty-one of this species; thirty-six per cent. of the food was vegetable, and sixty-four per cent. was animal, which was practically all insects, mostly taken in spring, when no fruit was ripe. Half the insects were beetles, mainly harmful species. The remaining animal food was chiefly grasshoppers, caterpillars, bugs, and spiders.

The Brown Thrasher more than repays us for the cultivated fruit that it eats by the number of insect pests that it consumes earlier in the season. While it eats considerable wild fruit and some that is useful to man, it probably pays for this by destroying many of the disgusting bugs that eat berries. As the Thrasher feeds much on the ground, it destroys many grasshoppers, crickets, white grubs, and May beetles. Professor Forbes states that in Illinois nearly half the food of this bird consists of waste grain picked from the droppings on the roads. He also asserts that it eats cultivated fruit in less proportion than do other Thrushes. There, as here, June beetles form a considerable per cent. of its food, and it eats both snap beetles and curculios. The Thrasher eats caterpillars, but mainly such species as are found on the ground. It picks up cutworms, cankerworms, and some gipsy moth caterpillars, but is not usually fond of hairy caterpillars. On the whole, it is a bird that should be protected by the farmer.

\section{Catbird.}

Galeoscoptes carolinensis.

Length. - A bout nine inches.

Adult. - Both upper and under parts dark gray; top of head and tail blackish; under tail coverts chestnut.

Nest. - Composed of sticks and twigs, bark and rootlets, placed in a bush or vine.

Eggs. - Dark, glossy, greenish-blue.

Season. - May to October.

The Catbird is very common in this State. Its voluble manner, cat-like cry, musical song, habits of mimicry, and bravery in defence of. its young are all too well known to need description. As an imitator, it is second only to the Mockingbird. I have heard the cry of the Bob-white or 
Quail and some of the notes of the Wood Thrush, together with those of many other birds, given by the Catbird. It may not be generally known that this bird, like many other species, often sings in a very low tone when it believes that danger is near. In October it sometimes repeats its spring

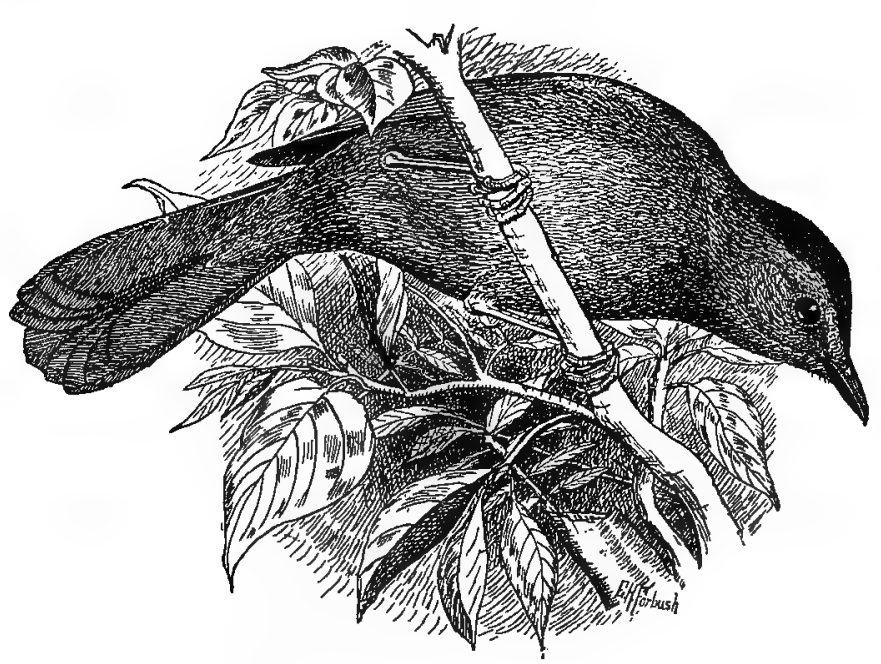

Fig. 60. - Catbird, one-half natural size.

song so softly that it seems to come from far away when uttered within a few feet of the hearer. The bird's moods are many. It is in turn a merry jester, a fine musician, a mocking sprite, and a screaming termagant, but always an interesting study, and never prosaic or mediocre.

No doubt the Catbird is useful, as it fills, in moist thickets, a place similar to that taken by its relative the Thrasher on the drier lands. Unfortunately, however, the poor bird has acquired a bad reputation. It is accused of sucking the eggs of other birds and destroying much fruit. The first charge must be dismissed as not proven, but the second is sustained by good evidence. Dr. Judd reports on the examination of two hundred and thirteen stomachs, from Florida to Kansas and Massachusetts. He finds that three per cent. of the food consists of carnivorous wasps and bees; spiders are also eaten; but the destruction of useful insects is more than made up for by the number of weevils, plant-feeding bugs, 
May beetles, and other injurious species taken. The destruction of the ground beetles eaten by the Catbird is probably at the worst a necessary evil. It eats many caterpillars, including cutworms, also grasshoppers and crickets. Ants and crane flies formed a large proportion of the insect food of some Catbirds dissected by Professor Forbes, who says, however, that in midsummer the Catbird subsists mainly on fruit, and only takes such insects as come its way. Young Catbirds while in the nest are fed very largely on insect food. Dr. Weed examined the stomach contents of three nestling Catbirds in Michigan, and found that ninety-five per cent. of the food consisted of insects, two per cent. of spiders, and three per cent. of myriapods. Sixty-two per cent. of this food was composed of cutworms, eleven per cent. of ground beetles, four per cent. of grasshoppers, three per cent. of May flies and two per cent. of dragon flies. Dr. Judd also found that the nestlings were fed almost entirely on insects. All these statements go to prove the value of the Catbird on the farm.

On the other hand, the adult Catbird often lives so largely on cultivated fruit in midsummer that were its numbers greatly increased it might become an unbearable pest to the fruit grower. Its destructiveness to small fruits varies, however, in different localities. Sometimes the Catbird will leave its favorite thickets and build its nest in the raspberry or blackberry bushes, or among the grapevines in the garden. A pair of these birds that occupied a nest in our garden at Worcester where they were surrounded by fruit did no injury compared with that inflicted by a pair of Catbirds that nested in the shrubbery near our garden at Wareham. There I found that the Catbirds came to the garden mainly for strawberries. They chose the best fruit, and seemed to live on that alone during the strawberry season. The Catbirds ate more fruit than the Robins, although the latter were far more numerous, and, as is usually the case, were blamed at first for the loss of all the fruit.

While the Catbird is often a pest to the fruit garden, eating, as it does, most small fruits, it is so useful in case of insect outbreaks that it deserves protection. Five Catbirds 
dissected by Professor Aughey during a locust irruption had eaten one hundred and fifty-two locusts. When injurious caterpillars are numerous, the Catbird attacks them. Its name appears in the list of birds which feed on brown-tail and gipsy caterpillars, cankerworms, forest caterpillars, and tent caterpillars. It also feeds its young on the hairy caterpillars of the gipsy moth and the brown-tail moth, and on many of the imagoes as well as those of native noctuids. I have frequently observed this habit. A Catbird used to come to my window early in the morning to get the eutworm moths that had flown against the screen in the night.

Mr. F. H. Mosher watched two pairs of Catbirds and their young in 1895, and found that the young were fed very largely on gipsy caterpillars. He says :-

'The Catbird when feeding is most busy in the morning until about 8.40. From that time she comes occasionally until from 3 to 4 o'clock, when she is more active again. In the morning she would come and eat two or three herself, and then carry one to her young. She would be absent about five minutes. After she had made two or three trips she would not stop to eat any herself. In the afternoon, during her period of greatest activity, she would make trips about erery ten minutes. She seemed to prefer larve to pupæ, but when hard pressed would take pupæ. 'The size of the larvæ seemed to make no difference to her, as she took the full-grown just as readily as the small.

Mr. Mosher thought in 1895 that the Catbird was, next to the Cuckoos and Orioles, the most important enemy of the gipsy moth. These three species alone would be enough, if in sufficient numbers, to check this insect in the localities which they frequent. The Catbird forages mainly on the ground and in shrubbery, but seldom in trees. The Cuckoos feed mainly among the lower branches, while the Orioles go up even to the topmost twigs.

From the evidence at hand we must conclude that, though the Catbird is sometimes a nuisance to the fruit grower, it must be tolerated and even encouraged for the good it does. The problem before us is not how to destroy the birds, but how to keep both birds and fruit. 


\section{WARBLERS.}

Of the twenty-five species and two sub-species of Warblers that may be confidently looked for each spring in Massachusetts, either as migrants or residents, only eight are generally distributed throughout the State in the breeding season, and two of these are rather local. Several other species breed here, but only locally or rarely. Only the more common familiar summer resident species, which are of great economic importance, will be mentioned here. The migrants are of great though lesser importance. Their abundance in migration is probably governed largely by the number of insects to be found upon the trees. Whenever large numbers of Warblers are seen here in migration, their presence may be taken as an indication of a plentiful supply of the arboreal insects on which chiefly they feed. The fact that Warblers live mostly on small insects does not lessen their usefulness, - it may even make them more valuable. Warblers are undoubtedly responsible for the destruction of many of the young caterpillars of the great cecropia, promethea, and luna moths, which, while still too small to do any harm, are killed off by birds. It should be noted also that many of the greatest pests are very small even at maturity. The onion fly, the Hessian fly, the wheat midge, and many injurious Lepidoptera and Coleoptera are among the tiny insects that are eaten by small birds. Only the smaller birds can follow insects to the tips of the slenderest twigs; therefore, the smaller the bird the greater its special usefulness.

We have already seen that Warblers have a great capacity for destroying small insects. In migration they seem to possess most remarkable appetites. Rev. Leander S. Keyser watched a Hooded Warbler, and found that it caught on the average two insects a minute, or one hundred and twenty an hour. He estimates that at this rate the bird would kill at least nine hundred and sixty insects a day, assuming that it sought them but eight hours. ${ }^{1}$

\footnotetext{
1 Papers presented at the World's Congress on Ornithology, 1896, pp. 41, 42.
} 
Mr. Robert H. Coleman, in a letter to the Biological Survey, stated, according to Dr. Judd, that he counted the number of insects eaten by a Palm Warbler, and found that it varied from forty to sixty per minute. 'The bird, he said, spent at least four hours on his piazza, and in that time must have eaten about nine thousand, five hundred insects.

I have seen Warblers eating from masses of small insects at such a rate that it was impossible for me to count the number of insects eaten. When larger insects are taken, the time given to each increases. The bird will sometimes spend at least ten minutes in the attempt to swallow a large caterpillar. It is difficult, therefore, to approximate the number of insects eaten by a Warbler in a day, except where it is feeding mainly on a particular species.

In this family we find birds that assume the care of the trees from the ground to the topmost twig. Some walk daintily along the ground, searching among the shrubbery and fallen leaves; others cling close to the bark, and search its every crevice for those insignificant insects which collectively form the greatest pests of forest and orchard ; others mount into the tree, skip from branch to branch, and peer about among the leaves or search the opening buds of the lower branches; others habitually ascend to the tree tops; while still others are in almost constant pursuit of the winged insects that dart about among the branches. We will first consider the common ground-frequenting species.

Northern Yellow-throat. Maryland Yellow-throat.

Geothlypis trichas brachidaclyla.

Length. - About five and one-quarter inches.

Adult Male. - Upper parts olive-green; forehead and mask black, bordered above by ashy-gray; under parts mainly bright yellow.

Adult Female. - Like the male, but without the black or ashy; under parts paler. Nest. - On or near the ground, supported by grass stems, leafy plants, or shrubs; deep, and composed mainly of leaves and grasses; sometimes roofed, and not infrequently hair-lined.

Eggs. - White, spotted with brown and lilac at the larger end. Season. - May to October.

This Yellow-throat is a bird of the brookside and swampy thicket; but it is not by any means confined to these localities, for it is found in the fruit garden and orchard as well as 
in the woods. While it feeds somewhat in trees, its habit, like that of other Warblers of the genus, is to keep near the ground and in shrubbery; hence it is often seen along bushy roadsides, particularly where the road crosses a swamp or stream. It usually keeps close to the underbrush, peering out from between leaves and stems, and occasionally taking short flights near the ground.

It greets all comers with a sharp chirp, or voices its alarm in a rattling, Wren-like chatter. In singing it sometimes mounts to a high perch in a tree or rises in air, but ordinarily delivers its song while pursuing its

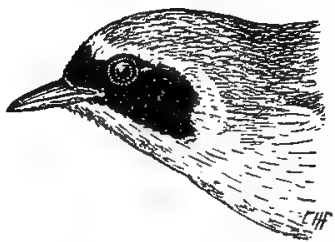

Fig. 61.-Northern Yellowthroat, two-thirds natural size.

usual avocations among the shrubbery. The song is a series of phrases, with the accent on the first syllable, thus, sich'-a-wiggle, sich'-a-wiggle, sich'-a-wiggle, or in some cases witchery, witchery, witchery. It is much varied in length and expression, but usually may be known by the repetition of the strongly accented syllable. Like many other Warblers, this bird has three or more variations to its strain, but with perhaps one exception they are all unmistakable.

The Yellow-throat usually arrives at its chosen haunts in Massachusetts early in May. It often lays two sets of eggs, and two broods are sometimes reared. In the fall flights the birds may be scen from time to time as they stop on their journey southward. One day you will find scarcely one; the next, the brooksides and river banks may be alive with them. This bird is undoubtedly among the most useful species which in summer frequent our shrubbery, woodlands, orchards, roadsides, and bushy pastures. In pastures the Yellow-throat eats many leaf hoppers, which are abundant among the grass and low-growing herbage that it frequents. Prof. Herbert Osborn has shown that on an acre of pasture land there frequently exist a million leaf hoppers, which consume, perhaps unnoticed, as much grass as a cow, if not more. The Yellow-throat, on account of its destruction of leaf hoppers and grasshoppers, may be ranked among the useful birds of the fields. In orchards it often feeds very 
largely on cankerworms, going long distances from its nest to get these caterpillars to feed to its young. Since one of these birds was seen to eat fifty-two caterpillars of the gipsy moth in a few minutes, it seems probable that it may yet be ranked among the efficient enemies of this pest. Case bearers, leaf rollers, and many other destructive caterpillars are greedily devoured, and it also catches and eats both butterflies and moths in considerable numbers.

Along the borders of woods it is very destructive to many beetles, flies, and especially to plant lice, of some species of which it is very fond. It often goes to grain fields, where, so Wilson says, it eats insects that infest them.

Oven-bird. Golden-crowned Thrush. "Teacher Bird."

Seiurus aurocapillus.

Length. - Six to six and one-half inches.

Adult. - Olive-brown above; crown dull orange or yellowish-buff, bordered by black stripes; white below; breast and sides streaked with blackish.

Nest. - On the ground in woods, often on knoll or hillside; generally roofed,

with entrance on lower side; usually made of sticks, rootlets, leaves, etc., and lined with hairs; that from which the accompanying cut was made was built entirely of pine leaves or "needles."

Eggs. - Creamy white, spotted with brown and faint lilac.

Season. - May to September.

How well I still recall that panorama of the dim woods that passed before my eyes when as a child of eight years I first began to wander off at daybreak to learn the secrets of nature. As I first stole through the shadows down the back of "Muddy Pond Hill," where the "cotton-tail rabbit" bounded away before me, where the "Partridge" burst into thunderous flight amid a whirl of scattered leaves, and dashed away through bending twigs and swaying branches, every sight and sound impressed itself vividly upon my youthful mind, but none made a more lasting impression than the song of the Oven-bird. To me the bird then seemed to say chick', KERCHICn', KERCHICK', repeating its single phrase an indefinite number of times, while the silent woods, acting as a sounding board, rang and reverberated with the crescendo strain. Later, when I lingered in the woods at evening until the stars came out and the 
bats were flying (for my days were spent at school, and there was no time but morning and evening in which to really live), I heard a burst of melody far above the tree tops, and saw the little singer rising against the glow in the western sky, simulating the Skylark, and pouring forth its

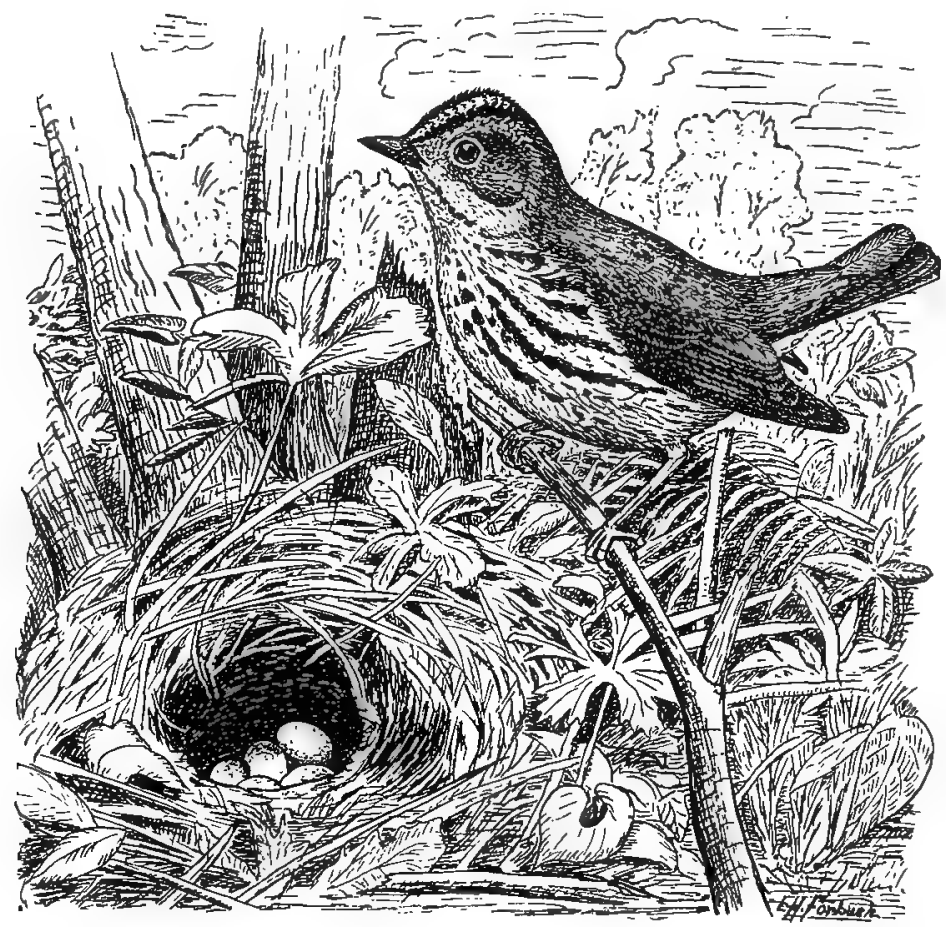

Fig. 62. - Oven-bird and nest.

melody, not to the orb of day but to the slowly rising moon; then, when the melody came nearer, as the exhausted singer fell from out the sky and shot swiftly downward, alighting at my very feet, I saw in the dim light that the author of this soaring vesper song was my little common, every-day friend, the Oven-bird. Night after night I listened to its flight song above the wooded hills of Worcester, where it is one of the usual sounds of evening. Years afterward, John Burroughs, the dean of nature writers, described its evensong, and people seemed to marvel as if it were a new 
discovery. It seemed to me impossible that any one who ever went out into the woods at evening should have missed hearing this characteristic song. But so it is. Some one describes for the first time some common sight or sound of the woods and fields, - something well known to all who frequent them, something which it. seems ought to be known to all the world, - and it is received with acclaim as a discovery. Mr. Burroughs has aptly given the Oven-bird the name of calling "Teacher, teacher," but here in Massachusetts it exhorts the teacher to teach somewhat as follows: "Teacher, teacher, TEACHER, TEACHER, TEACHER, TEACHER, TEACH." The bird is already becoming known as the "Teacher Bird." Its common alarm notes are a chuck or a sharp chick.

Its golden crown, its spotted breast, and its manner of walking upon the ground or along a limb, as well as its characteristic song, which is usually uttered when the singer is perched upon a horizontal limb in the woods, will all serve to identify the bird. The lift of the tail, which is characteristic of all birds of this genus, and which has given them the name of Wagtails, is more noticeable among the WaterThrushes than with this species. The Oven-bird is more distinctively a ground Warbler than any other common species except the Water-Thrushes. It feeds very largely from the ground, walking about silently and deliberately, as if in no hurry, and picking up its food from among the fallen leaves; but when alarmed it usually flies to the trees, among the branches of which the males sing and woo their intended mates. When the female, having young, is started from the nest, she drags herself along over the ground fluttering as if sorely wounded, in an effort to lead her disturber away from her home. Both parents are exceedingly affectionate toward their young, and endeavor to protect them by every means in their power.

When upon the ground it feeds like Thrushes and Towhees, finding grubs among the leaves, and picking up caterpillars or other insects that have dropped from the trees. In this way it finds many caterpillars of the gipsy moth in their hiding places among dead leaves or shrubbery. It 
often goes to orchards near the woods, and seeks cankerworms and other tree pests. Dr. Warren says that it eats earthworms. While mainly inseetivorous, this bird can subsist partly on farinaceous food. It picks up many small seeds, and dwellers in the woods find it coming about the doors for crumbs.

\section{Black and White Warbler. Black and White Creeper.}

Mniolilta varia.

Length. - About five and one-quarter inches.

Adult Male. - Streaked generally except on belly with black and white; belly white; fine streaks on sides of neck and lower back sometimes give a gray effect.

Adult Female. - Much the same, except duller, with colors more suffused; under parts mainly white, with obscure streaks on sides.

Nest. - On ground; much like Oven-bird's; similarly concealed, and often roofed, but smaller; it is sometimes built in a hollow tree.

Eggs. - White, brown-spotted at large end.

Season. - April to September.

This common, well-known Warbler, which rarely builds its nest in trees, resorts to them for a greater part of its food. The bird is usually found in woodlands, ranging from low river valleys to the slopes of high bills. It usually nests on dry land in deciduous woods, where it may be seen throughout the season creeping about old stumps, shrubbery, and the trunks and limbs of trees. It follows out the limbs, peering quickly here and there, over and back, in its endless search for insects.

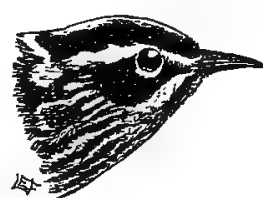

Fig. 63. - Black and White Warbler, twothirds natural size.

Its usual notes are a thin screep or chirp, and a sharp chick. The ordinary song is a repetition of such notes, not unmusical, and characteristic of the woods. Mr. Hoffman describes it as wee-see', wee-see', wee-see'; but the bird has another lay, far more musical and varied than this, which is often heard early in the scason, when the first males come. This burst of melody is usually preceded by a few notes of its common song. It chatters also when it is excited or disturbed by some enemy. This bird largely takes the economic place in summer that is so well filled by the Brown Creeper in the winter woods, but it is not so much confined 
to the tree trunks. Like the Creeper, it searches every cranny of the bark for insects; it feeds on wood-boring insects, bark beetles, click beetles, curculios, and the eggs of insects. But it does much more than this, for when it comes to Massachusetts the buds are about to burst, and all through the spring and summer it searches over the limbs, twigs, buds, and leaves, destroying caterpillars, beetles, and bugs that are found on bark and foliage. Now and then it startles a resting moth from a tree trunk, or observes one flying below, and, darting down, catches it in air almost as skilfully as a Flycatcher. Its swiftness and dexterity in flycatching seem to be derived largely from the impetus of its downward plunge, for, so far as I have observed, it never essays to follow insects that fly by above it.

The bird is very destructive at times to hairy caterpillars, eating large quantities of them; and, as it also destroys the pupæ and moths of these insects, it exerts considerable influence toward checking the gipsy moth. This Warbler is quite as valuable in the orchard as in the woodland, as it feeds on many orchard pests; but unfortunately it is not so commonly seen in orchards as in its favorite woods. Its food on those occasions when it descends to the ground is not very well known, but it often picks up eutworm moths that hide there, and Gentry says that it eats earthworms.

\section{Chestnut-sided Warbler. \\ Dendroica pensylvanica.}

Length. - About five and one-half inches.

Adult Male. - Top of the head yellow; back yellow and ashy, black-streaked; ear patch and wing bars, large spots on tail feathers, and under parts, white; a black patch extends from the lower mandible to and through the eye above, and below to a broad chestnut streak which runs down the side of the body.

Adult Female. - Somewhat similar, but duller.

Nest. - Usually in a low bush, lined with fine grasses.

Eggs. - White, with purplish or reddish brown spots and blotches.

Season. - May to September.

This species is a summer resident throughout most of the State, usually appearing here the second reek in May. In spring it may be seen gleaning insects in both woods and orchards and in all kinds of vegetation, from low shrubbery 
to tall trees; but, unlike the other species of Warblers hereinbefore considered, it does not commonly go to the ground for much of its food. During the breeding season it is largely a bird of the shrubbery on the borders of woodland, and, like the Yellow-throat, is common along bushy roadsides. There in warm weather it is often seen, with its tail elevated and its wings drooping, flitting occasionally from bush to bush, or catching insects in air, after the manner of the Myrtle Warbler.

Its common note is a sharp chirp, much like that of other Warblers ; but its spring song is loud, varied, and distinct,

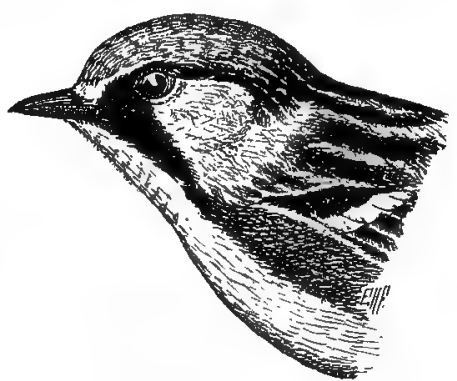

Fig. 64.-Chestnut-sided Warbler, naturgl size.

resembling most that of the Yellow Warbler. Its usual summer song is a soft, prolonged, rather weak but pleasing warble. The nest building of this Warbler is an interesting part of its life history. Its nest, though often built in localities frequented by the Yellow Warbler, is little like that of the latter except in shape. It is situated usually in a much lower shrub than is that of the Yellow Warbler, and is built more strongly and with more painstaking care. Mr. Mosher notes on May 17, 1899, that a pair of these birds had just completed a nest. They had been at work upon it for five days. The female first laid the foundation at the forking of three branches of an arrow-wood bush, about two and onehalf feet from the ground. She laid a few straws and fibers of plants, then bound them to the three branches by means of tent caterpillars' web. Then she brought a few straws at a time and placed them around the sides, shaping them by turning round and round. She bound them very firmly in place with the web, and thus fastened them to the three branches. When the sides were all finished she put in the lining. This consisted of fine grasses and soft fibers. The nest when completed was much less bulky than the Yellow Warbler's, but much firmer; the walls were not more than one-fourth as thick. 
The food of the Chestnut-sided Warbler is such that the bird must be exceedingly useful in woodland and shrubbery, and in orchard and shade trees as well, whenever it frequents them. It is probable that at times it destroys considerable numbers of parasitic hymenoptera, as it is rather expert as a flycatcher; but it is very destructive to many injurious beetles and caterpillars, being one of the most active consumers of leaf-eating insects. Small borers or bark beetles, plant bugs and plant lice, leaf hoppers, ants, and aphids are eaten.

In seasons of great want it eats a few seeds. Audubon says that he once shot several birds in Pennsylvania during a cold spell and snowstorm in early spring, and that the only food in their stomachs was grass seeds and a few spiders, but the birds were emaciated and evidently half starved. This Warbler is almost entirely insectivorous, and for this reason, perhaps, as soon as its young are well able to travel both young and old begin their southern journey. In September a few birds, probably from farther north, may be seen in autumnal dress, gleaning insects from the tree tops, and no more are seen until the following spring.

Yellow Warbler. Blue-eyed Yellow Warbler. Yellow Bird. Summer Yellow Bird. "Wild Canary."

Dendroica astiva.

Length. - About tive inches.

Adult Male. - Yellow; back a rich yellow-olive, occasionally streaked with orange-brown; breast also streaked narrowly with the same color.

Adult Female. - Similar, but duller; breast generally unstreaked.

Nest. - A deep, soft cup five to ten feet from ground, in a bush, or higher up in orchard or shade tree, or in a fork of small sapling or shrub.

Eggs. - Either bluish-white or greenish-white, with obscure lilac markings, and brown spots grouped around the larger end.

Season. - May to September.

The Yellow Bird is the most familiar of all our Warblers, for it has forsaken the woodlands for orchards and shade trees near dwelling houses. It arrives in May, when the first young leaflets begin to clothe the trees with verdure, and plays about like a rich yellow flame among the pink of the apple blossoms. It is often confused in the popular mind with the Goldfinch, which is also called the Yellow Bird, but which may be distinguished at once by the black of the 
crown, wings, and tail, for the Yellow Warbler has no black markings.

Although the Yellow Warbler is not now commonly found in the woods, it is sometimes seen within their borders, and is common in thickets along streams and roads, as well as in bushy pastures. It is not usually seen on the ground or in the tops of the tallest trees, but visits all parts of trees and shrubbery.

Its alarm note is a loud chirp. Its usual song has much the quality of a whistle, and may be expressed by the syllables we'-chee, we'-chee, wee'oo. The song is frequently

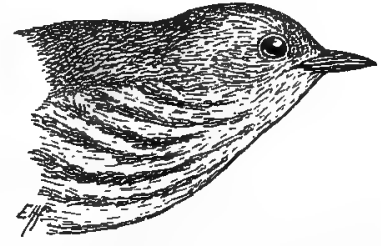

Fig. 65. - Yellow Warbler, twothirds natural size.

much longer, has several variations, and often closely resembles one song of the Chestnut-sided Warbler.

The nest building of this bird is performed entirely by the female; the nest is daintily but loosely constructed, and is very rapidly built. The following brief account of the nest building, taken from Mr. Mosher's notes, May 16, 1899, shows this bird to be an enemy of the cankerworm and the tent caterpillar : -

She first laid a foundation of a few straws and placed upon them the cotton or down from fern fronds. These she bound together with the silk from a tent caterpillar's web. Then she went alternately for the cotton and the silk, stopping occasionally at an apple tree and feeding for a moment or two on cankerworms. When I went past the nest at night I found she lad it nearly complete; the lining only was lacking.

It would be hard to find a summer bird more useful among the shade trees or in the orchard and small-fruit garden than this species. Almost entirely insectivorous, it feeds on many of the greatest pests that attack our fruit trees, vines, and berry bushes. Whenever the caterpillars of which it is fond are plentiful, they form about two-thirds of its food. It is destructive to the small caterpillars of the gipsy moth and the brown-tail moth, and is inordinately fond of cankerworms and other measuring worms. Tent caterpillars are commonly eaten. Small bark beetles and boring beetles are 
eaten, among them the imago of the currant borer. Weevils are greedily taken. A few useful beetles are sacrificed; among them ground beetles, soldier beetles, and small scavenger beetles. The Yellow Warbler has some expertness as a flycatcher among the branches, and seizes small moths, like the codling moth, with ease, but apparently does not take many parasitic hymenoptera, though some flies are taken. Plant lice sometimes form a considerable portion of its food. No part of the tree where it can find insect food is exempt from its visits, and it even takes grasshoppers, spiders, and myriapods from the ground, grass, or low-growing herbage. It usually leaves Massachusetts in August or early September.

\section{American Redstart. \\ Setophaga ruticilla.}

Length. - Five to five and one-half inches.

Adult Male. - Lustrous black; head, neck, and most of breast black; a wide orange band across wing quills, and another across basal parts of all but the middle tail feathers; sides of body and lining of wings flame color, a tinge of which sometimes extends across the lower breast; other lower parts mainly white.

Adult Female and Male of the First Year. - Similar, but without black; colors paler, the black replaced above by gray and olive and below by white; orange replaced by yellow, and a whitish line in front of and around the eye. Tail of young male darker toward tip than that of female.

Nest. - A neat, compact structure, in upright fork of sapling or tree.

Eggs. - Somewhat similar to those of the Yellow Warbler, but usually with fewer and finer spots.

Season. - May to September.

This species arrives in Massachusetts about the second week in May. Unlike the foregoing Warblers, it forages habitually from the ground and low underbrush to the very tops of the tallest trees. It is also a very active and expert flycatcher. Its bill is broadened at the base and its mouth is surrounded with bristles, like those of the Flycatchers and some other families that take their prey mostly upon the wing. The Redstart is almost constantly in nervous motion, darting and fluttering from twig to twig in pursuit of its elusive prey. In all its movements its wings are held in readiness for instant flight, and in its sinuous twistings and turnings, risings and fallings, its colors expand, contract, and glow amid the sylvan shades like a dancing torch in the 
hands of a madman. Chapman tells us that in Cuba most of our wood Warblers are known simply as "mariposas" (butterflies), but the Redstart's flaming plumage has won for it the name of " candelita," the "little torch," that flashes in the gloomy depths of the tropical forest. He gives the

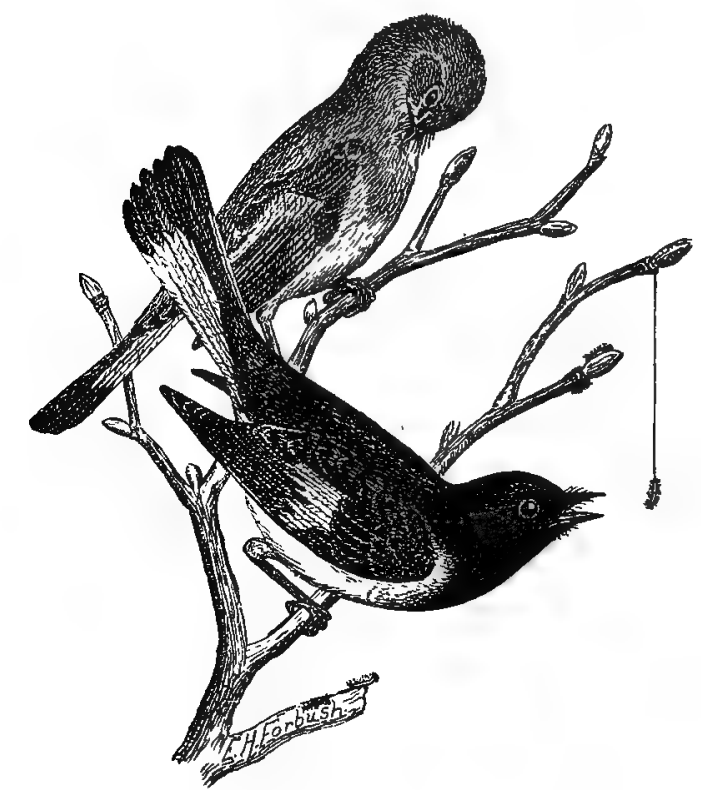

Fig. 66.-American Redatart. Lower figure, male; upper figure, female. One-half natural size.

song as ching, ching, chee, ser-wee, swee, swee-e-e, and this is a good description of its general character. The song varies, however, like that of other Warblers, but is usually more cheerful than musical. The alarm note of the Redstart is a sharp chirp.

The insect food of the Redstart is perhaps more varied than that of any other common Warbler. Apparently there are few forest insects of small size that do not, in some of their forms, fall a prey to this bird. Caterpillars that escape some of the slower birds by spinning down from the branches and hanging by their silken threads are snapped up in mid air by the Redstart. It takes its prey from trunk, limbs, twigs, leaves, and also from the air, so that there is no escape for 
the tree insects which it pursues unless they reach the upper air, where the Redstart seldom goes, except in migration. It has been named the flycatcher of the inner tree tops, but it is a flycatcher of the bush tops as well. While there are few small pests of deciduous trees that it does not eat in some form, it is not confined to these trees, but forages more or less among coniferous trees. Also it is seen at times in orchards, and gleans among shade trees in localities where the woods are cut away. It is impossible to weigh the pros and cons of this bird's food, for no thorough examination of it has ever been made. It is an efficient caterpillar hunter, and one of the most destructive enemies of the smaller hairy caterpillars. It catches bugs, moths, gnats, two-winged flies, small grasshoppers, and beetles. It probably secures a larger proportion of parasitic hymenoptera and diptera than most other Warblers, occasionally destroying a few wasps; otherwise, its habits seem to be entirely beneficial.

Black-throated Green Warbler.

Dendroica virens.

Length. - About five inches.

Adult Male.-Olive above; sides of head and neck yellow, often with darker line through eye; chin, throat, and breast black; belly white; sides striped with blackish; wings and tail dark; white wing bars; outer tail feathers marked with white.

Adult Female. - Yellow duller; black of throat largely obscured by gray.

Nest. - Usually fifteen to fifty feet up in a white pine, in a fork toward the end of a branch ; made of bark, twigs, and grasses, and lined with soft materials.

Eggs. - Creamy white, with brown and purplish markings grouped toward the larger end.

Season.-April to October.

The Warblers noted in the pages immediately preceding live largely among deciduous trees and shrubbery; but this species dwells by choice among coniferous trees, and in Massachusetts it stays principally in groves of white pine. While migrating in spring and fall it feeds anywhere in mixed deciduous woods, but it is evidently more at home among the pines, where it gleans its usual food from the lower branches to the tree tops. This bird does not commonly descend to the ground except to procure nesting material or to bathe. 
One day, as I stopped to drink at a spring in the woods, a beautiful male Black-throated Green Warbler shot down from a tall tree and alighted on a moss-grown rock that bordered the diminutive pool. Evidently he had not expected me, but was not at all afraid. He looked up at me inquiringly for a moment, and then, stepping into the

shallow water, dipped his head and

threw the drops in showers as he shook out his brilliant plumage in the bath. His ablutions finished, quite within reach of my hand, he mounted again to the tree top, and sent back his drowsy song.

This bird has several chirps which it utters to express different emotions, but

FIg. 67.-Black-throated Green Warbler, natural size. its song is most charming, harmonizing, as it does, with the whispering of the pines to the summer wind. It has a zeeing sound. Hoffman gives it as $\overline{z e e,} \overline{z e e,} z u, z i$. This is given with a little of the quality which characterizes the song of the harvest cicada, and often with a difference in the pitch of the first and last syllables. John Burroughs graphically represents the notes thus : $--\sqrt{ }-$ The upper lines signify the higher tones. Bradford Torrey translates the song as "Trees, trees, murmuring trees;" but a more practical writer assures us that the bird calls for "Cheese, cheese, a little more cheese." It has at least one other song of the same character, but longer and perhaps a trifle more varied. This is usually considered to be its entire repertoire; but no one can ever be quite sure that he knows all the notes of any bird. In the fall of $1905 \mathrm{I}$ heard in a small birch tree in Concord a song that resembled closely the lay of a Warbling Vireo. In fact, I mistook it for the song of that bird; but in trying to find the singer I soon learned that there was no Vireo in the tree, and that the song came from a young male Black-throated Green Warbler, which repeated it several times before my eyes.

Mr. C. A. Reed says he believes that when its nest is in danger of discovery this Warbler sometimes brings straws 
and places them on a branch in plain sight of the observer, in order to deceive him, and draw his attention away from the nest. He states that he has known of more than one occurrence of this kind. His observations seem to be corroborated by the actions of a bird that was nesting in our pine grove. When watched, it began carrying nesting material into an eld tin can that was suspended in a large pine tree; but when the attention of the observer was attracted elsewhere, it went no farther with its nest in the can. While the birds are building, the male brings some nesting material, but the female does the work of construction. The food of this Warbler, like that of others of the family, consists of caterpillars and other larve of many kinds, beetles, small bugs, and flies. Professor Aughey says that the stomachs of five specimens taken in Nebraska contained two hundred and twenty insects, - an average of forty-four to each bird; a large number of these insects were young locusts.

\section{Pine Warbler. Pine-creeping Warbler. \\ Dendroica vigorsii.}

Length. - Five and one-half to six inches.

Adult Male.-Above, olive; wings and tail dusky; two white wing bars; throat, breast, and line over eye bright yellow, somewhat clouded or streaked on sides with a darker shade.

Adult Female. -Duller; often with little or no yellow below; large white spots on two outer tail feathers of both sexes.

Nest. - In much the same situation as that of the Black-throated Green Warbler, but oftener in pitch pines; it is sometimes saddled on a horizontal limb, and is then flat and rather slovenly in build; usually lined with feathers.

Eggs. - White with brown markings, chiefly at larger end.

Season. - April to October.

The Pine Warbler has a marked preference for pine woods and groves; but, unlike the Black-throated Green Warbler, it seems to prefer the pitch pines, and is one of the few birds that habitually live and breed in the woods of this character that exist on dry and sandy lands, like those of Cape Cod. It has been called the Pine-creeping Warbler, from its habit of ereeping along the branches, and occasionally up and around the trunks of pines. For a Warbler it seems a rather slow and indolent bird; still, at times it is remarkably active. Its alarm note is a sharp chirp; its other notes are few and weak. The song is one of the most 
soothing sounds of the pine woods. It has in it the same dreamy drowsiness that characterizes the note of the Blackthroated Green Warbler, but is otherwise entirely different in tone and quality, being composed of a series of short, soft, whistling notes, run together in a continuous trill. It resembles, in a way, the song of the Chip-

ping Sparrow, except that it is softer and more musical. Otten the bird will sit for ten or fifteen minutes in one spot, and, as the song seems ventriloquial at times, the singer is then hard to find.

This bird is one of the earliest Warblers to arrive in spring. It is undoubtedly the particular guardian of the pines, about which it

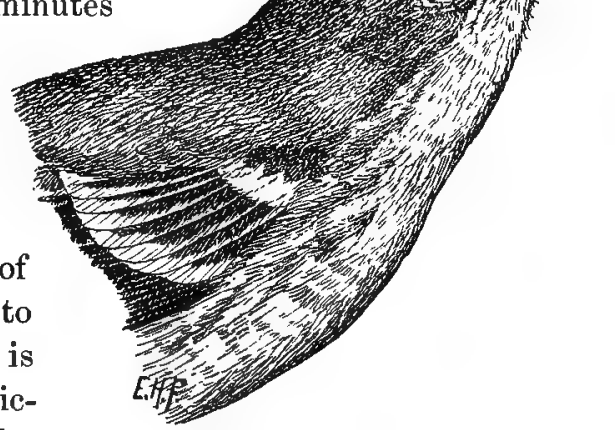

Fig. 68. - Pine Warbler, natural size.

remains until very late in the season, for it feeds mainly on insects that infest pine trees. It has been seen in Wareham in December and January. It is able to subsist to some extent on the seeds of pines, and when there is a good crop of pine seed it can remain longer than most other Warblers.

Myrtle Warbler. Myrtle Bird. Yellow-rumped Warbler.

Dendroica coronata.

Length. - About five and one-half inches.

Adult Male.-Above, slaty; black-streaked; wings and tail brownish, marked with white; chest clouded and streaked with black; two wing bars, throat, tail spots, lower breast, and belly white; crown, rump, and a patch on each side of breast bright yellow.

Female. - In spring, much like male, but duller; in fall, and male in fall, generally browner, with colors less pure and conspicuous.

Young. - Brownish above, white below; rump jellow.

Nest. - In bush or coniferous tree, usually lined with fine, soft materials.

Eggs. - White, marked with browns and purples.

Season. - April to November; winters in favorable localities.

This beautiful bird probably does not breed in Massachusetts except in some higher parts of northern Worcester 
County and among the western hills, but it is one of the most common migrating Warblers throughout the State.

The Myrtle Warbler has a variety of notes, but the one usually uttered both spring and fall is a soft chirp or chup, which, at a little distance, exactly resembles the sound pro-

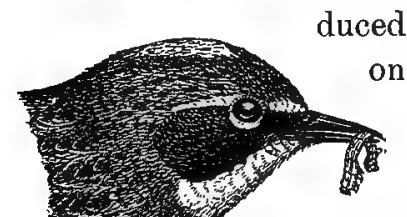
on wet ground or leaf mould. These sounds are so similar that after storms in the woods I have often found it difficult to distinguish the note of this Warbler from the splash of the large drops that were still falling from the trees. The song is a rather weak warble, very sweet, and often of long

Fig. 69. - Myrtle Warbler, nearly natural duration. Sometimes portions of it are given quite londly, in a jingling tone, resembling somewhat that of the Indigo Bird. It has quite as many variations as the song of any Warbler that I now recall.

The Myrtle Bird remains through the winter in some portions of the State where it can find food; and, as it frequents woodlands, orchards, and shade trees, as well as thickets, it is probably the most useful of the Warblers that are not common in summer. It remains in fall all along the coast where bayberries grow, and until the supply of this fruit becomes exhausted; then the birds must either move to more favored regions, or perish of cold and hunger, which latter not infrequently happens in hard winters. They do not, however, rely entirely on bayberries, but eat a few other berries and some seeds, and spend much time in searching for hibernating insects and insects' eggs. They are not confined to the sea coast in winter, for they can live on the berries of the red cedar; and I have found them wintering in sheltered localities in

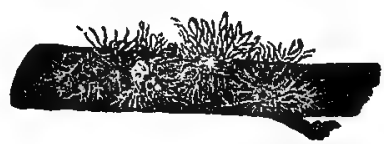

Fig. 70.-Woolly apple tree aphis, eaten by Myrtle Warbler. central Worcester County. Dr. Weed made a special study of the autumn food of this species. He found that they ate bayberries, caddis flies, various insect larvæ, beetles, plant 
lice and their eggs, house flies and other diptera, and a very few hymenopterous flies. I can only add to this the fact that I have seen this species feeding on the woolly apple tree aphis (Schizoneura lanigera) in late October and early November, after all the birch plant lice, of which these birds are very fond, had disappeared. This apple tree aphis is a particularly destructive species, which has done great injury in the past. Young trees are frequently injured by these aphids, which also attack the roots and the new growth on older trees. As spring approaches, the Myrtle Warbler feeds less on berries and seed, but eagerly hunts the early flies, moths, and gnats that appear on warm days in sheltered swamps and along water courses. It now becomes of great service to orchard and woodland, for large flights of these birds move slowly northward through the State, feeding very largely on the tree pests that develop with the opening foliage.

\section{VIREOS.}

The Vireos all normally seek orchard, woodland, or swampy thicket. The three species, however, that breed commonly in the greater part of Massachusetts, have all learned to nest about the habitations of man. They perform an economic service similar to that rendered by the Warblers, except that during summer they feed to a greater extent upon wild fruits. They live mainly among the foliage, and in action much resemble Warblers, except that, being heavier in build, their motions are usually more deliberate. The Solitary Vireo and the White-eyed Vireo breed here, but only uncommonly or locally. The latter is common in some places near the coast, but $I$ have found it in only a few favored localities in the interior. The Solitary Vireo is regarded as rare in the breeding season, but it probably breeds in nearly all the counties in most seasons. It may be present in a certain piece of woods during one breeding season and absent the next, and is sometimes fairly common in considerable areas in some counties. 


\section{Red-eyed Vireo.}

Length. - About six inches.

Vireo olivaceus.

Adult. - Upper parts grayish olive-green, changing to gray on the crown; a dark stripe on either side of the crown; a light stripe over the eye, and dark streak from bill through eye; under parts grayish-white, deepening to pale olive-yellow on the flanks; iris ruby-red.

Nest. - A pensile cup; usually hung by its upper edge from a fork, five to twenty-five feet from the ground.

Eggs. - White, spotted with dark brown at the larger end.

Season. - May to September.

The Red-eyed Vireo, although not so abundant as the Robin, is one of the most common and widely distributed summer birds. It breeds throughout the State. It is very

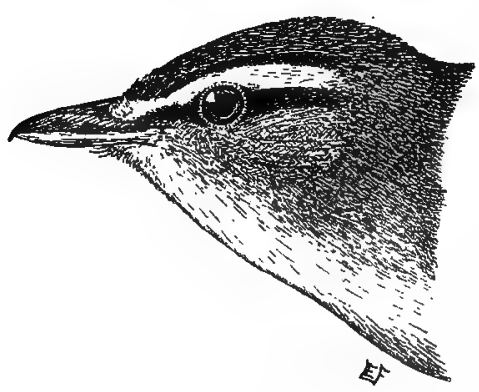

Fig. 71. - Red-eyed Vireo, natural size. devoted to its eggs and young, and sits very closely on the nest. The mother bird will often allow a person to walk by within arm's length while she remains quietly sitting. The parent birds feed and protect their young for a long time after they leave the nest. This Vireo sleeps very soundly; soon after sunset and before the shades of night have fallen the mother bird on her nest tucks her head under her wing, and is sometimes so oblivious to the world that she may be approached and taken in the hand. The Redeye is found wherever there are groups of deciduous trees, or woodlands and thickets. Its movements as it slips about among the branches are rather deliberate. It sings continually, but the song is intermittent, as though the bird were singing incidentally as a pastime, like a boy whistling at his work. The song is composed of phrases of a few syllables each, and the manner of its delivery, with many rising and some falling inflections and frequent pauses, led Wilson Flagg to name the bird the "preacher." Many years ago I learned that the preacher had other business than his preaching, and that he practised as he preached ; for it was through watching 
this species that I first became aware of the usefulness of birds to man. One sunny day in early boyhood I watched a Vireo singing in a swampy thicket. He sang a few notes, his head turning mean while from side to side, his eyes scanning closely the near-by foliage. Suddenly the song ceased; he leaned forward, sprang to another twig, snatched a green caterpillar from the under side of a leaf, swallowed it, and resumed the song. Every important pause in his dissertation signalized the capture of a larva. As the discourse was punctuated, a worm was punctured. It seems as if the preaching were a scrious business with the bird; but this seeming is deceptive, for the song inerely masks the constant vigilance and the sleepless eye of this premium caterpillar hunter. In the discovery of this kind of game the bird has few superiors. He goes about it in the right way. Minot says: "They have never struck me as very active insect hunters, since they devote so much of their time to their music." This is true, but the Vireo does not hunt active game so much as it seeks those defenceless larvæ that must depend upon their protective shape and coloring to conceal them from their enemies. These devices may insure them against some of their insect foes, but not against the Vireo. It is most astonishing to see him pick up caterpillar after caterpillar from twigs and foliage, where with the best glasses our untrained eyes can discern "nothing but leaves." And so the bird sings the livelong day, to while away the time as it searches over the foliage. This habit of song becomes so strong that the male bird sings while sitting on the nest to relieve his faithful mate. He sings all summer, and even into the fall. When his hunger is temporarily satisfied, he will sit on a twig and sing for minutes at a time. His common notes are an alarmed chatter and a querulous cry.

The Red-eyed Vireo is now becoming well recognized as a great insect eater. Mr. Arthur G. Gilbert informed me that he fed a young bird of this species a hundred grasshoppers in a day. When the last grasshopper had been swallowed the bird was well filled, for the tips of the insects' wings projected from the bird's bill. This Vireo is one of the most effective enemies of the gipsy moth and brown-tail moth. 
Moths and butterflies of many kinds are eaten; also assassin bugs, tree hoppers, and bugs that eat plants and fruit. Many beetles, among them boring beetles, bark beetles, and weevils, grasshoppers, katydids, locusts, - all are eaten. This bird at times becomes an expert flycatcher, taking horseflies, mosquitoes, and other gnats, and many gall flies. It appears to take a larger proportion of fruit than the other Vireos. In summer I have found many seeds of berries in the stomachs of these birds, and sometimes a stomach will be found nearly filled with blueberries. Raspberries, blackberries, and mulberries are commonly eaten. Professor King has found dogwood berries, berries of the prickly ash, and sheep berries in their stomachs; Dr. Fisher says they are fond of the fruits of the benzoin bush, the sassafras, and magnolia; and Dr. Warren asserts that they feed on poke berries and wild grapes.

\section{Warbling Vireo. \\ Vireo gilvus.}

Length. - About five and three-fourths inches.

Adult. - Upper parts generally brownish-gray, tinged more or less with olivegreen; sides of head lighter, with a rather light line above the eye, but no dark line through it; below, dull white, passing into yellowish on the belly and pale buff or olive on sides.

Nest and Eggs. - Much like those of the preceding species, but a trifle smaller; usually in a shade tree, from fifteen to fifty feet up.

Season. - May to September.

In appearance the Warbling Vireo is much like the Redeye, but it is smaller and less distinctly marked. In the

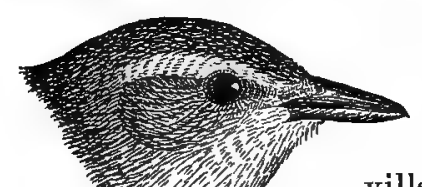
breeding season it is usually seen at no great distance from the large elms and other great shade trees that line country roads and village streets. It was found commonly in city shade trees until the introduced House Sparrow drove it out. The Warbling Vireo, like its closely related Fig. 72. - Warbling congeners, moves about amid the branches of trees, flying only occasionally to the Vireo, natural size.

ground, or moving from tree to tree in short flights. Its ordinary notes are similar to those of the Red-eye, but are 
less vigorous. Its song is a lather low, weak, but pleasing and continuous warble, resembling somewhat in quality the song of the Purple Finch, but not nearly so loud and bold. It has not the abrupt and intermittent phrasing of the song of the preceding species, but is sweeter, more tender, and less monotonous.

This bird is of immense service to man in the destruction of vast numbers of injurious insects that infest the trees about the house, garden, and orchard, as well as those of the woods. As it is quite a flycatcher, both crawling larva and winged imagoes suffer from its depredations. Horseflies and other dipterous insects, crane flies and mosquitoes, are all taken. Its food, however, consists largely of caterpillars and other leaf-eating insects; among these are the imported elm-leaf beetle (Galerucella luteola) and the twelve-spotted cucumber beetle. Grasshoppers are not neglected. Occasionally useful flies, ladybirds, or bees are killed, but the great majority of insects eaten are injurious. The fruit taken seems to be mainly wild and worthless berries.

Length. - Nearly six inches.

\section{Yellow-throated Vireo.}

Vireo flavifrons.

Adult. - Above, yellowish olive-green, shading into bluish-ash on rump; markings about eye yellow; white wing bars; wing and tail feathers dark, edged with whitish; below, yellow from throat to belly, which is white; sides olive, shading into gray.

Nest. - A rather large pensile cup, hung from forking twigs, three to twenty feet from the ground.

Eggs. - White, with black and brown or purplish spots about larger end. Season. - May to September.

The Yellow-throated Vireo was once evidently an inhabitant of open forests of great deciduous trees, although it is sometimes found in pines ; but since the destruction of the original timber growth in this Commonwealth it has learned to seek the great shade trees that have grown up along streets and about residences or in pastures. The groves of lairge oaks and other deciduous trees that are found on well-cared-for estates are among its favorite breeding places. It often dwells in old orchards. Thus it has come to live about the habitations of man, and in eastern Massachusetts is more 
commonly seen there in the breeding season than in deep woods.

The nest of this bird, which is about a week in the building, is outwardly one of the handsomest specimens of bird architecture to be found anywhere. It is difficult to see how

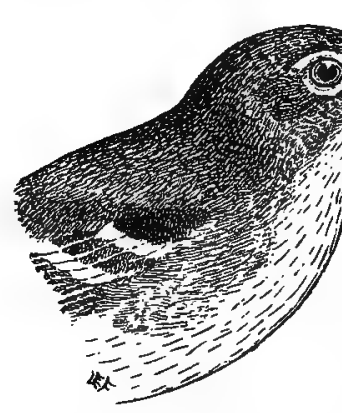

Fig. 73. - Yellow-throated Vireo, two-thirds natural size.

it is possible for a bird to construct such a nest, and cover it so tastefully with lichens and plantdown. Undoubtedly the skillful use of caterpillars' web serves in attaching these ornamental materials.

The bird is comparatively deliberate in both song and movement, and, though naturally shy when it was confined to the open woods, it has now become rather fearless, and may be readily watched with a glass as it moves among the tall trees. The song is a little louder than that of most Vireos, and may be easily distinguished from all others. It usually consists of two or three rich and virile notes, uttered interrogatively or tentatively, followed immediately by a few similar tones uttered decisively. The bird appears to ask a question, and then answer it. Its alarm notes are as harsh as those of an Oriole, and somewhat similar in quality.

This Vireo should be most carefully protected and encouraged to breed about the homes of man, for it feeds upon pests of the household, forest, and orchard. Common house flies and mosquitoes are eaten. In the orchard it attacks the apple plant lice, the hairy tent, gipsy, and tussock caterpillars, as well as moths of many species. It is quite destructive to the larvæ of butterflies also, while weevils and other beetles, grasshoppers, and leaf hoppers are eaten to a less extent. This species eats a few unimportant wild berries, such as the fruit of the red cedar; but so far as I have observed it is not so fond of fruit as the Red-eyed Vireo, and its only possible harmful habits seem to be the occasional destruction of a bee, a syrphus fly, or some hymenopterous parasite. 


\section{WAXWINGS.}

These beautiful but inconspicuous birds are noted for the peculiar appendage which in many specimens adorns the tip of each secondary quill, and is sometimes found on the tip of each tail feather also. These waxy appendages seem to be ornamental rather than useful. They resemble sealing wax, hence the name Waxwing. The Bohemian Waxwing, a northern species, is a rare winter visitor to Massachusetts. The Cedar Waxwing is the only other species found in America.

\section{Cedar Waxwing. Cedar Bird. Cherry Bird.}

Ampelis cedromum.

Length. - About seven and a quarter inches.

Adult. - Head long-crested; chin, forehead, space around eye, and line above it black; general color rich grayish or pinkish brown, with tints of reddisholive and purplish-cinnamon, changing on the after parts into ashy above and yellow and white below; wings and tail gray; tail tipped with yellow.

Nest. - Bulky; from six to fifteen feet up in an orchard or shade tree; composed of weeds, grass, roots, bark, leaves and twigs.

Eggs. - Light bluish, marked with black and indistinct bluish spots.

Season. - Resident.

This common bird, so richly endowed with beauty and grace, is no songster. Its charm consists in its elegant shape and its softness of plumage, with its insensible changes from one lovely tint to another. It moves about in silence, save as it utters a lisping, "beady" note or a "hushed whistle." Mr. Nehrling says that both male and female sing. I cannot doubt that he has heard this song, but from my own experience I am led to believe that it is rare in Massachusetts.

The Cedar Bird gets its name from its habit of feeding on cedar

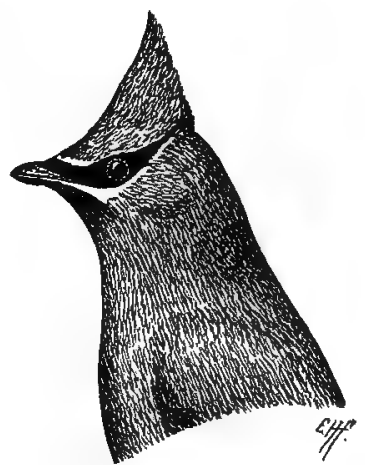

Fig. 74. - Cedar Bird, one-half natural size. berries in fall and winter. It often may be found on some parts of Cape Cod during the colder months. It is sometimes seen in other parts of the State in winter, and is at- 
tracted by the berries of the mountain ash. The northward migration is usually under way in March, but comparatively few birds are ordinarily seen in central Massachusetts until late in May. In spring and early summer they seem to feed almost entirely on insects. They are always plentiful at this season in a cankerworm year, and they deserve at such times the local name of "cankerworm birds," for they frequent infested orchards in large flocks, and fill themselves with the worms until they can eat no more. There is no doubt that the countless thousands of caterpillars that they destroy more than compensate for the cherries they eat, although in some seasons they are very destructive to cherries. Such little gluttons rarely can be found among birds. The Cedar Bird seems to have the most rapid digestion of any bird with which experiments have been made. Audubon said that Cedar Birds would gorge themselves with fruit until they could be taken by hand; and that he had seen wounded birds, confined in a cage, eat of apples until suffocated. They will stuff themselves to the very throat. So, wherever they feed, their appetites produce a visible effect. Professor Forbes estimates" that thirty Cedar Birds will destroy ninety thousand cankerworms in a month. This calculation seems to be far within bounds.

Cedar Birds are devoted to each other and to their young. Sometimes a row of six or eight may be seen, sitting close

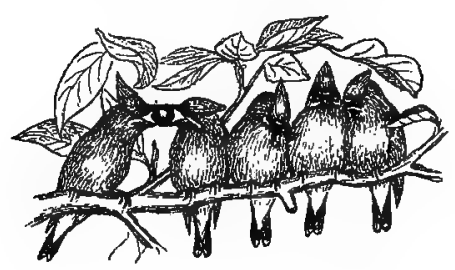

Fig. 75. - Passing the cherry. together on a limb, passing and repassing from beak to beak a fat caterpillar or juicy cherry. I have seen this touching courtesy but once, and believe it was done not so much from politeness as from the fact that most of

the birds were so full that they had no room for more, - a condition in which they can afford to be generous. Nevertheless, the manner in which it is done, and the simulation of tender regard and consideration for each other exhibited, render it a sight well worth seeing. They also have a habit of "billing," or" saluting one another with the bill. 
The food of these birds has been much discussed, and it has been clearly shown that they eat a larger proportion of fruit and a smaller proportion of insects than most birds. Here in Massachusetts they often merit the name of Cherry Birds, for they descend on the cherry trees in considerable flocks, and destroy a large quantity of fruit. Professor Beal, however, in examining one.hundred and fifty-two stomachs, found that only nine birds had eaten cultivated cherries, and that more than half the food consisted of wild fruit.

Mrs. Mary Treat writes of a town in which the elms had been defoliated for several years by the elm-leaf beetle, but the Cedar Birds came, and the trees were afterwards comparatively free from the beetles. During the time when the adult birds feed on cherries, the young are fed very largely upon insects, although fruit is given them as they grow older. These birds feed so much on wild fruit as it ripens, that it constitutes nearly seventy-five per cent. of their food; but

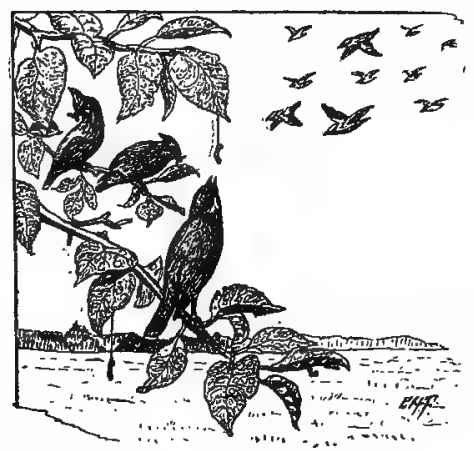

Fig. 76. - Good work in the orchard. later, after the young are reared, they turn flycatchers, and taking a high perch on some tree near a lake or river or on the borders of the woods, they sally out after flying insects. Grasshoppers, beetles, crickets, ichneumon flies, crane flies, and lacewings are all devoured by them. Bugs and bark lice are also on the bill of fare. While these birds are sometimes a pest to the fruit grower, they are, on the whole, beneficial to agriculture, and deserve protection.

\section{TANAGERS.}

This group of brilliant woodland birds is represented here by but two species; one of these, the Summer Tanager, is very rarely seen; the common Scarlet Tanager is one of the most valuable birds of orchard and woodland. 


\section{Scarlet Tanager.}

Piranga erythromelas.

Length. - About seven inches.

Adult Male. - Entire body bright scarlet; wings and tail black; in autumn much like female, but retaining the black on wings and tail.

Adult Female. - Greenish above; yellowish below; wings and tail darker and brown-tinged.

Nest. - Of fine twigs and straws; usually in lower branches of some large tree, but sometimes fully twenty feet up; occasionally in the orchard.

Eggs. - Light greenish-blue, with brown and purplish markings.

Season. - May to October.

This most gorgeous of New England birds flashes through the trees like a brand plucked from tropical flame; but it is a distinctly North American species, going south only in

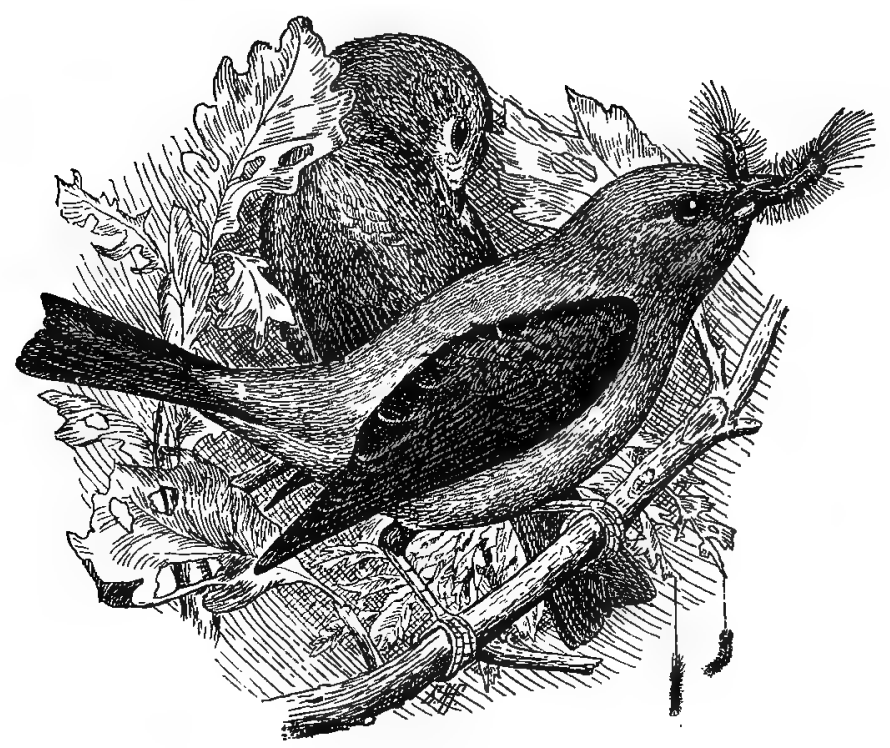

Fig. 77. - Scarlet Tanagers (male and female) and gipsy moth caterpillars.

its fall migration, and returning to its chosen northern home in the spring. The Tanager is a bird of large deciduous woods, and is less common among great tracts of pines, hemlocks, and other coniferous trees, although it is often seen in small groves of these trees, and sometimes nests there. The oaks are its first favorites, and wherever there 
are large groves of white oaks Tanagers are sure to come. They also frequent the detached oaks that are found in pastures near woodland. The chestnut is another favorite tree.

This bird seems to have increased somewhat in numbers within the last forty years, and for at least twenty years has been cominon and sometimes abundant in the greater part of Massachusetts. It is somewhat local, however, and is rarely as common anywhere as the Robin or Song Sparrow. It is distinctly an arboreal bird, and seeks its food mainly among the foliage of trees, where from the higher branches its song may be most often heard. The lay resembles somewhat that of a Robin, but is shorter and less varied, with a little apparent hoarseness or harshness in the tone.

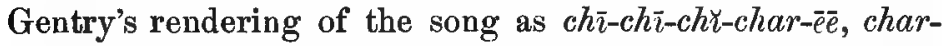
$\bar{e} \bar{e}-c h \bar{\imath}$, represents it fairly well. At times it seems ventriloquial, and the bird is difficult to find, for its brilliant plumage is not so conspicuous among the shadows of the foliage as one would naturally expect to find it. It sings at intervals all through the day, but more often at early morning and at night. A sudden noise, like a shout or the rumbling of a carriage along the road, sometimes startles the Tanager into song, or brings out the alarm note, chip, churr, or the sharp chip uttered by this bird.

After the leaves have attained their full size, the Tanager, which feeds mostly in the trees, is hidden much of the time by the foliage of the tree tops, and so is seldom seen except by those who know its notes and are looking for it. For this reason it is commonly considered rare.

In its food preferences the Tanager is the appointed guardian of the oaks. It is drawn to these trees as if they were magnets, but the chief attraction seems to be the vast number of insects that feed upon them. It is safe to say that of all the many hundreds of insects that feed upon the oaks few escape paying tribute to the Tanager at some period of their existence. We are much indebted to this beautiful bird for its share in the preservation of these noble and valuable trees. It is not particularly active, but, like the Vireos, it is remarkably observant, and slowly moves about among the branches, continually finding and persistently de- 
stroying those concealed insects which so well escape all but the sharpest eyes. Nocturnal moths, such as the Catocalas, which remain motionless on the tree trunks by day, almost invisible because of their protective coloring, are captured by the Tanager. Even the largest moths, like cecropia and luna, are killed and eaten by this indefatigable insect hunter. Mr. C. E. Bailey once told me that he saw a male Tanager swallow a luna moth nearly entire, removing only one of the insect's wings in the process; but this haste may have been caused by the attempts of several other birds to take his prey from him. Mr. Bailey brought me the wing of the moth that was dropped, lest its identity should be questioned. I once saw a male Tanager swallow what appeared to be a hellgramite or dobson (Corydalus cornutus) head first and apparently entire, though not without much effort. No one who will examine the plate of the luna moth, opposite this page, can fail to appreciate the capacity of the Tanager. It is difficult to see how the bird can accomplish such feats of deglutition. As a caterpillar hunter the bird has few superiors. It is often very destructive to the gipsy moth, taking all stages but the eggs, and undoubtedly will prove equally useful against the brown-tail moth. Leaf-rolling caterpillars it skillfully takes from the rolled leaves, and it also digs out the larvæ of gall insects from their hiding places. Many other injurious larvæ are taken. Wood-boring beetles, barkboring beetles, and weevils form a considerable portion of its food during the months when these insects can be found. Click beetles, leaf-eating beetles, and crane flies are greedily eaten. These beneficial habits are not only of service in woodlands, but they are exercised in orchards, which are often frequented by Tanagers. Nor is this bird confined to trees, for during the cooler weather of early spring it 'goes to the ground, and on plowed lands follows the plow like the Blackbird or Robin, picking up earthworms, grubs, ants, and ground beetles. Grasshoppers, locusts, and a few bugs are taken, largely from the ground, grass, or shrubbery.

Some useful ichneumon flies are destroyed, and a few spiders and their eggs. Nuttall says that Tanagers eat whortleberries and seeds, but so far as my observations and 


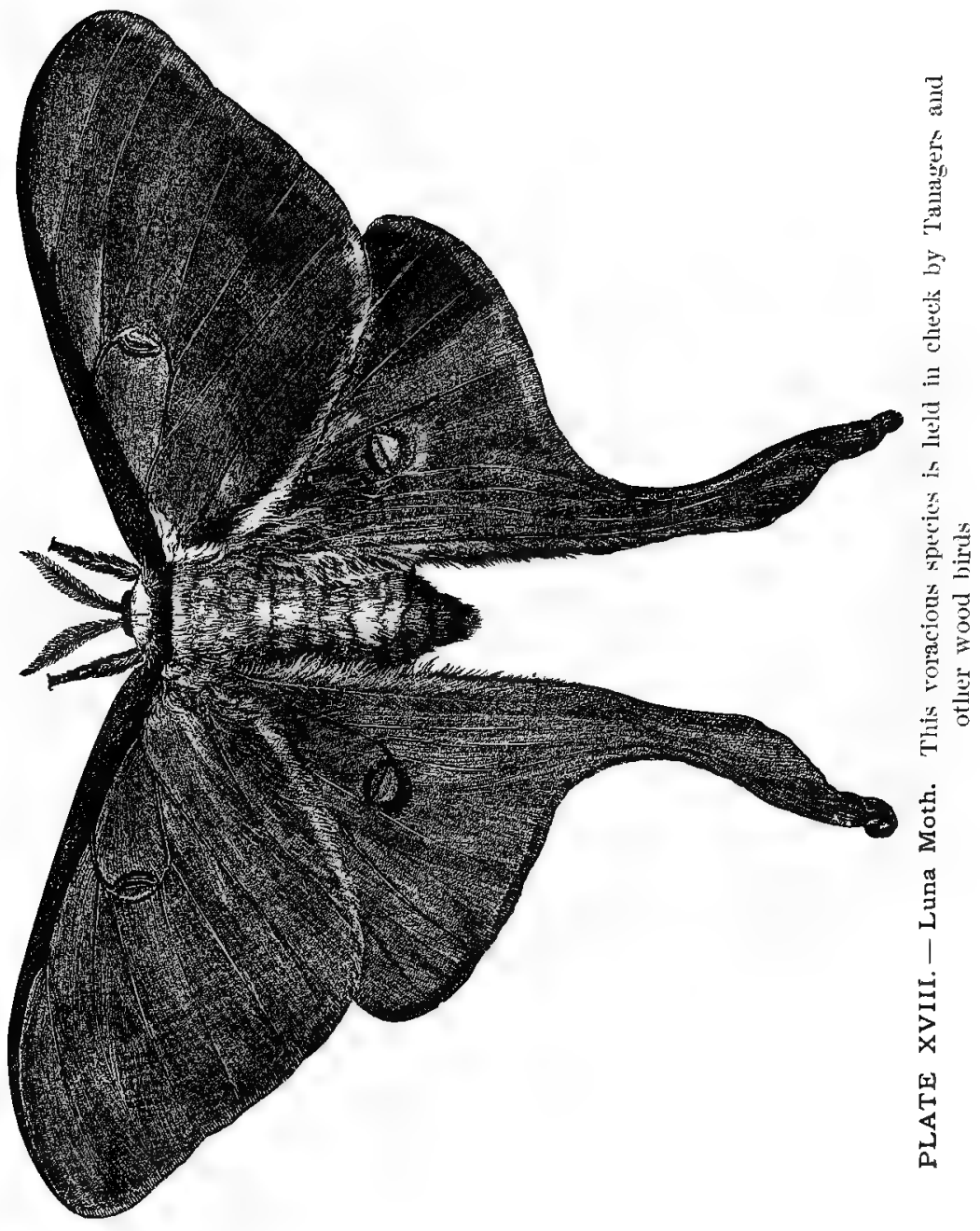



dissections go the bird seems to be almost entirely insectivorous, and in every way one of the most desirable species of woodland, orchard, and field.

FINCHES, GROSBEAKS, AND TOWHEES.

The Finch and Sparrow family is larger in numbers of both species and individuals than any other family of North American birds; but comparatively few of the species dwell and feed in orchard.or woodland. The Pine Grosbeaks, Pine Finches, Redpolls, and Crossbills are forest birds ; but they come here from the north mainly during the colder months of the year, when they feed largely on the seeds of trees, and are not particularly useful. There are only three common species belonging to the Sparrow family that habitually live in or near woods, and even these are often found in orchards and small groves. Most of the Sparrows find a large part of their food on the ground or near it. They all have strong, rigid, conical beaks, and muscular gizzards; all are seed eaters, and, as the family feeds to a great extent on the seeds of weeds and grasses, they live mainly in or near open fields. A few, such as the Chipping Sparrow, the Purple Finch, and the Goldfinch, build their nests in trees. But these get a large part of their food in pastures, fields, or gardens. The Goldfinch and Purple Finch, however, live so much in trees that they may well be included among the birds of woodland and orchard; while the Rose-breasted Grosbeak and the Towhee are entitled to be known as woodland birds, although often seen in orchard or garden.

The Goldfinch and the Purple Finch are more in the orchard and less in woodland than the Grosbeak and the Towhee. In spring and summer these finches feed on many orchard caterpillars. The Towhee is found mostly in young coppice growth, in thickets on the borders of woodland, and in briery tangles, but seldom in deep, dark woods. These four species of this family perform essential service for trees. The Towhee works on the ground and among the smaller sprouts, and the others work more among trees of larger growth. 


\section{Rose-breasted Grosbeak.}

\section{Zamelodia ludoriciana.}

Length. - Seven and three-fourths to eight and one-half inches.

Adult Male. - Above, mainly black; the black of head extending around under throat; wings and tail white-marked; rump white; upper tail coverts black and white; below, mainly white; middle breast and under wing coverts rose-red; the large bill appears white from below.

Adult Female. - The black of the male largely replaced by brown, except on throat, which is white; line over eye and space in front of eye white or whitish; a streak on crown also whitish, mixed with brown; no white on rump or tail; no rose on breast, and that under wings replaced by yellow.

Nest. - Built of twigs, fibers, and grasses; loosely made in bush or sapling, from five to twenty feet or more from ground.

Eggs. - Varying in color from pale greenish-blue to dull green; thickly marked with coarse spots of various shades of brown and purplish.

Season. - Early May to September.

The Rose-breasted Grosbeak should be accorded the most cordial welcome wherever it appears; for not many birds have such beauty of plumage and song, and at the same time such useful habits.

This is one of the few birds that has increased in numbers

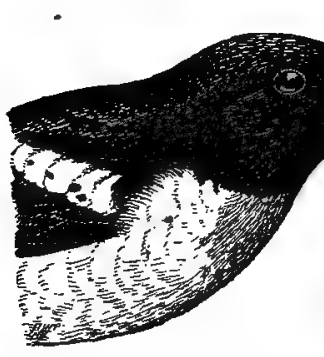

Fig. 78. $\rightarrow$ Rose-breasted Grosbeak, male, a bout one-half natural size. within the past forty years to such an extent that it is now found commonly in woods and thickets where many years ago it was considered rare. It is common, too, about the fields and gardens. Its sweet warbling may be heard from the tall shade trees of the village street. The introduction and spread of the Colorado potato beetle, which reached Massachusetts about thirty years ago, may have had something to do with this increase in the number of Grosbeaks, for they are among the few birds that will eat this beetle. They seek the beetles so assiduously everywhere that they are often locally known as "potato bug birds." This Grosbeak has now become common throughout most of Massachusetts, except on Cape Cod. The common note of this bird is a thin, sharp eek, quite different from that of any other eastern bird. The song is a strong, rolling carol, somewhat like that of the Robin in 
tone, but much purer and of far finer quality. It seems to convey to the listener not so much the bright good cheer of the Robin, as a sort of pure joy, expressed in most exquisitely liquid tones.

In May, when the Grosbeaks are mating, two or more of the males sometimes engage in fierce and even bloody battles for the favors of some coveted female. At such times the males join in a general melee, warbling meanwhile their choicest strains, until the weaker come to the ground exhausted, while the strong and favored bird leads his chosen bride away in triumph.

I well recall the day when, as a boy, I first found the nest of this bird, built high in an alder bush by a little run, on the edge of some great chestnut woods. A black-and-white bird of striking appearance sat on the nest, covering the eggs, and manifesting no alarm at my presence. I thought it a new species, for there was certainly no female Grosbeak of that color in the books. The mystery was solved when the bird left the nest. It was the first time

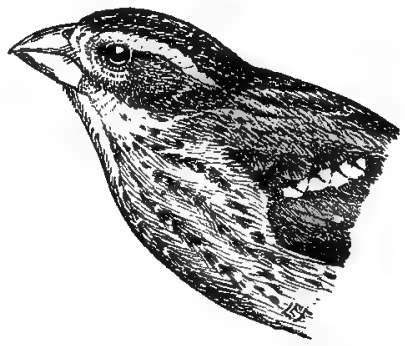

Fig. 79. - Rose-breasted Grosbeak, female.

I had discovered a male bird incubating. The Grosbeak is a gallant fellow, and relieves his mate of a large part of her duties. He is very affectionate and attentive. He sings while sitting on the nest, perhaps to while away the time, or to let his mate know that he is at his post. When danger is near he subdues his tone, until the song, pure and clear as ever, seems to come from far away. It dies down almost to a whisper, and then, as the danger passes, rises again to its full power. He is a model husband and a good father.

The Grosbeak gets its food largely among the trees, seeking it from the ground upward to the tallest tree top. Had this bird acquired the habit of feeding on any of the products of the farm or orchard, it might easily become a pest, as its large size, robust appetite, and strong beak would make it a formidable enemy to growing vegetables, grain, or fruit. 
Its bill seems well fitted to wrench out the seeds of coniferous trees from their cones, but a large part of its summer food consists of insects, among them many of the greatest pests of woodland, orchard, and garden. Hairless caterpillars are continually sought. Much skill is evinced in extracting leafrollers. The bird has been seen feeding to some extent on the caterpillars of the gipsy moth and the tussock moth. It is fond of beetles and their larve, particularly those of leafeating and wood-boring species. Dr. Warren found a few wasps and flies among the food of this bird. In early spring the eggs and hibernating pupæ of insects are taken from crevices in the bark. On the ground the Grosbeak finds large caterpillars like the army worm, and some grasshoppers and locusts. Here also it eats the seeds of weeds. Professor Beal says that he examined the stomachs of a few birds that were shot while eating green peas, but that the stomachs contained enough potato beetles, old and young, as well as other harmful insects, to pay for all the peas the birds would be likely to eat in a whole season.

The Grosbeak eats wild berries, and the seeds of the alder and birch. The fact that it takes buds and the ovaries of the blossoms of fruit trees leads Minot to regard it as an enemy to agriculture; but Mr. Brewster says truly that such pruning is seldom more severe than that practised by a thrifty horticulturist. The office performed by the Grosbeak, with its strong, cutting beak, is, as has been hereinbefore stated, merely a part of nature's pruning, which, though sometimes drastic, still in the long run benefits rather than injures the trees.

Towhee. Chewink. Ground Robin.

Pipilo erythrophthalmus.

Length.-From about eight to eight and three-fourths inches.

Adult Male. - Head, all round, neck and chest, wings and tail black; the two latter white-marked; sides and flanks chestnut; breast and belly white.

Adult Female. - Brown replacing the black of the male.

Nest. - On ground; usually sunken and often roofed over.

E'ggs. - White, rather finely and evenly spotted with light ashy and brown.

Season. - The latter part of April to October, rarely remaining all winter in southeastern Massachusetts.

This common and well-known bird always may be found in its season in sprout lands and thickets, where it scratches 
among the dry leaves on the ground. Like many other Sparrows, it scratches with both feet at once, jumping into the air and digging away the leaves with a quick motion of the feet, then brings its feet deftly under its body and lands on them. When disturbed it darts into a bush, with a whir

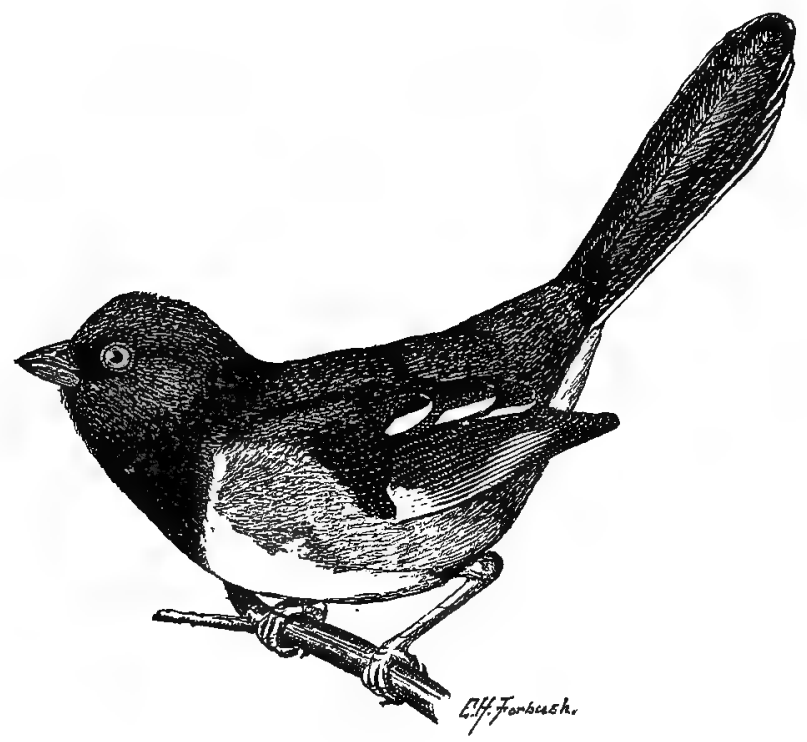

Fig. 80. - Towhee, male, about one-half natural size.

of wings, a flash of black, white, and chestnut, a quick flirt of its long tail, and, with crest slightly erected, sends back its call towhee', or the more nasal cheewink $k^{\prime}$, or kriink'. Its song as commonly sung may be rendered dick' you, fiddle-iddle, iddle, iddle, iddle. The first two notes are sometimes combined in a $d e^{\prime} a k$, but whether dick or the deacon is addressed, he is adjured to fiddle. The last notes run into a trill.

The Chewink rarely goes into the tree tops, though it often perches on the top of some small sapling while singing. Its food is obtained mainly from the ground, the shrubbery, and as high up the tree trunks as it can reach or jump. While scratching and digging among the leaves in early spring it unearths many dormant insects, and disposes of them ere they haye an opportunity to propagate their kind. 
Many beetle larva are thus found, among them the white grub of the May beetle. The bird finds many ground beetles and ants; it picks up the mature forms of Arctians, many. of the smaller nocturnal moths, and many hairy caterpillars. When it lives near gardens or cultivated fields it is said to feed on such pests as potato beetles and cabbage worms. Grasshoppers and cockroaches are eaten, also flies and earthworms. The vegetable food of this bird consists largely of fruit and weed seeds. It has been accused of pulling corn in some localities; but this habit probably occurs rarely, though its strong bill enables it to crack and devour hard corn. Wild berries are much eaten in summer. The only cultivated fruit I ever knew this bird to take was the gooseberry, a few of which it picked up from the ground where they had dropped.

Purple Finch. Crimson Finch. Red Linnet. Gray Linnet.

Carpodacus purpureus.

Length. - About six inches.

Adult Male. - Entire body suffused with tints varying from reddish-brown to rose-red or wine-purple, "like a brown bird dipped in diluted pokeberry juice," as Burroughs says.

Adult Female. - Olive-grayish; streaked above and below with dusky. The young male is much like the female.

Nest. - Usually at no great height, on coniferous trees; made of grass, twigs, and fibers, lined with horsehair.

Eggs. - Pale greenish, spotted and scratched with purplish-brown and black.

Season. - Resident; but irregular in winter.

The Purple Finch is naturally a bird of the woods, but it has learned to love the vicinage of human habitations, and lives about orchards or in groves or shade trees on well-kept estates, and is more commonly seen in such situations than in the woods.

The species is gregarious, and sometimes during the migrations or in winter they may be seen, in flocks of twenty to fifty individuals, roaming the country in search of the berries and seeds of which they are fond. The ordinary note is a sharp, hard chip, and they call to each other with a note which resembles the syllables $p \check{e}-w e e^{\prime}$. The song of the male is a sudden, joyous burst of melody, vigorous, but 
clear and pure, to which no mere words can do justice. When, filled with ecstasy, he mounts in air and hangs with fluttering wings above the tree where sits the one who holds his affections, his efforts far transcend his ordinary tones, and a continuous melody flows forth, until, exhausted with his vocal effort, he sinks to the level of his spouse in the tree top. This is a musical species, for some females sing, though not so well as the males.

This Finch appears at first sight to be destructive, for it devours buds and the blossoms of apple, cherry, peach, and plum trees, feeding on the stamens and pistils. Often I have seen a party of these birds thus destroying the blossoms of apple trees, and scattering the snowy petals about in a shower. They feed also upon the blossoms of the red maple, the seeds of such trees as the white ash, and the berries of the red cedar, mountain ash, and other trees. But, as with the Grosbeak, the pruning or cutting of buds, blossoms, and seeds of trees

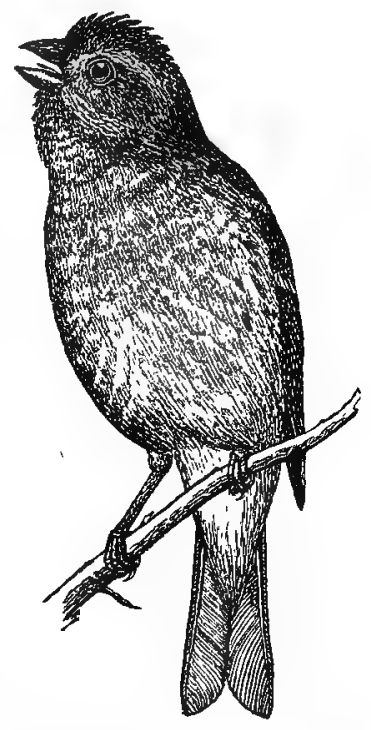

Fig. 81. - Purple Finch, male, about one-half natural size. is not ordinarily excessive. On the other hand, this bird eats many of the seeds of the most destructive weeds, ragweed being a favorite. The Purple Finch also destroys many orchard and woodland caterpillars. It is particularly destructive to plant lice and cankerworms. Its quest of weed seeds is sometimes rewarded by some insects which it finds on the ground, among them ground beetles and perhaps a few cutworms.

If a bird of this species is confined in a trap cage in spring, and exposed in a conspicuous place, most of the Purple Finches in the neighborhood may be trapped. The greater part of the "Linnets" in many localities have been taken in this way, despite the law and its officers, who are on the look- 
out for the lawbreakers. The birds have been sold in the bird stores or sent to Europe as red or gray Linnets. This may account for a local scarcity of this Finch in some places where it was formerly common.

American Goldfinch. Yellow Bird. Wild Canary. Thistle Bird. Astralaginus tristis.

Length. - About five inches.

Adult Male. - Bright, rich canary-yellow; crown black; wings and tail black, white-marked.

Adult Female.-Above, brownish-olive; below, grayish-white, tinged with yellow; wings and tail much like those of male, but more brownish.

Young. - Much like female.

Male in Winter. - Like female, but retaining his black-and white wings and tail. Nest.-A cup of grass and moss, down-lined; built in a fork or branch-croteh

- from six to forty feet up.

Eggs. - Bluish-white.

Season. - Resident, but local and wandering in winter.

The Goldfinch is almost as well known as the. Bluebird, and is even more brilliant in coloring. Its common call, per-chic'-o-ree, given repeatedly, as it bounds through the

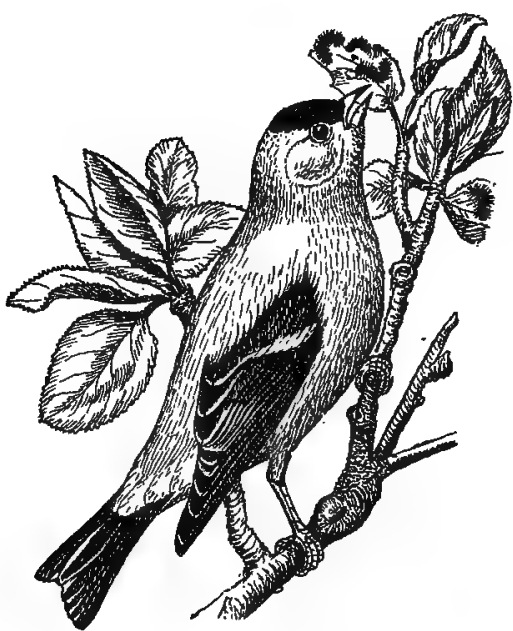

Fig. 82.-American Goldfinch, male, about one-half natural size. air in graceful undulations, will be recognized by all who are at all familiar with bird life. This bright bird wanders among orchards and groves, and flits a bout the fields, pastures, and gardens long after other birds have begun their family cares ; for it is not until July that the Goldfinch usually undertakes to build its nest. Its brood once reared, all the members of the family may be seen wandering about once more. In the garden they are sometimes known as "salad birds," for they are particularly attentive to nice, crisp lettuce, from which at early morning they drink the dew, and perhaps eat a fow tender morsels, no doubt paying for 
them by destroying some of the insects that infest the garden. The Goldfinches are almost always in company, and communicate with each other often with the most delightful cries; a common sweet call is whew-ee $e^{\prime} w h e w-e e^{\prime}$, and there are many Canary-like tones. The song of the male is sweet, and he more nearly merits the name of Wild Canary than does the Yellow Warbler. At times of unusual transport the singer rises in air and flutters in circles, singing a sweeter and more varied melody than that usually uttered from a perch.

The food of the Goldfinch is largely that of a typical Sparrow, as it feeds much on the seeds of weeds. Those seeds that are furnished with down, like the seed of the dandelion and thistle, are much sought after by this bird. Mrs. Mabel Osgood Wright says that if you desire the presence of Goldfinches in the garden you must plant sunflowers, zinnias, and coreopsis. The seeds of wild clematis, wild sunflowers, and ragweed are much sought by them. Goldfinches feed their young largely on plant lice, caterpillars, small grasshoppers, and beetles. During the spring, when unhampered by family cares, and wandering through fields and orchards, they feed considerably on cankerworms. They sometimes frequent grain fields, where they are said to devour noxious insects, including the Hessian fly. Goldfinches often feed very largely in winter on the eggs of plant lice; this has been observed many times. Mr. Kirkland examined the stomach of one of these birds, and found it contained two thousand, two hundred and ten eggs of the white birch aphid. Chermes larcifolia is a plant louse that is common on larches. It deposits great numbers of stalked eggs in April and May, which produce the young lice that feed on the trees in summer. Mr. Kirkland saw a flock of over forty Goldfinches going systematically over some infested larch trees, beginning at the top of a tree and working gradually down to the lower branches, then repeating the performance on the next tree. They subsist largely in winter on the seeds of birches and those of the button bush, as well as on weed seeds. I have never heard of their troubling cultivated fruit or doing any injury except by pilfering sunflower seeds. 
BLACKBIRDS, GRACKLES, ORIOLES, ETC.

Only two (Orioles) of the eight Massachusetts members of this family are distinctly arboreal. Although all the Blackbirds feed from trees, and Grackles nest there, they ordinarily obtain most of their food from the ground, and so must be considered among the birds of garden, field, or swamp. While all the Blackbirds congregate in large flocks in their migrations, the Orioles are never seen in such flocks. The Orchard Oriole is so rare in Massachusetts as to be of no economic importance. This leaves but one species to be considered among the birds of woodland and orchard.

Baltimore Oriole. Golden Robin. Fire Hang Bird. Hang Nest.

Icterus galbula.

Length. - Seven and one-half to eight inches.

Adult Male.-Head and neck all round, upper back, wings, and tail black; wings marked with white; terminal portions of three outer tail feathers yellow; all other parts yellow to intense orange.

Adult Female. - Much duller, the black largely replaced by brownish and the orange mainly by yellowish-olive; throat sometimes marked with blackish.

Iminature Males. - Resemble the female.

Nest. - A deep pouch (sometimes covered, with the entrance on the side), composed of tough fibers and long hairs interwoven; usually hung from the terminal twigs of elms, but often in șmall fruit trees.

Eggs. - Bluish-white, with irregular or zigzag lines of brown or black.

Season. - May to September.

This abundant and familiar species may be found wherever tall elms rear their heads along the village street. Even in the smaller cities this bird manages still to dwell, despite the obtrusive Sparrow and prowling cat. Its brilliant plumage and wild, free notes have always been characteristic sounds of the New England farmstead; for, although it prefers the elms, it frequents other shade and orchard trees, and even goes to the woods for food, though it seldom breeds there. Orioles increase in numbers with the advance of settlement and civilization.

The clear, wild calls of this bird are as well known as its musical song. The song, however, varies so much in tone and rhythm that no pen can ever adequately describe its many variations. Nearly every male has a distinctive song of his 
own. When we have once learned to recognize the song of a certain individual bird, we are able to note his arrival annually. An Oriole with a peculiar song nested near my home in Worcester for four consecutive years. Only last year I heard a new bird-note in Andover, and found that the bird was a Baltimore Oriole, singing a song unlike that of any bird of any species that I had ever heard before.

Its pendulous nest is usually suspended in such a manner that its natural enemies find it difficult of access, and the bird, a valiant fighter, does not hesitate to attack its enemies with

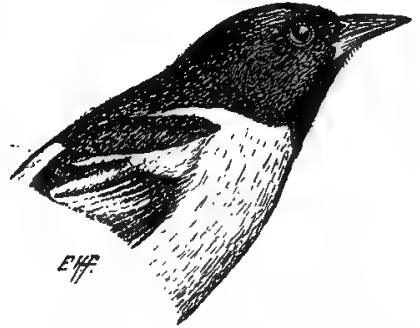

Fig. 83. - Baltimore Oriole, about one-half natural gize. its sharp beak, - a weapon not to be despised. It does the fiercest battle with the Kingbird, and may be seen sometimes struggling in mid air with this doughty adversary, until both birds fall to the ground breathless and exhausted. It sometimes succumbs, however, to the swarming numbers and extreme pugnacity of the "English "Sparrow, and where the Sparrows become most numerous they often drive out the Orioles. The Oriole itself, however, is not always guiltless in respect to other birds. Occasionally it destroys other nests, either to get material for building its own, or out of pure mischief. Mr. Mosher observed a male Oriole attempting to drive another away from its nest. The stranger would make a rush at the nest, and then the owner would grapple with him. This running fight was kept up for fully three hours. In the mean time the rogue Oriole went to a Redstart's nest, threw out the eggs, and threw down the nest. The next day an Oriole, probably the same bird,.was seen to throw out an egg from a Red-eyed Vireo's nest, when he was set upon and driven away by the owners. Three other instances have been reported to me by trustworthy observers who have seen Orioles in the act of destroying the nests or eggs of other birds ; but, so far as I know, few writers have recorded such habits, and they are probably exceptional. Indeed, the Oriole's bad habits seem to be few. It occa- 
sionally helps itself to green peas; but $\mathrm{Dr}$. Harris tells us, in his work on insects injurious to vegetation, that this Oriole splits open the green pods for the sake of the weevil

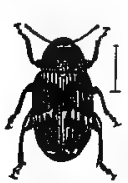

Fig. 84. - Pea weevil, $\mathrm{m}$ u cll enlarged. grubs contained in the peas, thereby greatly helping to prevent the spread of these noxious insects. Nuttall says that it takes the saccharine nectar from fruit blossoms. It eats cherries, but seems to prefer Juneberries and mulberries. Professor Beal says that several Orioles that were shot in cherry trees had no cherries in their stomachs, but some seeds of Rubus and Juneberries. John Burroughs told me years ago that it was very destructive to ripe grapes at his place on the Hudson River, but I have never heard of its injuring grapes in Massachusetts ; it usually leaves us before most grapes are ripe.

Having catalogued the sins of this bird, let us see what its good qualities are. Professor Beal finds that eighty-three and. four-tenths per cent. of the Oriole's food consists of animal matter, caterpillars forming thirty-four per cent. of the whole. Evidently the Oriole is one of the first among the birds known to de-

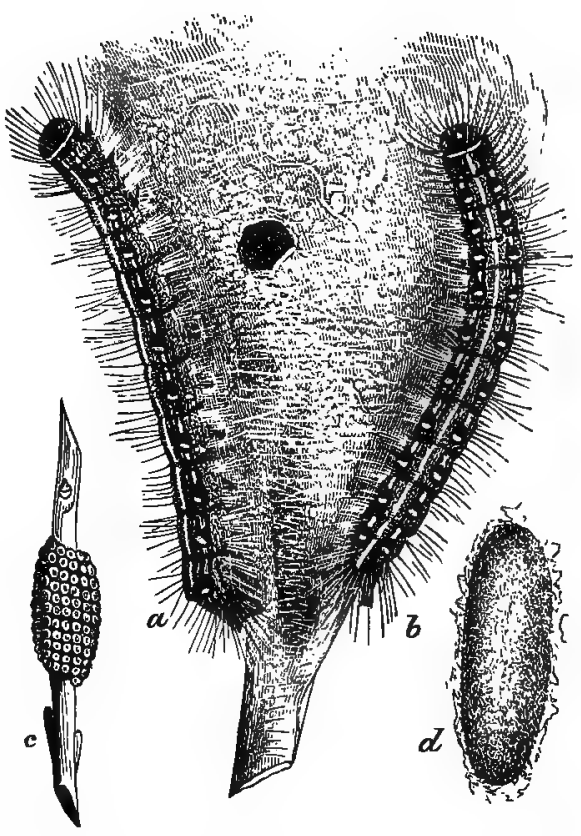

Fig. 85. - $a, b$, tent caterpiliars; $c$, eggs; $d$, cocoon. The caterpillar's are eaten by Orioles.

stroy hairy caterpillars, and for this alone it may be ranked as one of the chief friends of the orchardist and forester. The tussock, gipsy, brown-tail, tent, and forest caterpillars, 
the fall webworm, and even the spiny caterpillar of the mourning cloak butterfly, - all are greedily eaten by the Baltimore; and it does not usually swallow many, but merely kills them and eats a small portion of the inner parts. It thus destroys many more than would be needed to satisfy its appetite were they swallowed whole, while at the same time no recognizable portion of the caterpillar can be found in the bird's stomach. This is a habit about which, like many others, we can learn only by observation. Mr. Nash received a number of reports from correspondents in 1900 regarding the clearance of tent caterpillars from trees by these birds. They were watched day after day, and in the end

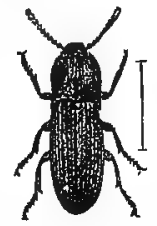

Fig. 86. - Click beetle, enlarged. cleared the orchards of the pests. An Oriole was seen to finish one nest of small caterpillars and begin on another while the observer was eating his breakfast. Young Orioles are fed very largely on injurious moths and caterpillars. The Baltimore Oriole is worth its weight in gold for its services in destroying both gipsy and brown-tail moths. The

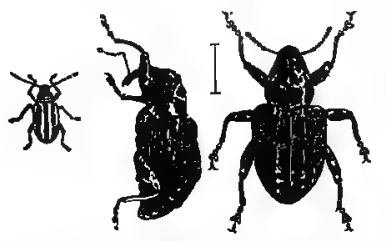

Fig. 87. - Cucumber beetle, natural size; and curculios, much enlarged. Both are eaten by Orioles. bird is particularly fond of snap beetles or click beetles, the parents of the destructive wireworns. Professor Beal says that more than five hundred species of these beetles are found in North America, and their larvæ are exceedingly injurious to a great variety of plants, particularly to corn, grass, and garden crops. As they attack the roots or work within the stalks, they are very difficult to control. Many birds eat either the beetles or larvæ. The very injurious May beetles and other leaf-eating beetles are taken by the Oriole, among them the striped squash beetle or cucumber beetle, one of the most destructive pests of the garden. Bagworms, curculios, wasps, bugs, plant lice, scale insects, March flies, and crane flies are among the insects eaten by this bird. 
The following, from Mr. Kirkland's notes, made at Malden in 1896 , shows that this bird is of value in woodlands, for the observations were made in the woods :-

A sawfly (probably Selandria) is at present one of the insects most commonly devoured by the Baltimore Oriole. These birds are very abundant around the experiment station, and I have repeatedly seen them feeding upon these sawflies, even as early as 4.30 one bright morning. By 6 or 7 o'clock these birds are well at work, feeding around the building. I have seen them eat cankerworms, and, what was more interesting, devour a large Tortricid larva, which rolls the leaves of the white oak. This larva rolls the leaf around itself, thus forming a kind of cylinder, within which it feeds. The Orioles put their bills into one end of the cylinder without tearing the leaf, and pull out the larva. 



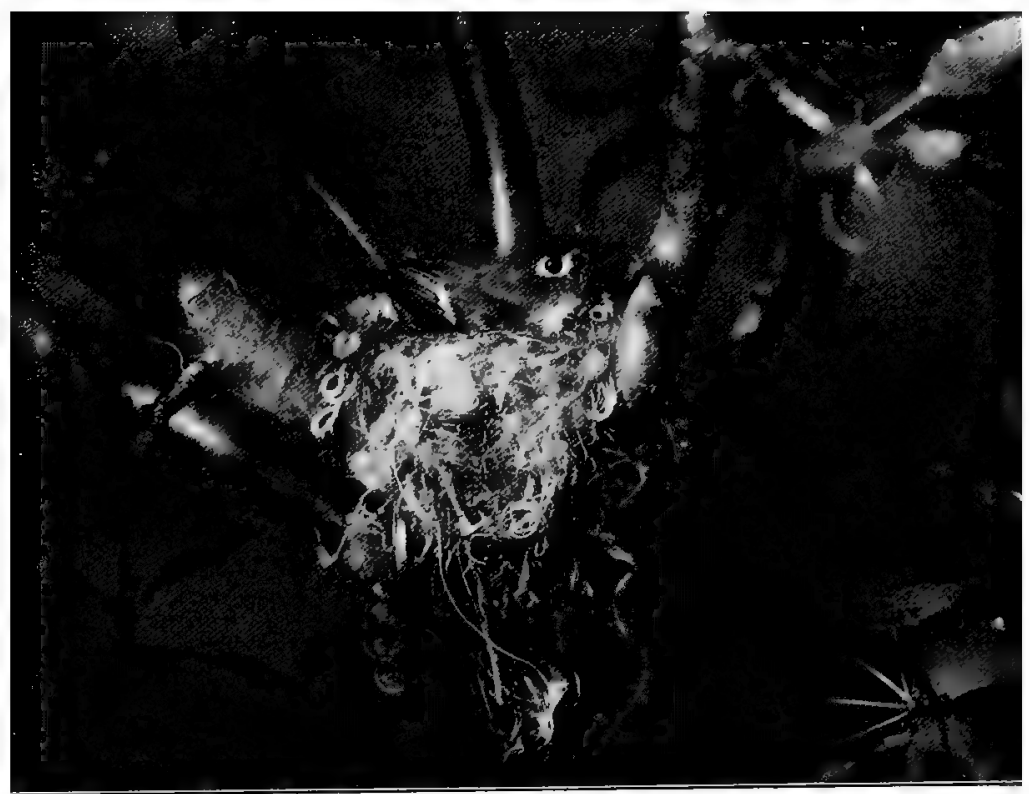

PLATE XIX. - Least Flycatcher on Nest. (Photograph, from life, by J. Chauncey Lyford.) 


\section{CHAPTER VI. \\ SONGLESS BIRDS OF ORCHARD AND WOODLAND.}

FLYCATCHERS,

This family consists of crested songless birds, that watch from dead limbs, posts, or other exposed perches, and take their prey mainly on the wing. They usually sit rather upright, with tail drooping, and wings in readiness for instant flight. The structure of the Flycatcher's bill and mouth is admirably adapted for the capture of winged insects. The bill is wide at the base, and the gape is deep and surrounded by so-called "bristles," which are of service in entrapping flying insects. While some species take nearly all their food on the wing, most of them also pick up insects from trees, shrubbery, and even from the ground.

Nine species are found in Massachusetts, but only four of these are generally common summer residents; the others are either migrants, rare, or casual or local residents.

\section{Least Flycatcher. Chebec.}

Empidonax minimus.

Length. - Between five and five and one-half inches.

Adult. - Above, usually dark olive-gray, often with a tinge of brown; under parts nearly white, shaded on the sides like the back; yellowish on belly; a broad eye ring and two wing bars yellowish-white or grayish-white.

Nest. - A soft cup; usually in a crotch of bush or tree, from five-to forty feet from the ground.

Eggs. - White.

Season.- May to August.

This is the common little Flycatcher of the orchard, village, and roadside. Its usual note, chebec', one of the characteristic sounds of May, comes before the apple blossoms, as a promise of summer. Few of these birds are seen early in May, while the weather is cool ; but the first warm, south wind usually brings a multitude, and nearly every orchard harbors a pair or more. The bird sits quite upright, occasionally throwing up its head as if to sing, as it utters its 
quick, emphatic note. At intervals it flits out after its flying victims, and, returning again to its perch on some old apple tree, awaits, with quivering wings, another opportunity. It prefers open woods and orchards, or shade trees growing on dry land, rather than dense forests or swamps. It is rather pugnacious, and, though it rarely molests other small birds unless they encroach on its domain, it is very brave in defence of its nest and young. The following, from $\mathrm{Mr}$. Mosher's notes, shows how it will defend its rights :-

MAY 15, 1899. - A pair of Least Flycatchers had just begun their nest in an apple tree by placing some bunches of cottony material and a few strings and straws. A female Oriole, happening along, appropriated the string for her own use, and carried it away. The Flycatchers came soon after, and were very much disturbed on finding the nest materials scattered, and had quite a talk over it. In a few moments the Oriole came back for more string, when both Flycatchers flew at her and snapped their bills savagely in her face. The Oriole did not seem to mind them much, and kept on going toward the nest. When the Flycatchers found they could not scare her in this way, they both attacked her fiercely, and pulled out quite a number of feathers, keeping up a steady scold. The Oriole attempted to retaliate, but when she attacked one of the Flycatchers the other struck her from the other side, and several times she was knocked completely off the branch. Finally she beat a precipitate retreat, one of the Flycatchers chasing her out of sight.

The call note of the Chebec is a wit, and the bird has a more subdued note, a peu, or wheu, often several times repeated. In the mating season the male sometimes utters a

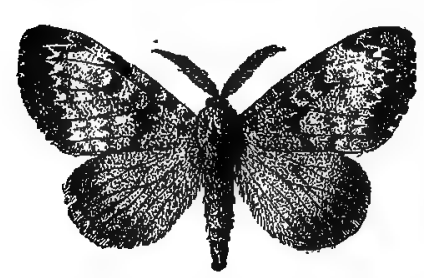

Fig. 88. - Gipgy moth, male, natural size. Oiten canght by the Least Flycatcher. series of twittering notes while hovering over the tree in which his mate is sitting.

Like all Flycatchers, this species catches flies, among them the common house fly, and also some useful parasitic flies. It is by no means confined to such food, however, but is particularly destructive to small beetles in flight, and in this respect it is most useful. It captures many moths, particularly those species that fly by day, as the gipsy moth; but 
it also picks up many which are stirring only very early in the morning or at evening. The bird watches for caterpillars, and when it sees one stir, flies from its perch and snaps up the luckless creature. This bird, in common with other Flycatchers, picks up many caterpillars that, to escape Warblers and other enemies, spin down on their webs or drop from the trees. The greatest service our little Flycatcher renders to man consists of the destruc-

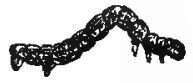

Fig. 89.- Cankerworm, natural size. tion of such orchard pests as boring beetles, bark beetles, the fly of the railroad worm, codling moths, gipsy moths, cankerworms, and other caterpillars.

Nuttall says that when the young are out of the nest they move about in company with the old birds, eating whortleberries and cornel berries.

\section{Wood Pewee.}

Contopus virens.

Length. - Six to about six and one-half inches.

Adult. - Tail notched; bill black above, light below ; upper parts dark brownishgray; two whitish wing bars; under parts whitish, the sides washed with dark gray, showing a light line down the centre of the breast.

Nest: - Rather flat, and usually saddled on a nearly horizontal limb, from ten to forty feet up, beautifully decorated externally with lichens.

Eggs. - Creamy white; handsomely marked, with a ring of dark spots around the larger end.

Secuson. - May to September.

The Wood Pewee is, as its name implies, a bird of either coniferous or deciduous. woodland; but it seems to prefer the more open, deciduous woods, particularly the oaks, on which its nest is often placed. It usually perches on dead branches at some height from the ground, and flies out to some distance, taking one or many insects at each sally.

The note of this bird is one of the characteristic sounds of the forest shades, and is heard throughout the day in those cool retreats where the heat of the summer sun is softened by the interposition of umbrageous foliage. Here, where sunshine and shadow fleck the leafy ground, the Pewee's call sounds ever pensive, sweet, and clear. The bird is thought by some to be of a sad disposition; but the sadness of its call, which harmonizes so well with its forest environment, 
is deceptive, for the Pewee is evidently happy, and delights in its plaintive tones. Its common call is $p e e^{\prime}-\breve{a}-u \cdot e e^{\prime}$, followed frequently by $p e^{\prime} e^{\prime}-e r$, uttered in a drawling manner,

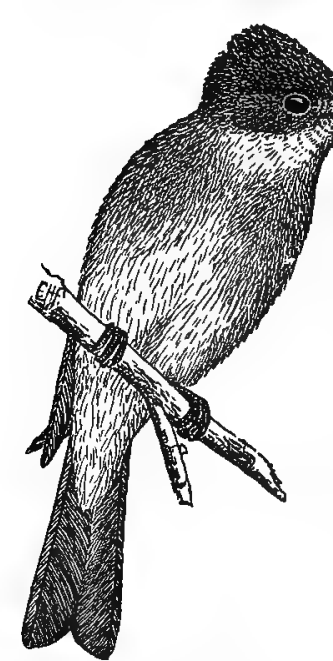

Fig. 90.-Wood Pewee, one-half natural size. and with considerable intervals between the phrases. Bendire says that the male has a low, twittering warble in the mating season. The bird also twits and twitters from time to time.

The nest merits more than the usual brief description. It is usually saddled on a dead limb, the outside adorned, like that of the Hummingbird's nest, with crustaceous lichens, so that when seen from below it looks like a knot on the branch. It is largely made of fine grasses and fibers, and often lined with them. As the nest is not deep, and rests on the top of the branch, the bottom is usually so thin that it would fall out were it not supported by the bark.

The food of the Pewee consists very largely of flying insects, but it often flutters about the foliage, picking off caterpillars and plant lice. Daily in the early morning and in the dusk of evening, even in the uncertain gloom of the deep woods, this bird pursues its prey unerringly. Flying beetles and ants, butterflies and

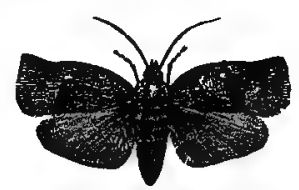

Fig. 91. - Tortricid or leaf-rolling moth, natural size.

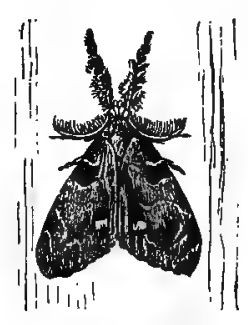

Fig. 92.-Tussock or paporer moth, naturnl size. moths, flies, gnats, mosquitoes, _ all are taken. The Pewee is useful in the destruction of small moths and their larvæ. The male cankerworm moths, tussock moths, Tortricid moths, and gipsy moths are conmonly eaten, while the young birds are fed largely at times on cankerworms. This bird takes some parasitic flies, and Bendire records an instance where it pilfered young trout from a hatchery. 
Phœbe. Phœibe Bird. Pewree. Bridge Pewee.

Sayornis phrebe.

Length. - About seven inches.

Actult Male. - Above, dull olive-brown; head dark, almost blackish; sides, and often the breast, shaded with same; tail notched; bill entirely dark.

Nest. - Built of mud, mossed over; grass or feather lined; placed on some beam of building or bridge, under the edge of a high bank or rock, or in a cave.

Eggs. - White.

Season.-April to October.

The common Phœbe is known throughout the State. It is as familiar and homelike as the Swallows, and deserves all the regard accorded it as a friend to man. This bird feeds almost entirely upon insects ; hence its preference for the vicinity of water and its apparent fondness for streams, for in such locations its source of food supply is augmented by the many insects that, like mosquitoes, pass the earlier part of their lives in water, and emerge later to fly about within range of the Phobe's quick and accurate eye. Perched on a dead twig, a mullein stalk, a post, or some similar vantage point, Phœbe scans the sur-

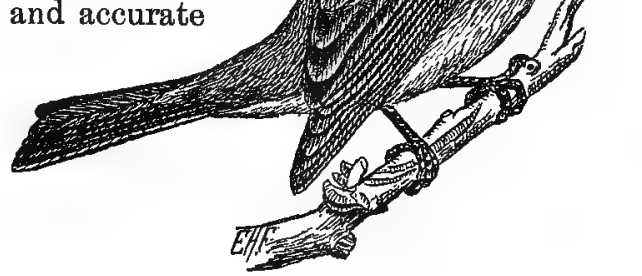

Fig. 93. - Phœbe, one-half natural size.

rounding space with eager eye, marking each insect that comes within her field of vision; and when her eye rests on one she covets, be it beetle, moth, or fly, she quickly leaves her perch and immolates the victim.

This Flycatcher, unlike the Wood Pewee, hawks about habitually near the ground, though it often takes a higher perch and flight. While sitting it often jets the tail, throwing it up even higher than it is represented in the cut; but usually the tail is held low. The Phœbe utters a loud chip, and it has a variety of softer tones; but the note most commonly heard may be given phee'be, phee'brizzy, — the first 
wiry note of each phrase longest, and heavily accented; the last short, and with a falling inflection. In the early spring this bird occasionally flutters about in a circle or rises high in air, repeating its notes very rapidly, with variations, as if attempting a flight-song. The Phobe, like the Wood

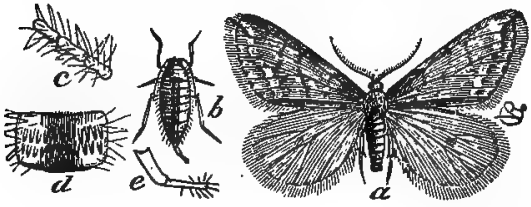

Fig. 94.- Moth of the spring cankerworm; $九$, male; $b$, female; $c, d, e$, structural details. Pewee, is able, because of some peculiarity of its sight, to pursue and catch insects in the dusk of morning or evening. Its note is among the first to be heard on a summer's morning, and may even mingle with the last notes of the Owl or those of the Whip-poor-will. I have heard it shortly after 3.30 A.M. This characteristic makes the Phobe extremely useful, as it is thus able to catch such nocturnal moths and other insects as ordinarily remain hidden in daylight, and seldom venture to fly except in dusk or darkness. It feeds on a variety of pests. Among them are the imported elm-leaf beetle, the striped cucumber beetle, the cankerworm moth, the cutworm moths, the brown-tail and the gipsy moths.

Professor Beal, who has examined a large number of Phobes' stomachs, finds the bird

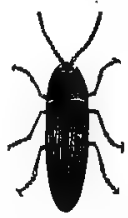

Fig. 95.-Wood. boring click beetle, enlarged. to be almost exclusively insectivorous. The insects eaten

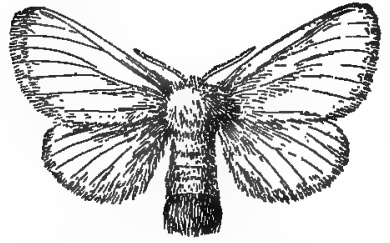

Fig. 98.- Brown-tail moth. belong mainly to noxious species of beetles, including May beetles, click beetles, and weevils, grasshoppers, wasps, and many of the flies that trouble cattle. The vegetable food is unimportant, consisting mainly of a few seeds, wild cherries, elderberries, and juniper berries. Now and then a raspberry or blackberry is taken. In the spring of $1868 \mathrm{Mr}$. C. J. Maynard found that some of these birds had their stomachs filled with hawthorn berries. Gentry says that they feed on horseflies, 
house flies, mosquitoes, and vast numbers of moths and butterflies in both larval and adult stages. Bendire asserts that Dr. Ralph told him that in Florida the Phœbe alights on the backs of cattle and follows them around, catching the flies on the animals, and fluttering above them in search of insects. The only harmful habit of this bird that I have heard of is also mentioned by Bendire, who says that it is said to eat trout fry.

As the young of the Phobe are fed enormous numbers of insects, as two broods are raised each year, and as in settled districts the bird has largely forsaken its natural nesting places for the habitations of man, it is now one of the most beneficial species. From year to year, as has been proven repeatedly, the bird returns to its favorite haunts; and the young birds, though driven away in the fall by the parents, like to find, when possible, a nesting site near their old home. This gives us a hint which may be utilized to increase the numbers of these birds about our farms.

\section{Kingbird. Bee Martin.}

Tyrannus tyrannus.

Length. - About eight inches.

Adult. - Above, very dark gray, crown and tail nearly black; tail feathers broadly tipped with white; a concealed orange or vermillion patch on crown; wing feathers and outer tail feathers white-edged; below, white, darkening on sides of breast.

Nest. - A bulky structure of straw, rootlets, strings, feathers, etc.; usually from ten to twenty feet up in an orchard tree in field or pasture; sometimes in a bush on the marshy shore of a pond or river ; rarely on a post, bridge, or building.

Eggs. - Creamy white, heavily marked mainly toward the larger end with brown and lilac.

Season. - May to September.

The Kingbird is almost as well known as the Robin or Bluebird. It is common throughout most of the State, except in heavily wooded regions. Bold and fearless, yct confident of man's protection, it seems to prefer the neighborhood of human habitations. It seeks its winged victins by taking its stand on some orchard tree, a fence wire, a post, or even a telegraph wire, where it sits turning its head from side to side, always on the watch. The perfection of this bird's sight is illustrated by a statement made by Miss 
Florence Merriam. She said that a Kingbird was seen to start from a telegraph pole one hundred and twenty-five feet from the observer, and fly to within twenty-five feet of him, for an insect that was invisible to the man at that distance. If a Crow or Hawk comes in sight, the Kingbird at once launches into the air with cries of fury, and chases the enemy

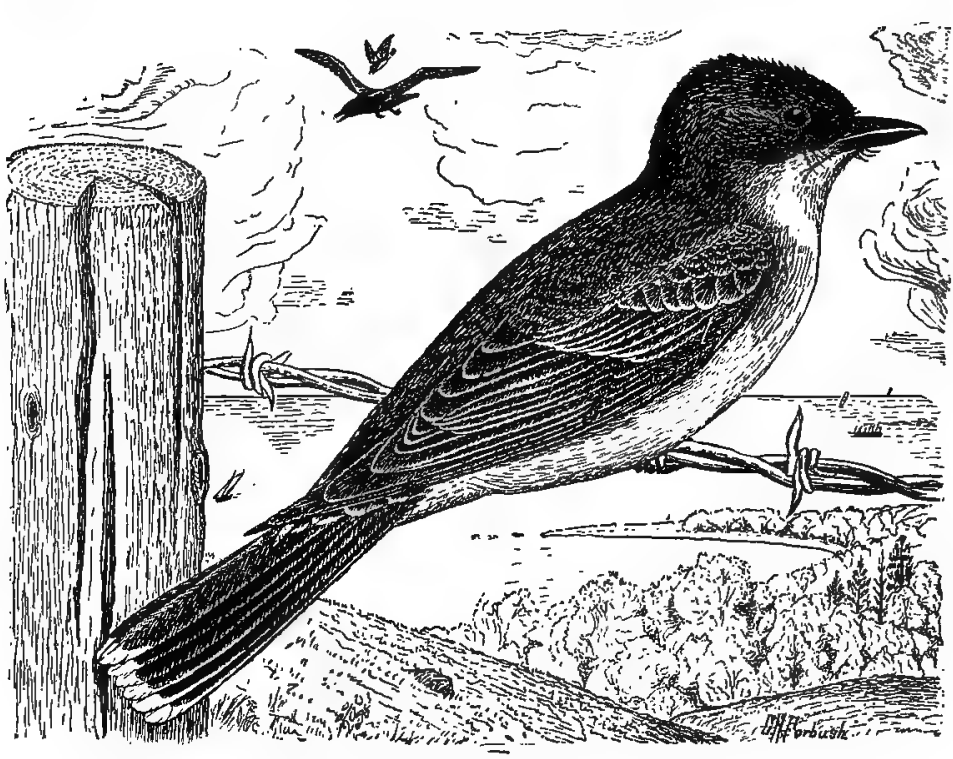

Fig. 97. - Kingbird, one-half natural size.

of its young beyond the confines of its chosen domain. Professor Beal relates an instance where a Hawk that had stooped to some young Turkeys was driven away by a pair of Kingbirds, and forced to give up its prey. The Kingbird possesses sùch remarkable powers of flight, and is so quick in turning, that under favorable conditions it can with impunity strike the swiftest Hawk and get away. The Kingbird's endeavor is to rise above its enemy and beat it toward the earth. This is its only feasible plan. I once saw a Kingbird attack a Cooper's Hawk that was flying low over a field. The small fighter overtook the Hawk at once and landed on its back, but after a time the Hawk managed to rise to some height and then shot off diagonally downward, leaving the Kingbird so fast that it appeared as if stationary in the air. This suggests 
what might possibly happen were the Hawk to rise quickly above its adversary. Nevertheless, the Kingbird fears him not. If an Eagle appears near the Kingbird's nest he is immediately assailed by all the warrior tribe and driven ingloriously from the field. The Kingbird thus acts as protector and friend to its weaker neighbors and to the farmer's poultry and Pigeons.

The brave bird sometimes does not hesitate to attack even man himself in defence of its nest. It used to be a favorite pastime with the boys on one farm to throw up a hat near a Kingbird's nest and see the birds attack it. I have seen a boy repeatedly struck on the head by the parent birds when he was climbing toward their nestful of young. Nevertheless, the Kingbird, in harrying his neighbors, sometimes meets his match in the Catbird, Oriole, Martin, or little Hummingbird. The following interesting account of the nesting of a Kingbird in a rather unusual situation is taken from Mr. Kirkland's notes :-

June 29, 1896. - Near the Shady Hill station, Bedford, Mass., a Kingbird has built its nest directly on the top of a fence post, and in a location where there is no shade whatever on the nest during the middle of the day. 'The fence stands beside a roadway, where in early summer teams pass a hundred times a clay. The fence is made of old railroad ties or posts, with barbed wire running between them. The nest is on the corner post, and from this corner a board fence extends at right angles down to the railroad track. 'The top of the post on which the nest is located is about six by eight inches, with a depression in the center where the wood has decayed. The nest occupies this depression, and is made of grass, string, and cotton waste. At the time of my visit to Bedford there were four partly fledged young in the nest, and these the old birds were constantly feeding. From their vantage ground on the telegraph wires near by they would swoop down, catch an insect or two, and then fly to the nest. I could approach within six feet of the birds. I was told by Mr. Beard, owner of Shady Ilill nursery, that during the hottest weather one of the parent birds would stand over the young ones, and, with wings outstretched and vibrating, would shade them and keep them cool.

In this large nursery there were many small trees, but scarcely a tree large enough for the Kingbird's nest. The insects on the young trees probably proved so attractive as 
a food supply that the birds placed their nest on the post, as the most accessible nesting place in the midst of plenty. Other similar instarices have been recorded.

The notes of this bird consist of a series of shrill and varied twitters, somewhat resembling those of a Swallow. In spring it often mounts into the air, and, rising high, frequently falls for a distance and then recovers itself, twittering fiercely all the time, as if engaged with an imaginary antagonist. It appears to be pursuing insects, which it sometimes follows to considerable heights, and having a frolic at the same time. In warm weather it will sometimes plunge into the water, and, rising again, shake its plumage like a Fish Hawk.

The Kingbird, although primarily a feeder on flying insects, can adapt itself to the pursuit of other food. In flying about

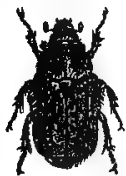

Fig. 98.-Cetonia, natural size. it often takes insects by skimming and fluttering over water, or by picking them from the grass or trees. After the severe rainstorm of June, 1903, when the air was swept clear of all flying insects by torrents of rain, Mr. Outram Bangs saw Kingbirds picking up from the ground dead or dying insects.

They sometimes alight on plowed lands, and pick up grubs and myriapods; they will also eat wild berries and seeds. Very large beetles are taken, such as May beetles and Cetonias, as well as some of the beneficial tiger beetles and ground beetles. Weevils of both grain and fruit, click beetles, grasshoppers and crickets, wasps, wild bees, ants, and fies are prominent among the food materials of this bird. Among the flies taken are house flies and several species that trouble cattle; but smaller insects, like mosquitoes, gnats, and midgets, are not ignored. Leaf hoppers and

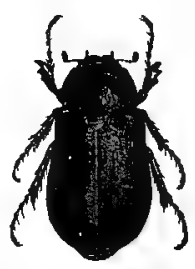

Fig. 99.- May beetle, natural size. many other bugs are taken; and a great variety of caterpillars, mostly of the hairless species, are eaten or fed to the young. This bird is destructive to moths of many kinds, among them the gipsy moth. In two and one-half hours seven of these birds were seen to take seventy-nine male and 
twenty-four female gipsy moths, and they killed in that time a great many more that could not be positively identified.

The Kingbird, therefore, is particularly beneficial about the garden and orchard, for it eats very little, if any, cultivated fruit. The only bad habit attributed to this bird is that of killing honey bees, and even while catching bees it seems about as likely to do good as harm. Professor Beal states that a bee raiser in Iowa, having good reason to believe that the Kingbirds were feeding upon his bees, shot a number near his hives, but an expert entomologist could find no trace of bees in their stomachs. The investigations of the Department of Agriculture seem to indicate that the Kingbird does not ordinarily reduce the aggregate number of working bees. Only fourteen out of two hundred and eighty-one stomachs examined contained any remains of honey bees. There were but fifty bees found, forty of which were drones, only four were positively identified as workers, and six were so much broken as to render the distinguishing of sex impossible. Professor Beal finds that the Kingbird feeds on robber flies, - insects which prey largely on other insects, especially honey bees. He considered nineteen robber flies contained in the Kingbirds' stomachs to be more than an equivalent for the working bees found; and the destruction of drones by Kingbirds is a benefit. On the whole, it seems probable that, while the Kingbirds eat some bees, they confine their bee-eating mainly to the drones, and also protect the bees by killing the moths and flies that prey upon them.

Dragon flies, which are believed to be useful insects, are killed by Kingbirds, but apparently more from necessity than choice, as the bird seems to pay little attention to them when insects more to its taste are plentiful. In studying the insect enemies of the gipsy moth, it was noticed that Kingbirds occasionally caught ichneumon flies. It was seen, however, that at the time when most of the beneficial ichneumon flies were depositing their eggs in the caterpillars, the Kingbirds were absent; but when these flies had done their work, when the moths had begun to emerge, and when an injurious or secondary parasite, Theronia melanocephala, was depositing its eggs in the living bodies of the beneficial 
primary parasites, then numbers of Kingbirds were attracted by the flying moths. It seems quite probable, therefore, that the destruction of parasitic insects by Kingbirds is as likely to be beneficial in such cases as injurious. ${ }^{1 .}$ As about ninety per cent. of the Kingbird's food consists of insects mostly injurious; as it has never yet been shown to be positively harmful in any respect; and as it acts as a protector to small birds and poultry on the farm, - there need be nothing further said to commend the bird to the farmer.

\section{HUMMINGBIRDS.}

The Hummingbirds are popularly believed to feed solely upon the nectar of flowers ; but they are probably of considerable economic importance, for the reason that, because of their small size and long, slender beaks, they capture many tiny insects that conceal themselves among the blossoms and foliage. Only one species of this distinctively American family has been found in Massachusetts.

\section{Ruby-throated Hummingbird.}

Trochilus colubris.

Length. - About three and three-fourths inches.

Adult Male. - Above, bright, glossy green ; throat metallic ruby-red; lower parts white.

Female and Young. - Similar, but without red on throat.

Nest. - A shallow little cup of soft, downy materials, covered externally with lichens, looking like a "moss-covered" knot on a branch; from five to sixty feet up.

Eggs. - White.

Season. - May to September.

This dainty, feathered gem, the smallest of all native birds, comes to us from the tropies when the south wind blows in May, and when bursting buds and flowers first afford it the honey, nectar, and tiny insects on which it lives. Often when the cherry trees are in bloom many of these little sprites

- It would seem from the above that the Kingbird was doubly useful: first, in killing the gipsy moth; second, in protecting the parasites of the gipsy moth from secondary parasites. But there may be some doubt regarding the habits of this Theronia. It is named by Professor Fernald. (Monograph of the Gipsy Moth, Forbush-Fernald, 1896, p. 376) as one of the most useful primary parasites of the gipsy moth, although he states that $\mathrm{Mr}$. C. E. Bailey captured a specimen in the act of stinging a gipsy pupa that was already parasitized by a dipterous insect. 
may be seen buzzing about among the petals, with a sound like that of huge bees. In power of flight the Hummer surpasses all other birds. The little body, divested of its feathers, is no larger than the end of one's finger, but the breast muscles which move the wings are enormous in proportion to the size of the bird. They form a large part of the entire trunk, and their power is such that they can vibrate the inch-long feathers of those little wings with such rapidity that the human eye can scarcely follow the bird when it is moved to rapid flight by fear or passion.

The Ruby-throat is exceedingly pugnacious in the nesting season. The males fight with one another, and, secure in their unequalled powers of flight, they attack other and larger birds. When the Hummingbird says "Go!" other birds stand not upon the order of their going, but go at once; while the little warrior sometimes accelerates their flight, for his sharp beak is a weapon not to be despised. Even the Kingbird goes when the warlike Hummer comes; the "English" Sparrow flees in terror; only the Woodpeckers stand their ground. When a person approaches the nest, the sharp squeaking or chirping of the angry Hummer is sometimes followed by the bird itself, for it has been known to dart at its human visitors. It seems to have an aversion for the diurnal sphinx moths, or "Hummingbird moths," as they are called, and frequently drives them away from its favorite flowers. Audubon says it is sometimes chased by "bumble" bees, but easily avoids them. Miss Florence Merriam, quoting Mrs. Bagg, described a fierce battle between Hummers and these large bees, in which the combatants on both sides fought until exhausted, tearing to pieces, in the mean time, the flowers among which they fought. The bee, with its poisoned lance, must be a dangerous antagonist for so small a bird.

The Hummingbird's nest, when newly built, with its two

Later, Mr. Bailey found that the Theronias which he watched invariably stung pupe that were dead, and contained parasitic pupee. Mr. F. H. Mosher has since made observations which confirm those of Mr. Bailey. This may either indicate that some one is in error, or it may be considered good ground for the hypothesis that this Theronia may be at one time or place a primary parasite, and at another a secondary parasite. If this is possible, it further complicates the relations between the Kingbird and the gipsy moth. 
tiny eggs, about the size and color of pea beans, lying on their soft, downy bed, is the prettiest bird home to be found in our orchards or woodlands. The nest is often built in an apple or pear tree in the orchard, sometimes in a rose bush in the garden, not quite as often in the woods ; but I once found two nests, with eggs, in high trees on the face of a precipitous cliff overlooking a lake. Although the nest in such situations is usually covered with lichens taken from the surrounding rocks or trees, the birds sometimes use other material. Mrs. Mabel Osgood Wright avers that she found a nest in the top of a spruce, some sixty feet from the ground, and that the nest was covered with flakes of spruce bark, instead of lichens. The nest is begun in June, and is about five or six days in the building. The eggs are incubated about eight or ten days, and the young remain in the nest usually, I think, about three weeks, although Audubon's observations do not agree with this. They are very tiny when first hatched, and grow at first rather slowly, for birds; but later they grow so rapidly that the nest, which is at first a neat cup, is extended by their swelling bodies until its interior more nearly resembles a saucer than a cup.

The nest represented in the accompanying illustrations was built in an apple tree in Concord. On July 3, when

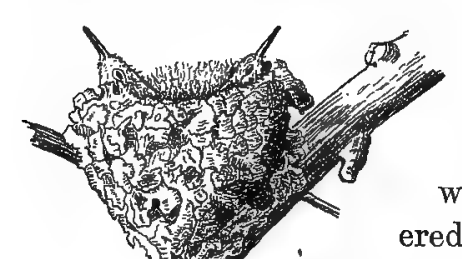
the young were probably about two weeks old, the first sketch was made. As will be seen (Fig. 100), the birds were still very small, and covered with down and pinfeathers. Their bills were quite short, and the

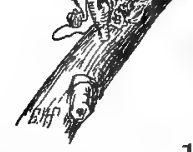
quills of the wings were not developed. The sketch taken just a week later (Fig.

Fig. 100.-Hummingbirds about two weeks old, one-half natural size. 102) shows them with their bills fully developed, their bodies well-feathered and full-winged, nearly ready for flight. As the young Hummers are fed mainly on minute insects and small or young spiders, a large number of the tiny creatures must be sacrificed to supply the aliment necessary for the astounding growth of a week. Some authors assert 
that the male bird assists the female in the care of the young; but in my experience the male is always absent, and the female alone provides for the young family. The feeding of such a family is a most interesting proceeding, as the birds are fed by regurgitation until the very day before they leave the nest. The following remarks on the appearance of the young birds and their feeding are taken from my notes of July, 1905 :-

How perfect are these little fledgeling wanderers, in their tiny, moss-covered cup, shaded from the southern sun rays by the green leaves which overhang and sur-

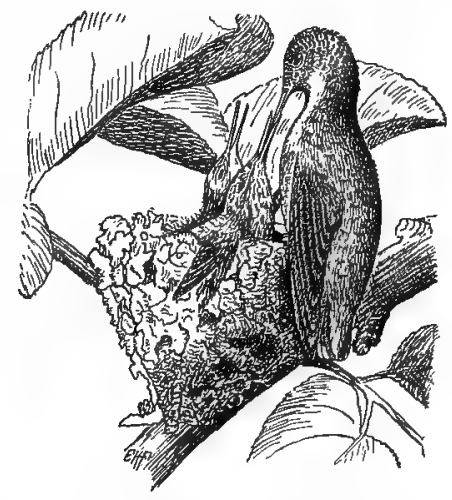

Fig. 101. - Mother bird feeding young, one-half natural size.

round the nest. Their dainty new feathers, of but a few days' growth, have been touched by the tender mother's breast alone or the gentle dew of heaven. Their inscrutable, brilliant dark eyes flash quick glances all around; no motion escapes them. One leans forward from the nest and attempts to pick a moving aphis from the limb. Their whole bodies throb quickly with the fast-surging tide of hot life pulsing through their veins. Now, with a boom like a great bee, the mother suddenly appears out of the air as she darts almost in my face. I am standing within two feet of the nest, and she hangs on buzzing wing, inspecting me, then perches on a limb just above my head, then on another a few feet away, her head raised and neek craned to its fullest extent. Buzzing about from place to place, she inspects me, until, satisfied, she finally alights on the edge of the nest at the usual place, where her constant coming has detached a piece of lichen and trodden down the fabric of the edge. The little birds raise themselves with fluttering wings, and the parent, rising to her full height, turns her bill almost directly downward, pushes it into the open beak of the young, and by working her gullet and throat discharges the food through the long, hollow bill as from a squirt gun.

Two days later, on the morning of the 11th, when $\mathrm{Mr}$. Brewster went to the nest, one young bird had gone, but the other sat on the edge. As he came up, it "flew like a bullet" up to the roof of the barn, a few rods away.

Undoubtedly the Hummingbirds live to some extent on 
the nectar of flowers. They are fond of sweetened waters and the sweet sap of maple trees, yet the greater part of their food is probably insects. They are so active in the pursuit of insects and feed on such small species that it is difficult to observe their fly-catching habits; but they have

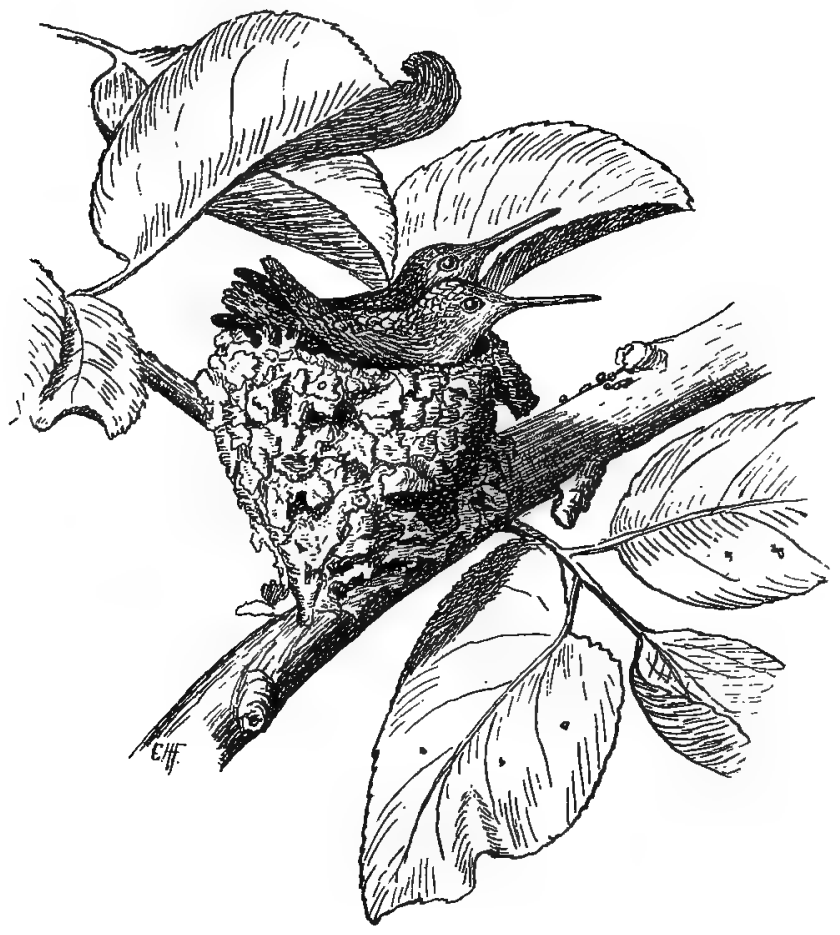

Fig. 102.-Young Hummingbirds nearly fledged, about two-thirds natural size.

been detected, as Wilson says, darting by the hour among the swarms of little insects that dance in the air on fine summer evenings. I have watched individuals hovering about the branches of trees and picking off small insects, apparently plant lice, or very small spiders. When kept for a time in confinement they have shown a liking for such flies and gnats as could be found in their limited quarters; and almost invariably when stomachs have been examined they have contained small winged insects or spiders, or both. Wilson, who opened "great numbers" of these birds, found 
them filled with insects about three times out of four. Dr. Warren records the examination of sixty-two Hummingbird stomachs. The food contents were mainly small spiders, beetles, or other insects; small worms and flies were also noted, but none was specifically identified.

\section{WOODPECKERS.}

This family comprises a highly specialized group of birds, the more typical of which are peculiarly fitted to secure their food by digging into the trunks or limbs of trees, in search of ants and other wood-boring insects which cut channels under the bark and into the wood. The feet of most Woodpeckers are four-toed, two toes being disposed in front and two behind. Some species, however, have but three toes. The tail is composed of stiff, hard feathers, with strong shafts. These modifications of the foot and tail assist the bird in climbing perpendicularly and in clinging to the bark of trees. While climbing or feeding, the two pairs of toes with their strong, sharp claws enable the bird to grip the bark and hold on, while the strong, sharp-pointed quills of the tail serve as a brace or support. The bird is thus more fully equipped for climbing than a telegraph lineman. The claws and tail take the place of the man's hands and spurs. But the Woodpecker's tools for drilling into the wood and extracting its living food are more wonderful than its climbing apparatus.

If any one who had never heard of a Woodpecker were to be told that the bird drilled holes into the solid wood by beating its head against a tree, he would be likely to regard the story as fiction. Nevertheless, that is very nearly what the Woodpecker actually does. The highly specialized apparatus that will permit of such constant hammering of beak and head against the trees without producing concussion of the brain, or the least inconvenience or injury to the bird, is certainly among the most wonderful features of bird anatomy.

A moment's reflection will convince any one that, unless the Woodpecker's skull were built on an unusual plan, it could not withstand such hard and continuous hammering. If we watch a Woodpecker drilling, we shall see that he 
draws back his head and body to the greatest possible distance from the tree, and then strikes with all his force, sending his strong beak powerfully into the wood. The skull of the typical Woodpecker is very thick and hard. Its connection with the beak is strong, but at the same time springy, and somewhat jar-deadening. The membrane which surrounds the brain is very thick and strong.

Maurice Thompson says that no person can doubt, after an examination of Woodpecker habits, that the birds are hard of hearing. He apparently believes that the continual concussion has deadened this sense. However this may be, it has not interfered with the bird's sight, which seems preternaturally keen.

The bill is shaped somewhat like a stout chisel, and is used as one. It strikes out small chips, and so drills its way, if

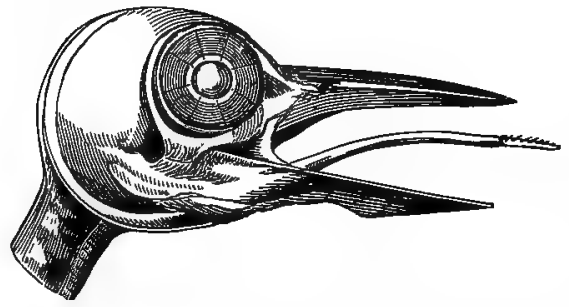

Fig. 103.- Skull and tongue of Woodpecker. (From Samuels.) necessary, even to the heart of the tree; but the most highly specialized organ of the Woodpecker is its tongue, which serves as an accessory to the bill in bringing to light the deep-lurking enemies of the tree.

The subjoined cut of the Woodpecker's skull (Fig. 103) shows the tongue slightly protruding from the open beak. Ordinarily the tongue lies in the depression of the lower mandible. It is slender, nearly round, and its upper surface is covered with very minute spines, directed backward; its tip is as hard as horn, with many strong barbs, which make of it a weapon more effective in its way than a fish spear. The machinery

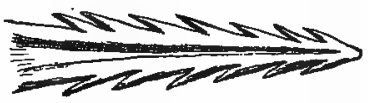

Fig. 104. - Spearlike tougue-tip of Downy Woodpecker, much enlarged.

for thrusting it forth is most perfect. The bone of the tongue, called the hyoid, has two branches which pass downward and backward from the lower jaw, up and around the back of the head, and over the top of the skull, where they 
either pass into the nostrils and so on in channels down toward the end of the upper mandible of the beak, or, turning to one side, coil themselves about the bony part of the eyeball. 'These branches of the hyoid are enclosed in sheaths which fit into a groove on the top of the skull. By means of this apparatus the tongue may be extended so that, in the Hairy Woodpecker, it may reach an inch and a half beyond the end of the bill. The tongue is propelled forward at need by powerful muscles, so that when the bird has drilled to the burrow of a boring beetle it can open the beak slightly, protrude the tongue, spear the insect and draw. it out and into the mouth. Birds which possess such implements for the destruction of boring insects must be immensely serviceable to man, for borers are difficult for man to control.

The utility of Woodpeckers is now quite generally recognized by foresters, and by entomologists who study forest insects. Dr. A. D. Hopkins, the most active and experienced forest entomologist in the United States, is quoted by Dr. E. P. Felt as asserting that Woodpeckers are the most important enemies of spruce bark beetles, and appear to be of inestimable value to the spruce timber interests of the northeast. Dr. Hopkins also states that Woodpeckers are the principal enemies of the destructive sap-wood borers.

It is sometimes argued that Woodpeckers are of little use as protectors of trees, since they never dig into living wood. This reasoning is based on an error, due to lack of careful observation. Nuttall speaks of a Flicker that dug a nest hole eighteen inches deep in a green sassafras. Dr. Hopkins figures a section of a living tree in which a hole four inches long, two wide, and five deep had been made by Woodpeckers in their search for boring larve. According to the annual wood rings around the entrance of the

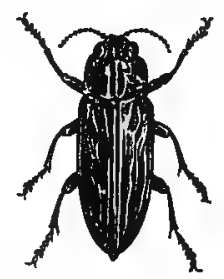

Fig. 105.-A pine borer. cavity, the tree recovered and lived at least fifteen years after the bird captured the borers. The work of Woodpeckers on living trees does not ordinarily attract much notice. They seldom need to dig far into live trees for borers, for most 
species that infest live trees are found during a part or all of their lives just under the bark or in the sap-wood not very far from the surface; and the Woodpecker can drill a small

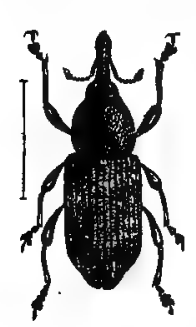

Fig. 106.-Pales weevil, a destruetive pine insect, eaten by Woodpeckers.

hole into the burrow, insert its open beak, and with its tongue spear and extract the insect. The wound soon heals, leaving no noticeable trace. A Woodpecker may thus reach insects at a depth of from one to four inches, according to the size of the bird. Dead trees, however, are riddled with borers in all their parts, and the birds are obliged to delve deeply to find them; therefore, the work of the birds in dead trees is most noticeable.

The chief value of the Woodpeckers consists in the fact that when they find a tree infested with borers they are likely to keep at work upon it until no more larræ can be found. Thus they often save the tree, and check an incipient outbreak of borers. Woodpeckers so engaged sometimes destroy parasites of boring insects. Such destruction of useful insects by these birds is of little consequence; for when the birds destroy the grubs, the parasites are not needed. When the birds are too few in numbers to prevent an increase of boring insects, the parasites also have a similar immunity from the attacks of birds, and so are free to exert their influence in restraining the borers. If Woodpeckers should eat an undue number of parasites, they might then be doing harm; but such cases probably seldom occur.

The Woodpeckers are also useful in providing homes for other birds. Most Woodpeckers each year hollow out from the wood a home for their young, and rarely, if ever, use it more than one season. Some species, of which the Downy and the Hairy Woodpeckers are familiar examples, also excavate holes to which they retire for shelter during winter nights. The larger Woodpeckers often make deep holes in dead trees while digging out large borers or colonies of ants. When the carpenter birds are through with these cavities they are sometimes used as nesting places by other birds that are unable to excavate for themselves. The deserted nests of the Downy Woodpecker are used by the Wren, the 



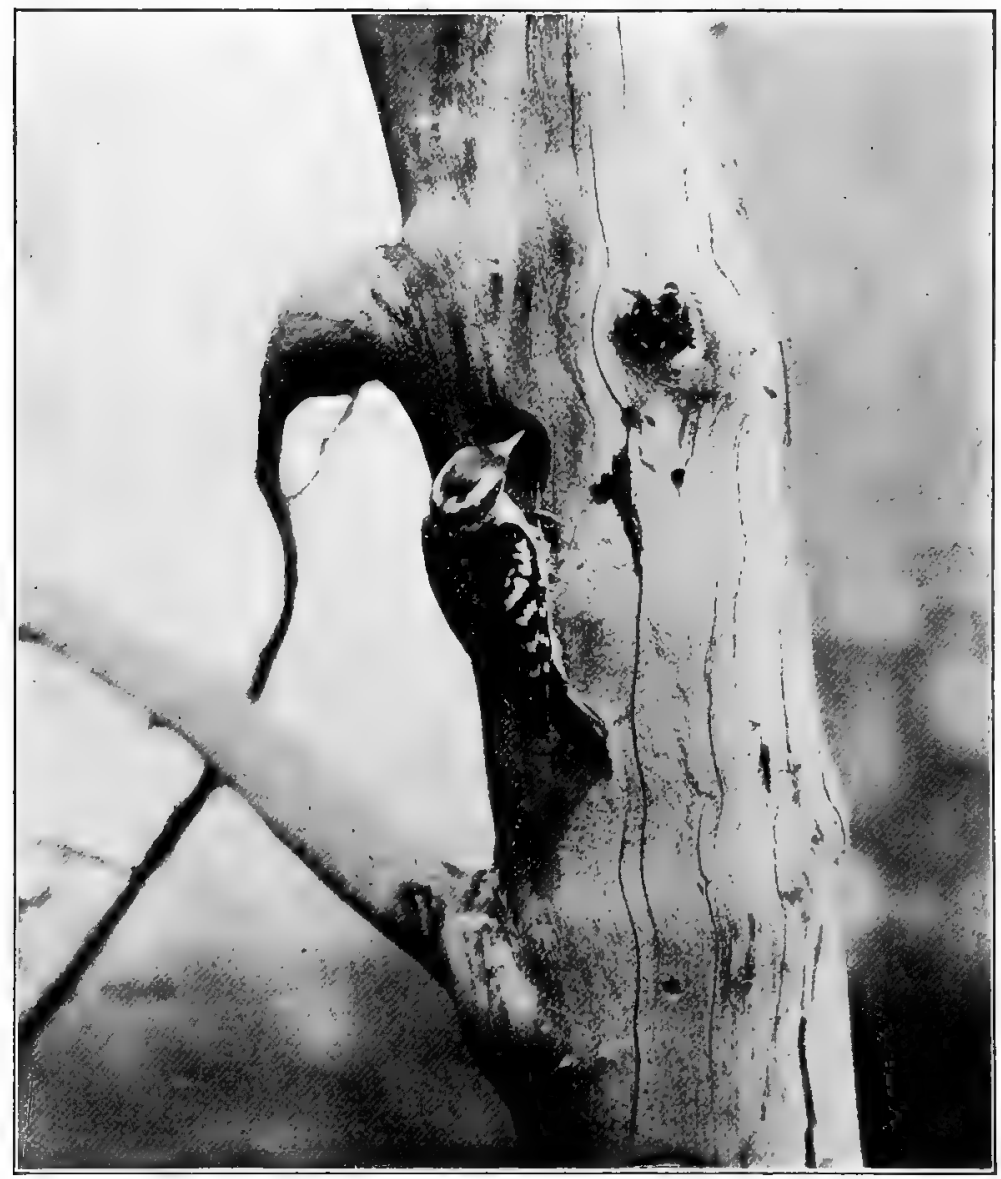

PLATE XX. - Downy Woodpecker at Nest Hole. (Photograph, from life, by C. A. Reed.) (From American Ornithology.) 
Chickadee, or even the Tree Swallow; those of the Hairy Woodpecker may be used by Bluebirds, Martins, or Swallows; those of the Flicker by the Screech Owl and the Wood Duck. The excavations made by Woodpeckers in securing insects are often used by the Chickadee or the Wren.

Notwithstanding their usefulness, however, the Woodpeckers have been subject to the most senseless and unjust persecution for many years, merely because a single species, which rarely breeds in Massachusetts, feeds largely on the sap and cambium layer of both fruit trees and forest trees. This species (the Yellow-bellied Sapsucker) has not the strong, barbed tongue of the typical Woodpeckers.

Eight species of Woodpecker occur in Massachusetts, but only two, the Downy Woodpecker and the Flicker, are common residents throughout the State. The Hairy Woodpecker is also common, though less so than the others, and more local: All other species are usually rare migrants, except the Sapsucker, which is seen regularly in spring and fall, and the Pileated Woodpecker, which is local.

It is a popular error to speak of all Woodpeckers as either Sapsuckers or Red-headed Woodpeckers. The males of all our Woodpeckers have red on the back of the head or nape ; but the Red-headed Woodpecker has the head, throat, and neck red all round. Although once common locally in Massachusetts, it is now rare ordinarily, and seldom breeds in the State. The birds now generally known in Massachusetts as "Red-headed Woodpeckers" are the species hereinafter described under their proper names.

\section{Downy Woodpecker. \\ Dryobates pubescens medianus.}

Length. - About six and one-half inches.

Adult Male. - Upper parts black, striped, and barred with white; a small scarlet patch at the back of the head.

Adult Femule. - Similar, but without the scarlet on head.

Young. - The scarlet patoh in the male gives place to reddish-brown.

Nest. - In a hole made by the birds in a dead stump or limb.

Eggs. - White.

Season. - Resident.

This sprightly little bird, the smallest of the Woodpeckers, is also the most useful. It is found commonly throughout 
most of the State wherever trees grow. Its sharp, clear, incisive notes are aptly compared by Chapman to the ring of a marble quarrier's chisel. Its only approach to a musical performance is its resonant drumming on a sounding hollow limb or bird box. This habit, which it has in common with other Woodpeckers, seems to be resorted to out of pure exuberance of joy and vigorous life ; it is, with this carpenter bird, a fitting substitute for song.

The nesting cavity is wrought out with happy labor in some dead limb. The entrance is just large enough to admit the owner by tight squeezing, and the interior is trimmed into graceful curves, rounding at the bottom into a receptacle for the snowy eggs. The birds sometimes carry the chips away, but are often careless of concealment, and let them fall about the foot of the tree.

Downy is a bird of the old orchard in summer. He prefers to inhabit trees that are neglected by their owners, and assumes the self-appointed guardianship of such trees in the happiest frame of mind imaginable. He does this for the reason that these neglected orchards harbor a host of insects and vermin, in the destruction of which he revels. Under those scales of bark there lurk in early spring the larvæ of the codling moth, which pass the winter in their loosely spun cocoons. Downy knows just where to find them. He circles the trunk and limbs, climbs up or comes down backward, and ever and anon he taps and sounds the bark, until the tell-tale vibration given back by the scale above the cocoon corroborates the evidence of his eyes. Every stroke with which he knocks on the door of an insect's retreat sounds the crack of doom. He pierces the bark with his beak, then with his barbed tongue drags forth the insect, and moves on to tap the last summons on the door of the next in line. Now and then an intelligent bird carries the warfare against the apple worm still farther, and pecks the fruit upon the tree; but, so far as my experience goes, he attacks only wormy fruit, and when he has the worm he leaves the apple.

Dr. Trimble, in his book entitled "Insects Injurious to Fruits," asserts that he found numerous instances where the bird had penetrated the cocoons of the codling moth. 
Dr. Rufus H. Petit, entomologist of the Michigan Experiment Station, says that in almost every case where cocoons of this insect were concealed under flakes of bark the birds had found them. "Such pierced cocoons," he says, "are the common thing in our orchards, especially where they have been above the snow line." Fig. 107, which is drawn from a reproduction of his photograph, shows the inner surface of a flake of bark, the remains of a cocoon attached, and the hole made by the bill of the bird.

A large part of the food of this Woodpecker, while in the orchard, consists of wood-boring beetles, their larvæ, and various bark beetles and weevils. Hardly another bird, excepting the suc-

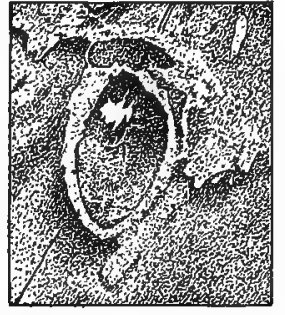

Fig. 107.-Coconn of cod. ling moth, pierced by Woodpecker. ceeding species, can compete with this in destroying borers, such as the round-headed apple borer, that infest fruit trees. In securing these insects it never does the trees any perceptible harm. In many cases it perforates the bark of apple trees with small, roundish holes, less than an inch apart, disposed in parallel horizontal rings. Nuttall says that these holes are made for the purpose of drink-

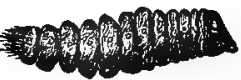

Fig. 108.-Apple tree borer. ing sap from the trees. But this work is not done for the sake of the sap, if, as Wilson says, it is always performed in the fall, at a time when the sap is not flowing; possibly the bird takes out bits of the cambium layer; Wilson believed it was delving for insects; but whatever the reason, the trees so perforated seem to be invigorated rather than injured by the process, which is not the case with trees similarly attacked by the true Sapsucker. The holes made by the Sapsucker are different in shape, being square rather than round.

Townend Glover, formerly entorhologist to the United States Department of Agriculture, stated that he observed the Downy making a number of small, rough-edged perforations in the bark of an ash tree, and found that wherever the bark had been thus injured the young larva of a wood-eating 
beetle had been snugly coiled underneath, and had been destroyed by the bird, thus proving conclusively to his mind that these holes are made for the purpose of finding insect food.

But Downy does not confine his attacks to the hidden enemies of trees; he takes caterpillars and weevils from twigs, buds, and branches. His young are largely fed on caterpillars of various sorts. Ants and plant lice - those ill-assorted masters and servants - are slaughtered in inmense numbers.

The following, from Mr. Kirkland's notes, exhibits this bird as a destroyer of the woolly aphis : -

While in Amherst, Oct. 20, 1895, I was able to approach to within six to eight feet of a Downy Woodpecker which was feeding on a small apple tree. The bird was busy hunting the twigs over for food. I saw it eat a number of leaf miners' (Tineid) cocoons, which were attached to the small twigs. Some of these were undoubtedly Bucculatrix pomifoliella. Other cocoons were not oblong, but elliptical; nearly all cocoons contained a small green larva. A subsequent examination of twigs which the bird had searched showed that the cocoons it had left were parasitized. On the tree were many bark lice (Mytilaspis pomorum), but I did not see the bird feed on them. The fact of greatest interest to me was that the bird apparently sought out the small cavities (made by pruning) on the branches, and fed upon the woolly aphis (Schizoneura lanigera), which had clustered in masses in the cavities. This aphis sometimes does considerable damage to apple trees. Mr. Frost is of the opinion that the aphis also prevents the healing over of wounds made by pruning. It is a well-known fact that clusters of this aphis commonly occur on the callus which develops around wounds, apparently making it their feeding ground.

The imagoes of nocturnal moths that rest on trees during the day are taken by this bird, and he eats the eggs of many insects. He may well be regarded as one of the best of the feathered friends of the orchardist. But it is in the woods and among the shade trees that the good qualities of the Downy come out strongest.

When the Metropolitan Park Commission first began to set out young trees along the parkways near Boston, some species of trees were attacked by numerous borers; but the Downy Woodpeckers found them out and extracted the grubs, 
saving most of the trees. The cut (Fig. 109) shows a portion of the top of one of these trees, riddled by the borer. The knife-cut at the botton exposes their galleries. The small perforations along the stem were made by the Woodpecker in extracting the grubs.

The untiring industry of this bird and the perfection of its perceptive powers may be shown by the experience of Mr. Bailey. On March 28, 1899, a Downy Woodpecker that he watehed climbed over and inspected one hundred and eighty-one woodland trees between 9.40 A.M. and 12.15 P.M., and made twenty-six excavations for food. Most of these holes exposed galleries in the trunks or in high branches where wood-boring ants were hiding. The openings that the bird drilled in piercing one of these tunnels in a branch some thirty-five feet from the ground are shown in Fig. 110. It had uncovered dormant black ants, and in each case had

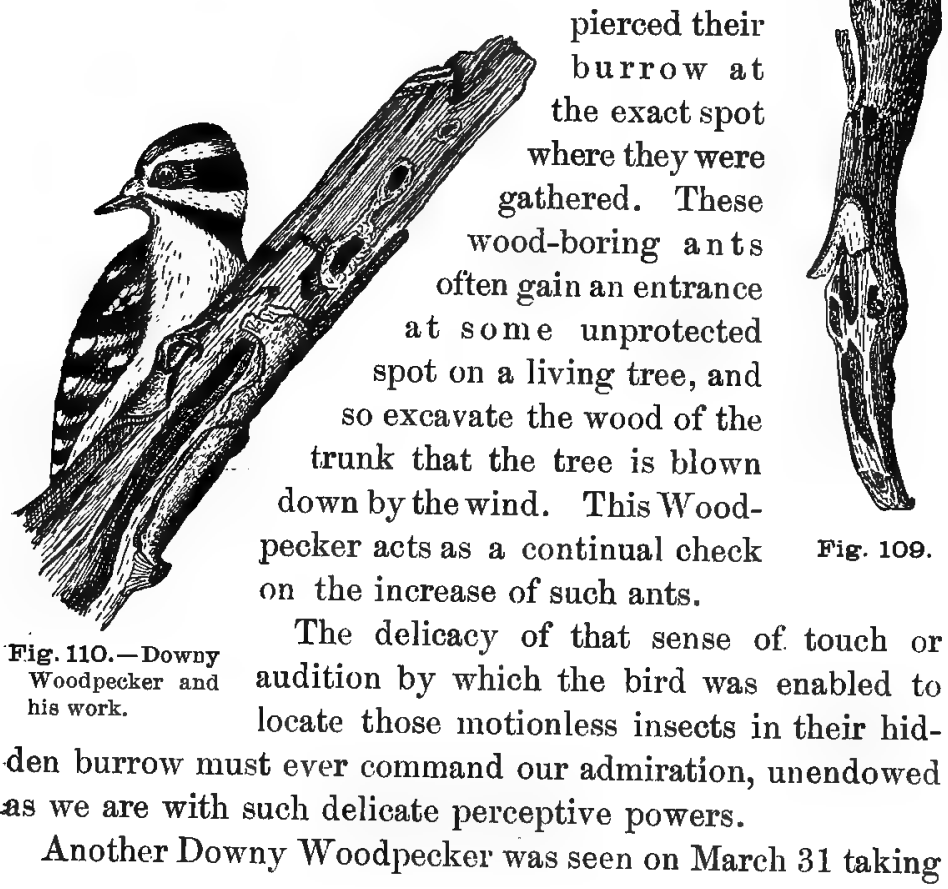


the larvæ of boring beetles from beneath the bark of oak trees. The bird seemed to know the exact spot at which to drill for each larva, for it always cut a small hole directly over the insect. The cut (Fig. 111) gives a view of the outer surface of a section of bark taken from a small oak. From this small

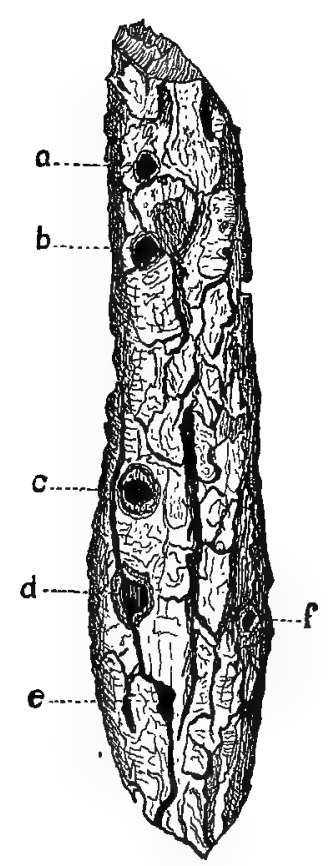

Fig. 111.

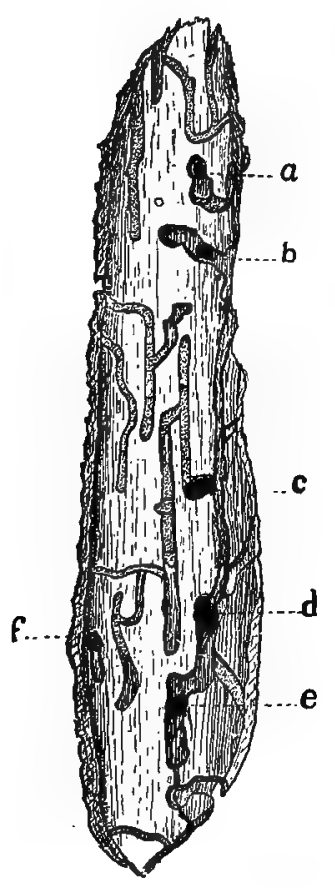

Fig. 112. piece of bark the bird probably secured at least six of the larvæ that were found in its stomach. The holes at $a, b, c$, $d, e, f$, indicate those from which the larvæ were taken. Fig. 112 gives a view of the inner surface of the same piece of bark, showing how true was the stroke of the bird, for its beak, piercing from the outside, went directly to the center of the burrow

where the dormant insects lay, entirely hidden from view. The letters $a, b, c, d, e, f$, indicate the holes where the bird's beak came through to the inner surface. Twelve ants and seventeen larvæ of boring beetles were found in its stomach.

The Downy Woodpecker is one of the most useful of all birds to the lumberman, for it feeds on such destructive insects as the bronze birch borer, the maple borer, and the pine weevil, - an insect of such importance that its habits merit some description here. This little insect (Pissodes strobi) deposits its eggs on the topmost shoots of the finest and most vigorous young white pines, and the young larvæ 
eat away the wood, and thus destroy the leading shoot or main stem of the tree. As the side shoots grow upward they also are attacked, and the tree is ruined for timber. Instead of growing a tall, straight trunk, it grows straggling branches. Quite often the leading shoot of a tree is attacked

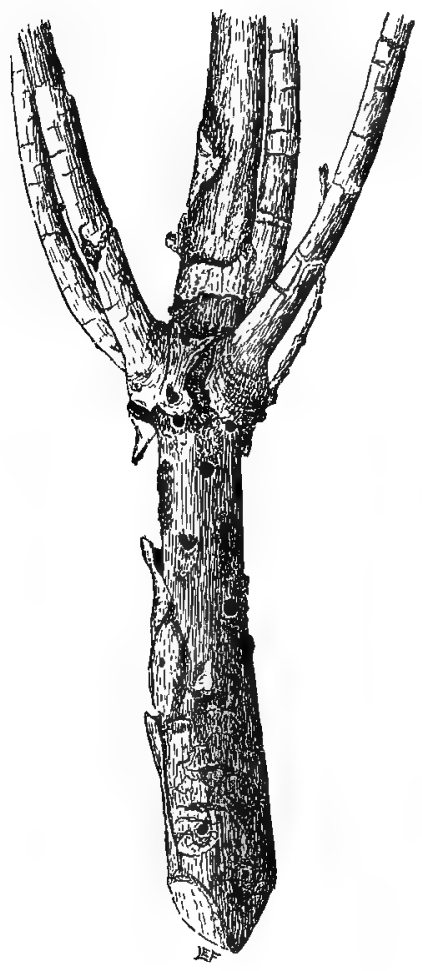

Fig. 113.- Pine top killed by pine weevill.

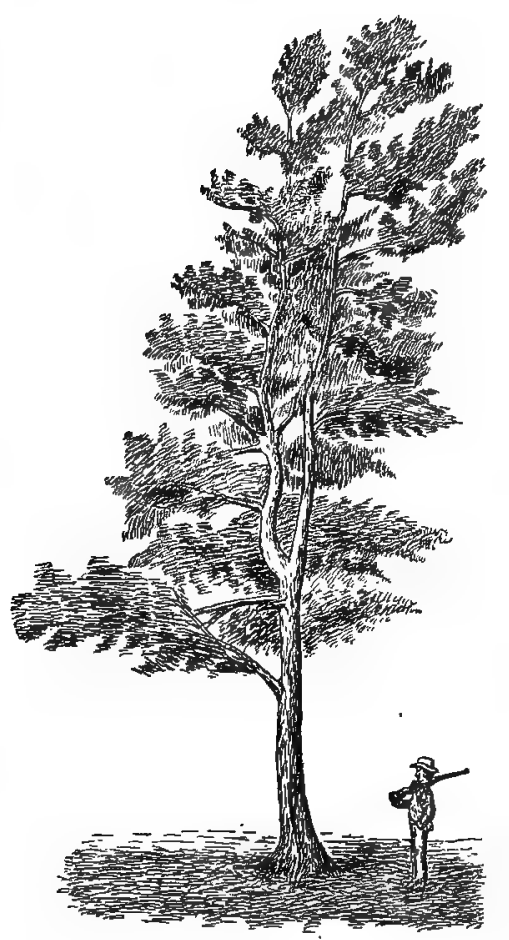

Fig. 114. - Tree crooked and ruined for timber by pine weevil.

in this way year after year. Each attack results in a crook in the trunk, and the tree when grown is fit only for kindling wood. Perhaps no insect is a greater pest to the lumbernan than this. While examining the work of this insect in a fine grove of young white pines I saw that many of the burrows had been perforated by birds, and the grubs extracted. It appears that Dr. Fitch also noticed this, for he says that small birds are very efficient in ferreting out and devouring 
the larvæ and pupæ of this weevil. He does not, however, name the birds. ${ }^{1}$

I have seen many shoots from which this insect had been removed by birds, and most of them showed the characteristic work of this Woodpecker. Some other Woodpeckers and the Chickadee are probably useful in this respect. The Downy Woodpecker hunts borers to the very twigs. Mr. Kirkland saw a mother bird pecking away at twigs infested by the oak pruner, taking out the larvæ and feeding them to her young.

There is some reason for calling the Downy a sapsucker. Occasionally he is accused of tapping the smaller limbs and twigs of maples and other trees for their sap. Nuttall says he has seen the bird drinking sap from the trees, and that it. bores into the wax myrtle for that purpose. I have never been able to observe this, and ornithologists generally deny that it is a fact. But Mr. Bailey's observations seem to - prove that the farmer is not altogether wrong in his appellation of the bird. The habit, however, seems to be not a common one. Mr. Bailey's experience has been spoken of in a paper read before the American Ornithologists' Union, and in another published in the annual report of the secretary of the Massachusetts State Board of Agriculture for 1900; but I am now able to present cuts from drawings of two stems tapped by the Downy, which show the ingenious method employed by the bird, also how its perforations differ from those made by the Sapsucker. The quotation from Mr. Bailey's field notes follows :-

At 12.30 I found a Downy Woodpecker, and watched him till 2.45; he took three larvæ from a maple stub, just under the bark. He next tapped two small swamp maples, four and six feet from the ground, and spent most of the time taking sajp. He tapped the tree by pecking it a few times very lightly; it looked like a slight cut, slanting a little. The bird would sit and peck the sap out of the lower part of the cut. The eut was so small the sap did not collect very fast. The bird would go and sit for a long time in a large tree, then it would come back and take more sap. It did this three times while $I$ was watching it. It did

\footnotetext{
- Insects Injurious to Forest and Shade Trees, by A. S. Packard. Fifth Report of the United States Entomological Commission, quotation from Fitch, p. 740 .
} 
not care to take any food but the sap. I could get within six feet of the bird without any trouble while it was taking sap. It then left and went into a large tree, and I lost it; but if I had stayed by the tree I think it would have come back before night, as it had done when I was watching it, for it was gone half an hour at one time.

The two young trees that were tapped were red maples (Acer rubrum). The incisions in each case were similar, and from their appearance we may assume that the bird first struck its bill into the bark from the right upward, and then from the left downward, leaving a small bridge of bark to cover the opening. It then took the sap by inserting its bill at the lower orifice, $a$, the upper one, $b$, allowing the free entrance of air to facilitate the flow of the sap out of the lower at $a$.

The vegetable food of this Woodpecker is varied and rather small in quantity. In spring it eats a

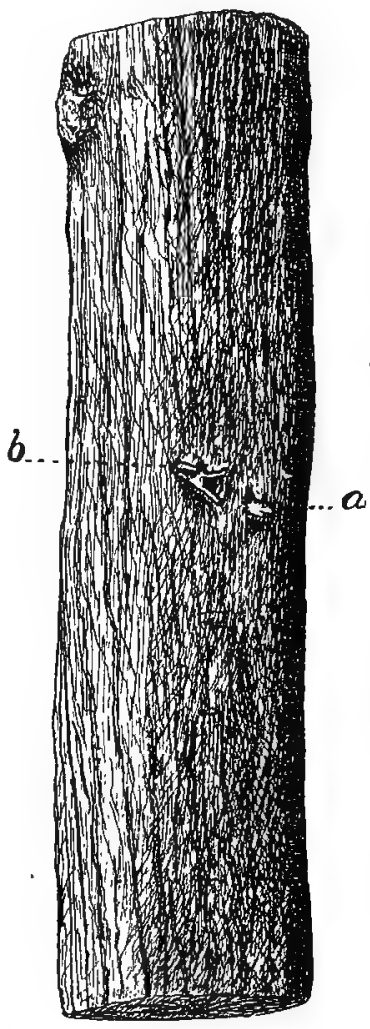

Fig. 115.

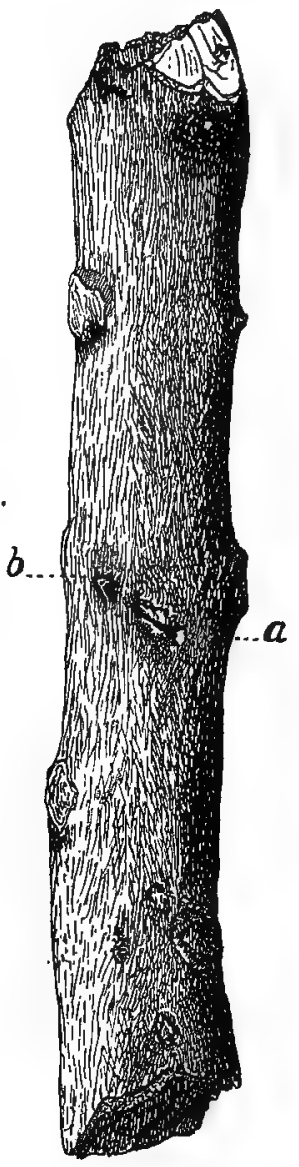

Fig. 116. few buds and petals of flowers; some berries, such as .Juneberries and wild strawberries, in summer; and in fall and winter it eats pokeberries, poison ivy, sumac, mullein, and other seeds. Frozen apples are eaten in winter. According 
to Professor Beal, Dr. Merriam found the stomachs of four birds filled with beechnuts, and has seen this species eat the berries of the mountain ash. It eats bayberries also.

\section{Hairy Woodpecker. \\ Dryobates villosus.}

Length. - About nine and one-half inches.

Adult. - Quite similar to the Downy Woodpecker, but much larger; the bill proportionately longer.

Nest. - A hole cut in a tree by the bird.

Eggs. - White.

Season.-Resident.

The Hairy Woodpecker, like the preceding species, lives to such an extent on the grubs of boring beetles and on wood-boring ants that it can find food at all times of the

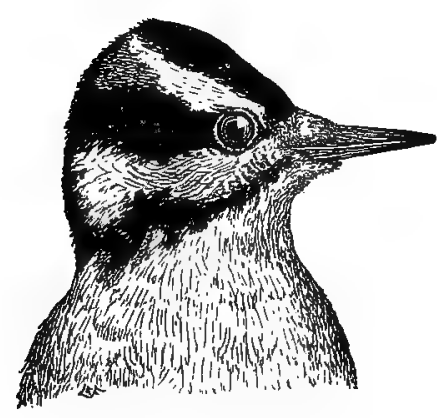

Fig. 117.-Hairy Woodpecker, maie, about one-half natural size. year. In very cold winters, however, when the trees are solidly frozen for months, both these species find it difficult to dig out borers from living trees. In the winter of 1903-04, which was exceedingly cold, the Woodpeckers were compelled to work on dry limbs and fence rails, wood piles, and any dry timber they could find. They do not disdain to help themselves to waste meat, fat, or suet in winter.

The Hairy Woodpecker is less common than the Downy, but individually is about as useful. Its sharp, clicking notes much resemble those of its smaller congener, but they are stronger, and have a wilder sound. The bird may be easily recognized by its large size and its vigorous, rapid movements. Like all Woodpeckers, its flight is rather undulating, as though, by reason of its excess of vigor, it could not help leaping and bounding through the air. It is usually shyer than the Downy, and is found more in timber lands than in orchards; but becomes tamer where it is not molested by man, and sometimes breeds in the orchard.

Maurice Thompson says that this bird strikes its bill into 
the wood and then for an instant holds the point of one mandible in the dent thus made, while it listens for the movements of the borer. He contends that the vibrations produced by the insect in the wood are conveyed through the bill of the bird to its brain.

This bird eats less animal food in proportion to its vegetable food than does the Downy Woodpecker; and according to Professor Beal it eats more beetles, more caterpillars, and less ants, than does its smaller relative. Beetles and

- their larvæ form fully one-third of its insect food, and a large part of these consists of the larger wood-boring insects. Its special usefulness inheres in its large size, its long beak and tongue, and its power of drilling deep into the trees and extracting from trunks and branches the larger pernicious borers. In this respect the bird is more nearly indispensable to the forester and orchardist than any other bird of the State, except perhaps the Pileated Woodpecker, which is so local as to be of much less value generally. Mr. J. M. Baskett tells of some Siberian crab trees in his yard that were attacked by borers. One of the trees died; but a Hairy Woodpecker came, worked diligently, and cleaned out all the grubs, thus saving the remaining trees.

This Woodpecker is often quite destructive to hairy caterpillars, and feeds its young on noxious larvæ of many species. It also attacks the pupæ or chrysalids of many injurious moths, among them those of the gipsy moth. Moths that hibernate in cocoons during the winter are particularly exposed to the attacks of this Woodpecker. Dr. F. M. Webster states that he saw one of these birds peck through the cocoon of the cecropia moth, and devour the contents. On examining more than a score of these cocoons, he found only two uninjured by the bird. Ants, grasshoppers, and spiders are eaten.

Its vegetable food is much like that of the Downy, but is consumed in much larger quantity. It sometimes takes a little corn; in summer it feeds much on wild cherries, and in the fall on wild grapes to some extent. Like the Downy, it eats a little of the inner bark or cambium from the tree trunks, and possibly may take some sap. 
While this bird often excavates a hole for a winter shelter, it sometimes sleeps exposed on a tree trunk. Mr. Bailey and I once watched one that slept for many winter nights on the north side of a tree trunk in a thick grove. It attached its claws to the bark and went to sleep in much the same position in which it ordinarily climbed the tree. It invariably went to the same tree at night, and was found in the same place at daylight each morning.

Northern Flicker. Golden-winged Woodpecker. Pigeon Woodpecker. Yellow Hammer. Partridge Woodpecker. Wake-up. Gaffer Woodpecker. High-hole, High-holder, etc.

Colaptes auratus luteus.

Length. - About twelve inches.

Adult Male. - Brown above; a scarlet crescent across the nape of the neck; top and back of head gray; back and wings barred with black; rump white; quill feathers of wings and tail black above, golden-yellow below; shafts of both wing and tail feathers yellow; throat pinkish-brown, running to buff on the breast, sides, and belly, which are marked with round black dots; a black crescent on breast, and a black patch on each side of head just below gape.

Adult Female. - Similar, but without the black "mustache."

Nest. - A hole in a tree, from four to forty feet from the ground.

Eggs.-Glossy white.

Season:- Resident; not very common in winter except in southeastern Massachusetts.

The Flicker, our largest and most common Woodpecker, is well known, in some one or more of its various forms, over the greater part of temperate America. It has over thirty vernacular names, a few of the most common of which are given above. A loud wăck, wăck, is the Flicker's announcement that spring has come. Its amorous w̌̌ck'-er, wřc $k^{\prime}-e r$, wick'-er, sounds from the orehards in early spring, as the male birds play about in curious antics, each trying in friendly rivalry to outdo the other in the display of his golden beauty, that he may thus attract and hold the admiration of the female. There is no fighting, but in its place an exhibition of all the airs and graces that the rival dandies can muster. Their extravagant, comical gestures, rapidly changing attitudes, and exuberant cries, all seem laughable to the onlooker, but evidently give pleasure to the birds. Their notes on such occasions have considerable variety, and are all pleasing. 
This bird often beats a long roll on a resonant branch. When flying away it is easily identified by the showy white patch on the rump, and when it flies overhead its golden wings and tail are plainly shown.

It is rather a shy bird, and it has reason to be, for, in spite of the law protecting it, the Flicker is hunted in most parts of its range. It is not a typical Woodpecker. Its bill is slightly curved, and its tongue has fewer terminal barbs than any other North American species. But the tongue is one of the longest, it is studded on the upper surface with fine points directed backward, and the salivary glands are large; in fact, this bird is more of an ant-eater than a Woodpecker. It Fig. 118. - Flieker, male, abont one-hal' natural frequents fields, or-

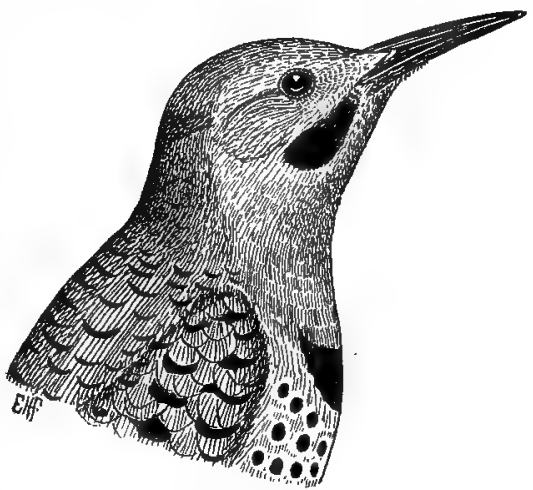
chards, and open spaces in the woods, where it strikes its long bill into anthills, and then thrusts out its still longer tongue, coated with sticky saliva, and licks up the outrushing ants by the dozen. Ants constitute about forty-five per cent. of its food. Though useful in some ways, ants are often great pests. Many kinds are decidedly harmful, as they attend, protect, and help to spread many aphids that are known as plant, root, or bark lice, which are among the greatest enemies of certain garden plants, shrubs, and trees. Ants infest houses, destroy timber, and have other harmful habits. They are eaten by many birds, of which the Flicker heads the list. It also takes beetles, grasshoppers, crickets, caterpillars, and other harmful insects. It is fond of wild cherries and wild berries, but takes very little cultivated fruit. Grass seed and weed seed are eaten to some extent. Occasionally it has been known to eat a little corn on the ear. Its most harmful habit is exhibited in southeastern Massachusetts, where, especially on Cape Cod, 
it winters in considerable numbers, and there bores holes into the summer cottages and finds winter shelter in the rooms, where it sometimes does some damage by pecking at the window sashes and curtains and in other ways. If the owners of these cottages had put up a few cheap birdboxes on their buildings or trees, with entrances large enough for the Flicker, the birds might have used the boxes, and never have contracted the criminal habit of breaking and entering.

\section{Yellow-bellied Sapsucker. \\ Sphyrapicus varius.}

Length. - About eight and one-half inches.

Adult Male. - Above, brownish or yellowish, marked with black and white; below, yellowish; sides black-streaked; a broad white stripe from shoulder along the black wing; crown and throat pateh crimson; border of both patches and line tlırough eye black; a black breast patch; belly yellowish. Adult Female. - Similar, except that the throat patch is whitish, instead of scarlet.

Nest and Eggs. - Much like those of other Woodpeckers.

Season. - Migrates north through the State in April, and south in September and October; breeds rarely in Berkshire County.

There would be no justification for including this handsomely marked bird among the useful species of Massachusetts, except for the fact that in thirty years no instance has come to my knowledge of its doing any appreciable harm here. There can be no doubt that it has killed trees in northern New England, where it breeds; but, as it does some good while here by destroying insects, citizens of the State can have no shadow of an excuse for destroying any Woodpecker, for all the other species that visit this State are more useful than this. The red crown and throat, and the broad white stripe or patch on the black wing, will distinguish it from more useful species.

\section{CUCKOOS, KINGFISHERS, ETC.}

Kingfishers feed mainly on fish, but occasionally subsist very largely on such insects as grasshoppers. These birds are no doubt necessary to help maintain the balance of nature whenever animals on which they feed tend to increase beyond normal numbers. They are not of sufficient 
economic importance, however, to receive more than this brief mention here. The Cuckoos, on the other hand, are particularly useful. They have the reputation of laying their eggs in other birds' nests. This is true of the European Cuckoo, which seems to be unable to complete her clutch of eggs rapidly enough to incubate them in one batch; therefore she leaves them to be hatched in the nests of other birds. This is rarely true, however, of the American species, which ordinarily build their own nests and hatch their own eggs. Audubon and Nuttall accused Cuckoos of robbing the nests of other birds, but there is little recent evidence of this habit. Like Woodpeckers, Cuckoos have the fourth toe reversed; but apparently the reversion of this toe does not now assist them in climbing, even if it ever did, for they do not climb like the Woodpeckers. They are long, slender, rather shy, modestly colored, and sedentary birds, which sit secluded among the leaves, and are heard more than they are seen.

\section{Black-billed Cuckoo. Rain Crow. \\ Coccyzus erythrophthalmus.}

Length. - Nearly twelve inches.

Adult. - Above, olive-brown and gray, with lustrous bronzy reflections; below, white; bill black; small white tips to all but the two central tail feathers. Nest. - Sticks loosely put together in a bush, vine, or low tree.

Eggs. - Greenish-blue.

Season. - May to September.

The Black-billed Cuckoo is common throughout most of the State. It seeks the bushy borders of streams, ponds, low woodlands, and swamps. It inhabits the glades of deciduous woods, and sometimes nests in thickets, but often visits orchards and fruit gardens. It is a bird of the trees and shrubbery, rarely leaving the leafy shades except to feed where caterpillars have defoliated the trees. Although somewhat sedentary, it flies rapidly and gracefully, but usually at no great height. Upon alighting in a bush or a tree it generally chooses a sheltered or hidden position, and, relying perhaps upon its close resemblance to the color of the foliage, it often may be closely approached.

Its notes vary much, but consist commonly of the syllable 
cow, cow, repeated monotonously many times, and sometimes preceded by a short chuckle. The bird often calls at night, and toward autumn its notes may sometimes be heard in the air as it passes overhead, probably in migration. Usually

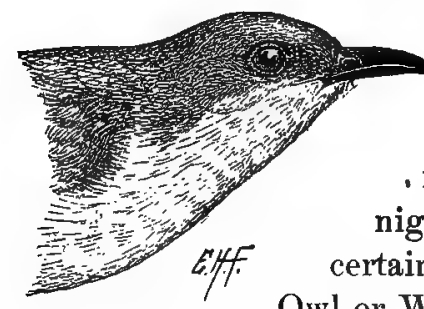

Owl or Whip-p

Fig. 119.-Black-

billed Cuckoo, onehalf natural aize. when the bird is heard at night in the spring and early summer it appears to be stationary. There is some - mystery in the wakefulness and night flight of Cuckoos, for they are seem slow and sleepy by day.

The Cuckoos are of the greatest service to the farmer, by reason of their well-known fondness for caterpillars, particularly the hairy species. No caterpillars are safe from the Cuckoo. It does not matter how hairy or spiny they are, or how well they may be protected by webs. Often the stomach of the Cuckoo will be found lined with a felted mass of caterpillar hairs, and sometimes its intestines are pierced by the

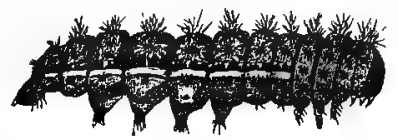

Fig. 120. - Caterpillar of the Io spines of the noxious caterpillars that it has swallowed. Wherever caterpillar outbreaks occur we hear the calls of the Cuckoos. There they stay; there they bring their nowly fledged young; and the number of caterpillars they eat is incredible. Professor Beal states that two thousand,

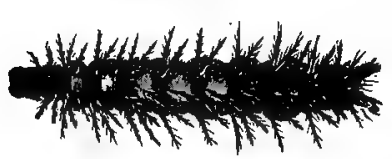

Fig. 121. - Spiny elm caterpillar. seven hundred and seventy-one caterpillars were found in the stomachs of one hundred and twenty-one Cuckoos, — an average of more than twenty-one each. Dr. Otto Lugger found several hundred small hairy caterpillars in the stomach of a single bird. The poisonous, spined caterpillars of the Io moth, the almost equally disagreeable caterpillars of the brown-tail moth, and the spiny elm caterpillar, are eaten with avidity.

While the above statements may apply to either of our 
Cuckoos, the Black-billed Cuckoo is the more common in Massachusetts, and is therefore probably the more useful. Grasshoppers, locusts, and other insects are often eaten, but practically no cultivated fruit and no grain.

\section{Yellow-billed Cuckoo.}

Coccyzus americanus.

Length. - About twelve inches.

Adult. - Bill black above, yellow beneath; upper parts olive-brown, with gray tints and metallic lusters; under parts white; a bright cinnamon tint on wings; two inner tail feathers olive; outer tail feathers blackish, two with white outer edge; all but two inner tail feathers broadly tipped with white. Nest. - A loose mass of sticks, in a bush or tree.

Eggs. - Usually larger and lighter colored than those of the preceding species. Season. - May to September.

This bird is long and slender, but it is a little larger and more robust in appearance than the Black-billed Cuckoo. A near view will show the yellow of the under mandible and
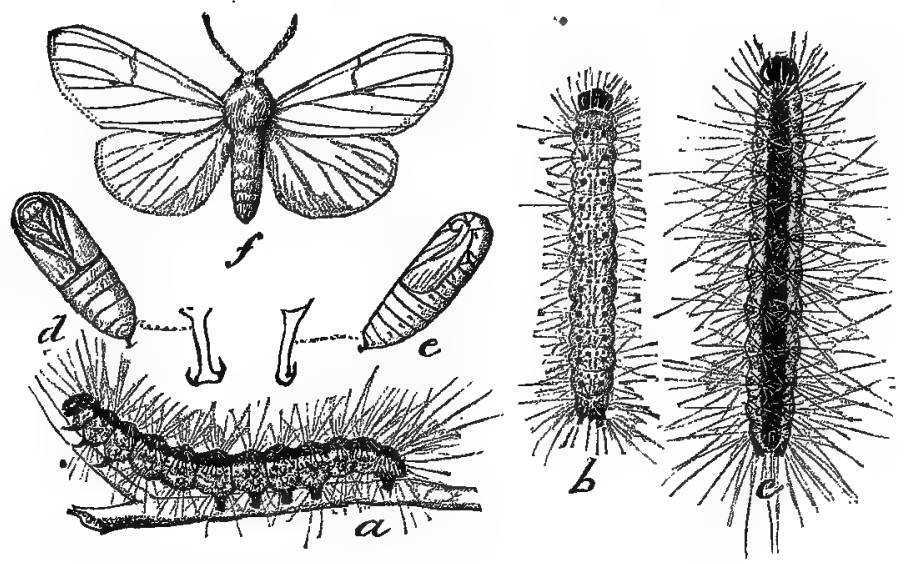

Fig. 122. - The fall web worm. The caterpillars $(a, b, c)$ are eaten by Cuckoos.

the characteristic markings of the tail, which serve to distinguish the bird in the field. Moreover, the notes of this species are heavier and coarser than those of the Black-billed Cuckoo. Schuyler Mathews well describes a characteristic cry of this bird as Gr-r-r-olp, cowlp, cowlp-olp-olp. All this is delivered with little if any variation in tone, and in a voice seemingly as deep as that of a Heron. 
The Yellow-billed Cuckoo is common in eastern Massachusetts, although it is rather more local than the preceding species; but it is rare in the highlands of the northern and western counties. Mrs. Mabel Osgood Wright states that this bird "seemed to follow an epidemic of tent worms" into Connecticut, and that it was abundant for two years in orchards and gardens containing fruit trees. She asserts that it did its work so thoroughly that orchards which were covered with caterpillar webs yielded a good crop later. She says also that the Cuckoos destroy many more than they can eat, by tearing the webs apart and squeezing the worms with their beaks. This is corroborated by the statements of gentlemen from Medford, who have told me that they have often observed this habit of the Cuckoo as practised on caterpillars of the gipsy moth and the brown-tail moth. It is said that these Cuckoos, which were formerly decreasing in numbers around Boston, are now increasing. They are no doubt attracted by the, abundant caterpillars. This species is apparently the greatest enemy to these pests.

\section{GROUSE, PARTRIDGES, ETC.}

This family of gallinaceous birds is represented in Massachusetts by four species. Of these, the Spruce Grouse is merely an accidental visitor; the Heath Hen is nearing extermination; and the Bob-white, now rare or wanting in many parts of the State, is more a bird of the field and garden than of the orchard or woodland. It is described on p. 325. This leaves only one species, the Ruffed Grouse, to be considered here, as the other species, introduced from time to time from other parts of the country, soon die out or are killed off by our arms-bearing population. This is particularly unfortunate, for Massachusetts, with her roeky, wooded hills, sandy plains, and fertile valleys, her stunted shrubby growths on Cape Cod and Martha's Vineyard, and her many fertile fields, is naturally a paradise for Grouse in summer, and produces an abundant winter food supply for these hardy birds. 



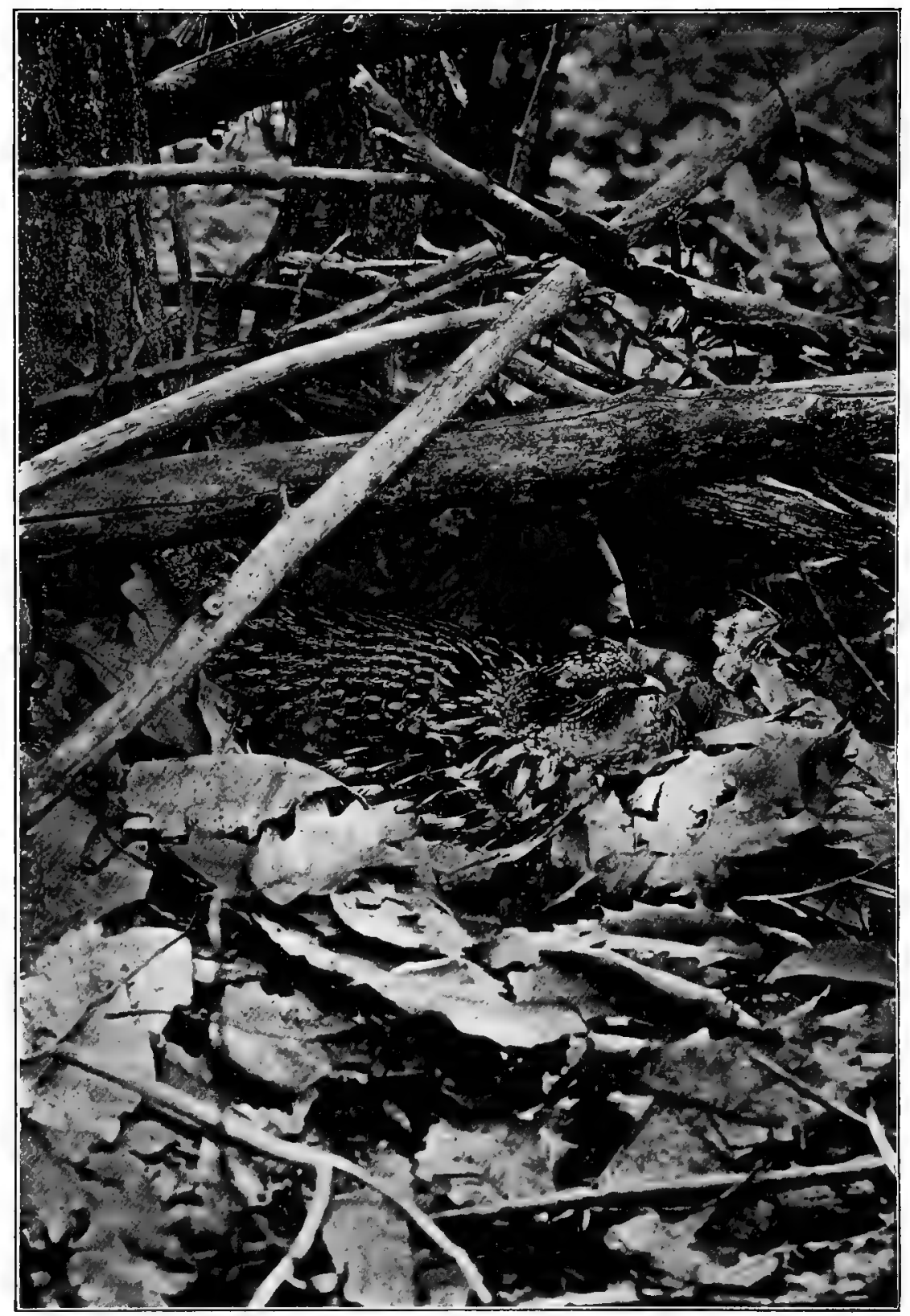

PLATE XXI. - Ruffed Grouse on Nest. (Photograph from life.) (From American Ornithology.) 


\section{Ruffed Grouse. Partridge.}

Bonasa umbellus.

Length. - Sixteen to eighteen inches.

Adult Male. - Upper parts reddish or yellowish brown, varying to gray; many markings; head crested; large ruffs of glossy black feathers on the sides of the neck; tail long and broad, varying from reddish-brown to gray, mottled and barred with lighter and darker shades; a broad blackish band near the tip; uncler parts tinged with buff, strongest on throat, barred and otherwise marked with darker shades, particularly on breast and sides.

Adult Female. - Similar, but smaller; ruffs also smaller.

Nest. - Lined with leaves, on ground in woods.

Eggs. - Buffy or yellowish white, sometimes speckled with a darker color.

This common bird, the "king of American game birds," was abundant in all our woods and was often seen in fields and orchards until its numbers were decimated by the gunner and the survivors driven to the cover of the pines. The characteristic startling roar of its wings, with which it starts away when flushed from the ground, and its habit of drumming on a log, have been often described. The speed with which the wings are beaten in drumming makes it impossible for the human eye to follow them, and make sure whether they strike anything or not. Naturalists, after long discussion, had come to believe that the so-called drumming of the Ruffed Grouse was caused by the bird beating the air with its wings, as described by Mr. William Brewster; but now comes Dr. C. F. Hodge, and reopens the controversy by exhibiting a series of photographs which seem to show that the bird in drumming strikes the contour feathers of the body. Strange as it may seem, there are many people who often take outings in the country, yet have never heard the drumming of this bird. This tattoo is most common in late winter and early spring, but may be heard occasionally in summer and not uncommonly in fall. While sounded oftenest during the day, it may fall on the ear at any hour of the night. In making it the bird usually stands very erect on a hollow log or stump, with head held high and ruffs erected and spread, and, raising its wings, strikes downward and forward. The sound produced is a muffled boom or thump. It begins with a few slow beats, growing gradually quicker, 
and ends in a rolling, accelerated tattoo. It has a ventriloquial property. Sometimes when one is very close to the bird the drumming seems almost soundless; at other times it seems much louder at a distance, as if through some principle of acoustics it were most distinctly audible at a certain radius from the bird. It is the bird's best expression of its abounding vigor and virility, and signifies that the drummer is ready for love or war.

The female alone undertakes the task of incubation and the care of the young. Once, however, when I came upon a young brood, the agonized cry of the distressed mother attracted a fine cock bird. He raised all his feathers, and, with ruffs and tail spread, strutted up to within a rod of my position, seemingly almost as much concerned as the female, but not coming quite so near. The hen sometimes struts toward the intruder in a similar manner when surprised while with her young. She can raise her ruffs and strut exactly like the cock.

The Grouse has so many enemies that it seems remarkable how it can escape them, nesting, as it does, on the ground. Instances are on record, however, where birds that probably have been much persecuted have learned to deposit their eggs in old nests of Hawks or Crows, in tall trees. Whenever the mother bird leaves the nest the eggs are easily seen, and while she sits it would seem impossible for her whereabouts to remain a secret to the keen-scented prowlers of the woods. But her colors blend so perfectly with those of the dead leaves on the forest floor, and she sits so closely and remains so motionless among the shadows, that she escapes the sharp-eyed Hawk. She gives out so little scent that the dog, skunk, or fox often passes quite near, unnoticing.

The Grouse does not naturally fear man; more than once in the wilderness of the northwest a single bird has walked up to within a few feet of me. They will sit on limbs just above one's head, almost within reach, and regard one curiously, but without much alarm. Usually in Massachusetts when a human being comes near the nest the mother bird whirs loudly away. She has well learned the fear of man; but in a place where no shooting was permitted, a large 


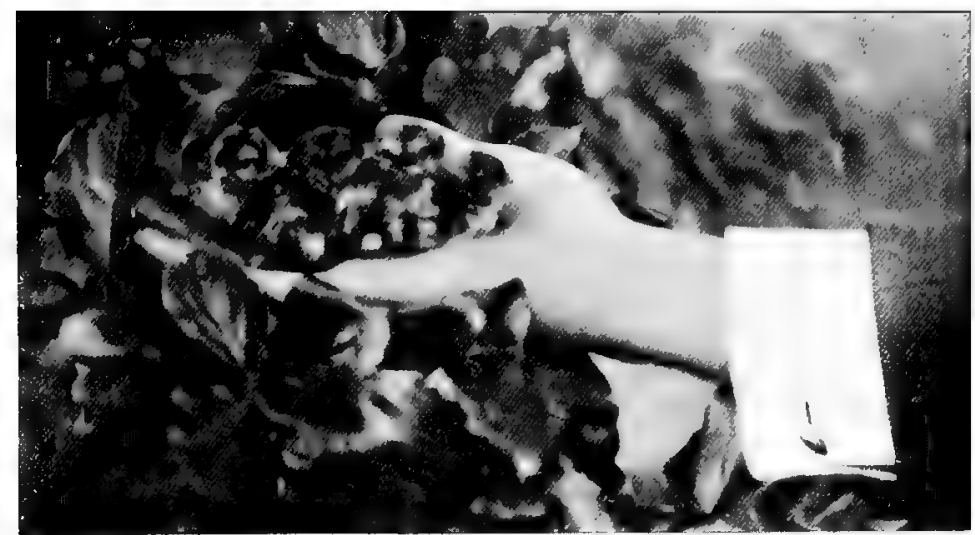

PLATE XXII. - Ruffed Grouse, One Day old. (Photograph, from life, by C. F. Hodge.) (From the annual report of the Massachusetts Commissioners on Fisheries and Game, 1905.)

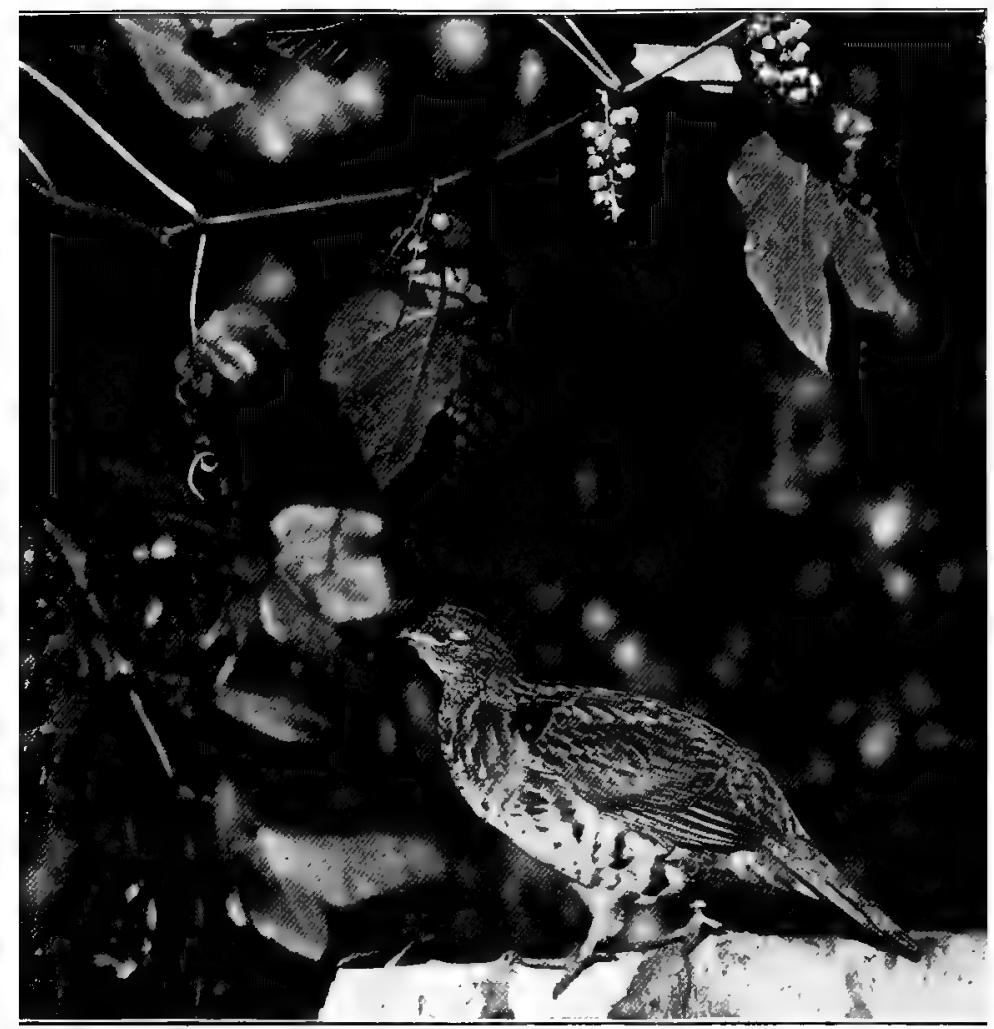

PLATE XXIII. - Ruffed Grouse, Four Months old. (Photograph, from life, by C. F. Hodge.) (From the amnual report of the Massachusetts Commissioners on Fisheries and Game, 1905.) 

gang of men were cutting underbrush, while a Partridge sitting there remained quietly on her nest as the men worked noisily all about her. Another bird that nested beside a woods road, along which I walked daily, at first would fly before I had come within a rod of her; but later she became confiding enough to sit on her nest while six persons passed close beside her. Evidently the bird's facility in concealing her nest consists in sitting close and keeping her eggs well covered. Her apparent faith in her invisibility is overcome only by her fear of man or her dread of the fox. When the fox is seen approaching directly toward her she bristles up and flies at him, in the attempt to frighten him with the sudden roar of her wings and the impetuosity of her attack; but Reynard, although at first taken aback, cannot always be deceived by such tricks; and the poor bird, in her anxiety to defend her nest, only betrays its whereabouts. Probably, however, the fox rarely finds her nest unless he happens to blunder directly into it.

Dr. C. F. Hodge made some interesting experiments with two trained bird dogs, a pointer and a setter, neither of which could find a Partridge as she sat quietly on her nest. The theory often used to explain this is, that the bird, being frightened, sits with her feathers drawn close to her body, and so "holds her scent." This is a matter, however, that should be investigated with scientific accuracy; for, in spite of all theories, the manner in which the bird escapes discovery still remains a mystery. The protection, whatever it is, is not always infallible, for occasionally a fox or dog discovers the sitting bird apparently by scent. Mr. William Brewster tells me that one of his dogs once found a Woodcock on her nest. All the young Grouse in a nest hatch at nearly the same instant, their feathers dry very rapidly, and they are soon ready to run about. When able to travel, they leave the nest, and from that moment they become wanderers on the face of the earth. It is often asserted that the Partridge leads her brood about after the manner of a Hen with her Chickens. This may be true in some cases; but I think the young birds usually scatter and forage mainly for themselves. They run about, stealing noiselessly along 
among the dead leaves, under the foliage of ferns and shrubbery, continually taking insects from leaf, stem, and frond, or picking them from the ground. Meanwhile, the mother marches slowly in their rear, perhaps to guard them against surprise from any keen-scented animal that may follow on the trail. She seems to be almost always on the alert, and a single warning note from her will cause the young birds to flatten themselves on the ground or to hide under leaves, where they will often remain motionless until they are trodden upon, rather than run the risk of betraying themselves by attempting to escape. For this reason any one who disturbs a Partridge with her brood should be very careful not to approach too closely, lest he tread on the young birds. When, as sometimes happens, the intruder has taken the mother unawares, and approached close to her tender brood, she seems nearly distracted in her anxiety, and, screaming, flies directly at her enemy. The sound she makes at such times has been likened to the whine of a young puppy; but to my mind her first cry more nearly resembles the squeal a rabbit gives when startled in the moonlit woods. When thus surprised the young may be seen for a brief moment as they run or fly, seeking a safe hiding-place, while the mother attempts to lead their pursuer away by feigning lameness and fluttering along the ground. Should this transparent ruse succeed, she then flies off as well as ever, and remains away until she believes all danger has passed, when she quietly returns and calls her brood. Evidently even the sharp-nosed fox finds it hard to detect the little birds so long as they lie quiet, and they seem to leave little or no scent as they run rapidly over the dry leaves. Some keen-eyed Hawk occasionally gets one, and they sometimes succumb to a disease aggravated by exposure to heavy, continuous rains. Woodticks and lice together are said to be fatal to them, and a spècies of botfly is said to attack them; but under ordinary conditions about half of each brood comes to maturity.

The wing quills grow very fast, and before many days have passed the little chicks can fly short distances. Audubon says he has seen them fly a few feet when but six or 


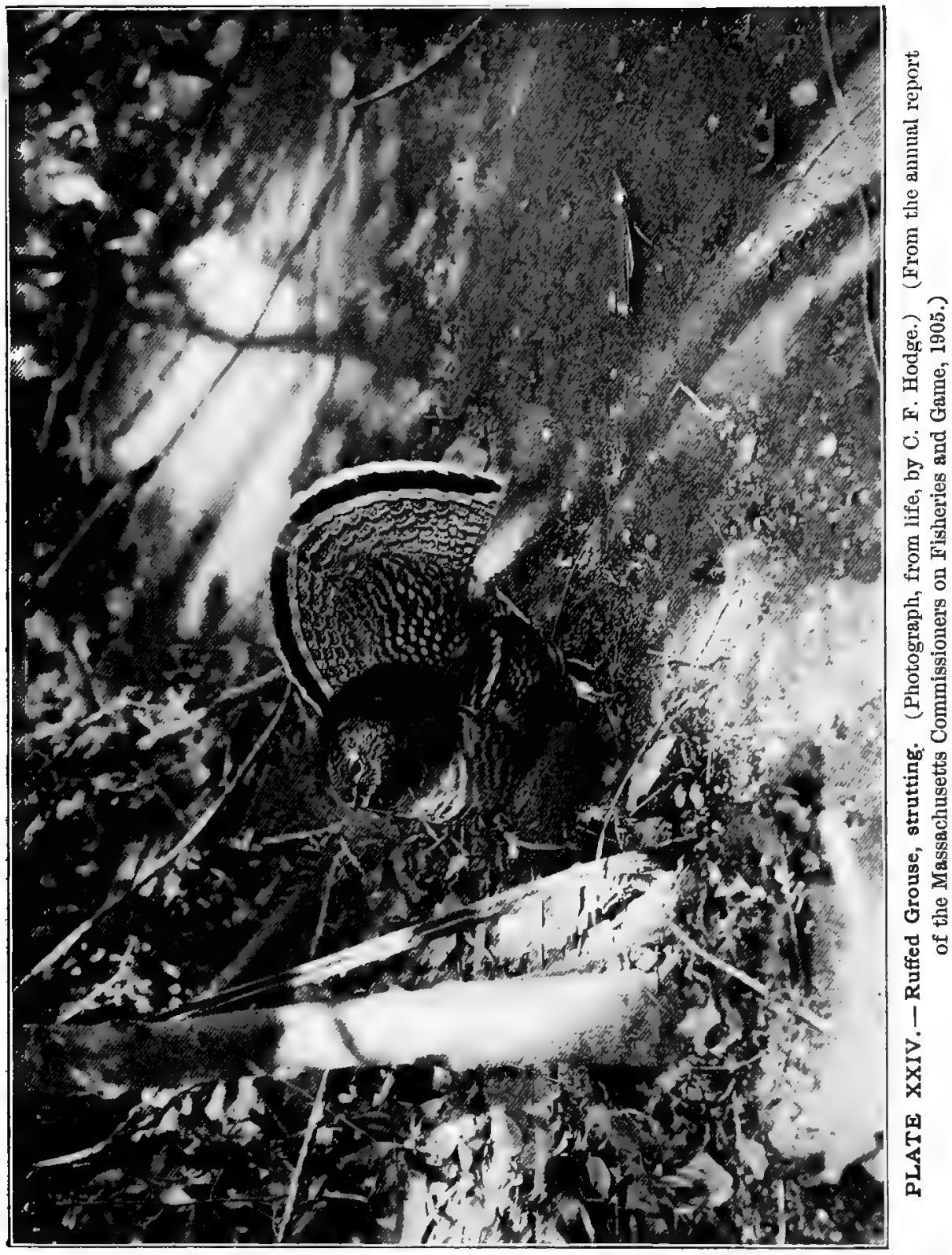



seven days old. I saw a single bird about three weeks old start from a hilltop with its mother, and, ascending among the tree tops, fly into a hollow more than a hundred yards away. Prof. C. F. Hodge told me that a three-weeks chick which be was rearing became frightened one day, and disappeared over the trees; an hour later it flew back.

During the fall, the Grouse keep together in small flocks. Sometimes a dozen birds may be found around some favorite grape vine or apple tree, but they are usually so harried and scattered by gunners that toward winter the old birds may sometimes be found alone.

As winter approaches, this hardy bird puts on its "snowshoes," which consist of a fringe of horny processes or pectinations that grow out along each toe, and help to distribute the weight of the bird over a larger surface, and so allow it to walk over snows into which a bird not so provided would sink deeply. Its digestion must resemble that of the famous Ostrich, as broken twigs and dry leaves are ground up in its mill. It is a hard winter that will starve the Grouse. A pair spent many winter nights in a little cave in the rocky wall of an old quarry. Sumacs grew there, and many rank weeds. The birds lived well on sumac berries, weed seeds, and buds.

Sometimes, but perhaps rarely, these birds are imprisoned under the snow by the icy crust which forms in cold weather following a rain, but usually they are vigorous enough to find a way out somewhere. The Grouse is perfectly at home beneath the snow; it will dive into it to escape a Hawk, and can move rapidly about beneath the surface and burst out again in rapid flight at some unexpected place.

The Ruffed Grouse is a bird of the woodland, and, though useful in the woods, it sometimes does some injury in the orchard by removing too many buds from a single tree. In winter and early spring, when other food is buried by the snow and hard to obtain, the Grouse lives largely on the buds and green twigs of trees; but as spring advances, insects form a considerable part of the food. The young feed very largely on insects, including many very destructive species.

While I have often observed the young birds feeding on 
insects, it was usually impossible to make out just what those insects were; but in confinement the young are very fond of flies, maggots, beetles, slugs, thrips, plant lice of various kinds, and spiders. Professor Forbes found mostly insects in the stomachs of three birds about three days old. They had eaten cutworms, grasshoppers, Lampyrid beetles, ants, parasitic wasps, buffalo tree hoppers, and spiders. Professor King found that a Grouse about a week out of the shell had eaten a white grub, seven spiders, and thirteen caterpillars. I found in July the remains of a young bird that had been killed by. a Hawk; it must have been at least six weeks old. Its stomach contained beetles and the seeds of weeds. The young are often found in grassy fields and pastures near woods. I have seen them apparently catching grasshoppers, crickets, and other grass-eating insects in such localities, and they seem as fond of such food as are young Chickens. Whenever such insects are plentiful, they form a part of the summer food of the birds. Young Grouse evidently are very useful as insect eaters, but as they grow older they depend more upon vegetable food. Dr. Judd, who has given the best account of the food of the Grouse, says that at Chocorua, N. H., in September, 1898, they were feeding very largely on the red-legged grasshopper or locust (Melanoplus femurrubrum), a very destructive insect. Seven adult birds, killęd in the breeding season, had eaten insects to the amount of thirty per cent. of their food.

The Ruffed Grouse at times eats many caterpillars, particularly those species which, like the cutworms and army worms, live largely upon the ground. It seems probable also that it takes caterpillars from the trees, as numbers of red-humped apple caterpillars

Fig. 123. - Red-humped caterpillar.
(Schizura concinna) and oak caterpil-

lars (Symmerista albifrons) have been found in its stomach. Dr. Judd says that the Grouse prefers beetles to other insects. This seems to be true of the young also, although when first hatched they appear to relish softer-bodied insects more. The old birds are persistent scratchers, and unearth many ground beetles, which they eat greedily. They sometimes 
feed on the potato beetle and other very injurious leaf-eating beetles, including flea beetles, grape-vine beetles, and May beetles. Also, they take wood-boring beetles, which they find mainly about stumps and fallen trees. Ants are eaten, and bugs, including leaf hoppers and tree hoppers. Many birds eat gall insects, but the Grouse eats them galls and all. Besides the insects taken, it eats a few spiders and small snails.

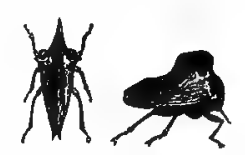

Fig. 124 . - Tree hoppers.

Although Grouse eat largely of insects during spring and summer, this habit has not been much noticed, chiefly because most of the birds whose stomachs have been examined were shot in the late fall or in the winter months, when the food is almost entirely vegetable. "The Ruffed Grouse," says Dr. Judd, "spends most of its feeding time in browsing and berry picking." In the fall, winter, and early spring, seeds, berries, buds, leaves, and even twigs, form its principal food. A great deal of this material is eaten throughout the year wherever it can be obtained. Dr. Judd gives the percentage of "browse" eaten as forty-eight and eleven hundredths of its entire food for the season, and the percentage of berries as twenty-eight and thirty-two hundredths. Buds form twenty per cent. of its food for the year. The seeds eaten are mainly tree seed, and those of such weeds as grow in clearings, along walls and fences, or on the borders of woods. Grain is very rarely taken. 'A partial list of the vegetable food of the Grouse is given below. It is largely compiled from the bulletin by Dr. Judd on the Grouse and Wild Turkeys of the United States, which is the most complete list yet published.

\section{Nuts or Seeds.}

Hazelnuts, beechnuts, chestnuts, acorns. Seeds of tick trefoil, hornbeam, vetch, hemlock, pitch pine, maple, blackberry lily, beggar's ticks, chickweed, sheep sorrel, sedges, violet, witch-hazel, beech drops, avens, persicaria, frost weed, jewel weed.

\section{Buds, Blossoms, or Foliage.}

Of poplar, birch, willow, apple, pear, peach, alder, hazel, beech, ironwood, horabeam, blackberry, blueberry, spruce, arbor vitæ, Mayflower, laurel, maple, spicebush, partridge berry, sheep sorrel, aster, 
green ovary of bloodroot, clover, purslane, wood sorrel, yellow sorrel, heuchera, chickweed, catnip, cinquefoil, buttercup, speedwell, saxifrage, live-forever, meadow rue, smilax, horsetail rush, azalea, false goat's beard, dandelion, cudweed.

Fruit.

Rose hips, gràpes, smooth sumac, dwarf sumac, staghorn sumac, scarlet sumac, poison ivy, partridge berry, thorn apple, cockspur thorn, scarlet thorn, mountain ash, wintergreen, bayberry, blackberry, huckleberry, blueberry, cranberry, sarsaparilla berries, greenbrier, hairy Solomon's seal, smooth Solomon's seal, black raspberry, raspberry, domestic cherry, cultivated plum, wild black cherry, wild red cherry, elder, red elder, black haw, nannyberry, withe rod, mapleleaved arrow wood, high-bush cranberry, mountain cranberry, snowberry, feverwort, black huckleberry, black alder, flowering dogwood, bunchberry, cornel, silky cornel, pepperidge, mulberry, bittersweet, manzanita, barberry, Virginia creeper.

By saving or propagating the plants in this list, something may be done toward increasing the numbers of this persecuted game bird. 


\section{CHAPTER VII.}

\section{T'HE UTILITY OF BIRDS IN FIELD AND GARDEN.}

In the grass field or meadow, as in the wood lot, natural conditions are simulated. Each year until haying time the grass offers cover and shelter for the nests of such birds as breed on the ground in natural meadows, savannas, or prairies. The grass and other plants of the field also provide food for birds, and for insects on which birds feed. As in woodlands, there is established a natural interdependence between the bird and its food and shelter, - the insects and the grass.

The habits of birds that live in fields have become adjusted to those of the native insects which also live there, so that the abundance of these insects is largely controlled by these birds, while the abundance of the birds is regulated chiefly by the rise and fall of the insects on which they feed. Some of the most useful birds of the farm live and breed in the fields; others breed along walls and fences. Early cutting of the grass on fields and meadows reduces the number of birds that breed there, for it destroys their nests or takes away the shelter of the grass from their young; but it also checks the grass insects, and exposes them to attacks from Robins, Crows, and other birds that nest in woodland or orchard, but prefer to feed in the field.

When, for any l'eason, the numbers of birds in the field are insufficient, insects increase; but in such cases the field birds are assisted in their work by birds of shore, swamp, orchard, and woodland. A similar service is often reciprocated to orchard or woodland by the birds of the fields, many of which flock to the trees to quell outbreaks of eatexpillars or other tree pests.

Grasshoppers, army worms, cutworms, and the grubs of May beetles are among the most destructive insect enemies of the grasses of this State. . Nearly all field birds feed upon 
such insects. Without birds it is doubtful if crops of grass could be raised; for the grub of a single species of beetle, if unchecked, could readily destroy all the grass roots of our meadows; and any one of several species of cutworms or army worms might be sufficient to destroy all the crops above ground. As it is, however, where the birds of the field are undisturbed they tend to hold the grass insects in check, so that the farmers are able to get good crops of grass without using any insecticides whatever. Therefore, we are largely indebted to birds for our grass crop.

Wherever the numbers of birds are much reduced, there is danger of a corresponding reduction in the grass yield. Prof. J. Y. P. Jenks once told of an experience related to him regarding an occurrence many years ago in Bridgewater, Mass. A great hunt was held by the townspeople in the spring of the year, and so many birds were killed that their bodies were used to fertilize the soil. The following summer the trees in that town were stripped of their leaves, and great patches of grass withered away and died. Such results must be expected wherever the number of birds in a region is suddenly and greatly reduced, and the pressure exerted by them upon the hosts of insects is as suddenly released.

In preparing the garden or cultivated field, natural conditions are overturned. If in making a garden we desire to use a piece of land covered with trees, we must first clear it. By cutting trees and uprooting and burning stumps and underbrush we remove the natural shelter and nesting places for birds, and to a great extent destroy their food. Some woodland insects may persist, and later attack the growing crops ; but the birds which formerly lived in the woods are driven away.

If the land intended for our garden be natural meadow or prairie, we must dispose of the grass, and so the sod is turned under. As in the woodland, both the shelter and nesting places of the birds are destroyed, together with most of their food. Such insects as pass part of their lives in the ground, like the white grubs and cutworms, may survive and eventually come to live on the fruits of our labors; but the birds are driven out. 
Usually there is no nesting place in the garden for treebreeding birds, and the operations of tillage and weeding make nesting unsafe and impracticable for the ground birds. Where tillage is not very frequent or strenuous, a few birds may nest in the garden. There was a time when Sparrows frequently built their nests in potato hills, and Sandpipers reared their young in cornfields ; but more intensive cultivation has driven them out. Birds now rarely breed in cultivated fields or gardens, except where trees, bushes, or vines furnish them nesting places; but the farmer prefers to have no trees in the garden, as they interfere with the cultivation of other plants, and so the birds are kept out. We have, therefore, practically no garden birds, and the service that we get from birds in the garden must be rendered by those which come there from woodland, orchard, swamp, field, or meadow, or those which, like the Swallows and Swifts, fly over the garden and take insects in the air.

But if a bird comes into the garden, it is often regarded with suspicion; and if it takes a few peas, strawberries, or a little corn, it is fortunate to escape with its life. All services the bird has rendered or may render are lost sight of in view of the fact that it has taken some of the fruits of man's toil. We can feed our cattle, our hogs, a vagabond homeless cat, a stray dog, or a tramp; but if a bird claims any of our bounty, capital punishment is not too severe for it.

The garden has become a paradise for insects. Here they find the most succulent food plants, finely developed, and grown in patches or masses, - often by the acre. Abundant opportunity is thus offered for the increase and spread of insects which confine themselves to a few food plants. Insects leave the wild plants on which they formerly fed, and gather to the feast in the garden. They increase in numbers; they multiply a thousand fold. The few birds that now venture into the garden select such insects as they like best, and the rest run riot among the crops.

Partly for the foregoing reasons, and partly because some of the most important garden pests have nauseous or poisonous secretions and are eaten by few birds, we get much less 
assistance from birds in our gardens than in our woodlands or tields. Nevertheless, the few species that follow the plow and glean among the various vegetables are of the utmost value to the farmer, who in the ordinary course must depend largely on them to protect his crops from certain insects that are difficult of control. Cutworms, army worms, and cabbage worms are a few of the garden pests which are eaten by birds, and which birds might control if sufficiently numerous. The squash bug and the Colorado potato beetle are two insects which are seldom eaten, or by but few birds.

Many of the birds of garden and field may be brought to assist the farmer in his battle against weeds. A weed is a useful plant in nature, and fulfils its purpose by filling barren or unoccupied soil with roots, preventing a waste of that most valuable fertilizing constituent, nitrogen, and adding, by its decay, to the amount of humus and plant food in the soil. In the garden and field, however, these wild plants are out of place, for the farmer wishes to cultivate the corn, the bean, the potato, or other useful plants and various grasses, all of which, if left to themselves, may be dwarfed, stifled, or replaced by a vigorous growth of weeds, which spring up unbidden from the soil.

Dr. Judd tells us that a single plant of one species of weed may mature as many as a hundred.thousand seeds in a season; and if these were unchecked, they might in the third year produce ten million plants. In competition with this bewildering multiplication, the corn or the bean, the wheat or the rye, with their comparatively few seeds, must soon succumb.

Constant use of the cultivator and hoe will do much to eradicate weeds from cultivated land, but they are always present in the grass field; and, as most of the grass is eut after the seeds have ripened, and fed to farm animals, there are always weed seeds present in the manure which is used in garden and field. Thus the farmer annually sows weed seed in his cultivated land.

Even when the garden is kept clear of weeds, there are still weeds around the edges of fields and gardens, and along roadsides, ditches, and hedgerows, which continually seed 
down the near-by land. Most land is full of weed seed, which retains its vitality for from five to seven years, so that weeds always spring up at once and spread rapidly in lands that are uncared for. The life of the gardener is a perpetual warfare against weeds. In this fight many birds of the field may be of some assistance against the weeds which annually spring up, flourish, and die, and therefore are dependent on seed alone to perpetuate their species. A goodly number of the birds of the field feed largely on the seeds of such weeds, and many of then subsist almost entirely on weed seeds during the fall, winter, and early spring. The quantity of such seeds annually eaten by birds in Massachusetts is beyond computation. Where seed-eating birds are numerous, they get nearly all the seeds of certain weeds; and if the farmer takes pains to attract and protect them, they may be of great assistance to him in the problem of weed destruction. Their benefits are greatest among hoed crops, for in such fields the largest number of weeds find opportunity for growth.

Dr. Judd says that the principal weeds which birds prevent from seeding are ragweed, pigeon grass, smartweed, bindweed, crab grass, lamb's quarters, and pigweed; but these are only a few of the seeds eaten by birds, as will be seen later. During cold weather many of the birds about the farm gorge themselves with the seeds of weeds, filling stomach and gullet almost to the throat. Some species feed in weedy gardens and fields; others are found more along the roadsides and the edges of thickets or woodlands; while still others, like the Snowflake and the Meadow Lark, seek open fields by preference. As a single Snowflake can eat a thousand seeds of pigweed at a meal, the effect produced upon a weedy field by a flock of one hundred or two hundred birds is very marked. They alight among the weeds, and as fast as each bird exhausts its part of the supply it rises and flies over the flock to the untouched weeds beyond; and so the flock rolls along, until perchance the birds have stripped the seed from practically all the exposed weeds in the field.

The various species of birds have different feeding habits. Goldfinches, Pine Finches, and Crossbills, for instance, cling 
to the weeds and take the seeds from the stalks; while Song Sparrows and Chipping Sparrows subsist largely on such seeds as they can find on, or reach from, the ground. Song Sparrows, Fox Sparrows, and Tree Sparrows are persistent scratchers, and dig out seed that has already fallen, and is buried by dead leaves, straw, earth, or other litter. Meadow Larks and Quail are useful in digging out seed from the ground, which, already buried, would otherwise spring up and grow. When the snow is deep, a large proportion of the seed-eaters must of necessity go south; but as soon as the ground is bare, they return to scratch and dig for their favorite food. Thus, as various species of differing habits and different haunts frequent the fields and their borders, and as the work of one supplements that of another, they exert together a constant repressive influence against the undue multiplication of weeds. The birds most actively employed in consuming weed seed in field and garden are Sparrows and Finches, Blackbirds, Cowbirds, Meadowlarks, Doves, and Quail.

Dr. Judd found about five hundred and twenty-five birds eating weed seed from a single acre of truck land on a Maryland farm, and estimated that they destroyed forty-six thousand seeds for their breakfast: About the last of April he attempted to learn what proportion of the weed seed on the place had been destroyed by birds during the fall and winter. In a wheat field where ragweed was plentiful it was difficult to find half a dozen seeds in a fifteen-minute search. In a growth of pigeon grass the examination of an area where there had been hundreds of seeds the year before would sometimes fail to disclose one ; and in some crab grass in the same field not one seed out of a thousand was left.

The following list of seeds eaten by birds, taken from Dr. Judd's interesting account of the "Birds of a Maryland Farm," will serve to indicate the habits of the same birds in Massachusetts. It will be noted that most of the weeds in this list are common here, and some of them are very abundant, widespread, and troublesome. Chickweed seeds mature very quickly, and purslane has to be dug up and carried out of the field, else it will persist in spite of the gardener. 
Noxious Seeds eaten by Birds.

Bull thistle (Carduus lanceolatus). I Sheathed rush-grass (Sporobulus Beggar's ticks (Bidens frondosa). vagino-florus).

Sneezeweed (Helenium autum- Poverty grass (Aristida sp.). nale).

Ragweed (Ambrosia artemisicefolia).

Yard grass (Eleusine indica).

Bermuda grass (Capriola dactylon).

Giant ragweed (Ambrosia trifida).

Sow thistle (Sonchus oleraceus).

Dandelion ('Taraxacum taraxacum).

Wild lettuce (Lactuca spicata).

Black bindweed (Polygonum convolvulus).

Pennsylvania persicaria (Polygonum pennsylvanicum).

Knotweed (Polygonum aviculare).

Climbing false buckwheat (Polygonum scandens).

Bitter dock (Rumex obtusifolius).

Curled dock (Rumex crispus).

Sheep sorrel (Rumex acetosella).

Crab grass (Panicum sanguinale).

Pigeon grass (Choelochloa glauca).

Green foxtail grass (Choetochloo viridis).

Broom-sedge (Andropogon virǵinicus).

Paspalum (Paspalum sp.).

Sedge (Cyperus).

Sassafras (Sassafras sassafras).

Blackberry (Rubus villosus).

Pokeberry (Phytolacca decandra).

Partridge pea (Cassia chamocrista).

Sweet clover (Melilotus alba).

Tick-trefoil (Meibomia mudiflora).

Snowdrops (Kneiffia fruiticosa).

Chickweed (Alsine media).

Amaranth (Amaranthus retroflexus).

Trumpet creeper (Tecoma radicans).

Yellow sorrel (Oxalis stricla).

Rib-grass (Plantago lanceolata).

Spurge (Euphorbia maculata).

Lamb's quarters (Chenopodium album).

Purslane (Portulaca oleracea).

Jewel weed (Impatiens). 


\section{CHAPTER VIII.}

\section{BIRDS OF FIELD AND GARDEN. \\ THRUSHES AND THEIR ALLIES.}

The food of Thrushes is alluded to on p. 155, and the woodland Thrushes are described on the pages following it.

\section{American Robin.}

Merula migratoria.

Length. - Nine to ten inches.

Adult Male.-Above, dark gray, olive tinged, browner on wings; head and tail blackish, with white marks ; breast ruddy, varying to bay; chin and lower tail coverts white; throat white, with black spots.

Adult Female. - Similar, but duller; head and breast paler.

Young. - Breast spotted with blackish.

Nest. - Of grass and mud, on tree, wall, building, or bank.

Eggs. - Greenish-blue; rarely spotted.

Season. - Resident, but rarest in late December and early January.

This large Thrush was named the Robin by the early settlers of Massachusetts, because it resembled somewhat in color the little Red-breasted Robin of England. Ornithol-

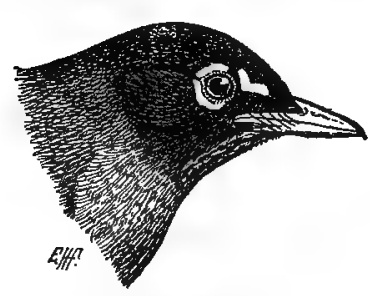

Fig. 125. - American Robin, about one-half natural size. ogists since then have called it the Migratory Thrush and the Redbreasted Thrush, but in vain; thus custom perpetuates error.

The American Robin, as it is now called, is the most generally common bird in Massachusetts. Its habit of foraging on the ground in gardens and fields, its fondness for fruit, its custom of seeking the vicinity of human dwellings, lawns, gardens, and cultivated fields, all have resulted in its increasing in numbers. As the forests were cleared away, the planting of fruit trees furnished it food and nesting places ; and so the Robin became part and parcel of our rural civilization. It nests by preference in an apple tree near farm buildings, but almost any nesting site will do, from a 



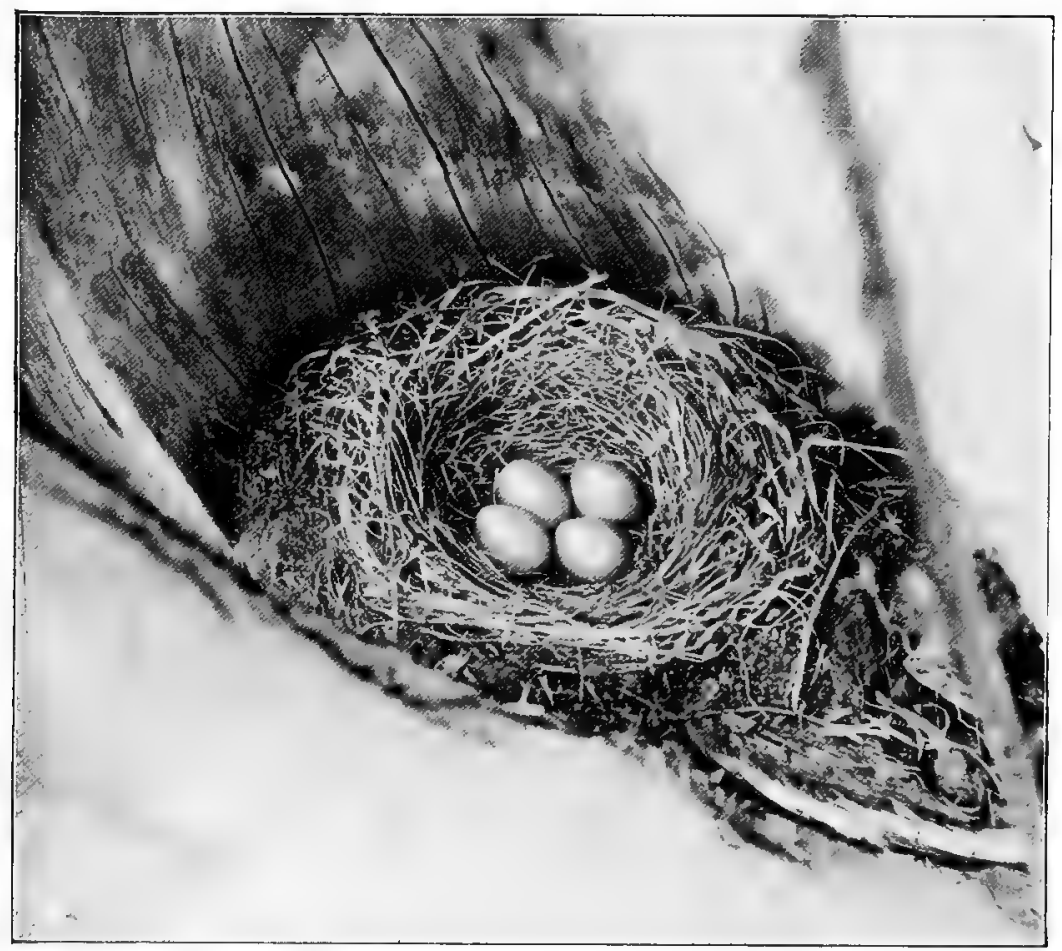

PLATE XXV. - Robin's Nest in Hollow Tree. 
pine tree in the woods to a wall overgrown with ivy, an overhanging sand bank, or a shelf over a cottage door. The nest is usually strengthened with mud, but not always. Last summer I found in a sand bank a nest that had no mud in its conposition. It needed none, for it was sunk in the sand and sheltered overhead by the overhanging turf. Apparently the birds were wise enough to see that in this case the mud was unnecessary. The Robin sometimes utilizes a hollow trunk for its nesting place, as may be seen by the accompanying cut, made from a photograph furnished by Mr. J. A. Farley.

The Robin prefers to have a roof over its nest; therefore it usually places the nest in such a situation that the growing leaves will shade it from the sun and shelter it from the rain ; but it often takes refuge under some roof built by human hands. Last summer I saw a Robin's nest built under the projecting roof of a small, open railway station. There the birds reared young, undisturbed by passengers or trains.

The economic position of the Robin has been discussed almost as freely as that of the English Sparrow or the Crow. Many fruit growers have long looked upon the Robin as an inveterate enemy, and it cannot be denied that this bird is sometimes a serious pest to the grower of small fruits. It is often asserted that the Robin and Catbird select the very choicest fruits. Professor Beal, however, believes that this is an error, and that the birds rather prefer wild fruit that is insipid or disagreeable to man.

My experience with birds in the strawberry bed convinced me, nevertheless, that Robin and Catbird picked out the reddest, ripest, and sweetest varieties in preference to all others. To test this preference, I set out here and there a plant of one of these varieties among the beds of more common fruit. In every case the birds found these plants and took about all the fruit. But I am led to believe, from what is known of their habits, that they selected this fruit by its color rather than by its taste or quality. When the early cherries are ripening, the birds attack the first point where a cherry turns red. The choice early fruit is taken because there is no ripe wild fruit, and at this season the birds have had no juicy berries for months, and are "fruit hungry." 
The destruction of small fruits by Robins usually bears hardest on small growers, or on families who raise only a little fruit for their own use. Large strawberry growers have told me that the birds do them no noticeable harm, nor have I known of any very serious and widespread destruction of cultivated fruit by Robins in this State. Much harm is said to have been done by them in other States, however, notably in New Jersey and California.

Notwithstanding the fact that the Robin is sometimes injurious to the interests of the small-fruit grower, it is one of the most useful of all birds to the farmer and orchardist, being probably as indispensable to the farm as any bird that could be named. The problem that must be solved by the fruit grower is how to prevent the Robin from destroying small fruits, for the farmer and orchardist are interested in seeing the numbers of this bird increased rather than diminished. The value of the bird to the farmer consists in the following facts. It remains in Massachusetts a large part of the year, and during the spring and early summer it lives almost entirely on insects and wornus, while insects form a considerable portion of its food for the rest of the season. It forages on fields, lawns, and cultivated grounds for many of the insects that the farmer finds most difficult to control. It also destroys many caterpillars, including hairy species, of orchard, woodland, and shade trees.

Professors Jenks in Massachusetts, King in Wisconsin, Forbes in Illinois, and Beal at Washington, and Mr. Wilcox in Ohio, have each studied the food of this bird. All these gentlemen regard the Robin as beneficial except Mr. Wilcox, who, while giving it due credit for a certain amount of the good that it does, believes that the small-fruit grower should be allowed to protect his crops by killing Robins where it seems necessary. It should be noted, however, that a large proportion of the Robins that Mr. Wilcox examined were shot about the fruit garden on the experiment station grounds when the fruit was ripe; and their food for the time being would not fairly represent the average aliment of the Robin, any more than would the food of the Robins shot about Mr. Trouvelot's insectary correctly represent the 
ordinary food of the bird in that region. In the one case much fruit and few insects were found in the birds' stomachs; in the other case the birds' stomachs were filled with the caterpillars of the American silkworm which Mr. Trouvelot was breeding, and contained no fruit, although wild berries were plentiful all about. The Robin might be a pest in Ohio and a blessing in Massachusetts. It is a great fruit eater, but it takes none of man's products except fruit, and in Massachusetts small fruits alone suffer materially from its attacks.

Professor Beal, who probably has examined more stomachs of Robins from different regions than any other investigator, states that vegetable food formed nearly fifty-eight per cent. of the contents of three hundred and thirty stomachs ; fortyseven per cent. of the vegetable matter consisted of wild fruits, and only a little more than four per cent. of varieties that were possibly cultivated. This seems to sustain the contention that, where wild fruit is plentiful, as it is in many parts of the country, it is preferred by the Robin to cultivated fruit. The greatest quantity of cultivated fruit is eaten in late June and in early July, when early cherries and strawberries ripen, and before there is much ripe wild fruit. Thus in Illinois Professor Forbes found that in June fifty-five per cent. of the food of the Robin consisted of cherries and raspberries, and fourteen birds that he examined, killed in July, had revelled in the fruit garden. Raspberries, blackberries, and currants formed seventy-nine per cent. of their food. Cherries made forty-four parts of the food eaten in August by fourteen birds, but two-thirds of these cherries were wild.

Where early wild fruits are plentiful the Robins do far less injury to cultivated fruits. A list of the wild fruits eaten by birds is given in another chapter. The Robin eats nearly all of them; therefore it is unnecessary here to speak further of the vegetable food of this bird, except to mention a few of its favorite fruits. Among these are : wild cherries, wild grapes of several species, the berries of the sour gum or tupelo, smilax, greenbrier, holly, all species of sumac, poison ivy, elder, huckleberries, blueberries, black- 
berries, cranberries, and Juneberries. The methods of protecting cultivated fruit against the Robin are given elsewhere.

The Robin is the "early bird that catches the worm." Who has not seen it hopping over the field or lawn, with head erect, looking and perhaps listening for

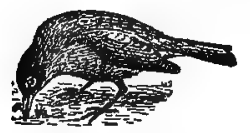
worms and grubs? All know the skill with which it finds them and drags them forth to daylight. Robins destroy numbers of earthworms every spring, and throughout the season they get as many as they can readily find. Earthworms have been considered useful creatures since Darwin's studies showed us how they help to cultivate the soil ; therefore at first sight we might regard the Robin's habit of eating them as injurious ; but worms are remarkably prolific, and were they to increase without check they might cultivate the fields and lawns so assiduously as to interfere with the growth of plants. Some city lawns where birds are not plentiful have been rendered brown and unsightly by the numerous heaps of castings thrown up by the too plentiful worms. We may safely set down the earthworm habit of the Robin to its eredit, so long as it merely assists in destroying the surplus crawlers. Earthworms, however, form only a small part of the Robin's food for the year. Worms are not found much at the surface in early spring, and during the dry weather of summer they are too far down for the Robin to find them; nevertheless, he is seen apparently "hunting worms" in the meadows and fields at any time from March to July, and in fact all through the season. If the ground is bare in January or February, Robins may be found now and then searching the fields for insects; if January and February are snowy, they begin the search in March or early April. They find dormant cutworms and other caterpillars in some numbers even in February. A very large per cent. of their food in February and - March consists of the larve of March flies (Bibio albipennis). Every investigator who has studied the food of Robins has found quantities of these insects in their stomachs. These larvæ live in colonies, and feed mainly on decaying vegetable 
matter. They are usually harmless, but sometimes eat living roots, and are believed to be capable of doing serious injury to grass lands. The fact that Robins feed almost constantly on March fly larvæ, thus keeping them under control, may account for the little injury that these insects ordinarily do. Professor Forbes took one hundred and seventy-five from the stomach of $\dot{a}$ single bird. Our bird is very destructive to caterpillars, especially the species that live on or near the ground.

The cutworm is the early worm that the Robin gets. These cutworms (the larve of Noctuid moths) are dull-colored, hairless caterpillars, that are most often seen on the ground. They usually hide during the day about the roots of plants, under matted grass, or under the loose soil along rows of plants in the garden. They come out of their hiding places at dusk, and feed. Their destructiveness consists in their manner of feeding. They often eat away the stems of young plants near the ground, thus destroying many plants for the sake of a few mouthfuls of food. Young cabbages, tomatoes, beans, etc., fall victims to these pests. Where cutworms are numerous, nothing can be successfully grown until they are killed off. Probably the various species are individually and collectively the most destructive of all caterpillars.

The Robin is abroad at the first break of day and until the dusk of evening. He finds the cutworms in the morning before they have crawled into their holes, and at night when they first venture out; and he digs them out of the earth at all hours of the day. Perhaps no other bird is so destructive to these caterpillars in gardens. Professor Forbes found that cutworms and other caterpillars formed thirty-seven per cent. of the food of nine Robins taken in March. Wilson Flagg watched the Robins about his house during a drought in July, when earthworms were not to be had. He asserted that the female bird carried off a cutworm as often as once in five minutes, and that he saw her take two and even three at a time. Professor Forbes found that nine May Robins had eaten cutworms to the extent of twenty per cent. of their food. These birds were taken in an orchard where canker- 
worms and other insects were plentiful. This shows what an extraordinary number of cutworms Robins will eat, even when other insect food may easily be had.

They are not at all particular regarding the kind of caterpillars they secure, but feed eagerly on most common species; even the woolly bear (Isia isabella) falls a victim. Wher-

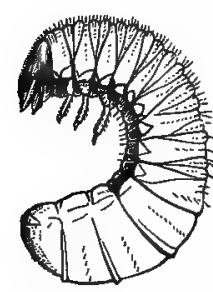

Fig. 126. - White grub, eaten by Robins. ever the gipsy moth, the brown-tail moth, or the forest tent moth swarm, the Robin eats their caterpillars. All the spanworms seem to be favorite morsels. The Robin takes cankerworms, tent caterpillars, curculios, leafeating and wood-boring beetles, and ground beetles. Many wireworms are taken, but the Robin renders no greater service on the farm than the destruction of the white grubs of May beetles and so-called "June bugs" of the genus Lachnosterna. These white grubs, if unchecked, destroy the roots of grasses to such an extent that they ruin the sod of meadows and fields, killing all the grass. In such cases the top of the dead turf may be peeled off, a mere worthless mass of dead, straw-like vegetation. The grubs cut off strawberry plants just below the ground, killing the plants and sometimes ruining whole beds. Corn and other grains are destroyed. Potatoes, turnips, carrots, and root crops of all kinds are eaten and ruined. Where the grubs are plentiful, hardly a plant is safe from their ravages. By reason of their subterranean habits, they are so difficult of control that were they not checked by their natural enemies it might be impossible for the farmer to raise hay, grain, or vegetables. Careful observation during three years on a farm convinced me that the Robin ranks first among the natural enemies of the white grub. In $1901 \mathrm{my}$ garden was seriously infested with white grubs; there was some fear that it would be difficult to raise either strawberries or roots; but it was soon seen that something was digging funnel-shaped holes along the rows, and taking out the grubs. A close watch was kept, to discover the author of this good work, and it was invariably found to be the Robin. The birds seemed to locate the grubs either by sight or hearing, and 



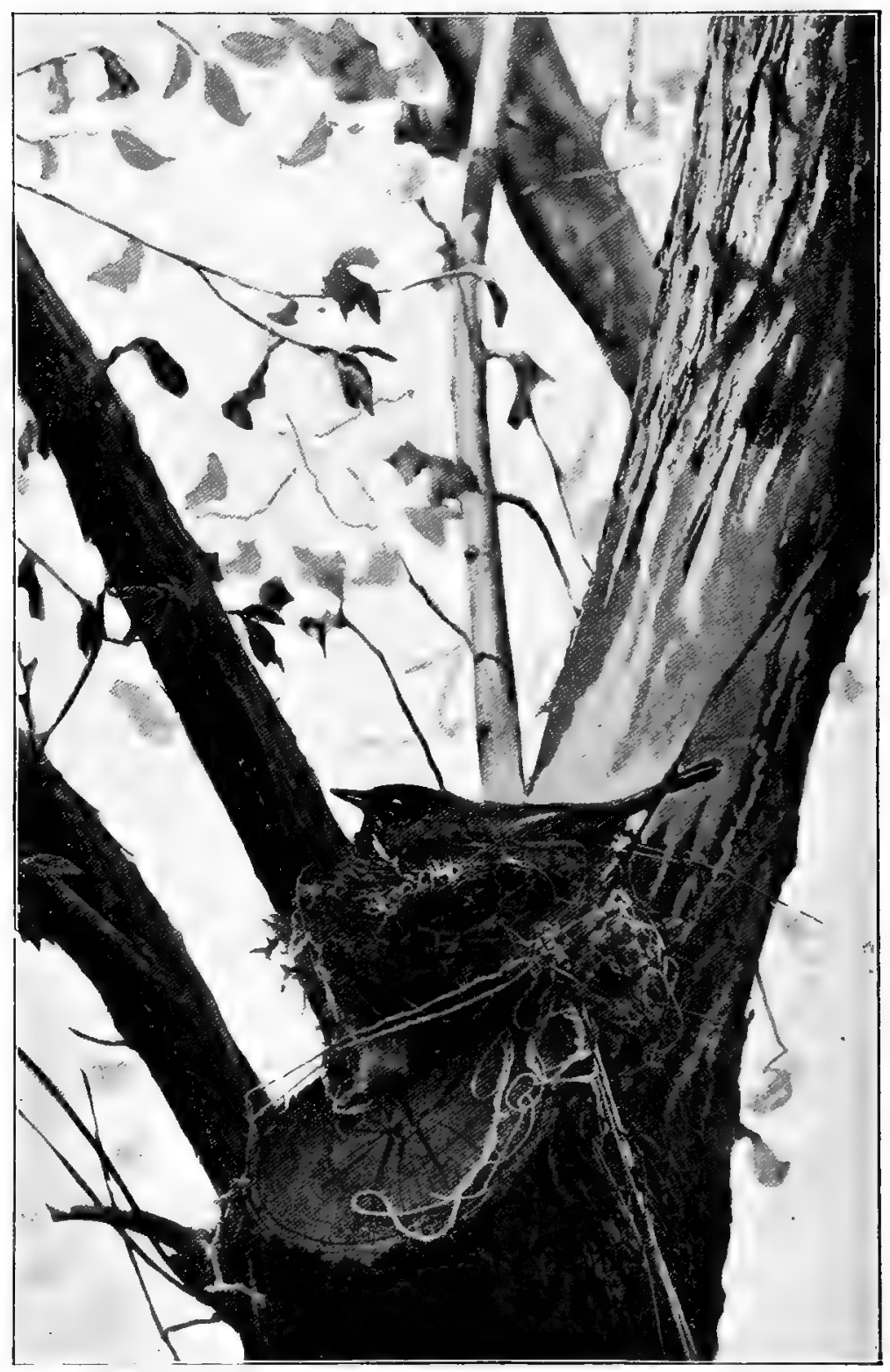

PLATE XXVI. - Robin on Nest. (Photograph from life.) (Copyright by C. A. Reed.) (From the annual report of the Massachusetts State Board of Agriculture, 1902.) 
dug down to them. The hole was often two to three inches deep, and they found the grubs unerringly. They might not have been able to do this had the surface not been kept well fined and mellow.

The Robin revels in a well-cultivated garden. If he is not molested, he will follow behind plow, hoe, or cultivator, and pick up the grubs that are turned up, before they are able to bury themselves in the soil. The Robins about our place soon learned to pick up grubs and worms that were thrown to them. The number that they find in a season is beyond computation. They were so diligent in our gardens and fields that the white grubs did no material injury. One mother bird that was following me one morning picked up three large grubs, one after another. She laid the first two down on hard ground, secured the third, and then after two or three futile attempts gathered them all in her beak and flew away to her nest near by, where she fed them to her eager young. The whole proceeding did not occupy over five minutes.

Wherever these grubs appear in such numbers as to destroy the turf on lawns, the Robin is always the most effcient agency for their destruction. Robins flock to such places, and find more grubs than does any other bird. In meadows remote from houses Crows may be equally efficient, but usually they are too shy to approach very near occupied dwellings. The efficiency of the Robin lies in its skill in finding and digging out the grubs (an accomplishment in which it appears to excel all other birds), and in its numbers; for, except in villages and cities, where Sparrows are more numerous, Robins are the most abundant birds. As the season advances, Robins are often very destructive to grasshoppers ; all orders of insects suffer from their attacks. Even in June and July, when the Robin eats cultivated fruit, insects comprise over forty per cent. of its food.

The character of the food of nestling Robins is very important, for the Robin normally rears two or three broods each year. Weed and Dearborn found that the largest single element consumed by the young consisted of cutworms and related caterpillars, which formed twenty-seven 
per cent. of their food. In my experience, caterpillars and grubs form a very large percentage of their food, particularly cutworms. A goodly number of earthworms are fed in spring, when they are to be had in abundance; but cutworms seem to be a favorite food at all times. Beetles (including curculios, snap beetles, and wireworms), grasshoppers, crickets, Noctuid moths, spiders, snails, katydids, grass blades (probably picked up with insects), and a few seeds, are all found in the stomachs of the young.

Mrs. Irene G. Wheelock watched the nest of a pair of Robins, and in three hours sixty-one earthworms, sixteen yellow grubs, thirty-eight other insects, four grasshoppers, and a few dragon flies and moths were carried to the nestlings. The last few days that they were in the nest, food was brought to them every three minutes.

The earliest broods reared get practically no fruit, but the late broods are fed some fruit while in the nest, and after they leave the nest they live more largely on fruit than do the parent birds, probably because it is easier to find than insects, which the young birds are at first not skillful in capturing.

The Robin thrives wherever there are gardens and orchards. In the prairie States, where there is little native fruit, it has become very destructive to cultivated small fruits, and even to apples; but in Massachusetts, where wild fruit is plentiful, its principal depredations may be mostly obviated by planting early mulberries or shadberries. The Robin deserves the protection it now receives from the law.

\section{Bluebird.}

Sialia sialis.

Length. - Six and one-half to seven inches.

Adult Male. - Above, bright azure blue; breast and under parts bright chestnut, except the belly, which is white, or bluish-white.

Adult Female. - Similar, but much duller or paler.

Young. - Mostly brown, with blue on wings and tail; breast speckled with brownish and white.

Nest. - In a hole in a tree, post, or in a bird house.

Eggs. - Pale blue, rarely white.

Season. - March to November; seen rarely in winter months.

The Bluebird is perhaps first of all birds in the affections of the rural population of New England. Its gentle note, at 
first a mere wandering voice in the skies, comes down to us a sure augury of returning spring. The Robin, Song Sparrow, and Blackbird renew the vernal prophecy; but when the Bluebird warbles gently from the leafless trees, and flits from fence to house top, we feel that the very spirit of the spring has come.

The Bluebird is usually common, locally at least, in Massachusetts by the middle of March, and flights may be seen going south in September and October. The bird is seldom seen later than November; but it is quite possible that occasionally a few winter in southeastern Massachusetts, as they

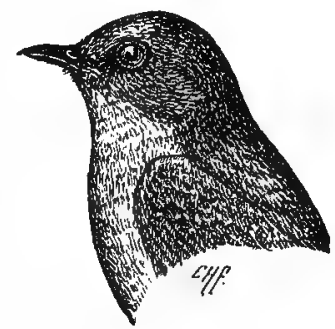

Fig. 127.-Bluebird, alout one-half natural size.

have been reported there in December and January, and a few are said to winter in the same latitude in Connecticut. Wherever dense red cedar and sumac thickets are numerous and fruitful, there is food enough to carry through the winter such Bluebirds as may venture to stay. It is quite probable that some of the early birds which come from the south in February are starved and frozen during the extreme cold weather and snowstorms which sometimes follow their appearance; most of them, however, contrive to exist until warm weather appears.

This bird often rears two or three broods. The male bird takes care of the young after they have learned to fly, while the female prepares a nest for the next brood.

The Bluebird needs no defence; it has long been regarded as a harmless species, for it takes practically none of man's products, and boards itself. Nevertheless, it is probably not as useful as the Robin, - a bird which has been widely reviled as a pest. However, the utility of the Bluebird must be acknowledged, although it perhaps eats more beneficial insects in proportion to the harmful ones than does the Robin. The Bluebird comes close to the Robin as a cutworm destroyer, and at times it is an efficient caterpillar hunter. It is valuable in the orchard in repressing outbreaks of cankerworms. As it eats the furry caterpillars of Arctians and other hairy species, it is of especial value in Massachusetts. It is a 
persistent foe of the Orthoptera. Grasshoppers constitute nearly twenty-two per cent. of its food for the year, and in August and September more than sixty per cent. Altogether, seventy-six per cent. of its food for the season consists of insects or allied forms, and the other twenty-four

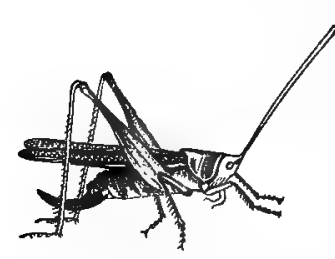

Fig. 128. - The Bluebird's bread. per cent. is made up of wild fruit and other vegetable substances, taken mainly in winter. In selecting its food, the Bluebird, like the Robin, is governed as much by abundance as by choice. The regetable food of the Bluebird proves its harmlessness to crops. It consists almost entirely of wild berries ; a few blackberries are eaten, and a little grass and asparagus. Undoubtedly the Bluebird well deserves the welcome annually accorded it.

\section{WRENS.}

Five species of Wren are found in Massachusetts, but only one, the House Wren, was ever of much economic importance in garden or field.

The Winter Wren is ordinarily seen in woodlands and thickets. It comes here chiefly in migration, and is not common enough to be of much service to man.

The Carolina Wren is rare, and the two Marsh Wrens are seldom if ever seen except in wet lowlands.

\section{House Wren.}

Troglodytes ä̈don.

Length. - About five inches.

Adult.-Upper parts brown; lower parts grayish-brown, sometimes grayishwhite; wings, tail, and flanks faintly barred with blackish; tail often held erect.

Nest. - Composed of sticks and rootlets, in a hollow tree or any accessible cavity. Eggs. - Six to eight; white, thickly speckled with reddish-brown.

A once common and familiar species, but now no longer a regular summer resident in the greater part of Massachusetts, the Wren is apparently doomed to give way before the advance of the House (or "English") Sparrow. Attention is called, however, to the desirable qualities of the Wren, in 



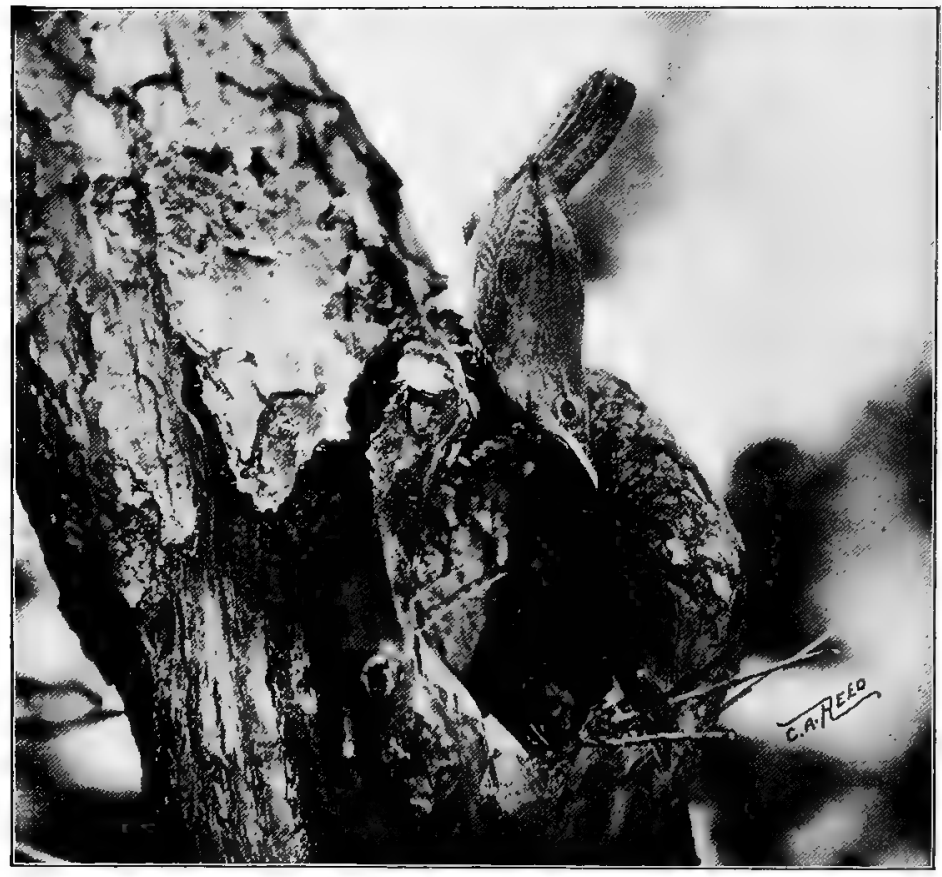

PLATE XXVII. - Wren at Nest Hole. (Photograph, from life, by C. A. Reed.) (From American Ornithology.) 
the hope that wherever it still remains people may be induced to provide tenements for it and protect it from the Sparrow, and so assist it to increase in numbers.

This sprightly little bird seeks the homes of man partly because of the nesting places afforded by the hollow trees of the orchard, and partly because of the number of insects it finds about house, barn, orchard, and garden. Its pert appearance, as it dashes about with short, upraised tail; its bubbling, ecstatic song; its sharp, scolding notes, as it creeps about the wood pile or berates the family cat, were once familiar sights and sounds, not only about the farmhouse, but even in city yards and gardens, for, until the Sparrow came, the Wren was in many localities a common village and city bird. A valiant little warrior, it is well able to protect its young against the intrusion of other small native birds, and has even been known to defend its home successfully against the dreaded cat; but it has given ground before the Sparrow mob, and is now rarely seen in the cities. The few individuals now left nest mainly in remote orchards.

Its alarm note is a sharp chirp, but its song is an indescribable burst of nelody. It bubbles forth as if the bird were too full of joyous music to express it properly, for the sweet and pent-up notes seem to crowd each other in the attempt to escape from longer confinement. In this respect the music is much like that of the Bobolink, but it is entirely different in quality. In spring the males sing a large part of the time.

The Wren is one of the most active of birds, and when its large and growing family is in the nest it is almost continually occupied in searching the shrubbery, orchard, wood pile, fence, or wall, as well as the vegetables in the garden, for insects. Nest building gives scope to its feverish industry, and a single pair will sometimes build two or three nests at almost the same time, if they can find convenient receptacles. for them.

- It is almost entirely beneficial in its food habits. Professor Beal finds that ninety-eight per cent. of its sustenance consists of animal matter, composed of insects and their allies, 
and two per cent. of vegetable matter, which is made up of bits of plants taken accidentally with the insects. Half of the animal food is grasshoppers and beetles; the remainder mostly caterpillars, bugs, and spiders.

The Wren does not range far from its nest, and when that is near the garden it gets a large part of its food there. In Medford we succeeded in getting two families of Wrens to nest in boxes, one on the house, the other in an apple tree. The entrances to these boxes were round holes a little less than an inch in diameter. The Sparrows could not get in, and so the Wrens were unmolested.

The only injurious habit of the Wrens seems to be their mischievous conduct in breaking and even eating the eggs in the nests of other birds. This habit seems to be common to individuals of this and other species of Wren, but it has been recorded so seldom in Massachusetts that no one need hesitate to put up boxes for them. Unless something can be done to provide for their increase, they are likely to disappear from the State.

\section{SPARROWS.}

Some members of this group, particularly the Finches and Grosbeaks, have been included in previous pages, among the birds of orchard and woodland (see p. 215); the remaining common species are mainly birds of the field that nest on or near the ground, and get most of their food in fields, gardens, or pastures.

Although they are all seed-eating birds, they live largely on insects during spring and early summer, and their young are fed mainly on such food. In fall and winter Sparrows feed on the seeds of grains, grasses, and weeds, although they are not then averse to insect food when they can find it.

Dr. Judd, in his important paper, "The Relation of Sparrows to Agriculture," states that the value of these birds to the agriculturist is greater "than that of any other group whose economic status has thus far been investigated." $\mathrm{He}$ says, nevertheless, that the native Sparrows contrast markedly in this respect with the introduced "English" Sparrow, which is a pest. The great bulk of the food of Sparrows consists 
of seed, fruit, and insects. The native Sparrows destroy very little grain, great quantities of weed seeds and insects, and hardly any cultivated fruit; they are, therefore, almost entirely harmless. They frequent grass fields, cultivated fields, and gardens, and in some cases orchards; thus their good work is done where it is of great benefit to the farmer.

Dr. Judd tells us that the food of Sparrows consists of from twenty-five to thirty-five per cent. animal matter, and from sixty-five to seventy-five per cent. vegetable matter; this is exclusive of the mineral matter, which is mostly swallowed as an aid to digestion. Beneficial insects seldom amount to more than two per cent. of the food; this is a very low average. The Flyeatchers and Swallows take a very much larger per cent. of useful insects. Sparrows may do some slight harm in distributing the seeds of weeds; but, as their stomachs grind the food most thoroughly, it is probable that very few seeds pass through the alimentary canal in a condition to germinate.

On the other side of the account we find that insect pests make up from ten to twenty per cent. of the year's food; these are mainly grasshoppers and cutworms, army worms and their allies, and beetles, such as click beetles and weevils. Bugs are eaten in small quantities. While nearly all the native Sparrows eat Geometrid caterpillars, like the cankerworms, only a few have been known to eat the hairy species. Such weevils as injure clover and strawberries are destroyed in large numbers; also some flea beetles and leaf-eating beetles are eaten.

The young of Sparrows are almost entirely insectivorous until they leave the nest; and, as many of these birds usually rear at least two broods in a season, they do great good in the gardens and fields while rearing their young.

When the good work of destroying insect pests is practically over for the season, the Sparrows turn at once to the ripening seeds of weeds. The number of such seeds that a single bird will eat in a day has never been ascertained; but a Tree Sparrow was found to have in its stomach seven hundred seeds of pigeon grass, and a Snowflake had taken at one meal a thousand seeds of pigweed. The Japanese mil- 
let (Panicum crus-galli), a wild barnyard grass or weed improved by cultivation, is much sought by birds. The seed is larger than that of most weeds, and yet a single Sparrow will eat a large number in a day. During the hard winter of 1903-04 about thirty Sparrows came to our window to feed on this seed, which was there supplied to them. Several hours of each morning and afternoon were thus spent. As they were constantly moving and changing positions, it was difficult to follow any one bird more than a few minutes at a time; nevertheless, some accurate figures were obtained regarding the number of seeds eaten in a given time by certain birds. A Fox Sparrow ate one hundred and three seeds in two minutes and forty-seven seconds. There were five Juncos eating at about the same rate all this time. A Song Sparrow ate thirty-four seeds in one minute, ten seconds; a Junco ate twenty-eight in forty-eight seconds; another, sixty-six in one minute, eleven seconds; another, one hundred and ten in three minutes, forty-five seconds; while a Song Sparrow ate one hundred and fifty-four in the same length of time. This Song Sparrow had been eating for about half an hour before the count began, and continued for some time after it was finished. A Junco ate ninety-three seeds in two minutes, fifteen seconds; and another ate seventy-nine in two minutes, twenty seconds. It is readily seen that thirty seeds a minute was below the average for these birds; and if each bird ate at that rate for but a single hour each day, he would destroy eighteen hundred seeds each day, or twelve thousand, six hundred a week. There were many days, when the ground was covered with snow, that certain birds spent several hours each day eating seeds at my window. This we know, for there were but two Fox Sparrows and two Song Sparrows in the neighborhood, and all four were often at the window at the same time. Most of the day the birds, when not at the window, were picking up such seeds as they could get elsewhere from the weeds about the place or from the chaff and hayseed provided. They ate more than a bushel of seed at the window, besides all the weed seeds they found elsewhere. Moreover, they ate hayseed that they picked up.in the barn and sheds, and fine particles of 
grain and small seeds that they found in the poultry yards and scratching-sheds. When Professor Beal states his belief that the Tree Sparrows in the State of Iowa eat eight hundred and seventy-five tons of weed seeds in a winter, it seems, in view of our experience, a low estimate.

Not far from the house was a patch of Japanese millet about ten rods long by one wide. This was allowed to stand until fully ripe, and then reaped and threshed out for the seed. As it stood a little too long, much seed fell and was left on the ground for the birds, - probably two bushels or more. During the winter they cleaned this up so thoroughly that only about a dozen stalks sprang up the next spring at one end of the patch.

When Sparrows flock normally about a weed patch, they gather up nearly ninety per cent. of the seed during a winter; but when more are attracted by extra food, they often get nearly all the seeds, as they did that year about our garden. Dr. Judd examined a rectangular space of eighteen inches where Sparrows had been feeding in a smartweed thicket. He found eleven hundred and thirty mutilated seeds, and only two whole ones. No smartweed grew there the following year. Sparrows were still feeding on these and similar seeds on May 13, and a diligent search showed only half a dozen whole seeds in the field. Weed seeds form more than half the food of mature Sparrows for the year.

This great group of birds comprises species of such varied habits that it is represented everywhere. Sparrows, Finches, Grosbeaks, or Buntings are found not only in the woods, fields, and city streets, but in swamps and marshes, and among the desert sand hills of Cape Cod and Ipswich. They range from the mountain top to the sea level, and from the shores of the sea to the farthest western boundary of the State; even at sea migrating Sparrows are sometimes seen, for they not only cross wide bays and estuaries, but they visit remote islands, and are sometimes blown out to sea.

In the following pages some of the more common and useful species will be considered. The "English" Sparrow will be treated among the enemies of birds. 
Indigo Bunting. Indigo Bird.

Cyanospiza cyanea.

Length. - About five and one-half inches.

Adult Male. - Bright, lustrous indigo-blue, deepest on head, and often with a greenish tinge; wings and tail dark brown, with blue marks and tints.

Adult Female and Young. - Upper parts light brown, sometimes faintly, but never prominently, streaked; under parts brownish-gray; breast and sides faintly streaked.

Nest. - In low bush.

Eggs. - White.

Season._-May to September.

This bright blue Bunting is one of the most brilliant of northern birds. The color of the male is so dark that at

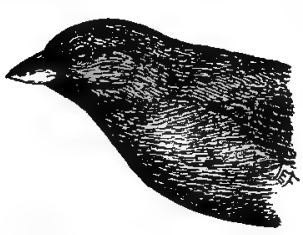

Fig. 129.-Indigo Bunting, male, about one-balf natural size. a distance it seems almost black. The male requires three years to attain full plumage. It frequents bushy pastures, sprout lands, and old fruit gardens grown up to weeds. In late August and September it is seen in sweet-corn patches or cornfields.

Its song is a rather rich and pleasing refrain, with a metallic ring or jingle. A few notes seem to exhaust its vocabulary and its breath at the same time, but it is soon ready to try again. Perseverance is its unfailing virtue, for it sings, intermittently, all through the long, hot summer day. Its alarm note is a sharp chip.

It feeds more on the caterpillars that infest trees and bushes than do most Sparrows, and takes many such larvæ to its young. It is fond of grasshoppers, and takes some insects from the garden. It eats the birch plant louse with avidity. A few flies, mosquitoes, or gnats are taken; cankerworms and other measuring worms, the larvæ of several species of butterflies, and the imagoes of nocturnal

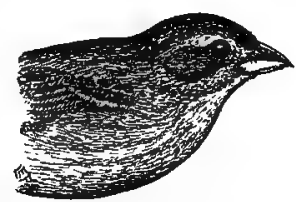

Fig. 130 - Indigo Bunting, female. and Tineid moths, with small beetles of different species, constitute a portion of its insect food. The larger part of its food consists of seeds, many of which are those of weeds. During its short stay with us it is one of the few useful species seen much about the garden, and is of some service in the orchard. 
Song Sparrow. Ground Sparrow. Ground Bird.

Melospiza cinerea melodia.

Length. - About six and one-half inches.

Adult Male. - Above, brown; the back streaked with a darker shade; top of head reddisl-brown, mottled with blackish streaks; a streak of light gray through center of crown and one over the eye; a dark line through eye and two on the lower jaw; breast and sides whitish, spotted with dark brown, the spots usually massed in the center of breast, where they form a large spot or cluster; tail rounded and rather long.

Nest. - Usually on ground or in bush, rarely in tree.

Eggs. - Whitish, endlessly varied with browns.

Season.-Resident, but not common in winter.

Few birds are better known than the Song Sparrow, and few are better friends to man. Those who do not know the bird will recognize it as the sweet singer of March and April, with a large bloteh in the middle of its spotted breast. It prefers moist land near water, and may be found along the banks of brooks and the shores of ponds or rivers. The nest is often sunk in the sloping bank of some brook or ditch. According to Thoreau, its song, as expressed by the country people, runs thus: "Maids! maids! maids! hang on your teakettle-ettle-ettle." It has a charac-

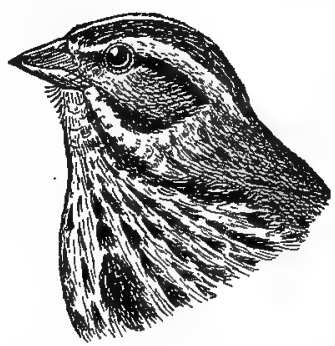

Fig. 131.-Song Sparrow, about two-thirds natural size.

teristic chenk, evidently an alarm note, and several other notes.

The Song Sparrow is at home in rich, moist gardens, and feeds among crops like cabbage and celery, which are often raised on lowlands. It is destructive to cabbage plant lice and cutworms. It eats some caterpillars of the gipsy moth, the brown-tail moth, and several of the hairless pesț among the Geometrids. Leaf hoppers and spittle insects, grasshoppers, locusts, crickets, and click beetles are among the pests that it destroys. It picks up a few snails and aquatic insects around the water. Flies and their larvæ are relished. Earthworms and spiders are frequently taken. Only two per cent. of the food consists of useful insects; injurious species make up eighteen per cent. The vegetable food 
consists of small fruit, mostly wild, four per cent. of grain, mostly waste, picked up in the fields, while fifty per cent. of the entire food of the year is composed of the seeds of weeds. Dr. Judd remarks that the chief value of this bird as a seed-eater lies in its habit of eating the seeds of polygonum; these seeds are not so much eaten by other birds. But the Song Sparrow eats the seed of chickweed, purslane, sorrel, dandelion, and dock, all of which are common in Massachusetts gardens. More than half the grass seed eaten belongs to such troublesome species as crab grass and pigeon grass. Witch grass and barnyard grass are among the seeds that are often freely eaten by this useful bird.

The Song Sparrow sometimes learns to come about the door for crumbs. A pair built a nest on the ground in our garden; but a cat found it. Then a nest was built in a bush ; this suffered a fate like the first. Then the birds went up high among the thick sprouts on the trunk of an elm, built another nest, and reared their young in safety. They were wiser in their way than men, who, in spite of their superior intelligence, continue to build their homes on the shores of rivers which periodically overflow their banks, or on the slopes of volcanoes that occasionally burn or bury cities.

The Song Sparrow is a bird to cultivate. Friendly, cheery, musical, harmless, gentle, useful, — what more can be desired?

Slate-colored Junco. Black Snowbird.

Juneo hyemalis.

Length. - About six and one-fourth inches.

Adult Male. - In winter, all upper parts, and lower parts from chin to breast, dark slaty-gray; lower breast and belly white; two outer tail feathers and part of third white; bill pinkish-white, blackish at tip.

Adult Female. - Similar, but lighter, and usually more rusty.

Young. - Browner, and slightly streaked; throat and breast paler.

Nest. - On ground.

Eggs. - White, spotted with brown.

Season.-Resident, but most common in spring and fall.

The Snowbird does not often breed in Massachusetts, excepting on the higher lands of the north-central and western parts of the State. Pairs are said to nest occasionally in ice houses, which are certainly cool, if not suitable situations. It is a bird of the Canadian fauna, and it winters in Massachusetts wherever conditions are favorable. In the 
southeastern portion of the State, where the ground is bare in sheltered places through much of the winter, or where weed seed, chaff, and other food can be secured, this bird is common in the colder months. Its notes at this season are chiefly Sparrow-like chirps.

It is useful here mainly because of its consumption of weed seeds in spring, fall, and winter. Juncos come from the north with the first hard frost, and are among the most abundant of our fall migrants. They feed very largely on the seeds of amaranth, lamb's quarters, sorrel, wild sunflower, and other pernicious weeds.

A flock of these dark birds on the

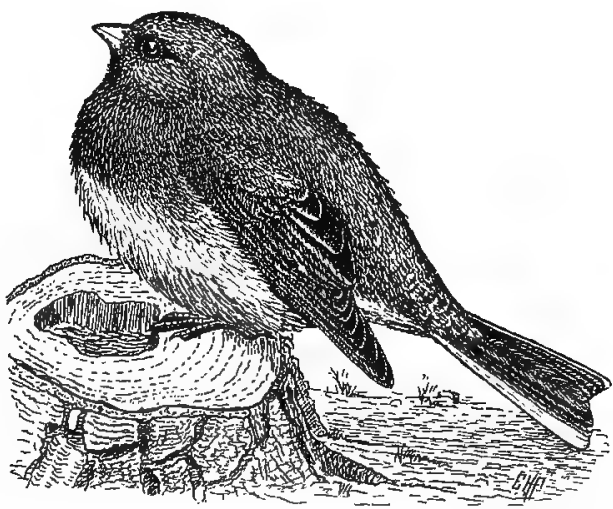

Fig. 132. - Slate-colored Junco, one-half natural size. new-fallen snow is an interesting sight on a cold winter's day, as they come familiarly about the house or barnyard. Audubon says that in winter they burrow in stacks of corn or hay for shelter at night during the continuance of inclement weather. As spring comes they begin to sing much like the Chipping Sparrow. They now converse together with a musical twittering, and about the first of May they leave for their northern breeding ground.

\section{Field Sparrow. Bush Sparrow. \\ Spizella pusilla.}

Length. - About five and one-half inches.

Adult. - Crown and back reddish-brown; back feathers showing pale edgings and lightly streaked with blackish; whitish wing bars; cheeks and sides of head, to crown, gray; a reddish-brown streak behind the eye; below, gray; breast washed with pale buff; bill pale reddish.

Nest. - On ground or in low bush.

Eggs. - Small, white, with rather fine brown spots.

Season. - April to October.

The Field Sparrow is a common summer resident of Massachusetts. It arrives in southeastern Massachusetts some- 
times as early as the latter part of March, but usually delays its coming until April. It frequents bushy pastures and worn-out fields, or dry, sandy sprout lands. On its first appearance it seeks the shelter afforded by a wooded or bushy

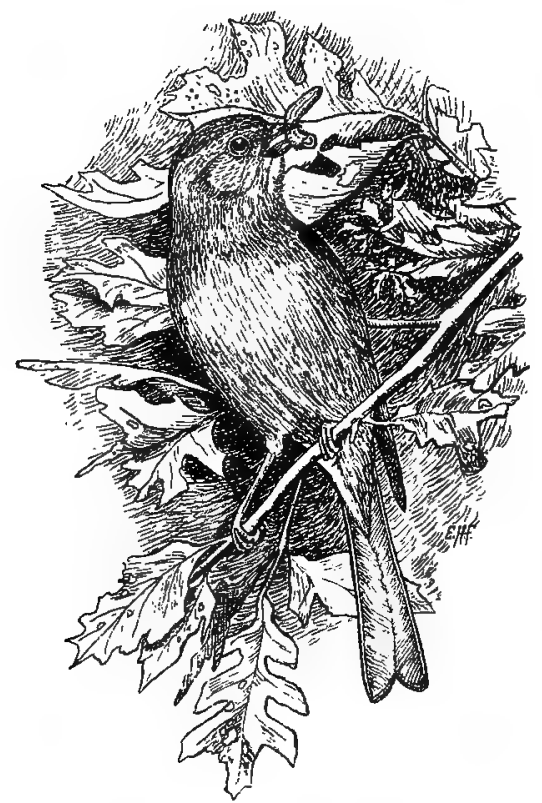

Fig. 133.-Field sparrow, one-half natural size. southerly slope, and forages from the underbrush out into the fields.

The song of the Field Sparrow is one of the sweetest sounds in. nature. It is a fine, clear strain, opening with a few modulated notes, and ending in a pensive $d i$ minuendo trill, as clear as the sound of a bell. It is a characteristic sound of the dry upland, when the still, warm June day sleeps upon the hills, and shimmering heat waves rise from the warm turf. The bird has also a series of Sparrow-like chirps and twitters, but nothing to compare with its song, which, though varied, is usually the same in character in all parts of Massachusetts. Dr. J. A. Allen says that the song of the males in Florida is very different from that of the northern birds.

The Field Sparrow is generally shyer than the Song Sparrow or the Chipping Sparrow, and is usually found more away from the farm buildings, and in the open field, pastures, or "scrub." It quite often alights on trees to sing or feed. I have found it feeding on cankerworms, tent caterpillars, and the caterpillars of the brown-tail moth. It is therefore of some value in woodland and orchard. It is seldom seen in the garden except when ripe weeds are to be found; but it is more often found in cornfields and potato fields, and Gentry says that it eats cabbage worms. It is useful in the fields, 
as it destroys May beetles, leaf hoppers, and sawflies. It eats more useful insects than some other Sparrows, and takes a good many spiders, some ants, and some earthworms. It also eats the seeds of many weeds, but feeds largely on the seeds of grasses and a little grain, mostly oats. A dozen of these Sparrows collected in a wheat field had eaten no wheat, but were feeding on weed seed.

The Field Sparrow, though less valuable to the farmer than some other species, is useful, and fills a place of its own.

Chipping Sparrow. Chippy. Chipper. Chip Bird. Hair Bird.

Spizella socialis.

Length. - Five to five and one-half inches.

Adult. - Crown bright reddish-brown; back brown, dark-streaked; a light-gray line over the eye, a blackish line through it; cheeks and under parts light gray or pale ash; tail slightly notehed.

Young. - Breast, sides, and top of head streaked.

Nest. - Lined with hair; in a bush, vine, or tree.

Eggs. - Light bluish, with a ring of dark spots around the larger end.

Season. - April to October.

This is the little dooryard bird that nests in the apple trees about the house, and picks up crumbs on the old stone doorstep. It is common in village dooryards, along the roads, in orchards, pastures, and particularly in gardens and plowed lands. It holds the distinction of being the most familiar and useful of all Sparrows in the yard and garden. Unlike some other Sparrows, it is often found far from bushy coverts, in the very center of plowed fields.

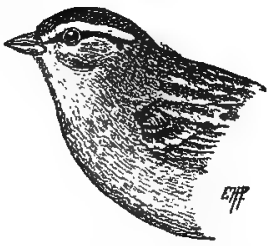

Fig. 134.-Chipping Sparrow, about one-half natural size.

The song of the Chipping Sparrow is a mere string of dry chips, sometimes repeated very rapidly and almost running into a trill, sometimes more slowly. On a spring morning the sound of the distant birds answering one another in different keys gives an impression like the rising and falling of the breath of a sleeper in the fields. Occasionally some talented bird modulates its usual song, giving a somewhat more musical, varied rendition, which suggests some of the songs of Warblers. The ordinary notes are a variety of 
chips, a sort of squeak, and a series of querulous twitters, uttered when the bird is angry. The males are sometimes pugnacious, and have been known to fight to the death.

The Chippy feeds very largely in spring and early summer on small caterpillars, and is therefore very useful in the

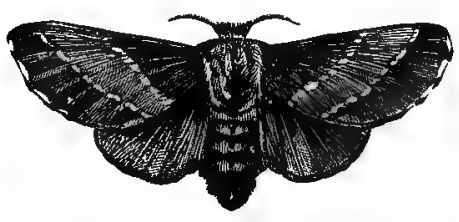

Fig. 135. - Moth of the tent caterpillar, natural size. orchard. Mr. Kirkland saw a single bird eat fifty-four cankerworms at one sitting. The Chippy is destructive to hairy caterpillars. It was the Chipping Sparrow that frequently interfered with experiments upon gipsy caterpillars, by breaking through the net that enclosed them and stealing the hairy worms. This bird is a persistent enemy of the caterpillar of the brown-tail moth, the tent caterpillar, and that of the tussock moth. Nocturnal moths, particularly Arctians, and Tineid moths are caught in the air. Currant worms do not come amiss. It is destructive to the codling moth and the moths of the tent caterpillar and the forest tent caterpillar. In all, thirty-eight per cent. of the food of the Chipping Sparrow consists of animal matter, three-fourths of which is made up of noxious insects. In June ninety-three per cent. of the food consists of insects, of which thirty-six per cent. is grasshoppers, caterpillars form twenty-five per cent., and leaf-eating beetles six per cent.

I have been much impressed with the value of this bird in the garden during the spring and summer months. It destroys at least three species of caterpillar on the

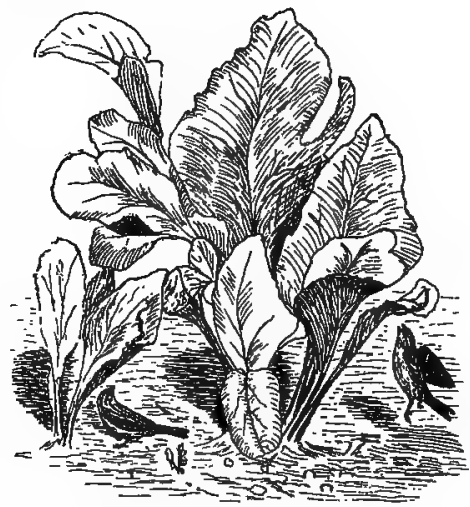

Fig. 136. - Chipping Sparrows bunting beet worms.

cabbage. It is the most destructive of all birds to the injurious pea louse (Nectarophora destructor), which caused a loss of three million dollars to the pea crop of a single 


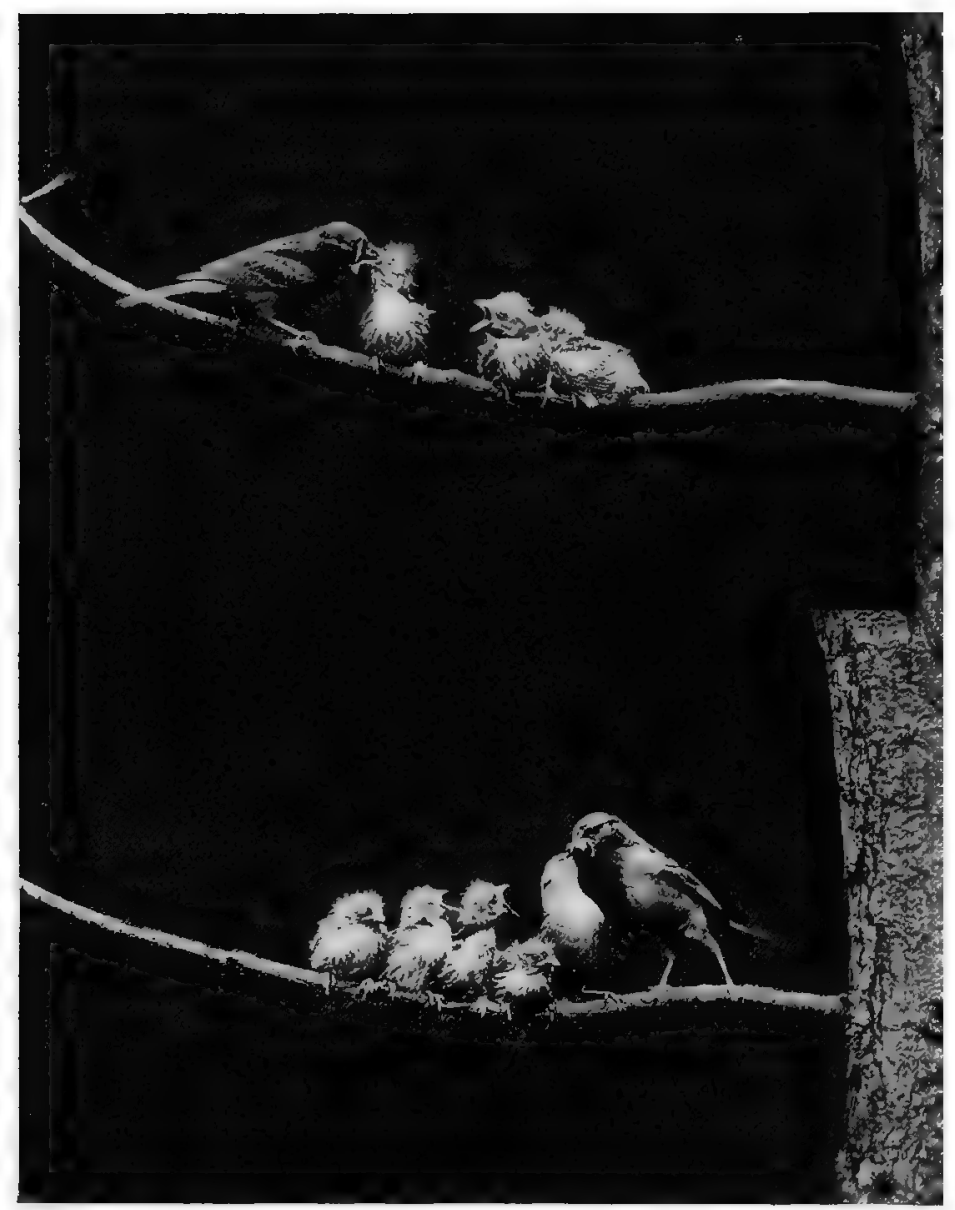

PLATE XXVIII. - Chipping Sparrows feeding their Young. (Photograph, from life, by C. $\mathrm{A}$. Reed.) (From the annual report of the Massachusetts State Board of Agriculture, 1902.) 

State in one year. It is a persistent destroyer of the grubs that mine the leaves of beets. I watched one bird secure eleven of these grubs in a few minutes. It feeds on the eggs of the parsley butterfly (Papulio polyxenes), and also takes young larvæ of this species and other insects from the leaves of celery, lettuce, and other small truck. I have no doubt that an investigation of the food of this bird in the garden would show it to be of great value to the market gardener. It likes to feed on cultivated ground, in the shade of the green leaves of vegetables. It creeps about noiselessly up and down the rows, an unseen and unnoticed influence for good. Injurious heetles, bugs, leaf hoppers, grasshoppers, and ants are taken freely.

Its vegetable food is of less importance than its animal food. It eats wild cherries, and Professor Beal says that he has seen it take a few cultivated cherries. Only four per cent. of the seeds eaten are grain, principally oats. Chickweed seed is commonly eaten, and some seeds of clover, ragweed, amaranth, wood sorrel, lamb's quarters, purslane, knotweed, and black bindweed; forty-eight per cent. of the seed eaten is grass seed, of which twenty-six per cent. is crab grass and pigeon grass, - two common weeds. The seeds of crab grass form the most important part of the vegetable diet whenever they can be obtained, for then the birds fill themselves with those only. Many Sparrows eat seeds whenever they are obtainable, even in summer, when insects are plentiful. The seeds of the dandelion are among the earliest that the Chipping Sparrow finds in summer. It frequently seeks the seeds of this plant on lawns. It takes them one by one from the opening heads, and spends so much time in this manner that it must consume a great deal of this seed. In August it sometimes visits oat stubble, where it picks up fallen grain.

Dr. Judd found that, on the one side, only one per cent. of the food eaten was composed of useful insects, while more than twenty-five per cent. consisted of insect pests; and, on the other side, grain composed four per cent. and weed seeds forty per cent. of the food. These figures clearly show the good service rendered to man by the Chipping Sparrow. 
Tree Sparrow. Winter Chippy.

Spizella monticola.

Length. - About six inches.

Adult. - Crown chestnut; line over eye dull white; line through eye dark (not black); back bay, black-streaked; tail dusky, with light edgings; two prominent white wing bars; below, whitish; side of head, throat, and upper breast tinted with ash; breast with a central dusky spot; lower breast and sides tinged with pale brownish.

Season. - October to April.

The Tree Sparrow is a common winter resident of most parts of the State. The species is almost as regular in appearance as the Junco, but not so plentiful. Though called

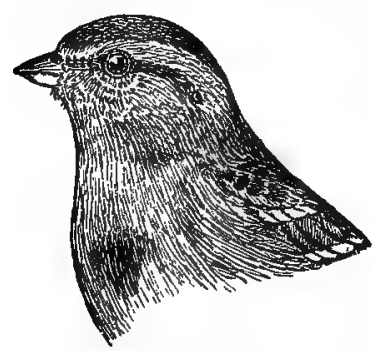

Fig. 137. - Tree Sparrow, about one-half natural size.

the Tree Sparrow, it is largely a ground Sparrow while in Massachusetts. Wherever it can find a plentiful supply of food and good shelter it remains throughout the winter, unless driven south by snows so deep as to cover its food supply. It frequents thickets on the sheltered side of hills, near swamps, meadows, or weedy fields.

In such fields it often feeds far from bushy cover, but flies quickly to the thicket upon the approach of danger.

This species usually goes in flocks, and individuals are not commonly seen alone; although a single bird may sometimes be found with a flock of Juncos. It feeds mainly on the ground, and picks up the seeds of weeds as they fall. A snowfall merely brings the birds nearer the tops of the weeds, and so long as there is plenty of seed they are as happy as the Snowbirds. They can climb about among the stronger weed stalks, clinging like a Goldfinch. Often two birds may be seen feeding from a single weed, while another hops about on the snow below, gleaning the seeds that fall. This species follows the Juncos into weedy vegetable gardens, and flocks about farms and haystacks to pick up seeds. The Tree Sparrows are among the few birds that can "look our winters in the face and sing." They are occasionally heard singing in November and December 
and late in February, when deep snow covers the ground. The song is among the sweetest of Sparrow notes, but not very strong. It slightly resembles that of the Fox Sparrow: Like other Sparrows, they chirp and twitter from time to time, but the full chorus of a flock in winter is a sound worth going far to hear.

Seeds form ninety-eight per cent. of the Tree Sparrow's food while it remains in the United States. It feeds very largely on pigeon grass, crab grass, and other grasses, and on the seeds of ragweed, amaranth, lamb's quarters, and other weeds. Only one per cent. of the food consists of grain, while fifty per cent. is weed seed. It therefore renders some service, and does no harm.

\section{White-throated Sparrow. Peabody Bird. \\ Zonotrichia albicollis.}

Length. - About six and three-fourths inches.

Adult Male. - Above, brown, black-streaked; crown black, with a central white stripe; a white stripe above the eye, changing to yellow from eye to bill; below this another black stripe extends along the sides of head behind the eye; sides of head gray, a paler shade on breast; large throat patch and belly white; sides brownish; wings with two inconspicuous white bars.

Adult Female. - Similar, but duller.

Young. - Crown dark brown; line over eye buffy; throat patch dirty white.

Nest. - On ground or in a low bush.

Eggs. - Pale, and heavily spotted.

Season. - Spring and fall; local in summer; very rare in winter.

This large and handsome Sparrow is a migrant through the State in spring and fall; many breed in the north-central and western parts of the State, some in northern Worcester County, and many others in the Berkshire hills. Occasionally one remains through the winter in the southeastern portion of the State; but most of the White-throats that are seen here are passing south in September and October, or going north late in April or during the first part of May. The great body of the White-throats usually passes through the State within three weeks

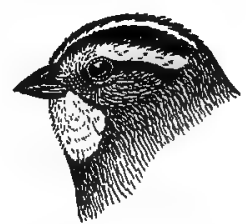

F1g. 138. - Whitethroated sparrow, one.half natural size.

in spring and fall. They find shelter in brush piles, thickets, or shrubbery, where they scratch about among dry leaves on the ground. 
The alarm note is a metallic chip; and the song, which is often heard in May, is a sweet whistled strain, which has been rendered "Old Sam Peabody, Peabody, Peabody," and from this fancied resemblance to these words it is called the Peabody Bird.

In May, when the White-throat passes north, it is of some service in the destruction of beetles. In the fall it feeds to some extent on berries and berry seeds, but its main usefulness at this season lies in the destruction of weed seeds. It is very fond of the seeds of ragweed and polygonum. Dr. Judd says that in October (when these birds are common in Massachusetts) ragweed seed constitutes forty-five per cent. of their food.

\section{Grasshopper Sparrow. Yellow-winged Sparrow.}

Coturniculus savannarum passerinus.

Length. - About five inches.

Adult. - Upper parts generally biown, streaked with black on back, much variegated, quail-like, and mixed with gray on rump; crown very dark, with a buffy line through it; a buffy-yellow stripe over eye; under parts buff, fading to whitish on the belly; no noticeable breast streaks; wings below the bend edged with bright yellow, ordinarily concealed from view; tail short.

Young. - Similar, but breast streaked with blackish.

Nest. - On ground.

Eggs. - White, brown-spotted.

Season. - May to September.

The Grasshopper Sparrow is comnon locally in eastern Massachusetts, but rare or wanting in many localities. In the southeastern part of the State it is hardly locally common, except in Nantucket. It is found through middle and southern Worcester County and in the Connecticut valley, and is probably much more common than is generally believed, as it is never conspicuous, and is largely confined to the open fields, where it readily hides in the grass. Minot says "they frequent almost exclusively dry fields, particularly such as do not contain a luxuriant vegetation." While this appears to be true of eastern Massachusetts, where many neglected fields are of that character, it is not altogether true of Worcester County. Although this Sparrow is never found in swamps, it is seen occasionally in meadows, and often inhabits fertile 
grass lands and cultivated fields. Many years ago, in Westborough, I found two nests of this species while hoeing in potato fields, and the birds were then common in a stretch of fertile rolling fields and meadows east of Worcester.

It is never found habitually in meadows, however, like that closely related species, Henslow's Sparrow; for, while the latter, so far as I have observed, always breeds in wet land, the Grasshopper Sparrow breeds on the slopes near by. I have never seen Henslow's Sparrow on the drier land except near Amherst; and the Grasshopper Sparrow is rarely seen in wet spots, even where the two species occupy the same fields. While these two Sparrows are locally common, neither of them is generally so. They resemble each other so closely that it is rather difficult to distinguish them in the field except by their notes and their habitat. The streaks on the breast of the Henslow's Sparrow will identify it when they can be seen. The notes, however, are quite different. The common note of the Henslow's Sparrow somewhat resembles the syllable kee' chick. When its nest is approached, the bird will allow the observer to get within a few feet, as it moves through the grass like a mouse, reiterating this note. The ordinary notes of the Grasshopper Sparrow are a chir like the note of an insect, and a sharp chick. The song, which is often uttered from the top of a wall, a fence, or a stone in the field, much resembles the stridulation of a longhorned grasshopper, and gives the bird its name. The lay is very weak, and often passes unnoticed, or is mistaken for the song of some insect. Minot gives it as $c h i c^{\prime}-c h i c^{\prime}-\alpha-s \bar{e} \bar{e}$, with the chief accent on the last and highest syllable, - a very good description.

The food of this bird while in Massachusetts is probably about seventy-five per cent. animal matter, largely insects. This Sparrow is very destructive to cutworms, army worms, wireworms, click beetles, weevils, and grasshoppers ; spiders, myriapods, snails, and earthworms are eaten in small quantities. It eats no cultivated fruit, very little grain, and some seeds of grasses and weeds. It takes fully forty times as many injurious as beneficial insects, and is one of the most useful birds of the fields. 


\section{Savanna Sparrow.}

Passerculus sandwichensis savanna.

Length. - About five and one-half inches.

Adult. - Brown above; feathers generally pale (or gray) edged, and dark-streaked ; a narrow whitish stripe through crown, and a yellow line above the eye; white or buffy below, thickly streaked with dusky; a cluster of streaks on the breast is sometimes gathered into a blotch, as in the Song Sparrow, but the tail is short and notched, rather than long and rounded, as in the Song Sparrow, and not noticeably marked.

Young. - Similar; colors more suffused; no yellow over eye.

Nest. - On ground.

Eggs. - Bluish-white, marked thickly with brown.

Season.-April to November.

The Savanna Sparrow is a common summer resident along portions of the seacoast, and through the central and western parts of the State. It is found along river valleys, in upland meadows, fertile fields, and pastures. In eastern and southern Massachusetts it breeds only locally or near the coast, but in Worcester County and through the central and western parts of the State it is common in favorable localities.

Although a bird of the meadow or savanna, it is common in many open fields and pastures of the hill country. It has a Sparrow-like chirp, but its notes and song otherwise much resemble those of insects, particularly the chirping of crickets, although the song is perhaps a trifle more musical than that of the Grasshopper Sparrow. Mr. Hoffman describes it well as two or three preliminary chirps, followed by two long, insect-like trills, the second a little lower in key than the first, thus : tsip, tsip, tsip, tseeeeeeeee, tse-ee-ee-ee. The song is often given from a stone, post, or fence. This bird is rarely seen off the ground, an occasional perch on a stone heap or fence being usually the only deviation from this rule; but it sometimes perches fifteen to twenty-five feet up in a tree, or flies from tree to tree along the edge of a field. Although it often lives and breeds in the hill country, it may be seen in fresh-water marshes during migrations, and frequents such spots as are dear to Rails and Swamp Sparrows. In the south it is an inhabitant of wet fresh-water meadows or savannas.

Nearly half the food of the Savanna Sparrow while in 
Massachusetts consists of insects, mainly injurious species, such as are eaten by other Sparrows. It is particularly fond of beetles. It eats more ants than do most Sparrows, many cutworms, a few spiders, and some snails. The vegetable food consists largely of the seeds of pigeon grass, panic grass, wild rice, and marsh grasses.

\section{Vesper Sparrow. Grass Finch. Bay-winged Bunting.}

Poocetes gramineus.

Length. - About six inches.

Adult. - Above, grayish-brown, finely streaked with dusky; crown finely streaked, but with no dividing line; cheeks buffy, with a dark patch; a narrow white eye ring; below, whitish (buffy where streaked), narrowly streaked with brown or black on breast and sides; a bay patch near the bend of the wing; tail clark, moderately long; outer tail feathers white.

Nest. - On ground.

Eggs. - Dull white or buffy, with many spots, usually overlaid by large dark marks and scrawls.

Season.-April to October.

The Vesper Sparrow is, next to the Song Sparrow, the most abundant ground Sparrow in Massachusetts. It is gen-

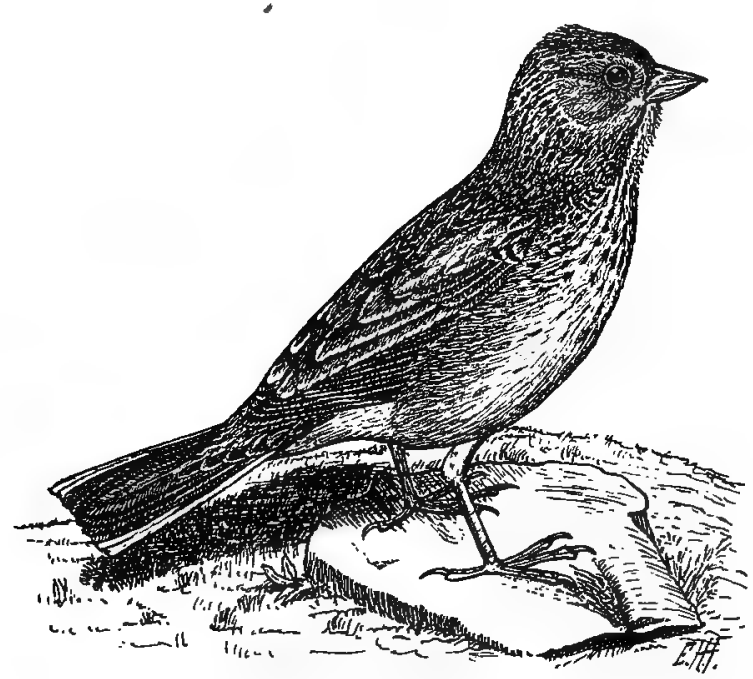

Fig. 139. - Vesper Sparrow, one-half natural size.

erally distributed wherever there are open fields and upland pastures, but it is not a bird of the meadows, and is not as common in some parts of southeastern Massachusetts as else- 
where. It is not a dooryard bird, like the Chipping Sparrow or Song Sparrow, but prefers upland fields, hill pastures, and plowed lands, at some distance from the farm buildings. It is sometimes seen in vegetable gardens.

It is not so closely confined to the ground as some other ground Sparrows, but perches on ridgepoles, wires, and trees. It frequently runs along the ground in pastures or potato fields, keeping just ahead of the obscrver as he walks. When the female is startled from her nest of young, she uses all her arts to entice the intruder away, fluttering along the ground with white-bordered tail spread conspicuously, and dragging her wings as if sorely wounded, - a tempting bait to lead the disturber away. The white outer feathers in the tail are not often clearly visible when the bird is standing, but usually may be seen when it flies.

The song of this bird, while perhaps less cheery than that of the Song Sparrow, is sweeter, and seems to carry farther as it floats down from the hills after sunset. The bird sometimes sings to greet the rising moon, and even flutters into the air, like the Skylark, with an exquisite burst of song. Mr. Burroughs has well named it the Vesper Sparrow. The ordinary notes are the usual Sparrow-like chips and calls.

In summer most of the food of this bird consists of insects, of which beetles and grasshoppers form the bulk. Since it frequents pastures, it picks up many dung beetles; weevils, click beetles, ground beetles, and leaf beetles seem otherwise to be preferred to other kinds. Grasshoppers form the principal food in midsunmer; cutworms are also eaten, and the bird does good work as an insect eater in field and garden. It is also useful as a destroyer of weed seeds, eating less grass seed than some other Sparrows, but a great variety of the seeds of weeds which it finds in cornfields and other fields, and in gardens.

BLACKBIRDS, GRACKLES, ETC.

This family has been mentioned on p. 224, and one of its members, the Baltimore Oriole, has been described among the birds of orchard and woodland (see pp. 224-228).

The Rusty Grackle is a mere migrant through the State 
in spring and fall, and is not of much economic value here; therefore, its description is omitted. The other species of the family will be considered here, for they all frequent meadows, grass fields, or cultivated lands.

The Bronzed Grackle and the Purple Grackle are both found in the State, but, as they are alike in form, notes, and habits, they are both known as Crow Blackbirds, and will not be treated separately.

\section{Purple Grackle. Crow Blackbird. \\ Quiscalus quiscula.}

Length. - Twelve to thirteen and one-half inches.

Adrult Male. - Variously purple, green, blue, violet, and bronzy; wings and tail mainly purplish; dark purplish or steel-blue on neck and breast; back greenish or bronzy; iris straw-yellow.

Adult Female. - Similar, but browner.

Nest. - A bulky structure, often built in tall coniferous trees.

Eggs. - Greenish, spotted and streaked with black and brown.

Season.-March to November. (This form intermingles with the succeeding one.)

\section{Bronzed Grackle. Western Crow Blackbird.}

Quiscalus quiscula aneus.

Adult Male. - Similar to above, but body brassy or bronzy; head, neck, and upper breast mainly steel-blue; wings and tail violet and steel-blue.

Adult Female. - Similar to that of the Purple Grackle. Both the above forms look black at a distance, and then are not distinguishable from one another; both forms have the tail long.

Nest, Eggs, and Season. - Like those of the Purple Grackle; winters rarely.

These birds, the largest of the family in Massachusetts, find their normal habitat about meadows or marshes; but they have taken kindly to civilization, and, where they are not much persecuted, are common about lawns, fields, and gardens. They may often be seen walking about on Boston Common or in the Public Garden. They build their nests in tall shade trees near suburban and city residences or about cemeteries, and they frequent well-kept lawns. They are so large and powerful that not even the Sparrow can drive them out; and if the Sparrows attack their eggs or young, the Blackbirds are not slow to retaliate with effect.

These birds are conspicuous, and when close at hand are unmistakable. The tail is often held with its outer feathers upturned like the sides of a boat, particularly when they fly, 
which they do usually at some height, in rather a labored manner, keeping about the same level. The ordinary note is a sort of hoarse, loud chuck, and the song sounds much like the rather musical creaking of a rusty hinge. They have also a metallic, jangling note, and when a number perch on a

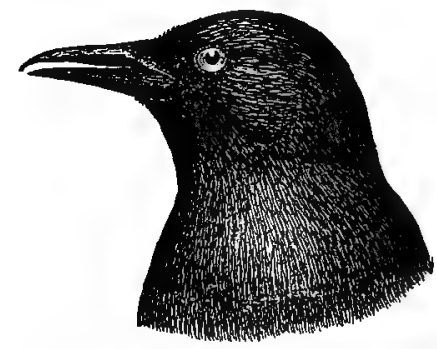

Fig. 140.-Crow Blackbird, male, one-half natural size. favorite tree and sing in chorus, the clanging and creaking they produce are indescribable.

When not disturbed, they breed in companies, often in groves of white pine; but where they are much shot at, they separate, and each pair finds a secluded place for its nest. As soon as the young are reared, the birds gather in flocks of hundreds or even thousands, and forage together. In migration they sometimes travel in immense armies. A great flight of these birds passed over Concord on Oct. 28, 1904. From my post of observation, on a hilltop, an army of birds could be seen extending across the sky from one horizon to the other. As one of my companions remarked, it was a great "rainbow of birds;" as they passed overhead, the line appeared to be about three rods wide and about one hundred feet above the hilltop. This column of birds appeared as perfect in form as a platoon. The individual birds were not flying in the direction in which the column extended, but diagonally across it ; and when one considers the difficulty of keeping a platoon of men in line when marching shoulder to shoulder, the precision with which this host of birds kept their line across the sky seems marvellous. As the line passed overhead, it extended nearly east and west. The birds seemed to be flying in a course considerably west of south, and thus the whole column was gradually drifting southwest. As the left of the line passed over the Concord meadows, its end was seen in the distance, but the other end of this mighty army extended beyond the western horizon. The flight was watched until it was nearly out of sight, and then followed with a glass until it disappeared in the distance. 
It never faltered, broke, or wavered, but kept straight on into the gathering gloom of night. The whole array presented no such appearance as the unformed flocks ordinarily seen earlier in the season, but was a finer formation than I have ever seen elsewhere, among either land birds or water-fowl. It seemed to be a migration of all the Crow Blackbirds in the region, and there appeared to be a few Rusty Blackbirds with them. After that date I saw but one Crow Blackbird. It was impossible to estimate the number of birds in this flight. My companions believed there were "millions."

The character of the food of the Crow Blackbirds is very well known. The large flocks in which they gather in autumn are very destructive to ripening corn, and some individuals destroy birds' eggs or young birds ; otherwise, in Massachusetts the birds are largely beneficial. They sometimes pull up a little sprouting corn, but are not nearly so destructive in this respect as the Crows. Dr. Warren tells of the dissection of thirty-one birds that were shot in a Pennsylvania cornfield : nineteen showed only cutworms in their stomachs; seven had taken some corn, but a very large excess of insects, mainly beetles and cutworms, with earthworms; the remaining five had eaten chiefly beetles. The Crow Blackbird industriously follows the plow, and picks up many beetles, grubs, cutworms, and some earthworms. In spring and summer its food in Massachusetts is mainly insects.

Nearly twenty-five hundred stomachs of the species have been examined in Washington. The food for the year was composed of over thirty per cent. annimal and almost seventy per cent. vegetable matter, which shows that the birds are almost as omnivorous as the Crow. Insect food forms twentyseven per cent. of the whole. The greater part is taken in summer. Beetles, particularly Scarabæids like the "June bug" or "rose bug," Carabids or ground beetles, curculios or weevils, form a large part of the food. The Grackles seem to be fond of white grubs, and the stomach is often packed with these insects. Grackles are not so skillful in digging them out as is the Robin, but they are sly enough to snatch the grub away from the Robin when he has secured one. They are very destructive to grasshoppers and locusts, 
which in August make over twenty-three per cent. of their food, and are found and eaten by them in nearly every month of the year. A good many caterpillars are eaten, mainly those species that are found on the ground, such as cutworms and army worms; but the birds flock to caterpillar outbreaks, eating both hairy and hairless species. Crow Blackbirds destroy both gipsy moth and brown-tail moth; bugs, ants, and spiders are eaten also. Mice, birds and eggs, frogs, lizards, salamanders, snakes, fish, crustaceans, mollusks, and snails form a portion of the Grackles' food. The vegetable food, beside corn and other grains, consists of rather a small quantity of fruit, mainly wild seeds, nuts, acorns, and weed seed. Seventy per cent. of the food of the young birds consists of insects similar to those eaten at the same season by their parents.

To sum up: the Crow Blackbirds, though destructive to corn and to a less extent to other grain, are indispensable because of the vast amount of insects they destroy. In the west they are so numerous that the farmer often must defend himself against them; but in Massachusetts their destruction is not often necessary, and they are seldom shot by husbandmen except when gathered in flocks among the corn.

Meadowlark. Old-field Lark. Marsh Quail.

Sturnella magna.

Length. - Ten to eleven inches.

Adult. - Upper parts brown, with many dark-streaked, pale-edged feathers; tail short; outer tail feathers largely white; a light line through middle of crown; a light line over eye, yellow from eye to bill, and dark streak behind eye; below, chiefly yellow, with a large black crescent on breast. Adult in Winter. - Redder above; lower parts duller.

Young. - Under parts paler; crescent replaced by a few black markings.

Nest. - On the ground in a field; usually arched over.

Eggs. - White, with brown spots.

Season.-Resident.

This handsome and well-known bird is a common summer resident of Massachusetts, and often remains all winter in seasons when there is little snow, or in favored localities. In the southeastern part of the State, especially in Barnstable County, it may usually be seen in winter in sheltered situations on marshes or meadows. During and after snow- 
storms it becomes quite domesticated, and seeks food along roads and about dooryards and poultry houses; but ordinarily the Lark is a shy bird, and keeps well out of gunshot in the open fields. This species has learned caution in the north because of continual persecution by gunners; but I have seen Meadowlarks as tame as Sparrows in the pine barrens of southern Florida.

The Lark is a bird of the meadows, as its name implies; but it also frequents dry fields, and sometimes may be seen perched high in a tree on some hilltop, from which it sings its clear refrain. Old fields are favorite nesting places, probably in part because the dead and uncut grass offers concealment for the nest, and in part because in such fields the nest is undisturbed by the mower. This bird is an adept at concealing its nest, which sometimes has. a covered approach. It resorts to stratagem to puzzle the searcher. When the female comes from or goes to

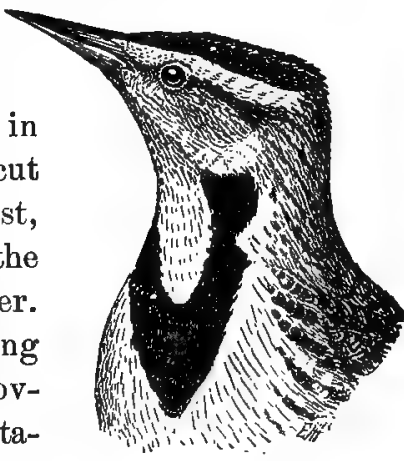

Fig. 141.-Meadowlark, one-half natural size. the nest she often runs through the grass for some distance, and seldom flies to it directly. Mrs. Irene G. Wheelock, in recording her attempts to find a nest, states that the male carried butterflies and dragon flies time after time to a point one hundred yards from the nest, in an apparent attempt to befool the searcher.

Its flight is an alternation of fluttering and slow sailing, and it usually shows its white tail feathers often, especially on rising and alighting. When on the ground it does not hop like the Robin, but walks more like the Crow, occasionally opening and closing its tail, showing the white feathers conspicuously.

Its common alarm note is a rather sharp chatter, not loud, but shrill, which often follows or precedes a long, piercing call. The ordinary song is a rather plaintive but pleasing whistle of a few notes, the last usually held for several seconds. This song is uttered either from the ground, from 
a perch, or while the bird is on the wing. Rarely a talented individual soars aloft, uttering an ecstatic flight song, which compares favorably with that of the most celebrated songsters. I have heard this in full volume but once, and then found it difficult to believe that it came from the throat of a common Meadowlark. It was not at all suggestive of that bird's ordinary song, except in some of the last notes, nor did it in the least resemble that of the Western Meadowlark; it more resembled the music of the Bobolink, but was louder and not so hurriedly given.

The Meadowlark is now quite generally protected by law at all times, and no bird more fully deserves such protection. It is practically harmless, and takes nothing that is of any use to man except a few small grains and seeds. On the other hand, it is one of the most useful birds of the fields, perhaps the most valuable. In summer almost ninety-nine per cent. of its food consists of insects and allied forms. It eats about all the principal pests of the fields, and is particularly destructive to cutworms, hairy ground caterpillars, and grasshoppers. In summer it gets but few seeds, but in fall and winter it takes many weed seeds. It visits weedy cornfields and gardens in search of ragweed and other seeds, of which it devours enormous quantities, which make up about one-third of the food for the year. Even in winter it prefers insects when it can get them. Mr. C. W. Nash says, in his "Birds of Ontario," that several specimens shot in winter contained only insects, taken about market gardens. Professor Beal says that even in December and January the insect components of the food are thirty-nine and twentyfour per cent., respectively ; and in March, when insects are still hard to obtain, the quantity rises to seventy-three per cent. Professor Beal makes an ingenious and very moderate estimate, from which be concludes that twenty-five dollars' worth of hay is saved annually in an ordinary township by Meadowlarks, through their destruction of grasshoppers, and he values hay at only ten dollars per ton. When we consider that grasshoppers, green grasshoppers, locusts, and crickets all together form twenty-nine per cent. of the food of this bird for the year, and that it is almost entirely in- 
sectivorous by preference, and when we consider also the additional injury that must occur were the insects and their progeny allowed to increase through a lack of Meadowlarks, the value of the bird becomes evident.

\section{Red-winged Blackbird. Marsh Blackbird.}

Agelaius ghoniceus.

Length. - About nine and one-half inshes.

Adult Male.-Black, with a light-edged scarlet patch at bend of wing; often only the light edges of this patch show when the wings are closed.

Adult Female. - Smaller; grayish-brown, streaked heavily with dark brown or blackish.

Young. - Similar to female.

Nest. - In grass or bush; rarely in a tree.

Eggs. - Pale bluish, with spots and scrawls of darker colors and black.

Season. - March to August.

Few birds are better known than the Red-winged Blackbird. Almost every small bog hole or swamp about the farm harbors a pair or more of these birds. They are common about ponds and meadows. The males arrive in flocks, usually in March, and sometimes may be heard singing gaily while the ground is still deeply covered with snow. Their song is as characteristic a sign of spring as is that of the early wood frog, and their notes have something of the same quality. They carry a suggestion of boggy ooze. The common note is a single chuck, and

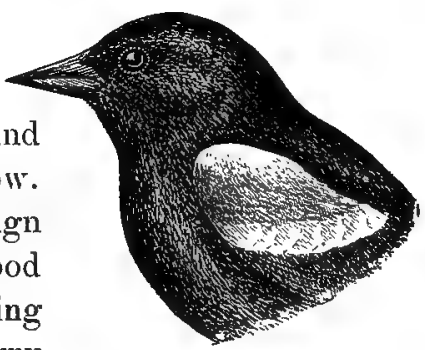

Fig. 142.-Red-winged Blackbird, male, one-half natural size.

the ordinary song resembles the syllables quong-ka-reee', the first two uttered quickly. Some individuals have a more musical song, ending with a jingle akin to that of the Bobolink.

Although the Red-wings almost invariably breed in the swamp or marsh, they have a partiality for open fields and plowed lands; and most of the Blackbirds that nest in the smaller swamps adjacent to farm lands get a large share of their food from the farmer's fields. They forage about the fields and meadows when they first come north in spring. Later, they follow the plow, picking up grubs, worms, and 
caterpillars; and should there be an outbreak of cankerworms in the orchard, the Blackbirds will fly at least half a mile to get cankerworms for their young. Wilson estimated that the Red-wings of the United States would in four months destroy sixteen thousand, two. hundred million larvæ.

They eat the caterpillars of the gipsy

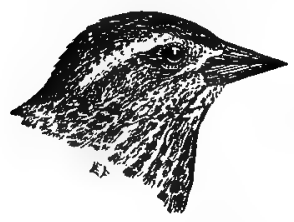

Fig. 143.- Red-winged Blackbird, female, about one-half natural aize. moth, the forest tent caterpillar, and other hairy larvæ. They are among the most destructive birds to weevils, click beetles, and wireworms. Grasshoppers, ants, bugs, and flies form a portion of the Red-wings' food. They eat comparatively little grain in Massachusetts, although they get some from newly sown fields in spring, as well as from the autumn harvest; but they feed very largely on the seeds of weeds and wild rice in the fall. In the south they join with the Bobolink in devastating the rice fields, and in the west they are often so numerous as to destroy the grain in the fields; but here the good they do far outweighs the injury, and for this reason they are protected by law.

\section{Cowbird. Cow Blackbird. Cow Bunting.}

Molothrus ater.

Length. - Seven and one-half to about eight inches.

Aclult Male. - Lustrous black, with a rich, lustrous brown head and neck. Adult Female. - Brownish-gray, slightly darker on wings and tail.

Nest. - That of some other bird.

Eggs. - White, speckled all over with brown.

Season.-April to October.

This much-maligned bird, which builds no home of its own, and depends on others to hatch and rear its young, is, nevertheless, an essential part of nature's plan. Birds that. rear their own young are confined by necessity to a certain radius about their nests; but the scattered bands of Cowbirds form a wandering, unattached light squadron of insect destroyers, which all summer long can go wherever their presence is most needed. In the warmer months of the year they feed almost entirely on insects, but during the colder months they live on seeds. 
Throughout the season the sexes intermingle promiscuously, from the time the females arrive in the spring. As usual with other species, the males come first, and may be seen singly, in small flocks, or with other species of Blackbirds. They perch in the tops of tall trees, and their only song is a long, thin whistle, high keyed and little varied. The common note is a chuck.

The females soon arrive from the south, and then flocks may be seen in which they usually predominate. The eggs are deposited from April to June, in the nests of other and usually smaller birds. An egg is dropped slyly when the owner of the nest is absent, and generally after she has laid some of her own. Sometimes the little foster mother refuses to adopt the offspring of another, and abandons the nest, or builds another nest above the first one; but usually she good-naturedly settles down upon her nest to incubate.

The Cowbird's egg is larger than those of the foster mother, and is commonly deposited in the center of the nest. Perhaps it gets more heat than the other eggs, for it hatches first. The young Cowbird grows faster than the other chicks, and gets about all the food. It is soon able to dislodge its smaller and weaker foster brothers and sisters, who perish; then the young Cowbird monopolizes the entire time and care of its foster parents. It is no uncommon thing to see a small Warbler or a Chipping Sparrow feeding a young Cowbird twice its own size; but as soon as the stranger is well able to shift for itself, it joins a flock of its own species.

Grasshoppers seem to be its favorite animal food, but leaf hoppers, also very destructive to grass, are freely taken. Undoubtedly the Cowbird is of great benefit to pastures, where it follows the cattle about, picking up insects that start up around them. Weevils and curculios are commonly eaten; also caterpillars, but to a less extent than other Blackbirds eat them. Cowbirds take wasps, ants, and flies in small quantity, and a number of spiders. Vegetable food, however, forms the main part of the Cowbird's subsistence in spring and fall, and, according to Professor Beal, it constitutes nearly seventy per cent. of all the food for the year. A large part of this, however, is weed seed, of which the seed 
of ragweed, barn grass, and panic grass form probably the greatest portion; but the Cowbird eats more grain than the Red-winged Blackbird. Undoubtedly its food habits are on the whole beneficial; but, as every Cowbird is reared at the expense of the lives of at least two other birds, the reputation of the species suffers accordingly, and its social habits are certainly not exemplary, if judged by human standards.

Boholink. Skunk Blackbird. Reed Bird. Rice Bird.

Dolichonyx.oryzivorus.

Length. - About seven and one-fourth inches.

Adult Male. - In spring and early summer, mainly black; nape creamy buff; streaks on upper back grayish-white; shoulders and lower back ashy-white; in August and September the plumage resembles that of the female.

Adult Fremale and Young. - Upper parts brown, dark-streaked; lower parts yellowish-brown, unstreaked.

Nest. - On ground, in grass.

Eggs.-Gray, spotted with brown and overlaid with dusky streaks, blotches, and scrawls.

Season.-May to September.

The Bobolink is the harlequin of the spring meadows. He is a happy-go-lucky fellow, with his suit on wrong side up, the black below and the white above; a reckless, rollicking

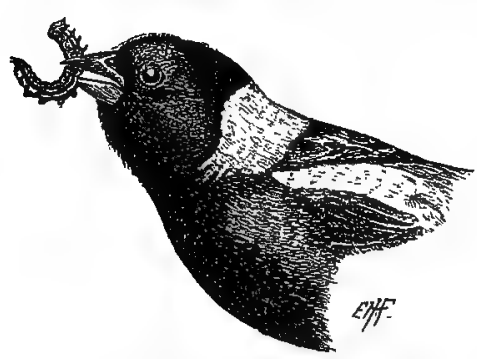

Fig. 144. - Bobolink, male, and army worm, one-half natural size. sort of a fowl, throwing care to the winds, and always bent on a lark. His spirits are of the effervescent kind, and his music bubbles irrepressibly forth at such a rate that half a dozen notes seem to be crowding upon the heels of every one uttered. Indeed, this is about the only bird that completely baffles the latter-day "interpreters" of bird music. His notes tumble out with such headlong rapidity, in an apparent effort to jump over each other, that it is next to impossible for the scribe to set them down in the proper sequence of musical notation. Nevertheless, this harum-scarum expression of irrepressible joy is of the most pleasing character, and ranks among the finest music of the fields. 
The males chase each other madly, and swiftly pursue the females over the grass tops; or, sailing with down-bent wings, pour forth their torrent of music. The alarm note is a metallic chent. When the young have been reared, the males begin to lose their striking dress, the song ceases, and early in August the Bobolinks are seen flying about in small flocks, uttering mellow chinks, as they prepare for their southern journey.

In May, June, and July insects form about eighty-five per cent. of the Bobolink's food. The bird is very destructive to grasshop-

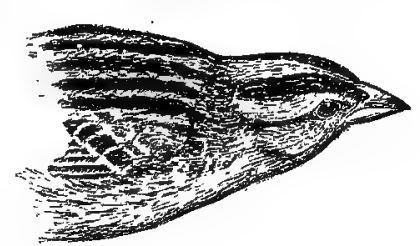

Fig. 145. - Bobolink, female. pers and caterpillars, particularly to the army worm. It eats some parasitic Hymenoptera, and this may be looked upon as a bad habit; but otherwise little fault can be found with the Bobolink while it remains in the meadows of the north.

In the south, however, the Bobolinks, together with the Blackbirds, cause an annual loss of fully two million dollars to the rice growers, and would destroy the whole crop were not all the hands on every plantation engaged during the "rice bird" season in shooting or frightening the birds. This continued shooting undoubtedly has had some effect on the number of birds breeding in the north, and Bobolinks are not now so generally common in Massachusetts as they were forty years ago. They have been reduced some by early mowing in the nesting fields, but their diminution from year to year is hardly perceptible.

\section{PIGEONS AND DOVES.}

This group of birds is now represented in Massachusetts by but one species, the Mourning Dove, as the Passenger Pigeon appears to have disappeared, and may now be extinct. The Mourning Dove, which is often mistaken for it, is now protected by law at all times, and probably will be saved from the fate of the Pigeon. Presumably all the supposed "wild Pigeons" now reported by different observers in Massachusetts are Mourning Doves. 
Mourning Dove. Carolina Dove. Turtle Dove.

Zenaidura macroura.

Length. - Nearly twelve inches.

Adult Male. - Upper parts mainly grayish-blue, shaded with olive-brown; head and neck brown, with a bluish overcast; sides of neck iridescent, with reddish and golden reflections; a black spot below the ear; outer tail feathers and wing feathers show bluish when spread; all outer tail feathers have a black bar and a white tip; tail rather elongated and pointed; lower parts purplish, changing to yellowish on belly, bluish on sides, and whitish on chin.

Adult Female. - Similar, but duller.

Young. - Grayer than female; many feathers have whitish edgings.

Nest. - A mere platform of sticks, at a moderate height in a tree, near trunk.

Eggs.-Two; white.

Season. - April to Oetober.

The Mourning Dove was never so abundant in this State as the Passenger.Pigeon, for Massachusetts is near the northern border of its range; still, it was once common where it is now rare, particularly in western Massachusetts, but it is now so uncommon generally as to be of little economic importance. In some parts of Middlesex, Plymouth, and Barnstable counties it is still common locally in spring and summer, and its mournful cooing is heard almost daily. A variety of notes has been attributed to this species, but I can recall only the "coo," and a twittering sound that appears to be made by the wings when it first rises in flight.

This Dove is of no great value as an insect eater, for it feeds largely on seeds. Wheat, oats, rye, corn, and barley are all eaten, forming about thirty-two per cent. of the food, but perhaps three-fourths of this is waste grain picked up in the fields. Buckwheat is a favorite food. Some grain is taken from newly sown fields, but the greater part. of the food consists of weed seeds. Nash says that the crops of these birds are often so full of seeds that, if a bird is shot, the crop bursts open when it strikes the ground. He says that bindweed is a favorite food. A Dove that was examined at the Department of Agriculture was found to contain ninety-two hundred seeds, mostly those of noxious weeds, and none of useful plants. This was rather an unusual number, but it shows what the bird is capable of doing as a helper on the farm. 
GROUSE, PARTRIDGES, ETC.

The Grouse are treated among the birds of orchard and woodland, on pp. 266-274.

Bob-white. Quail.

Colinus virginianus.

Length. - About ten inches.

Adult Male. - Upper parts mainly reddish-brown, with dark streaks and light edgings; forehead and broad line over eye white; throat patch white, bordered with black; tail short, gray ; crown, upper breast, and neck all round brownish-red; breast and belly whitish, narrowly barred and marked with crescent-shaped black marks; sides reddish-brown.

Adult Female. - Similar, but duller; without the black on the head, and the white mainly replaced by buff.

Nest. - On ground, among bushes, grass, or grain.

Eggs. - White, often stained with brown.

Season. - Resident.

No bird is more typical of the southern New England farm than the Quail.1 Its clear and mellow call is still a characteristic sound of spring and early summer. The plowman hears it as he drives his team afield, and it mingles with the ringing sound of the whetstone on the scythe.

The Quail is an inbabitant of the transition zone, and cannot maintain itself much farther north than Massachusetts except along the coast, where the winters are less severe than in the interior. It gets its sustenance mainly from the ground; hence, when the earth is deeply covered with snow

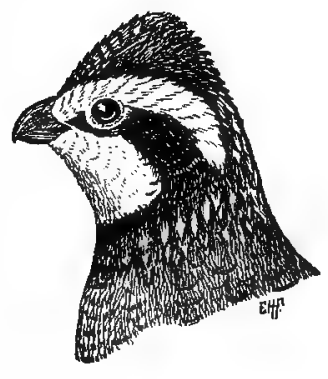

Fig. 146. - Bob-white, onehalf natural size. its food is hard to obtain, and many Quail are starved or frozen under the snow during hard winters, as was the case during the winter of 1903-04. Such winter killings occur many times during a century, and the birds have always partially recovered their lost ground; but unless they can receive absolute protection for a series of years after such seasons their recovery will be rendered increasingly difficult,

1 The name Quail is a misnomer, for the bird is not a Quail, but more nearly a Partridge, as it is called in the south. It resembles the Quail of Europe, hence the New England name, which will undoubtedly "stick." 
on account of the great accession to the number of gunners. The Quail is not easily extirpated, for, unlike the Woodcock, it waits until the weather is mild before beginning its nest; and it is very prolific, and sometimes rears more than one brood in a season. From twenty-four to forty-two eggs are said to have been found in a single nest, but these were probably the product of more than one bird.

The pure strain of the old race of Massachusetts Quail is believed to have been practically eliminated by shooting and winter killing, and most of the birds now existing in the State are supposed to represent a mongrel race, - an admixture of the blood of Massachusetts birds and those of the south and west. Some naturalists assert, however, that no introduced southern birds survive their first winter in Massachusetts ; but Mr. H. H. Kimball, secretary of the Massachusetts Fish and Game Protective Association, who has been instrumental in introducing and "planting" many of these birds, has trustworthy evidence that in some cases at least they have wintered well and become established.

The breeding season of the Bob-white extends through May, June, and July, and the males may be heard calling occasionally as late as the first of October. According to Dr. Judd, $\mathrm{Mr}$. Robert Ridgway found a clutch of freshly deposited eggs in a nest in southern Illinois on October 16, and H. C. Munger found another set in Missouri in January. The parent bird was found, later, frozen on the nest. This seems to indicate a latent tendency, like that of the domestic fowl, to lay eggs at any season of the year, - a trait which might give added value to the species in domestication. The nest is usually made in grass land, in some old field, or in a bushy thicket along its border, and is often well concealed.

Young Quail are said to run about the moment they are ratched. While this may be an exaggeration, probably all the eggs in a litter are hatched at about the same time, and the young birds are able to leave the nest very soon afterward. The first downy chicks are usually seen in July. They are very small, and are streaked somewhat like Bantam or Brown Leghorn chicks. Their protective coloring is such as to render them invisible when motionless on the ground, 
where they squat with closed eyes at the first danger signal. The driver of my heavy farm wagon saw a mother bird one day in the road before him. He stopped the slow team at once, but too late to save three of the young that, hidden in the rut, had been run over by the wheels. He found and picked up a live one squatted there.

All through the breeding season the common call of the male, "Bob-white," or "Bob-Bob-White," may be heard, particularly just before a rain, and the farmers translate the cry as "More-wet," or "Some-more-wet." At a distance this call is a clear whistle. Dr. Judd says that when uttered within ten feet of the hearer it loses its melody and becomes a mere nasal shriek. At the approach of danger the bird can reduce the volume of sound at will, so that when it stands within twenty or twenty-five feet of the listener its whistle seems to come from a point many rods away, - an accomplishment which I have heretofore noted as possessed by other birds. The call when thus subdued is of exactly the same tone and pitch as usual, quite as clear, and delivered in exactly the same way. So far as my observations go, the bird when calling sits or stands in its usual position, throwing up its head slightly in enunciating "Bob," and then throwing it well back and pointing the bill skyward when uttering the "white," as is shown in the accompanying figures, after sketches from the wild bird.

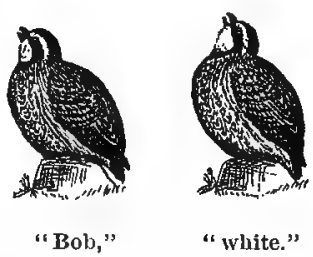

Fig. 147. - The morning call.

Dr. Judd watched a Quail that called in a somewhat similar manner, except that when three notes were given it depressed its bill almost to its breast in uttering the second. He thus describes the calls of the mated birds :-

Then followed a series of queer, responsive "caterwaulings," more unbirdlike than those of the Yellow-breasted Chat, suggesting now the call of a cat to her kittens, now the scolding of a caged gray squirrel, now the alarm notes of a mother Grouse, blended with the strident cry of the Guinea Hen. As a finale, sometimes came a loud, rasping noise, not unlike the effort of a broken-voiced Whip-poor-will. 
When the broods are scattered by the gunner, they are reassembled again by a whistled call of the old bird, which has been given, "ka-loi-kee, ka-loi-kee," and is answered by the whistled, repeated response, "whoil kee." The syllables are almost run together. The first call is uttered with a rising and the other with a falling inflection. It is plainly the rallying call and answering cry. When the scattered covey gets together, musical twitterings are often heard. At night they repair to some favorite locality, where they sleep on the ground in a ring, heads out and shoulder to shoulder. 'In this formation there are always some birds to face and discover danger, upon whichever side it approaches. One spring into the air gives each bird wing room, and off they fly in all directions, an animated "feathered bombshell," exploding in the darkness with a roar of pinions sufficient to startle and possibly baffle an enemy, as the belated traveller who has happened to disturb them at night will attest. They sometimes gather into the same formation in the daytime.

In Massachusetts the birds usually roost in thickets, blackberry tangles, or woods, and often use the same roosting place for several nights in succession. They feed largely in fields, gardens, and cultivated land; but when pursued they often take to the swamps or woods, where they perch in trees, usually on the side farthest from the pursuer, sitting upright on the branches or crouching close to the trunk. Their habits during the shooting season are well known. A great deal of ink has been used in discussing the question whether the Quail is able to "hold its scent," as it is a well-known fact that dogs are frequently at fault in trailing this bird. When the dog is alone, the bird, even in open ground, apparently gives itself little uneasiness, but simply settles quietly down where it stands until it lies flat on its breast, with head drawn down so close to the shoulders that it might well pass for a brown clod. It remains thus, allows the dog to pass within a few yards or even a few feet, and keeps quiet until all danger is past. But let a human being appear, and much greater precautions are taken. I have seen a bird in open ground run and hide in a slight hollow, or conceal itself by crouching between two sections of 
a stump. If there are trees near by, it runs quickly and squats upon the ground behind a tree or close to its trunk. Its resemblance to its surroundings is so close that it seems to disappear, effacing itself before one's eyes like a witch in a fairy tale, as it flattens itself on the ground. Bob-white naturally "lies to a dog," for it seems to have a supreme contempt for the blundering animal. This apparent confidence in its own invisibility is often fatal, however, where trained bird dogs are entered against it.

There is some reason to believe that the Quail is migratory at times. Some people relate that Quail have been seen flying south in large flocks at the approach of winter; others aver that many have been drowned while crossing large bodies of water; still others tell us that the birds migrate long distances by running; but every covey that I have been able to watch has passed the winter not far from the place where it was reared. These observations have often been interrupted by the destruction of the entire brood by farmers, gunners, or sportsmen. A great many broods "migrate" in this manner, never to return. Still, probably Grouse and Quail sometimes become restless in the fall, and move about the country; but it is extremely doubtful if there are any general movements of either species that can be designated as autumnal or vernal migrations in the ordinary sense in which these terms are applied.

The feeding habits of the Bob-white are such that it must be ranked by the farmer as one of the most useful birds of field and garden. It is very nearly harmless, as it takes little grain or fruit. Occasionally in the cornfield it pecks at a broken-down ear of corn, and it picks up a good deal of waste grain in the stubble of oats and wheat. It sometimes eats a few strawberries, but these are evidently not a favorite food, for birds in captivity have refused them when hungry. On the other hand, Bob-white, during spring and summer, feeds on many of the most destructive pests of garden and field, and in fall and winter eats great numbers of the seeds of many noxious weeds. Dr. Judd makes some interesting calculations regarding the quantity of insects and weed seeds consumed by the Bob-white in Virginia and North Carolina. 
Estimating that there are four birds to each square mile in these States, and that each bird consumes half an ounce of weed seed daily from September 1 to April 1, he concludes that one thousand, three hundred and forty-one tons are eaten by Quail annually in the two States; and, as insects form about one-third of the birds' food from June 1 to August 1, he estimates that Quail consume three hundred and forty tons of insects in these States within those two months.

It is somewhat remarkable that the Quail feeds on most of the superlatively destructive crop and garden pests of North America, among them the Rocky Mountain locust, chinch bug, cotton worm, Mexican cotton boll weevil, army worm; Colorado potato beetle, striped cucumber beetle, May beetle, bean leaf beetle, and several species of grasshoppers. More than one-third of its food for August consists of insects, of which very few are useful species. The Quail eats many ground beetles, but mainly those species which feed to some extent on vegetation, and which become destructive if allowed to increase unduly. It is probably the most effective enemy of the Colorado potato beetle. A correspondent wrote me that he had watched the Quail feeding on potato beetles and other insects on his farm, and believed that each bird raised on his place was worth five dollars to him as an insect killer. He declines to allow any more Quail to be killed on his farm. Dr. Judd says that Mr. C. E. Romaine of Crockett, Tex., wrote that Quail were nesting ahout his fences and even in his garden, and had kept his potato patch.entirely free from the "Colorado potato bug." From seventy-five to over one hundred potato beetles have been found in Quails' stomachs. Clover-leaf beetles, corn-hill bugs, wireworms, and many other beetles and larvæ are eaten. Professor Aughey found five hundred and thirty-nine locusts in the stomachs of twenty-one birds, or an average of twentyfive apiece. The Bob-white not only finds many cutworms, but picks up the parent moths, as well as ants, flies, and spiders.

The young are at first fed almost entirely on insect food. Mr. Nash says they eat their own weight of insects daily. As an insect eater the Quail is worth its weight in gold to 
the farmer and gardener. If it could be protected and increased in numbers, and if it could be allowed to come confidently about the farmstead, perhaps it would become the most useful bird of the garden.

In late spring and early summer its vegetable food is largely confined to such seeds as it can pick up, and to green grass, chickweed, sorrel, clover and other succulent leaves; and some buds. In the perennial problem of weed destruction there is no greater ally of the farmer than this bird. It eats the seeds of over sixty species of weeds. Seeds form over one-half its food, and among them the ragweed seems to be the favorite. As many as two hundred to three hundred seeds of smartweed, five hundred of the red sorrel, seven hundred of the three-seeded mercury, and one thousand of ragweed have been eaten at a meal. According to Dr. Judd, five thousand seeds of green foxtail and ten thousand of pigweed have been found in a single bird. As the fall advances, Quail find acorns and pine seed in the woods, and in the thickets they seek wild fruit that nature provides for winter bird-fare. Although the Quail feed by preference on the ground in winter, when the snow is deep they seek shelter in tangles and thickets, where wintering berries grow. Wherever the ground is swept bare of snow by the wind the Quail wander about, feeding on dried leaves of plantain and other plants, with such weed seeds and dried grasses as they can find. Mr. William Brewster tells me that the native Quail of New England eked out an existence on the berries of the red cedar when the snow lay deep on the ground, but that the introduced Quail apparently have not acquired the habit, and so succumb more readily to the New England winter. From all the studies made regarding the food of the bird, it is clear that the farmer should never shoot it, or allow it to be shot on his land. If the Massachusetts market must be supplied with Quail, they must be reared artificially, for the time is coming when no Quail can be obtained from other States. The laws of most States now prohibit their shipment to other States, and there are not birds enough here to supply a tenth of the demand. 


\section{PHEASANTS}

Pheasants are closely related to the Pea Fowl and the Domestic Cock. They are natives of Asia, but several species have been introduced into England and America.

\section{Ring-necked Pheasant. \\ Phasianus torquatus.}

Length. - Varying according to length of tail, but reaching three feet.

Adult Male. - Head and neck dark, burnished blue, with reflections of other shades; a white ring around neck; back orange-brown to reddish, with black and other variegations; breast coppery-chestnut, with purplish edgings and some greenish gloss; tail olive-brown, with red-purplish edgings, and crossed with blackish bars; bare skin of head scarlet.

Adult Female. - Smaller; tail shorter, and general plumage brown, marked with blackish.

Young. - Similar to female.

Nest. - On ground.

Eggs. - Similar to those of a small domestic fowl.

Season. - Resident.

The Ring-neck was first imported into Oregon from China, and was introduced into Massachusetts from the Pacific coast in 1894 by the Massachusetts Commissioners on Fisheries and

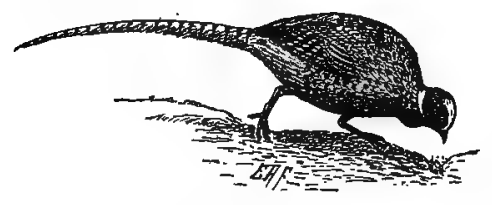

Fig. 148. - Ring-necked Pheasant.

Game, who have since propagated the birds and liberated them in various parts of the State. It was brought to this country under the name of Mongolian Pheasant, but is quite distinct from that species, to which it has only a general likeness. When its acclimatization here was proposed, I wrote the late John Fannin, then curator of the Provincial Museum of British Columbia, inquiring whether the Pheasants which had been introduced there had proved injurious to native birds or farm crops. He replied that on Vancouver Island, where Pheasants were then numerous, they had driven the Grouse to the woods; but that this did little harm, as Grouse were naturally wood birds, while the Pheasants were birds of the open country. They were doing some damage to crops, but this had not caused any cry for their abatement, and the people generally considered them a valuable acquisition. 
In $1897 \mathrm{Mr}$. F. H. Mosher confined two adult birds at Malden. They were given some choice of food, and were fond of grain, weed seeds, vegetables, fruit, and insects. They ate seventy full-grown gipsy moth caterpillars in half a day. Within another half day they ate one hundred and eight egg-bearing female gipsy moths. No young birds could be secured for experiment.

In 1903 complaints began to come in that Pheasants were injuring crops and killing game birds. Circulars sent out to three hundred correspondents in different parts of the State brought replies regarding these birds from over two hundred people. A considerable number of correspondents had never heard of the species in their vicinity. Forty-two stated that the bird was not then present in their sections. Thirty asserted either that it was very rare in their vicinity or had disappeared. Pheasants were reported as numerous only near Winchester, where the State pheasantry was located, in a few other places where they were being bred, and in portions of Essex County, where they had an opportunity to breed on large estates on which no gunning was allowed. Forty-five persons stated that Pheasants were doing no injury to crops or game birds. Three persons complained that Pheasants were killing Bob-whites and Ruffed Grouse; and nine asserted that Pheasants were injuring crops, principally corn, tomatoes, peas, beans, cabbages, and potatoes. Practically all these complaints came from those few sections where the birds were becoming numerous. Pheasants have taken more of my sprouting corn than have either Crows or squirrels. They do not pull it up, as the Crows do, but dig it up with the beak. In other localities they are said to "pull more corn than the Crows." In the fall they eat what corn they can reach from the ground, and in Wareham they are said to dig "bushels" of potatoes.

The evidence regarding the killing of game birds was merely circumstantial. Several reputable persons asserted that since Pheasants had become common they had found "both Partridges and Quail with their heads pecked open." Other birds of these species were said to have borne evidence of having been slain in combat with a larger bird. 
One man is reported to have seen a Pheasant kill a Partridge. I watched the Quail and Pheasant feeding together at Wareham, and one day saw a Pheasant strike a Quail on the head with its beak, exactly as a hen will sometimes strike and kill a strange chicken. In this case, however, the Quail escaped, but gave the Pheasant a "wide berth" thereafter. One observer reports that a lady was feeding Quail in winter, and that a cock Pheasant habitually drove the Quail away and ate the grain.

Pheasants do much good by destroying insects, and there need be no fear that these birds will ever become numerous enough throughout the State to do great harm. Generally they appear to be unable to hold their own. The common report is that "Pheasants have been turned loose here, but have all disappeared." No eatable bird of the size of a Pheasant can ever increase much in numbers in Massachusetts except on land where it can be protected from all shooters.

SNIPE, SANDPIPERS, WOODCOCK, ETC.

Most of the birds of this order, which includes the Plover, are known as shore birds or marsh birds, and are seen mainly in migration on the shores of the sea or large bodies of fresh water. Three species either are, or once were, common summer residents of this State, and all three go to fields or cultivated land for a large part of their food. One, the Spotted Sandpiper, is still quite common; and another, the well-known Woodcock, may again become so if it can be protected from excessive shooting. Another still, the Bartramian Sandpiper or Upland Plover, which was once a common summer resident of upland fields, has long been on the road to extermination, and can now be saved only by enacting and enforcing stringent laws for its protection in those States where it breeds, as well as in the more southern States, where the birds find neither rest nor mercy. Most of the other species of this order, which once migrated along the coast in countless numbers, are of economic importance principally as food; but, with fow exceptions, the larger species are so reduced in numbers that they are at present of little account in any economic sense. 


\section{Spotted Sandpiper. Tip-up. Teeter.}

Actitis macularia.

Length. - About seven and one-half inches.

Adult. - Above, olive-brown, ash-tinged; below, white, spotted with rounded blackish marks; a row of white spots on the wing; outer tail feathers white-barred.

Young. - Breast unspotted, with a slight grayish cast on white of breast.

Nest.- On ground, on the shore of a pond or river, or in a field or pasture.

Eggs. - Buffy, thickly speckled with dark brown and black; very large for the size of the bird, and quite pointed at small end.

Season.-April to September.

The Spotted Sandpiper, once a common and familiar bird along all our ponds and streams, is still fairly common in suitable localities throughout the State. It is not a gregarious species, nor does it travel much along the seashore, and so it has largely escaped the decimation that many other Sandpipers have suffered at the hands of the gunner. It is the only Sandpiper commonly found about inland waters in June and early July. As it walks it repeatedly raises and lowers the hinder part of its body with a teetering motion. This is particularly noticeable when the bird is alarmed, and uttering its cry of peet-weet, peet-weet. This note is often repeated when the bird is startled, and may be heard along the sandy margin of ponds or rivers in the dusk of evening. Here it wades in, at times up to its belly. On occasion it can swim well, and sometimes when wounded and hard pressed it will dive deeply, using its wings and flying swiftly under water, like a Loon. It often builds its nest and rears its young in or near cultivated lands, at a considerable distance from any water. The young are able to run about soon after they are hatched, and they wander away from the nest, brooded and cared for at need by the mother, who is very solicitous for their welfare. Their safety lies in their protective coloring. They are fed largely on insects, and the parents in summer seem to be very fond of similar food, which they pick up about cultivated fields. Like all other birds of the field, this Sandpiper catches grasshoppers and locusts. Six of these birds dissected by Professor Aughey in Nebraska contained ninety-one locusts and one hundred and forty-two other insects. 
Bartramian Sandpiper. Upland Plover.

Bartramia longicauda.

Length. - Nearly twelve inches.

Adult. - Upper parts generally light tawny-brown, with dark or blackish markings; outer tail feathers barred with black and brown, and tipped with white; inner webs of larger wing feathers barred with black and white; breast and sides buffy or tawny, marked lightly with blackish; belly whitish.

Nest. - A mere hollow in the ground.

Eggs. - Buffy or whitish, speckled with dark brown.

Season. - May to September.

This fine, large Sandpiper, commonly called the Upland Plover, is a bird of the grass-field and pasture. It is not often seen near the shore, except as it feeds in migration on the grassy hills of Ipswich and other coast towns, or on Nantucket, where it breeds. It is a bird of the uplands, often found breeding in the interior, at long distances from rivers or ponds, and usually in upland mowing fields. Forty years ago it bred commonly in considerable areas of the State, but now it is rare or wanting everywhere in the breeding season except in a few localities in some counties. Its note is a melodious, long, rolling whistle, uttered much in flight. Just after the bird alights it raises its wings high over its back, stretches them, and then folds them in place.

As the law now protects this bird at all times, it is to be hoped that its numbers will increase, as it is one of the most valuable birds of the field. It is an indefatigable insect hunter, living very largely on such insects as grass-eating caterpillars and grasshoppers.

\section{American Woodcock.}

Philohela minor.

Length. - Ten to twelve inches; bill nearly three inches.

Adult. - Upper parts brown and russet or buff, mixed with gray and marked with blackish; back of head black, barred with yellowish; dark line from eye to bill; under parts pale, warm brown, varying in intensity; tail black, tipped with white; eye large, well back and high up.

Nest. - On ground in moist land.

Eggs. - Large, buff-colored, with chocolate and stone-gray spots and markings. Season. - March to November; rare in winter.

This favorite game bird was once a common summer resident of this State, but is now becoming rare in the breeding 


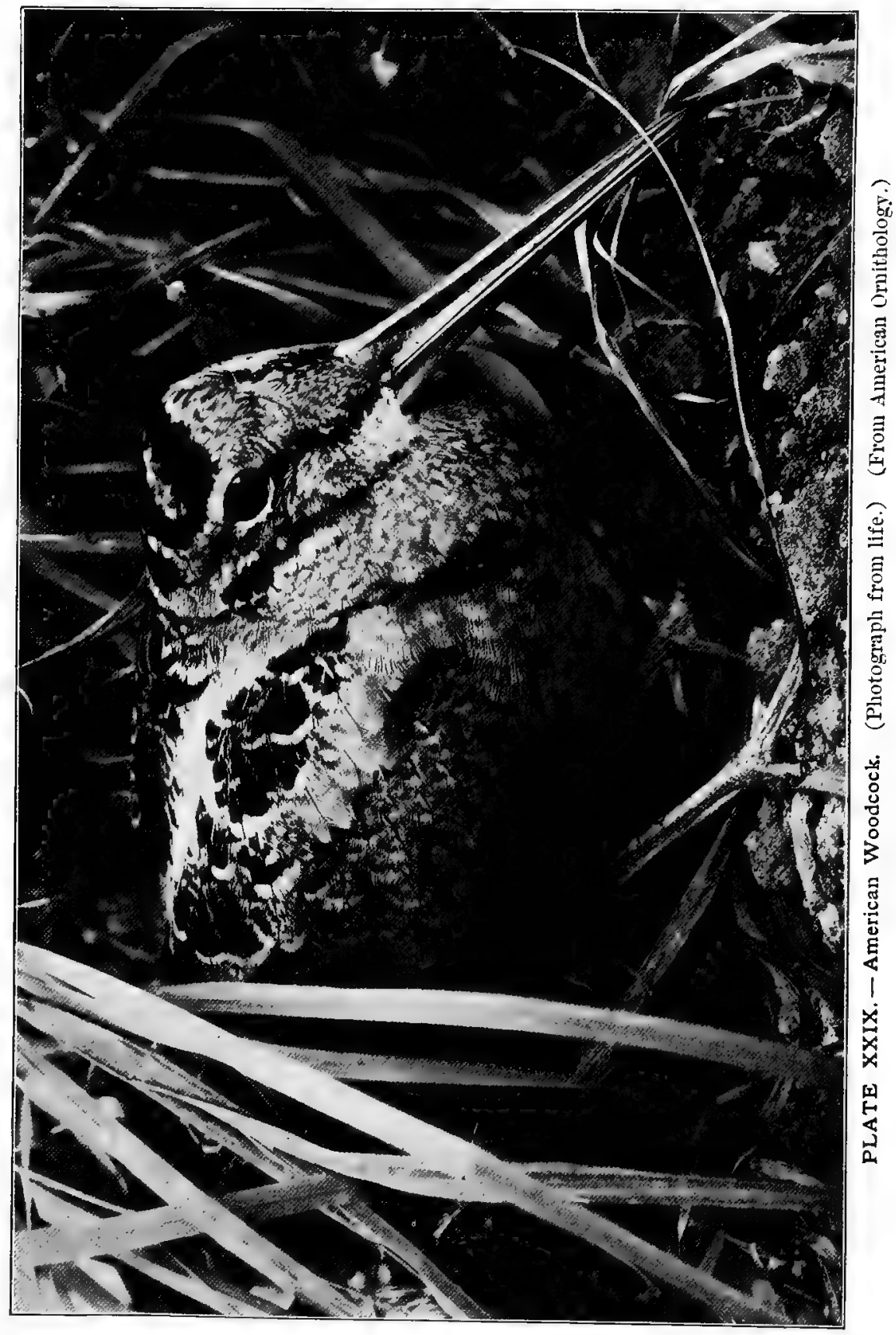



season. It feeds in low, swampy woodland, boring in the mud for worms, and also in low pastures, where it destroys many insects. In late summer it often goes to the uplands, where it feeds in cornfields, asparagus fields, fruit gardens, and pastures. At such times the bird may be seen among the currant bushes or vegetables, where in early morning it feeds with the Robins. When suddenly flushed it sometimes rises with a tremulous whistling sound, similar to that made by the wings of the Mourning Dove. Although in summer it frequents fields, gardens, and pastures, it sometimes forsakes them in very dry weather for the wooded shores of ponds or rivers. The Woodcock evidently feeds much at night or during the dusk of morning and evening, when it is almost always active. When startled in the daytime it is normally sluggish, and rises just over the tops of the bushes or undergrowth, flutters a short distance, and alights ; but late in the fall a strong bird that has been hunted and shot at will start up like a flash and fly wild high and far, sometimes fanning the air so rapidly with its wings that they appear as a mere nebulous haze, like those of the Hummingbird in flight. Its curious flight song is uttered in the breeding season, when it rises high in the dusk of evening, sending back a series of twittering and whistling sounds.

The Woodeock is hunted throughout its range. As it grows rarer in the north, gunners and sportsmen follow it south in winter. Great numbers of Woodcock are slaughtered there when all the birds of the species are massed in a limited area.

\section{Wilson's Snipe. \\ Gallinago delicata.}

Length. - Ten and one-half to eleven and one-half inches; bill about two and one-balf inches.

Adult. - Upper parts brownish-black, varied with bay and tawny; crown black, with a light central stripe; upper tail coverts tawny, with dark bars; tail feathers above bright chestnut, with a black bar near the tip, which is whitish; beneath, white, but breast and sides tinted with brown, speckled and barred with dusky.

Season.-Spring and fall.

The Snipe is a not uncommon migrant, and may be found in favorable localities in late March and April, and again in 
September and October. It is not an upland bird, but is seen chiefly in fresh-water meadows and lowlands along streams. It is sometimes met with in low, moist gardens. Mr. William Brewster says, in his "Birds of the Cambridge Region," that during exceptionally wet autumns great numbers of Snipe occasionally visit the truck farms of Arlington and Belmont, to feed in the water-soaked fields of corn, potatoes, and other crops. As they do not injure the crops, but probe the ground with their long bills, in search of worms and larvæ, it is probable that they do considerable good at such times. The Snipe when started from the ground usually goes off in a rather low, erratic course, but when well up in the air it sometimes makes a long and steady flight. It may be identified by its long bill. It seems to be somewhat nocturnal, particularly on moonlit nights, when its note may be heard as it flies about the meadows or runs over them. Its alarm note is a barsh scaipe, and it utters also a muffled "bleat." It feeds mainly on worms, grasshoppers, and other small forms of animal life. This bird's chief economic value lies in the delicacy of its flesh, and as an object of sport it has few superiors. 


\section{CHAPTER IX.}

\section{BIRDS OF THE AIR.}

There are no birds that so well deserve the designation "fowls of the air" as those that get their subsistence by pursuing flying insects. Eagles and Vultures, Frigate Birds, Albatrosses, and some other sea birds, are endowed with great powers of flight, but all must descend to earth or water for their food; but Swallows, Swifts, and Nighthawks win their sustenance from the air. They may be said to live in the air, as, with few exceptions, they seldom alight except to rest or to attend to their domestic affairs.

Unfortunately, the precise character of the food that many of these insect-eating birds procure high in air is not well known. We see the Swifts and Swallows darting about at great heights on clear summer days. We know that they must be catching flying insects; but what insects are flying at such a height, and why? They must be winged imagoes. Have they finished the business of life, and are they then sporting for a few brief hours in sunlight before death overtakes them? Are they migrating on the wings of the wind to fresh fields? Are they useful, or injurious, insects? No one knows.

When Swallows or Swifts are flying low their food can be studied, and we have some definite information regarding its character at such times. They are known to take many parasitic Hymenoptera, but whether these insects are taken before or after they have propagated, whether most of them are mainly beneficial, or injurious, parasites, we have little information. Therefore, the effect produced by this habit of these birds is not well understood. We know, however, that many injurious insects, such as flies, gnats, mosquitoes, moths, beetles, and plant lice, when about to reproduce their kind, are captured by these feathered skimmers of the air. We know that the Swallows pursue insects all day, until the 
twilight Bats come out; that Nighthawks "sweep the sky" through the later hours of daylight; and that Whip-poorwills and Swifts are sometimes a-wing throughout the night. So that whenever insects are flying there are birds to pursue them. These birds of tireless pinion cover a wide territory, and form a most potent check on insect life.

\section{SWIFTS.}

The spine-tail Swifts are Swallow-like birds that rarely if ever alight, except upon their nests or on the perpendicular sides of chimneys, rocks, hollow trees, or buildings.

\section{Chimney Swift.}

Chalura pelagica.

Length. - About five and one-fourth inches.

Adult. - Sooty-brown, paling to gray on throat and breast; tail rather short, spiny, and somewhat cigar-shaped, fan-shaped when spread; wings blackish, long, narrow, and slightly curved.

Nest. - Of sticks, glued to the wall of a chimney, hollow tree, or barn.

Eggs. - White.

Season. - April to September.

The Chimney Swallow, as it is commonly called in the country, is one of the common sights of the summer twilight as it flies twittering above trees and house tops. When building its nest it breaks off twigs from the trees as it flies, and glues them to the chimney with its own saliva. It is a most expert insect catcher, and while hawking about for food for its young fills up its mouth and cheeks with insects, carrying them much as a chipmunk carries corn. It appears to be of a playful disposition. I saw a Swift one day in Concord apparently amusing itself by chasing Cedar Birds, that were fly-catching, over the river. When a Cedar Bird flew out over the water the Swift turned and chased it back into the trees again, often following so closely as to seem about to attempt to swallow the frightened and fleeing bird.

Swifts catch flies, small beetles of various kinds, flying ants, bugs, grasshoppers, and other insects, and spiders. A notion exists that these birds introduce bedbugs into houses; but so far as I know it has never been proven that there is any parasite common to both human beings and birds, with perhaps a single exception, - the woodticks. 



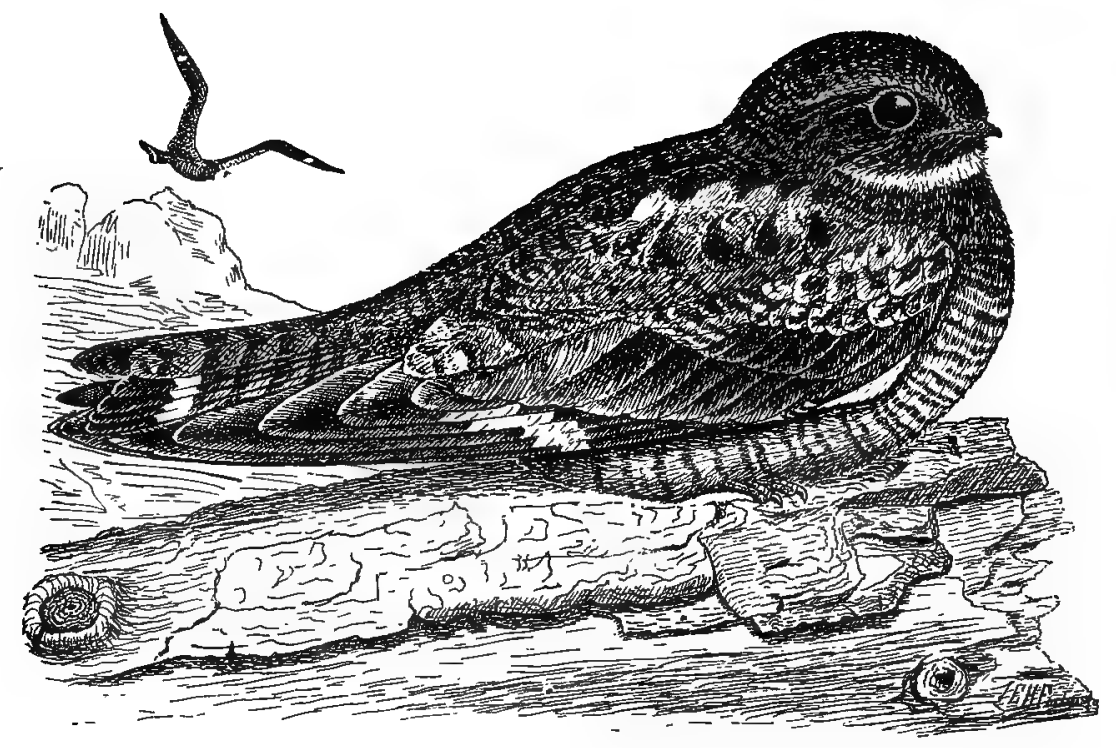

PLATE XXX.-Nighthawk.

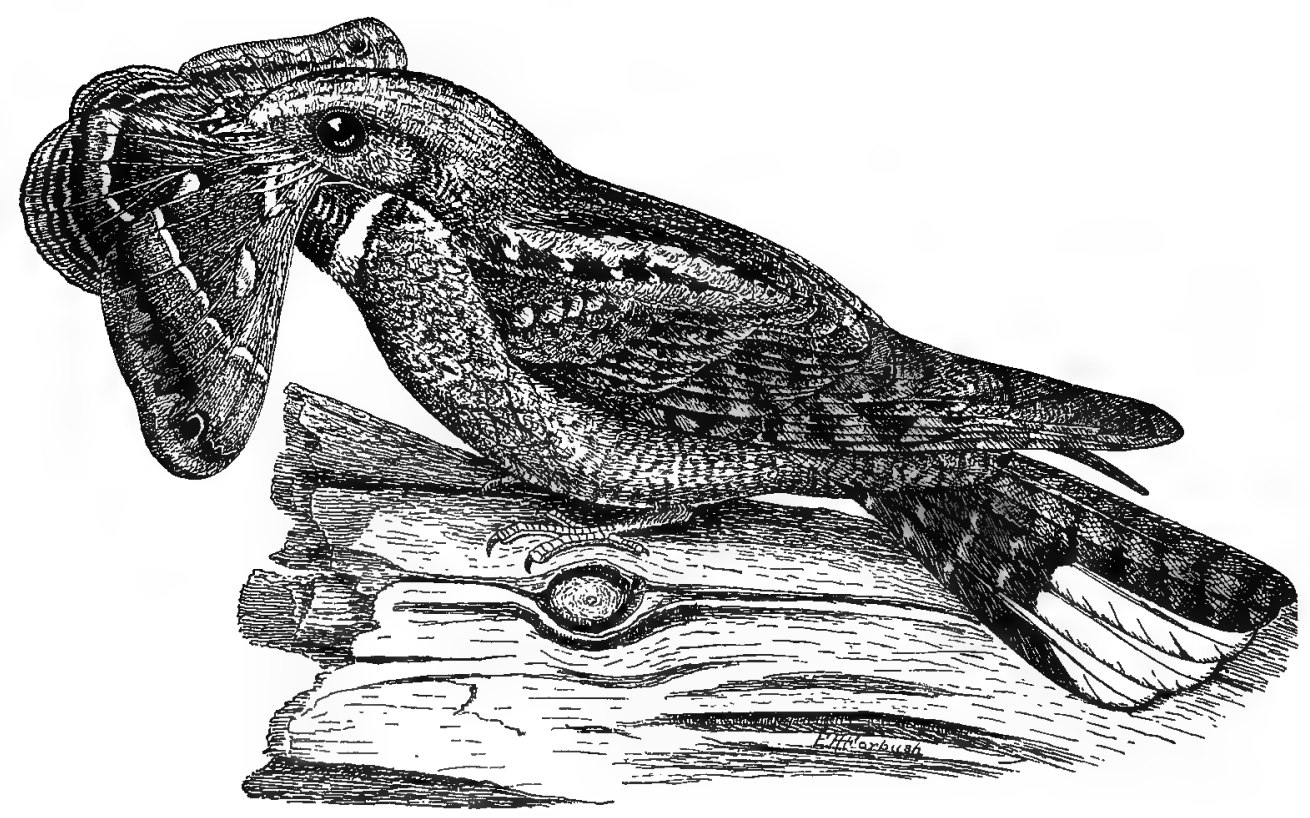

PLATE XXXI. - Whip-poor-will. 
NIGHTHAWKS, WHIP-POOR-WILLS, ETC.

Birds of this family are especially fitted for the capture of flying insects. Their beaks are small and weak, but their mouths are very capacious, their gullets are large, and their stomachs enormous. Some species fly high over open country; others live mainly in the woods. Together with the Owls and Bats they form a night police for the control of nocturnal insects.

Our two common species, the Nighthawk and the Whippoor-will, are frequently confounded; but in appearance, habits, and color of eggs they are so different that this mistake could not be made except by the most superficial observer.

Nighthawk. Bull Bat.

Chordeiles virginianus.

Length. - Nine to ten inches.

Adult Male. - Above, black, gray, and tawny, mixed and mottled; wings long and narrow, crossed by a broad white bar which shows best in flight; tail slightly forked or notched, all except the two middle tail feathers crossed near tip with a white band; throat with a broad band of white; breast blackish, marked with gray; other under parts gray (sometimes tinged with buffy), barred with blackish.

Adult Fernale. - Similar, but duller; throat band buff; no white on tail.

Eggs. - Laid on bare ledge, rocky ground, or a gravel roof.

Season. - May to September.

The Nighthawk is neither a night bird nor a Hawk, unless it may be called a mosquito Hawk. It flies chiefly at evening, but is seldom heard to cry after dark, and often may be seen flying about during the greater part of the day, sometimes at great heights. It has deposited its eggs on gravel roofs in cities for at least forty years, and probably longer. It may be seen on summer afternoons hawking for insects high over the eity streets. The usual note is a $s-k-i-r-k$ or $s-c-a-i-p-e$, a little like the call of Wilson's Snipe, - rather a startling squeak when heard close at hand.

This is the only loud note I have ever heard uttered by this bird, except the boom which accompanies its sudden descent through the air, and which is supposed to be made by the wings. The Nighthawk is very devoted to its young, which, like its eggs, are so protectively colored that they are 
almost invisible when seen from above as they squat on their natal rock. The mother either tries to drive an intruder away by approaching him with open mouth, or feigns lameness and so attempts to entice him into pursuit.

It is probable that the Nighthawk is one of the most useful of all birds. It ranks next to the Flicker in the destruction of ants, and it takes them when they are flying and about to propagate. Professor Beal estimated that the stomachs of eighty-seven Nighthawks which he examined "contained not less than twenty thousand ants, and these were not half of the insect contents." One Nighthawk's stomach held remains of thirty-four May beetles. Great numbers of grasshoppers are caught by these birds. Potato beetles, cucumber beetles, leaf hoppers, bugs, and enormous quantities of gnats and mosquitoes have been found in their stomachs. Nighthawks are absolutely harmless, as they never take fruit or grain, grass or vegetables. They are protected by law at all times, and should never be shot or molested. Unfortunately, they are now rare in parts of this Commonwealth where they were conmon years ago.

\section{Whip-poor-will.}

Antrostomus vociferus.

Length. - About ten inches.

Adult Male. - Above, finely mottled and barred with black, gray, and yellowishbrown; wings barred with black and brown, in general browner and not so dark as the Nighthawk; throat and upper breast blackish; other under parts buff, marked with blackish; a narrow white band just below throat, and terminal portion of three outer tail feathers white.

Adult Female. - Similar, but band below throat buff, and tail feathers narrowly tipped with yellowish-white.

Eggs.-On ground in woods; a creamy white, beautifully marked with shades of purple or laviender.

Season. - May to September.

In moonlit woods, through dark and shady dells, over wide pastures, and by the lone farmhouse door the Whippoor-will flits softly through the silent night. Its flight is not as noiseless as that of an Owl; but the bird is even more mysterious than the Owls themselves. Its night flight and weird but melodious call have aroused superstitious fancies, until the Whip-poor-will has been accredited with all sorts of uncanny attributes; nevertheless, it is, like 



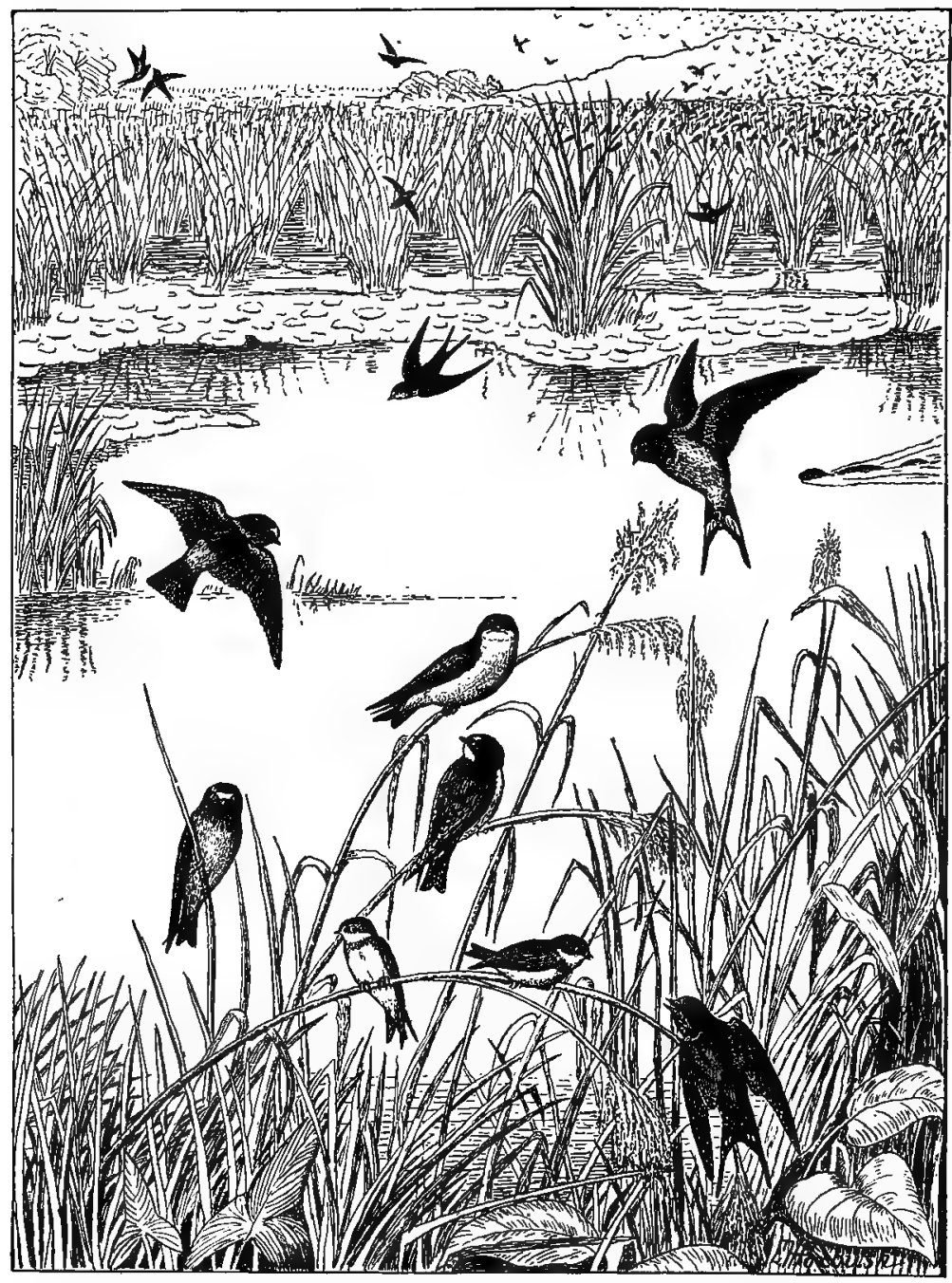

PLATE XXXII. - A Swallow Roost.

Tree Swallow.

Cliff Swallow.

Barn Swallow.

Bank Swallow. 
the Nighthawk, one of the most friendly and useful of birds. Its supposedly ill-omened cry is sometimes heard from the ridgepole or from the orchard trees. Mr. James Buckham, in an interesting article in "Zion's Herald," calls attention to the fact that the Whip-poor-will is often a doorstep singer. It sometimes sits on the broad stone step before the farmhouse door and calls whipowill repeatedly. When close at hand a soft cluck may be heard after each phrase. The bird may be distinguished from the Nighthawk by its shorter wings and long, rounded tail.

The Whip-poor-will is an animated insect trap. Its enormous mouth is surrounded by long bristles which form a wide fringe about the yawning cavity, and the bird flies rather low among the trees and over the undergrowth, snapping up nocturnal insects in flight. It is perhaps the greatest enemy of night moths, but is quite as destructive to May beetles and other leaf-eating beetles. Hairy caterpillars, like the tent and tussock caterpillars, as well as spanworms, grasshoppers, and ants, are sometimes eaten in large numbers.

\section{SWALLOWS.}

This family of daylight air-coursers has four common representatives in this Commonwealth. The Purple Martin, common until within a few years, is now generally rare except in migration. The illustration of the Swallow roost, although taken from a sketch made on the Musketaquid, was nevertheless suggested by Ernest Thompson Seton's beautiful drawing, now reproduced in Chapman's "Bird-Life." It shows the four common Swallows, and exhibits their habit of roosting in reeds. Swallows collect in flocks throughout the season of migration. In July, as soon as the young are reared, they begin to flock at night near bodies of water, and prepare to migrate. Swallows gather in winter in the great swamps of southern Florida in enormous flights, which, after uniting in one, discharge into the reeds at dusk. The descent of such a multitude resembles in appearance a great waterspout topped by an enormous black cloud. In the morning they, scatter out over the country to feed. 
Bank Swallow.

Riparia riparia.

Length. - A little over five inches.

Adult. - Dull mouse-brown above; white below; a broad brownish band across the breast; tail slightly forked.

Nest. - In a hole made by the bird in a sand bank.

Eggs. - White.

Season.-April to August or September.

This bird nests naturally in communities in sand banks along rivers, where the insects which form its food are plentiful. It early took advantage of man's habit of digging into the sand, and probably increased in numbers as roads and railroads were cut through the country and sandpits opened. In this State its numbers have now decreased much, owing partly to the digging away of many banks in which it formerly bred, but more to incessant persecution by egg collectors, cats, "English" Sparrows, and other predatory animals. There are many sand banks in eastern Massachusetts formerly occupied by these birds which now know them no more.

The note is a rather harsh twitter. This bird is almost entirely insectivorous, feeding on gnats, fies, grasshoppers, Tortricid moths, and many insects that are injurious to field and meadow grasses. Plant lice and spiders also form a portion of its food.

Tree Swallow, White-bellied Swallow. White-breasted Swallow. House Swallow.

Iridoprocne bicolor.

Length. - Nearly six inches.

Adult Male.-Dark irridescent blue-green above; white below; tail slightly notched.

Adult Female. - Upper parts usually duller.

Young. - Upper parts brown; a faint dusky collar across the upper breast.

Nest. - In hollow tree or bird house.

Eggs. - White.

Season.-April to October.

When the Tree Swallows left their natural homes in hollow trees to nest in bird houses they probably increased somewhat in numbers; but since the advent of the "English" Sparrow the Tree Swallows have been driven away from many of the bird houses in villages and cities where they 
formerly dwelt, and some have gone back to hollow trees. This bird is still common wherever it can nest unmolested by the Sparrows, and sometimes, though rarely, it nests in the same bird house with these impudent foreigners.

Its note is a rather sharp but sometimes musical twitter. It is probably more useful than the Bank Swallow, for it is oftener seen about houses and gardens, where it catches flies, mosquitoes, and garden insects. Leaf-eating beetles, cankerworms, cabbage butterflies, small moths, click beetles, rove beetles and other beetles, winged ants, and many other flying insects form part of its food. It usually leaves for the south in August or September, but sometimes stays much later where bayberries or sumac berries, upon which it feeds, are plentiful.

\section{Barn Swallow.}

Hirundo erythrogaster.

Length. - Six to seven inches, or a little more.

Adult.-Above, very dark blue; tail deeply forked, showing white markings when spread; forehead, throat, and upper breast chestnut; lower breast and belly buff.

Nest. - Built of mud, straw, and feathers; usually plastered to a rafter in a barn or shed.

Eggs. - White, covered with brown spots.

Season.-April to September.

The note of the Barn Swallow brings to mind visions of fields of waving grass, wide barns, and well-filled mows, for this Swallow follows the cattle. It is a bird of the pastoral country, the farm, and the hayfield. Originally it nested in caves or on rocky cliffs. The rude barns of the early settlers offered it abundant safe nesting places, while the clearing of the land and the increase of cattle augmented the numbers of its insect prey. Swallows must have multiplied wonderfully with the settlement of the country, but they have rather decreased of late years.

The twitter of this Swallow is musical; its flight is the poetry and grace of motion; its plumage is attractive to the eye; and its life is largely spent in destroying the insect foes of the farmer and his cattle. It is particularly serviceable about grass fields. The moths of the smaller cutworms, those of Arctians and Crambids, are among the injurious insects that it gleans when flying low over the grass. Every 
one who walks among the tall grass in the fields may notice how Swallows capture the moths that fly up about the foot passenger. Prof. C. H. Fernald states that while he and his friends were walking through the grass at his home at Mt. Desert several Swallows invariably attended them and fed on different species of Crambus in abundance. These observations were continued during several years. ${ }^{1}$ Codling moths, cankerworm moths, and Tortricid or leafrolling moths are gathered from the orchard by the Swallows. Horseflies, house flies, mosquitoes, gnats, and crane flies are commonly caught. The only apparently harmful habit that I have observed is that of picking up parasitic insects in flight over fields infested with army worms or cutworms.

\section{Cliff Swallow. Eaves Swallow.}

Petrochelidon lunifrons.

Length. - About six inches.

Adult. - Dark bluish above; forehead cream white and rump light chestnat;

throat chestnut; other under parts whitish; tail ends squarely.

Nest. - Built mainly of mud, under the eaves of barns or out-buildings.

Eggs. - White, spotted with reddish-brown.

Season.-April to August.

When the first explorers reached the Yellowstone and other western rivers, Swallows were found breeding on the precipitous banks. As settlers gradually worked their way westward the Swallows found nesting places under the eaves of their rough buildings. In these new breeding places they were better protected from the elements and their enemies than on their native cliffs, and so the Cliff Swallow became the "Eaves Swallow," and, following the settlements, rapidly increased in numbers and worked eastward. Audubon saw them first on the Ohio in 1815 . They were seen near Lake Champlain in 1817, at the White Mountains of New Hampshire in 1818 , at Cincinnati in 1819 , and in 1830 they had reached Winthrop and Gardiner, Me. They increased and spread rapidly over the eastern States, and probably reached their maximum in numbers from 1840 to 1860 . They were

\footnotetext{
- Professor Fernald states that the Crambids feed at the roots of grasses, and that they undoubtedly destroy a large amount of grass without being discovered. Professor Webster wrote him that in Ohio hundreds of acres of grass had been destroyed by these moths.
} 
very numerous in Massachusetts up to about 1865 , but since the introduction of the Sparrow their numbers have been slowly decreasing here, and now there are large areas where they do not breed. Apparently they are now more plentiful than ever in some parts of Maine, and possibly some of the Massachusetts birds may have migrated there.

Their ordinary note is a rather harsh chirp. Their food is very similar to that of the Barn Swallow, as they frequent similar situations. Wherever a colony of these birds is located they must have a considerable effect on insect life. They fly much over bogs and meadows, and with the Barn Srallows are useful in destroying the pests of the grass lands and cranberry bogs.

\section{Purple Martin. Black Martin.}

Progne subis.

Length. - About eight inches.

Adult Male. - Deep, lustrous steel-blue; wings and tail dark brown; tail slightly forked.

Adult Female. - Brown above, glossed on head and back with blue or purplish; forehead and throat mottled with gray; breast brownish; belly whitish.

Nest. - In a hollow tree or bird house.

Eggs. - White.

Season.-April to August.

Many years ago Dr. Brewer wrote Audubon that an unusually cold season had destroyed all the Purple Martins in the neighborhood of Boston. Since then other occurrences of this kind have been reported, but there was no permanent widespread diminution in their numbers until the "English" Sparrows became numerous. Then the Martins were gradually driven away, until they bred only locally, and had disappeared from a

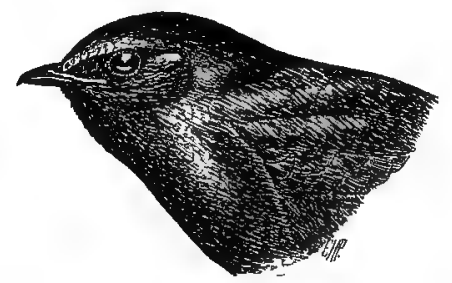

Fig. 149. - Purple Martin, male, about one-half natural size.

large part of the State. The June storms of 1903-04 nearly completed their extirpation from the State as breeders, and except in a few favored localities their boxes are now (1906) all taken by the Sparrows.

The Martin is a southern bird, and cannot long withstand 
cold storms in the breeding season. It is also one of the most purely insectivorous of all birds, and feeds almost entirely on winged insects. Therefore, when the air is cleared of flying insects by long, cold rains or hard frosts, it must starve. Its note is a full-toned chirruping carol, musical

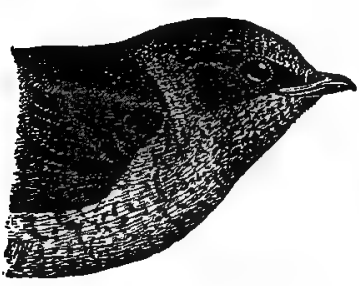

Fig. 150. - Purple Martin, female. and clear, beginning peuo-peuoреuо. It feeds largely on some of the greatest pests of the farm. Rose beetles and May beetles are caught in large numbers. John S. Russell writes that a quart of the wing cases and other rejecta of that common pest, the striped cucumber beetle, were taken from a hole in a

Martin box; and Dr. Packard makes a similar statement. House flies and flies that trouble horses and cattle are taken in considerable numbers from the sides of houses and barns. Mr. Otto Widmann states, in "Forest and Stream," that thirty-two parent Martins made three thousand, two hundred and seventy-seven visits to their young in one day, - June 27, 1884.

Every effort should be made to induce these birds to again take up their abode throughout the State. 


\section{CHAPTER $\mathrm{X}$.}

\section{BIRDS OF MARSH AND WATERSIDE.}

The birds of wet, waste lands, fresh-water meadows, marshes, swamps, and the shores of ponds and rivers seem at first sight to be of no importance from an economic point

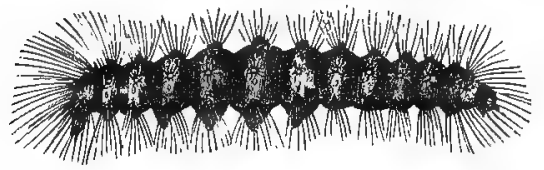

Fig. 151.-Salt-mar'sh eaterpillar. This species is eaten by marsh birds. of view. Still, most of the Marsh Wrens, Sparrows, Herons, and water-fowl that live in such localities undoubtedly help to prevent uprisings of such field pests as the army worms, the green grasshoppers, and the saltmarsh caterpillars, that sometimes multiply so in lowlands as to overrun and devastate the upland crops. The Herons are of some further service to man, for, besides eating insects, they help to prevent the undue increase of meadow mice, reptiles, and frogs. Space will not permit detailed descriptions of the marsh birds and water birds, but a brief mention may be made of some of the most important species.

\section{PERCHING BIRDS.}

Song Sparrows, Savanna Sparrows, Blackbirds, Grackles, and Bobolinks, all of which spend more or less time in wet meadows and marshes, have already been described. Swifts and Swallows hawk over meadows, marshes, streams, and ponds, but the Swamp Song Sparrow or Swamp Sparrow (Melospiza georgiana) is rarely seen far away from its favorite marshes or swamps. It is a dark species, with a chestnut cap, a whitish throat, and a

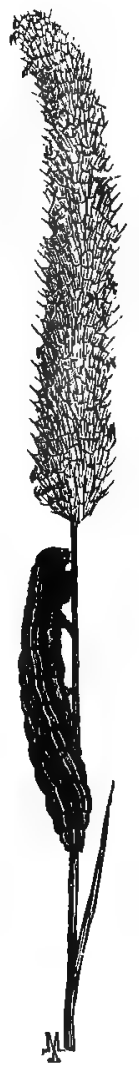

Fig. 152.Army worm. 
breast unstreaked; and it sings all summer long about the bushy margins of grassy swamps and marshes and in the reeds or bush clumps of river meadows. Its song slightly resembles that of the Chipping Sparrow, but is more varied and pretentious. Its sharp chink and busy chirping as it

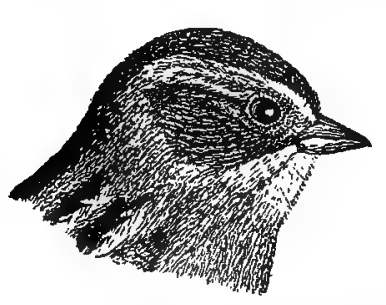

Fig. 153. - Swamp Sparrow, about two-thirds natural size. fusses about its lowly nest greet the ears of the canoeist as he floats down the placid stream.

Another bird whose song is commonly heard along the shores of marshy river's is the Longbilled Marsh Wren (Telmatodytes palustris). It is found commonly near streams along the coast, and up the river valleys of eastern Massachusetts, but is not so common in the central or western counties except along the Connecticut River. It sings among the reeds, cattails, and marsh grasses, a voluble, joyous, typical Wren song, which is kept up all day and may often be heard at night. It is an unmistakable Wren, with cocked tail and rapid, nervous motions. The Short-billed Marsh Wren (Cistothorus stellaris) is one of the smallest of birds. It is not as common as the other species, and frequents sedgy meadows and wet lands along brooks. Its song more nearly resembles that of a Sparrow than that of the typical Wren. Marsh Wrens build the little globular nests, each with an opening in the side, that are found among the cat-tails or the meadow grass.

\section{RAILS.}

Rails are confined to the shores of ponds and rivers or to marshes and wet meadows, where they skulk amid the rushes, cat-tails, grasses, and water plants, and are more often heard than seen. The old saying, "As thin as a rail," might have originally been applied to these birds, for their bodies are so thin that they readily slip between the stems of the grasses. Although no longer as plentiful as in the past, they still breed here, and many pass through the State in migration.

The two common species are the Virginia Rail (Rallus virginianus) and the Carolina or Sora Rail (Porrana caro- 
lina). The Sora is a dark, handsome bird, nearly as large as a Quail. It has the forehead, chin, and throat black, an ashy breast, and a short, yellow bill. The Virginia Rail is about an inch longer, having a long, curved bill and a lightcolored throat. Many strange notes that are heard on the marsh at morning or evening or during the night may be attributed to Rails. Both species nest close to the ground in marsh or meadow. Thin as the Rails are ordinarily, they become very fat in autumn, when they are shot in great numbers for food.

\section{HERONS.}

Every pond or stream with shallow waters has its resident or visiting Herons, and as all species of Herons are now protected by law, it is hoped that the decrease of the larger species may be arrested.

Near the seashore and the larger bodies of water a bird is sometimes seen to rise from the marsh, uttering as it flies a loud, explosive quock. It is larger than a Crow, has a blackish back and crown, a short tail, light under parts, and grayish wings. It folds its long neck, tucks its long legs up behind; and flies off slowly, its wing tips bending well downward at every stroke. This is the Black-crowned Night Heron (Nycticorax nycticorax noevius), which flies chiefly at evening, but may often be seen abroad in the daytime, particularly on cloudy days. Young birds are brown above, streaked and dotted with white, but all have the same note. They usually nest in communities on trees in swamps.

There is hardly a shallow pond or large stream in the State, remote from cities, from which one may not flush a smaller, dark-green bird, with dark, bluish wings, which rises either silently or with a sharp peok; takes a reef in its neck, stows its legs, and flies away steadily, keeping at about the same level. The downward bend to its wing tips as it flies seems to be even more pronounced than in the Night Heron. This is the Green Heron (Butorides virescens). It has several peculiar, startling notes, and an explosive, weird wowoogh, given as if in a stage whisper, that is sometimes uttered when it is perched on a tree. This species nests in trees, often singly, but sometimes in companies. 
In early spring, or in August or September, a tall, dark, lone bird may be seen stalking by some pond, along the seashore, or on tidal flats. It is far larger than other common Herons, and when it flies sometimes gives utterance to harsh, loud croaks, and spreads a pair of great wings that seem as large as those of the Eagle. This unmistakable bird is the Great Blue Heron or Blue "Crane" (as it is sometimes wrongly called) (Ardea herodias), which lives largely on fish, frogs, and meadow mice.

Another species is sometimes started from the grassy meadow or the marshy fen. This is a large brown bird, about the size of the Night Heron. The under part of its neck is distinctly streaked with brown and white, and there is a black streak on the side of the neck. It is a skulker, seeking concealment by preference, and flying only when hard pressed. Its flight is slow and awkward, and it usually does not fly high or far, but alights again among the grass or reeds of the marsh. Sometimes on rising it utters several harsh, rattling croaks. This is the American Bittern (Botaurus lentiginosus), - a bird that lives in the bog and nests there. It seldom, if ever, alights in trees. Its most common spring note consists of a series of choking, gurgling sounds, that resemble the noise made by an old-fashioned wooden pump, and may be represented by the syllables unka-chunk, repeated several times. This has given the bird the vernacular name of "plum pud'n." Sometimes at a distance only a single note can be heard, which sounds like the stroke of a mallet on a stake. Hence the name Stake Driver; but how it came by the name of Indian Hen I am unable to say. The Bittern is perhaps the most useful of all the Herons, for it frequently goes to low fields and pastures, where it industriously hunts grasshoppers and other Orthoptera. A small species, the Least Bittern (Arietta exilis), may sometimes be heard cooing in the marshes, but is seldom seen. The top of the head, back, and tail are black; elsewhere the bird is mainly brown, lighter below. It often sits erect, facing the observer, its bill pointing upward, and so it is unnoticed among the reeds or flags. Its habits are little known. 


\section{WATER-FOWL.}

We have no means of knowing how many species of water-fowl once bred about the ponds and rivers of the State, but there are now but two important species that breed here in any numbers, and one of these, the Wood Duck (Aix sponsa) (see frontispiece), is now rapidly growing rare in most of the State. This bird, of exquisite loveliness, was once the most common wild-fowl that nested along the shores of our wooded streams and ponds. It is now. protected by statute at all times; but only the most rigid enforcement of the law can save this, the most beautiful of American wild ducks, from extermination. It is not as shy as the Black Duck, and it frequents small ponds and wooded streams that afford cover to the gunner and can be easily shot across. The young are hatched in a nest in some hollow tree or stump, and are often carried to the water by the mother bird. They are fortunate if they are not all killed by some gunner as soon as they are big enough for the table. The bird is harmless, and is at times a great insect eater. It should be saved from the fate of the Passenger Pigeon, Heath Hen, and Wild Turkey.

The Black Duck (Anas obscura) is more common, and has of late somewhat increased in numbers, owing, probably, to improved and better-enforced laws for its protection. It is not, as its name implies, a black bird, but is dusky, with a lighter neck and throat. The under sides of its wings are also lighter in color. It breeds on the ground, mainly in marshes and bogs, or on islands in ponds, and is well distributed in suitable localities throughout the State. It is normally very destructive to grasshoppers, but in this State it seldom ventures far from. its fastnesses in the bog, except as it goes to the sea or large bodies of water, which give it a good outlook and some chance of safety.

The other pond and river Ducks and the Geese are mere migrants through Massachusetts. The sea Ducks are not known to be of much value to man except through the recreation their pursuit affords. The service rendered to man by sea birds is referred to on p. 80 . 


\section{CHAPTER XI.}

\section{CHECKS UPON THE INCREASE OF USEFUL BIRDS.}

He who has any doubt about the former abundance of the larger birds in Massachusetts should read the accounts published by some of the earlier voyagers and settlers regarding the great numbers of water birds, shore birds, game birds, Hawks and Eagles, Great Auks, Cranes, Herons, wild Swans, Canada Geese, Snow Geese, Brant Geese, and Turkeys, that were found, in the early years of the colony. We read of a thousand wild Turkeys reported as seen in a day, of forty Partridges seen in one tree and sixty Quail in another, of furty or fifty Ducks killed at a shot, of twelve score shore birds killed at two discharges of a fowling piece, of flocks of Passenger Pigeons that obscured the sky to the horizon in all directions, and of nesting places where for miles the trees were loaded with Pigeons' nests.

It is now well known that the Great Auk and the Labrador Duck have become extinct; that wild Turkeys, Swans, Passenger Pigeons, Cranes, and Snow Geese have practically disappeared from the State; and that the shore birds, game birds, and fresh-water Ducks have decreased tremendously in numbers. No records regarding the increase or decrease of the smaller birds have been made until within recent years, and we know only in a general way that certain species, like Swallows, Sparrows, and Robins, increased with and after the clearing and settling of the country, and that within the last half century there has been a considerable local decrease of these and other native birds, particularly about the centers of population. ${ }^{1}$ Also, it is evident that small birds are not nearly as plentiful here as they are in

. Director William T. Ḣornaday of the New York Zoölogical Park estimated, from reports received by him, that birds had decreased twenty-seven per cent. in Massachusetts during the fifteen years previous to 1898 . The result of my own inquiries regarding the decrease of birds in Massachusetts was embodied in a report of one hundred and three pages made to the State Board of Agriculture in 
some States farther west, and that they are not numerous enough to fully control the insects on which they feed.

It is certainly desirable, then, to take measures to increase the number of useful birds, and any inexpensive means of accomplishing this end is worthy the most careful consideration of thoughtful people.

When one is asked what controls the numbers of birds, he finds himself at a loss for a ready answer. There are many well-understood checks upon their increase; others are more obscure. We can understand, for example, why the larger game birds and shore birds have decreased in numbers; but it is difficult to see why the Dickcissel or Black-throated Bunting has disappeared from the Atlantic seaboard and is now seldom found east of the Alleghanies, why the Red-headed Woodpecker has so nearly disappeared from Massachusetts, or why certain resident species as well as certain migratory species are common one season and uncommon the next.

To effectually protect birds we must first understand the chief causes of mortality among them. Comparatively few wild birds die from disease or old age. Most of them perish from lack of food, the severity of the elements, or the attacks of their enemies. The destruction of birds by storms, great and widespread as it is, probably never occurs óver regions extensive enough to utterly exterminate any species. Their destruction by starvation and cold is usually coextensive only with the area of severest storm. Under normal conditions the decimated species usually repopulate the country in a few years. Many young birds are killed by storms in the nesting season. Many migrating birds are blown into the sea and drowned. Fortunately for the birds, they are ordinarily enabled by migration to avoid the severity of winter ; but they are unable in this way to escape the destructive agencies set at work by man along their lines of migration. In annual, perennial, widespread, and complete bird destruction, man takes the lead among all other forces of nature.

1905; and as copies of this report-The Decrease of Certain Birds and its Causes; with Suggestions for Bird Protection - can be obtained of the secretary of the Board at the State House, its conclusions will not be reiterated here. 


\section{THE DESTRUCTION OF BIRDS BY MAN.}

Man is responsible for the extinction of species or for their disappearance from great tracts of country. He cuts down the forest and drives out the larger wood birds. $\mathrm{He}$ destroys the birds that injure his crops or flocks. He introduces animals which destroy birds, and he shoots birds for food, money, or sport. It is only since civilized man reached this country that the Great Auk has become extinct, and that the Passenger Pigeon, which roamed in countless millions over a continent, has been swept away. It is since then that the Prairie Chicken, once found in the east, and so plentiful in Kentucky that it was considered fit food for slaves and swine only, has been pushed toward the far west. The wild Turkey has been nearly driven out of the Atlantic States by man. The White Egret and the Carolina Parrot have almost disappeared. The Bartramian Sandpiper or Upland Plover, the Wood Duck, and the Woodcock must follow if not fully protected. Man exterminates birds for money, little recking that he is killing the "goose that lays the golden egg."

The greatest enemies of game birds, and, therefore, the greatest factors in their extermination, are the epicures, the people who buy birds to eat. The marketmen merely supply the existing demand. The call for game birds has been so insistent and the price paid for them so remunerative that marketmen have often organized to defeat legislation for the protection of game. Observing people who have frequented the markets have read from the butcher's stall the story of the decrease of game birds. Within thirty years, tons of Passenger Pigeons have stood in barrels in the Buston market, and men now living can remember when the eastern markets were glutted with Quail and Prairie Chickens. The war of extermination waged on game birds is a blot on the history of American civilization. It is paralleled only by the destruction of birds for millinery purposes, which has some shockingly cruel aspects.

Here again the dealers - the milliners - are not so much to blame as the public, for the former cater to the wants of women only as fashion dictates. In civilization we still 
cling to our rings, beads, and feathers, - the ornaments of the savage. Within thirty-five years the skins of Bluebirds, Scarlet Tanagers, and Baltimore Orioles have been in good demand in Massachusetts for hat ornaments. The brutal savagery which is characteristic of this phase of bird destruction has been well illustrated in the extermination of the Egrets of the United States. Twenty-five years ago these beautiful birds were abundant in some southern States; stragglers occasionally came north as far as New England. They are shy birds during most of the year, feeding chiefly in deep swamps and along lonely water courses. In the breeding season they gather into heronries, commonly called "rookeries," where they build their nests. Then much of their shyness disappears under the stress of providing for and protecting their young. Unfortunately for them, their nuptial plumes are perfect in the breeding season. Fashion demanded the plumes. Nesting time was the plume hunter's opportunity. There was little difficulty, then, in securing the birds by shooting them when they were sitting on the nests or hovering over their helpless young. So the old birds were shot, the plumes stripped from their backs, and the young left to starve in the nests or become the prey of Hawks, Crows, or Vultures. When I was in Florida, in 1878, great flights of these birds were seen along the lakes and rivers of the southern counties. One heronry was estimated to contain three million birds. Ten years later they were rare everywhere, and now they are practically extirpated. They have been pursued along the coasts of Mexico and into Central and South America. The search is extending into all countries where they may be found. Half-savage Indians and negroes are enlisted in the slaughter, supplied with guns and ammunition, and sent wherever they can find the birds. The misery and suffering entailed can be imagined. Thus are the "stub" plumes, "aigrettes," and "ospreys" procured. They are not manufactured, and, whatever their color when sold, they were originally stripped from the back, head, or neck of some white Heron or Egret. The absolute extinction of these plume-bearing species is assured unless women will stop wearing the plumes. A similar slaughter took place 
among the sea birds along the Atlantic coasts. 'The birds were shot down on their breeding grounds and their wings cut off. Many human lives have been lost by reason of this nefarious business. In 1905 a warden employed by the National Association of Audubon Societies to protect the birds was murdered by plume hunters. The reader may be spared further details of this barbarous trade.

The number of birds killed in the United States each year before the business was checked by law and public sentiment cannot be even estimated, but some figures can be given. A single local taxidermist handled thirty thousand bird skins in one year. A collector brought back eleven thousand skins from a three months' trip. About seventy thousand bird skins were sent to New York from a small district on Long Island in about four months. American bird skins were shipped to London and Paris. We may judge of the demand there for birds from the fact that from one auction room in London there were sold in three months over four hundred thousand bird skins from America and over three hundred and fifty thousand from India. One New York firm had a contract to supply forty thousand skins to a Paris firm.

In Massachusetts this trade bore most heavily upon the Gulls and Terns, which were driven out from many breeding places along the coast. From 1870 to 1890 this business was at its height in this country; and, as the market in Europe is still brisk, no doubt some birds are still killed here for millinery purposes, and some are still worn here, despite the laws which prohibit any one from killing native birds or selling or wearing their feathers.

The danger to birds multiplies with the increase of population. Gunners and sportsmen shoot birds mainly to supply the markets or for recreation; but many persons shoot birds, large or small, merely for sport or practice. There is a class of foreigners who shoot small birds for sport, and eat them. These people go out in squads, and each man shoots at every bird within range, whether sitting or flying. The Italians are tremendously destructive to bird life. In southern Europe the larger birds are now so scarce 



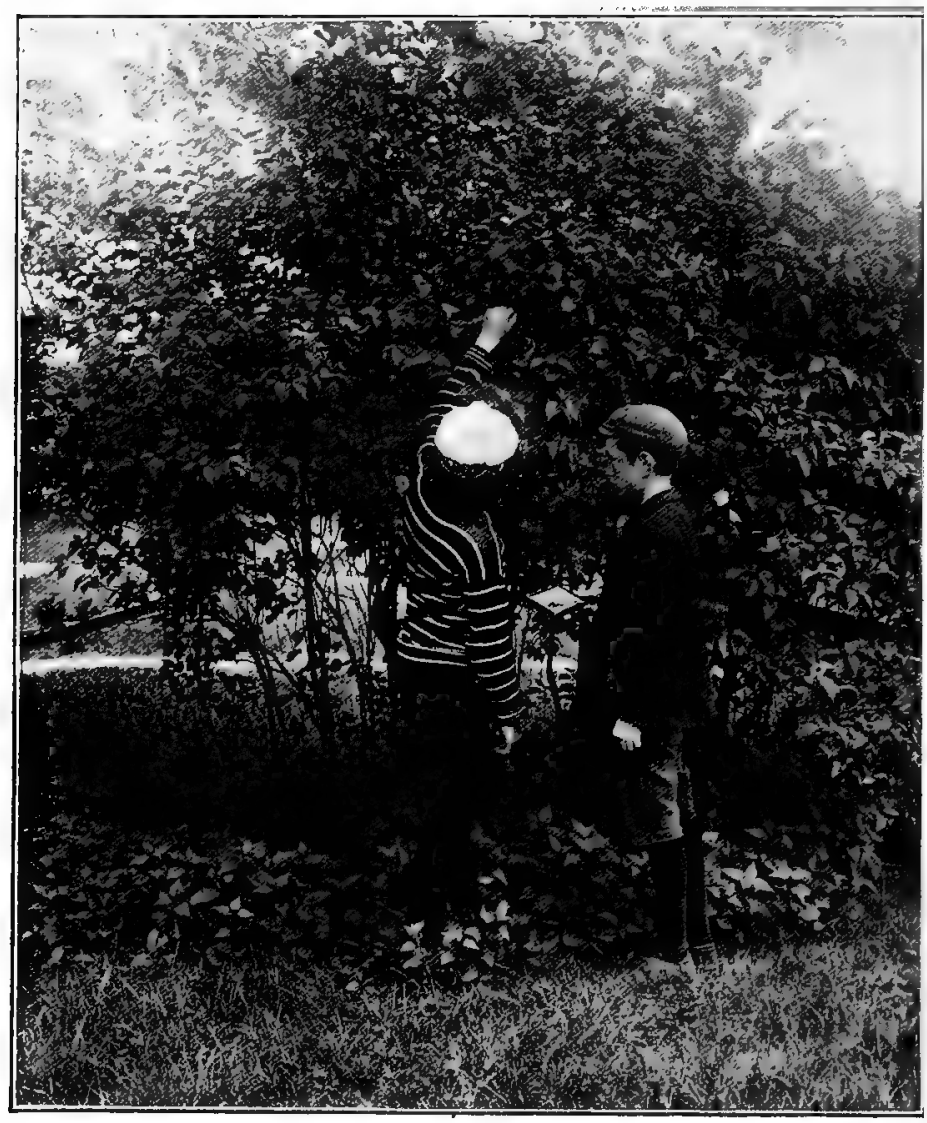

PLATE XXXIII. - Nest Robbers. A cause of the decrease of birds in many localities. (Photograph by A. C. Dike.) 
that the people have taken to killing the smaller species, and the killing of small birds is regarded as sport. An Italian sportsman will secure a small live $O w l$, fasten it on a pole to attract the birds, take his station near by, and shoot every small bird that appears; poachers stretch great nets in places where birds come to feed or drink; and thus the small birds that are reared under protection in northern Europe are slaughtered on their migrations in the south. The steady stream of immigration from Italy to America constitutes $\dot{a}$ great menace to the smaller birds, as well as to all birds and all animals that are eatable. Unless this element of population is prohibited from carrying guns, the effect of their inroads upon bird life will soon

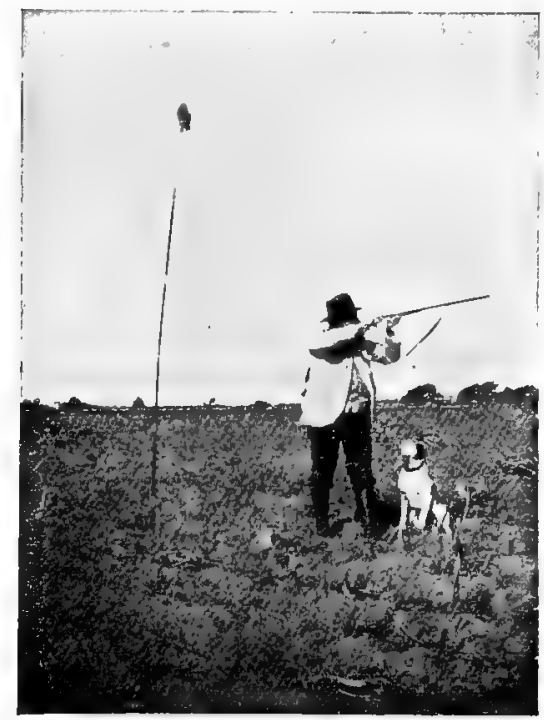

F'ig. 154. - The Italian sportsman and his decoy Oivl. (From Bird-Lore.)

be manifest here. Trustworthy correspondents state that the Italian contract laborers kill practically all the birds in the neighborhood of their camps. Many Italians trap birds by means of birdlime or trap cages. Boys with shot guns, "air rifles," and various destructive weapons, shoot at anything that offers a fair mark. The improvement in firearms and the reduction in their price go hand in hand with the constant increase in the number of people able to bear arms, the augmentation of the number of crack shots, and the accession to the number of dogs trained to hunt birds.

Snares are still much used, even where forbidden by law. Children, especially boys, destroy the nests and eggs of birds, thus constituting a considerable check on bird increase. The mania for collecting birds' eggs is widespread. Some boys use the nests of birds for targets and their eggs 
for missiles in the same spirit in which such young savages murder the toads about a pond. Something is wrong with a system of education under which such wholesale abuses of useful creatares are possible.

There are many indirect ways in which man reduces the numbers of birds. Marshes are drained, and the sustenance of marsh birds destroyed. Reservoirs are made, and the haunts of land birds overflowed. The building of dams for manufacturing purposes holds back the waters of rivers, so that heavy rainfalls in the breeding season flood the nests of many marsh birds, destroying eggs and young. Thus Rails, Bitterns, and Marsh Wrens are drowned or driven away. Thousands of birds and their nests are burned by fires in the woods. Swifts are sometimes suffocated in numbers by coal tires built in nesting time. Lighthouses and electric light towers are the obstacles on which many birds are dashed to death in their nocturnal migrations. Telegraph, electric light, trolley car, and telephone wires are all deadly; their number is constantly increasing. Thousands of Woodcocks and many other birds are killed by flying against them. Wire fences are nearly as fatal to Grouse and other low-flying birds.

Last but perhaps not least among the causes which decrease the number of birds about the centers of population there must be enumerated the clearing up of underbrush, shrubbery, vines, and thickets. Many birds of the tangle are driven out when this cover is destroyed and replaced by well-kept lawns and fields. The work against the gipsy moth and the brown-tail moth, necessary as it is, has reduced the number of birds in many localities because of the clearing up and burning of undergrowth and the thinning out of trees, which had to be done. Where the caterpillars of these moths have defoliated large tracts of wooded country this also has decreased the birds, for it has left their nests exposed to the sun and to their enemies. Several correspondents have expressed the opinion that birds are killed by the use of arsenical insecticides, such as Paris green and arsenate of lead, in spraying. Dead birds have been picked up in different localities soon after orchard or shade trees have been 


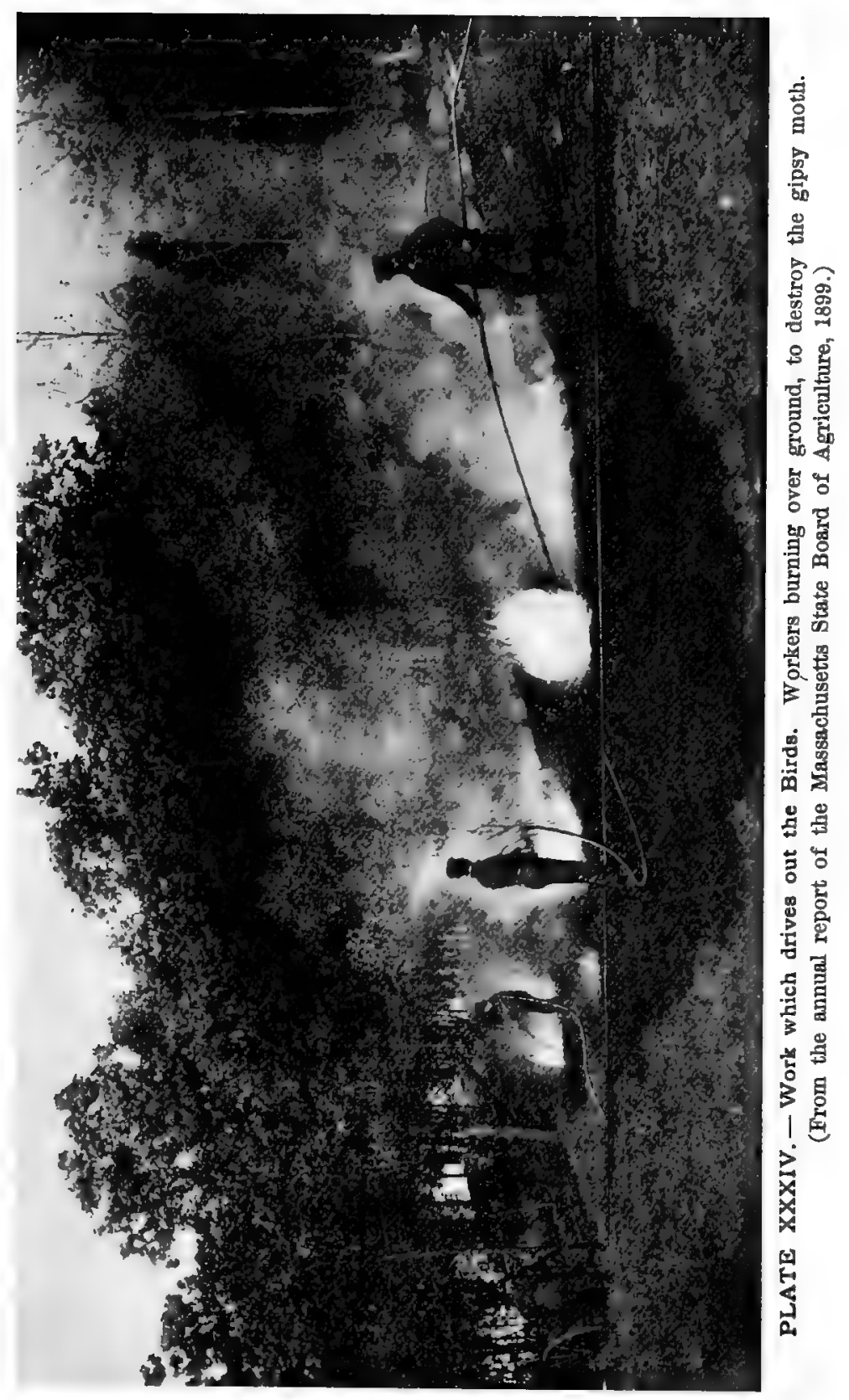



sprayed. Mr. Robert Ridgway noticed that birds decreased very much in numbers in a section of Illinois where practically all the farmers began spraying their orchards; but in a recent letter he expresses some doubt as to whether spraying, or a bounty crusade against the Sparrows, caused the diminution of birds. The reduction of birds in such cases may perhaps be explained by the fact that the insects had been destroyed by spraying, leaving the birds without food. Mr. William Brewster has observed two instances where the spraying of shade trees caused a sudden decrease in the numbers of birds, and in both cases several dead birds were found. The stomachs of some of these birds are to be examined for traces of arsenic, and this ought to determine whether they have been poisoned. Birds usually reject sickly insects, and would not be likely to eat those which showed the effects of poison; but gipsy caterpillars will carry more poison in proportion to their size than would kill a man, and they will still appear healthy. It has been noticed in some cases that birds have avoided trees that have been sprayed with arsenate of lead, but in other cases they have not. This subject should be further investigated.

\section{THE NATURAL ENEMIES OF BIRDS.}

Under nature, the indigenous natural enemies of birds cannot be regarded as the cause of any material reduction in the numbers of the smaller species. Under man's rule, however, the conditions may be so changed that certain natural enemies of birds may become positively harmful. For this reason, if for no other, the bird protectionist should carefully study the effect produced upon birds by their enemies. Any natural enemy of birds which becomes unduly numerous may prove seriously restrictive to their increase, and may require severe checking.

Foreign species introduced and liberated in a new country may constitute a serious danger to bird life. Still, many people have deliberately introduced mammals and birds from other countries and liberated them here. Fortunately, perhaps, few of these attempts to saddle foreign species upon us have proved successful. There can be but little objection 
to the introduction of domesticated species so long as they can be kept in subjection; neither can there be much danger in introducing game birds, except that they may replace our native species, which, rather, we should try to foster and increase in numbers; but there is often a possibility that any introduced bird or mammal that will bring no money to the pocket of the hunter or marketman may become a pest. We have had such an experience with the "English" Sparrow, and we may yet regret the more recent importation of the European Starling. The plague of rablits in Australia and that of the mongoose in the Island of Jamaica illustrate the danger of introducing species.

If the money, time, and thought that have been expended in this work by acclimatization societies and by individuals could have been utilized in protecting, domesticating, and propagating useful native species, it might have given better results.

\section{INTRODUCED FOUR-FOOTED ENEMIES.}

Cats.

We have already introduced into this country a terrible scourge to birds, - the domestic cat. My statement heretofore published, that the mature cat in good hunting grounds kills, on the average, fifty birds a year, is certainly within bounds. Kittens and half-grown cats do not catch many birds, but the old eat that wanders off into the fields and woods is terribly destructive. Of course where there are many cats each one cannot kill so many birds, for there are not enough birds to furnish each cat its full quota. Mr. William Brewster tells of an acquaintance in Maine who said that his cat killed about fifty birds a year. When asked why he did not get another cat, he said that it would be of no use, for they were all alike. Mr. A. C. Dike writes that his family owned a cat which was well cared for and a particular pet. They watched it through one season, and found that it killed fifty-eight birds, including the young in five nests. Nearly a hundred correspondents scattered through all the counties of the State report the cat as one of the greatest enemies of birds. The reports that have come in of the torturing and killing of birds by cats are absolutely 


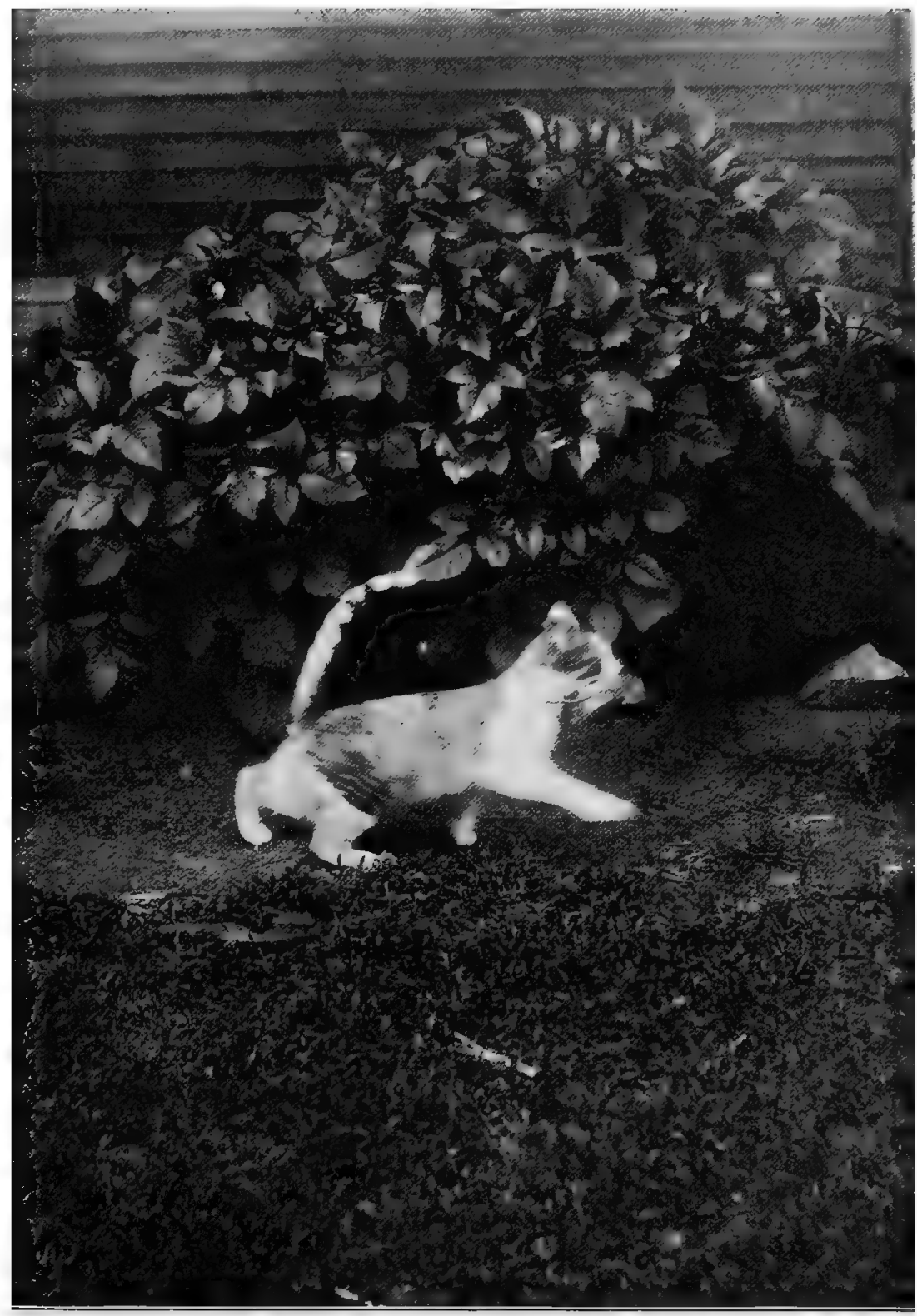

PLATE XXXV. - Cat with Young Robin. This pet cat killed fifty-eight birds in one year. (Photograph, from life, by A. C. Dike.) 

sickening. The number of birds killed by them in this State is appalling.

It is quite true, however, that some cats do not kill many birds, and that some intelligent or high-bred cats may be taught not to kill any. Some cat lovers believe that each cat kills on the average not more than ten birds a year; but I have learned of two instances where more than that number were killed in a single day, and another where seven were killed. If we assume, however, that the average cat on the farm kills but ten birds a year, and that there is one cat to each farm in Massachusetts, we have, in round numbers, seventy thousand cats killing seven hundred thousand birds annually. ${ }^{1}$

If we add to the cats kept on farms the enormous number of village and city cats, many of which have good opportunities for catching birds, we shall see the chief reason for great mortality to birds and their young about our villages and cities. If cats are allowed their liberty at night during the nesting season, they, unnoticed, rob many birds' nests. The cat is more dangerous to birds than is any native mammal that roams our woods, for it is nocturnal, a splendid climber, a good stalker, a strong leaper, and is very quick and active. Unfortunately, the cat is only half domesticated, and easily goes back to a wild state. If the dog loses its master it will soon find another, but the mature cat is more likely to run wild. Thousands of these wild or half-wild cats roam the country; destroying game birds, squirrels, field mice, chickens, and any animal they can master. The effect produced by cats is convincingly shown where they have been introduced on islands, and have nearly exterminated rabbits and greatly decreased the numbers of birds. John Burroughs says that cats probably destroy more birds than all other animals combined. William Dutcher, president of the National Association of Audubon Societies, considers the wild house cat one of the greatest causes of bird destruction known. He says that the boy with the air gun is not in the same class with the cat.

1 Probably there are some farms on which no cats are kept, but on one farm in Worcester County thirteen are quartered and on another sixteen. 
Possibly no individual cat can kill as many birds in a season as a single Cooper's Hawk, but there are probably a hundred cats in the State to each bird Hawk. A friend who was raising Pheasants near a village was obliged to kill more than two hundred cats in a few years. Another Pheasant raiser, far from any village, found it necessary to kill about two hundred wandering cats the first year. He was troubled by Hawks also, but the number seen and killed was comparatively small. Such evidence goes to show that the cat is particularly attracted by young birds. Dogs are less destructive than cats, but they kill some birds, and eat some birds' eggs.

\section{NATIVE FOUR-FOOTED ENEMIES.}

There is something to be said against the fox, raccoon, mink, skunk, and weasel as enemies of birds, but none of these animals do much harm unless they are unusually abundant. In that case any one of them may become pernicious. This is most true of the fox and the weasel and least true of the skunk, which is a great insect killer. Nevertheless, the fox and the weasel kill many mice and other small mammals, and so are of some service to the farmer. The relation of squirrels to birds is more important.

\section{Squirrels.}

Some individual squirrels are habitual nest robbers. This includes all species, but the red squirrel is the worst culprit. Where squirrels have the nest-robbing habit they may do more harm among birds than any other mammal except the cat. They are active, can climb to almost any bird's nest, and can defend themselves when attacked by the parent birds. Red squirrels and gray squirrels will rob nests either on the ground or in trees, taking eggs or young as they find them. The chipmunk usually molests only those nests that are on or near the ground.

The squirrels about my home in Wareham have this habit to some extent. It may have been acquired, but in one case, at least, it seems to have been inherited or instinctive. Some young red squirrels were taken from the nest 
before their eyes were opened, and while they were still taking their mother's milk, and could never have tasted birds or eggs. They were afterwards given to Mr. C. Allan Lyford, and reared in a cage at Worcester. One day, when they were well grown, one was given its liberty. The first thing it did was to climb an apple tree, go to a Robin's nest, and begin eating out the brains of a young bird. However, its eagerness for fresh meat may have been caused by a lack of animal food in its cage diet. This habit of killing young birds has been reported from several counties in the State, and must be widespread. Squirrels are quite carnivorous. When meat is put up on trees for birds, squirrel.s frequently come and eat it; also, they are destructive to apples, pears, cherries, strawberries, and sometimes even to grapes, and they dig up seed corn in planting time; but they have two good habits, - they plant trees and they eat insects. Once in summer, when there were no nuts, acorns, or buds for squirrels to eat, I saw a gray squirrel in the woods go over a black oak about fifty feet in height, searching systematically, branch by branch, with its nose close to the bark, and apparently catching about all the insects resting there. It went to a brown-tail moth web, and spent some time there. I distinctly saw one caterpillar in its mouth. The tree had been considerably infested by leaf hoppers and caterpillars. As it had a small top, and could easily be examined, I climbed and inspected it after the squirrel had gone. My search occupied about half an hour. The smooth, clean bark formed a dark, glossy background, on which insects could plainly be seen, and the foliage was thin, and not hard to examine; but I could find only about a dozen insects, and no brown-tail caterpillars. Since then I have observed other similar cases. It is not so widely known that squirrels eat insects as that they rob birds' nests. Possibly their virtues may balance their faults; but we shall never be able to determine their economic position until a thorough study of their food habits can be made. 


\section{Rats and Mice.}

Rats and mice kill some birds. Probably the tree-climbing white-footed or deer mouse is one of the greatest enemies that birds have among these smaller rodents, but under natural conditions it is held in check by Owls.

\section{FEATHERED ENEMIES.}

Eagles are growing rare, and the more common Bald Eagle feeds mainly on fish, hence it need not be reckoned among the enemies of birds, although it may kill a féw crippled Ducks.

Hawks.

A very few species of Hawks are probably the most destructive native natural enemies of birds. All other Hawks kill comparatively few. The Falcons, which are represented here by three species, the Sparrow Hawk (Falco sparverivus), the Pigeon Hawk (Falco columbarius), and the Duck Hawk (Falco peregrinus anatun ), are pernicious. None of these, however, are very common in the State, and for this reason, mainly, their depredations are not to be compared with those of the bird-killing Hawks. The Sparrow Hawk, a great insect killer, kills fewer birds than either of the others, and is regarded as a friend to the farmer. The other two Falcons are uncommon or rare, and therefore kill few birds in this State; but there are three species of pernicious Hawks: the American Goshawk (Accipiter atricapillus), the Cooper's Hawk or "Partridge Hawk" (Accipiter cooperii), and the Sharp-shinned Hawk or "Chicken Hawk" (Accipiter velox). The Goshawk is an uncommon or periodical winter visitant, but the other two are fairly common, and individually are probably the most destructive of all the natural enemies of birds. They are slaty or bluish above, with rather short, rounded wings, and long tails. When flying at any heignt they progress by alternate periods of flapping and soaring. They may be known by their shape and by their manner of tlight.

The Buzzards, or Hen Hawks, so called, get comparatively few birds, but some individuals kill poultry. The Red- 



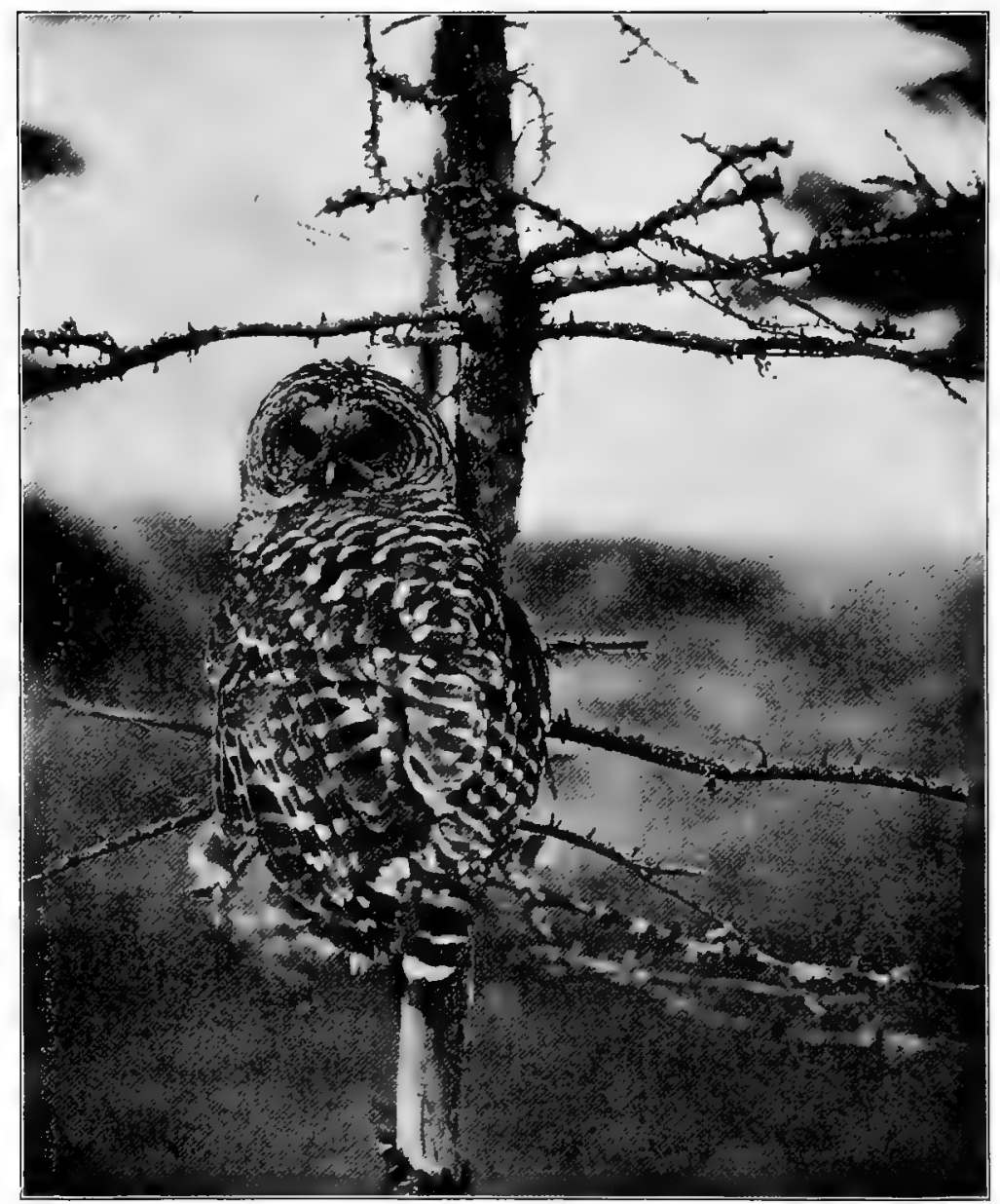

PLATE XXXVI. - Barred Owl. (Photograph, from life, by C. A. Reed.) (From American Ornithology.) 
shouldered Hawk (Buteo lineatus) is the most common and also the most useful. This species feeds largely on meadow mice. All the Buzzards are very destructive to field mice or other small rodents, and on the whole may be regarded as useful to the farmer. These are the large Hawks, with long, broad wings, that are often seen soaring in circles.

The Marsh Hawk or Bog Hawk (Circus hudsonius), a long, slender bird, the male of which is very light in color, and the female brown with a white rump, is often seen flying low over the meadows. This bird also is a great destroyer of meadow mice, and is in general very useful.

\section{Owls.}

All the Owls kill birds, but most species kill but few, and live mainly on mammals, particularly rodents like mice, rabbits, and hares, on the increase of which they constitute an effectual check. The Snowy Owl (Nyctea nyctea) and the Hawk Owl (Surnia ulula caparoch) are rather rare winter visitors; but the Great Horned Owl (Bubo virginianus), our largest resident species, is a great feeder on skunks, "cotton-tail" rabbits, and mice, although it also kills some game birds and small birds. This is the Owl that hoots in the winter woods, $H \bar{n} \bar{o}^{\prime}$ hoo hoo, $H_{\bar{o}} \bar{o}^{\prime}$ hoo hoo, Whōo'. It is often called the Cat $\mathrm{OWl}$, because of its long ear tufts ; or the Hoot $\mathrm{Owl}$, because of its lugubrious cries.

The Barred Owl (Syrnium varium) is another large Owl that hoots lugubriously, but its call usually ends with a hollow hoo'aw, given with a falling inflection. It has a large, round head, without ear tufts, and is barred with brown across its whitish breast. This bird is also a mouse eater, but, like the Great Horned Owl, it kills some poultry and game.

The Short-eared $\mathrm{Owl}$ (Asio accipitrinus) is a medium-sized Owl, light yellowish-brown in color, streaked with blackish above and colored plain buff below. It lives much about meadows and marshes, where it hawks around in the dusk as the Marsh Hawk does by day, quietly picking up mice. It seems to be a very silent bird, and its long wings carry it about in soundless flight, to the undoing of its prey. At times it kills a good many small Sparrows on the marsh. 
The American Long-eared Owl (Asio wilsonianus) is a bird of similar size and shape, but with a trifle larger head, and very long ear tufts rising from near the middle of it. It is dark brown above and light below. This is a longwinged bird of the woods, a night hunter, hiding in thick foliage of coniferous trees by day. It is a great killer of wood mice and nocturnal insects, and kills a few birds.

The Screech Owl (Megascops asio), the smallest of the eared Owls, is hardly as large as a Quail. It has two color phases that are not attributable to age or sex, some individuals being reddish in color, while others are gray. Its wailing cries are frequently heard about orchards in towns and villages, as well as in the woods, and it commonly nests in hollow orchard trees. This is one of the most useful of all Owls. It is very destructive to moths, caterpillars, and beetles, as well as wood mice and field mice. In winter it enters barns and sheds, where it kills mice, and sometimes when driven by hunger it kills and eats Doves. During the breeding season it kills some small birds, particularly if mice are not plentiful enough to furnish an abundance of food for its young.

The Saw-whet or Acadian Owl (Nyctala acadica) is a little brown Owl, with no eartufts. It is the smallest of all the native species of Massachusetts. It is rather uncommon, but very useful, as it feeds mainly on mice and insects and rather rarely on birds.

The Barn Owl, perhaps the most useful of the family, is rare here.

On the whole, while. Owls must be ranked among the enemies of small birds, they usually do so much more good than they do harm that only under exceptional conditions can they be regarded as injurious, although the Horned Owl is commonly considered pernicious because of its destruction of game.

Crows and Jays.

The Crows, Jays, and Magpies have acquired a world-wide reputation as nest robbers. The common Crow and the Blue Jay manage to live up to their reputation. My report on the Crow and some additional notes on the destructiveness 



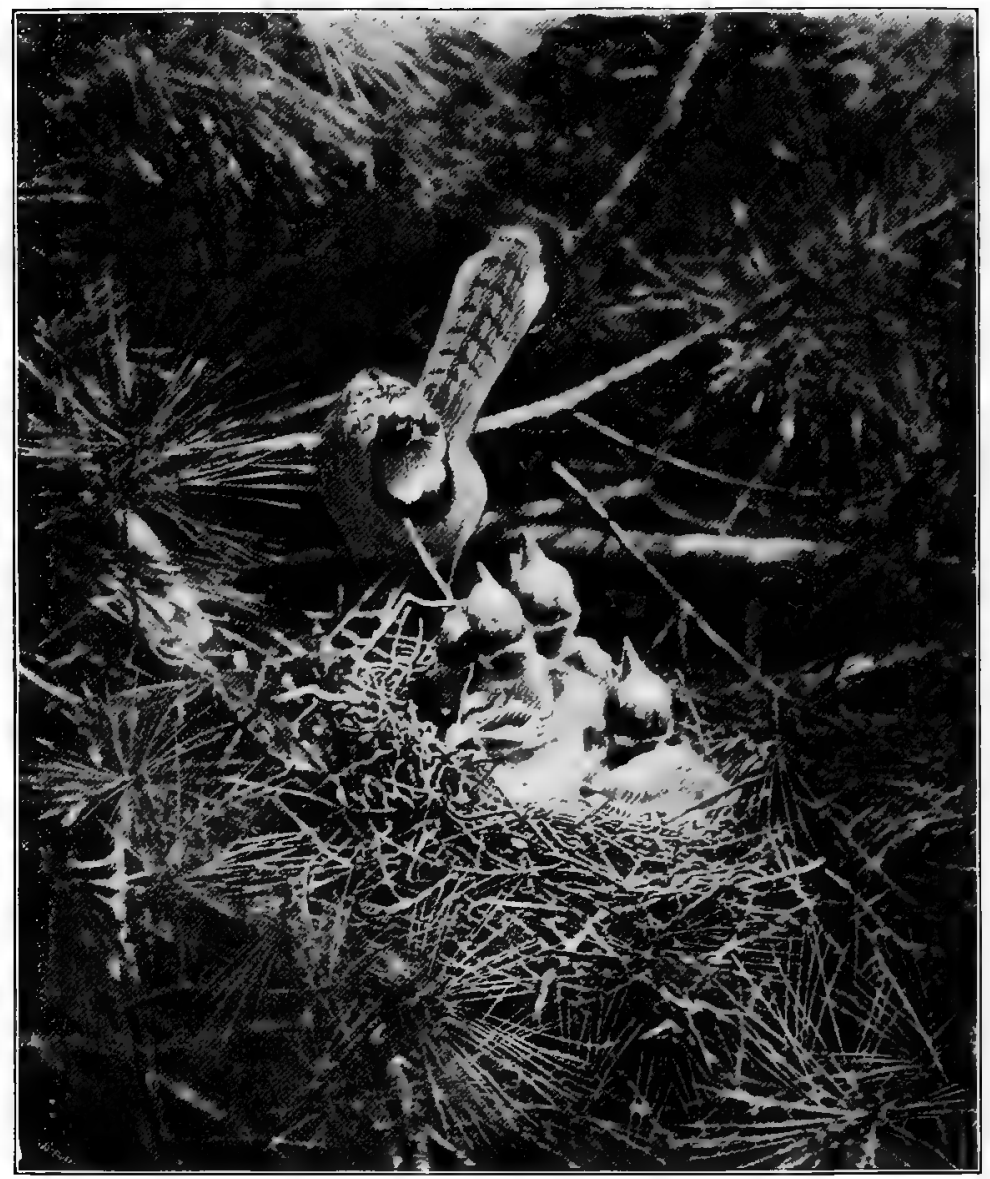

PLATE XXXVII. - Blue Jay's Nest in Author's Grove. (Photograph, from life, by C. A. Reed.) (From American Ornithology.) 
of both Crow and Jay have been published elsewhere. ${ }^{1}$ The American Crow (Corvus americanus) is a most deadly enemy to birds from the size of the Chipping Sparrow to that of the Night Heron, Ruffed Grouse, and Black Duck, for it continually steals the eggs and young of such birds and poultry. The evidence on this point is so convincing and voluminous that it is impossible to avoid this conclusion, although it is quite probable that only certain individual Crows are the criminals. Crows not only destroy eggs and young birds; but they have been known to band together to hunt down and kill adult birds as large as the Ruffed Grouse.

The well-known Blue Jay (Cyanocitta cristata) is destructive to the eggs of the smaller birds, whose nests it robs systematically, and it has frequently been seen to kill the young. The Robin and other larger birds will drive the Jay away from their nests, but it often succeeds in robbing them by stealth. Vireos, Warblers, and Sparrows it regards very little, and plunders their nests without noticing their agonized cries. Jays and Crows together sometimes make it very difficult for other birds to raise any young. It would not be advisable to exterminate the Crow, for it has many useful habits; but it should not be allowed to increase at the expense of the smaller birds. Crows are valuable as grasshopper killers, and they are destructive to the gipsy moth. Jays eat the eggs of the tent caterpillar moth, and the larvæ of the gipsy moth and other hairy cater-

1 See The Crow in Massachusetts, Annual Report of the Massachusetts State Board of Agriculture, 1896, pp. 285-289; Two Years with the Birds on a Farm, Tbid., 1902, pp. 147-149; and The Decrease of Certain Birds, Ibid., 1904, pp. 498502 . 
pillars. Mr. S. Waldo Bailey informs me that Blue Jays tear open the winter webs of the brown-tail moth and eat the young larvæ.

The House Sparrow.

The House or "English" Sparrow (Passer domesticus) is the only one of the smaller birds that has repeatedly been seen to destroy the nests of other birds, break their eggs, kill their young, mob them, and drive them avay from their homes. It occupies the houses of Bluebirds, Martins, Swallows, and Wrens, and the. nests of Barn Swallows, Cliff Swallows, and Bank Swallows, and, by persistency and force of numbers, drives the owners away. All careful observers who have watched the Sparrow ever since its introduction, and have noted the effect produced upon other birds by its presence, agree that it is pernicious.

Being a small bird, it necessarily eats many insects ; but it lives more on grain and less on insects than any of the native birds that it supplants, and is one of the few species that deserves no consideration at the hands of the farmer.

\section{Shrikes.}

The Shrikes or Butcher Birds are regarded as beneficial; but our winter visitor, the Northern Shrike (Lanius borealis), kills many small birds. It pursues Tree Sparrows,

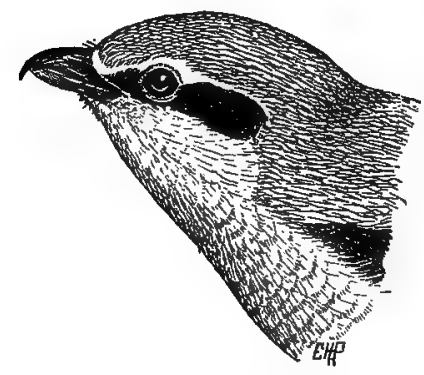

Fig. 156. - Northern Shrike, one-half natural size. Juncos, Song Sparrows, and Chickadees, overtakes and strikes them while they are in flight, sometimes eating them, but oftener leaving them to hang on trees, where they furnish food for other birds. When one sees the little Butcher killing Chickadees and hanging them up, his faith in its usefulness receives a great shock. Shrikes are probably of less value here than in their northern homes, where in summer they feed much on insects. Their chief utility while here consists in their mouse-hunting proclivities. 
Other Bird Enemies.

Some Gulls and the larger Grackles or Crow Blackbirds are accused, with some justice, of nest robbing. There seems to be little satisfactory evidence against the Cuckoos, except the general aversion shown toward them by other birds.

Probably individuals of many species occasionally eat the eggs of other birds or molest their nests, as do the Wrens. Since we have acquitted the Catbird of the charge of robbing birds' nests, it is only fair to state that John Burroughs writes that he saw a Catbird in the act. Still, we cannot conclude that this is a common habit with the Catbird; it is probably exceptional, as with the Oriole. While all the smaller birds have their quarrels, it is not probable that many of them seriously molest other species.

\section{REPTILIAN ENEMIES.}

All the common snakes, except, perhaps, the little green snake, eat birds and eggs. Birds exhibit great dread of snakes, but the Brown Thrasher or the Catbird will attack them bravely in defence of their young. Some birds seem to be incapacitated by terror when a snake appears at the nest, and are rendered incapable of any effectual defence. The common black snake is the greatest enemy the birds have among native Ophidians, for it climbs trees with the greatest ease, and is so swift that it is able to catch young birds when they first leave the nest; and sometimes it strikes down an anxious parent.

\section{FISH.}

Large trout, bass, pickerel, or pike occasionally catch young birds that fall into the water, and young water birds while swimming are often in danger from them. Older birds learn to avoid the rush of the fish. I have seen a Grebe spring into the air to escape a pickerel that darted at its feet.

With this brief glance at the reasons for the decrease of birds, and this enumeration of the natural enemies which serve to regulate the increase in the numbers of birds, we may now turn to the problem of bird protection. 


\section{CHAPTER XII.}

\section{THE PROTECTION OF BIRDS.}

The first and most important step in bird protection to be taken by the individual is to attract the birds about his home, and endeavor to increase their numbers. The farmer is especially well situated to do this. His garden, orchard, and fertile fields lie about his buildings; and birds under protection naturally gather about the farm home. The dweller in a village or a city suburb is also well situated for bird protection, proyided he can fence out the cat and suppress the Sparrow, for there the natural enemies that live in the woods are absent, and the gunner is shut out. Some of the most successful bird colonies have been established in city gardens. Birds about the home can be readily watched and protected at all seasons; their habits, their wants, and their enemies can be observed and studied; safe nesting places can be provided, and each colony thus established sends out annually many young birds to populate the surrounding region. This accomplished, with little expense and trouble, the farmer or gardener is the gainer, for birds are not now generally numerous enough to keep down the insects in our orchards, gardens, and fields, or to hold in check the weeds in our cultivated grounds. If, however, by furnishing extra food and nesting facilities, we can attract about our homes more birds than the land normally supports, and there maintain them, they will form a very effective check on both weeds and insects.

It may be difficult for the individual to secure a permanent increase of migratory insectivorous birds on his farmstead, for most of the young that are reared becdme victims of casualties during migration; but he can increase the number and size of the broods reared on his place, and thus augment the summer bird population, and he can double the usual number of winter visitants found there. He may do much 
better than this. Prof. C. F. Hodge has in three years been able to show an increase of three hundred per cent. in the native bird population of a city block. Whenever the best methods of attracting and protecting birds become generally known and practised, a general increase of birds, and a consequent great benefit to the farmer, must result.

\section{METHODS OF ATTRACTING BIRDS.}

He who is about to purchase a farm or a country place may, by keeping in mind the natural features which attract birds, secure a location perfectly adapted to their wants. Such a place should be so situated as to provide shelter from cold, northerly winds and storms. It must be 'well watered, and should be provided with small patches of coniferous trees, and windbreaks of trees, shrubs, and vines. Large groves of pines or other conifers are not particularly desirable, as they provide nesting places for Crows, Jays, Hawks, and other enemies of small birds. It should have a great diversity of vegetation, including a variety of fruitbearing plants. A portion of the land should be wooded. If there are too many trees, they may be cut in much less time than it takes to grow them; and those trees, shrubs, and vines that are especially attractive to birds may be left. It is well to leave some dead trees or dead limbs in which the Woodpeckers can breed, for, unless these birds can be induced to nest about the farm, the trees will suffer from many insidious insect foes.

He who already owns a farm will usually have little diffculty in making it a paradise for birds, but he may find it more troublesome to protect them from their enemies. Those who have groves of large white oaks are fortunate indeed, for it takes many years to grow these fine trees. The acorns are sought by birds and squirrels, and the trees support thousands of insects which are eaten by such useful birds as the Blue Jay, Scarlet Tanager, Rose-breasted Grosbeak, and Baltimore Oriole. The white or gray birch is another important tree, for many birds feed on insects which infest it in spring, summer, or autumn, and others feed on its seeds in winter. The common gray alder has seeds 
which birds eat in winter. The elms ripen their seeds early, thus providing bird food in June, while their branches furnish favorite nesting places for Robins, Orioles, and Vireos. The spanworms which infest these trees are sought by nearly all small land birds. The maples are favorite

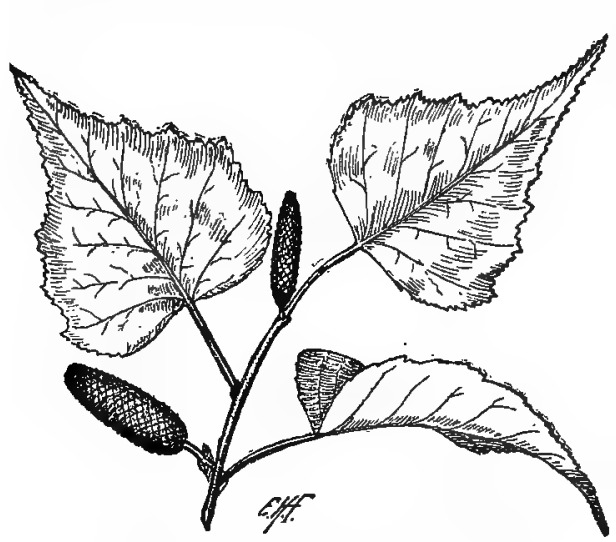

Fig. 157.-Seed catkins of the gray bireh. nesting trees, and their seeds, which sometimes remain on the trees, form a staple article of food for the Pine Grosbeak. The seeds of the ash are eaten by Grosbeaks and Purple Finches. Among the coniferous trees none are more attractive to certain birds than the white pine, the pitch pine, and the larch or hackmatack. The first two offer insect food to many Warblers; their cones and shoots are utilized by birds and squirrels in winter. The spruces and hemlocks also have their following among the birds. These conifers are valuable for the shelter they provide in winter to all birds, from Owls to Sparrows.

There are numerous fruit-bearing trees, shrubs, and vines that are essential to bird welfare. In the present state of our knowledge of bird food it would not be difficult to name most of these plants, giving with each a provisional list of the birds that feed upon it; but it will be sufficient for the present purpose to give merely a list of the plants, indicating by an asterisk which are among the most important as furnishing food for a large number of birds.

\footnotetext{
A List of Fruil-bearing Trees, Shrubs, und Tines furnishing Food for

Wild sarsaparilla,

* American mountain ash

* European mountain ash,

* Staghorn sumac,

\section{Birds.}

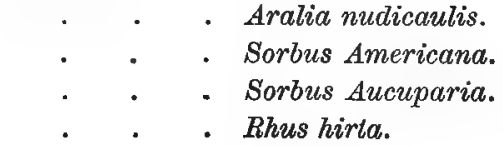





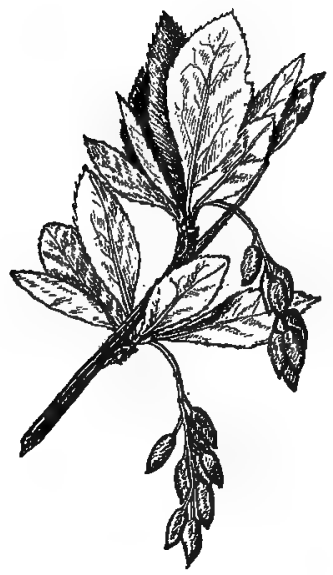

Barberry.

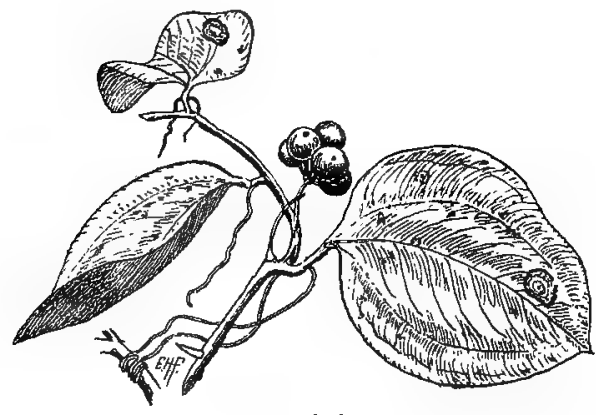

Greenlurier.

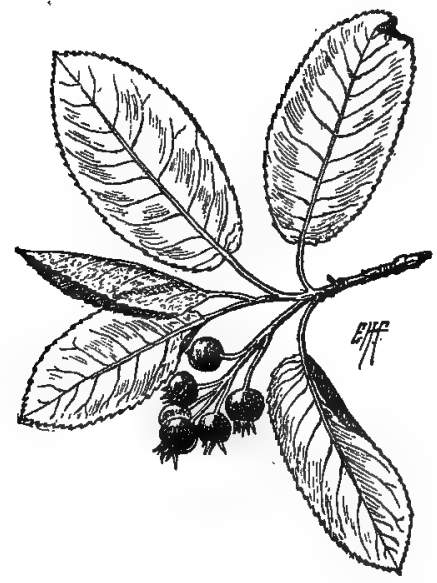

June Berry.
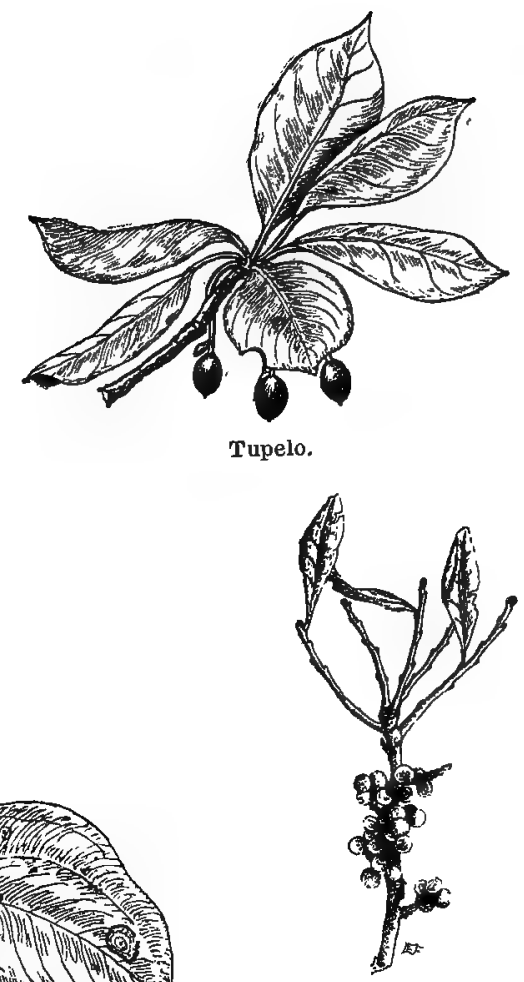

Bayberry.

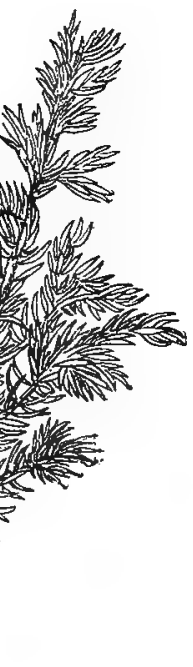

Ground Juniper.

PLATE XXXVIII. - Fruits that are valuable as Bird Food. 
* Smooth sumac, . . . . Rhus glabra.

Poison sumac, poison dogwood, . Rhus Vernix.

Poison ivy, . . . . . Rhus radicans.

- Raspberries, thimbleberries, and

blackberries, . . . Rubus.

(All species are eaten by birds.)

Wild or dwarf rose, . . . Rosa humitis.

('The hips of other species are probably eaten.)

Red-berried elder, red elder, . . Sambucus pubens.

* American elder, sweet elder, black

elder, . . . . . . Sambucus Canadensis.

Sweet gum, . . . . . . Liquidambar Styraciflua.

Wild gooseberries and currants, . Ribes.

(All species.)

Moonseed, Canada moonseed, . . Menispermum Canadense.

- Virginia creeper, - woodbine, . Parthenocissus quinquefolia.

Wild grapes, . . . . . Vitis.

(All species.)

Probably all the thorn trees (Cratagus), including the English hawthorn (Cratcegus Oxyacanthu).

Sassafras, . . . . . Sassafras Sassafras.

* Red mulberry, . . . . Morus rubra.

* Russian mulberry, . . . . Morus alba, var. Tatarica.

- Hackberry, nettle tree or sugar berry, Celtis occidentalis.

American holly, . . . . Ilex opaca.

- Winterberry, black alder, . . 1lex verticillata.

(Probably other species of holly (Ilex) are also eaten.)

Climbing bittersweet, stafftree, wax-

work, . . . . . . Celastrus scandens.

* Bayberry (wax myrtle),. . . . Myrica Carolinensis.

* Barberry, common (European), . Berberis vulgaris.

* Shad bush, June berry, . . . Amelanchier Canadensis.

Red chokeberry, . . . . Aronia arbutifolia.

(Probably the black chokeberry is also eaten.)
Beach plum, . . . . Prunus maritima.

(And probably other plums.)

Wild red cherry, bird cherry, . . Prunus Pennsylvanica.

Sand cherry, . - . . Prunus pumila.

* Black cherry, rum cherry, . . Prunus serotina.

* Choke cherry,. . . . . Prunus Virginiana.

Withe-rod, . . . . . Viburnum nudum.

Sweet viburnum, Nanny plum, sheep

berry, . . . . . . Viburnum Lentago.

Cranberry tree, . . . . Viburnum Opulus. ${ }^{1}$

1 Probably the berries of the arrowwoods of this genus are also eaten by birds. 
* Greenbrier, catbrier, bullbrier, . Smilax rotundifolia.

Spice bush, fever bush, . . . Benzoin Benzoin.

* Blueberries and huckleberries, .Vaccinium and Gaylussacia.

(Nearly all species eaten.)

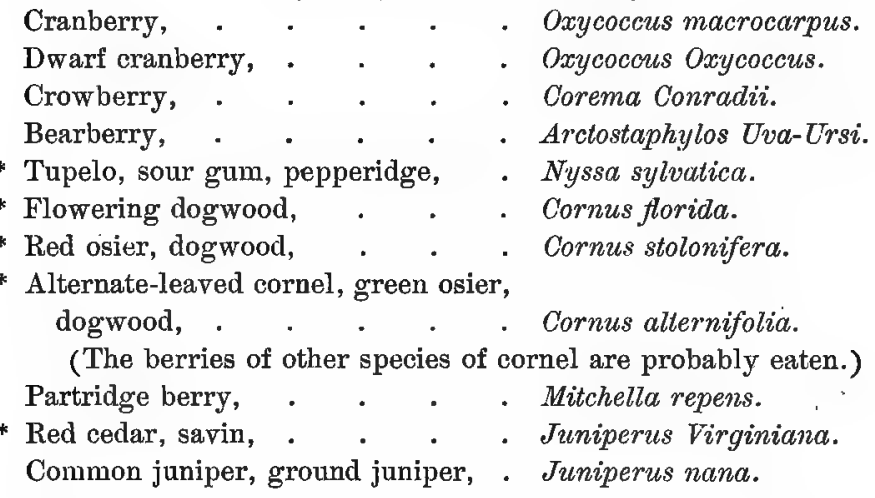

This list probably does not include all the native trees, shrubs, and vines that bear a more or less pulpy fruit and contribute largely to the sustenance of birds, but it is believed that it comprises those of most importance, with the addition of a few valuable introduced species.

There are many trees, not named in the above list, that attract a few birds. The willows, for example, are frequented by certain Warblers. Among the shrubs, the fruit of the burning bush (Euonymus atropurpureus) is sought by some birds. The berries of the nightshade (Solanum nigrum), though believed to be poisonous, are eaten by birds. The pokeweed (Phytolacca decandra) furnishes a fruit which, though it is believed to have poisonous properties, is eaten by very many birds.

Those fruit-bearing plants which retain their fruit in winter are of great importance. Such plants enable many birds to exist through our winter storms. The bayberry is among the most valuable of the low-growing shrubs. Nearly all the winter birds, from the Kinglet to the Crow, eat these berries. Where the bushes are not covered with snow, the supply at Wareham usually becomes exhausted in February, after which the Myrtle Warblers and many of the winter Sparrows disappear. The bayberry bushes, being low, are sometimes covered with the drifting snow, and then the 
birds must seek their food from larger and higher shrubs, trees, and vines. The mountain ash, black alder, and red cedar are favorite fruiting trees in winter; while among shrubs, barberry and sumac are much sought.

Fortunately, many of the trees or shrubs which furnish food and shelter for birds are suitable for use in the ornamentation of grounds. Hedges may be made of holly or bawthorn. The red cedar and other coniferous trees are highly ornamental. Elm, maple, and ash trees are all in demand for shade. Some of the shrubs may be used as borders for drives or massed to hide defects in the landscape. The

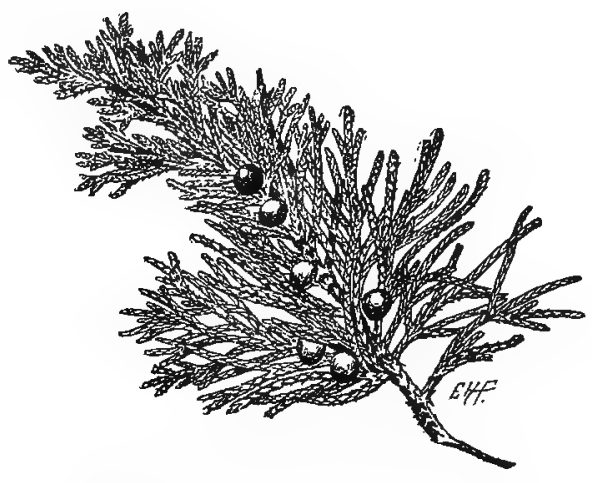

Fig. 158. - Fruit of the Virginia juniper or red cedar.

Virginia creeper may be utilized in place of the imported ivy vines. Many of the plants in our list may be employed in forming tangles along stone walls, about rocky eminences, or on the borders of swamps or ponds. Such tangles, overgrown by smilax or other vines, form safe retreats for small birds when pursued by Hawks, and furnish secure nesting places. They also provide sheltered retreats for the winter birds.

\section{Feeding and Assembling the Winter Birds.}

The results of assembling the winter birds about the farm and orchard are of the utmost value to the farmer. Prof. H. A. Surface, State Zoölogist of Pennsylvania, writes that a Mr. Mann, a well-known pear grower of Rochester, N. Y., told him that one year the pear tree psylla had destroyed his entire pear crop, and that he thought there were no prospects of a crop the following year; but Nuthatches came and worked "in flocks" in his orchard all winter, and in the spring he could find hardly an insect. Thus these Nuthatches saved him thousands of dollars in one winter. 
We may properly include under the head of winter feeding the provision of food for such land birds as migrate through New England in late fall, winter, or early spring, and those that are resident in winter. At that season the farmer is likely to have more time to attend to birds than in summer, and in the colder months they most need our help. No doubt thousands of birds, that might have been saved with very little trouble on the farmer's part, have been starved in hard winters.

We may expect to be visited in autumn by Robins and other migrating Thrushes, some of which, in favorable seasons, may remain through the winter. To keep such birds in winter we must have sheltering evergreens, and vines, shrubs, and trees which retain their fruit. The berries of the Virginia creeper are especially acceptable to Thrushes.

It is very desirable to keep with us as long as possible the many species of Sparrows which pass through the country on their way south in fall, and to persuade as many as we may to remain through the winter. Careless husbandry tends to bring these birds about in spring and fall, when they gather to feed on weed seeds in neglected gardens and fields; but, if we wish to have them continue this good work all through the winter and spring, they must be provided with food, under shelter, to which they can resort during snowstorms and afterward, while the snow lies deep or when all vegetation is covered with a coating of ice from the driving sleet or freezing rain. The Sparrows seem to prefer, as a place of refuge from their enemies, the shelter afforded by thickets and tangles of deciduous bushes and vines, such as may sometimes be found on the south side of a hill near the edge of a swamp. A fer brush piles will give them additional shelter. A little chaff scattered in the dooryard will bring them about the house whenever a flurry of snow covers the ground. Where there are scratching sheds for poultry, with the south side of each shed open except for its screen of poultry netting, the birds will find shelter and food on cold and stormy mornings. Birds readily pass through ordinary two-inch mesh poultry netting, and when once in the shed they are safe from the attacks of cats and Hawks. Where 


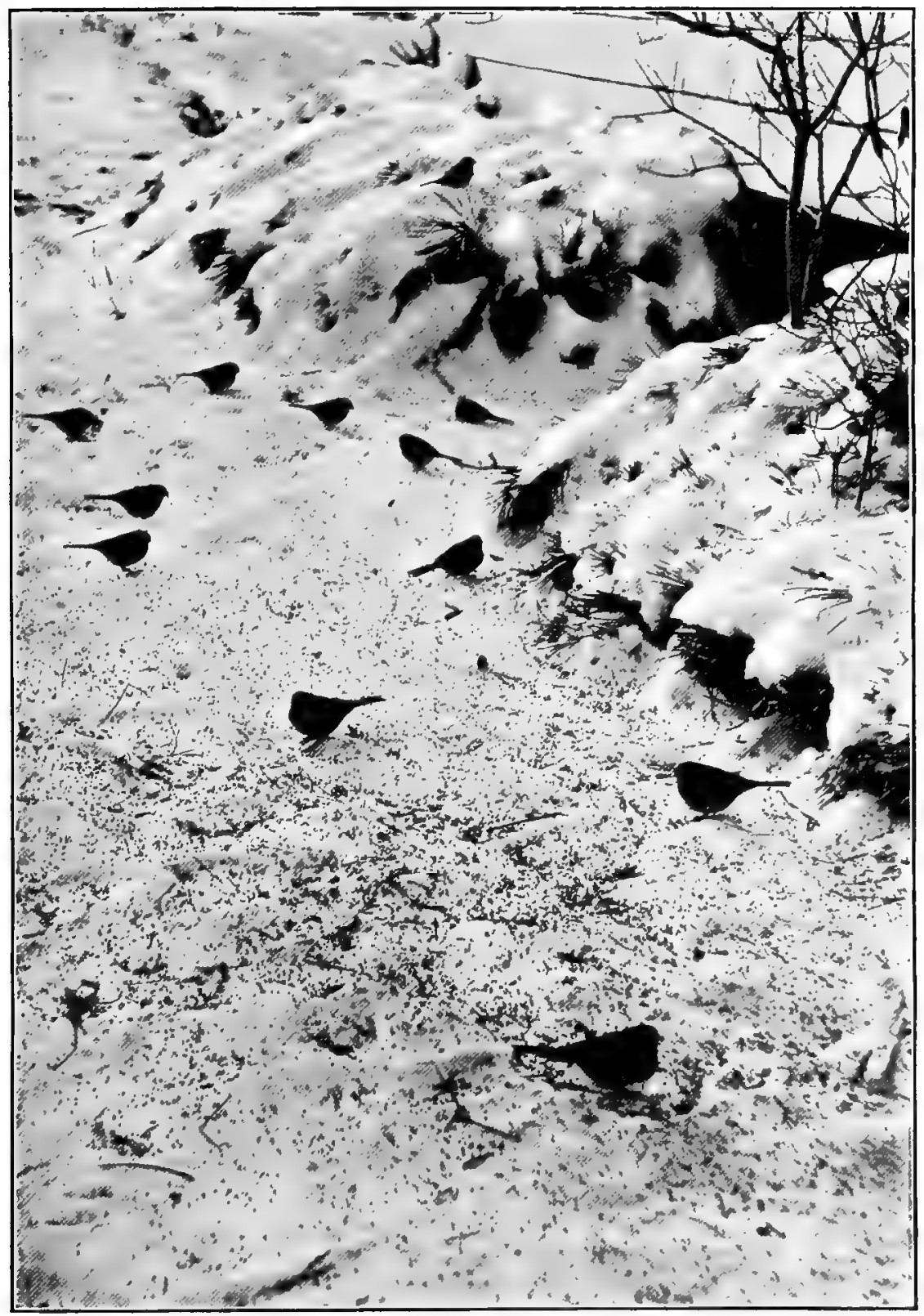

PLATE XXXIX. - A Bountiful Repast. Juncos and a Tree Sparrow picking up seed from the snow beneath author's window. 



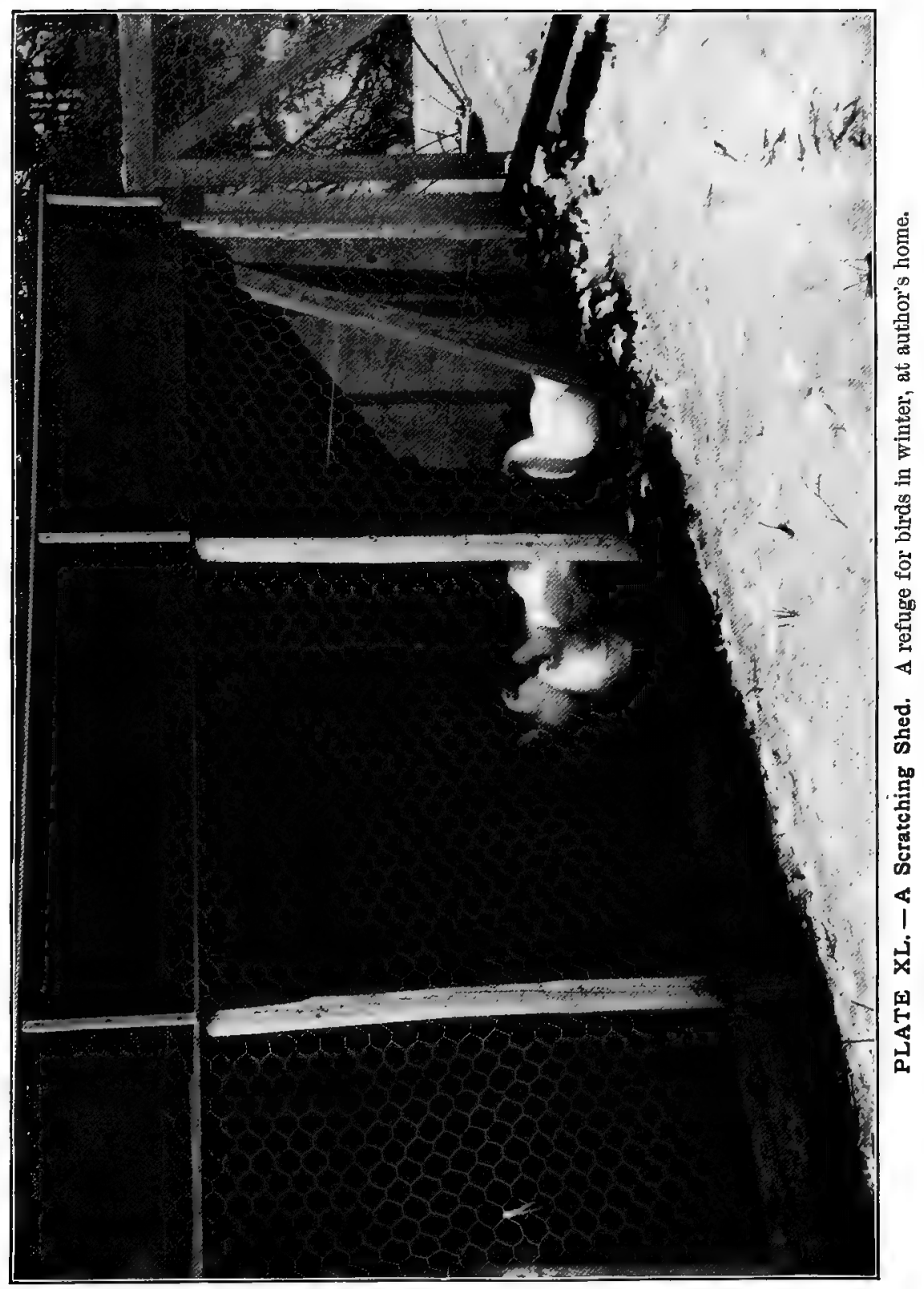



there are no cats, any shed near the house, and opening toward the south, will be a good feeding place for birds. They will go there to feed when snow lies deep on the ground. At other times they will feed mostly in weed thickets, fields, and gardens.

There are so many kinds of seeds that are relished by birds that there will be no difficulty in furnishing them a liberal supply of food when they need it. The farmer will find on his barn floors chaff mixed with enough seed to feed a large flock of birds through the entire winter. This should be gathered from the leavings of the latest cut first crop of hay, for there will be less matured seed of any kind in the early cut hay. Those who wish to provide more attractive food have their choice of the various seeds sold at the bird stores. Farmers often grow sunflowers for the fowls. These will attract Goldfinches; sunflower heads or detached seeds make a good winter food for birds. It is a good plan to give one or more of the children a small patch of land near the house, on which to raise Japanese millet. If sown broadcast on rich, moist soil, it will grow from five to seven feet in height, and the large seed heads will supply an immense quantity of seed. It takes but three or four square rods of land to produce all the seed one will need for birds, for a bushel or two ought to suffice for an ordinary winter.

Winter is the time, if ever, to feed the Jays and Crows. If they do not molest the smaller birds they can do little harm, and they may do much good. Hang up a choice bit of carrion in the orchard or in the edge of the woods. It should be seven or eight feet from the ground, so as to be out of the reach of dogs or foxes. The skinned carcass of a fox or a cat will do very well. It should be so placed that the Crows can find no convenient roost within easy reach of it. It will then last the longer, and keep more of them from starvation. When the snow is deep they can resort to it one or two at a time, and when patches of ground become bare they will hunt meadow mice and dormant insects in the fields and thickets. By feeding them you may prevent their eating all the bayberries and other berries on which some of the smaller birds depend for food. Jays are also of great 
benefit to the orchard, by eating the eggs of the tent caterpillar moth.

Woodpeckers, Nuthatches, and Chickadees are all attracted by animal food. Juncos and Tree Sparrows acquire a taste for it during deep snows, when their usual food is buried. Unsalted bones, with meat, fat, or marrow attached, beef or

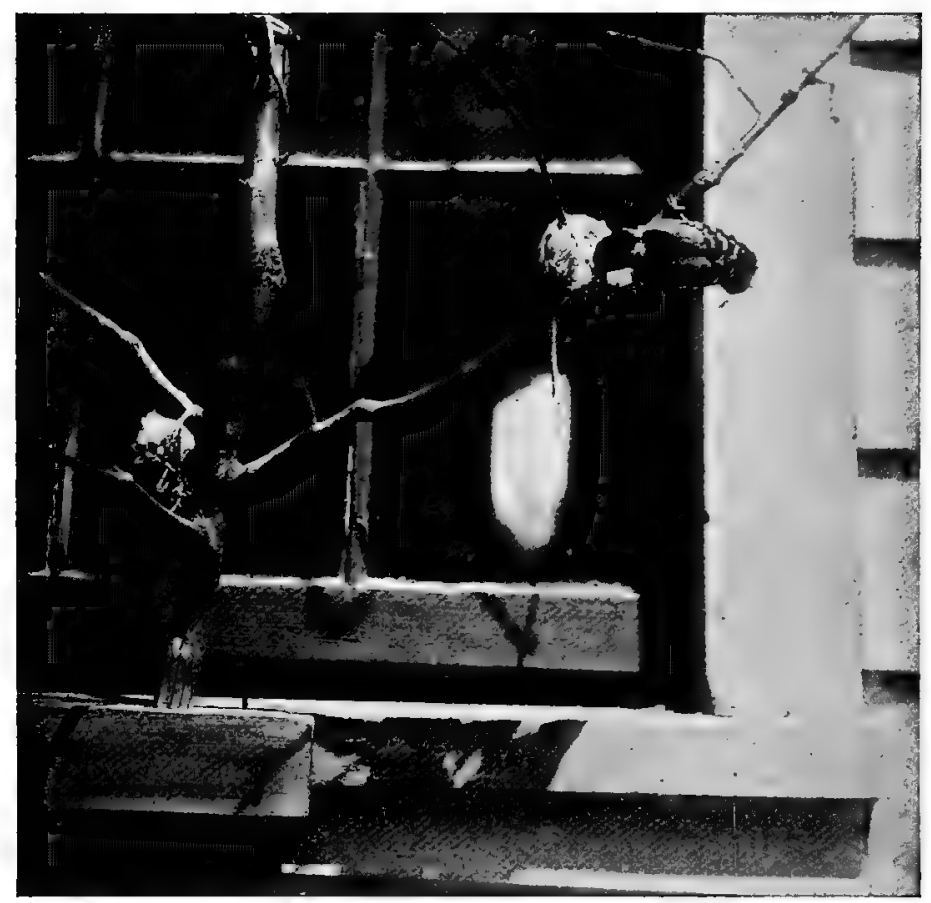

Fig. 159. - Downy Woodpecker feeding on suet at the author's window. (From BirdLore.)

mutton tallow, fat, or suet may all be used for this purpose. Beef bones from the market, hung upon or wired to the orchard trees, will furnish food for these birds. Some bones should be split, to expose the contents. Fat or suet will give the needed animal heat on which birds must rely during cold, stormy weather. Pork rind, even, may be used; but salt meat is believed to be bad food for birds, although some will eat it, and Crossbills appear to be very fond of it. If a bird can get food enough, it can withstand very cold weather; but if it starves, it soon freezes. Bones or suet should be put 


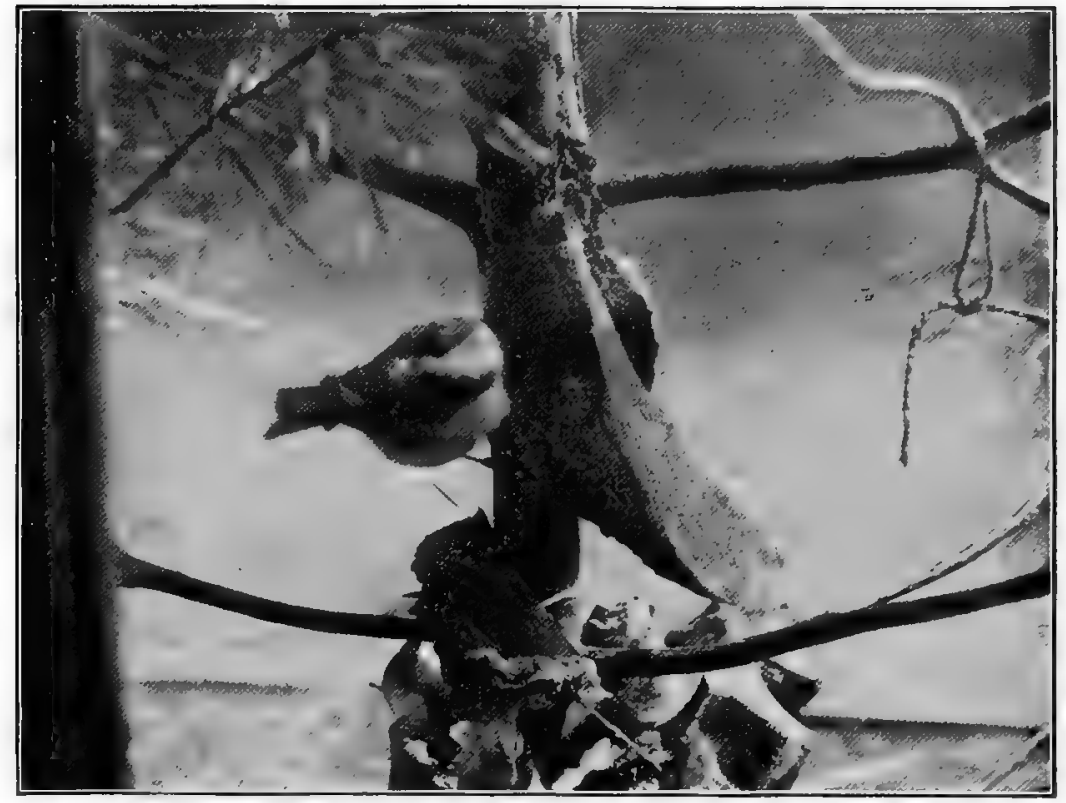

PLATE XLI. - Chickadee seen through Window, at Author's Home.

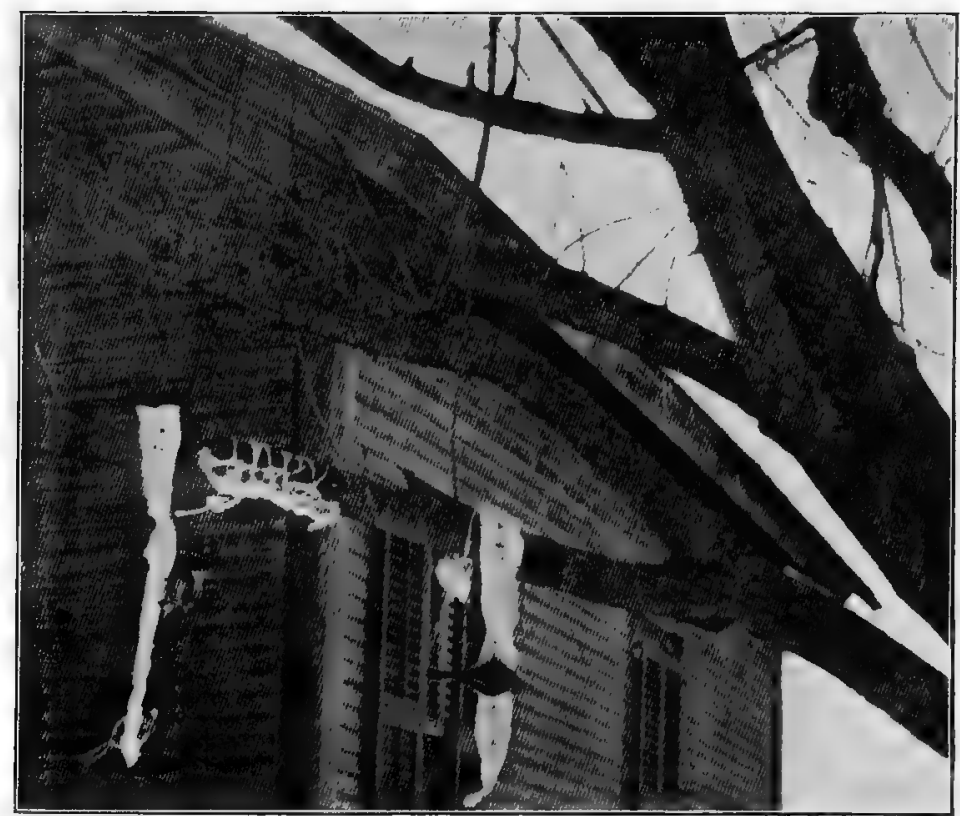

PLATE XLII. - Chickadees on Pork Rind. (Photograph by A. C. Dike.) 




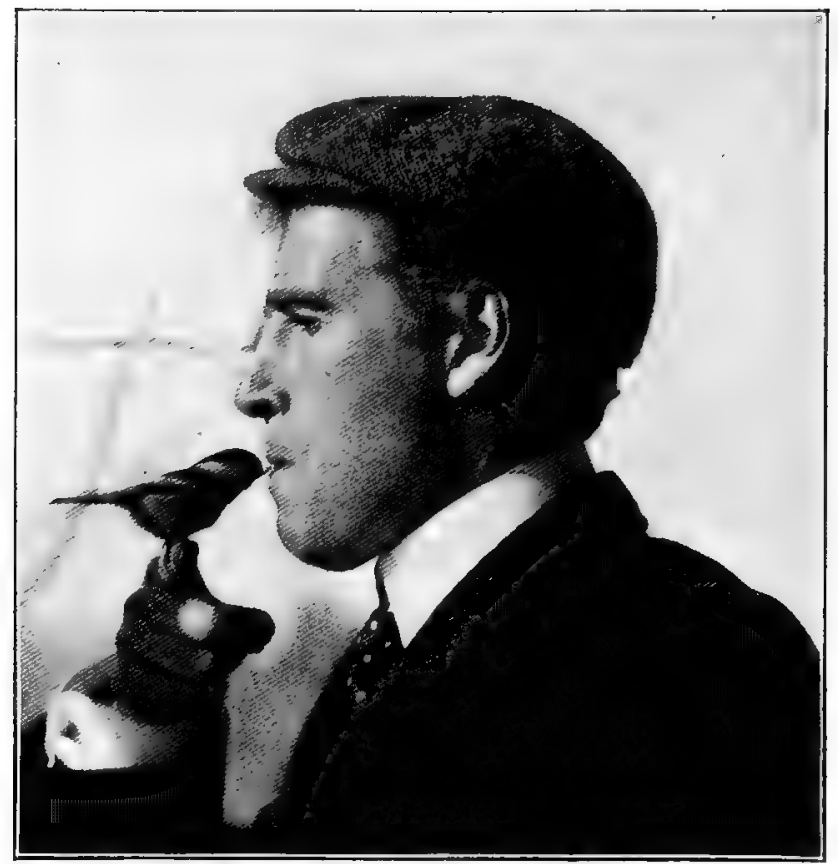

PLATE XLIII. - Ernest Harold Baynes taming a Chickadee.

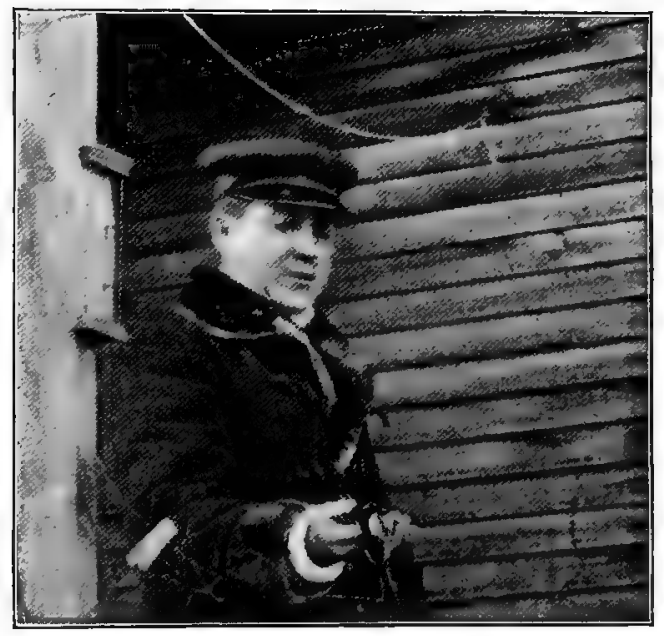

PLATE XLIV. - Chickadee feeding from the Hand. (Photograph by A. C. Dike.) 
out in October or early in November. It is important to begin early, so that the birds may form a habit of coming to the food before winter comes on. It should be renewed occasionally until late in spring. This will keep birds about the orchard all winter, where they will spend most of the time in hunting for the eggs and other forms of insects. Food should be put up on or near those trees which are known to be infested by insects.

Chickadees and Nuthatches are remarkably unsuspicious, and any one who cares to spend a little time in the effort may readily teach them to eat from the hand. Several other species may be enticed to

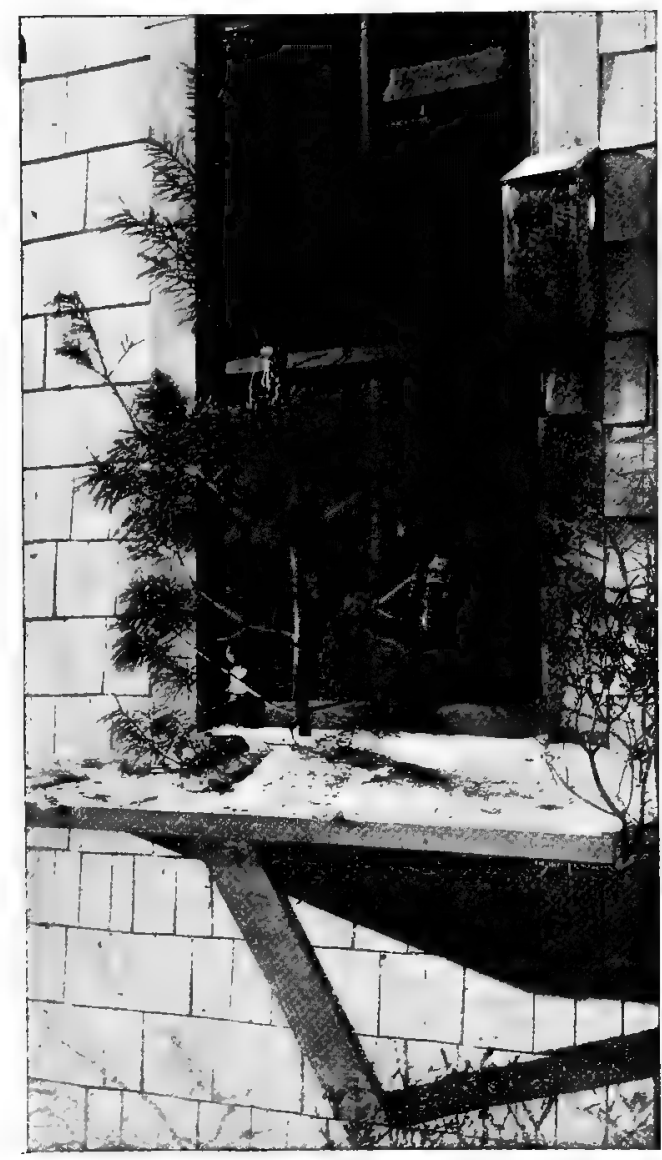

Fig. 160.-The birds' Christmas tree at the author's farm. house. (From Bird-Lore.)

our windows, where their habits and manners may be studied in comfort even in the most blustering winter weather. We accomplished this as follows: small shrubs or branches of trees were fastened upright on each window sill, extending over the entire window, and fastened at each side to the window frame, as shown in Fig. 159. To these branches pieces of meat were attached, about a foot apart. The suet 
should be wound on firmly with string or wrapped in wire netting, so that it cannot be carried off bodily. At first the birds would come only one at a time, but when they became accustomed to this method of feeding, four or five birds would feed together at a window. Chickadees usually came first, Nuthatches and Downy Woodpeckers next, and Blue Jays last.

While these birds were being enticed to the windows, the Sparrows were fed with seeds and crumbs thrown out upon

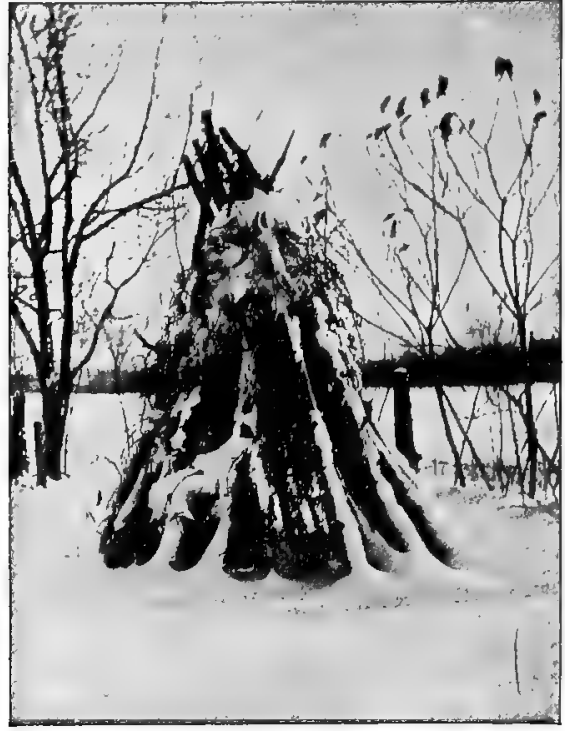

Fig, 161. -The birds' tepee. (From Bird-Lore.) the snow. Next, a shelf or table four and one-half feet long and two feet wide was made of rough box boards. This was bound round with a narrow cleat and covered with burlap, to prevent seeds and crumbs from blowing off. A little pine tree was next set up in the centre of the food table, the table or shelf was fastened under a window sill on the south side of the house, various food materials were attached to the tree and spread upon the table, and the "birds' Christmas tree" was ready.

The Chickadees came to it at once, and the first snowstorm brought the native Sparrows. At first there was quarreling among them, as all wanted to feed at once, and both tree and table were small ; but necessity finally brought about more amicable relations, and at last many birds of different species would feed together. At first the Sparrows were shy, and flew off at the first movement made by any one inside. Later, one could sit by the window and see perhaps eight or ten birds of three or four species busily feeding, a 


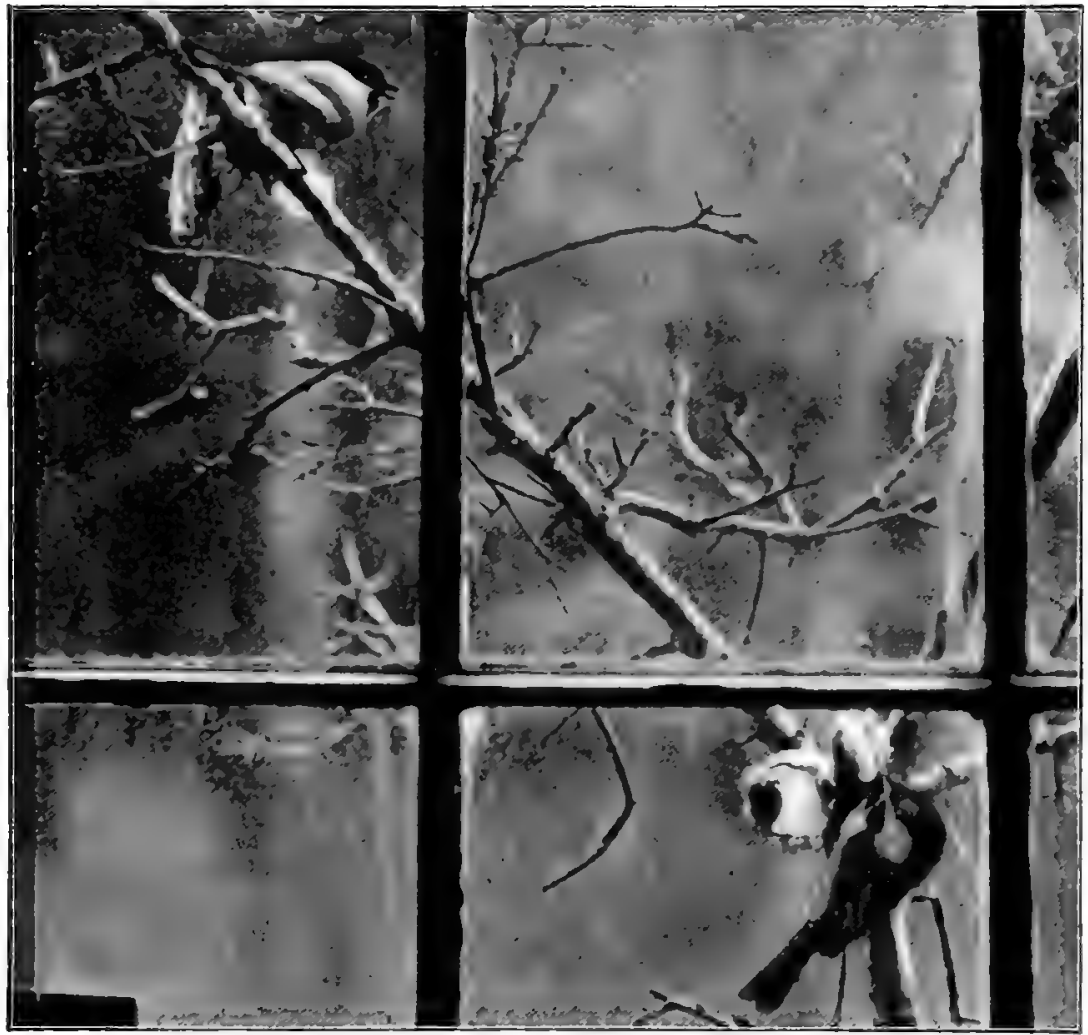

PLATE XLV. - Chiclsadees seen on a Frosty Morning, through Author's Window. 



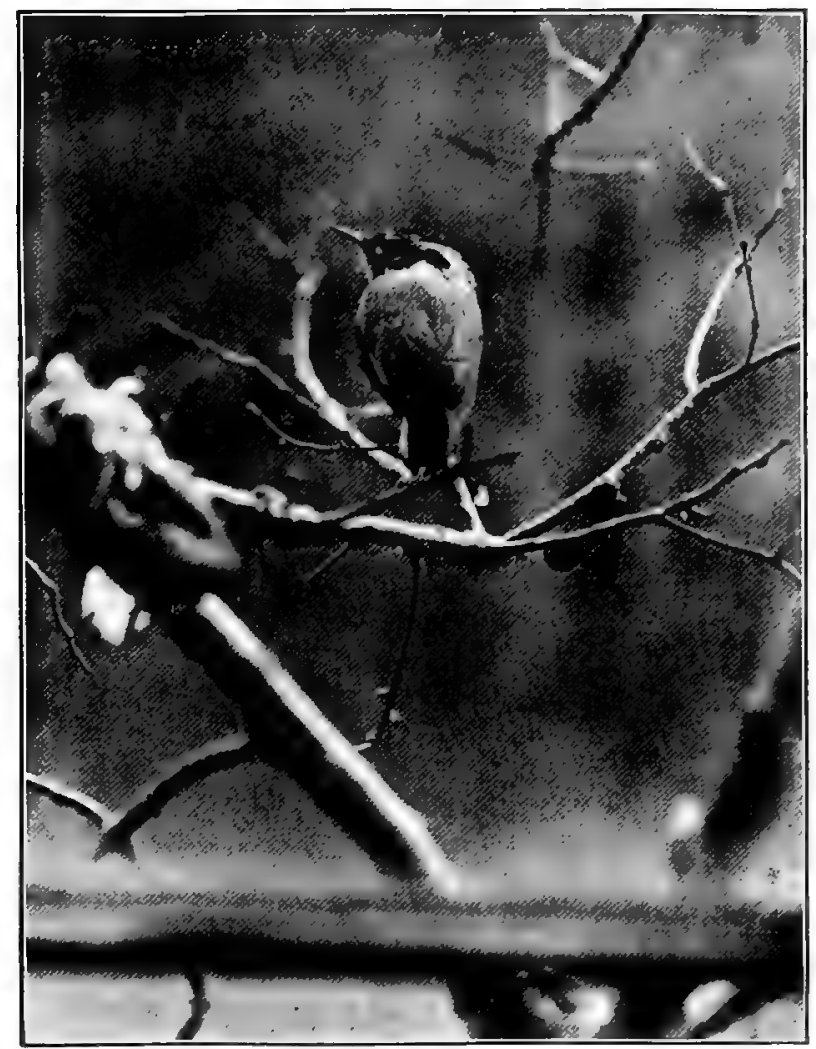

PLATE XLVI. - A Red-breasted Nuthatch at the Window. (Photograph, from life, by C. Allan Lyford.) 

few feet away. Quick motions on the part of the observer should be avoided. If the birds are shy, a lace sash curtain may be put up. They cannot see through this, and may be watched at leisure.

We have fed the birds in this way for years. A flock of Juncos and Tree Sparrows and two Fox Sparrows remained about our house through the hard winter of 1903-04. Many Jays came to the trees near by, and some to the windows. Crows came within twenty yards of the house. Myrtle Warblers occasionally came to the windows. Downy Woodpeckers, two species of Nuthatches, Flickers, Creepers, Kinglets, Crossbills, Robins, Grouse, Quail, and Pheasants were seen about the house from time to time. A large dry goods box in which grain and chaff were scattered was set out on the north side of the house. This box was open only on the south side. The Quail and Pheasants soon found it. Then it was moved daily a little nearer the house, until the birds had learned to feed about the

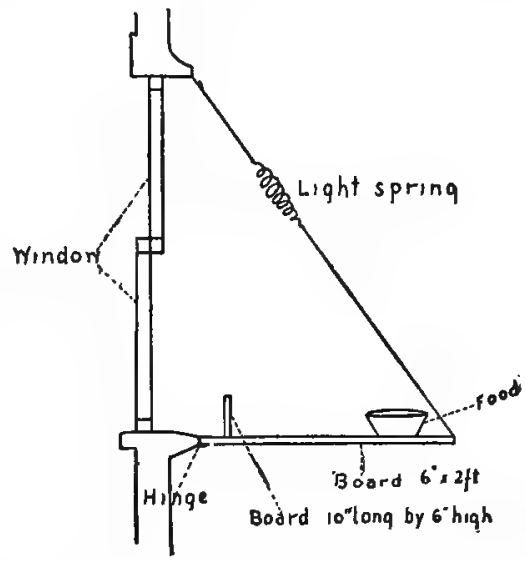

Fig. 162.-Design for a Sparrow-proof shelf. (From Bird-Lore.) door-yard. ${ }^{1}$ The presence of so many birds gave a healthy stimulus to observation, and served to break the monotony of winter isolation on the farm. While in the bleaker portions of the State it may not be possible to assemble so many, some may be attracted anywhere.

Even our city friends who try this plan need not despair of seeing, now and then, besides the ubiquitous Sparrow, some of the wild birds of field and woodland. In many lo-

\footnotetext{
${ }^{2}$ It is of the utmost importance to provide food and shelter for Quail in winter. An old box or barrel, a shelter of rails in a fence corner, or a "birds' tepee" of bean poles, any one of which is kept supplied with a little grain, may carry through a severe winter Quail enough to stock a whole township by their increase.
} 
calities the swarming House Sparrows will come to the feast and drive the native birds away. A hinged shelf (Fig. 162) supported by a light spring, which has been designed by a contributor to Bird-Lore, is believed to be Sparrow-proof.

This method of feeding gives an opportunity to see what foods are selected by wild birds when given their choice. It is interesting to note that the birds at our windows have not learned to eat bread except in the shape of fine crumbs. When birds learn that bread is good, they will eat it from the loaf. Many kinds of food may be utilized; doughnuts, frozen milk, pork rind, nuts, and seeds all find favor with the birds. Jays prefer chestnuts and corn. Sand and coal cinders give birds the wherewithal to grind their food when snow covers the usual supply of material on the ground.

Every family living in the country in winter needs the pleasure and community of interest to be bad in thus catering to the wants of the birds. Each farmhouse should have at least one window shelf for them. We should teach the children to feed them and watch for them. Thus we may benefit both child and bird, and gain pleasure and profit for ourselves.

\section{Attracting the Summer Birds.}

The term "summer birds" may be defined as including all summer residents, or those birds whieh remain through the summer to breed. In winter we have only to offer food to the birds to attract them; shelter and protection will retain them; but in summer birds must have food, water, protection, and a home. Food in quantities they always need, especially when engaged in rearing, their young. Nature provides this in summer, but we may help them even then by putting out favorite foods. The supply of suet should be kept up until hot weather, and it is better to continue it all summer, for its presence may decide some of the resident birds to remain and nest near the house or in the orchard. The male Chickadee will take suet to feed to his sitting mate, and the parent birds will take it for a part of their own food while feeding their young mainly on insects.

If we wish to attract useful birds to the garden, it is well 
to begin to feed birds when they are migrating in April, by scattering a little cracked corn, oats, wheat, barley, or millet seed in the yard near the garden or along the garden paths. This may attract Sparrows, Thrashers, and Blackbirds, some of which may decide to remain in the vicinity for the summer. These birds and the Robins and Catbirds will make themselves useful by feeding on insects at plowing time.

Birds will drink and bathe even in winter, when they can find water; but in summer they must have water for both purposes. When the streams are frozen, snow takes the place of water; but in summer, if water is not at hand, birds must get it by drinking dew and by eating fruits or succulent green vegetation. Where there is running water about the house or garden, they may do very well without further provision for their needs; but it is best in any case to arrange a place where they can drink and bathe without being exposed to the attacks of cats and Hawks. A shallow pan set on the window shelf or on the top of a post on the shady side of the house, some four or five feet from the ground, will answer every purpose. A shelving stone may be put in, to give a varying depth of water in different parts of the pan. The water should not be more than two inches deep anywhere, and not more than half an inch deep on one side of the pan. If this is put out in the spring, and the birds become accustomed to visiting it, they will require less fruit than usual. The water should be changed every day. This pan will be a source of enjoyment to the household during the noontime, when all may watch the birds bathe and splash the water about. Where there is running water a drinking fountain may easily be arranged. This may be placed on the lawn, slightly elevated, and supplied from a drip; such a fountain should need little attention. Ornamental fountains and watering troughs are often so deep that there is no chance for birds to drink or bathe. There should always be shallow water somewhere. Most ornamental ponds have no provision for birds. The water is too deep or the coping too high. In such cases a large stone with a surface shelving into and just beneath the water, or 
a shallow floating basin, provided with a wide wooden rim to keep it afloat, may be used.

There are usually springs or brooks about the farm, where birds can drink or bathe; but too often the long grass or

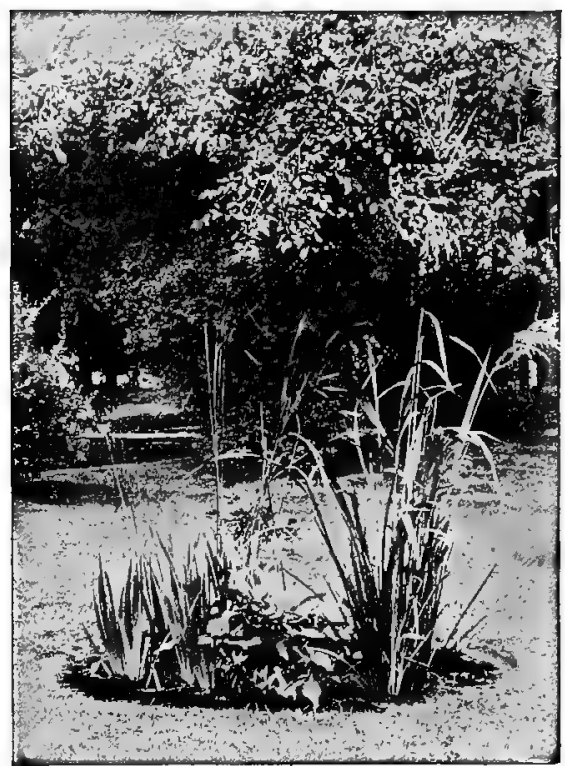

FIg. 163.-Mr. Chapman's bird bath. (From Bird-Lore.) low bushes about these drinking places conceal the crafty cat, which lies in wait to catch birds when their feathers are wet from bathing. A fountain on the closely cropped lawn, like the one designed by $\mathrm{Mr}$. Chapman, is admirable if cats can be kept from it.

When the cherry trees are in blossom the Hummingbirds come. There should be a succession of nectar-bearing flowers in the garden, to attract them. The gladiolus, honeysuckle, and bee balm are favorite flowers, but many others lure the Hummingbirds.

\section{Providing Nesting Places about Buildings.}

When the tide of bird life begins to turn northward in the spring, and before farm work becomes pressing, we should see that plenty of suitable nesting places are provided about our buildings for the birds, and that there is an abundant supply of nesting material with which they can construct their homes.

Birds, like men, are largely controlled by circumstances. The presence or absence of a nesting place may decide a pair of birds for or against the acceptance of a certain locality as a place of residence.

In the rough buildings of our grandfathers there were 
always openings left for the birds to enter. The rafters were round or rough-hewn timbers, on which they could find points of attachment for their nests. Most barns now built are closely boarded and battened, clapboarded or shingled to the ground. No entrance hole is left for the birds. The timbers are sawn so smoothly that the birds, if they get in, can find no safe attachment for their nests. Even where the eaves project so as to give sufficient shelter for Swallows, the mud with which they build their nests will not stick to the planed and painted boards.

Let every farmer having such a barn cut an ornamental opening at least a foot wide in each gable, leaving it open all summer, so that the Swallows may fly in; or, better still, cut an opening three or four feet long over the barn door, through which Swallows can go at will. Let him nail rough cleats horizontally on some of the rafters, or put up little bracket shelves thereon; and let each farmer having a barn with wide, projecting eaves put up a long shelf, cleat, or joist on the side of the barn within a foot of the eaves, for the Eaves Swallows; and we may in time have more Swallows than ever before, provided care is taken to shoot marauding English Sparrows. If we had more Swallows and Phœbes we should have fewer flies, mosquitoes, and garden pests.

The Chimney Swifts have been driven away by the construction of modern chimneys, and destroyed by unseasonable storms. They still nest in the large chimneys of the older houses. A box made of boards planed on the outside may be built of the size and shape of an old-fashioned chimney, with similar divisions, and firmly fastened upon the roof of a building, to attract the Swifts. It is not necessary that it be high, or even that it be upon the top of a building; but it should be out of reach of cats. Possibly a few thin, wooden cleats nailed horizontally inside will assist the birds. By means of a door in such a structure, and an arrangement of mirrors, the habits of these interesting birds may be studied.

The Phœbe prefers a roof over its head, such as is sometimes furnished by the upturned roots of a large tree, a 
bridge, barn, shed, or unoccupied house. It will occupy almost any shed, barn, or barn cellar near a pond or stream, but its nest is sometimes broken down for lack of a proper support. A box like that in Fig. 164 will be acceptable to the Phœbe if nailed up to the plate or rafters of a low shed.

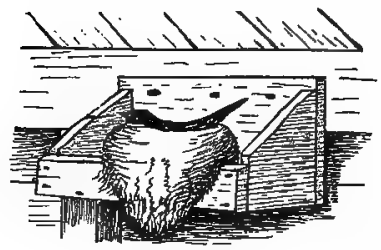

Fig. 164.- Phœbe's nest in box. If the shed is closed, an opening should always be left for the birds. An open window, with a few bars across it to keep out cats and human intruders, is all that is necessary. Phobes sometimes build on a shelf under projecting eaves. They particularly like a rough stone building. Robins will often build in rough boxes or trays, or on shelves put up under eaves or piazzas, in arbors or even in buildings.

Having provided nesting places for all the birds that may be induced to nest within our buildings, we may next turn our attention to making nesting boxes.

\section{Bird Houses and Nesting Boxes.}

Since the use of the axe and saw in woodland and orchard has deprived many birds of their natural nesting places in hollow trees or limbs, there is no better way of providing for an increase of the numbers of such birds than by furnishing them with artificial building sites. Bluebirds found drowned in cisterns, Owls, Flickers, and Wood Ducks found dead in the stove pipes of unoccupied buildings, all show the straits to which birds are now driven in the search for a nesting site. All apertures that lead to such death-traps should be closed, and a plentiful supply of artificial breeding places should be provided.

What more interesting occupation can there be for the children on the farm than that of preparing nesting boxes for the birds? This is the surest way of increasing the summer bird population, for birds do not lack food in summer so much as safe nesting places in which to rear their young.

Unfortunately, however, a great obstacle to success with. 
native birds is found in all cities and most villages of the State. The introduced House or "English" Sparrow comes first, and occupies the boxes. The Sparrow will nest in all boxes except those that are suspended by a wire or rope. Bluebirds and Tree Swallows will sometimes occupy such Sparrow-proof boxes; but the farmer need not use them, for he can keep his place clear of Sparrows by a vigorous use of the shotgun, and by putting up nesting boxes he may bring back the native birds. There are many localities where the Sparrow has never been very troublesome, and where native birds have continued to breed practically unmolested. In such places we may put up fixed bird houses, with the confident expectation that Tree Swallows or Bluebirds will nest in them, which is more than can be said of the swinging boxes. Nevertheless, where Sparrows are very troublesome, the only Fig. 165.-Sparrow-proof box, bird box that is practical is one that

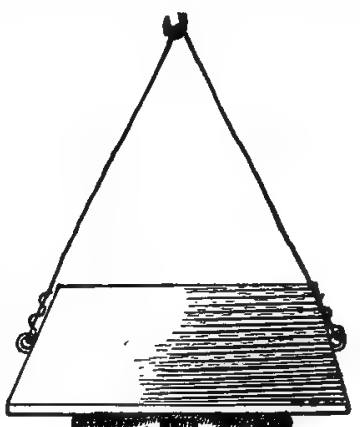
is hung by wire. Sparrows seem to be afraid of any box or perch that is not firmly fastened.

Wrens are not generally common, and the Purple Martins were so decimated by the storms of June, 1903, that people who can establish Martin colonies will be fortunate indeed; but the Flicker, the Chickadee, and the Screech Owl are among the possibilities, while we may by chance attract the White-breasted Nuthatch, Crested Flycatcher, or little Sawwhet Owl.

Let no one neglect to put up bird houses because of the expense. No money need be expended. Birds are not very fastidious about their quarters. Old, weather-beaten lumber seems to be more attractive to them than that which is newly planed or painted, probably because it resembles in appearance the weathered stumps or limbs in which they naturally find their homes. Very acceptable nesting boxes may be 
made from a hollow limb sawed in sections, with tops and bottoms made of an old board, and a hole bored in each section for an entrance.

Artistic imitations of hollow limbs may be made of papiermaché, but this involves some expense. The best imitations of a hollow log that I have seen were constructed of the bark and wood of a sound tree. In Bird-Lore for JanuaryFebruary, 1905, and in the Youth's Companion of April 13, 1905, I described the method of making these boxes, but at that time they were untried. They have since had two seasons' trial, with very satisfactory results. To Mr. William Brewster belongs the credit of their invention, and I have made a considerable number after his design. White birch and chestnut were used, as it was believed that the bark of these trees would be most durable, but Mr. Brewster now suggests that elm bark is probably best of all. Those portions of the trunks used were from four to eight inches in diameter. 'The boxes were made in summer, as the bark will not usually peel well before about June 20 , and then only for a short time. When the tree had been cut down, the trunk was sawed into sections from ten to eighteen inches long, according to the size of the boxes desired. Only straight sections, free from knots or branches, were used. A branch of the right size, however, may, when cut off, leave a hole in the bark that can be utilized as an entrance for the birds.

These domiciles may be made as follows: an incision is made on the side intended for the back of the box, through both outer and inner bark, from the top to the bottom of each section ; then, on the opposite side, some two or three inches from the top, bore through the bark, with an auger or extension-bit, a hole of the size desired for the entrance. If such tools are not at hand, the aperture may be cut with a gouge, a chisel, or even a knife. Next insert a wedge-shaped stick into the incision at the back and under the inner bark, to start it off, and with this implement peel it very carefully. In peeling birch, be careful not to separate the inner and outer layers of the bark. Be particularly cautious when working about knots or rough places. The bark will make the sides of the box, and two sections, each an inch thick, 

, 


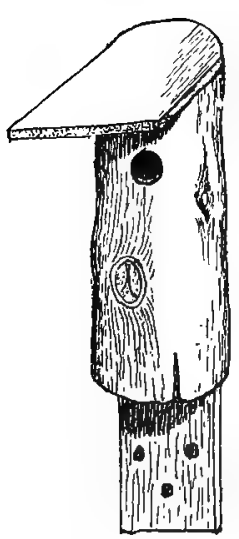

Fig. 1.

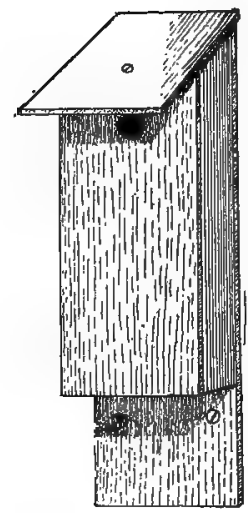

Fig. 4.

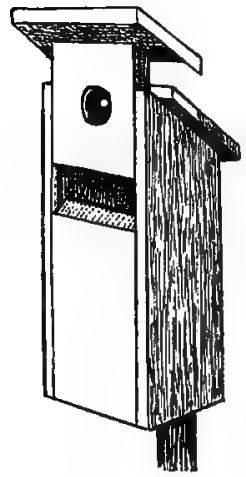

Fig. 7.

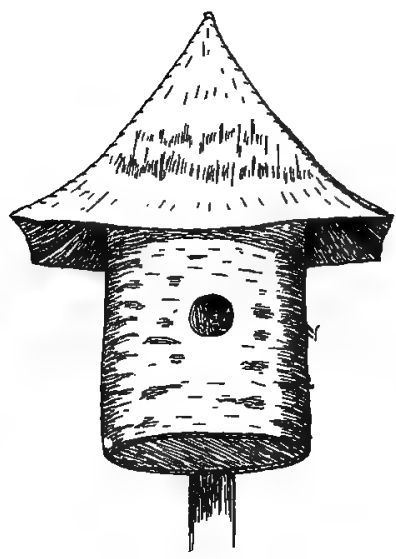

Fig. 2.

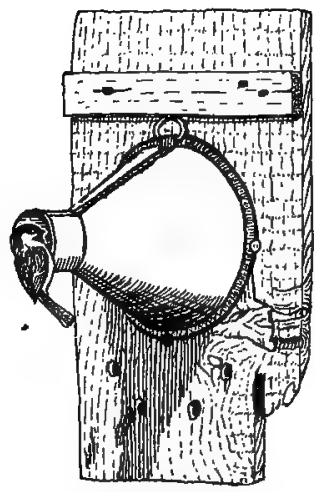

Fig. 5.

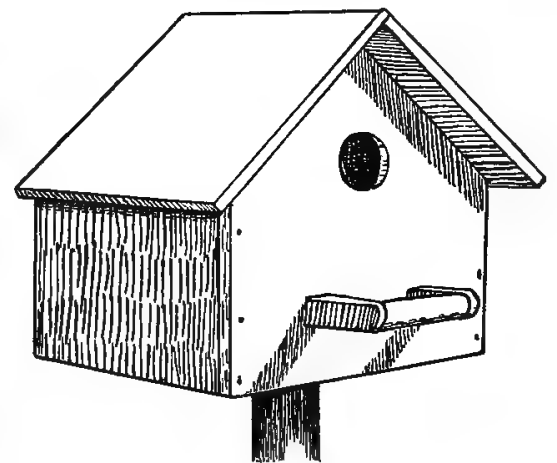

Fig. 8.

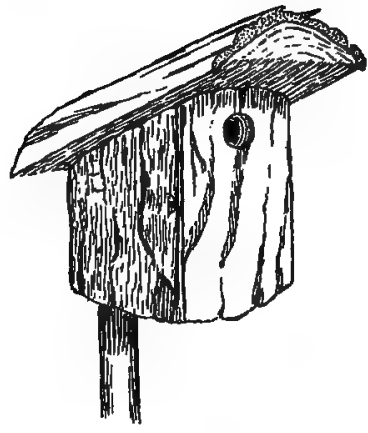

Fig. 3.

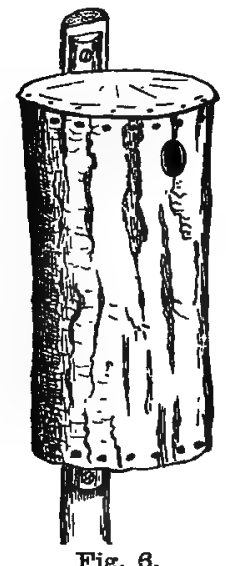

Fig. 6.

PLATE XLVII. - Bird Houses and Nesting Boxes. Fig. 1, hollow limb nesting box; . Fig. 2, birch bark bird house; Fig. 3, slab bird box; Fig. 4, cat-proof box; Fig. 5, a use for an old funnel; Fig. 6, chestnut-bark nesting box; Figs. 7 and 9 , boxes with slide frouts; Fig. 8 , house for Tree Swallow. 
sawed from the ends of the stick, will make the top and bottom. These must be reduced in size by a shave until the bark can be lapped fully half an inch at the incision on the back. Now tack the bark to the bottom and top. Such a box may be put up by nailing or screwing a short stick or pole over the lap on the back, which stick can in turn be nailed or screwed to the support. To make the roof watertight, a piece of thin, green bark from a young pine may be put on and tacked down over the edges. It will fit like soft leather, and make a neat appearance ; but experience has shown that it will not long resist the effect of sun and rain. A more permanent covering may be made by using a piece of tin or zinc, as shown in the figure of the chestnut bark box (Plate XLVII, Fig. 6); or a roof may be made of birch bark, as shown in Plate XLVII, Fig. 2. To make the expected nest accessible to examination, the top of the bark sides might be fastened to a hoop, and

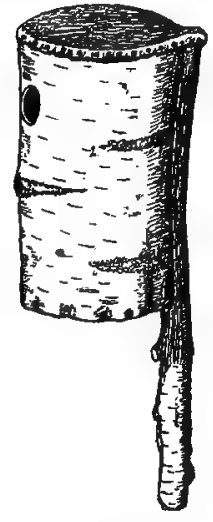

Fig. 166.-Birchbark nesting box, for Chickadees. the whole capped by a tin or wooden cover, like that of a lard pail or a berry box. The best support is a slim pole.

Serviceable dwellings for birds may be made of the shells of gourds. Seedsmen advertise the seed, and any one can grow gourds. Squashes, even, may be utilized. The hardshelled, old-fashioned winter crook-neck would make a stout castle for a Bluebird. or a Martin.

Four old shingles and two pieces of old board will make a box like that shown in Fig. 167. This may be nailed up in a tall tree near the house, or on a building. It must be out of reach of cats, or the young are likely to be clawed out of the hole by these stealthy marauders. To checkmate the cat, a much deeper box may be made, with a small, highplaced round hole for the entrance, and a sloping, overhanging roof, which helps to keep out both water and cats. (See Plate XLVII, Fig. 4.) There is another advantage in a box of this pattern. The young birds find it rather hard to get out of such a box at first. They have to make many attempts, and when they finally escape they are quite strong 
and less likely to be caught by cats, Crows, or snakes than they would be if reared in a box from which they could get out before they were fully fledged.

For practical utility a nesting box should not only provide the birds with an acceptable nesting site, but it should also furnish them perfect protection from the elements and their

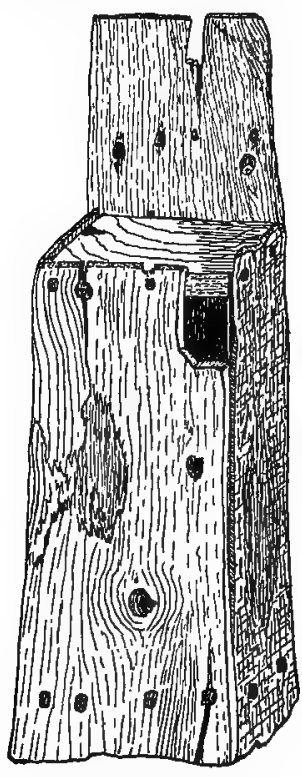

Fig. 167.-Shingle box, for Bluebirds. larger enemies, and should be so made that the interior can be quickly examined and the contents removed, if necessary. The roof or cover should be hinged or made to take off, so that if any young bird fails to get out it may be liberated; while if undesirable tenants, such as mice, Sparrows, or squirrels, get in, they may be ousted. The box is much more satisfactory as a protective device if made so strong that neither Woodpeckers nor squirrels can easily enlarge the entrance sufficiently to allow enemies of the occupants to get in. All these essentials may be secured without expense by using worn-out or discarded utensils or receptacles.

An empty tomato can may in a few minutes be made into a nesting box by slitting the tin of the opened end twice and turning down the piece between the slits, thereby making a hole not over an inch wide and high. It can be put up very quickly by placing the bottom of the can against a tree trunk and nailing it there with two wire nails driven diagonally through the edge, or by fastening it to a piece of board or a pole, which can be attached to a tree or building. The cover may be kept in place by pinching the mouth of the can a little. The tomato can box is shown in Plate XLVIII. This is a practical box for Wrens, and it may be used by Bluebirds if the entrance is made larger.

When holes are cut through tin, the sharp edges round the opening should be turned over with a pair of pliers, that the birds may not injure themselves in going in or out. Rusty 


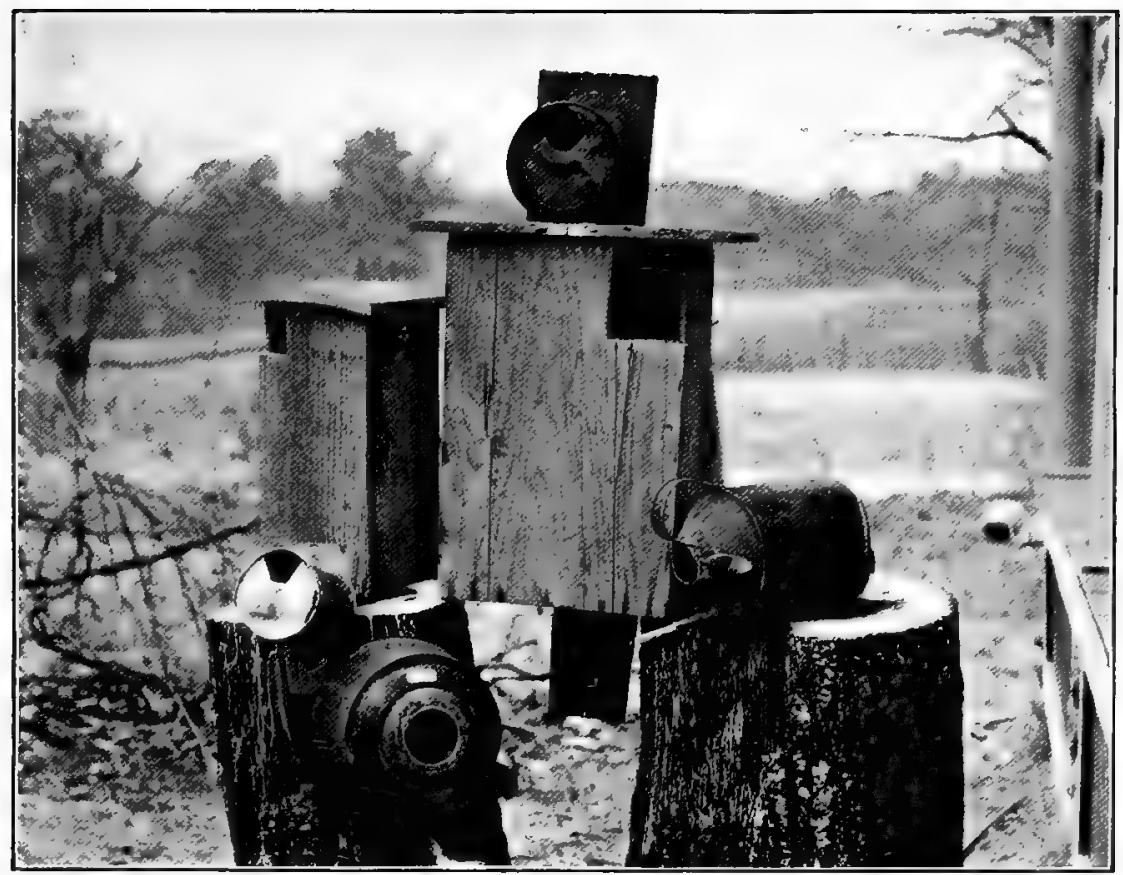

PLATE XLVIII. - Inexpensive Nesting Boxes. Tomato can, Bluebird box, old teakettle, peach can, Owl box, and kerosene can.

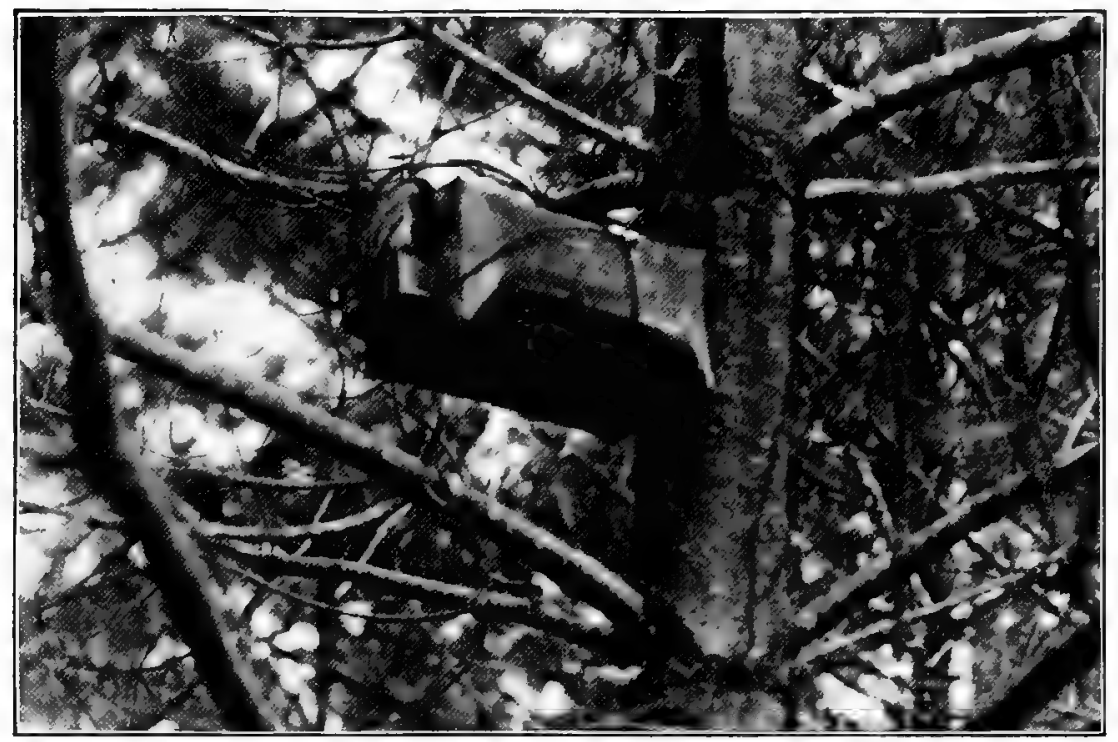

PLATE XLIX. - Chickadee about to enter its Nest, in an Old Varnish Can. 

or painted tin is best, for birds seem suspicious of bright surfaces. There should be a few nail holes in the lower side, to allow the escape of any water that may drive in.

A large funnel may be nailed to a piece of board, and the board fastened on the side of the barn; or the funnel itself may be fastened to the building. This may be used by a Wren or a Chickadee. (See Plate XLVII, Fig. 5.) An old coffee pot may be set upon a post, or fastened to a bracket which may be set against the side of a building. Milk cans, lard pails, flower pots, teakettles, and many other utensils may be utilized, and fastened up in various ways to trees or buildings; and, although they may not be ornate, the birds will find them useful. There should be no projection or limb immediately beneath a nesting box, to give cat or Crow a foothold from which to reach into the nest; but it is always better to have a small limb or stick, as a perch, within a few feet, to serve as a rest for the parent birds. Small wooden boxes, such as may be found at the stores, if not over six by eight by fifteen inches, may be used. Those who have time and lumber to spare may make bird houses of any shape to suit their tastes; but a few suggestions as to construction and situation will not be out of place.

If one wishes to accommodate only a certain species of bird, the entrance to the nesting box should be made so small that no larger bird can enter. Boxes made on this principle for small birds will protect the eggs and young from Crows and Jays. A round hole one and one-fourth inches in diameter will do for either Wrens or Chickadees; but a Wren can use a smaller opening, just the size of a silver twenty-fivecent piece, and such a doorway is small enough to keep out "English" Sparrows. The Chickadee can use a one and oneeighth inch hole, but some will not be content with one less than one and one-fourth inches in diameter. Bluebirds and Tree Swallows can pass through a one and one-half inch aperture. This is usually large enough, and will keep out Jays. The two-inch hole usually recommended is too large, for it will admit both Martins and squirrels. These entrances may be round, square, or oblong. If made oblong, the measurements given should be used horizontally, the vertical diame- 
ter being made a little larger. The Flicker will sometimes enter a knothole, only two and one-half inches in diameter, in an old apple tree; but if so small an opening is made in a box put up for this bird, it may not use it. For a Flicker or a Screech Owl the entrance should be made at least three or three and one-half inches in diameter.

In making boxes of the form illustrated as the cat-proof box (Plate XLVII, Fig. 4), the following inside dimensions are sufficient. Boxes for Wrens or Chickadees may be made twelve by four by five inches, with the entrance hole close to the top. They may be placed from six to twenty-five feet from the ground. ${ }^{1}$ A perch is not necessary. Boxes for Flickers are best if made from hollow limbs or covered with bark. These birds do not need perches. If limbs with the bark on are used, they should be cut in late summer, autumn, or early winter, when the bark will adhere. A box for a Flicker may be eight by ten by fifteen inches, and should be placed from six to twenty-five feet up. A similar box twelve inches square and fifteen high would be ample for a family of Screech Owls. ${ }^{2}$ A box twelve by five by six inches is ample for Swallows or Bluebirds, and should be placed from twelve to thirty feet from the ground. Swallows and Bluebirds like perches. The long diameter of the box should be from front to back. The sitting bird will then face the entrance, - a good position for defence. A single tenement will accommodate a family of Martins, but a colony of these birds should be secured, if possible.

Some writers have recommended putting up boxes with the entrance facing the east or north. This may be right in

1 The distances from the ground as given here are not arbitrary. I have known the Chickadee, for instance, to nest at different heights, from two to fifty-five feet from the ground.

2 This size of box is probably none too large for the Screech Owl, as three or four young birds soon render the edges of the nest very filthy, and on this account probably require extra room. Nevertheless, a pair of Screech $O$ wls at our home in Wareham reared a brood of four young in the grocery box shown in the upper figure on Plate XLVIII. Allowing the birds to be the best judges of what they want, the dimensions of this box, seven by eleven by fifteen inches, and the size of the entrance, three by four inches, may be useful to those who wish to attract this bird. It was noted that during the daytime, at least, the mother $O$ wl in this box always sat with her head away from the entrance, and in the darkest corner, - an incubating position sometimes assumed by the day birds that nest in boxes. 


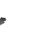




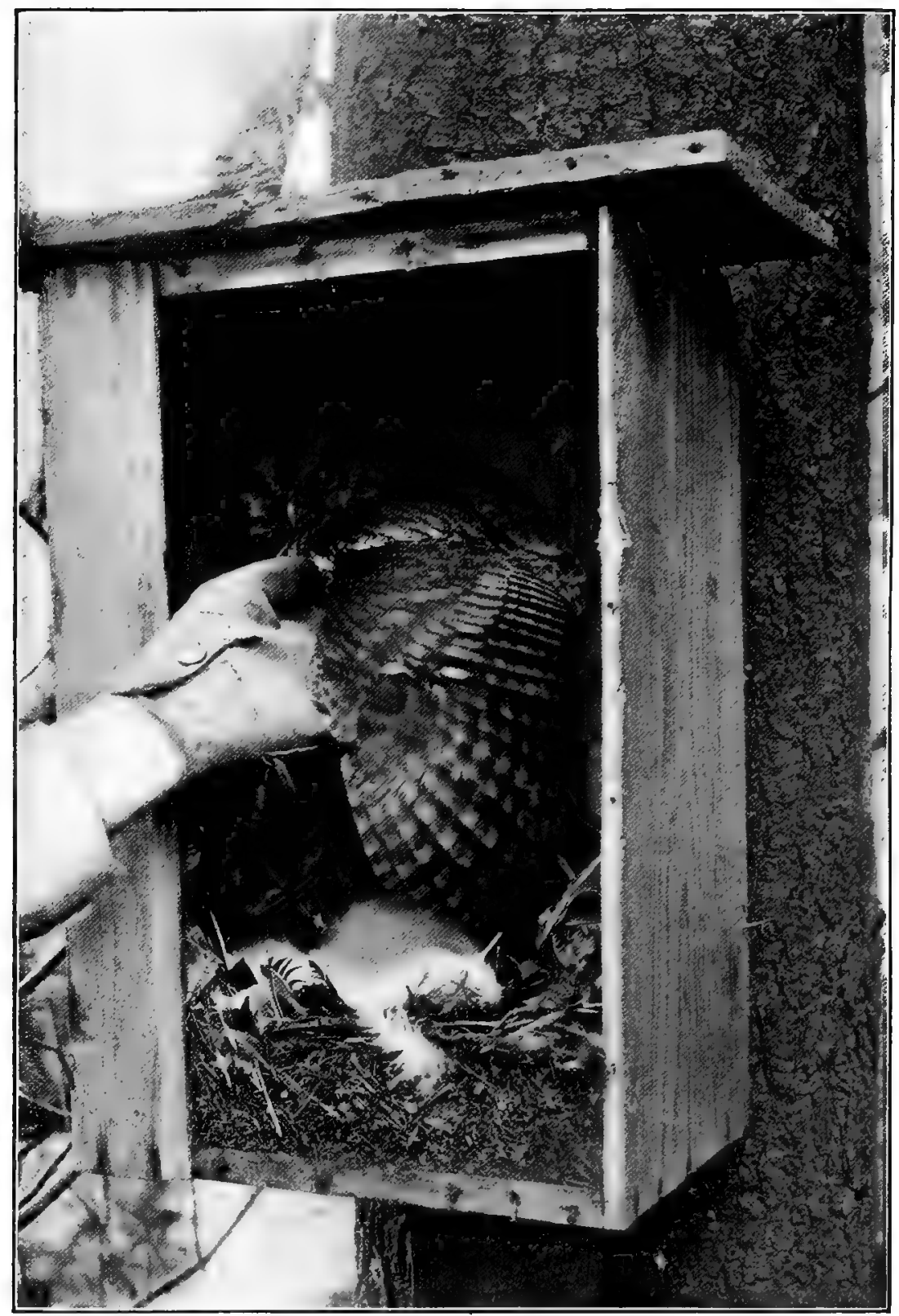

PLATE L.-Owl Box, at Author's Home. The front has been removed, and the mother lifted to show the downy young. (Photograph, from life, by C. Allan Lyford.) 


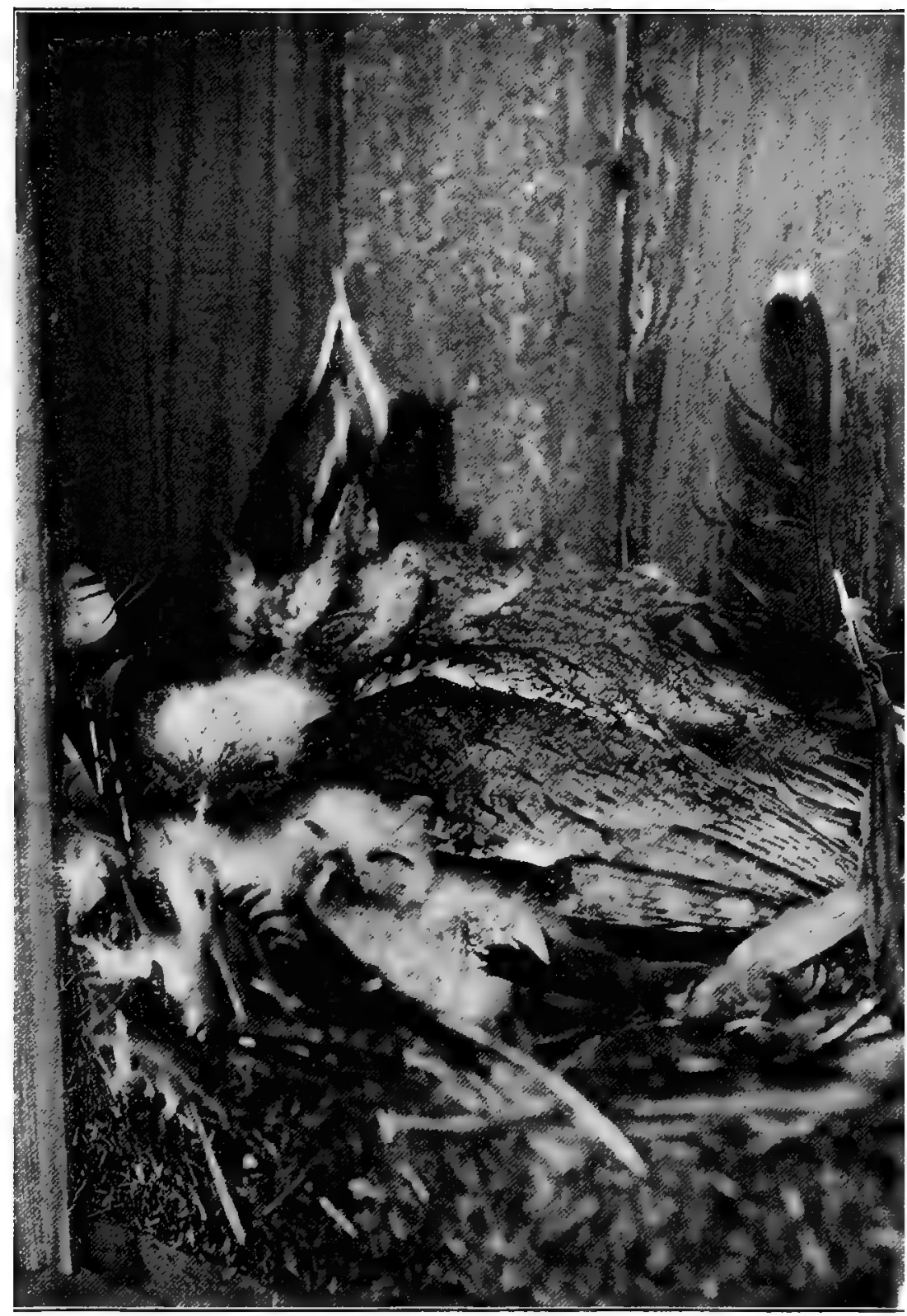

PLATE LI. - Owl on Nest. This view, taken later, shows growth of young, and also feathers of Blue Jays killed by Owl. (Photograph, from life, by C. Allan Lyford.) 

Europe or west of the Rocky Mountains, but it is unsafe here, where our severest rainstorms come from the northeast. The entrance should face the south or west, wherever possible. It is also best to have boxes, especially tin ones, so situated that they will be shaded by trees or buildings

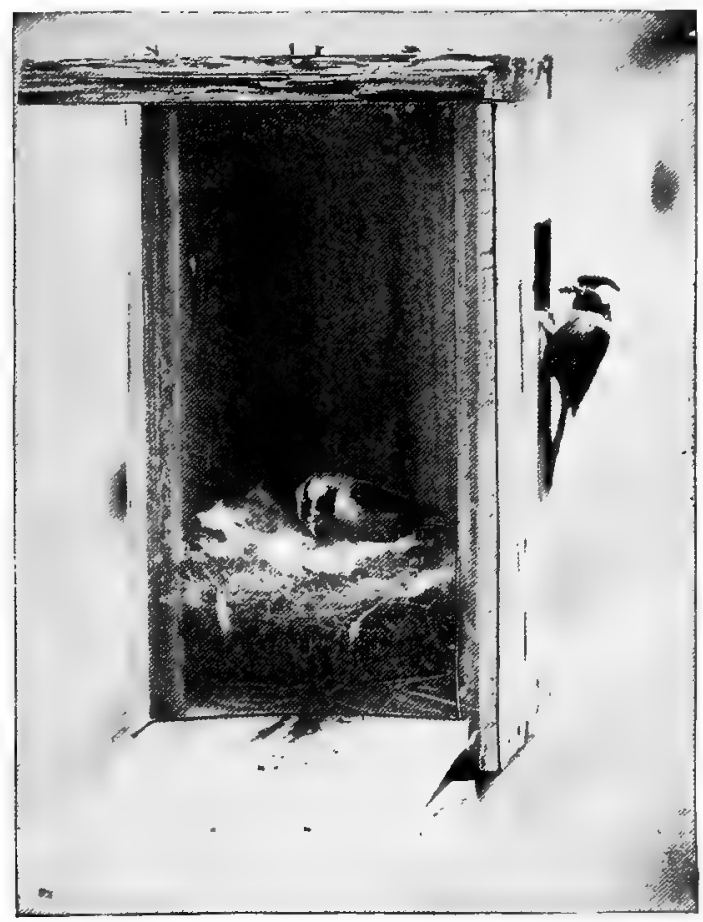

Fig. 168. - Chickadees feeding their young in an observation box at the author's window. (From Reed's American Ornithology.)

during the hotter part of the day. By these precautions we may guard against the danger of having the young birds wet and chilled by cold storms or overheated by the sun. In very hot weather young birds in unshaded boxes sometimes die from excessive heat.

Those who wish to study the domestic affairs of birds may construct an observation box with a door on one side, back of which a pane of glass is set. Such a bird house may be set up on a window sill, so that by opening the door the feeding and care of the young birds may be watched through the 
glass. I have often thus watched Bluebirds and Chickadees feeding their young.

Thus far it has been my intention to show how, expense may be avoided in the construction of nesting boxes. Nevertheless, expensive ornamental bird houses add to the attractiveness of a country home, and may be displayed where old tin

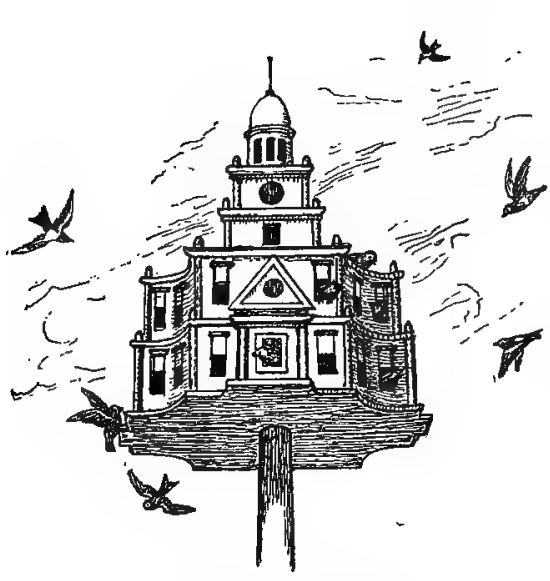

Fig. 169. - A Martin box. cans and cheap boxes would be out of place. In building such bird houses the best plan is to imitate the design of some dwelling. A pretty cottage or a country villa may be constructed in miniature. The large bird houses sometimes made are highly ornamental; but most of our native species are not social in their nesting habits, and when a large house is put up it is likely to be occupied either by a single pair of birds or by Purple Martins or House Sparrows. Such houses are sometimes occupied by both Martins and Sparrows, but in such cases the Sparrows usually in the end drive out the Martins. If the Sparrows can be driven arvay, there is no bird that can be so readily increased in numbers by putting up nesting boxes as can the Purple Martin. When once a colony of Martins becomes established, it will in a few years fill several large bird houses with its increase. The experience of Mr. J. Warren Jaccbs, who established a large colony, illustrates this. ${ }^{1}$ A few Martins are returning to some of their old homes in this State; they should be encouraged. The houses should be either taken down in fall and not put up until the Martins return in spring, or the entrances to the rooms should be closed up until spring, that the Sparrows may have no opportunity to get in before the Martins return. Were the Sparrows de-

1 The Story of a Martin Colony, by J. Warren Jacobs, Waynesburg, Pa. 
stroyed and more Martin boxes put up, we might have, in time, more Martins than ever. ${ }^{1}$ A house for a large Martin colony ordinarily involves the expenditure of a considerable sum ; but a very good house, that will accommodate a colony of ordinary size, may be made from a flour barrel. The roof is of zinc, or of wood covered with painted canvas. The Martin house should be placed on a pole at least fifteen to twenty feet high. It should have several large rooms, with entrances two to three inches in diameter, that it may provide room enough for several pairs of birds, and that each tenement may be readily inspected and cleaned when necessary, and the whole house should be painted in light colors, that the young birds may not suffer too much from the rays of the hot sun. It should be so constructed that the young birds may not be readily crowded out of the nest, and so become the prey of cats. Such a catastrophe may be guarded against by

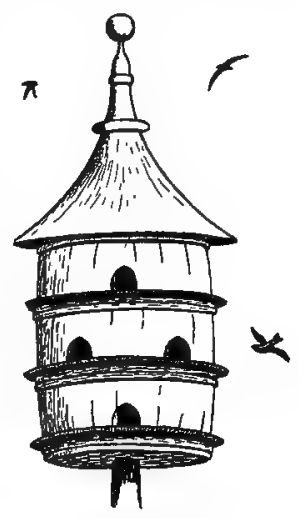

Fig. 170. - A Martin barrel. having a shelf or piazza extending round the house beneath each tier of doorways, and constructing a railing at least three inches high round the platform. Each of these platforms should have a slight downward pitch, to carry off the rain and prevent it from driving into the doorways below. There should be no brackets beneath the box, for they afford the cat a foothold. Many other designs will suggest themselves. A barrel might be covered and roofed with bark and the railings made of twigs. In fitting up the rooms, a square box should first be made, to go up the center of the barrel.

\footnotetext{
${ }^{1}$ An attempt might be made to establish the Martins by bringing here in the night from other States bird houses occupied by Martins, young and old, and setting them up on poles prepared for them in suitable localities here. There is reason to believe that such introductions would succeed if carefully conducted when the young had made about half their growth. One successful attempt is on record. There is a plentiful supply of food here for Swallows and Martins. The increase of mosquitoes and flies in many localities since the summer of 1903, when so many of these birds were destroyed, has attracted wide attention. The reinstatement of the Martins is an important matter, which should engage the attention of the State Board of Agriculture.
} 
All the rooms will be backed by this, and the pole will go into it. The pole may be made to go into a socket in the ground, and then both pole and house may be taken down in the fall and kept under shelter until the Martins return in the spring; or, if the pole is hinged near the bottom, the box may be still more readily taken indoors. This will prevent the Sparrows from intrenching themselves within. If a cedar pole is used, the bottom should be well tarred wherever it comes in contact with the ground. It should be set deep in the ground to give it the requisite firmness. If the nests of Martins are dusted occasionally with fresh insect powder, it will relieve them of the vermin which always congregate in large, occupied bird houses.

\section{Furnishing Nesting Material.}

An abundance of suitable and easily accessible nesting material may chiefly influence some birds in choosing a site for a home.

It is now believed that the Parula Warbler breeds only where the usnea moss grows luxuriantly, for in this moss she usually secretes her nest, constructing it largely of the same material. Robins, Swallows, and Phœebes must have mud for nest building. The Chipping Sparrow lines her nest with hair, usually that of the horse, cow, or deer. Vireos and Orioles must have hair or strands of some kind to construct the pendent fabrics which they skillfully weave. If we hang nesting materials on bushes, trees, or fences, or place them on the ground in the open, where birds will be in no danger from cats while securing them, this may prove to be the final "straw" which will decide several pairs of birds to nest on our premises. Such supplies, when watched, furnish ready means of tracing the nest builders to their nests. We can then take means to protect the nests from marauders. Rootlets, fibers of birch, cedar or grape vine bark, straw, fine hay, hair, feathers, thread, twine, rope yarn, jute, sphagnum moss, - all will serve a purpose. It is important to furnish twine, hemp, yarn, or some similar material for the Orioles; otherwise they may get it by tearing to pieces the nests of other birds which have used such materials. In 
dry weather we may provide mud for Robins, Swallows, and Phobes to use. At such a time a Robin has been seen to wet its feathers and then trail them in the dust to make mud for its nest. Put a pan of mud or clay on the window shelf, and see if the birds do not find it. All other nesting material should be exposed constantly from April to August.

\section{Feeding the Summer Birds.}

The food table or window shelf should be supplied with food all summer. It may help out some bird when in times of storm or temporary scarcity it can hardly find sufficient food for its young. We can make feeding experiments with grains and seeds, nuts and fruits, cooked foods, cereals, bread, and cake. There should be some food at hand for insecteating birds and their young, that we may teach them to trust us. Taming an old bird in summer is usually up-hill work; but now and then a Catbird or Robin, more confiding than the rest, may learn to come to be fed or even take food from the hand. Practically all birds will eat hairless caterpillars, such as the cankerworms; most of them are fond of grasshoppers and meal worms. We may now and then find it necessary to feed some young birds, when cold storms cut short the natural food supply.

Occasionally a young bird jumps or falls from the nest before it is full-fledged and strong. Such birds are likely to fall a prey to cats, snakes, or Crows; but we may be able to save them by a little care or a few days' feeding. It will not do to return the young fledgeling to the nest, as usually it will not stay there. If the weather is warm and the parents are at hand, the youngster may now be put in a cage with an oil cloth cover over its top, and the cage hung on the branch of a tree near the nest, where the parents sometimes will feed the fledgeling through the bars. It can be watched a little, taken in, and kept very warm for a few nights, when it may be allowed to go with the rest of the brood. If the parent birds are dead or have deserted the helpless young, it will be something of a task to supply by hand the wants of the young birds, as they need feeding often during daylight, and should be fed about all they will eat. Grasshoppers and 
hairless caterpillars, with chopped lean meat and a few earthworms cut up, will make a good substitute for the natural food. Those who wish to experiment in this way should read the chapter on taming and feeding birds in Nature Study and Life, by Prof. C. F. Hodge. They may thereby avoid mistakes, save much trouble, and prevent a useless sacrifice of bird life.

Our experience in attracting Bluebirds, Wrens, and Chickadees about the house by means of food and nesting boxes proves conclusively that we may easily domesticate these birds. Our experiments with the Chickadee will serve to illustrate how a species may be induced to leave its nesting places in the woods to nest and live about dwellings and under man's protection. We first cut down all the decaying trees near the house, leaving the birds neither dead wood in which to make holes, nor natural hollows in which to find shelter, - but not before we had put up artificial nesting boxes on the house and on the near-by trees. This was done in the fall, that the birds might become accustomed to the change before another nesting season, and that they might find sbelter in the boxes during the cold winter nights. It seems remarkable that Chickadees which naturally breed in decayed stumps or hollow trees should come to seek the shelter of old tin cans in winter; but eventually they did so, going early to these shelters, and nestling together there in company for mutual protection from the cold.

In the mean time, food was put out near the house windows, where nesting boxes had been put up. In the spring a single pair of Chickadees nesterl and reared seven young in a wooden box fastened to a window sill. The next year two pairs reared young in boxes within two rods of each other ; one was on the house, the other in an apple tree near by. The present year (1906) three pairs have reared young, and two of them have successfully brought off two broods each. In 1905 a pair accepted a wad of cotton placed in a box, dug out a hollow in it, and reared young there. This nesting box is situated upon a window frame three feet from an outside kitchen door. The illustration (Plate LIII) shows the bird and her nest. 


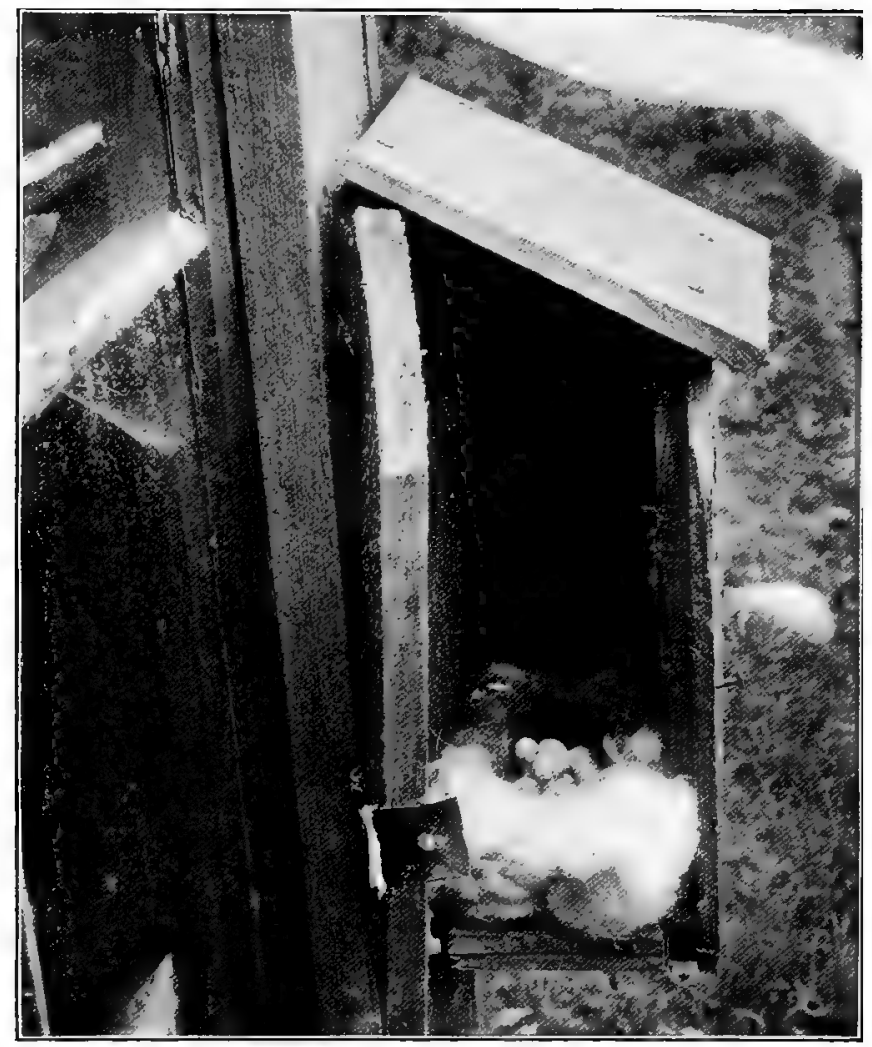

PLATE LII. - Chickadee's Nest, made of Cotton, in Box on Author's Window. 


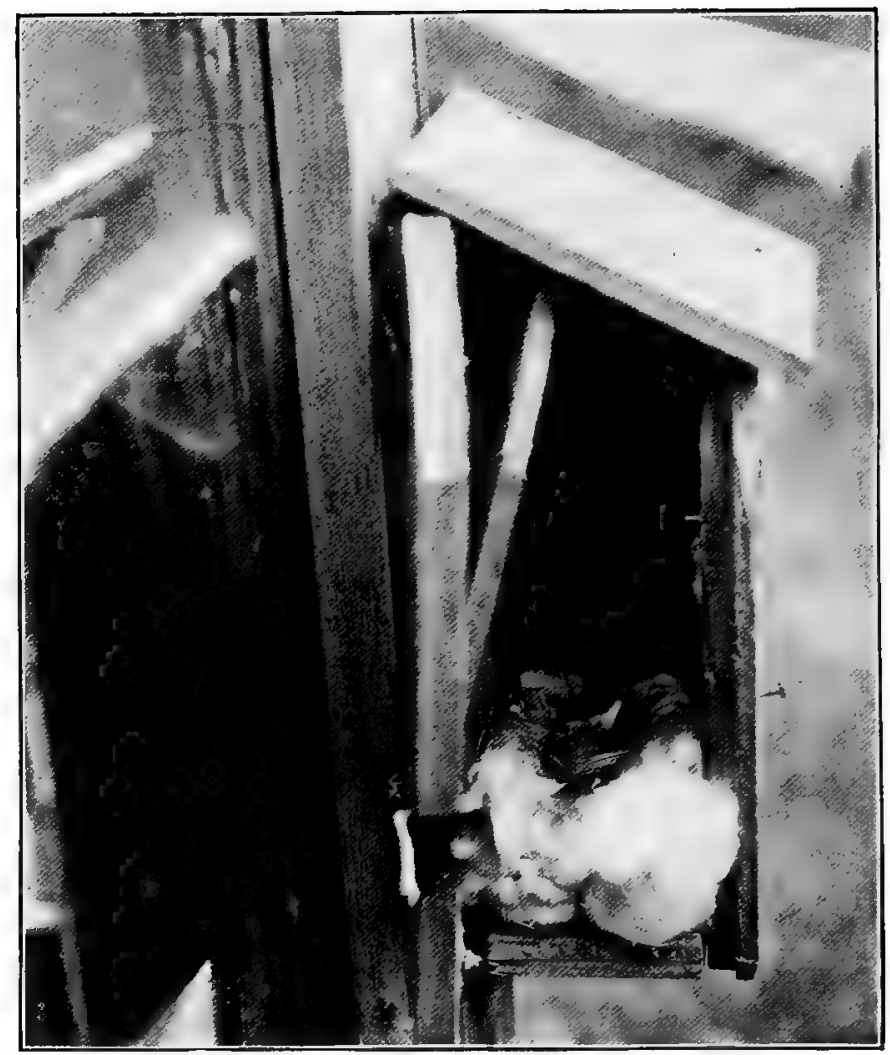

PLATE LIII. - Chickadee on Nest. 


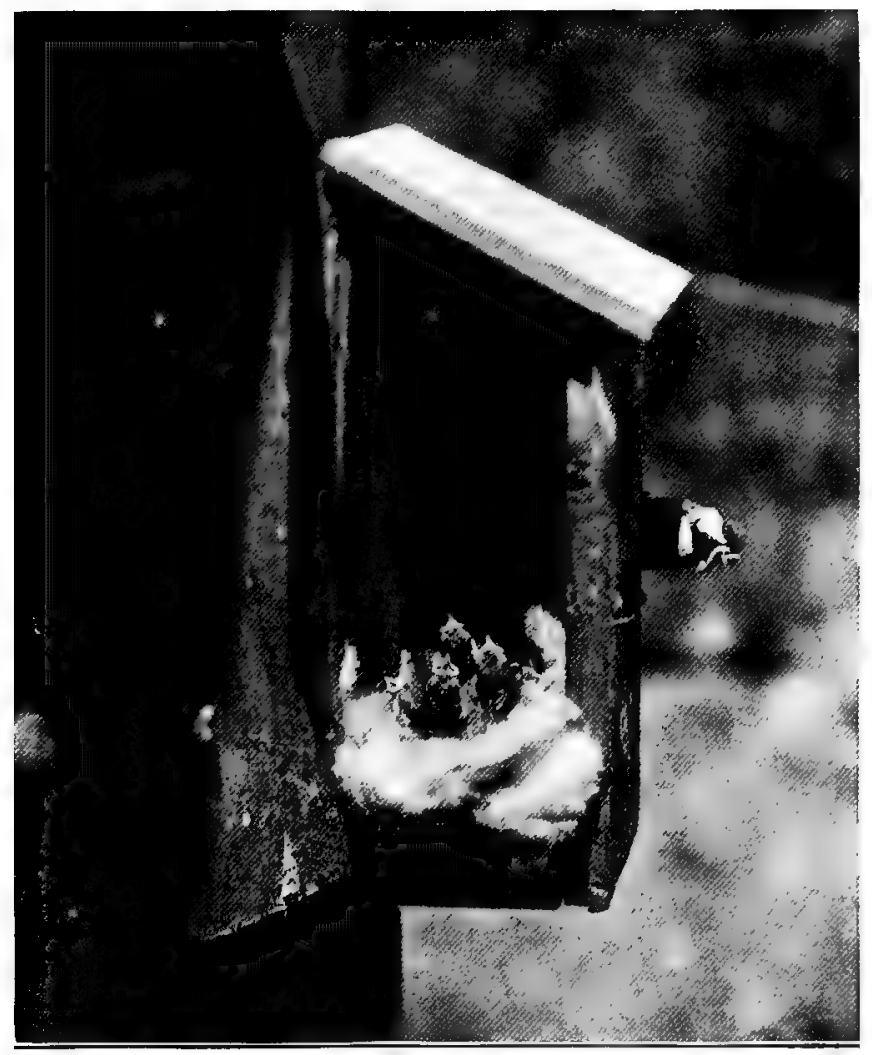

PLATE LIV. - Mother Chickadee bringing Food to Young. 


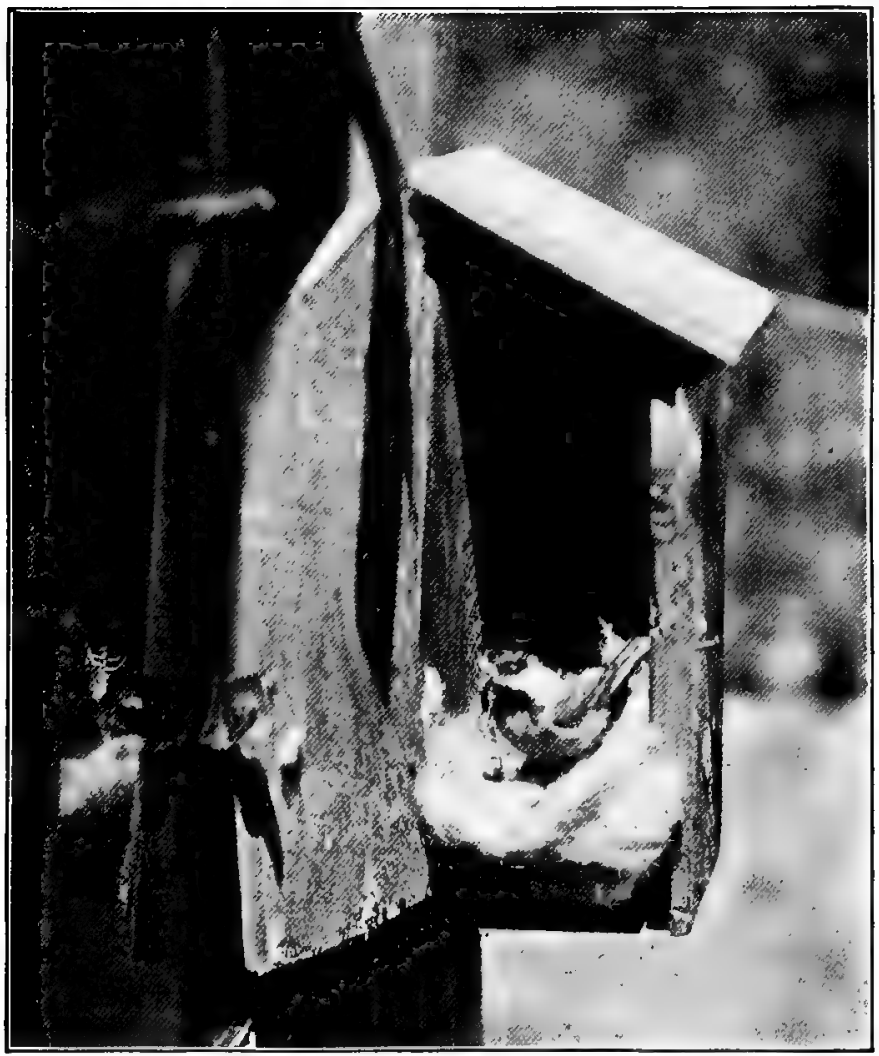

PLATE LV. - Mother Chickadee cleaning Nest. 
An incident occurred in connection with this box which shows how easily birds may be induced to occupy a nesting site, and what influence an ample food supply may have in deciding them. Two Chickadees came to the box in the spring of 1906, and went in and out of it for several day's, but finally seemed to be dissatisfied, and went away. A few days later a piece of suet was fastened to the window sill. Within twenty-four hours the birds found it. They visited it frequently, and at once began carrying nesting material into the box. A supply of suet was kept there, and two broods were reared in that box. The old birds fed on the suet often when hard pressed to fill the nine hungry mouths in the nest; but even then the young were fed on insects.

The Chickadees did not utilize a tin can for nesting purposes until 1904, when, during a call on a neighbor, I saw two Chickadees looking his house over in search of a nesting place. I called his attention to them, and he expressed a wish for a bird house. I took an old two-quart can from the dump, made a wooden stopper for it, cut a small bole in the stopper, and nailed the can up in the nearest tree. The Chickadees examined it, and within twenty minutes began building. Here they safely reared a brood. Evidently they preferred a wooden doorway to their castle, but since then they have learned to dispense with the wood.

The next summer my neighbor, Mr. Lewis E. Carr, wired up in a pine near his house an old varnish can that the boys had somewhat distended during their annual Fourth of July celebration. The Chickadees took up their quarters in it at once, and also nested in it in 1906. This can and its bird occupant are shown in Plate XLIX. Chickadees now occupy at least three cans of various sizes and descriptions. They seem to prefer those that are put up on or near houses. There is every reason to believe that, were it not for the introduction of the House Sparrow, several useful native birds might easily be induced to breed about our houses, and even in the cities, as familiarly as the Sparrow now does. 
Attracting Water-fowl.

The water-fowl have been hunted until they have become so wild that attracting them seems at first sight an utterly hopeless task. Nevertheless, it can be accomplished if only a place can be found where they may rest and feed unmolested. Wild Ducks soon learn where they are safe. Along the water front at Titusville, Fla., no shooting is allowed, but out on the river gunning is not prohibited. About the wharves and along the beach at the hotel wild Scaup Ducks swim, dive, and dress their plumage as unconcernedly as if there were not a man in sight. They sometimes come ashore and walk about on the grass near the hotel. They swim at ease among the small craft at the wharves, and act much like domesticated Ducks; but when the same birds get out on the river beyond the dead line, they can hardly be approached within gunshot by a fast-sailing boat. Wild-fowl, if undisturbed, will settle in the most unlikely places. A pair of Wood Ducks came regularly to a small pool in the grove not far from our house, until disturbed by workmen passing by. Those who have large estates containing ponds, where Ducks can be protected, may attract them by seattering grain in the water and on the shores. This has been successfully tried. A few "gray call Ducks" will prove an additional attraction. If the pond or stream has wooded shores, an attempt should be made to induce the Wood Ducks to breed. This may be done by putting up nesting boxes. One reason for the present scarcity of Wood Ducks in this portion of New England is, that summer camps are now established on many of the ponds where these birds formerly bred. Another reason is, that there are few hollow trees in which they can breed. People having suitably located woodlands should put up nesting boxes made in imitation of hollow logs, for the Wood Ducks. A box for these birds should be at least two feet long. It may be placed either perpendicularly or at an acute angle, and fastened not far from the ground on a tree near the water. It should have an opening at least four inches in diameter. Every thing possible should be done to prevent the extermination of this beautiful bird, and to secure an increase in its numbers. 


\section{THE PROTECTION OF BIRDS AGAINST THEIR NATURAL ENEMIES.}

Those who are successful in assembling birds about their homes are likely soon to find that they have also inadvertently attracted creatures to prey upon them. When our winter colony of birds was at the height of its numbers, in January, 1903, it was noticed that the birds were growing nervous and easily frightened. Soon one was seen to be minus a tail. Then their numbers began to decrease. An investigation revealed the cause, - two cats and a Sharpshinned Hawk. One day during my absence the Hawk struck a Blue Jay within twenty foet of the window. If we expect to conserve our small native land birds and increase their numbers, something more becomes necessary than protection from the gunner, the small boy, or the milliner's agent; for in woods where all shooting is prohibited the enemies of birds, particularly Hawks, squirrels, Crows, and Jays, are likely to increase in numbers, while the smaller birds decrease. This was the case in the Middlesex Fells Reservation, soon after the Metropolitan Park Commission took it. Four years' experience on my own place in protecting birds from gunners resulted in a very decided increase in the numbers of squirrels, Crows, and Jays, and a corresponding decrease among the smaller birds. Apparently less than ten per cent. of the smaller birds raised any young in 1902. During a long stay on the estate of $\mathrm{Mr}$. William Brewster, at Concord, Mass., in the breeding season of 1903, it became evident to me that the numbers of the smaller birds breeding in his woods had decreased much in the previous six years. No shooting had been allowed for several years on this estate of nearly three hundred acres. The owner had protected the game and birds from destruction by man; but the results, so far as some of the smaller wood birds were concerned, were disappointing. The Wood Thrushes nearly all disappeared. Where there had been five pairs of Redstarts breeding a few years before, only one pair was seen in 1903, and they disappeared later. Comparatively few birds were able to rear their broods that year, except the Robins and 
other birds that nested near the house, the ground-nesting birds, and those that bred in nesting boxes or hollow trees. Crows and Jays were common, though not increasing rapidly, and both Cooper's and Sharp-shinned Hawks were present (probably only one pair of each). Squirrels of three species were more numerous than I have ever seen them elsewhere. Since that year the number of birds about the house seems to have increased. This may be due in part to the fact that the Cooper's Hawk no longer breeds on the place; also, that the squirrels about the house do not molest the birds much, while many birds have been attracted by food plants and nesting boxes.

When it is found, on prohibiting shooting within certain limits, that the smaller birds are decreasing, we may infer that they are preyed upon by creatures that were formerly held in check by gunners. If this be true, then neither the gunners nor the sportsmen need be looked upon as the unmixed evil that some of us have been inclined to consider them; and the farmer who has no time to protect birds may safely allow honorable men to shoot on his land. Evidently the bird protectionist may be forced to the conclusion that, in order to protect birds, he must sometimes destroy some of their natural enemies, even if among these he is obliged to kill some birds. Hawks, Crows, Jays, and squirrels have become so accustomed to the persecutions of the gunner that they are able in a sense to persist in nearly normal numbers in spite of him; and when we eliminate shooting, they may increase, to the detriment of the species on which they prey. In a biographical notice of the late Henry D. Minot the following appears: "On the home grounds from seventy-five to a hundred nests were built every spring, and the broods therein successfully reared, for the birds were carefully protected. Cats, Hawks, gray squirrels, Crows, Jays, and snakes were summarily dealt with; every note of alarm was promptly answered with an efficient rescue, and all the spring and early summer the air was filled with the melody of happy birds." 1

\footnotetext{
- The Iaand and Game Birds of New England, by Henry D. Minot. Second edition, edited by William Brewster.
} 
What a great number of young birds must have gone out into the world from that place. The policy pursued by $\mathrm{Mr}$. Minot may serve as a model for the protection of a colony of small birds, and, if followed faithfully elsewhere, it ought to have the same gratifying results. Having undertaken a portion of the management of creation by introducing and cultivating strange plants and trees, and destroying the larger wild animals and the Eagles, Hawks, and Owls which formerly helped to keep Crows, Jays, snakes, squirrels, and other predatory creatures in check, we must not now shirk the responsibility that rests upon us to protect the timid and defenceless birds which we have left exposed to their increasing enemies. But, if we accept the burden of protecting birds, we must exereise our poiver with wise discretion. It should not be inferred, for instance, if a gray squirrel destroys the young of a pair of Robins, that this is a habit with all gray squirrels. Those who have large estates, on which they can protect birds and game, are particularly fortunate if they have in their employ keepers who ean intelligently discriminate in such matters; otherwise, serious mistakes may be made. Millais, in his magnificent work on British surface-feeding Ducks, relates that in 1884 Brown-beaded Gulls began to increase in the bog at Murthly. The keeper said that the Gulls were killing young Teal. Another experienced keeper suggested that this was probably the work of a single Gull. The Gulls were watched, a pair of birds were seen together, one of which began to kill ducklings. Both birds were shot, and no more ducklings were killed that year. In 1890 another pair of Gulls began killing young Teal ; sixteen were found dead. The two culprits were shot, and no more young Teal were killed that season. Millais cansiders that individual Gulls are as dangerous to young Ducks as any of their numerous enemies; and yet probably only two, or at the most four, of the large number at the bog were actually doing the killing. ${ }^{1}$ Had not the gamekeeper been an intelligent observer, a hundred innocent Gulls might have been shot, and the guilty birds might have escaped to

\footnotetext{
1 Nevertheless, observers agree that the habits of bird-killing and egg-eating are quite general among certain species of Gulls.
} 
continue their nefarious work elsewhere. Millais confidently advances the theory that a few individual birds do the mischief for which perhaps the whole race is blamed. He believes that the individual criminal among birds does his work stealthily, and so is seldom observed; that his family is fed on the results of his rapacity; and that the young acquire similar tastes and habits, which in time may spread from family to family and from one community to another. He states that years ago the Rooks of southern England were practically innocent of stealing eggs or young birds, though their cousins in the north were nest-robbers even then. He says that now there is hardly a community of Rooks in the south of England that does not contain individuals with the nest-robbing habit. The view that certain depraved individuals among birds and mammals are responsible for most of the unusual depredations on other birds and mammals is held by many observers. The Marsh Hawk and the Redshouldered Hawk are among the most useful of all Hawks; but I have known individuals of both these species to be destructive to birds or young poultry. If such individuals can be shot, it will be a decided benefit to all concerned.

Where Cooper's and Sharp-shinned Hawks cannot be shot, they may be caught by setting steel traps in their nests.

It is quite probable that some Crows do not habitually steal the eggs and young of other birds. In fall, winter, and early spring we may welcome Crows about our farm buildings. They may do much good in the fields in summer, but, as a measure of safety, they should be kept as far away from small breeding birds as possible. Poison will kill some and drive the rest away; but exposing poison in this way is illegal, and there is great danger of poisoning useful birds. Egg-eating Crows may be trapped by exposing an egg on the ground in such a way that the Crow must step into a concealed trap to get the egg. After two or three have been caught in this way, the others will avoid the place. Our laws which deny protection to the Crow are wise, for it is one of those species which, though at times most useful, may become a pest if not held severely in check.

Watch the Jays, and shoot every one that is found dis- 
turbing the nests of other birds. The actions of the birds and their manner toward the Jay are usually sufficient indication of its character. It is not very difficult to surprise the Jay in its raids on birds' nests. It may possibly be necessary now and then to kill a Crow Blackbird that has the nest-robbing habit.

No native bird should be exterminated, for they all serve some useful purpose; but if the introduced House (or " English") Sparrow could be exterminated, one of the chief obstacles to the increase of native birds about villages and cities would be removed. This is now a hopeless task; but much has been effected in some localities by feeding the birds on poisoned whèat. Such work, however, should never be attempted except by skillful and experienced persons, as otherwise there is much danger of poisoning poultry, Pigeons, and native birds. A persistent shooting of the birds, together with the continual removing of their eggs from all nesting boxes, will eventually drive them out of a locality.

All who desire to harbor and protect birds must eliminate the bird-killing cat. The cat is of some service in preventing the increase of rats and mice in dwellings, as well as that of other small rodents of the fields and woods; but the vermin of the house may be controlled by traps and poison, while those of the field may be restrained by Hawks and Owls. A ferret will in a short time drive all the rats from a building. A smart fox terrier or a good "ratter" will practically exterminate the rats about a farmhouse. As the cat is not an absolute necessity, and as it is a potent carrier of contagious diseases, which it spreads, particularly among children, it would be far better for the community if most of the bird-killing cats now roaming at large could be painlessly disposed of. The Society for the Prevention of Cruelty to Animals has added another to its long list of good works by chloroforming many thousands of homeless vagrant cats in the cities. The Animal Rescue League is not far behind in this good work, which ought to be extended farther into the country districts. Where the cat is deemed necessary in farm or village, no family should keep more than one good mouser, which should never be allowed to have its liberty 
during the breeding season of the birds, unless it has been taught not to kill them. Cats can be confined during the day in outdoor cages, as readily as rabbits, and given the run of the house at night. Massachusetts law does not give the cat protection, and all cats found running at large may be treated as wild animals. All wild or "woods" cats should be shot at sight. Marauding cats may be trapped by box traps baited with catnip, and held for the owner, or killed if no owner appears.

Farmers know well how to deal with foxes, weasels, minks, skunks, and raccoons: They regard squirrels as pests ; but it is extremely probable that it is only the individual squirrel that robs birds' nests. Mr. A. C. Dike writes me that one season when he was carefully watching the birds about his place he saw the eggs and young in eight birds' nests destroyed by the red squirrel; but that in each case the same squirrel was the culprit, for he was able to identify it, because it had lost a part of its tail in escaping from the cat. Squirrels often nest in hollow trees in which birds have already established themselves, thus driving out the birds. It is quite possible that in some localities many of the squirrels may have acquired the habit of killing birds. When this is evident the squirrels should be killed. Unfortunately, the law protects gray squirrels at the only time when this habit can be observed. Where birds show no alarm when squirrels approach their nests, the presumption is that the squirrels are innocent. The beauty and grace exhibited in the forms and motions of squirrels have made them favorites with many people, who will not wish to kill them. Others will wish to avoid killing Crows, Jays, Hawks, or even cats. But all should regard it a duty to protect the nests of birds from these marauders. Some experiments in this direction have been made. It is a simple matter, as has been described, to protect such birds as will build in nesting boxes; but those that nest on the ground are peculiarly liable to the attacks of their enemies, and other means of protecting them may possibly be devised.

Years ago I secured a translation of a paper published in France by Xavier Raspail, entitled "The Protection of Use- 
ful Birds," in which he gives a method of protecting their nests from their enemies. Of sixty-seven nests observed from April to August, only twenty-six prospered. Of the forty-one destroyed, fifteen were known to have been robbed by cats, eight by the garden dormouse, three by Jays, and two by Magpies. He protected twenty nests either by furnishing the birds vermin-proof bird boxes to build in, or by surrounding the nests with wire netting. Only two of these were robbed of eggs or young, and they were pillaged by animals that got through or under the netting. These simple methods of protection assured the rearing of one hundred and two young birds from nineteen nests. Comparing these figures with those from the unprotected nests, we find that, proportionately, only seven pairs of parents out of the twenty would have succeeded in rearing their young had their homes been unprotected. The paper lacks a complete description of the method of putting up the wire nest protectors. There is nothing to show whether the enclosure was without a cover, or whether an opening was left in the top just large enough to admit the parent birds; but the mesh used was, in some cases at least, small enough to keep out mice, or about one-fifth to one-sixth of an inch in diameter. The language used seems to indicate that the nests on the ground were merely enclosed by a circular fence of wire netting. Mons. Raspail says that nests so protected are not attacked by weasels or mice. There seems to be nothing to prevent these animals from climbing over the wire, except that they may stupidly strive to get at the nest from below, and so walk around the cage without seeking an entrance above. The sly fox, perceiving the smell of iron, might suspect a trap. Probably Crows and Jays, being also suspicious of a trap, would not enter these enclosures. The surrounding of the nests with netting in no case caused the birds to desert their home, even when it was done as soon as the nest was completed and before the eggs were laid. This method might be worth a trial.

Where nesting trees are isolated, cats and squirrels may be kept out of them by the use of either of the devices shown in the cut (Fig. 171), for these animals cannot climb up a per- 
fectly smooth surface. Nesting boxes mounted on poles may be guarded in this way. Zinc is the best material. A wide piece of wire netting, shaped like a hat brim, and fastened around a tree, will prevent cats and squirrels from climb-

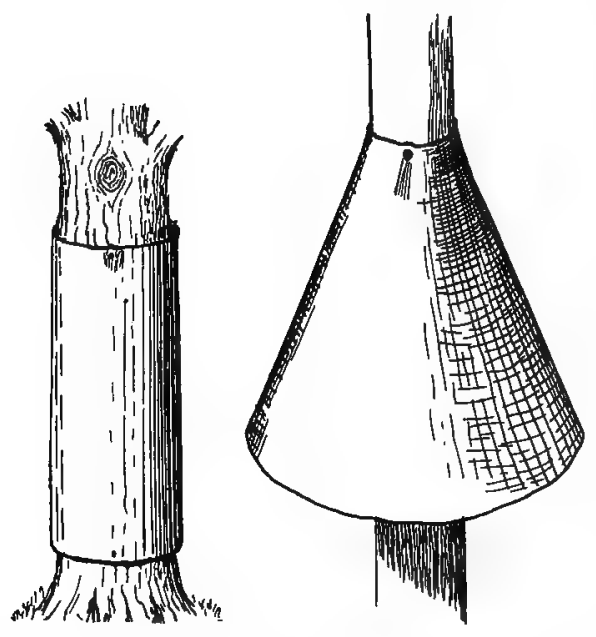

Fig. 171. - Zinc bands to prevent cats or squirrels from climbing trees or poles. ing it. A smooth, tall, slim pole, made of a peeled sapling pine set in the open, is rarely climbed by cats or squirrels.

Thick thorn bushes often serve as safe nesting places for birds. Bundles of thorny sticks tied around tree trunks will keep cats out of the trees. An island in a small artificial pond is also a refuge from cats. The best cat-proof fence for a city garden is that used by Mr. William Brewster at Cambridge. It is made of wire netting some six feet in height, surmounted by a fish seine of heavy twine, which is fastened to the top of the wire. The top of the net is then looped to the ends of long, flexible garden stakes. This fabric gives beneath any weight, and offers so unstable a footing that no cat ever succeeds in scaling it. Mr. Brewster's garden has become famous for the numbers of birds that breed there, and the migrants that visit it year by year.

\section{THE PROTECTION OF FARM PRODUCTS FROM BIRDS.}

Serious losses sometimes occur from injury inflicted on crops or poultry by birds. It is well to remember, however, that, while the harm done by birds is conspicuous, the compensating good that they do is usually unnoticed. In most cases it is best not to kill them, but to protect both birds and crops ; for by killing too many birds we may disturb the biological equilibrium, and bring about a greater 
injury than the one we attempt to prevent. The destruction of too many corn-pulling Crows, for example, might be followed by such an increase of grubs and grasshoppers that no grass could be grown; or the extermination of Hawks and Owls might be succeeded by the destruction of all the young fruit trees by hordes of mice. Moreover, other evils, far less simple and easily traceable, might result, for the widening ripples that man creates by disturbing the balance of nature are likely to be felt in the most unexpected places.

Most birds earn more of our bounty than they receive, and that portion of our products which they ordinarily eat may be justly looked upon as but partial payment for their services. Nevertheless, the farmer must protect his property from excessive injury, such as sometimes occurs when the natural food supply of birds is cut short, or when too many are gathered upon a small area.

To protect Grain from Crows and Other Birds.

The following spring measures are recommended :-

1. Tar the seed corn, as follows: "Put one-fourth to onehalf bushel of corn in a half-barrel tub; pour on a pailful of hot water, or as much as is necessary to well cover the corn ; dip a stick in gas tar, and stir this briskly in the corn; repeat until the corn is entirely black; pour off onto burlap (bran sacks are excellent); spread in the sun and stir two or three times during the day. If this work is done in the morning, and the day is sunny, the corn will be ready for the planter the next day without any other care. The hot water softens the tar so that just enough will adhere to the corn, and the corn is completely glazed by the sun. This is by far the quicker way of tarring corn, is harmless and effectual, and $I$ have for years planted with a machine corn treated in this way." 1

2. Scatter soaked corn often about the borders of the field.

3. Plant the seed three or four inches deep. This is said to prevent corn-pulling by Crows, and must be effectual on heavy soil.

\footnotetext{
1 Ethan Brooks, in Annual Report of the Massachusetts State Board of Agriculture, 1896, p. 294.
} 
4. Surround the field with a line of twine, strung on upright poles, and suspend rags, streamers, pieces of bright tin, etc., from the twine.

5. A frequent change in scarecrows is advisable. A barrel hung on a leaning pole puzzles the Crow.

To drive Blackbirds from a cornfield in autumn, a charge of fine shot fired from a long distance, so as to rattle among them, will be effectual without injuring them.

To protect grain from the House (or "English") Sparrow a liberal use of the shotgun is usually successful. Poisoned wheat has been used in extreme cases.

To protect Small Fruits.

It is not usually good biology to shoot birds for eating fruit. It is better to provide fruit enough for both birds and man, especially wild fruit, which birds prefer. The following protective measures are recommended :

1. To protect strawberries and cherries (May and June), plant Russian mulberry and June berry or shadberry, or plant several trees of the soft early cherries, to furnish food for the birds. The Governor Wood is a type of the kind they prefer. (G. T. Powell.)

2. To protect raspberries and blackberries (July and August), plant mulberry, buckthorn, elder, and chokeberry. (Florence Merriam [Bailey].) Also, plant some early sweet berries, and let the fruit remain until dead ripe, to attract the birds from the others. Strawberries may be thus protected. (Prof. H. A. Surface.) The larger fruits, such as apples, pears, and peaches, are not much injured by birds in Massachusetts.

3. Where it is found impossible to protect small early cherry trees in any other way, it will pay to cover them with fine fish net while the fruit is ripening.

4. If Kingbirds nest near cherry trees, they will keep other birds away. Bees, particularly drones, attract Kingbirds.

To protect Poultry from Hawks and Crows.

1. Rear the young chicks or ducklings on grassland, in portable brooders or coops to which movable runs are attached. Poultry reared in this way is much finer for the 
table than if allowed to run. The stock intended for laying may be given free range when four months of age, or when too large to be attacked by Crows or most Hawks.

2. Kingbirds, Martins, or our largest Hawk, the Osprey or Fish Hawk (Pandion haliaëtus carolinensis), if allowed to nest near the coops, will protect all poultry from Hawks. All these birds are confiding wherever they are unmolested. Where the Osprey is protected it will build its nest in a tree near the farmyard. It never troubles poultry or small birds, and should be protected by law at all times.

3. Hawks may be frightened away from the poultry yard if a general shout is raised whenever one appears.

4. When a Hawk has flown off with a chicken it should be followed quickly but cautiously, and may be shot while absorbed in eating its prey.

\section{GENERAL PROTECTIVE MEASURES.}

The first and most important step in protecting birds from their human enemies is to create a public sentiment in favor of birds, by teaching their value and the necessity for conserving them. This is a legitimate work for State boards of agriculture and State boards of education. Free lectures on this subject, illustrated by stereopticon, should be given at teachers' institutes and State normal schools, at gatherings of school children held for the purpose, at farmers' institutes, and before farmers' clubs and grange meetings. Some work of this nature has been done by the Massachusetts State Board of Education and by the ornithologist of the State Board of Agriculture, but much more should be done.

There are ample reasons for introducing economic nature study in the schools. The utility of birds and the means of attracting and protecting them should be taught in home and school as the most important bird study. A feeding shelf for birds should be put up at a window of every country school-house, or upon the flag pole. Children should be induced to plant trees, vines, and shrubs that furnish food for birds. The making of nesting boxes should be taught in the schools. This is a good subject for manual training classes. The boy who learns to feed birds and to furnish 
them with houses will always be their friend. Boys should be taught to exchange the gun for the camera, the sketch book, or the note book. Children should be cautioned not to disturb the nests of birds during the breeding season; but the nest census, taken after the leaves have fallen, is instructive and harmless.

An educational propaganda should be carried on in those States in which the birds that breed in Massachusetts or pass through it are killed in their migrations. Every State should have an official economic ornithologist, among whose duties should be investigation of the relations of birds to insect and other pests, and the production of popular leaflets and newspaper articles on birds and their conservation. When public sentiment in favor of bird protection is thoroughly aroused, then, and not till then, will effective laws be enacted, respected, and enforced.

\section{Game Protection.}

The conservation of fish and game is a vital preliminary step in bird protection.

It is plain that, having necessarily destroyed the larger predatory animals, man must hold in check the creatures on which they formerly fed. This is the task of the angler and the sportsman, and it is a legitimate one, in so far as it disposes of only the surplus fish, mammals, and birds; but the tendency to go farther than this must be sharply curbed, for wherever the larger game mammals and game birds are exterminated, people begin to shoot the smaller species. So long as the supply of game is kept up, just so long are the song birds comparatively safe.

A mere glance at the history of game legislation in Massachusetts or any other eastern State is enough to make one wonder that any native game now exists. From the settlement of Massachusetts until the year 1817 there was practically no limit to the amount of bird shooting that any one might legally do at any season of the year. Until that year the only legislation enacted regarding birds provided bounties for their destruction. Among other species, the Ruffed Grouse or Partridge was the victim of local 
bounty laws. By 1817 most of the larger game mammals and game birds were nearing extermination, and people were beginning to shoot Robins, Larks, Snipe, and Woodcock, in place of larger birds. A law was then passed protecting these birds from March 1 to July 4, and Partridges and Quail were protected from March 1 to September 1; but this law was nullified locally by town option, for any town meeting could annually suspend its operation.

The most stringent game legislation of the middle nineteenth century period was a series of acts, not for the protection of the birds, but for the benefit of people engaged in netting Wild Pigeons. The penalties for disturbing Pigeons about net beds were heavier than those for merely killing game out of season. They even included a term in jail.

It would be ludicrous, were it not pathetic, that we withhold adequate statutory protection from game birds until they are practically exterminated. Protective statutes come too late. It is only within recent years, when the Passenger Pigeon and Heath Hen have become nearly extinct, that statutes protecting them at all times have been enacted and retained on the statute books. We have only just succeeded (1906) in getting enactments protecting the Wood Duck and the Bartramian Sandpiper or Upland Plover at all seasons. Unless stringent laws can be passed and enforced in other States, as well as in Massachusetts, the extinction of these birds is even now imminent.

The game laws of Massachusetts for 1906 protect all "song and insectivorous birds," Doves, Pigeons, Heath Hens, Pinnated Grouse, Pheasants, Bartramian Sandpiper or Upland Plover, Herons, Bitterns, Wood Duck, and most Gulls and Terns throughout the year. Other game birds and wildfowl are protected, but inadequately. Eventually the shooting season must be shortened.

Measures and Legislation necessary for the Protection of Game and Birds.

To provide against the extermination of game, there must be established throughout the country a series of State reservations, maintained as places of refuge for game, where 
it can be absolutely protected at all seasons. Large forest reservations have already been acquired by the United States government and by several States. In January, 1906, New York had reserved nearly a million and a half acres, and Pennsylvania had purchased, or contracted for, seven hundred and fifty thousand acres. Connecticut, New Jersey, and other States have adopted reservation policies; and, as Alfred Akerman, late State Forester of Massachusetts, well says, this Commonwealth ought to extend its policy of park reservation to include genuine State forests. There are about three million acres in Massachusetts that are of little value except for forestry. Under rational forest management we might, in time, grow most of the lumber used here, instead of buying it in the north, west, and south. This land is the natural stronghold of the Ruffed Grouse, the red deer, and many other game mammals and birds. A goodly portion of it should be devoted to the preservation of the forests and the game. ${ }^{1}$

Some of the great ponds of the State should be set off as reservations for water-fowl; marshes and sandy shores should be taken as refuges for sea fowl and shore birds; and islands should be reserved as breeding places for sea birds. Undoubtedly the profits from the forest reserves would, in time, pay the cost of maintaining the entire system. Prussia owns six million acres of forest land, from which the government derives a net annual revenue of $\$ 9,000,000$; and France receives a net yearly income of $\$ 1.91$ per acre from its large government forest.

While this policy is being inaugurated, other legislation is imperative. Laws must be enacted, whenever it becomes necessary, protecting certain birds at all times for a series of years, and those laws must be enforced with a strong hand. Spring shooting destroys the naturally selected breeding stock which has survived the dangers of fall and winter; it should be absolutely prohibited. More and more stringent regula-

1 A large part of the forested land of the State will probably always remain in the hands of private owners or corporations. Farmers on adjoining farms may band together, and, by posting notices on their lands, they may protect the game of considerable tracts. Farmers in some towns are now trying this plan. Wealthy owners of large tracts have a still better opportunity to work for the public good. 



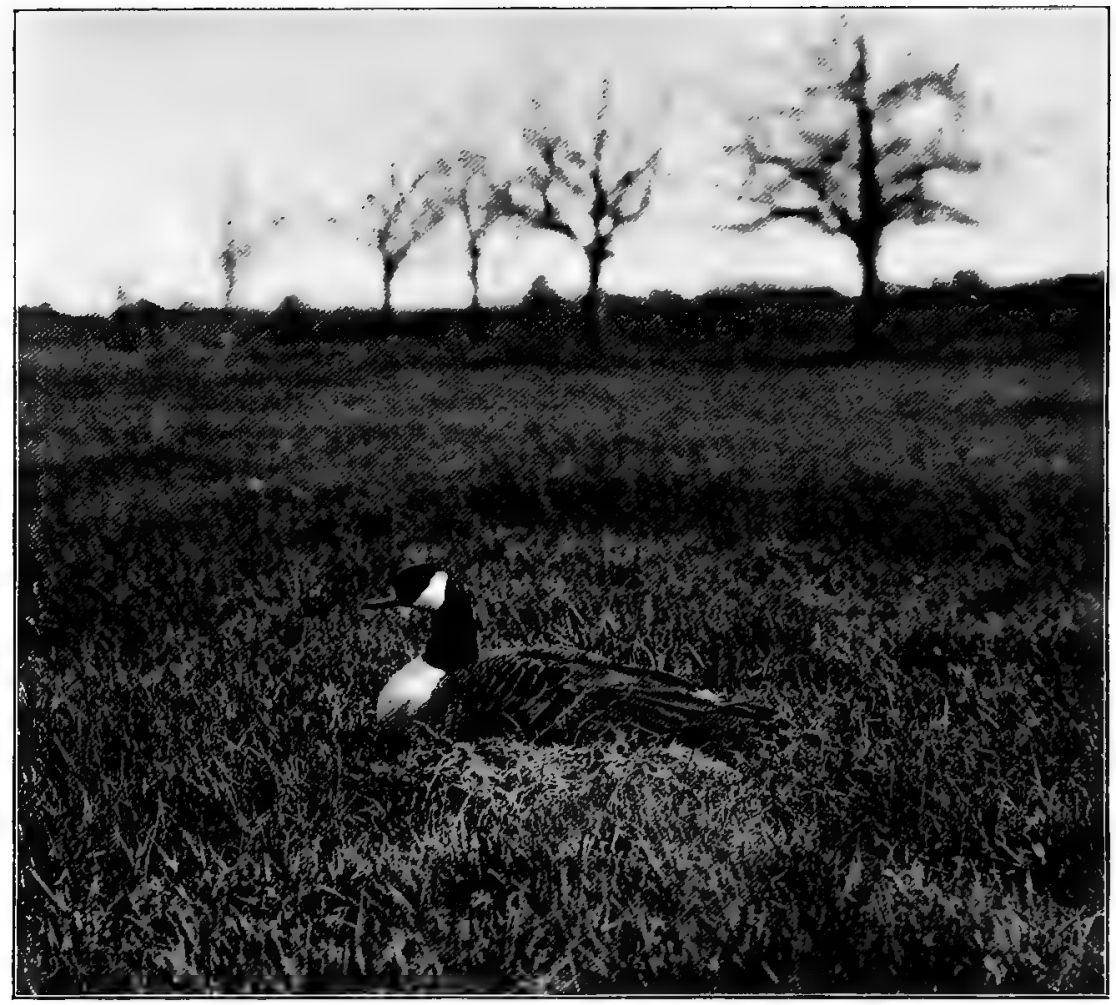

PLATE LVI. - Domesticated Canada Goose on Nest. (Photograph, from life, by I. Chester Horton.) 
tions will become necessary regarding the marketing and shipment of game. The hunting license, which is now finding favor in many States, must sooner or later be adopted here.

It is doubtful, however, if all these measures will result in replenishing our woods with game in its former abundance. The restocking of covers with birds from other Statesan excellent method, which has long been practised by game protective associations - is likely to come to an end, for already most States do not allow shipments of birds to points outside the State boundaries.

Artificial Propagation of Game Birds.

The greatly increased demand for game birds must be met by a new source of supply. The only promising method available for restocking is artificial propagation and feeding. Pheasants, Quail, Wood Ducks, Mallards, Teal, and other wild-fowl may be reared in great numbers if the work is scientifically done. It was interesting to observe the large number of Pheasants and Mallards successfully reared in 1905 by Mr. Bayard Thayer at Lancaster. This is the work in which commissioners on fisheries and game, game protective associations, and wealthy land owners must engage if we are to have game in its former abundance. A beginning may be made by importing experienced gamekeepers from England and Scotland, where, notwithstanding the long settlement of the country and the density of the population, people have game for their own use, and export a great deal to this country to supply our depleted markets. Artificial propagation is the most important work of the century concerning game birds. Many thousands must be reared and liberated annually in every Atlantic coast State, until the covers are well stocked and the marshes again swarm with game birds and wild-fowl.

Attempts should be made to domesticate game birds. In more than three centuries since the discovery of the American continent only one American bird, the Turkey, has become widely distributed through domestication. There is no doubt that Quail, Grouse, and Wood Ducks may be readily tamed, and the Canada Goose has been long known 
to be capable of domestication. More attention to this subject might add largely to the quantity of our food supply, and provide a source from which the stock of game could be replenished. The restocking of the State with a plentiful supply of game would keep within her borders a part at least of the more than two million dollars which is annually spent in other States by her sportsmen, and it would provide recreation at home for those who cannot afford the expense of travel.

THE MOVEMENT FOR BIRD PROTECTION.

In setting forth the measures necessary for the protection of birds, one cannot ignore the fact that a great movement for bird protection is under way and has already accomplished great good. The Audubon societies of the country have so influenced public sentiment as to practically stop the wearing of the feathers of useful American birds. The American Ornithologists Union was enabled, through moneys raised by the efforts of Mr. Abbott H. Thayer, to protect the sea birds on many islands along the coast of the United States for several years. ${ }^{1}$ This work and the general one of protecting native birds and other animals have been taken up by the National Association of Audubon Societies, under the leadership of Mr. William Dutcher of New York. The untiring devotion of his time and means to this cause is bringing forth fruits in the shape of improved legislation and aroused public sentiment in many States. Through his earnest efforts this movement is receiving deserved endowment, which will undoubtedly result in its perpetuation. Game protection has been taken up by the Biological Survey of the United States Department of Agriculture, and a very efficient officer, Dr. T. S. Palmer, has been placed in charge of the enforcement of the Lacey act. State governments have been assisted by the strong hand of the United States in enforcing advanced legislation. The central government has co-operated with the Audubon societies and game protective associations of

\footnotetext{
1 The Massachusetts colony of Terns and Gulls at Muskeget Island was saved from extermination first through the efforts of Mr. William Brewster and others and later by the continuous work of Mr. George $\mathrm{H}$. Mackay.
} 
different States. This co-operation has resulted in a great general improvement in State laws and their enforcement. This movement, now so well under way, gives promise of preserving a large part at least of the wealth of our fauna, which we may be said to hold as trustees for posterity.

For the benefit of those persons who are interested in caring for and protecting birds, a list of some officials and associations who will help to further the work is appended :-

Bureau of Biological Survey, United States Department of Agriculture, Washington, D. C., Dr. C. Hart Merriam, chief, Henry W. Henshaw, administrative assistant. The Survey distributes a large number of authoritative publications on the food habits and utility of birds. Dr. T. S. Palmer of the Survey, assistant in charge of game preservation, has literature on that subject for distribution, and is prepared to furnish information that will aid in the enforcement of the game and bird laws.

The National Association of Audubon Societies (offices, 141 Broadway, New York), William Dutcher, president, T. Gilbert Pearson, secretary, is helping the cause of bird protection everywhere by every means in its power. It sends, out excellent illustrated leaflets to teachers, and directly influences legislation.

The Massachusetts Commission on Fisheries and Game (Room 158, State House, Boston), Dr. George W. Field, chairman, is the legally constituted authority for the enforcement of the fish, game, and bird laws of Massachusetts. The commission furnishes, on request, a poster containing an abstract of these statutes. A copy of this is posted annually in each post-office in the State. The officers of the commission attend to all complaints of infractions of these laws. The commission is also engaged in propagating Pheasants, Quail, and Grouse.

The State Board of Agriculture (room 136, State House, Boston), J. Lewis Ellsworth, secretary, distributes bulletins, reports, and nature leaflets on birds and bird protection; also cloth posters, on which are printed extracts from the trespass laws.

The Massachusetts Fish and Game Protective Association 
(216 Washington Street, Boston), William Brewster, president, Henry H. Kimball, secretary-treasurer, is the most influential and effective game protective organization now actively at work in the State. It furnishes game birds to restock depleted covers, grain for game birds in winter, and posters containing abstracts of the game laws. Its officers also assist in the enforcement of the statutes. Practically all the game protective associations of Massachusetts are affiliated with this organization.

The Massachusetts Audubon Society (234 Berkeley Street, Boston), William Brewster, president, Miss Jessie E. Kimball, secretary, is one of the most powerful forces for bird protection in the State. Its local secretaries are numerous, and its influence is widely felt. This association takes no direct action to enforce the law; its chief function is to influence public sentiment, and secure protective legislation. The secretary has literature for distribution, and the association publishes charts and provides lectures on birds.

The Massachusetts Society for the Prevention of Cruelty to Animals (19 Milk Street, Boston), George T. Angell, president, Hon. Henry B. Hill, vice-president, furnishes cards for posting in public places, offering rewards for the conviction of persons killing birds or taking their nests or eggs. This society, whose good work is well known, also furnishes free literature advocating kindness'to birds and other animals.

There are other associations that take an interest in the protection of birds. The Animal Rescue League, the League of American Sportsmen, the Agașsiz Association, and many minor societies and sportsmen's organizations, lend their influence to strengthen this movement. Sportsmen's periodicals have done much for the protection of birds and game. The Forest and Stream Company of New York, under the direction of Mr. J. Bird Grinnel, supported the first Audubon Society for years, both editorially and financially. Writers like Herbert K. Job, Ernest Harold Baynes, and A. C. Dike are peuning helpful articles for newspapers or periodicals. Nature books are teaching altruistic ideas regarding birds. 
All these agencies must help to hasten the day when our woods shall teem with game and birds; when our lakes and rivers shall be populous with wild-fowl; and when our people, young and old, shall welcome, protect, and cherish our feathered friends of orchard, garden, and field. If this volume shall help in any degree to bring about this consummation, it will not have been written in vain.

Papers on Ornithology, Publisiled by the Massachusetts State BOARD OF AGRICULTURE.

\section{Essays and Lectures.}

Utility of Birds. Wilson Flagg. Annual report of the Massachusetts State Board of Agriculture, 1861 (Part II.), pp. 50-78.

Agricultural Value of Birds. E. A. Samuels. Ibid., 1865 (Part T.), pp. 94-117.

The Utility of Birds to Agriculture. Frank H. Palmer. Ibid., $187 \mathrm{f}$ (Part II.), pp. 107-120.

Insect-eating Birds. Frank H. Palmer. Ibid., 1872 (Part II.), pp. 194-210.

Birds of Massachusetts. Dr. B. H. Warren. Ibid., 1890, pp. 34-57. The Regulative Influence exerted by Birds on the Increase of Insect Pests. E. H. Forbush. Massachusetts Crop Report, September, 1894.

Birds as Protectors of Orchards. E. H. Forbush. Annual report of the Massachusetts State Board of Agriculture, 1895, pp. 347-362.

The Crow in Massachusetts. E. H. Forbush. Ibid., 1896, pp. 275296.

Nature's Foresters. E. H. Forbush. Ibid., 1898, pp. 279-294.

Birds as Destroyers of Hairy Caterpillars. E. H. Forbush. Ibid., 1899 , pp. 316-337.

Birds Useful to Agriculture. E. H. Forbush. Ibid., 1900, pp. 36-61.

Birds as Protectors of Woodlands. E. H. Forbush. Ibid., 1900, pp. 300-321.

Two Years with the Birds on a Farm. E. H. Forbush. Ióra., 1902, pp. 111-161.

Special Reports.

Ornithology of Massachusetts, List of Species. E. A. Samuels. Annual report of the Massachusetts State Board of Agriculture, 1863 (Part I.), Appendix, pp. xviii-xxix.

Report on the Birds of Massachusetts, by the State Board of Agriculture to the House of Representatives, under the resolution of May 28, 1890. Ibid., 1890, pp. 267-273. 
The Destruction of Birds by the Elements in 1903-04. E. H. Forbush. Ibid., 1903, pp. 457-503.

The Decrease of Certain Birds, and its Causes, with Suggestions for Bird Protection. E. H. Forbush. Ilid., 1904, pp. 429-543.

\section{Nature Leaflets.}

No. 12. Winter Birds at the Farm. E. H. Forbush. 1902.

No. 14. Owl Friends. E. H. Forbush. 1903.

No. 15. Bird Houses. E. II. Forbush. 1903.

No. 16. Our Friend the Chickadee. E. H. Forbush. 1903.

No. 22. Hints for Out-door Bird Study. E. H. Forbush. I. How to identify Birds. 1904.

No. 23. Ibid. II. How to find Birds. 1904.

No. 24. Ibid. III. How to approach Birds. 1904.

No. 25. Ibid. IV. How to attract Birds. 1904.

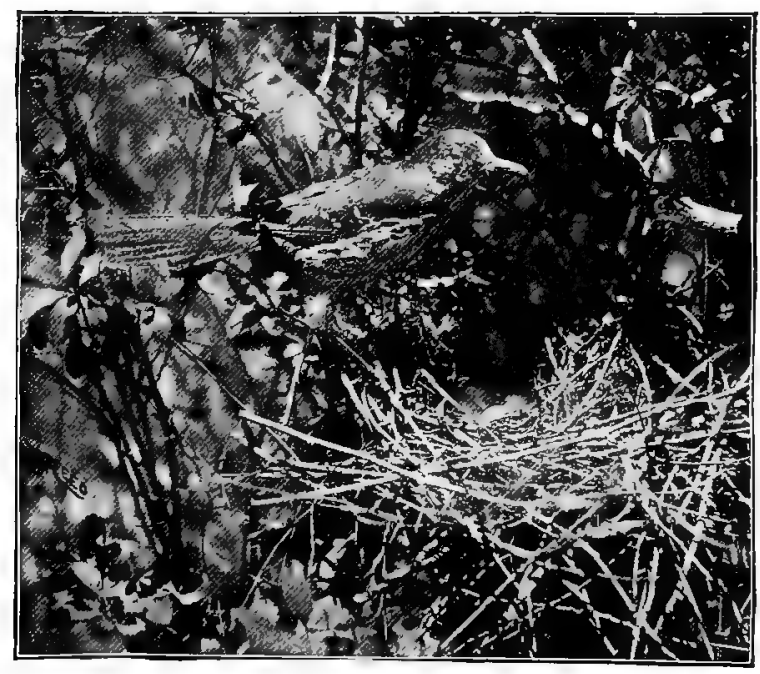


I N DEX. 



\section{INDEX.}

[Heavy-faced type indicates the principal reference to a species. In most instances a brief description of the bird referred to may be found on the page thus indicated.]

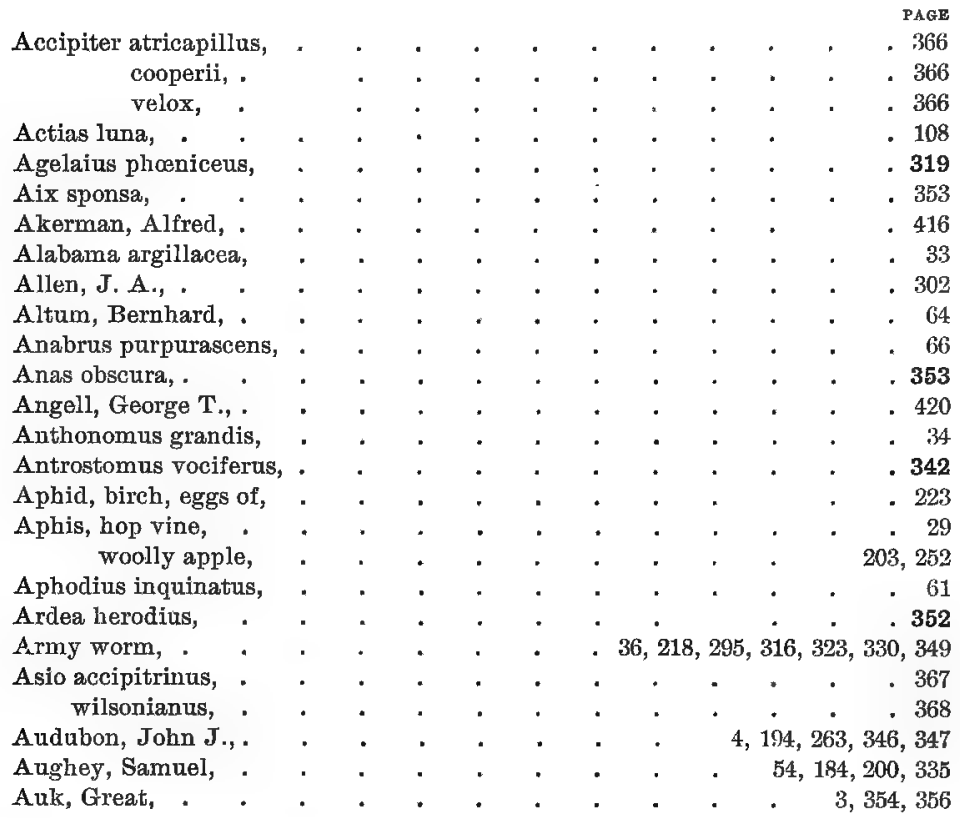

Bailey, Charles E., . 124, 142, 166, 169, 170, 175, 178, 214, 240, 241, 253, 256

Baird, Spencer F.,

Ballou, H. A.,

Bangs, Outram,

Bark louse, oyster-shell,

Barton, B. S., .

Baskett, J. M.,

Baynes, Ernest Harold

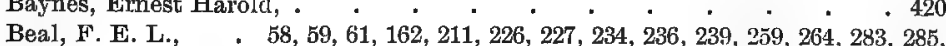

- 13

. 45

- 238

168,175

54

- 259

$293,305,318,321,342$

$16,27,29,216,218,330,342$ elm-leaf, . . . . . . . . . . . . 207, 211, 234 May, . rose, . striped cucumber, . $\quad . \quad$. $\quad . \quad$. $\quad . \quad 227,234,342,348$

Bendire, Charles,

$10,11,183,220,227,234,238,348$ 232,235 


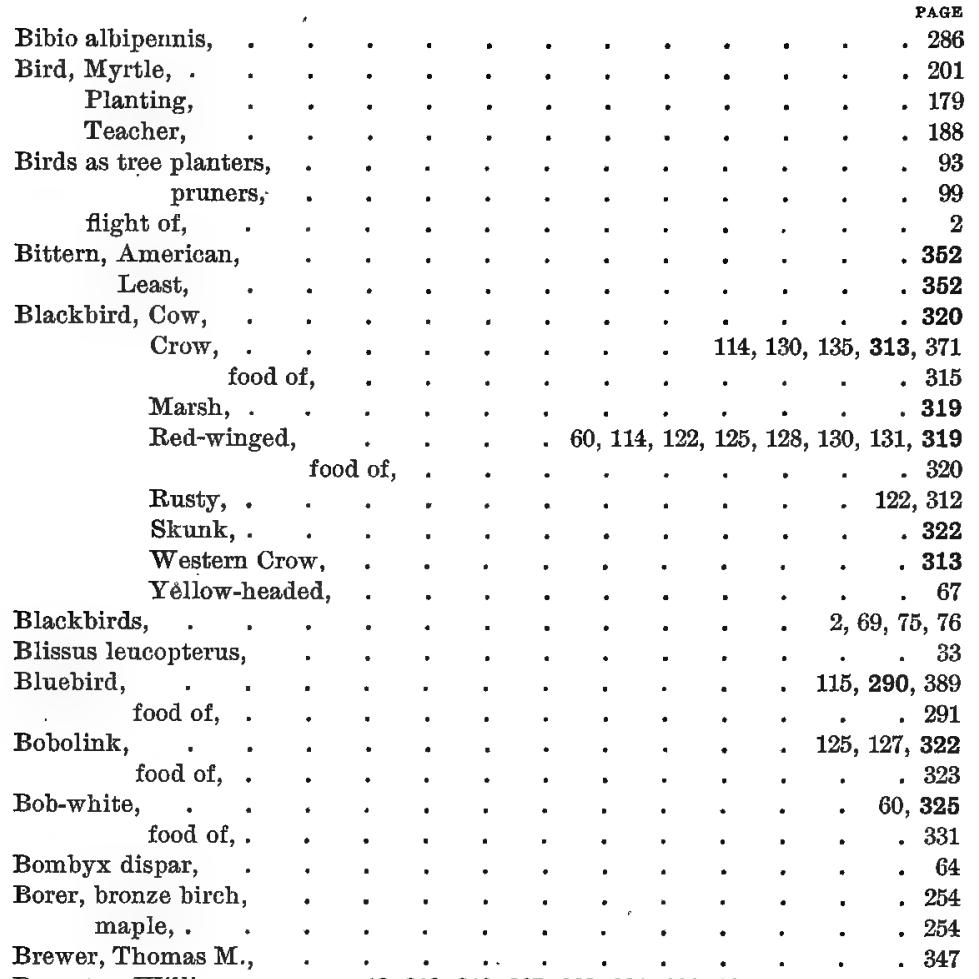

Brewster, William, $\quad$ - $\quad 13,218,243,267,269,331,338,390,404,410,418,420$

Bruchus hibisci, estate of

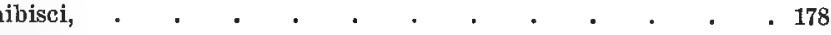

Bruner, Lawrence, . . . . . . . . . . . . . . . . 109

Bubo virginianus, . . . . . . . . . . . . . . 367

Bucculatrix pomifoliella, . . . . . . . . . . . . 252

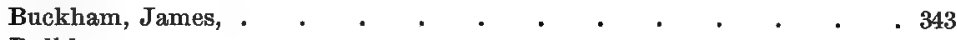

Bull bat, . . . . . . . . . . . . . . . 341

Bunting, Bay-winged, . . . . . . . . . . . . . . . 311

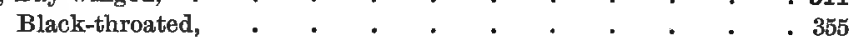

Cow,

Indigo,

320

Burroughs, John,

$115,122,298$

$189,190,199,226,312,363,371$

Butterfly, mourning-cloak,

parsley, eggs of,

caterpillar of, . . . . . . . . . $\quad .227$

Cabbage worms,

Canary, Wild,

Cankerworm, fall, .

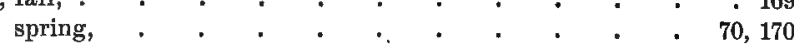

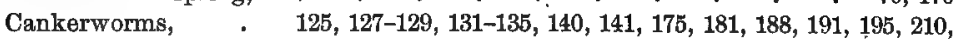
$221,231,295,302,304$

Carpocapsa pomonella, . 
PAGE

Carpodacus purpureus, . . . . . . . , . . 220

Catbird; . . . $\quad 57,58,108,109,115,122,125-128,139,181,283,371$

food of, . . . . . . . . . . 182

Caterpillars, American tent, . $\quad 117,118,123,126,127,130-136,195,208,226,302$,

brown-tail moth,

304,343

forest tent, .

$130-140,184,302,304,370$

gipsy moth,

63, $125,126,128,129,133-136,138,141,144,145$,

$157,160,175,181,184,188,195,205,208,218,226$,

333,369

oak, . . . . . . . . . . . . . 272

red-humped, . . . . . . . . . . . . 272

tussock moth, . . . . . . . . . . . 120

Cecidomyia destructor,

. 33

Cedar Bird,

Certhia familiaris americana,

Chretura pelagica,

Chapman, Frank M.

Chebec,

Chermes larcifolia,

Cherry Bird,

Chewink,

$. \quad . \quad . \quad . \quad . \quad 126,127,139,218$

Chickadee, . . . 53, 115, 122, 124, 129, 130, 136, 140, 143, 145, 146, 163, 400

Chinch bug,

food of,

$167-171$

Chip Bird, Chipper, Chippy, .

- $27,28,33$

$\cdot \quad \cdot, \cdot, \cdot, 303$

Chordeiles virginianus, . $\quad$, . . . . . . . $\quad$. 341

Circus hudsonicus, . . . . . . . . . . . . . 367

Cistothorus stellaris, . . . . . . . . . . . . 350

Clercy, J. O., . . . . . . . . . . . . . . 74

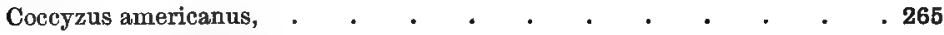
erythropthalnus, . . . . . . . . . . . . 263

Colaptes auratus luteus,

Coleman, Robert H.,

Colinus virginianus,

Colt, W. C.,

Contopus virens,

Corydalus cornutus,

Cotton worm, .

Coturniculus savannarum passerinus,

Cowbird,

Crane, Whooping, .

Creeper, American Brown,

Black and White,

food of,

.260

. 186

- 325

- 110

. 231

- 214

- 33

. 308

- 320

- 67

. 177

. 178

144, 191

Crickets, western, . . . . . . . . . . . . 65, 66

Crow, . 2, 8-11, 26, 45-50, 75, 97, 114, 115, 125, 126, 129, 137, 145, 146, 333, 369 trapping the, . . . . . . . . . . . 406

Cuckoo, Black-billed, . . $\quad$ - 114, 115, 125, 128, 136, 138, 139, 142, 144, 263

food of, . . . . . . . . . 264

Yellow-billed, . $\quad$. $\quad 60,61,114,115,126,128,138,140,146,265$

food of, . . . . . . . . 266

Curlews, . . . . . . . . . . . . . 68,75

Cutworms, $\quad$. $\quad 11,27,34,44,157,160,181,183,287,291,295,315,316,318,330$

Cyanospiza cyanea, 
Dearborn, Ned,

Dendroica æestiva, coronata, pensylvanica, vigorsii,". virens,

Diacrisia virginica,

Dickcissel,

Dike, A. C.,

Diomedea immutabilis,

Diplosis tritici,

Dobson, .

Doryphora decemlineata,

Dove,

Carolina,

Mourning,

Turtle,

Duck, Black, .

Wood, .

Dutcher, William,

Eagle, Bald, .

Egrets, destruction of,

Elaphidion villosum,

Elliot, D. G., . H. W.,

Ellsworth, J. Lewis,

Euproctis chrysorrhea,

Euranessa antiopa,

Falco columbarius, peregrinus anatum, sparverius,

Fannin, J.,

Farley, J. A.,

Felt, E. P.,

Fermald, C. H.

H. $\mathrm{T}$,

Field, G. W.,

Finch, Crimson, Grass, .

Fire Hang Bird, food of,

Fisher, A. K.,

Fiske, W. F.,

Fitch, Asa,

Flagg, Wilson,

Fletcher, James,

Flicker,

Northern, .

food of, tongue of,

Flies, crane, house,

PAGR

. $45,48,61$

194

201

192

200

. 198

120

. 355

$362,408,420$

- 82

- 32

. 214

- 16

13,25

. 324

60,324

. 324

. 353

. 353

$363,418,419$

- 366

- 357

99

84

82

- 419

39

$\mathbf{1 6}$

366

366

366

332

283

$69,120,247$

$142,240,346$

37

419

220

. 311

$122,125,220$

- 221

. 224

$66,79,80,206$

28,255

$73,204,287$

- 35

$60,126,139,146,249$ 122,260

- 261

. 261

207,211

208, 235 
Flies, March, .

May,

robber, .

Flycatcher, Great-crested,

Least, food of,

Forbes, S. A.

Fürst, Herman,

Galeoscoptes carolinensis,

Galerucella luteola,

Gallinago delicata,

Game birds, destruction of,

Gentry, T. G.,

Geolplypis trichas brachidactyla,

Glover, Townend, .

Goldfinch, American,

$$
\text { food of, }
$$

Goodell, Henry H.,

Goodmore, S. E.,

Gophers,

Goshawk,

Grackle, Bronzed,

Purple,

Rusty,

Grosbeak, Rose-breasted,
PAGE

. 280

- 130

. 230)

$114,115,141,144$

$114,115,122,130,133,141,143,229$

. $. \quad . \quad . \quad . \quad . \quad 231$

$17,60,155,160,181,183,210,272,285$

\section{food of,}

Ground Bird,

Ruffed,

food of, .

food plants, list of

Grub, white, .

Guano,

Gull, Brown-headed, Franklin's,

Gulls, utility of,

Hair Bird,

Hang Nest,

Hares,

Harris, T. W.,

Harvey, F. L.,

Hawk,

Bog, .

Chicken,

Coopers,

Duck,

Fish, .

Marsh,

Pigeon,

Red-shouldered, .

Sharp-shinned,

Sparrow,

Hawks, trapping, 
Heath Hen, . . . . . . . . . . . . 26, 266

Heliophila unipuncta, . . . . . . . . . . . 36

Hellgramite, . . . . . . . . . . . . . 214

Helops acreus, . . 178

Henshaw, Henry W., . . . . . . . . . . . 419

Hemerocampa leucostigma, . . . . . . . . . . . 120

Heron, Black-crowned Night, . . . . . . . . . . 351

Great Blue, . . . . . . . . . . 67, 352

Green,

High-hole, High-holder,

Hill, Henry B.,

Hirundo erythrogaster,

Hodge, C. F.,

Hoffman, Ralph,

Hopkins, A.D.

Hornaday, William T.,

Howard, L. 0 .

Hummingbird, Ruby-throated,

Hylocichla fuscescens,

. 351

260

420

. 345

267, 269, 271, 373

$191,199,310$

. 247

- 354

$153,154,162$

122,240

242,244

. 156 mustelina,

. 158

Indian Hen,

Indigo Bird,

Insects, parasitic, predaceous, transformations of,

Io caterpillar,

Iridoprocne bicolor,

Isia Isabella,

food of, .

. 352

$137,139,298$

$18-20,240$

- 17

13-15

- 264

344

120

Jay,

$\cdot \quad \cdot \quad \cdot \quad \cdot \quad \cdot \quad \cdot \quad \cdot \quad \cdot \quad 12,94,404,409$ Blue, . . . 11, 114, 115, 126, 129, 132, 136, 138, 139, 144-146, 369

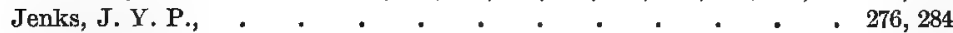
Job, Herbert K., . • • • • • • • • • • . 420 Judd, Sylvester D., 121, 178, 181-183, 186, 272, 273, 278-280, 294, 300, 305, $326,327,329-331$

Junco hyemalis, Junco, Slate-colored, food of,

. 300

$122,296,300$ 301

Kaltenbach, J. H. Keyser, Leander S., Kimball, H. H., King, F. H.,

Kingbird,

Kinglet, Golden-crowned, food of, Western,

Kingfsher, Ruby-crowned,

Kinglets,

Kirby and Spence,

Kirkland, A. H., .

- 32

173,185

- 326

$175,206,272$

. 114, 115, 127, 136, 141, 143, 145, 235

238

57

. 262

- 161

- 161

. 160

$30,64,73$

. $29,37,45,51,136,175,228,237,252,256,304$ 
PAGE

Lachnus strobi,

Lanius borealis,

Lark, Old-field,

Larus franklinii,

Lawrence, Samuel C.,

Leopard moth,

Loucarctia acræa,

Lilford, Lord,

Limnet, Gray,

$$
\text { Red, . }
$$

Lintner, J. A.,

Liparis monacha,

Locust, Rocky mountain, ravages of,

Lyford, C. Allan,

\section{Martins, .} food of,

Mathews, Schuyler,

Mavis, Red,

Maynard, C. J.,

Meadowlark, food of,

Megascops asio,

Melanoplus femur-rubrum, spretus,

Melospiza cineria melodia,

Merriam georgiana. georgiana,
C. Hart, .

Merula migratoria,

Mice, field, meadow,

Midge, wheat,

Millais, J. G.,

Millinery trade,

Minot, H. D.

Mniotilta varia,

Mosher, F. H.,

Moth, brown-tail, cecropia, codling,

fall cankerworm, eggs of . gipsy, . . $38,39,128,142-144,147,148,192,205,214,231,232,234,238$,

leopard, 
Moth, tent caterpillar, eggs of, tussock,

Munger, H. C.,

Musselman, C. C., .

Nash, C. W.,

Nectarophora destructor,

Nighthawk,

food of food of Red-breasted

White-breasted, food of,

Nuthatches, food of,

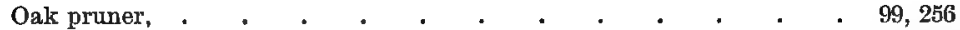

Oriole, Baltimore, . $70,114,115,122,125-128,131-133,136,137,140,143,224,230$ food of,

Orioles,

Osborm, Herbert,

Osprey, American,

Otus brachyotus,

Oven-bird,

food of,

. 226

Orehard,

Owen, Daniel E.,

Owl, Acadian,

American Hawk,

American Long-eared,

Barm,

Barred,

- 224

69,108

. 187

. 413

. 78

. $115,122,124,127,134,141,114,146,188$

Great Horned,

Hoot,

Saw-whet,

Screech,

Short-eared,

Owls,

Snowy,

. 190

. $42,45,51$

. 368

. 367

. 368

79,368

. 367

. 367

- 367

. 368

. 368

78,367

- 367

- 77

Packard, A. S.,

Paleacrita vernata,

Palmer, T. S.,

Paudion hiligetus carolinensis,

Papilio polyxenes, .

Partridge,

Parusatricapillus,

Pea louse,

Peabody Bird,

Pear tree psylla,

Pélicot, $\mathrm{P}$. 


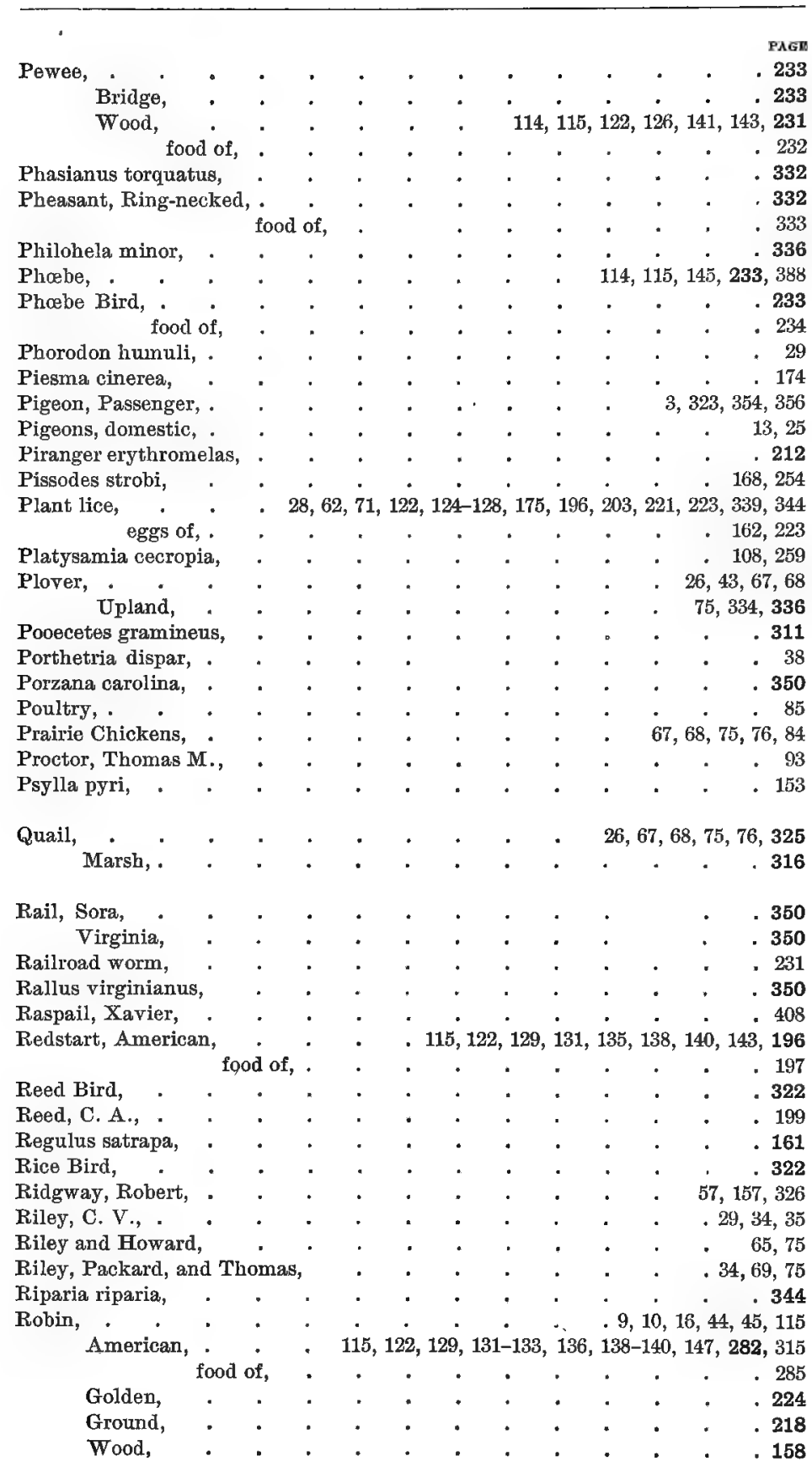




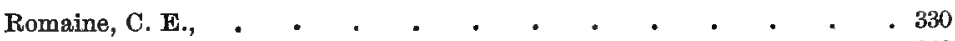

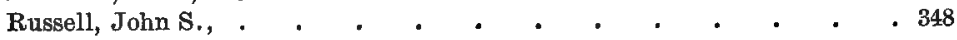

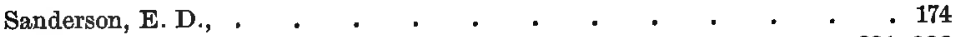

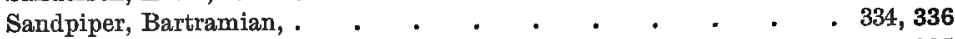

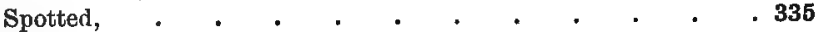

Sapsucker, Yellow-bellied, . . . . . . . . . . 114, 115, 262

Sayornis Phœbe, . . . . . . . . . . . . . 233

Scale, San José,

Schizoneura lanigera,

Schizura concinna,

Seeds eaten by birds,

Seton, Ernest Thompson,

Setophaga ruticilla,

Shaw, Henry,

Shrike, Northern, .

Slirubs, fruit-bearing,

Sialia sialis,

Silkworm, American,

Sitta canadensis,

Snipe,

Snowbird

$$
\text { Wilson's, }
$$

Black,

Spanworm, currant,

Sparrow, Chipping, food of,

- 151

203,252

- 272

281,296

. 343

. 196

- 142

370

374

. 290

30, 108

. 176

171

107

43

. 337

59

. 300

. 112

$55,114,115,122,126,136,143,303,398$

$138,140,141,292,294,344,370,389,304$ Field,

Fox food of,

Grasshopper,

Ground,

Henslow's,

House,

Savanna,

Song,

food of,

Swamp,

Tree,

Vesper,

food of

White-throated

Yellow-winged,

Sparrows, food of,

Sphyrapicus varius,

Spizella monticola, pusilla,

Spoonbills, socialis,

$114,122,127,131,140,301$

$42,114,128,134,141,296,299$ 
Stake-driver,

Starlings,

Stockwell, J. W.,

Stumella magna,

Swallow, Bank,

Barn

food of,

Chimney,

food of,

Cliff

Eaves,

food of, .

House,

Tree,

food of,

White-bellied,

White-breasted,

Swift, Chimney, food of,

PAGE

- 352

17,65

36,37

. 316

60,344

. 344

345

345

. 340

61,346

. 347

346,387

. 344

344, 389

- 345

.344

. 344

$128,340,387$

- 340

Tanager, Scarlet, Summer

food of

$63,115,122,125,127,135,137,144,146,212$

\section{Teeter,}

Tegetmeier, W. B.

Telea polyphemus,

Telematodytes palustris,

Terns, eggs of,

Thayer, Abbott $\mathbf{H}$., Bayard,

Theronia melanocephala, Thistle Bird,

Thompsou, Maurice, Thoreau, Henry D.,

Thrasher, Brown, food of

Thrush, Brown, Golden-crowned, Hermit,

Song,

Tawny,

Wilson's,

Wood,

food of,

Thrushes, food of,

Tip-up,

Titmice,

Titmouse, Black-capped,

Torrey, Bradford,

Towhee, .

$$
\text { food of, }
$$

Toxostoma rufum,

$$
\begin{array}{r}
.213 \\
. \quad 335 \\
. \quad 79 \\
30,108 \\
.350 \\
. \quad 80 \\
. \quad 82 \\
. \quad 418 \\
.417 \\
. \quad 239 \\
.222 \\
246,258 \\
96,299 \\
134,179 \\
. \quad 180 \\
131,179 \\
.188 \\
45,156 \\
.158 \\
.156 \\
137,156 \\
.157
\end{array}
$$

$115,134,179$

$126,127,131,179$

$115,136,137,156$

$93,115,126,127,133,134,139,158$

. 159

- 108

- 155

. 335

- 17

. 163

- 199

$114,115,122,143,218$

- 220

179 


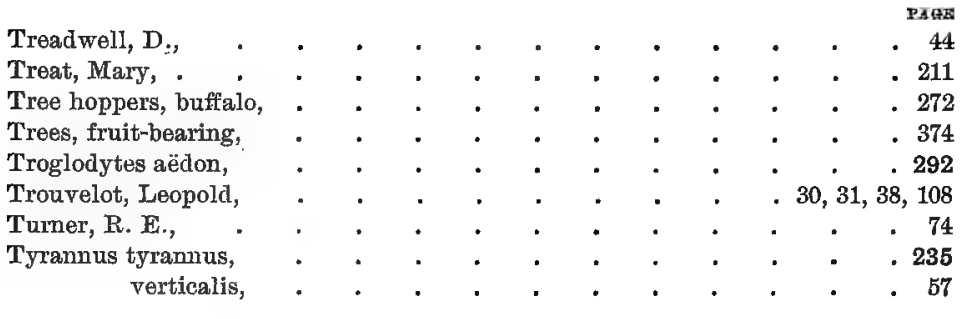

Veery, . . . . . . . . . . . . . . . . 156

Vines, fruit-bearing, . . . . . . . . . . . 374

Vireo, Red-eyed, . . . 51, 115, 122, 125, 127, 129, 136-138, 140-142, 146, 204 food of, . . . . . . . . . 205

Solitary, . . . . . . . . . . . . . 203

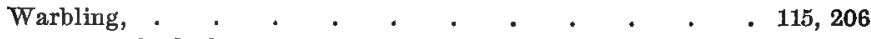

food of, . $\cdot$. $\quad \cdot \quad \cdot \quad \cdot \quad \cdot \quad \cdot \quad \cdot \quad \cdot 207$

White-eyed,

115,203

Yellow-throated, $\quad$. . . . . 115, 122, 125, 134, 138, 140-142, 207

Vireo flavifrons,

food of, . . . . . . . . . . 208

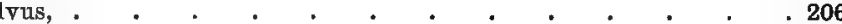

Vulture, olivaceus,

Wake-up,

. 204

3,4

Warbler, Black and White, . 115, 122, 124, 125, 127, 130, 132, 135, 140, 141, 191

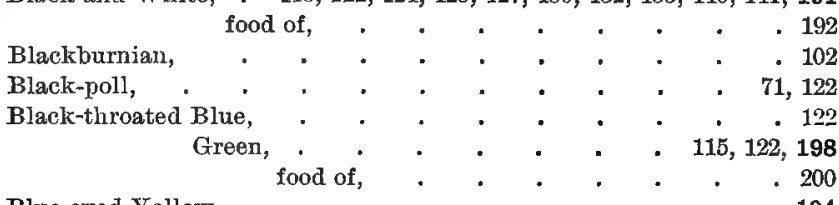

Blue-eyed Yellow, . . . . . . . . . . 194

Chestnut-sided, . . . 115, 122, 126, 127, 132, 134, 136, 139-141, 192

food of, . . . . . . . . . 194

Golden-winged, . . . . . . 115, 131, 132, 134, 137, 141

Hooded, . . . . . . . . . . . . 185

Magnolia, . . . . . . . . . . . 122

Myrtle, . . . . . . . . . . . $71,122,153,201$

Nashville,

food of, . . . . . . . . . . . . . 202

Palm,

$115,131-133,139$

Parula,

Pine,

food of,

- 186

$115,122,126,132,398$

Pine-ereeping,

Yellow,

food of,

Yellow-rumped,

Warblers,

Warren, B. H.,

. 200

. 201

. 200

. $115,122,127,132-136,140,141,143,194$

. 195

. 201

- 185

. $60,191,206,218,245,315$ 
PAGE

Waxwing, Bohemian, . . . . . . . . . . . 209

Cedar,

Webster, F. M.,

Weed, Clarence M.,

Weed and Dearborn,

Weevil, Mexican cotton boll, pea, white pine,

Wells, D. A.

Wheelock, Irene G.

Whip-poor-will,

Widmann, Otto,

food of,

Wilson, Alexander,

Wilson and Bonaparte, Wood, E. W.

Woodpecker, Downy,

Gaffer, .

Golden-winged,

Hairy,

Partridge food of,

Pigeon, .

Wren, House,

Red-headed,

259,346

$45,48,55,168,183,202$

$51,57,289$

34,330

. 226

168,254

56,73

. 290

. 342

- 343

- 348

244,320

4

, 70

$114,115,122,129,144,146,248,249$

food of,

Long-billed Marsh,

Rock,

Short-billed Marsh

Wright, Mabel Osgood,

. 250

. 260

. 260

$114,115,146,247,248,258$

. 259

. 260

. 260

249,355

$54,115,292$

. 293

54,350

- 54

. 350

223,242

Yellow Bird, . . . . : . . . . . . . . . . 194, 222

Summer, . . . . . . . . . . . . . . 194

Yellow-hammer,

- 260

$127,135,138,186$

$62,115,122,186$

Northern

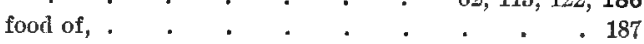

Zamelodia ludoviciana, . . . . . . . . . . . 216

Zonotrichia albicollis, . . . . . . . . . . . . . . . 307 





